\title{
LIGANDDESIGN OF SULFUR-CENTERED Chelates
}

\author{
Dissertation zur Erlangung des \\ mathematisch-naturwissenschaftlichen Doktorgrades \\ der Georg-August-Universität Göttingen
}

\author{
vorgelegt von \\ Dipl. Chem. Thomas Schulz \\ aus Osterburg
}

Göttingen 2010 
D7

Referent: Prof. Dr. D. Stalke

Korreferent: Prof. Dr. G. M. Sheldrick

Tag der mündlichen Prüfung: 15.03.2010 
Die vorliegende Arbeit wurde in der Zeit vom Oktober 2006 bis Januar 2010 am Institut für Anorganische Chemie der Georg-August Universität Göttingen unter der Leitung von Prof. Dr. Dietmar Stalke angefertigt. 



\title{
LIGANDDESIGN OF SULFUR-CENTERED Chelates
}

\author{
Dissertation zur Erlangung des \\ mathematisch-naturwissenschaftlichen Doktorgrades \\ der Georg-August-Universität Göttingen
}

\author{
vorgelegt von \\ Dipl. Chem. Thomas Schulz \\ aus Osterburg
}

Göttingen 2010 

Eingereicht am:

Referent:

Co-Referent:

Datum der mündlichen Prüfung:

Prüfer Anorganische Chemie:

Prüfer BWL:

Prüfer Kristallographie:

Erweiterte Prüfungskommision:
29.01.2010

Prof. Dr. D. Stalke

Prof. Dr. G. M. Sheldrick

15.03.2010

Prof. Dr. D. Stalke

Prof. Dr. J. Geldermann

Prof. Dr. H. Sowa

Prof. Dr. U. Klingebiel

Prof. Dr. O. Wenger 
"Gott gibt die Nüsse.

Aber er knackt sie nicht auf."

(Johann Wolfgang von Goethe) 


\section{CONTENTS}

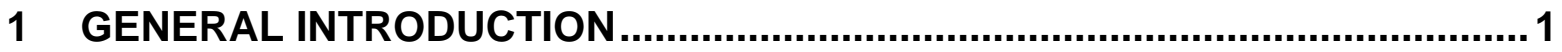

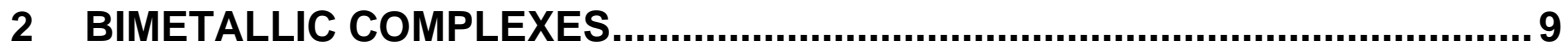

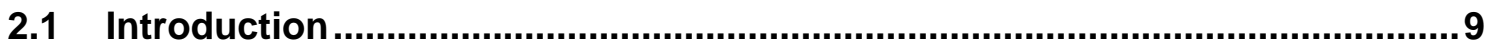

2.2 Bimetallic Complexes with Cyclopentadienyl Ligands .................................11

2.3 Coupled Diimidosulfinates...........................................................................

2.3.1 Diimidobenzenyl- and diimidobiphenylsulfinates ………........................... 15

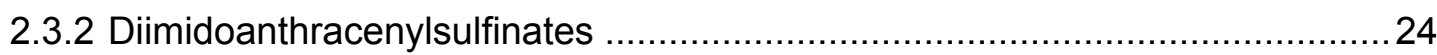

2.4 Magnesium Sulfinates and Sulfonates ........................................................ 39

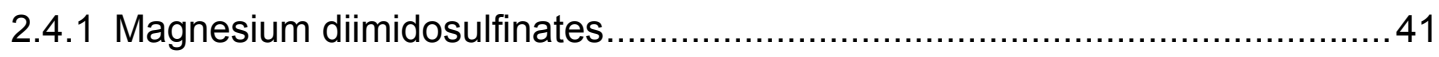

2.4.2 Magnesium triimidosulfonates ………………………….......................... 51

3 FIELD TEST OF THE INCOATEC MICROFOCUS SOURCE.........................67

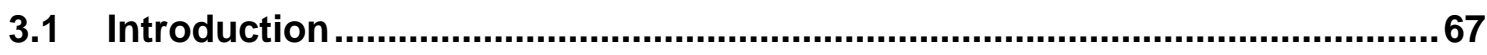

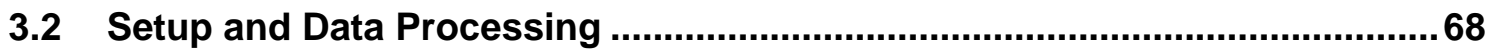

3.3 Comparisons of the Beam Profiles ............................................................... 72

3.4 Data Quality after Integration.....................................................................

3.5 Data Quality after Scaling with SADABS ………….......................................76

3.6 Data Quality after Refinement.......................................................................

3.7 Experiments with Crystals that Matched the Beam Diameter .......................80

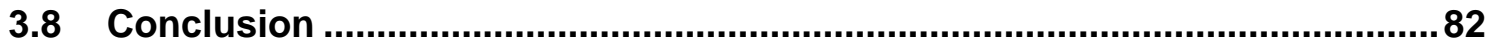

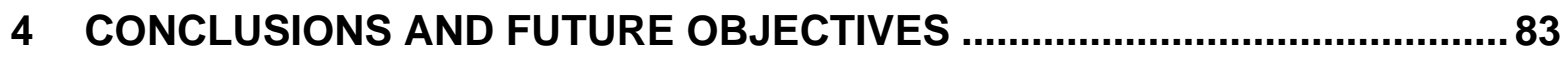

4.1 Bimetallic Complexes.................................................................................... 83

4.2 Field Test of the Incoatec Microfocus Source ……....................................... 85 
5 ZUSAMMENFASSUNG UND ZUKÜNFTIGE ZIELE.................................... 86

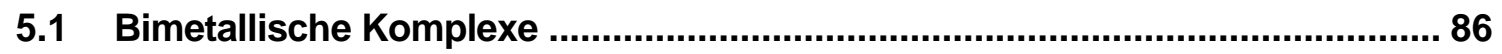

5.2 Feldversuche mit der Incoatec Microfocus Source ................................... 88

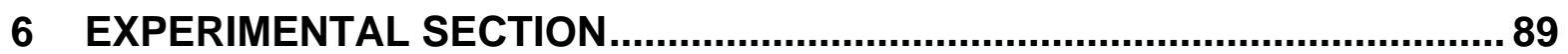

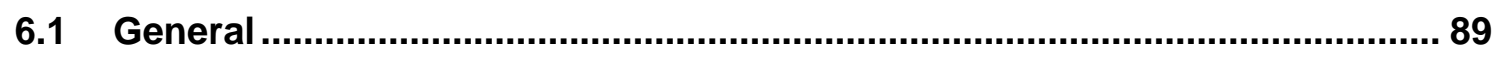

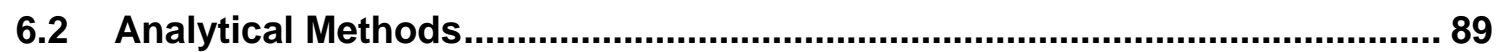

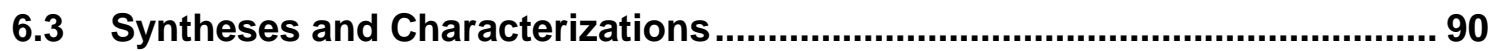

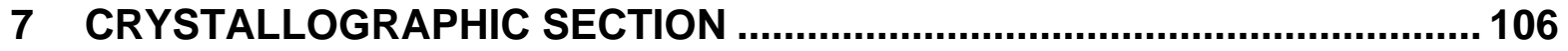

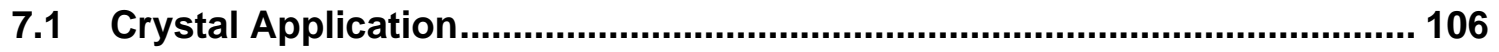

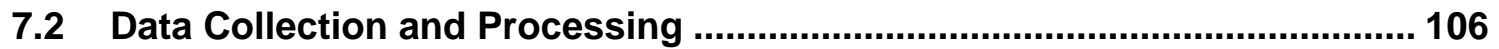

7.3 Structure Solution and Refinement .............................................................. 108

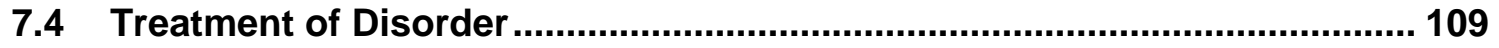

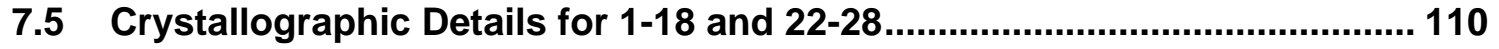

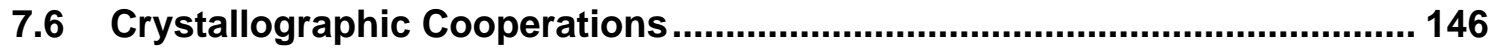

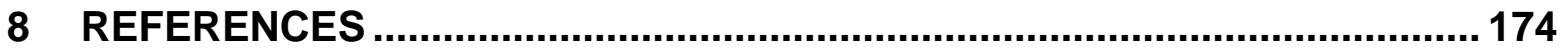




\section{ABBReViations}

\begin{tabular}{|c|c|}
\hline$\AA$ & Ångstrom \\
\hline ADP & anisotropic displacement parameters \\
\hline $\mathrm{Bz}$ & benzyl \\
\hline calc. & calculated \\
\hline CCD & charge coupled device \\
\hline $\mathrm{Cp}$ & Cyclopentadienyl \\
\hline e.g. & for example \\
\hline esd & experimental standard deviation \\
\hline Et & ethyl \\
\hline $\mathrm{Et}_{2} \mathrm{O}$ & diethyl ether \\
\hline GoF & goodness of fit \\
\hline $\mathrm{h}$ & hour(s) \\
\hline Hal & halogen atom \\
\hline $1 \mu \mathrm{S}$ & Incoatec Microfocus Source \\
\hline M & molar \\
\hline $\mathrm{Me}$ & methyl \\
\hline MeLi & methyl lithium \\
\hline MS & mass spectrometry \\
\hline${ }^{n} \mathrm{Bu}$ & normal-buthyl \\
\hline${ }^{n} \mathrm{BuLi}$ & normal-buthyl lithium \\
\hline NMR & nuclear magnetic resonance \\
\hline $\mathrm{Ph}$ & phenyl \\
\hline Pic & picolyl \\
\hline ppm & parts per million \\
\hline $\mathrm{R}$ & hydrogen atom or alkyl or aryl group \\
\hline $\mathrm{rt}$ & room temperature \\
\hline${ }^{t} \mathrm{Bu}$ & tert-butyl \\
\hline${ }^{t} \mathrm{BuLi}$ & tert-butyl lithium \\
\hline tube & sealed tube \\
\hline THF & tetrahydrofuran \\
\hline TMEDA & tetramethylethylenediamine \\
\hline vs. & versus \\
\hline
\end{tabular}




\section{LIST OF COMPOUNDS}

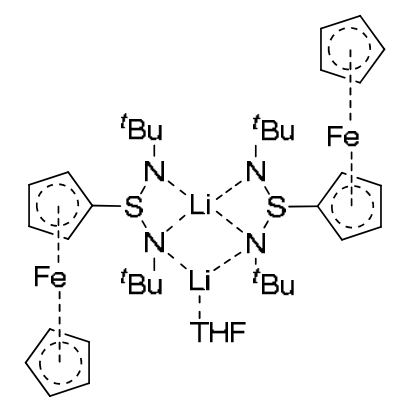

1

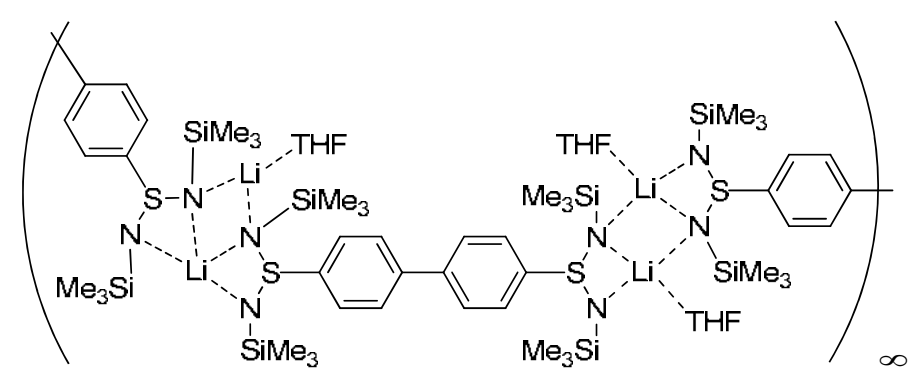

3

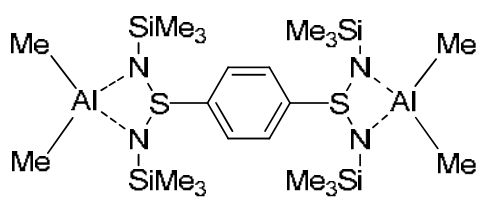

5

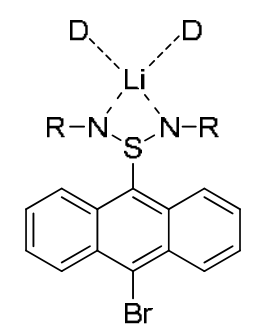

7: $R={ }^{t} \mathrm{Bu}, \mathrm{D}=\mathrm{THF}$ 9: $\mathrm{R}={ }^{t} \mathrm{Bu}, \mathrm{D}=\mathrm{Et}_{2} \mathrm{O}$

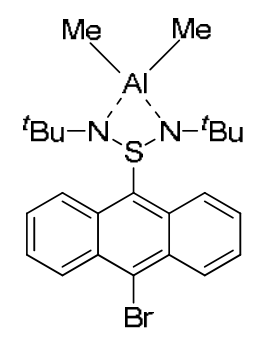

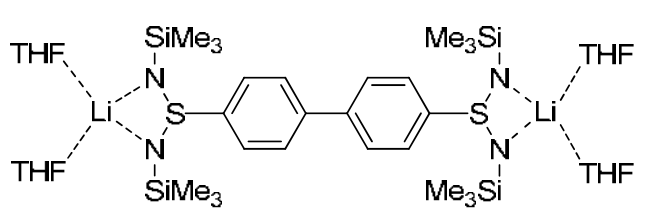

2

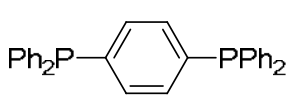

4

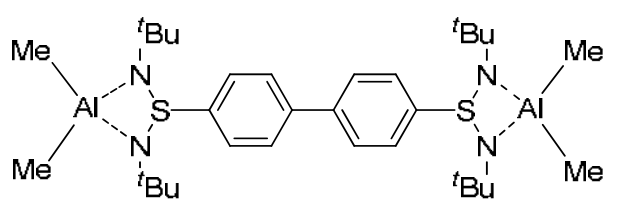

6

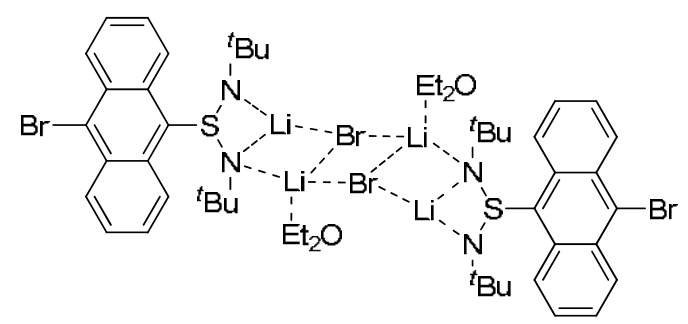

8

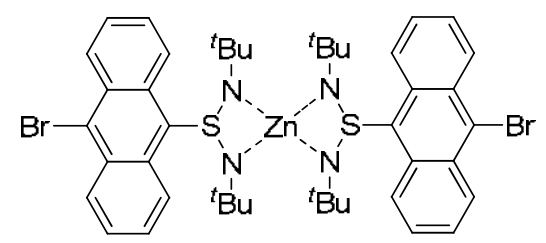

11 


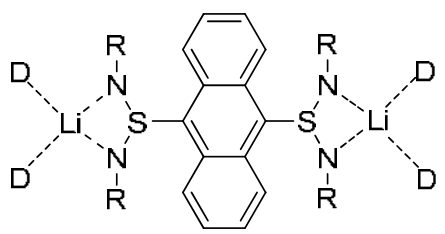

12: $R={ }^{t} B u, D=T H F$ 13: $R={ }^{t} B u, D=T H F$

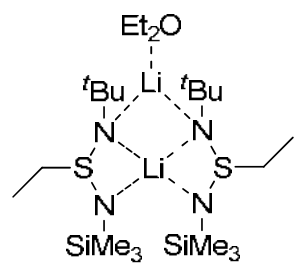

15

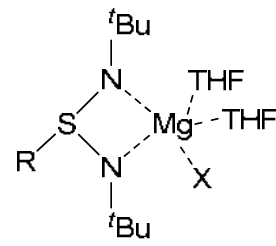

17: $\mathrm{R}=\mathrm{Me}, \mathrm{X}=\mathrm{Br}$ 18: $\mathrm{R}={ }^{n} \mathrm{Bu}, \mathrm{X}=\mathrm{Cl}$

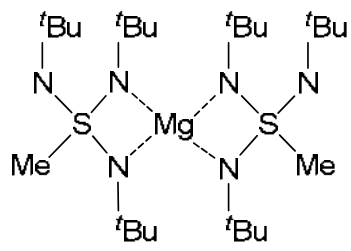

27

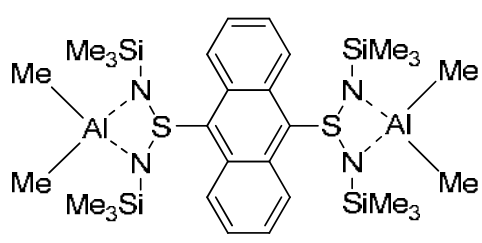

\section{4}

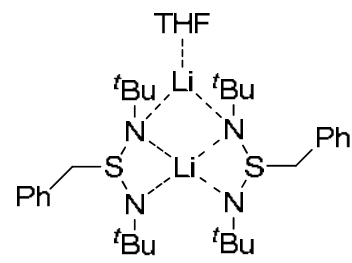

16

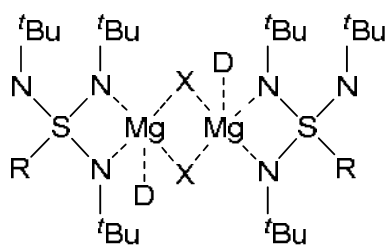

$22-26$

22: $\mathrm{R}=$ methyl, $\mathrm{X}=\mathrm{Br}, \mathrm{D}=\mathrm{THF} ; 2 \mathrm{23}: \mathrm{R}={ }^{n}$ butyl, $\mathrm{X}=\mathrm{Cl}$; $\mathrm{D}=\mathrm{THF}, 24: \mathrm{R}=$ phenyl, $\mathrm{X}=\mathrm{Cl}$; $\mathrm{D}=$

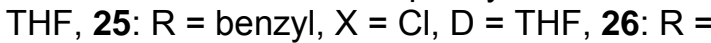
methyl, $\mathrm{X}=\mathrm{Br}, \mathrm{D}=\mathrm{Et}_{2} \mathrm{O}$

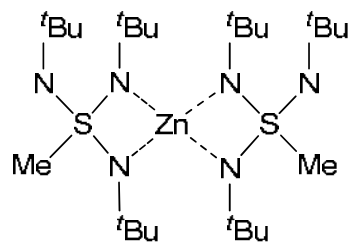

28 



\section{GenERAL INTRODUCTION}

Catalysis is a synonym for acceleration or progress and now more than ever a crucial part of our world. The word catalysis is derived from the Greek word " $\kappa \alpha \tau \alpha \lambda v \sigma i \varsigma$ " meaning unbind or repeal. Today a catalyst is defined as: "A substance that increases the rate of a chemical reaction without itself undergoing any permanent chemical change". [1]

Nearly every chemical reaction performed on an industrial scale today uses catalysts, but the triumphal procession of catalysis started a long time ago. Catalytic reactions have been known and used by mankind since the very origins of civilization long before any chemical concepts were in place. One of the first catalyzed processes utilized by man was the production of alcohol through fermentation (see Figure 1-1).

Even in this early period of time empirical experiments were made, mostly associated with food production. Although the first mentioning of a catalytic process reaches back to the eighth century, when the Arabic alchemist Jabir ibn Haiyan explained the synthesis of ether by

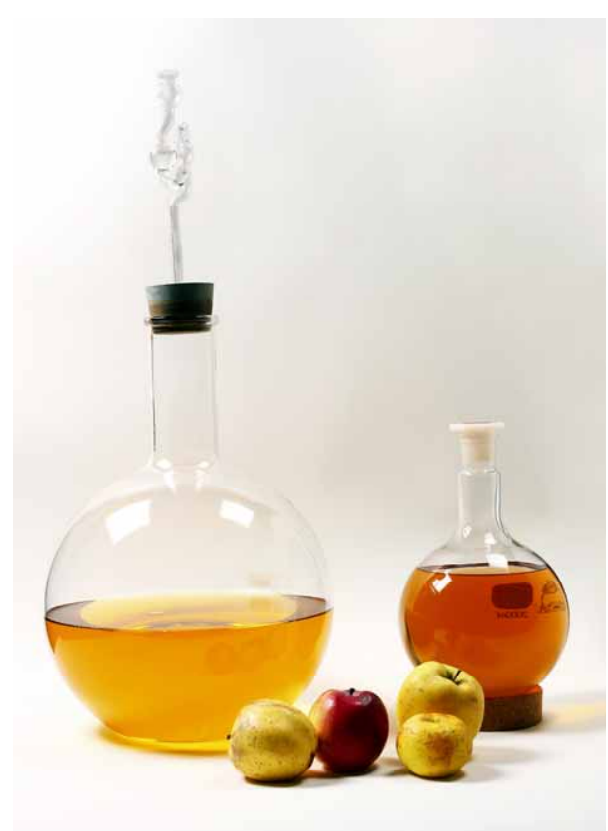

Figure 1-1: Fermentation of fruits, one of the first catalyzed reactions used by mankind.

dehydration of alcohol with the help of mineral acid, an understanding of catalytic processes was not developed before the early 1800s. Davy in $1817^{[2]}$ and Döbereiner around $1823^{[3,4]}$ found platinum to be an effective catalyst for reacting gaseous mixtures. While Davy developed a safety lamp for miners, Döbereiner designed the prototype of a lighter. In spite of these findings it took another decade before Berzelius in 1835 introduced the term "catalysis" or "catalytic force". ${ }^{[5]}$ Although the scientists of this time were not sure how catalysis worked, it became more and more important in the course of the industrialization. Prominent examples are the production of ammonia from elemental hydrogen and nitrogen developed by $\mathrm{Haber}^{[6,7]}$ or the oxidation of ammonia to nitric acid found by Ostwald. ${ }^{[8]}$ Opposed views concerning catalysis and how it worked hindered the search for an explanation for quite some time. The different opinions about the driving force behind catalysis 
ranged from a vis occulta ${ }^{[9]}$ similar to the vis vitalis ${ }^{[10]}$ to the idea that the catalyst could transfer some of its attributes to the reagents of a reaction. This debate was ended by Ostwald (see Figure 1-2) who found out that catalysis is a kinetically controlled phenomenon and therefore stated: "Catalysis is the acceleration of a slowly proceeding chemical reaction through a foreign substance". ${ }^{[11,12]}$
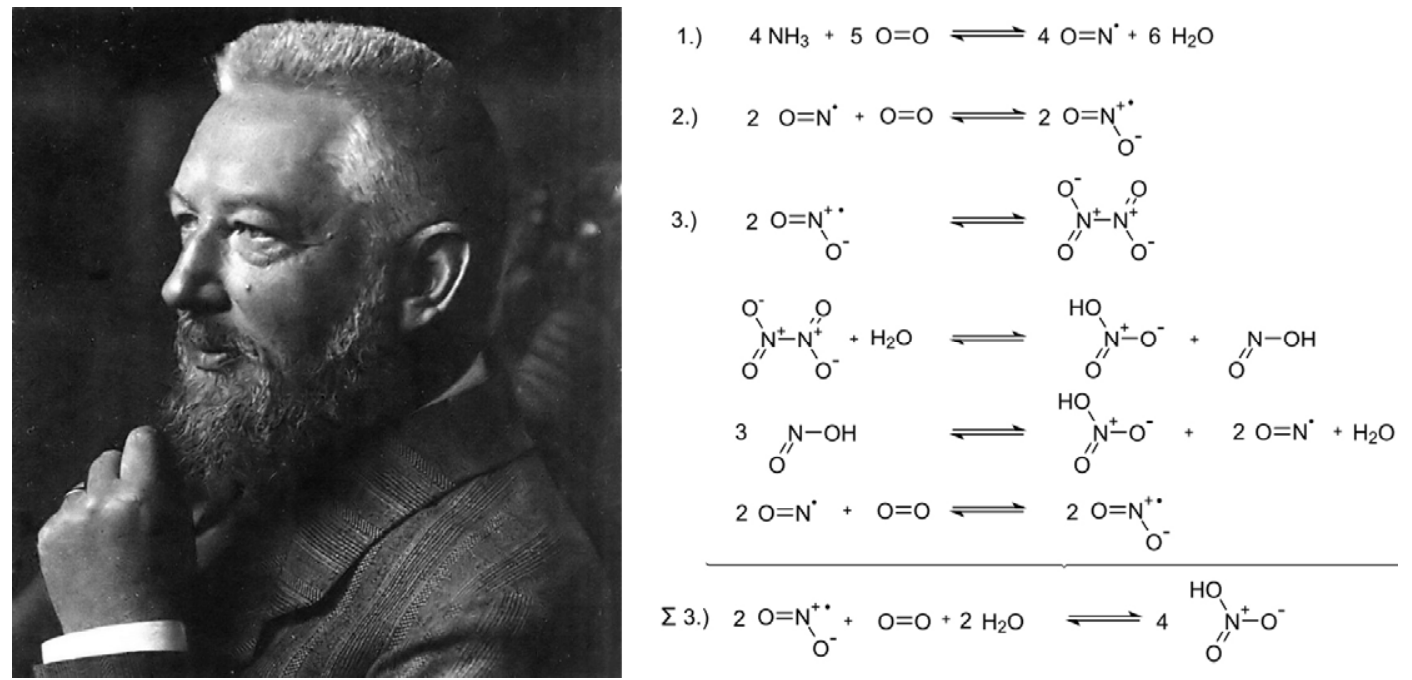

Figure 1-2: Picture of Ostwald (left) and the chemical reactions taking place during the Ostwald procedure for the synthesis of nitric acid (right).

After finding that catalysis does not lead to a totally different reaction pathway but only accelerates the existing one, it was now possible to try to quantify catalysis instead of qualifying it. For his findings in the field of catalysis Ostwald received the Nobel Prize in 1909. ${ }^{[13]}$ At the same time a subdivision into homogeneous, heterogeneous and biological (enzymatic) catalysis was introduced. The heterogeneous catalysts, impelled by the discoveries of Langmuir, who found that chemisorption is an integral part for heterogeneous catalysis (see Figure 1-3), ${ }^{[14]}$ flourished in the beginning of the $20^{\text {th }}$ century bringing forth such catalytic processes like the Fischer-Tropsch reaction ${ }^{[15]}$ which opened the way for the conversion of nearly all sources of carbon via synthesis gas to alkanes, alkenes and alkanols. Further important reactions under the participation of heterogeneous catalysts are the first industrial steam-reforming processes pioneered by Houdry ${ }^{[16]}$ or the first Ziegler-Natta polymerizations (1953). ${ }^{[17,18]}$ Even today the Langmuir-Hinshelwood mechanisms $^{[19]}$ are of importance to scientists trying to scale up laboratory projects to industrial scale processes. ${ }^{[20,21]}$ 


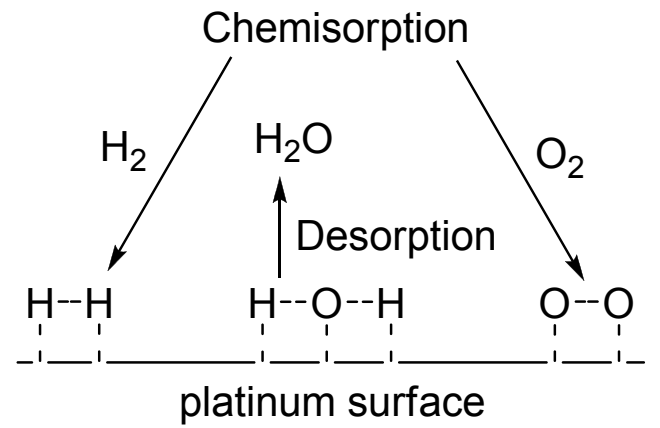

Figure 1-3: Detonating gas synthesis as example for the effect of heterogeneous catalysts.

Another important finding in the beginning of the $20^{\text {th }}$ century was the concept of the active site in catalysts discovered by Taylor. Although it was not used to its full extent at this time it should become very important later in many catalytic processes and especially for biological catalysis where it is the central concept. ${ }^{[22]}$ The advent of homogeneous catalysts began later with the Wacker process ${ }^{[23,24]}$ and the discovery of the rhodium-based hydrogenation catalysts by Wilkinson (1964). ${ }^{[25,26]}$ The advantage of the homogeneous over the heterogeneous catalysis is the higher efficiency because the reaction is not limited to the surface of the catalyst but can proceed in the whole reaction medium. Therefore, the homogeneous catalysts were catapulted to the forefront of research in this time.

A retrospective from the beginning to the middle of the $20^{\text {th }}$ century shows how catalysis has promoted the evolution of mankind. One of the first catalyzed reactions used by the chemical industry was the Haber-Bosch procedure to obtain ammonia from elemental hydrogen and atmospheric nitrogen. Since ammonia is the precursor for fertilizers, pesticides and herbicides, mankind could strongly increase the yield of crop from a certain area of land. While in 1900 one farmer was feeding four persons this number had nearly tripled in 1950 and today one farmer can feed over 130 persons. ${ }^{[27]}$ An additional example for the profitable development through catalysis is the cracking of oil. Thanks to new catalysts, cracking, isomerization and alkylation of crude oil were possible. With the necessary fuel at hand, motorization and aviation took place in the Thirties and Forties, making people more mobile and finally leading to globalization.

In the second half of the $20^{\text {th }}$ century further insights in the fields of structure, bonding and reactivity enabled a progression from simple empirical search to rational design of catalysts. Development of the "three way catalyst", which prevented large cities from over-pollution, and the beginning of asymmetric catalysis, which was a milestone for modern medicine, are both examples for the great achievements made 
in this period of time. The Nobel Prize awarded to Knowles, ${ }^{[28,29]}$ Noyori ${ }^{[30,31]}$ and

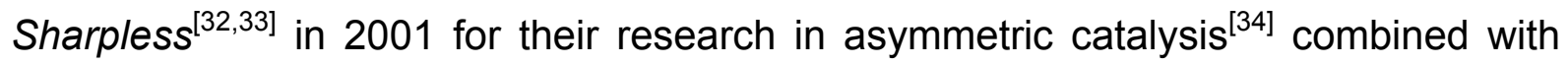
the need for economic and green chemistry and the necessity of a substitute for oil as fuel for global economy further emphasizes the need for well developed catalysts in the $21^{\text {st }}$ century. This is also confirmed by the following figures concerning catalysis: today more than $90 \%$ of the industrial production of chemicals is based on catalysis. ${ }^{[27]}$ In 2006 the amount of world-wide produced catalysts was about one million tons with a value of more than 12 billion U.S. dollars. ${ }^{[35]}$ Taking into account that usually the value of the catalysts is less than $0.1 \%$ of the product obtained, the global market for goods produced with the help of catalysis is worth 12 trillion U.S. dollars which is equivalent to around $40 \%$ of the World Gross National Product.

The major part of the catalyzed reactions in the world can be allotted to the production of polymers. Polymers are one of the most important materials world-wide since their attributes can be tuned by the chain-length, tacticity or the co-polymers that can be added. This is why many different products ranging from plain bags over plastic bottles to car tires can be obtained (see Figure 1-4).
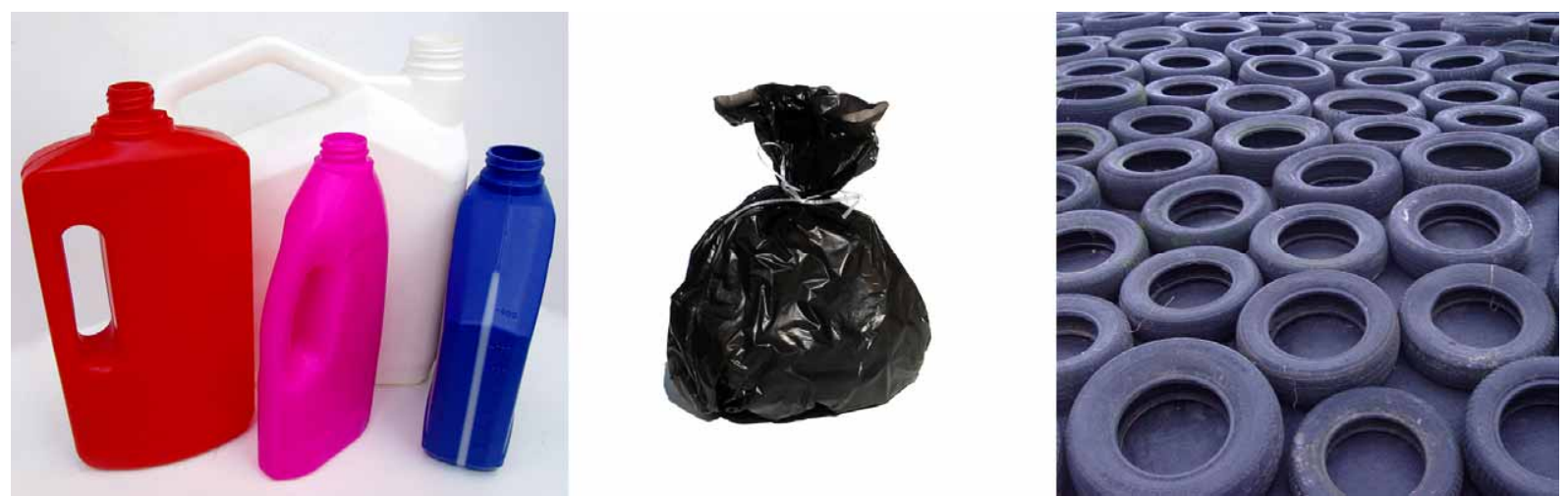

Figure 1-4: Different materials originating from polymers.

One of the most versatile techniques in respect to the variations of polymers is the Ziegler-Natta polymerization. Using a group 4 metal complex and a group 13 co-catalysator, ${ }^{[36-39]}$ a catalytic active cationic species ${ }^{[40,41]}$ is generated which is able to coordinate and insert the used olefine continuously. The use of suited catalysts not only permits the reactions to run under mild conditions but in contrast to other techniques (radical, cationic or anionic) also other properties like the molecular mass, the branching or the tacticity can be controlled. ${ }^{[42,43]}$ Although the first catalysts, discovered by Ziegler and Natta, consisting of a group 4 halogen complex and an aluminum alkyl, ${ }^{[4]}$ neither were especially reactive nor exhibited any selectiveness, constant development has made the Ziegler-Natta polymerization one of the most 
used techniques even today. Shortly after the discovery by Ziegler and Natta, catalysts of the second generation $\left(\mathrm{MgCl}_{2} / \mathrm{TiCl}_{4} / \text { aluminiumalkyl }\right)^{[45]}$ were still not found to be very reactive but could influence the tacticity of the polymers. The next big step towards today's catalysts was made by Kaminsky and Sinn. ${ }^{[46,47]}$ Although metallocene complexes were known for quite some time, the polymerization experiments of Kaminsky and Sinn revealed the true potential of this class of compounds. Using methylaluminumoxide as co-catalyst, ${ }^{[48]}$ the metallocene complexes showed an activity unknown up to that day (10 to 100 times higher than the classical Ziegler-Natta catalysts) ${ }^{[49]}$ Besides the increased activity an additional advantage of the metallocene complexes is that the active species is only one molecule and not a composite, which is why they were termed "single-site catalysts". ${ }^{[50]}$
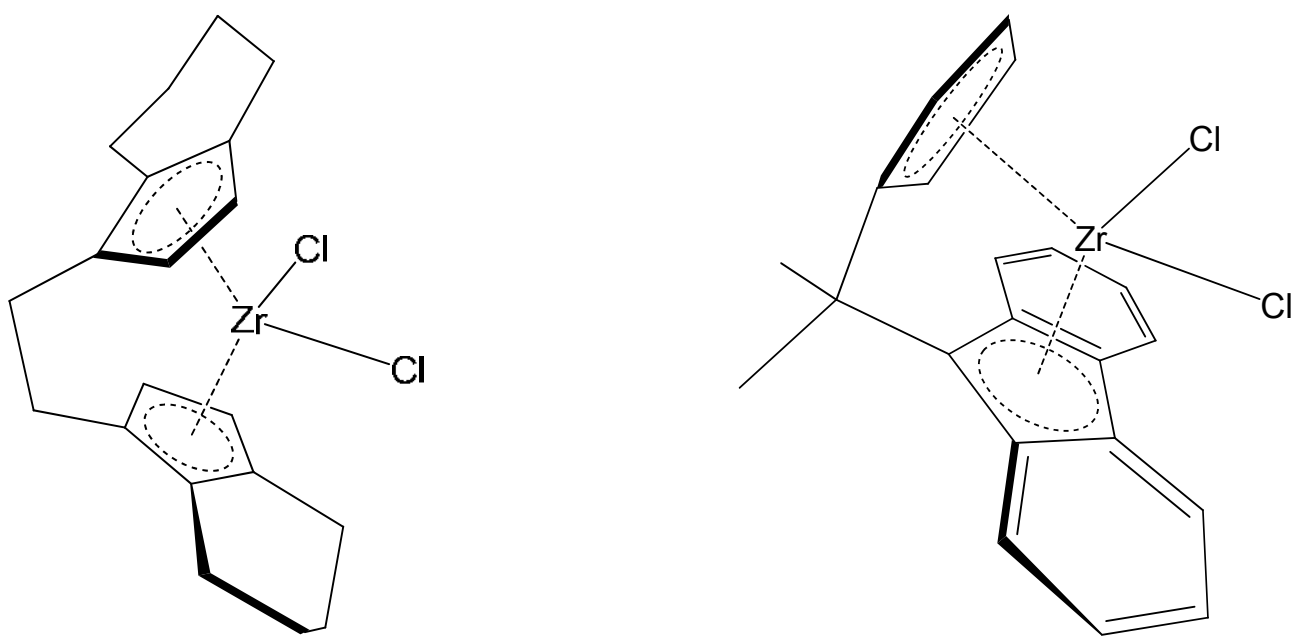

Figure 1-5: Ansa-metallocene catalysts yielding isotactic (left) and syndiotactic (right) polymers.

In contrast to the composites used before, it was now possible to control the tacticity of the polymers even better by the introduction of chiral ligands. Some of the most prominent examples for metallocene catalysts are the ansa-metallocenes developed in the late Eighties. Depending on the used ansa-metallocene (see Figure 1-5) isotactic $^{[51]}$ or syndiotactic ${ }^{[52]}$ polymers can be obtained. Constant development lowered the consumption of the catalysts and the co-catalyst significantly. Today one mole of catalyst (e. g. zirkonocenes) is sufficient to synthesize 875 tons of a polymer with defined tacticity ${ }^{[27]}$ while some catalysts are very active even at a low ratio of cocatalyst to catalyst. ${ }^{[53,54]}$ Additionally, it is now possible to introduce copolymers into the product resulting in new polymers with interesting attributes. ${ }^{[55-58]}$ 
But all these syntheses are only possible if the right catalyst is used. However, to obtain the mentioned catalysts, not only a central metal atom is needed. First and foremost a suitable ligand is needed to make catalysts work. The demands for a ligand are numerous and versatile. It needs to stabilize the metal atom in the right oxidation state, make the catalyst soluble, leave enough space at the reactive site and block the pathways for wrong substrates. Furthermore, it is desirable that the ligand is adaptive and is able to coordinate more than one metal because bimetallic and heterobimetallic complexes are often found to be superior to their monometallic counterparts. ${ }^{[59,60]}$ Last but not least it is desirable that a center of chirality can be introduced so that asymmetric catalysis is also possible.

Sulfuriimides and their corresponding monoanions fulfill all of the above described requirements. By isoelectronic replacement of the oxygen atom in sulfur oxo anions by a NR group, one obtains the corresponding sulfurimides. This kinship already illustrates the adaptability of this class of ligands since according to Langmuir ${ }^{[61,62]}$ isoelectronic compounds often resemble the original ones in many properties (e. $g$. coordination chemistry). As expected, the sulfur-nitrogen compounds show various coordination motifs as depicted in several reviews. ${ }^{[63-65]}$ In addition Figure 1-6 further illustrates the flexibility of the diimidosulfinates. ${ }^{[66-69]}$

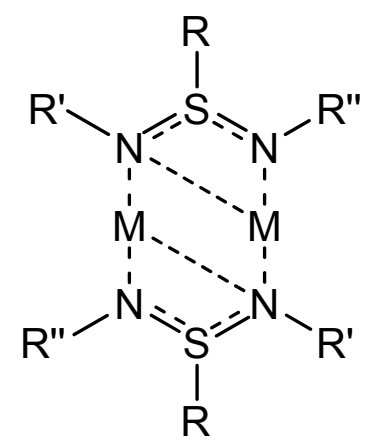

motif I<smiles></smiles>

motif IV<smiles></smiles>

motif II<smiles></smiles>

motif V<smiles></smiles>

motif III<smiles></smiles>

motif VI

Figure 1-6: Binding modes of the diimidosulfinates ( $M=$ metal, $D=$ donor, $R, R^{\prime}, R^{\prime \prime}=$ organic group). 
Although there are commonalities, the sulfurimides exhibit several traits that are different from the sulfur oxo anions and make them more suitable for the design of catalysts. Because of the NR groups the sulfur-nitrogen compounds tend to form discrete molecules instead of polymeric networks. ${ }^{[70-72]}$ In addition the sulfurimides and the corresponding sulfinates and sulfonates are soluble in nearly all organic solvents and the organic groups can be used as "adjusting screws" with which the sterical demand of the ligand can be tuned. The nucleophilic addition of an organic substituent to the electro-positive sulfur atom yields the sulfinates and sulfonates. Therefore, a center of chirality can be introduced effortlessly at the sulfur atom if an asymmetric sulfurimide is used. ${ }^{[73-75]}$ In addition the sulfinates and sulfonates not only show their adaptability by the large amount of possible binding modes but also through the flexibility in the positioning of the NR groups. Because of this flexibility, C-N-S-N torsion angles reaching from $0^{\circ}$ to more than $50^{\circ}$ can be found. ${ }^{[76-78]}$ Furthermore the sulfinates and sulfonates are known to stabilize a variety of different metals in many oxidation states. ${ }^{[79-82]}$ Last but not least the diimidosulfinates exhibit a sterical demand very similar to that of a cyclopentadienyl ligand and in addition they show an electronic configuration that is comparable with amidinate or $\beta$-diketaminate ligands which are known to stabilize a huge number of different metal atoms even in unusual oxidation states. ${ }^{[83-85]}$

Although monoanionic, the sulfinates and sulfonates can be transferred into dianionic ligands if a suitable organic substituent is added to the sulfurimide. By deprotonation of the a-carbon atom it is possible to generate a second negative charge within the ligand. The resulting $\mathrm{CR}_{2}$-group is also isoelectronic to an oxygen atom making these sulfur ylides analogues to the sulfite and sulfate dianions. ${ }^{[72,86,87]}$

Taking all the above-mentioned facts into account, the sulfurimides seem to be the ideal choice as starting material for the synthesis of ligands that are capable of forming bimetallic complexes. 


\section{Scope of this Thesis:}

The aim of this work was to synthesize ligands which are capable of coordinating several metal atoms, forming bimetallic or heterobimetallic complexes. Since sulfurimides have been studied extensively in our work group ${ }^{[69,78,88-90]}$ and exhibit a lot of benefits for the synthesis of bimetallic complexes, they were to be used as starting point to obtain this goal.

Owing to their electrophilic sulfur atom nearly any nucleophile can be added to the sulfurimides yielding a variety of diimidosulfinates and triimidosulfonates. ${ }^{[82,91]}$ This trait opens up a lot of possible synthetic pathways to obtain the desired ligands. Keeping this in mind, different approaches to synthesize bimetallic complexes were to be investigated in this work. At the same time the arbitrary sulfur bound group and the substituents on the nitrogen atoms leave enough possibilities to tune the molecular structure of the diimidosulfinates and triimidosulfonates. Furthermore it was to be examined how flexible the ligands react to the requirements of organic groups with variable steric demand. It has been shown in several publication that the monoanionic diimidosulfinates and triimidosulfonates are able to coordinate hard metals like lithium as well as soft metals like barium. ${ }^{[67,77]}$ This feature was also to be used to broaden the field of available metals that can be coordinated by the mentioned ligands. Since the coordination capabilities of the pending imido group in triimidosulfonates have not been investigated in detail, ${ }^{[00]}$ this lack of knowledge was also to be filled during this work.

Besides the described chemical experiments, a new X-ray source was to be tested. The Incoatec microfocus source $(\mathrm{I} \mu \mathrm{S})$, an air-cooled $30 \mathrm{~W}$ microfocus sealed tube combined with graded multilayer mirrors, was to be compared with a conventional Bruker sealed tube with monocapillary. Since the I $\mu \mathrm{S}$ was mounted on a D8-platform already equipped with the Bruker sealed tube, comparison measurements can be performed utilizing the same crystal in the same orientation. Because the $I \mu S$ exhibits a very narrow beam profile with a high flux density, small as well as large crystals were to be measured to ensure, that the measurements do not give a systematic advantage to one source. Furthermore, a variety of compounds (organic molecules, organometallic compounds and heavy metal salts) were to be employed as test crystals. In the final experiment at least two data sets were to be recorded with crystals fitting the beam diameter of each source. The comparison of these data sets should be sufficient to illuminate the abilities of both sources. 


\section{Bimetallic Complexes}

\subsection{Introduction}

It has been known for quite some time that complexes which contain two or more metal atoms display interesting features. For example the "communication" between these metal atoms within one complex ${ }^{[92-95]}$ has been a major topic for many scientists since the first discovery of Prussian Blue ${ }^{[96,97]}$ or other mile stones like the finding of the Creutz-Taube ion (Figure 2-1). ${ }^{[98]}$

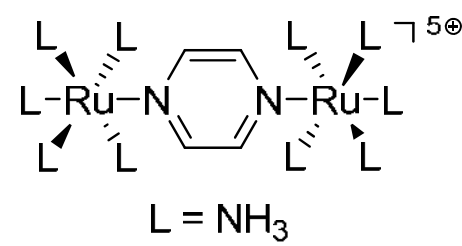

Figure 2-1: Lewis formula of the Creutz-Taube ion.

The intramolecular interactions between metals are of considerable interest for the electronic properties of materials or for electron transfer reactions in bioinorganic systems. While the search for new molecular wires ${ }^{[99-101]}$ and the investigations on other electron transfer processes ${ }^{[102-105]}$ mainly focus on subjects like rate constants and activation barriers, bioinorganic scientists try to model natural systems to get a better insight into the processes of biological systems. ${ }^{[106]}$ One prominent example for such a system is the respiratory protein hemerythrin which can be found in several marine invertebrate phyla. ${ }^{[107]}$ It has an active site with two iron atoms which upon coordination of an oxygen molecule exhibit a "one site addition two site oxidation" which means that by coordinating one substrate both metal atoms get oxidized (see Scheme 2-1). ${ }^{[108]}$ To get further insight into this multi-electron oxidation would be an enormous step towards the understanding of other multi-electron processes. With this intent in mind many multi-redox systems are investigated. ${ }^{[109,110]}$

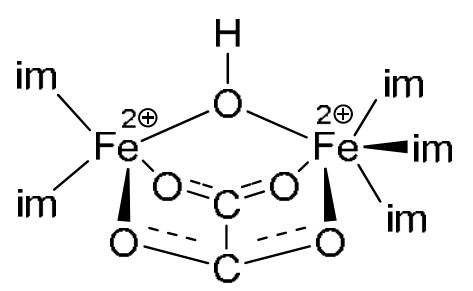<smiles>O=[O+][O-]</smiles>

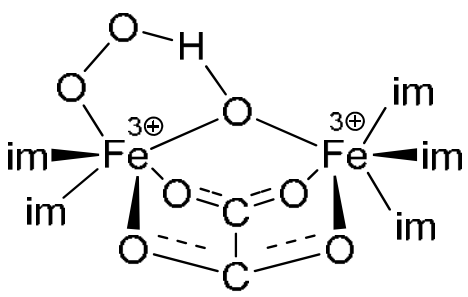

$\mathrm{im}=$ imidazole ligand

Scheme 2-1: Coordination of $\mathrm{O}_{2}$ in hemerythrin 
Aside from the "communication" that can be investigated, it is sometimes helpful to have more than one metal atom present in one complex. ${ }^{[59]}$ Multimetallic compounds often have stronger redox abilities than their monometallic counterparts. ${ }^{[11]}$ Furthermore the reductive elimination of halogens can be facilitated by bimetallic complexes, ${ }^{[60]}$ to name just two examples. Another field of application is the synthesis of conjugated organometallic complexes, ${ }^{[102-104]}$ polymers ${ }^{[112,113]}$ and new materials. ${ }^{[14,115]}$ By incorporating metals into the polymers many chemical and physical properties can be influenced. The diverse number of oxidation states and coordination geometries open up a multitude of possibilities to alter the polymers in the desired fashion. Last but not least, multimetallic compounds often exhibit greater catalytic activity than their monometallic counterparts. ${ }^{[59]}$ One keyword in this regard is the "synergetic effect" that two or more metals can have on each other. This way a good catalyst can be further improved by the introduction of a second metal into the catalytic active complex. In the case of catalysts heterobimetallic complexes are often superior to their homobimetallic complements. ${ }^{[116-118]}$ They are known to be excellent catalysts for a variety of reactions. The main area of application is naturally the polymerization of various alkenes ${ }^{[33,116,119]}$ but also the catalytic enhancement of organic reactions. ${ }^{[120-122]}$ Furthermore, oxidation reactions can be enhanced by the use of heterobimetallic catalysts. ${ }^{[117,123]}$ The most prominent example for the success of two different metals in catalysis are surely the Ziegler-Natta catalysts. ${ }^{[124-126]}$ The combination of an aluminium co-catalyst and a titanium complex makes it possible to polymerize olefines under mild conditions. Even stereospecific polymerization or polymers with defined tacticity are possible with the right catalyst. ${ }^{[2,43]}$ Although up to now the two metals are added separately from each other it would be entirely reasonable to test complexes in which both metals are already present. Since the forming of the active species can then proceed intramolecular instead of intermolecular an increase in activity should be possible.

As the above described facts show, there is a vast area of application for multimetallic complexes and compounds. Therefore, it seemed feasible to examine different approaches to synthesize new ligands that are capable of coordinating more than one metal atom. As already pointed out in the introduction, the main building block for these ligands was always a sulfuriimide. The reasons for this choice are described in detail in the "Scope of this thesis". The fact that the diimidosulfinates and the triimidosulfonates are also subject to SET processes ${ }^{6-8}$ made them additionally interesting for the synthesis of the multimetallic compounds. 


\subsection{Bimetallic Complexes with Cyclopentadienyl Ligands}

The first strategy for the synthesis of a multimetallic complex was to make use of the cyclopentadienyl $(\mathrm{Cp})$ anion, which is often employed in transition metal chemistry and is an integral part in many catalytic active complexes. ${ }^{[127-129]}$ It was planned to use the Cp-anion to coordinate transition metals and a sulfurdiimide as second coordination site for main group metals.

(a)<smiles>[R]N=[S-]([O-])[O-]</smiles>

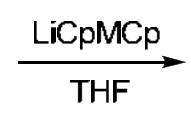

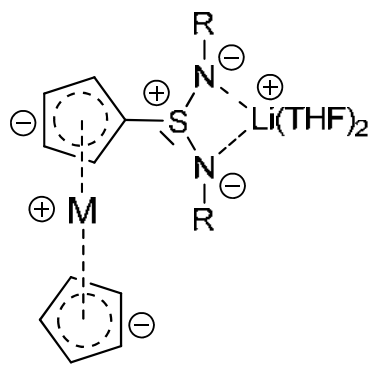

(b)
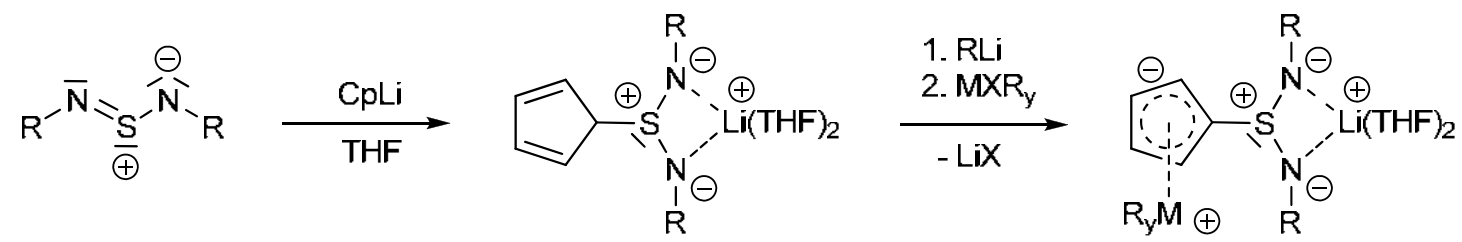

$\mathrm{M}=$ transition metal $\mathrm{R}=$ organic group

Figure 2-2: Possible reaction pathways to heterobimetallic complexes.

As Figure 2-2 shows, a sulfurdiimide was reacted either with a lithiated metallocene a or a Cp-anion b. While method a would lead directly to a heterobimetallic complex the product of method $\mathbf{b}$ has to be lithiated again and a second reaction with $\mathbf{a}$ transition metal salt has to be performed to yield the heterobimetallic complex.

First of all it was tested if the sulfurdiimides can be connected to a metallocene. After the lithiation of ferrocene a nucleophilic attack with a sulfurdiimide as electrophile yielded [(THF) $\left.\left\{\mathrm{Li}\left(\mathrm{N}^{t} \mathrm{Bu}\right)_{2} \mathrm{SCpFeCp}\right\}_{2}\right](\mathbf{1})$.

1 crystallizes as a dimer with one lithium atom being coordinated by all four nitrogen atoms of the two diimidosulfinates resulting in a tetrahedral geometry and the other lithium atom coordinated only by one nitrogen atom of each ligand and a THF molecule resulting in a trigonal planar geometry. This structural motif is well known for diimidosulfinates and 1 exhibits no unusual bond lengths and angles. Only one of the $\mathrm{C}-\mathrm{S}-\mathrm{N}$ angles is more acute $\left(99.3^{\circ}\right)$ than in comparable structures. 

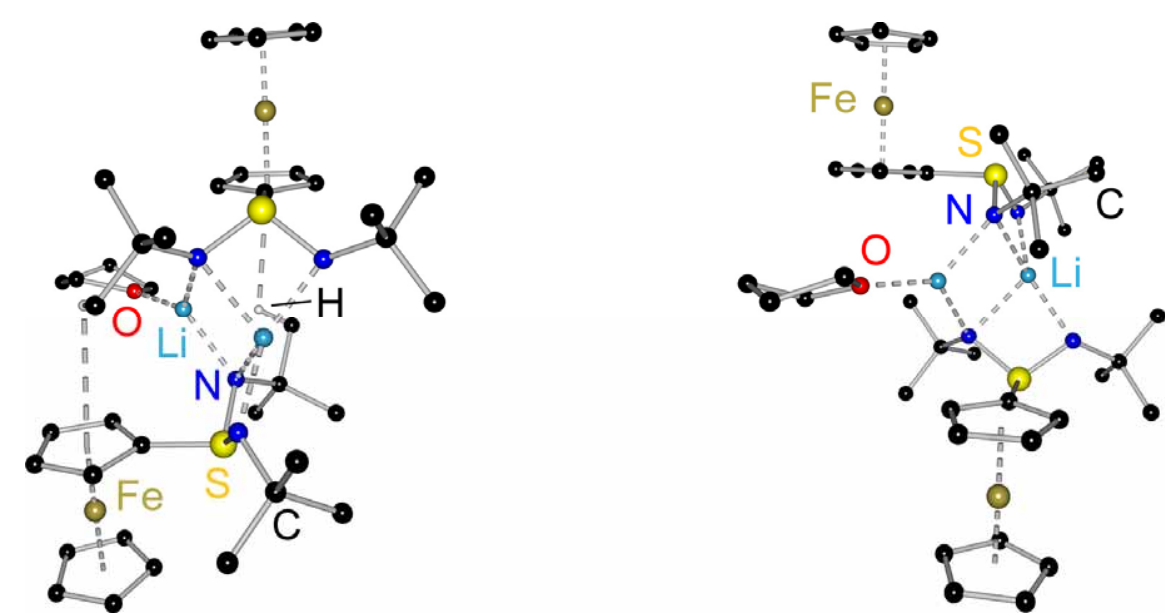

Figure 2-3: Crystal structure of $\left[(\mathrm{THF})\left\{\mathrm{Li}\left(\mathrm{N}^{t} \mathrm{Bu}\right)_{2} \mathrm{SCpFeCp}\right\}_{2}\right]$ (1)with (left) and without (right) hydrogen bond. All hydrogen atoms except for the one forming the hydrogen bond have been omitted for clarity.

This is probably due to the interactions between one hydrogen atom of the ${ }^{t} \mathrm{Bu}$ group and the $\pi$-density of one Cp-anion (see Figure 2-3). Although Roesky showed by synthesizing $\left[\mathrm{Cl}_{3} \mathrm{Sn}\left(\mathrm{N}^{t} \mathrm{Bu}\right)_{2} \mathrm{SCpFeCp}\right]^{[130]}$ that it is possible to exchange the metal coordinated by the diimidosulfinate no further experiments where made in this direction since the number of metallocenes that can be easily metallated is very limited. Besides, in most cases the coordinated transition metal atoms carry no further substituents and are mostly in the wrong oxidation state to exhibit any catalytic activity.

Therefore the more general approach $\mathbf{b}$ described in Figure 2-2 was further investigated. Although 1 shows that it is possible to add the $\mathrm{Cp}$-anion to a sulfurdiimide, the reaction of lithium cyclopentadienyl and tert-butylsulfurdiimide afforded only the reagents. A reaction with magnesium $\mathrm{Cp}$ instead of lithium $\mathrm{Cp}$ yielded the same result. Seemingly, the $\mathrm{Cp}$-anion cannot compensate for the loss of its aromatic character and therefore it does not react with the sulfurdiimide. Another reaction in which one equivalent of MeLi was added later to deprotonate the $\mathrm{Cp}$ substituent right after the addition and therefore restoring the aromaticity failed, too.

The results of Reent who investigated the structures of $\mathrm{Cp}$ lithium, indenyl lithium and fluorenyl lithium with different donor bases display that $\left[(\mathrm{PMDETA}) \mathrm{LiC}_{9} \mathrm{H}_{7}\right]$ shows in contrast to the $\mathrm{CpLi}$ structures a significant part of $\sigma$-bonding in the interactions between the lithium atom and the anion (see Figure 2-4). ${ }^{[131]}$ 

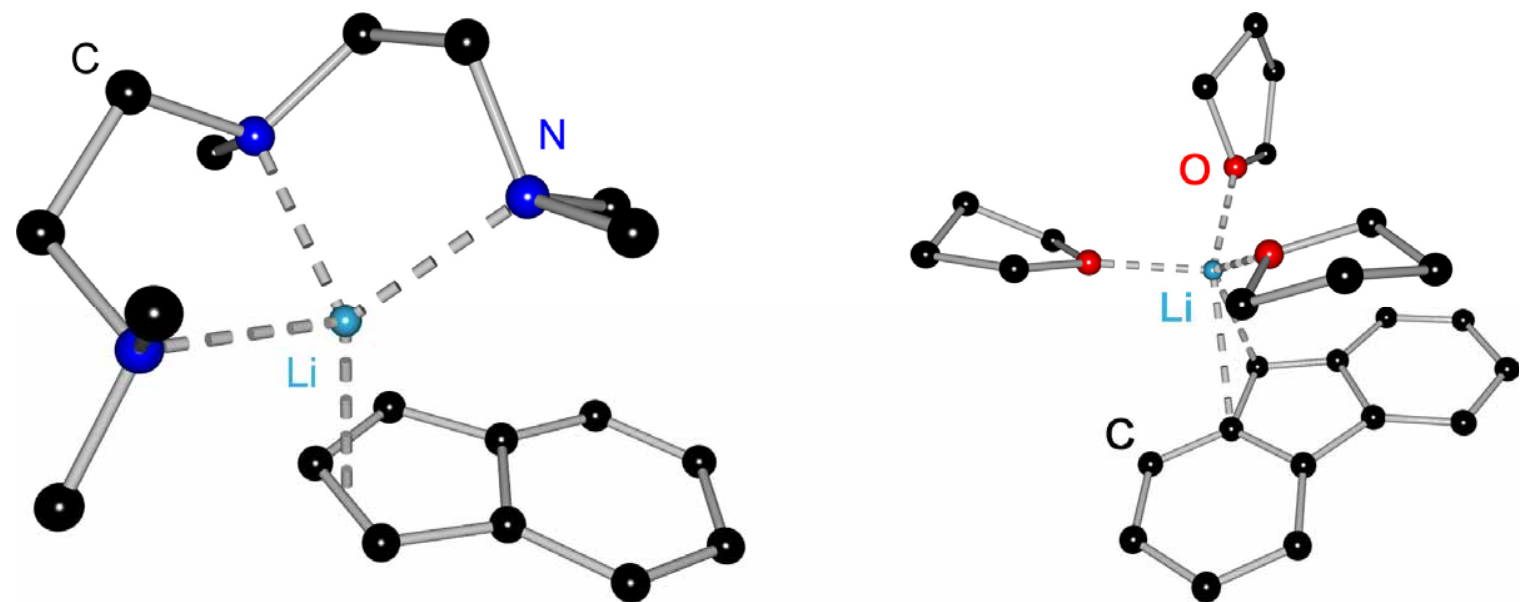

Figure 2-4: Crystal structure of $\left[(\mathrm{PMDETA}) \mathrm{LiC}_{9} \mathrm{H}_{7}\right]$ (left) and $\left[(\mathrm{THF})_{3} \mathrm{LiC}_{13} \mathrm{H}_{9}\right]^{[132]}$ (right). All hydrogen atoms have been omitted for clarity.

For that reason it was tried to add $\left[(\mathrm{PMDETA}) \mathrm{LiC}_{9} \mathrm{H}_{7}\right]$ to the tert-butylsulfurdiimide hoping that the electron density of the indenyl anion is more $\sigma$-localized and therefore would facilitate a reaction. Unfortunately this presumption did not prove to be true. In a last attempt to synthesize a diimidosulfinate with a sulfur bound group that is similar to $\mathrm{Cp}$, fluorene was lithiated and afterwards reacted with tert-butylsulfurdiimide. Admittedly the fluorenyl anion looses the aromaticity at the central five-membered ring but due to the phenyl rings attached to it the loss of energy should be smaller than for the $\mathrm{Cp}$ anion or the indenyl. However the reaction did not yield the desired product, either. Therefore the idea of synthesizing a ligand as shown in Figure 2-2 was abandoned.

\subsection{Coupled Diimidosulfinates}

To combine two metals in one molecule it is often feasible to use Janus-head ligands. ${ }^{[133-135]}$ These ligands have the possibility to coordinate hard and soft metals ${ }^{[136-138]}$ by employing two different coordination sites. Since diimidosulfinates are known to be able to coordinate hard metals like lithium ${ }^{[67,69]}$ but also soft metals like caesium ${ }^{[67]}$ and barium ${ }^{[139]}$, they are an obvious choice for the design of a Janushead ligand. By the linkage of two diimidosulfinates it should be possible to synthesize ligands that are capable of coordinating all kinds of different metals (see Scheme 2-2). 


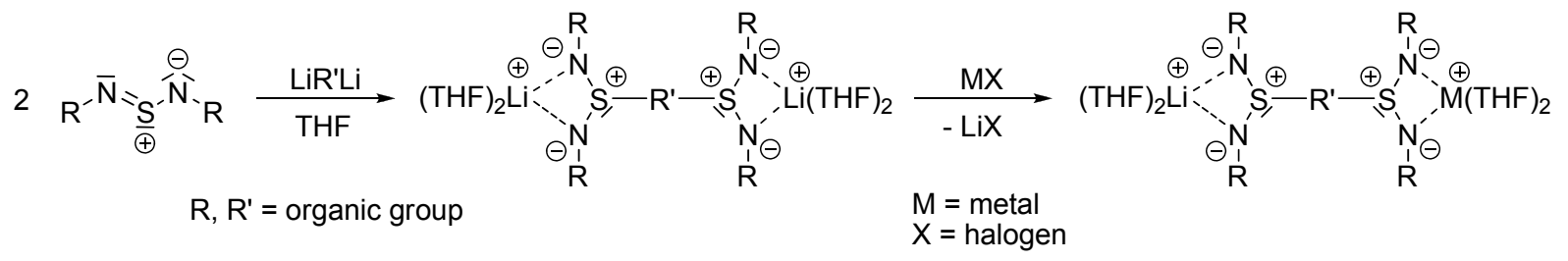

Scheme 2-2: Synthesis of coupled diimidosulfinates.

In addition, the tendency of the diimidosulfinates to dimerize could in the case of coupled diimidosulfinates lead to possible metal containing polymers.

Earlier investigations in our group already showed that it is possible to connect two sulfurdiimides by an organic spacer (see Figure 2-5). Walfort succeeded in coupling two sulfurdiimides and also two sulfurtriimides by a methylene bridge. ${ }^{[72,140]}$ Selinka was able to achieve the same with a thiophene, dithiophene and a selenophene bridge ${ }^{[91]}$ Because of these results the attempt to broaden this field of organic spacers seemed promising.
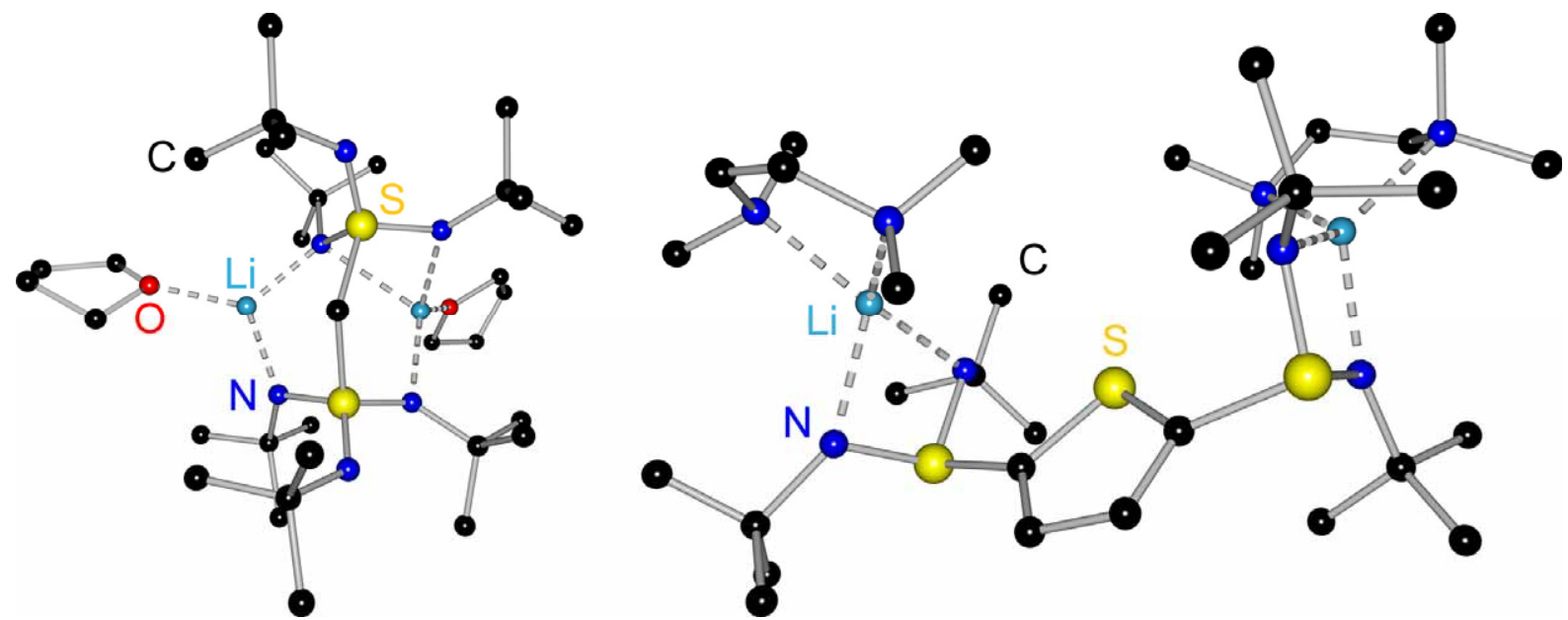

Figure 2-5: Crystal structures of a coupled triimidosulfonate (left) and a coupled diimidosulfinate (right). All hydrogen atoms have been omitted for clarity.

The metal exchange reactions of the described coupled lithium diimidosulfinates were up to this point totally uninvestigated. Walfort as well as Selinka only synthesized the lithium complexes. Therefore, studies on the reaction with different metal halogens and metal amides were of special interest. 


\subsubsection{Diimidobenzenyl- and diimidobiphenylsulfinates}

Since aryl groups are more rigid and therefore tend to give less intramolecular side reactions when doubly metalated ${ }^{[141,142]}$ it seemed to be an obvious choice to employ aromatic frameworks like dibromobenzene and dibromobiphenyl as organic spacers (see Figure 2-6). In addition, aromatic spacers are suitable "wires" for the electron transfer processes between two metal atoms. ${ }^{[143]}$ Another advantage of the mentioned aryl groups is the possibility to use different regioisomers. By the use of either 1,4-dibromobenzene and 1,3-dibromobenzene or biphenyl and 4,4'-dibromobiphenyl it is possible to vary the distance of the coordination sites and thereby also the space between both metal atoms. With this strategy in mind the organic groups where lithiated and reacted with different sulfurdiimides.<smiles>[AlH2]c1cccc(Cl)c1</smiles>

$\mathrm{Li}$<smiles>[Al]c1ccc(Cl)cc1</smiles>

Li<smiles>Clc1ccc(-c2ccc(Cl)cc2)cc1</smiles><smiles>Clc1ccccc1-c1ccccc1Cl</smiles>

Figure 2-6: Lithiated spacers for the synthesis of coupled diimidosulfinates.

For the synthesis of the coupled lithium diimidosulfinates 1,4-dibromobenzene, 1,3dibromobenzene, 2,2'-dibromobiphenyl and 4,4'-dibromobiphenyl were twofold lithiated with ${ }^{n} \mathrm{BuLi}$ or ${ }^{t} \mathrm{BuLi}$ in the case of the dibromobenzene compounds. Unfortunately, the reactions of 2,2'-dilithiumbiphenyl and 1,3-dilithiumbenzene with sulfurdiimides did not afford the desired products. The reason for this is probably the smaller distance between the lithiated positions. Apparently, there is not enough space for the addition of two sulfurdiimides. The other spacers reacted readily with the sulfurdiimides (see Scheme 2-3) and yielded the coupled diimidosulfinates $\left[(\mathrm{THF})_{4} \mathrm{Li}_{2}\left\{\left(\mathrm{NSiMe}_{3}\right)_{2} \mathrm{~S}_{2} \mathrm{C}_{12} \mathrm{H}_{8}\right](2)\right.$ and $\left[(\mathrm{THF})_{1.5} \mathrm{Li}_{2}\left\{\left(\mathrm{NSiMe}_{3}\right)_{2} \mathrm{~S}_{2} \mathrm{C}_{12} \mathrm{H}_{8}\right]_{\infty}(3)\right.$. 


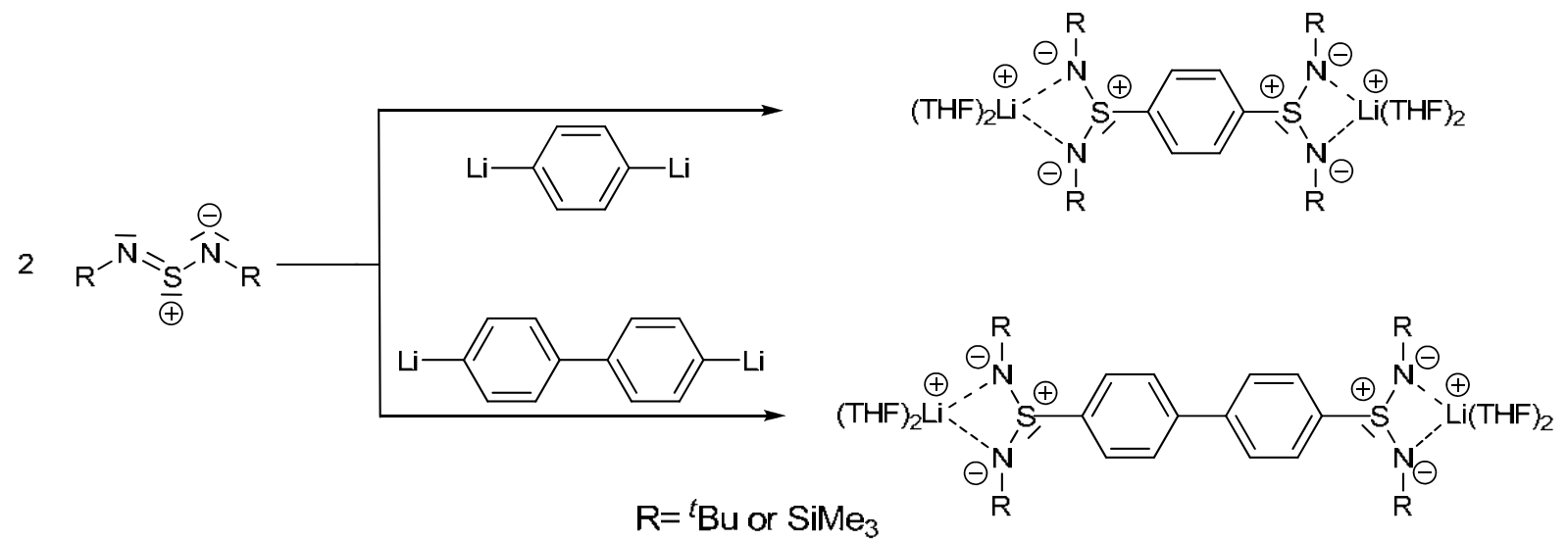

Scheme 2-3: Synthesis of coupled lithium diimidosulfinates.

Unfortunately, $\left[\left\{(\mathrm{THF})_{2} \mathrm{Li}(\mathrm{NR})_{2} \mathrm{~S}_{2} \mathrm{C}_{6} \mathrm{H}_{4}\right]\right.$ could not be isolated and characterized due to the inevitable forming of lithium bromide during the synthesis of 1,4-dilithiumbenzene. Several attempts to separate the lithium bromide or prevent its accruement during the course of the synthesis failed. It seems that the twofold lithiated benzene is highly reactive and attacks the formed $\mathrm{RBr}(\mathrm{R}=n$-butyl, tert-butyl) yielding lithium bromide. ${ }^{[144]}$ Attempts to separate the lithium bromide from the product by using polar solvents failed, too. This indicates that the formed lithium salt gets coordinated by the 1,4-dilithiumbenzene and so evades the separation. This hampers further experiments since the molecular weight is unknown and the amount of 1,4-dilithiumbenzene appointed for a reaction can not be determined. In addition, this makes it nearly impossible to get reliable evidence of the forming of $\left[\left\{(\mathrm{THF})_{2} \mathrm{Li}(\mathrm{NR})_{2} \mathrm{~S}\right\}_{2} \mathrm{Ph}\right]$ from NMR spectra since they are not free of side products, as it is not possible to make equimolar reactions. The crystal structure could also not be obtained since the lithium bromide crystallizes a lot better then the lithium diimidosulfinate. Due to this problems the 1,4-dilithiumbenzene was reacted with diphenylchlorphosphane to validate if the lithiation was successful. The reaction yielded 1,4-diphenylphosphanylbenzene (4) that apparently crystallizes better than the lithium bromide and could therefore be structurally characterized (see Figure 2-7). 


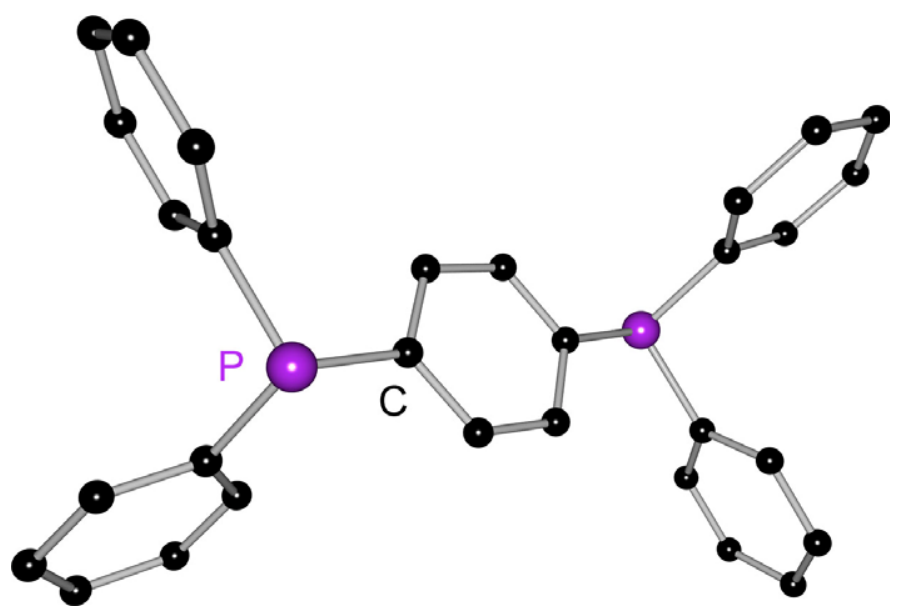

Figure 2-7: Crystal structure of $\left[\left\{(\mathrm{Ph})_{2} \mathrm{P}\right\}_{2} \mathrm{C}_{6} \mathrm{H}_{4}\right](4)$. All hydrogen atoms have been omitted for clarity.

As expected the structure shows a trigonal-pyramidal geometry around the phosphorous atom and both diphenylphosphane units arranged trans to each other. The bond lengths and angles within the molecule exhibit no unusual values. The formation of $\mathbf{4}$ shows that the twofold lithiation took place and that a reaction with an electrophile is possible.

In comparison to the dilithiated benzene 4,4'-dilithiumbiphenyl seems to be less reactive and therefore no lithium bromide is formed during the synthesis. The reaction of 4,4'-dilithiumbiphenyl with sulfurdiimides yielded the coupled diimidosulfinates 2 and $\mathbf{3}$. Remarkably, 2 crystallizes at $-30^{\circ} \mathrm{C}$ in the triclinic space group $P \overline{1}$ (see Figure 2-8) with half of the molecule in the asymmetric unit. In contrast to most of the diimidosulfinates described in the literature, the molecule does not dimerize but accomplishes the favored fourfold coordination of the lithium atom by coordination of two THF molecules. Up to now, monomeric diimidosulfinates were only know with a bidentate donor base like TMEDA. ${ }^{[82]}$ Otherwise only triimidosulfonates or the $\mathrm{S}\left(\mathrm{N}^{t} \mathrm{Bu}\right)_{4}{ }^{2-}$ anion are known to crystallize as monomers when THF is the only donor base present. ${ }^{[0,90]} \mathbf{2}$ shows a disorder of the coordinated THF molecules and the biphenyl framework. Interestingly the percentages of both disorders are exactly the same. A look at the packing plot reveals the cause of this feature. The disorder of the THF molecules induces the disorder at the central phenyl rings and vice versa by hydrogen bonds to the $\pi$-system (Figure 2-8 left). The system can either form one stronger hydrogen bond with the $\pi$-system (orange hydrogen: $2.97 \AA$ ) or two hydrogen bonds the one with the $\pi$-system being a little bit weaker (green hydrogen: $3.09 \AA$ ) and another one with one of the nitrogen atoms (black hydrogen: $3.01 \AA)$. 


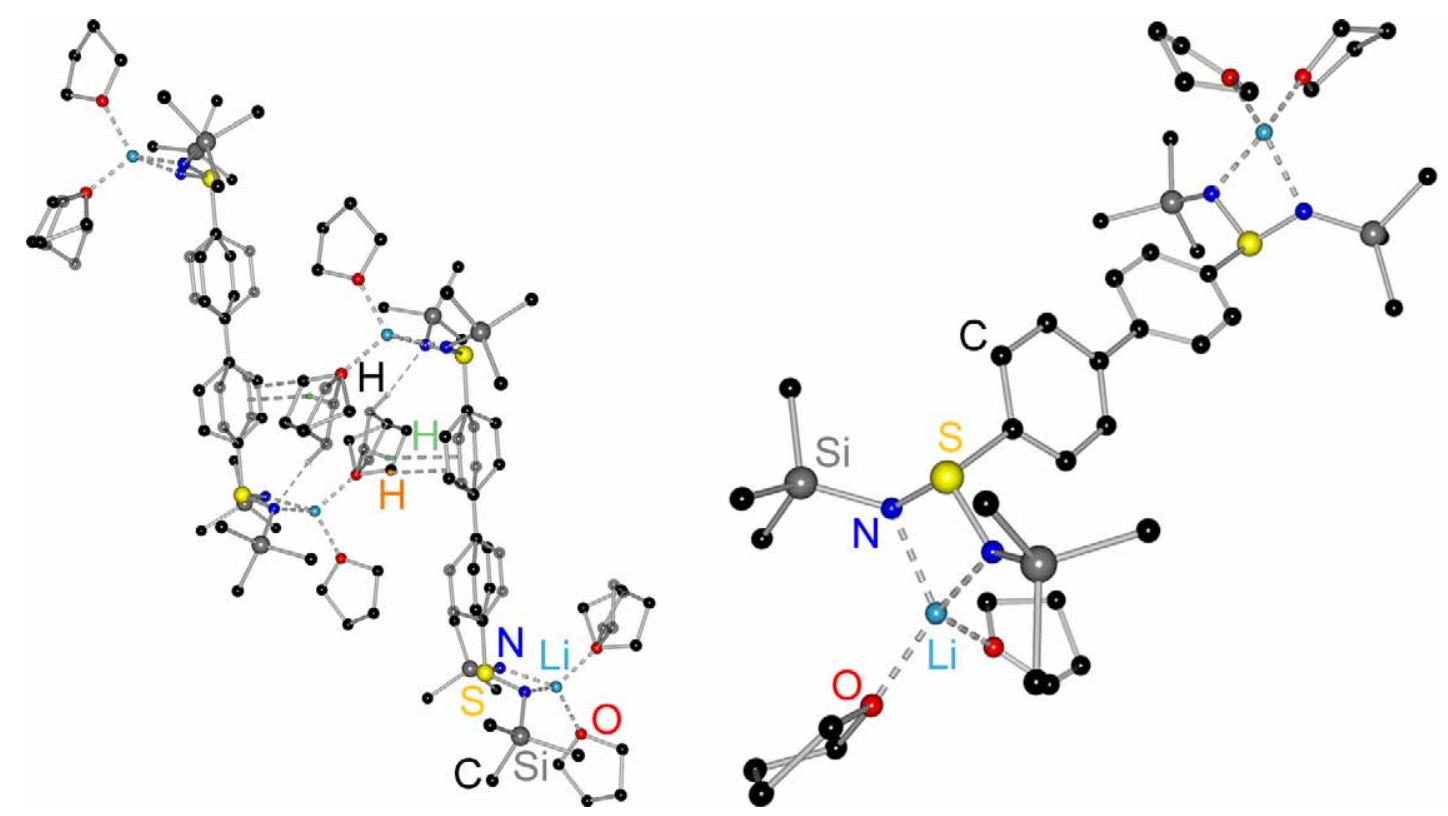

Figure 2-8: Crystal structure of [(THF $)_{4} \mathrm{Li}_{2}\left\{\left(\mathrm{NSiMe}_{3}\right)_{2} \mathrm{~S}_{2} \mathrm{C}_{12} \mathrm{H}_{8}\right]$ (2) with (left) and without (right) hydrogen bonds. All hydrogen atoms except for the ones forming the hydrogen bonds have been omitted for clarity.

When the reaction of dilithiumbiphenyl with trimethylsilylsulfurdiimide is carried out in a 1:1 THF/hexane mixture and the saturated solution is stored at room temperature, 3 is obtained. In contrast to 2 it oligomerizes (see Figure 2-9) as one would expect from previous known lithium diimidosulfinate structures ${ }^{[67,68,140]}$ and forms polymeric chains in the solid state. Interestingly, $\mathbf{3}$ shows two different coordination geometries depending on the dimerization course. On one side of the biphenyl framework the oligomerized molecules are arranged linear to each other while on the other side the molecules are aligned nearly perpendicular $\left(99.4^{\circ}\right)$. When the biphenyl groups are perpendicular to each other one lithium atom is coordinated by two nitrogen atoms of both molecules while the second one is coordinated by one nitrogen atom of each ligand and a THF molecule. This results in a distorted tetrahedral geometry for the first lithium atom and a trigonal planar for the second one. When the ligands are arranged linear to each other a step-shaped coordination motif is formed. Both lithium atoms are coordinated by two nitrogen atoms of one ligand, one nitrogen atom of the other ligand and one THF molecule resulting in a tetrahedral geometry around the metal atoms (see Figure 2-9). 


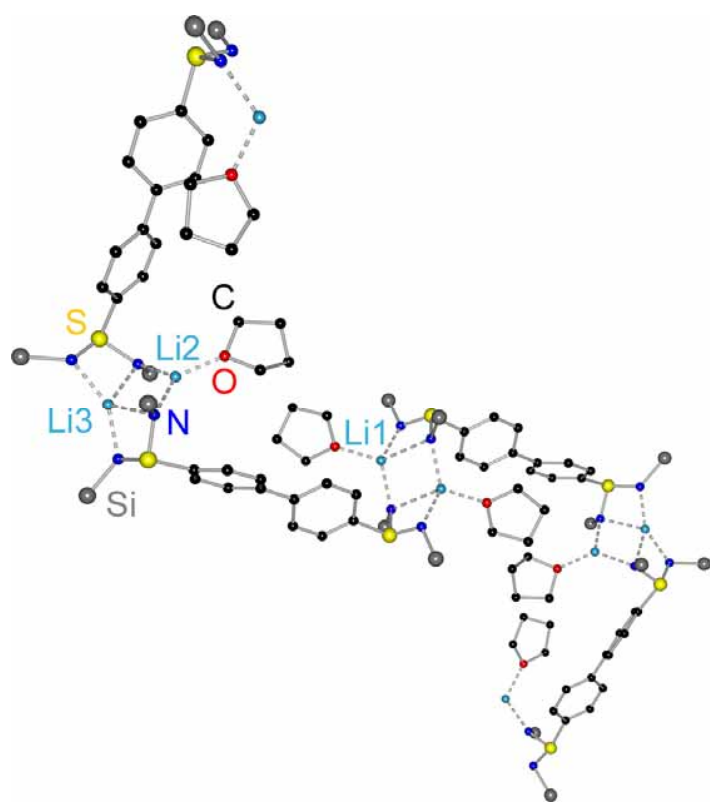

Figure 2-9: Part of the crystal structure of $\left[(\mathrm{THF})_{1.5} \mathrm{Li}_{2}\left\{\left(\mathrm{NSiMe}_{3}\right)_{2} \mathrm{~S}_{2} \mathrm{C}_{12} \mathrm{H}_{8}\right]_{\infty}\right.$ (3). All hydrogen atoms and the carbon atoms of the trimethylsilyl groups have been omitted for clarity.

Both structural motifs are known for lithium diimidosulfinates and the bond lengths and angles are mostly in the normal range compared with the structures already described in the literature. ${ }^{[139,145]}$ When comparing the bond lengths and angles of 3 with $\left[(\mathrm{THF}) \mathrm{Li}\left(\mathrm{NSiMe}_{3}\right)_{2} \mathrm{SPh}\right]_{2}$ which also exhibits the mentioned step-shaped structural motif, it is noticeable that the $\mathrm{N}-\mathrm{S}-\mathrm{N}$ backbone does not change significantly, only the distances around the lithium atoms differ slightly (see Table 2-1). For the step-shaped alignment in 3 the shortest Li-N distance (1.98 $\AA$ ) is shorter by $0.03 \AA$ while the longest $\mathrm{Li}-\mathrm{N}$ bond $(2.42 \AA)$ is longer by $0.03 \AA$ compared to $\left[(\mathrm{THF}) \mathrm{Li}\left(\mathrm{NSiMe}_{3}\right)_{2} \mathrm{SPh}_{2}{ }^{[76]}\right.$ The second motif exhibited by 2 can also be observed in $\left[\left(\mathrm{Et}_{2} \mathrm{O}\right)\left\{\mathrm{Li}\left(\mathrm{NSiMe}_{3}\right)_{2} \mathrm{SPh}\right\}_{2}\right] .{ }^{[76]}$ While the Li2-N and Li2-O distances are nearly the same in both structures, the differences in the coordination of Li3 are more distinct. Comparison with $\left[\left(\mathrm{Et}_{2} \mathrm{O}\right)\left\{\mathrm{Li}\left(\mathrm{NSiMe}_{3}\right)_{2} \mathrm{SPh}\right\}_{2}\right]$ shows that both $\mathrm{Li}-\mathrm{N}$ distances are clearly shorter in 3 . The change of the donating solvent from $\mathrm{Et}_{2} \mathrm{O}$ to $\mathrm{THF}$ seems not to be the reason for the differences since the bond lengths around Li2 are similar in both structures. This leaves only the polymeric form of $\mathbf{3}$ as a reason for the distinctions.

Taking a look at the three different lithium atoms present in $\mathbf{3}$, it is apparent that the $\mathrm{Li}-\mathrm{N}$ and $\mathrm{Li}-\mathrm{O}$ distances around Li2 are the shortest. Since Li2 exhibits only three instead of four coordinative bonds it has to make up for it by stronger and therefore shorter bonds. Especially the Li-O distance is $0.06 \AA$ shorter than in $\mathbf{2}$ and even 0.09 A shorter than the Li1-O bond in $\mathbf{3}$. 
Table 2-1: Selected bond lengths $[\AA]$ and angles for 2, 3, $\left[(\mathrm{THF}) \mathrm{Li}\left(\mathrm{NSiMe}_{3}\right)_{2} \mathrm{SPh}\right]_{2}$ and $\left[\left(\mathrm{Et}_{2} \mathrm{O}\right)\left\{\mathrm{Li}\left(\mathrm{NSiMe}_{3}\right)_{2} \mathrm{SPh}\right\}_{2}\right]$.

\begin{tabular}{|c|c|c|c|c|}
\hline Compound & 2 & 3 & {$\left[(\mathrm{THF}) \mathrm{Li}\left(\mathrm{NSiMe}_{3}\right)_{2} \mathrm{SPh}\right]_{2}$} & {$\left[\left(\mathrm{Et}_{2} \mathrm{O}\right)\left\{\mathrm{Li}\left(\mathrm{NSiMe}_{3}\right)_{2} \mathrm{SPh}\right\}_{2}\right]$} \\
\hline \multicolumn{5}{|l|}{ Distances } \\
\hline S-N (av.) & $1.601(2)$ & $1.600(4)$ & $1.610(2)$ & $1.609(3)$ \\
\hline S-C (av.) & $1.810(2)$ & $1.793(4)$ & $1.803(3)$ & $1.808(4)$ \\
\hline Li1-N & $\begin{array}{l}2.040(3) \\
2.082(3)\end{array}$ & $\begin{array}{l}1.989(8) \\
2.426(8) \\
2.055(8)\end{array}$ & $\begin{array}{l}2.022(5) \\
2.393(5) \\
2.054(5)\end{array}$ & \\
\hline $\mathrm{Li} 2-\mathrm{N}$ & & $2.019(8)$ & & $2.033(5)$ \\
\hline Li3-N & & $\begin{array}{l}2.199(8) \\
1.984(5)\end{array}$ & & $\begin{array}{l}2.245(5) \\
1.994(3)\end{array}$ \\
\hline Li1-O & $\begin{array}{l}1.941(3) \\
1.947(4)\end{array}$ & $1.973(8)$ & $1.974(5)$ & \\
\hline $\mathrm{Li} 2-\mathrm{O}$ & & $1.886(13)$ & & $1.897(9)$ \\
\hline \multicolumn{5}{|l|}{ Angles } \\
\hline $\mathrm{N}-\mathrm{S}-\mathrm{N}(\mathrm{av})$. & $104.0(1)^{\circ}$ & $105.9(2)^{\circ}$ & $105.9(1)^{\circ}$ & $105.7(1)^{\circ}$ \\
\hline C-S-N (av.) & $103.0(1)^{\circ}$ & $103.2(2)^{\circ}$ & $104.3(1)^{\circ}$ & $103.0(3)^{\circ}$ \\
\hline
\end{tabular}

Finally, the fact that both compounds can be crystallized shows that the energy difference between $\mathbf{2}$ and $\mathbf{3}$ must be rather small. From the variety of known dimeric diimidosulfinates it is evident that $\mathbf{3}$ exhibits a favorable coordination for the lithium atoms but what is the reasons for the existence of 2 . An explanation might be the formation of hydrogen bonds in the solid state. While in $\mathbf{3}$ only intramolecular hydrogen bonds can be found, in 2 the stability of the solid state structure is further enhanced by intermolecular hydrogen bonds (see Figure 2-8).

As mentioned before, up to now only lithium complexes of the coupled imidosulfinates where known. Therefore extensive metal exchange reactions of the synthesized coupled diimidosulfinates where carried out. To accomplish the synthesis of the desired bimetallic complex various metal halogens and metal amides of aluminum, calcium, tin, zinc, titanium and copper where reacted with the lithium complexes. Unfortunately the lithium precursors seem to be extremely stable. Therefore, nearly all reactions yielded only the reactant or unidentifiable product mixtures. A possible explanation can be concluded from the structure of 3. 
Apparently the coupled lithium diimidosulfinates have the potential to polymerize thereby possibly forming stable polymeric molecules in solution. Because of the extensive polymers the metal exchange reaction is probably not easy from a steric point of view. In addition, the exchange of a lithium atom with another metal atom does not lead to a new discrete molecule but only to a lithium polymer doped with another metal. Therefore, the formation of a single product is somewhat hindered. Even if the polymer gets terminated, no unitary product could be isolated, but only polymers of different chain lengths. These facts plus the strong $\mathrm{Li}-\mathrm{N}$ interactions might prevent a metal exchange or the isolation of a defined product.

In spite of all failed experiments, the reaction with dimethylaluminumchloride was successful. The lithium diimidosulfinates were treated with half an equivalent of $\mathrm{AlMe}_{2} \mathrm{Cl}$ at $-78{ }^{\circ} \mathrm{C}$ (see Scheme 2-4). The reactions proceeded smoothly and afforded $\left[\left\{\mathrm{Me}_{2} \mathrm{Al}\left(\mathrm{N}^{t} \mathrm{Bu}\right)_{2} \mathrm{~S}\right\}_{2} \mathrm{C}_{12} \mathrm{H}_{8}\right](\mathbf{5})$ and $\left[\left\{\mathrm{Me}_{2} \mathrm{Al}\left(\mathrm{NSiMe}_{3}\right)_{2} \mathrm{~S}_{2} \mathrm{C}_{6} \mathrm{H}_{4}\right](\mathbf{6})\right.$.
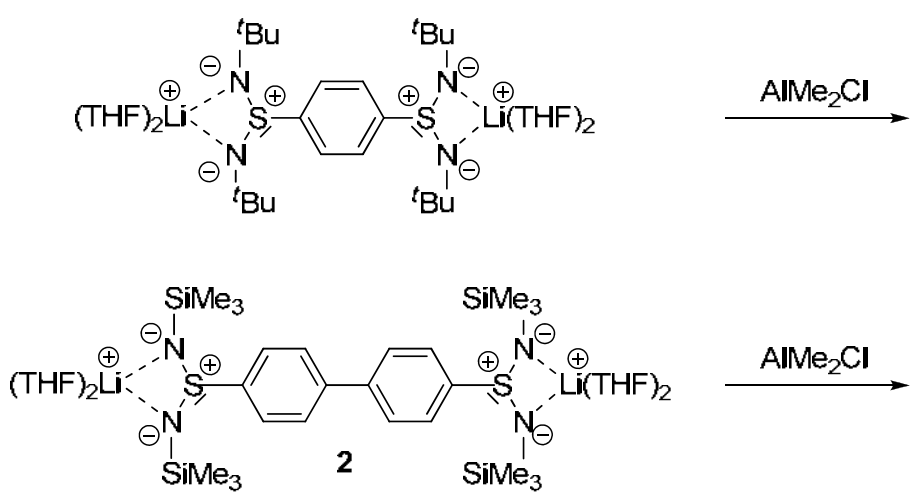
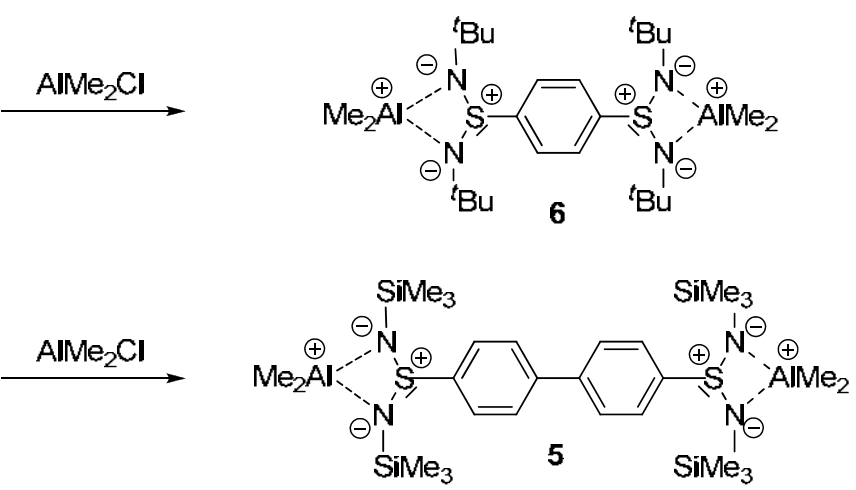

Scheme 2-4: Synthesis of 5 and 6.

Both compounds could be crystallized and structurally characterized. Although only half an equivalent was used for the exchange both lithium positions got replaced by dimethylaluminum. In the case of $\mathbf{6}$ the amount of the used lithium diimidosulfinat could not be determined unequivocally due to reasons discussed earlier but since the molecular mass of $\mathbf{2}$ was known, it seems that the exchange reaction with dimethylaluminumchloride is not selective enough to substitute only one lithium atom. 5 and 6 show nearly the same structural motif. The N-S-N planes exhibit a similar angle to the aromatic spacer planes $\left(120.0^{\circ}\right.$ for 5 and $125.1^{\circ}$ for $\left.\mathbf{6}\right)$ and in both structures the two sulfurdiimido moieties are arranged trans to each other (see Figure 2-10). Both aluminum atoms show a tetrahedral geometry with the $\mathrm{N}-\mathrm{Al}-\mathrm{N}$ angle being clearly smaller than the ideal tetrahedral angle and all other angles around the metal atom being slightly larger. 

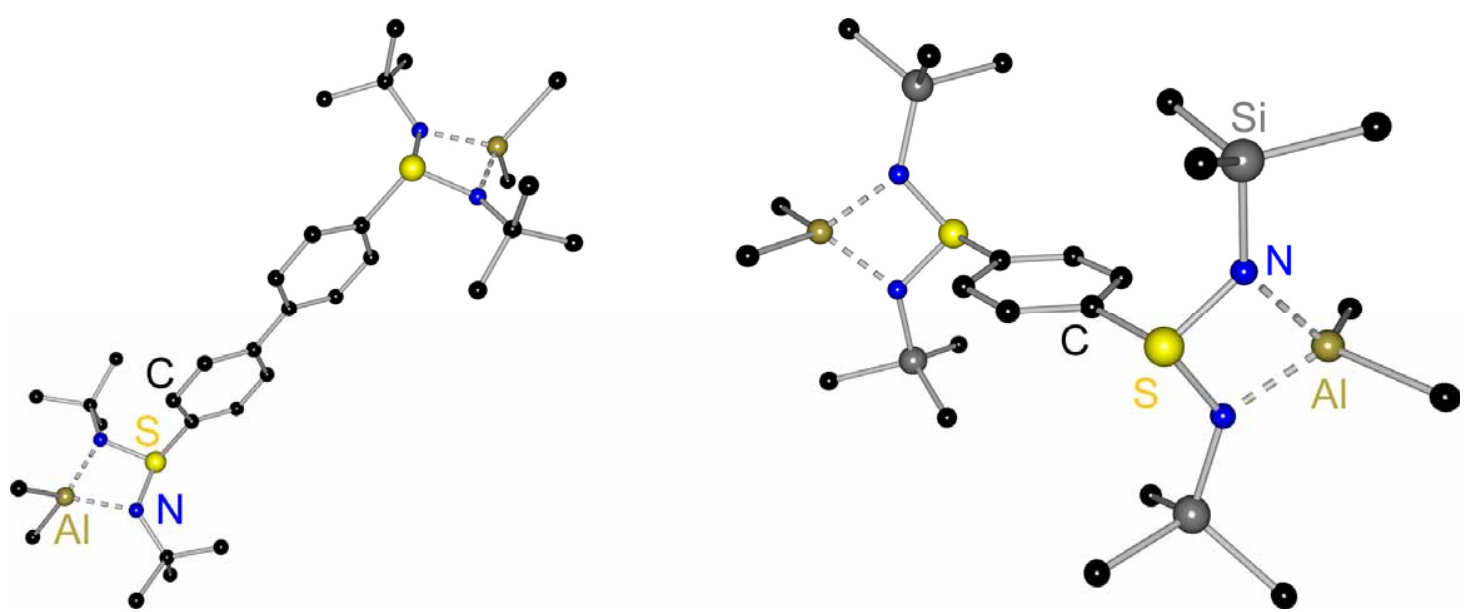

Figure 2-10: Crystal structure of $\left[\left\{\mathrm{Me}_{2} \mathrm{Al}\left(\mathrm{N}^{t} \mathrm{Bu}\right)_{2} \mathrm{~S}_{2} \mathrm{C}_{12} \mathrm{H}_{8}\right](5)\right.$ (left) and $\left[\left\{\mathrm{Me}_{2} \mathrm{Al}\left(\mathrm{NSiMe}_{3}\right)_{2} \mathrm{~S}\right\}_{2} \mathrm{C}_{6} \mathrm{H}_{4}\right](6)$ (right). All hydrogen atoms have been omitted for clarity.

All bond lengths and angles are similar and in the same range as other known aluminum imido sulfur complexes. ${ }^{[00,146]}$ Only small differences can be seen in the S$\mathrm{N}$ and $\mathrm{Al}-\mathrm{N}$ bond lengths (see Table 2-2). In 5 the $\mathrm{S}-\mathrm{N}$ bond length are elongated by $0.02 \AA$ while the $\mathrm{N}-\mathrm{Al}$ bond lengths are shortened by the same distance. This is due to the negative charge on the nitrogen atom that is used to strengthen either the bond to the aluminum atom or to the sulfur atom. These small differences arise probably due to the change of the organic group at the nitrogen atoms from tert-butyl to trimethylsilyl and the change of the organic spacer.

2 and both aluminum diimidosulfinates exhibit nearly the same structural motif (see Figure 2-10). Only the metal and the two donor groups (from THF to methyl) are changed otherwise the geometry is preserved.

Table 2-2: Selected bond lengths $[\AA]$ and angles $\left[{ }^{\circ}\right]$ for 5 and $\mathbf{6}$.

\begin{tabular}{cccccc}
\hline Compound & $\mathbf{5}$ & $\mathbf{6}$ & Compound & $\mathbf{5}$ & $\mathbf{6}$ \\
\hline Distances & & \multicolumn{5}{c}{ Angles } \\
S-N1 & $1.6435(17)$ & $1.6219(21)$ & & & \\
S-N2 & $1.6481(18)$ & $1.6246(23)$ & N-S-N & $91.17(9)$ & $94.94(12)$ \\
S-C & $1.7955(20)$ & $1.8005(23)$ & & & \\
Al-N1 & $1.9082(17)$ & $1.9291(17)$ & N-Al-N & $75.90(7)$ & $76.49(10)$ \\
Al-N2 & $1.9148(19)$ & $1.9355(17)$ & & & \\
& $1.9574(29)$ & $1.9580(29)$ & & $105.71(9)$ & $105.05(11)$ \\
Al-C & $1.9803(25)$ & $1.9588(32)$ & C-S-N & $106.30(9)$ & $105.36(11)$ \\
\hline
\end{tabular}


When comparing the lithium diimidosulfinates with $\mathbf{5}$ and $\mathbf{6}$ the only differences that can be seen lie in the $\mathrm{M}-\mathrm{N}$ bond lengths (average Li: $2.04 \AA$ vs. average Al: $1.92 \AA$ ) and resulting from this distinction the $\mathrm{N}-\mathrm{S}-\mathrm{N}$ angles (average Li: $103^{\circ} \mathrm{vs}$. average Al: $93^{\circ}$ ) are also different. If the metal-nitrogen bonds are shortened the sulfur-metal distances get smaller, too. To prevent both atoms from getting to close to each other the $\mathrm{N}-\mathrm{S}-\mathrm{N}$ angle is then widened. In addition the $\mathrm{S}-\mathrm{N}$ bond lengths are slightly elongated in $\mathbf{5}$ and $\mathbf{6}$ (average $1.64 \AA$ and $1.62 \AA$ ) compared to $\mathbf{2}$ and $\mathbf{3}$ (average $1.60 \AA$ ) probably because the aluminum atom acquires more of the negative charge at the nitrogen atom resulting in smaller electrostatic interactions between the sulfur atom and the nitrogen atom. Otherwise the distances and angles in the ligands are the same.

The described experiments showed that the organic compounds 1,4-dibromobenzene, 1,3-dibromobenzene, biphenyl and 4,4'-dibromobiphenyl can be easily twofold lithiated. Due to steric hindrance only 1,4-dilithiumbenzene and 4,4'-dilithiumbiphenyl react with sulfurdiimides to give the coupled diimidosulfinates 2, 3, 5 and $\mathbf{6}$. The reactions showed that aryl groups are perfect candidates for the linkage of two ligands since the twofold lithiation proceeds nearly quantitive and without side reactions. The rigid body of the aryl groups makes intramolecular side reactions nearly impossible resulting in high yields and purity of the dilithiated products. Furthermore the sulfurdiimides react smoothly with the lithiated spacers resulting in the desired coupled diimidosulfinates, which are obtained in good yields.

The formation of $\mathbf{3}$ is especially interesting since it proves that the coupled diimidosulfinates may be suitable compounds for the synthesis of metal containing polymers. When the right conditions are present the mainly monomeric coupled diimidosulfinates oligomerize. This behavior is not unexpected since the diimidosulfinates tend to crystallize as dimers when coordinating monocations as well as dications. Thus the possibilities to tune the attributes of the polymer by changing the metal atom are nearly infinite. Although the addition reactions worked out well and yielded $\mathbf{2}$ and $\mathbf{3}$ the following metal exchange reactions where unsatisfying. Most of the used metal reagents were either not reactive enough to accomplish the desired metal exchange or not selective enough to only substitute one of the two lithium atoms. This shows that although the linked diimidosulfinates seem to be good ligands for bimetallic molecules a heterobimetallic complex can probably not be synthesized that way. Therefore, one has to either find better suited metal compounds or another 
way to synthesize a heterobimetallic complex. A possible idea would be to build up the molecule step by step. First a spacer has to be found which can be selectively lithiated. Then one could lithiate only one of the two possible positions, add the sulfurdiimide and make the metal exchange without worrying about the selectiveness. Afterwards the second position could be lithiated to build up the additional coordination side. A promising candidate for this kind of synthesis is 9,10dibromoanthracene, as studies in our working group showed that is possible to selectively lithiate only one of the two carbon atoms carrying a bromine atom. ${ }^{[147]}$

\subsubsection{Diimidoanthracenylsulfinates}

\subsubsection{Mono-diimidoanthracenylsulfinates}

The results presented in chapter 2.3.1 made it evident that the main problem is not the synthetic access to coupled diimidosulfinates but the following metal exchange. Reactions of metal halogens or metal amides that work with lithiumorganyl diimidosulfinates do not give the expected products when reacted with the coupled lithium diimidosulfinates. Even if a reaction takes place not one but both lithium atoms get exchanged making the synthesis of a heterobimetallic complex impossible. ${ }^{[146]}$

To bypass this problem an organic spacer with two halogen atoms that can be selectively lithiated at one position should be employed. After the lithiation of one halogen atom, the product could be added to one equivalent of a sulfurdiimide and a metal exchange reaction could be performed. After building up one side of the molecule, a second lithiation and addition of a second sulfurimide should yield the desired heterobimetallic complex (see Scheme 2-5).

Earlier investigations in our working group showed that it is possible to selectively Itihiate only one of the two bromine atoms in 9,10-dibromoanthracene. ${ }^{[148]}$ In addition Schwab succeeded in substituting one bromine atom by a phosphane and could afterwards still replace the second bromine atom by a lithium atom. ${ }^{[147]}$ Therefore, 9,10-dibromoanthracene seemed to be an interesting spacer for the coupling of two diimidosulfinates. The results of the experiments with this organic spacer are presented in this chapter. 


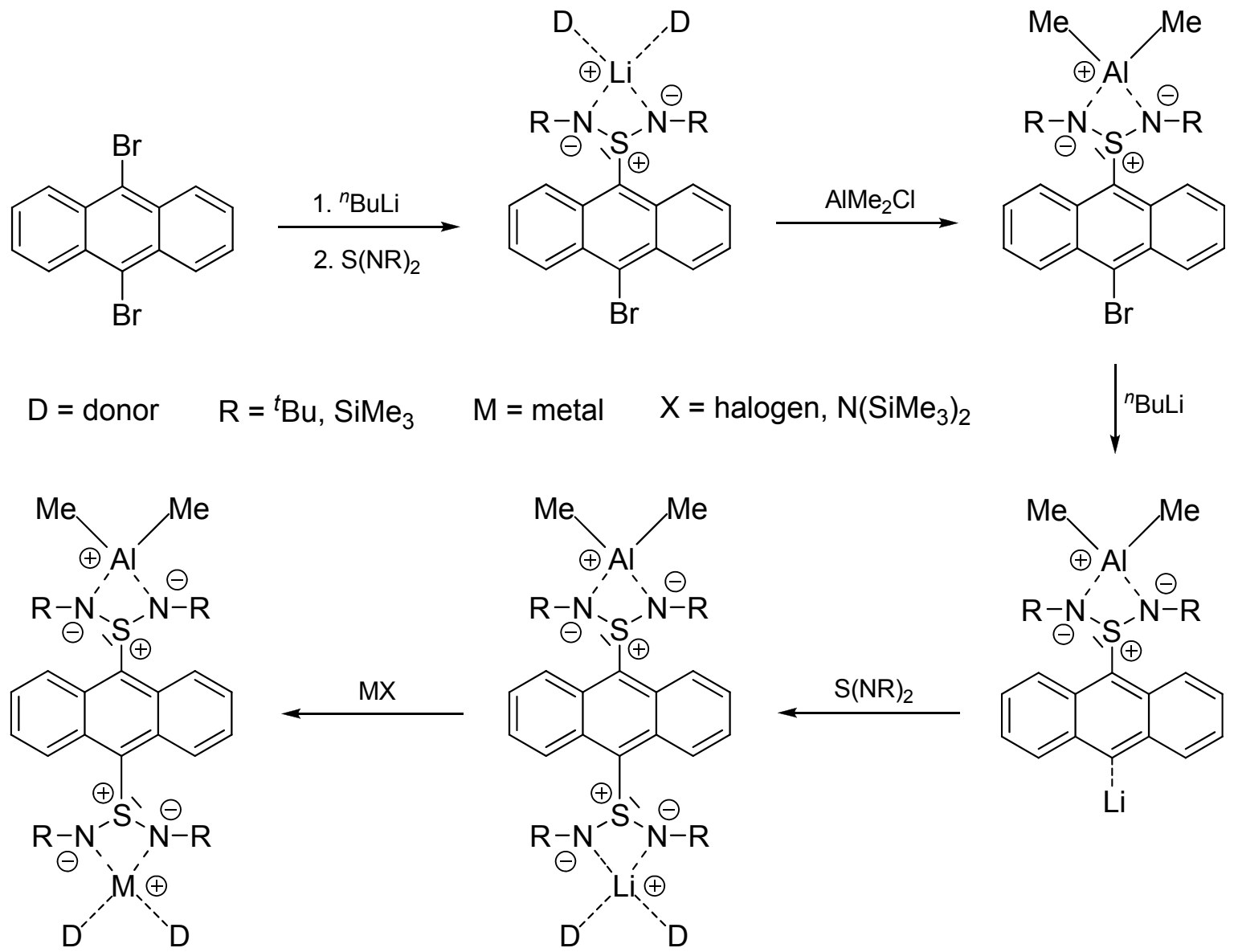

Scheme 2-5: Possible reaction pathway to coupled heterobimetallic diimidosulfinates.

In a first series of experiments one of the two bromine atoms in 9,10-dibromoanthracene was lithiated with ${ }^{n} \mathrm{BuLi}$ and the product was afterwards reacted with bis-tert-butyl-sulfurdiimide or bis-trimethylsilyl-sulfurdiimide (see Scheme 2-5). The reactions proceeded smoothly and afforded depending on the reaction time and temperature $\quad\left[(\mathrm{THF})_{2} \mathrm{Li}\left(\mathrm{N}^{t} \mathrm{Bu}\right)_{2} \mathrm{SAnBr}\right] \quad(7), \quad\left[\left(\mathrm{Et}_{2} \mathrm{O}\right)(\mathrm{LiBr}) \mathrm{Li}\left(\mathrm{N}^{t} \mathrm{Bu}\right)_{2} \mathrm{SAnBr}\right]_{2} \quad$ (8) and $\left[\left(\mathrm{Et}_{2} \mathrm{O}\right)_{2} \mathrm{Li}\left(\mathrm{NSiMe}_{3}\right)_{2} \mathrm{SAnBr}\right](9)$. If the temperature rises too high during the lithiation or the reaction time is too long, the lithiated anthracene can react with the formed ${ }^{n} \mathrm{BuBr}$ resulting in the formation of lithium bromide. ${ }^{[144]}$ In the following reaction with the sulfurdiimide the lithium bromide can then be incorporated into the crystal of the formed anthracenyl diimidosulfinate resulting in the formation of $\mathbf{8}$. After the isolation of the lithium anthracenylsulfinates, 7 was reacted with various metal halogens and metal amides. Again the lithium complex seemed to be very stable resulting in many failed metal exchanges. Only with two metal halogens namely zinc dibromide and dimethylaluminum chloride a reaction proceeded. Both metal complexes $\left[\mathrm{Me}_{2} \mathrm{Al}\left(\mathrm{N}^{t} \mathrm{Bu}\right)_{2} \mathrm{SAnBr}\right](\mathbf{1 0})$ and $\left[\mathrm{Zn}\left\{\left(\mathrm{N}^{t} \mathrm{Bu}\right)_{2} \mathrm{SAnBr}\right\}_{2}\right](\mathbf{1 1})$ were structurally characterized. 
Unexpectedly 7 and 9 crystallize as monomers with the lithium atom four-fold coordinated by the two nitrogen atoms of the diimidosulfinate and two donor molecules (see Figure 2-11). Up to now the diimidosulfinates where known for a lot of dimeric structural motifs ${ }^{[69,139]}$ but monomeric structures where only exhibited in the presence of a multidentate ligand like TMEDA ${ }^{[82]}$ or by triimidosulfonates. ${ }^{[70,90]}$
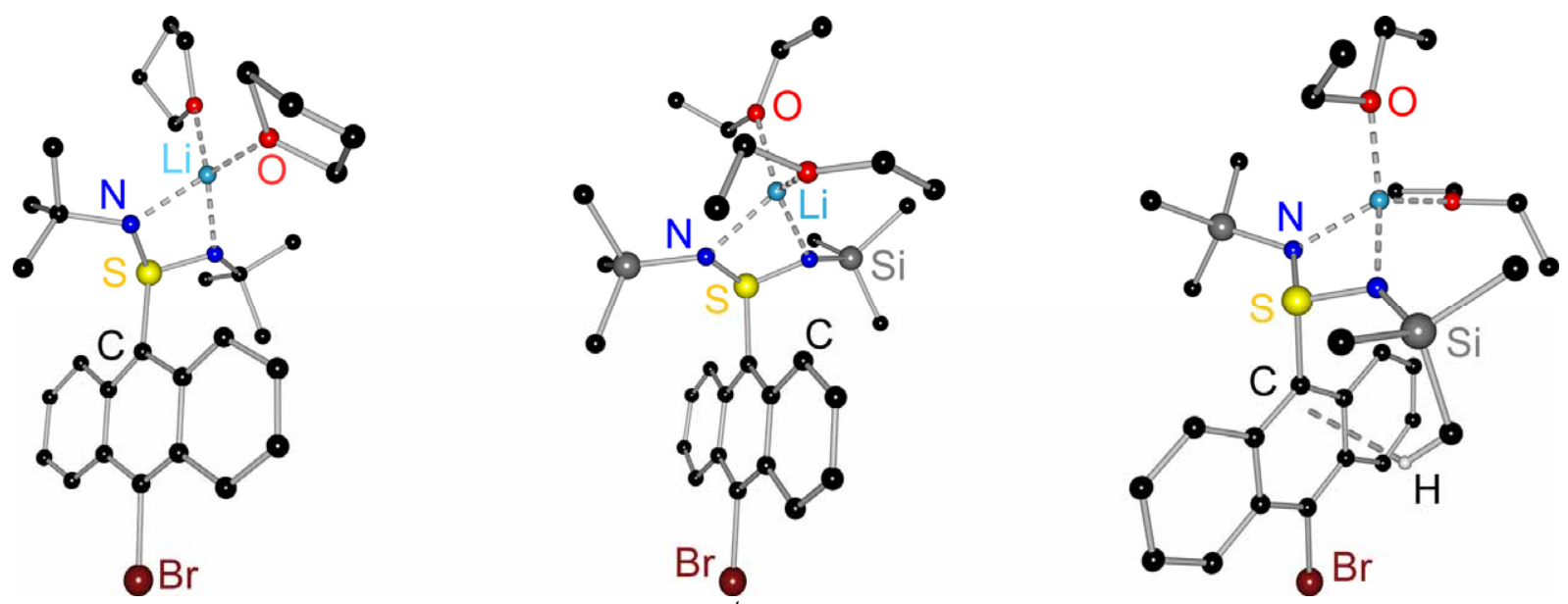

Figure 2-11: Crystal structure of [(THF) $\left.)_{2} \mathrm{Li}\left(\mathrm{N}^{t} \mathrm{Bu}\right)_{2} \mathrm{SAnBr}\right]$ (7) (left), $\left[\left(\mathrm{Et}_{2} \mathrm{O}\right)_{2} \mathrm{Li}\left(\mathrm{NSiMe}_{3}\right)_{2} \mathrm{SAnBr}\right](9)$ (middle) and 9 with hydrogen bond (right). All other hydrogen atoms have been omitted for clarity.

Because $\left[(\mathrm{THF})_{4} \mathrm{Li}_{2}\left\{\left(\mathrm{NSiMe}_{3}\right)_{2} \mathrm{~S}_{2} \mathrm{C}_{12} \mathrm{H}_{8}\right]\right.$ (2) also crystallizes as a monomer ${ }^{[146]}$ one could assume that one reason for this uncommon structural motif is the aryl group that is connected to the sulfur atom. The biphenyl and the anthracene substituent both have the possibility to form hydrogen bonds to their $\pi$-systems. A look at the packing plot of 2 (see Figure 2-8), 7 (see Figure 2-12) and 9 reveals intermolecular as well as intramolecular hydrogen bonds with distances around $3 \AA$ between the hydrogen atoms and the $\pi$-systems of the next molecule.

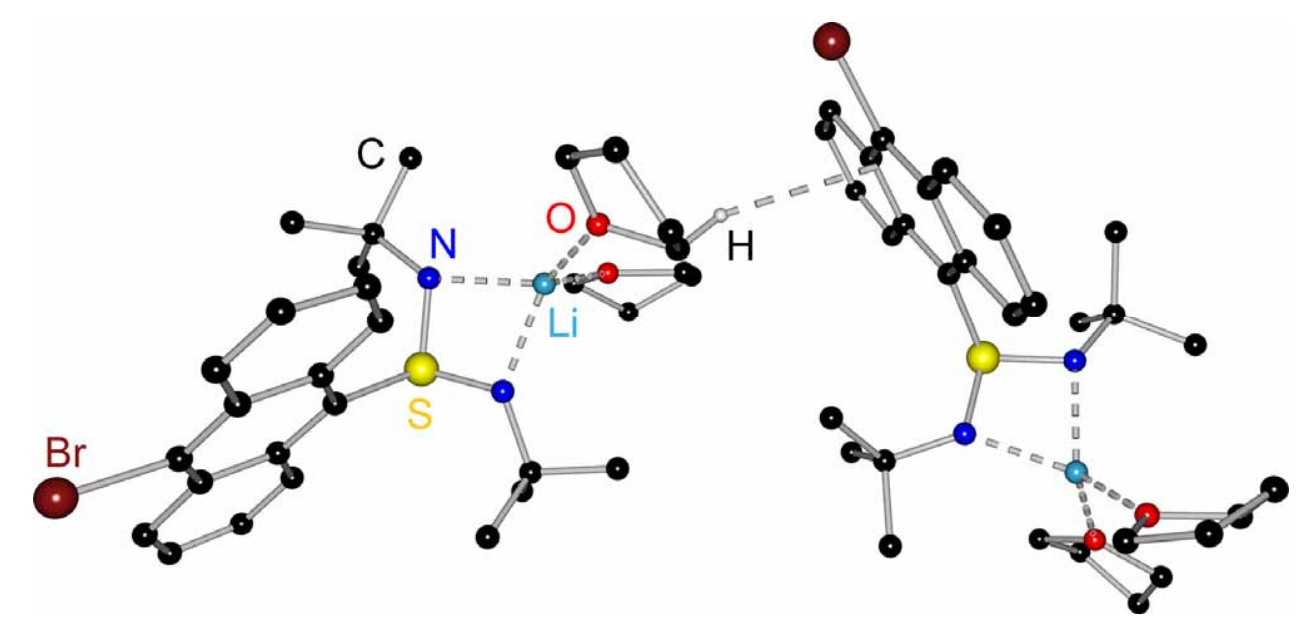

Figure 2-12: Intermolecular hydrogen bond within the solid state structures of 7. 
$\left[(\mathrm{THF})_{1.5} \mathrm{Li}_{2}\left\{\left(\mathrm{NSiMe}_{3}\right)_{2} \mathrm{~S}_{2} \mathrm{C}_{12} \mathrm{H}_{8}\right]_{\infty}\right.$ (3), the analogue to 2 in which the coupled diimidosulfinates form a polymeric chain, shows no intermolecular hydrogen bonds but only intramolecular ones. By dimerizing or polymerizing it is difficult to impossible for the system to form hydrogen bonds between the molecules in the solid state. The fact that $\mathbf{2}$ and $\mathbf{3}$ could both be crystallized indicates that the energy difference between the two is only minimal. For 7 it seems to be favorable to change the coordination mode of the lithium atoms to obtain a maximum of interactions between hydrogen atoms and the $\pi$-system of the aryl groups. The forming of hydrogen bonds after polymerization would be even more difficult than in $\mathbf{3}$ because of the higher steric demand of the anthracene compared to the biphenyl framework.

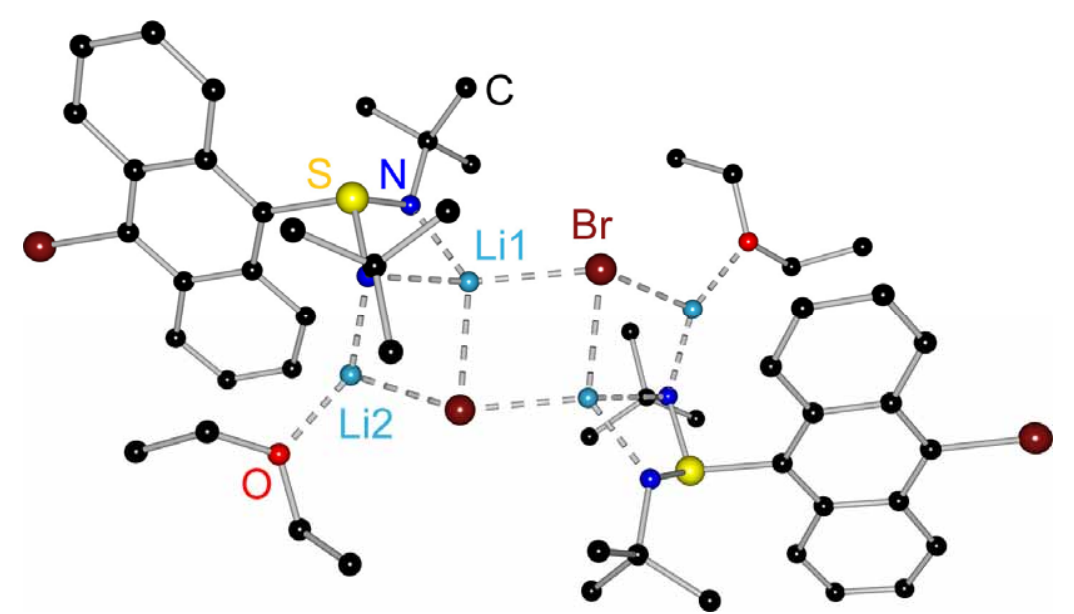

Figure 2-13: Crystal structure of $\left[\left(\mathrm{Et}_{2} \mathrm{O}\right)(\mathrm{LiBr}) \mathrm{Li}\left(\mathrm{N}^{t} \mathrm{Bu}\right)_{2} \mathrm{SAnBr}\right]_{2}$ (8). All hydrogen atoms have been omitted for clarity.

In contrast to $\mathbf{7}$ and $\mathbf{9},\left[\left(\mathrm{Et}_{2} \mathrm{O}\right)(\mathrm{LiBr}) \mathrm{Li}\left(\mathrm{N}^{t} \mathrm{Bu}\right)_{2} \mathrm{SAnBr}\right]_{2}$ crystallizes as a dimer with one equivalent of lithium bromide per molecule (see Figure 2-13). Although a similar structure is known for a triimidosulfite ${ }^{[81]} \mathbf{8}$ is the first diimidosulfinate crystallizing with incorporated lithium bromide. 8 forms a step-shaped structure in the solid state that shows some similarities to another step-shaped structural motif that is common for diimidosulfinates. ${ }^{[67,68,76]} \mathrm{Li1}$ and Li1A, the lithium atoms in the inner part of the staircase, exhibit a distorted tetrahedral coordination geometry like the lithium atoms in 7 while Li2 and Li2A are nearly trigonal planar coordinated (see Figure 2-13). Table 2-3 shows that in 7 and 9 the lithium atom is coordinated much more symmetrically than in $\mathbf{8}$. Since one nitrogen atom is always coordinating a second lithium atom in most known lithium diimidiosulfinates the coordination is normally very unsymmetrical. 
Table 2-3: Selected bond lengths $[\AA]]$ and angles $\left[{ }^{\circ}\right]$ for 7, 8, 9 and 10.

\begin{tabular}{ccccc}
\hline Compound & $\mathbf{7}$ & $\mathbf{8}$ & $\mathbf{9}$ & $\mathbf{1 0}$ \\
\hline Distances & & & & \\
S-N1 & $1.602(4)$ & $1.641(3)$ & $1.601(3)$ & $1.643(2)$ \\
S-N2 & $1.603(4)$ & $1.613(3)$ & $1.603(3)$ & $1.641(2)$ \\
S-C & $1.860(5)$ & $1.832(3)$ & $1.850(3)$ & $1.815(3)$ \\
M1-N & $2.020(9)$ & $2.242(6)$ & $2.070(5)$ & $1.924(3)$ \\
M2-N1 & $2.009(8)$ & $1.977(6)$ & $2.076(5)$ & $1.920(2)$ \\
Li-O/Al-C & $1.957(8)$ & $1.971(6)$ & & $1.959(3)$ \\
Li1-Br & $1.947(8)$ & $1.925(6)$ & $1.975(5)$ & $1.977(3)$ \\
Li1A-Br & & $2.582(5)$ & $2.014(5)$ & \\
Li2-Br & & $2.504(6)$ & & $108.58(10)$ \\
Angles & & $2.496(6)$ & & \\
N-S-N & $97.52(19)$ & $102.03(12)$ & $102.74(11)$ & $91.06(10)$ \\
N-M-N & $73.50(28)$ & $73.40(19)$ & $74.24(17)$ & $75.15(8)$ \\
C-S-N & $108.12(20)$ & $108.29(12)$ & $104.40(12)$ & $10.26(10)$ \\
\hline
\end{tabular}

This symmetrical coordination can also be seen in the $\mathrm{S}-\mathrm{N}$ bond lengths that are untypically alike and relatively short. Since both nitrogen atoms are only coordinating one lithium atom there is enough electron density left to strengthen the sulfur nitrogen bond. The short $\mathrm{S}-\mathrm{N}$ bond lengths result in a very acute $\mathrm{N}-\mathrm{S}-\mathrm{N}$ angle since the sulfur lithium distance would otherwise be too small. The same holds true for $\mathbf{1 0}$ where the short Al-N bond lengths are responsible for the acute $\mathrm{N}-\mathrm{S}-\mathrm{N}$ angle. Therefore $\mathbf{7}$ and $\mathbf{9}$ are more comparable to monomeric imidosulfinates like $\mathbf{1 0}$ or $\left[(T M E D A) L i\left(N^{t} B u\right)_{2} S_{(}\left(\mathrm{SC}_{8} \mathrm{H}_{5}\right)\right]^{[82]}$ than to dimeric lithium diimidosulfinates. Between 7 and 9 only marginal differences can be seen except for the $\mathrm{N}-\mathrm{Li}$ and $\mathrm{O}-\mathrm{Li}$ distances that are distinct smaller in $\mathbf{7}$ and one $\mathrm{C}-\mathrm{S}-\mathrm{N}$ angle that is more acute in $\mathbf{9}$ (see Figure 2-14). 


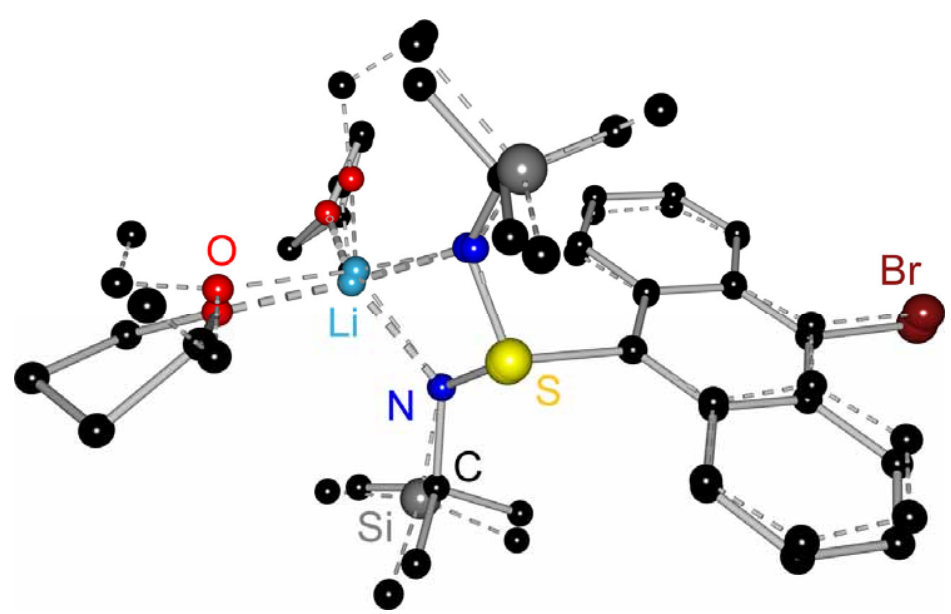

Figure 2-14: Molecular structure overlay of 7 and 9.

As the overlay of the structures shows there are no sterical reasons for the elongation of the mentioned bonds in $\mathbf{9}$.

But when the hydrogen atoms are taken into account it is noticeable that the $\mathrm{C}-\mathrm{S}-\mathrm{N}$ angle is more acute because the diimidosulfinate is leaning to one side to form an intramolecular hydrogen bond between the $\pi$-system of the anthracene and one hydrogen atom at the trimethylsilyl group (see Figure 2-11).

Since the $\mathrm{N}-\mathrm{Si}$ bond in $\mathbf{9}$ is longer than the $\mathrm{N}-\mathrm{C}$ bond in $\mathbf{7}$ the $\mathrm{C}-\mathrm{S}-\mathrm{N}$ angle has to be more acute for the hydrogen bond to be effective. In order to enhance this interaction with the $\pi$-system the $\mathrm{N}-\mathrm{Li}$ bonds are also elongated. In addition, the $\beta$ effect of the silicon atom could also be another reason for the longer distances. $[149,150]$

On the other hand, $\mathbf{8}$ is very similar to known lithium diimidosulfinates with nearly all bond lengths and angles about the same size as in the literature. As expected all bond lengths to Li2 are shorter than the comparable ones to Li1 since Li2 exhibits only three donor contacts. Apart from that only one $\mathrm{C}-\mathrm{S}-\mathrm{N}$ angle is uncommon. Compared to the other $\mathrm{C}-\mathrm{S}-\mathrm{N}$ angles in Table $2-3$ it is very acute. This is probably due to the position of the second lithium atom forcing the diimido ligand to bend to this site of the anthracene substituent.

As pointed out earlier, 10 exhibits the same structural motif as 7 (see Figure 2-15). Only the $\mathrm{S}-\mathrm{N}$ and the $\mathrm{N}-\mathrm{M}$ bond lengths differ slightly because of the metal exchange from lithium to aluminum. The aluminum atom is stronger coordinated by the nitrogen atoms resulting in a shorter $\mathrm{N}-\mathrm{M}$ and a longer $\mathrm{S}-\mathrm{N}$ distance. Otherwise both compounds are very similar in the solid state. 


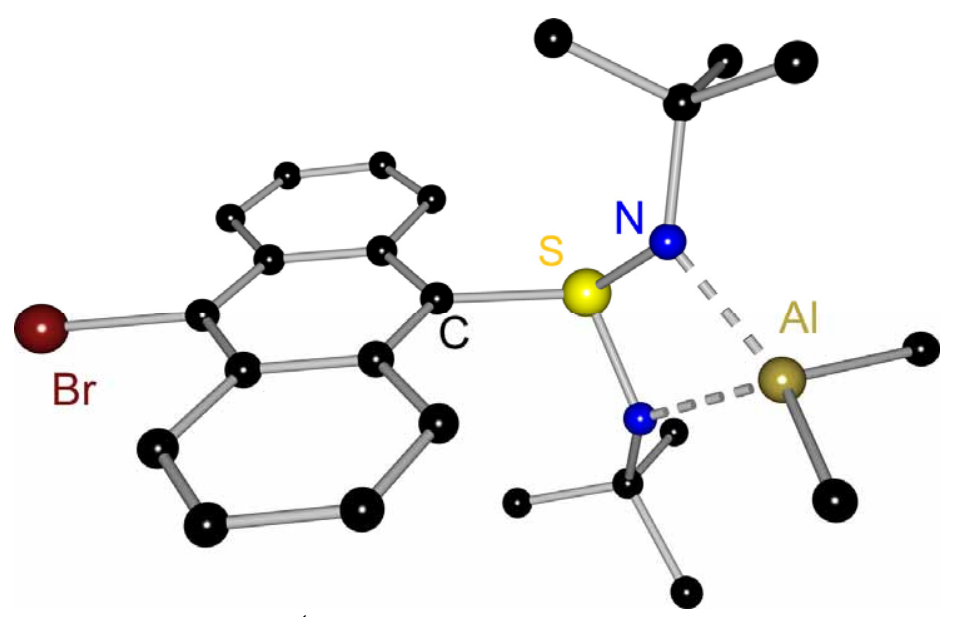

Figure 2-15: Crystal structure of $\left[\mathrm{Me}_{2} \mathrm{Al}\left(\mathrm{N}^{t} \mathrm{Bu}\right)_{2} \mathrm{SAnBr}\right](10)$. All hydrogen atoms have been omitted for clarity.

The comparison with $\mathbf{5}$ and $\mathbf{6}$ reveals no distinct differences, either. In addition to the successful metal exchange reaction with dimethylaluminumchloride another metal complex could be obtained. Although the reaction proceeded with zinc bromide the product $\left[\mathrm{Zn}\left\{\left(\mathrm{N}^{t} \mathrm{Bu}\right)_{2} \mathrm{SAnBr}\right\}_{2}\right]$ (11) could only be obtained in a very poor yield. The few crystals were heavily twinned and resulted in a solid state structure with very high standard deviations for the bond lengths and angles. Therefore only the structural motif is discussed here.

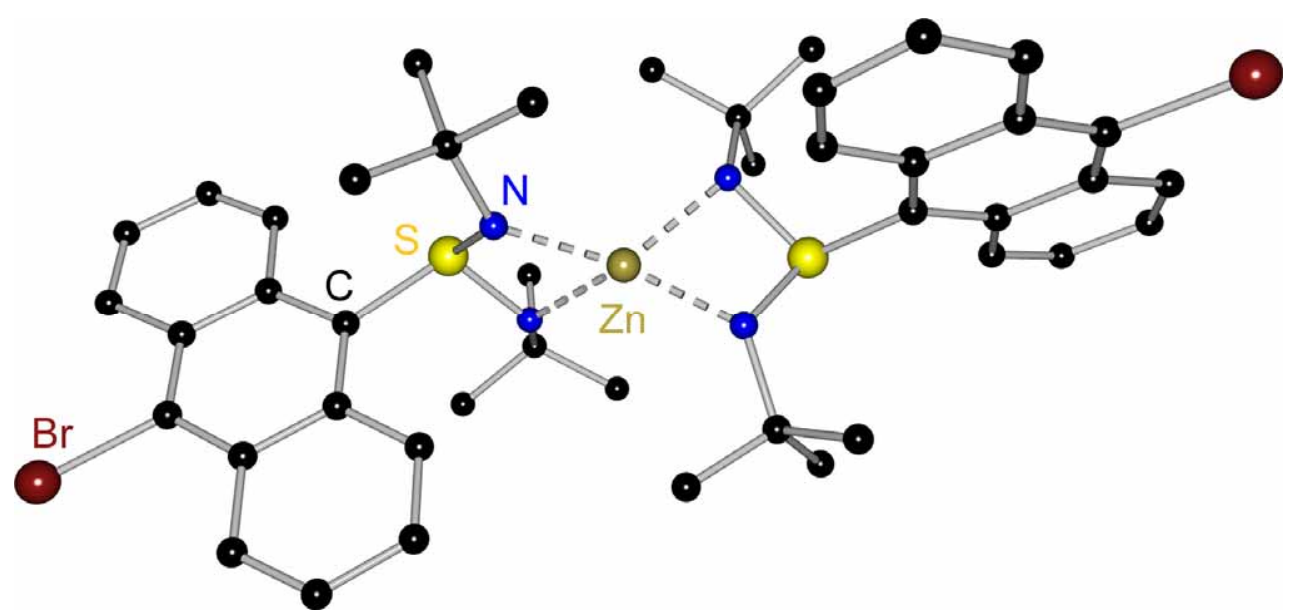

Figure 2-16: Crystal structure of $\left[\mathrm{Zn}\left\{\left(\mathrm{N}^{t} \mathrm{Bu}\right)_{2} \mathrm{SAnBr}\right\}_{2}\right]$ (11). All hydrogen atoms have been omitted for clarity.

Figure 2-16 shows that $\mathbf{1 1}$ forms a dimer in the solid state structure which is similar to other dicationic metal complexes of diimidosulfinates. ${ }^{[82,90]}$ The zinc atom which is coordinated by the four nitrogen atoms of the two diimidosulfinates exhibits a distorted tetrahedral coordination polyeder. As expected the two $\mathrm{N}-\mathrm{Zn}-\mathrm{N}$ planes are standing perpendicular to each other with the sulfur atoms deviated to one side of the $\mathrm{N}-\mathrm{Zn}-\mathrm{N}$ planes while the anthracenyl group is bent towards the other side. 
In addition to some interesting structural features the mono-diimidoanthracenylsulfinates exhibit also some unusual characteristics in solution. The NMR spectra of all discussed compounds reveal an unexpected number of peaks.

For the mono-diimidoanthracenylsulfinates one would expect three peaks with a distribution of $2: 2: 2$ for the protons bonded to the anthracene ringsystem with the protons 4/5, 1/8, 3/6 and /2/7 being equivalent in the NMR. But integration shows that for 7, 8 and 10 all protons are unequivalent (see Figure 2-17). For an easier understanding the notation of the anthracene framework is shown in Figure 2-18.

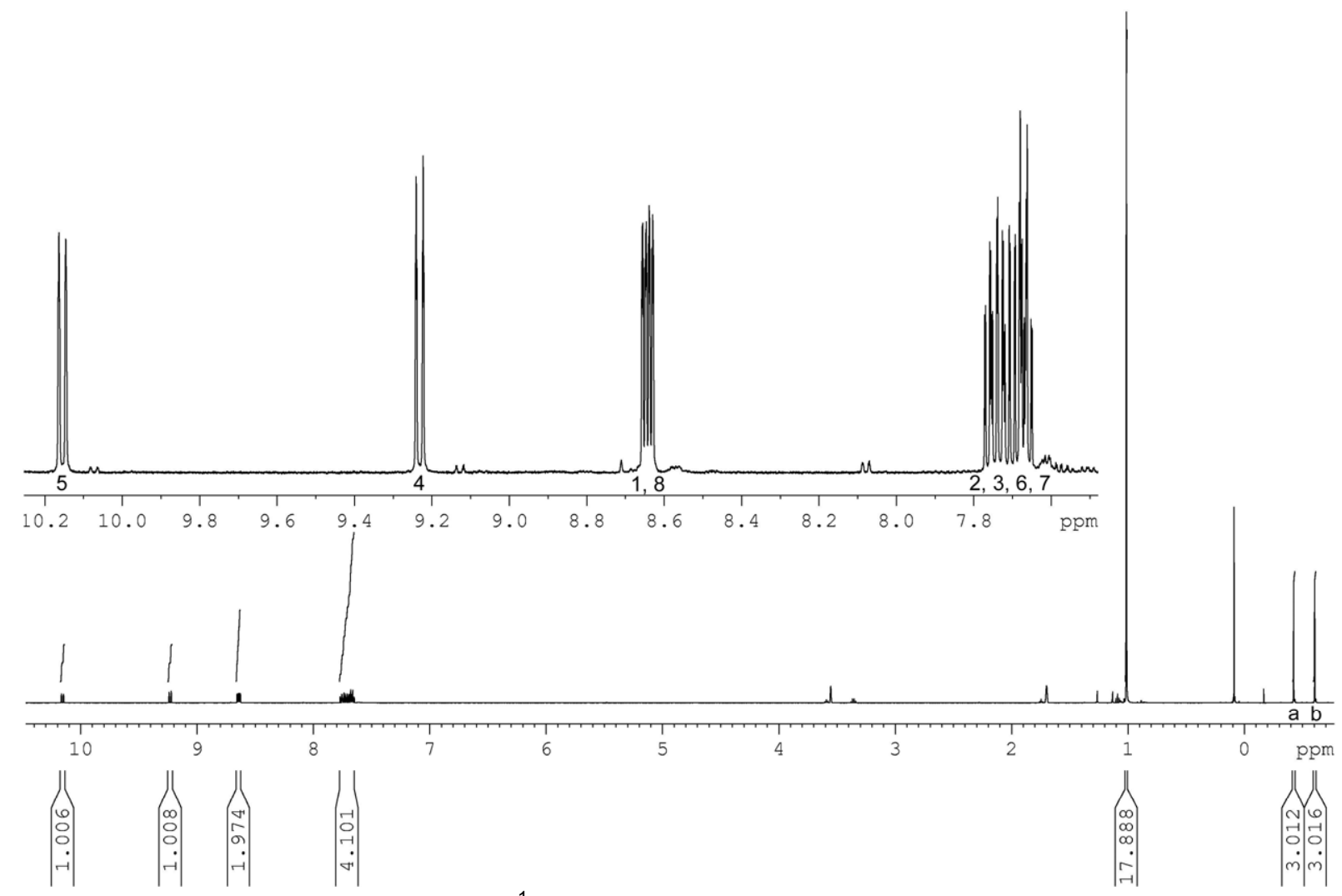

Figure 2-17: ${ }^{1} \mathrm{H}-\mathrm{NMR}$ of $10\left(500.132 \mathrm{MHz}, \mathrm{d}_{8}-\mathrm{THF}\right)$.

This leads to the assumption that the rotation around the S-C bond is hindered even at room temperature. A similar phenomenon was observed for isopropylphosphanylanthracenes. ${ }^{[151]}$ Schwab found that the rotation around the P-C bond is slow at low temperature enough to make all protons lose their magnetic equivalency. In addition, one of the protons nearest to the phosphorous atom is clamped between the isopropyl groups attached to the phosphorous atom while the proton on the other side can interact with its lone pair. The same phenomenon can be observed for the diimidoanthracenysulfinates with the exception, that the rotation around the bond is hindered even at room temperature. 
Nevertheless, for the trimethylsilyl substituted diimidosulfinate 9 the expected 2:2:4 distribution can be found. This fact is probably due to the longer $\mathrm{N}-\mathrm{Si}$ bond length (1.87 $\AA$ compared to $1.47 \AA$ for $\mathrm{N}-\mathrm{C}$ ) making a rotation around the $\mathrm{S}-\mathrm{C}$ bond possible. Anyhow, the signals are still very broad which might be an indicator that the rotation around the $\mathrm{S}-\mathrm{C}$ bond is slightly hampered, too.
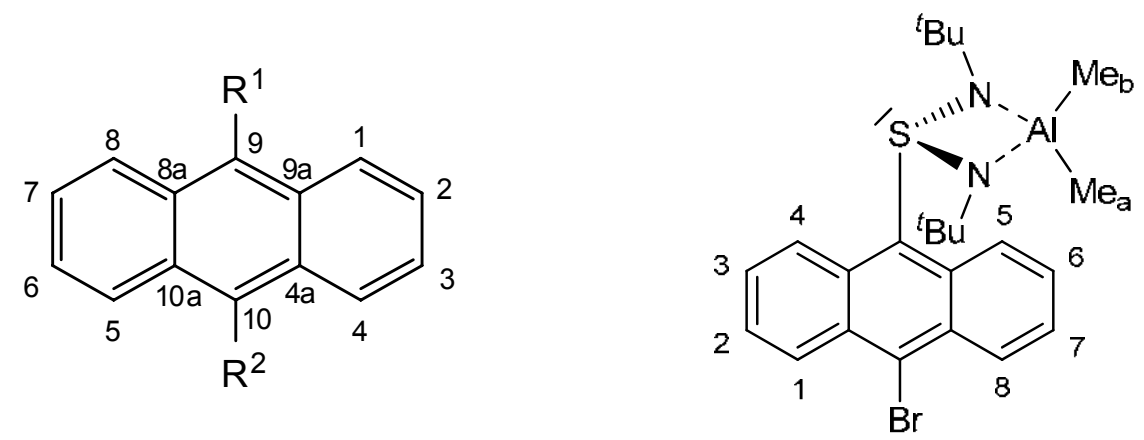

Figure 2-18: Notation of the anthracene framework (left) and probable arrangement of 10 in solution (right).

A NOESY experiment showed that the hydrogen atom situated between both nitrogen atoms is the one with the highest chemical shift ( $\left.\mathrm{H}_{5}: 10.15 \mathrm{ppm}\right)$. Although the protons of the ${ }^{t} \mathrm{Bu}$ groups yield cross peaks with $\mathrm{H}_{5}$ and $\mathrm{H}_{4}$ only one cross peak between $\mathrm{H}_{5}$ and one of the methyl groups attached to the aluminum atom can be seen. This strongly indicates that $\mathbf{1 0}$ exhibits the same structural conformation (see Figure 2-18) in solution as in the solid state.

Another interesting feature is the higher chemical shift of the protons for the lithium compared to the aluminum complexes. This is probably due to the higher steric demand of the THF coordinated lithium cation compared to the $\mathrm{AlMe}_{2}$ cation.

\subsubsection{Bis-diimidoanthracenylsulfinates}

After the synthesis of the mono-diimidoanthracenylsulfinates it was tried to substitute the bromine atom in those compounds by a lithium atom. In order to find the right conditions the mono-diimidoanthracenylsulfinates were reacted with diverse lithium bases ( ${ }^{n} \mathrm{BuLi}$, MeLi and ${ }^{\mathrm{t}} \mathrm{BuLi}$ ) in several solvents and at different temperatures. Unfortunately, the reactions yielded not the desired products but only the reactant, unidentifiable mixtures or side-products (see Figure 2-19). 


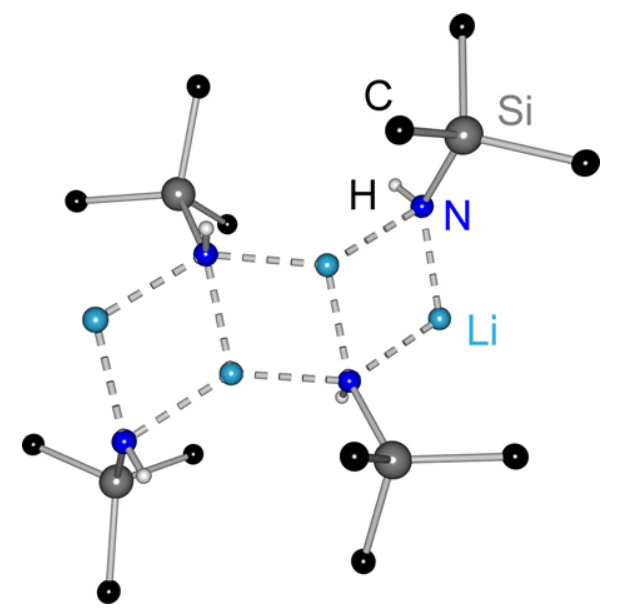

Figure 2-19: Side-product from the reaction of lithium bases with 9 .

It seems that the addition of the electron withdrawing sulfurdiimide reduces the electron density in the anthracene framework so far that a second lithiation is not favoured. To avoid this problem, the monolithiated anthracene was first reacted with diphenylphosphane. Since Schwab $b^{[147]}$ succeeded in the synthesis of asymmetric substituted 9,10-bis-phosphanylanthracenes it seemed possible to lithiate the resulting phosphanylanthracene again and then add a sulfurdiimide to the mixture.
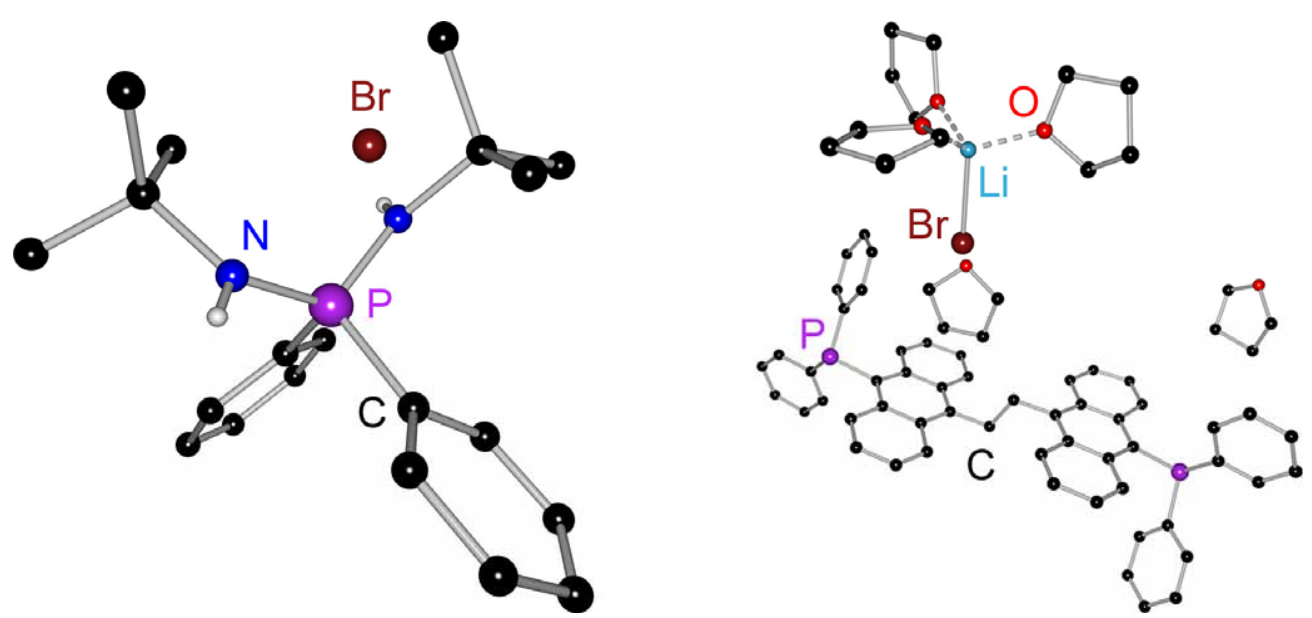

Figure 2-20: Side-products from the reaction of lithium bases with mono-phospanylanthracenes.

But again the reaction did not proceed as planned. The lithiation was also hampered by the electron withdrawing effect of the phosphane and the reactions yielded only side-products or unidentifiable mixtures (see Figure 2-20). Unfortunately, the few side-products that could be isolated provided no hint on the general course of the reactions. 
For that reason the idea of a sequenced lithiation was abandoned and both bromine atoms were lithiated in one step. Afterwards, the 9,10-dilithiumanthracen was reacted with different sulfurdiimides (see Scheme 2-6) resulting in the formation of $\left[\left\{(\mathrm{THF})_{2} \mathrm{Li}\left(\mathrm{N}^{t} \mathrm{Bu}\right)_{2} \mathrm{~S}\right\}_{2} \mathrm{An}\right](\mathbf{1 2})$ and $\left[\left\{(\mathrm{THF})_{2} \mathrm{Li}\left(\mathrm{NSiMe}_{3}\right)_{2} \mathrm{~S}\right\}_{2} \mathrm{An}\right](\mathbf{1 3})$.<smiles>O=POCO</smiles>

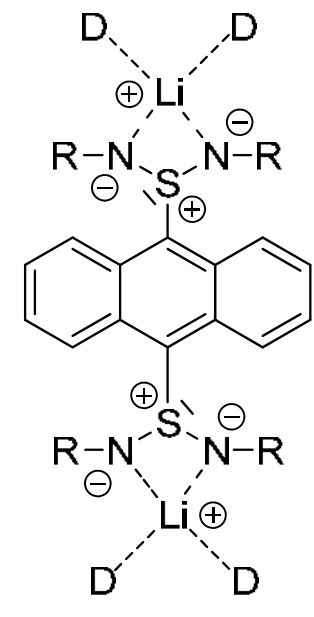

$12 \mathrm{R}={ }^{t} \mathrm{Bu}$

$13 \mathrm{R}=\mathrm{SiMe} 3$

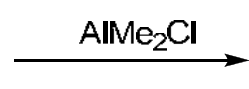<smiles>[R]N1CN([R])[Al]1(C)O[Na]</smiles>

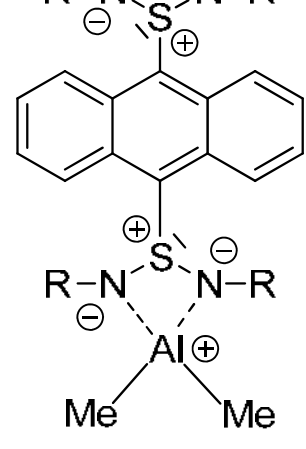

$14 \mathrm{R}={ }^{t} \mathrm{Bu}$

Scheme 2-6: Synthesis of 12, 13 and 14.

After their isolation 12 and $\mathbf{1 3}$ were reacted with one equivalent of different metal halogens and metal amides. Unfortunately, the previously discussed problems appeared again and most metal exchange reactions failed. Hydrolysis with subsequent deprotonation was also no option since the diimidoanthracenylsulfinates decomposed when exposed to tert-buylammonium chloride. Only the reaction of $\mathbf{1 2}$ with $\mathrm{AlMe}_{2} \mathrm{Cl}$ afforded [ $\left.\left\{\mathrm{Me}_{2} \mathrm{Al}\left(\mathrm{NSiMe}_{3}\right)_{2} \mathrm{~S}\right\}_{2} \mathrm{An}\right]$ (14). In the case of $\mathbf{1 3}$ only a few crystals of the aluminum species that were heavily twinned could be obtained. Regrettably, the measured data set of $\left[\left\{\mathrm{Me}_{2} \mathrm{Al}\left(\mathrm{N}^{t} \mathrm{Bu}\right)_{2} \mathrm{~S}\right\}_{2} \mathrm{An}\right]$ was not good enough to discuss the bond length and angles but only the structural motif (see Figure 2-22). The NMR spectrum of the solution hinted on a successful metal exchange but the lack of crystals and the sensitivity of the product made an unequivocal characterization of the product impossible. Unfortunately, the reaction with $\mathrm{AlMe}_{2} \mathrm{Cl}$ results in the formation of a bimetallic complex rather than a heterobimetallic one. This phenomenon was already described earlier in this work when benzene and biphenyl spacers were employed (see section 2.3.1). Therefore it has been confirmed that $\mathrm{AlMe}_{2} \mathrm{Cl}$ is too reactive and not selective enough for the exchange of just one lithium atom. 
12, 13 and 14 crystallize solely as monomers (see Figure 2-21) with half of the molecule in the asymmetric unit. They all exhibit the same structural motif whereas in 14 the lithium atom and the two coordinating THF molecules are substituted by a $\mathrm{AlMe}_{2}$ fragment (see Figure 2-22).
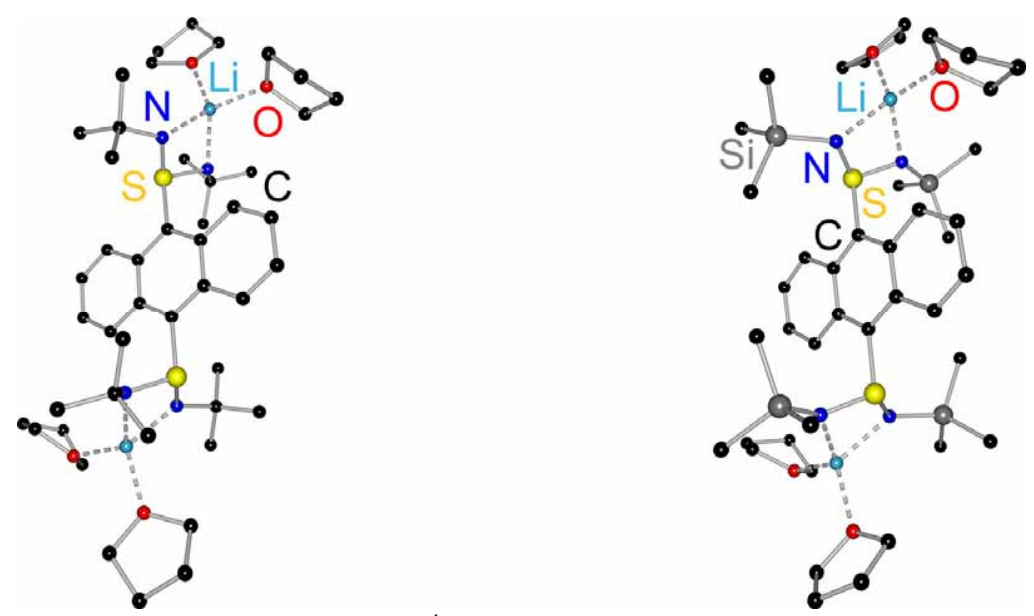

Figure 2-21: Crystal structure of $\left[\left\{(\mathrm{THF})_{2} \mathrm{Li}\left(\mathrm{N}^{t} \mathrm{Bu}\right)_{2} \mathrm{~S}\right\}_{2} \mathrm{An}\right](12)$ (left) and $\left[\left\{(\mathrm{THF})_{2} \mathrm{Li}\left(\mathrm{NSiMe}_{3}\right)_{2} \mathrm{~S}\right\}_{2} \mathrm{An}\right](13)$ (right). All hydrogen atoms have been omitted for clarity.

As described earlier in this work the diimidosulfinates normally tend to dimerize to realize the favored four-fold coordination of the lithium atom. $\mathbf{7}$ and $\mathbf{9}$ broke with this rule of thumb and so do 12 and $\mathbf{1 3}$. The coordination of the lithium atom is analogous to the coordination in 7. As expected in all three bis-diimidoanthracenylsulfinates the coupled diimdosulfinates show a transoid arrangement to minimize the steric strain.
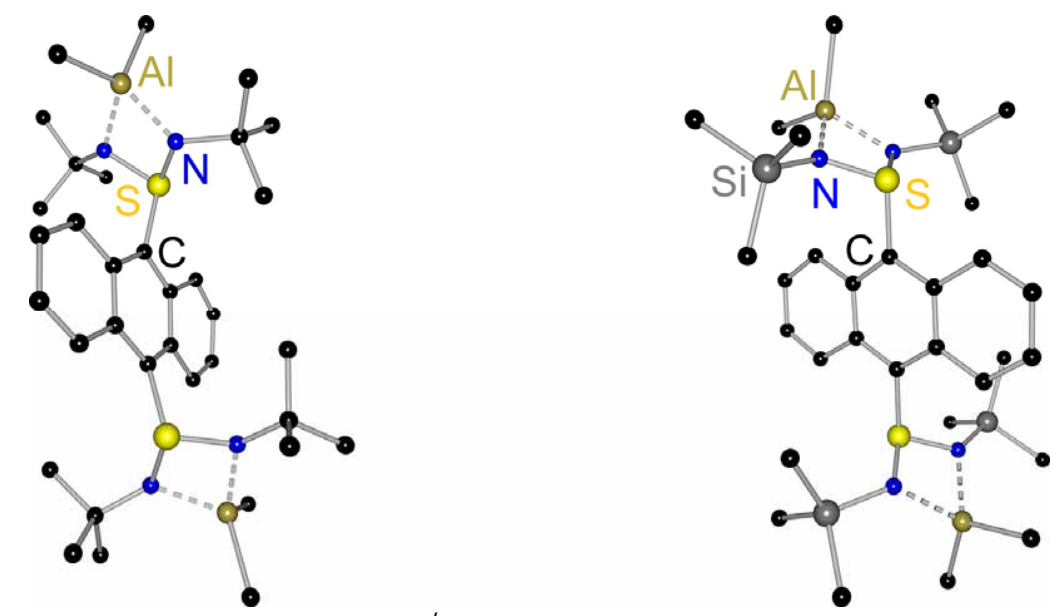

Figure 2-22: Crystal structure of $\left[\left\{\mathrm{Me} e_{2} \mathrm{Al}\left(\mathrm{N}^{t} \mathrm{Bu}\right)_{2} \mathrm{~S}\right\}_{2} \mathrm{An}\right]$ (left) and [\{Me $\left.\left.\mathrm{Ml}_{2} \mathrm{Al}(\mathrm{NSiMe})_{2} \mathrm{~S}\right\}_{2} \mathrm{An}\right]($ 14) (right). All hydrogen atoms have been omitted for clarity.

Comparisons of 12 and 13 with 7 and $\mathbf{9}$ show no distinct differences (see Table 2-4). 7 and 12 exhibit nearly the same bond lengths and angles as do 13 and 9 . Comparison between the tert-butyl and the trimethylsilyl substituted compounds 
show only distinct differences in the Li-N distances which are longer in $\mathbf{9}$ and $\mathbf{1 3}$ resulting also in a slightly more obtuse $\mathrm{N}-\mathrm{S}-\mathrm{N}$ angle. These small differences probably arise from the change of the substituents on the nitrogen atoms. As already discussed in the previous chapter the $\beta$-effect of the silicon atom and the forming of a hydrogen bond are the driving forces behind this change in the bond lengths.

Table 2-4: Selected bond lengths $[\AA]$ and angles $\left[{ }^{\circ}\right]$ for 12,13 and 14.

\begin{tabular}{cccc}
\hline Compound & 12 & 13 & 14 \\
\hline Distances & & & \\
S-N1 & $1.6164(18)$ & $1.6000(17)$ & $1.6313(12)$ \\
S-N2 & $1.6178(17)$ & $1.6032(17)$ & $1.6253(12)$ \\
S-C & $1.8522(21)$ & $1.8431(19)$ & $1.8272(13)$ \\
M1-N & $2.0215(39)$ & $2.0376(38)$ & $1.9442(12)$ \\
& $1.9956(40)$ & $2.0432(38)$ & $1.9435(13)$ \\
Li-O/Al-C & $1.9503(40)$ & $1.9574(37)$ & $1.9639(16)$ \\
Angles & $1.9525(42)$ & $1.9364(37)$ & $1.9642(15)$ \\
N-S-N & & & \\
N-M-N & $98.08(9)$ & $101.85(9)$ & $94.78(6)$ \\
C-S-N & $74.89(14)$ & $75.09(13)$ & $76.12(5)$ \\
& $106.04(9)$ & $106.26(9)$ & $109.37(6)$ \\
\hline
\end{tabular}

After the comparison of the monosubstituted and the disubstituted anthracenes it is obvious that the coupled diimidosulfinates apparently have no influence on each other. The same can be concluded when $\mathbf{1 0}$ and $\mathbf{1 4}$ are being compared. Only minor changes can be observed in the $\mathrm{Al}-\mathrm{N}$ and $\mathrm{S}-\mathrm{N}$ bond lengths. As pointed out these changes rather arise from the change of the substituents on the nitrogen atoms than from the second substitution at the anthracene framework.

Apparently the change from tert-butyl to trimethylsilyl groups on the nitrogen atoms leads to a small elongation of the $\mathrm{M}-\mathrm{N}$ bonds and a small shortening of the $\mathrm{S}-\mathrm{N}$ distances. This might be an indication that more of the negative charge at the nitrogen atom is used to strengthen the $\mathrm{S}-\mathrm{N}$ bond because the positive charge at the metal is additionally stabilized by the $\beta$-effect of the silicon atom of the trimethylsilyl groups. ${ }^{[149,150]}$ A closer look at all diimidoanthracenylsulfinates displays that for the monomeric lithium complexes the $\mathrm{S}-\mathrm{C}$ bond length is clearly elongated. While the 
sulfur-carbon distance for the aluminum complexes as well as for the dimeric complex $\mathbf{8}$ is in the normal range for diimidosulfinates the bond lengths in all other compounds are distinctly longer. Another comparison with the diimidosulfinates coupled by the biphenyl and phenyl spacer shows that in these compounds the carbon sulfur bonds are near to $1.80 \AA$ (as are most known aryl substituted diimidosulfinates) while the $\mathrm{S}-\mathrm{C}$ bonds for the anthracenyl diimidosulfinates are near $1.85 \AA$. Elongated $S-C$ bond lengths could up to now only be observed for diimidosulfinates with tert-butyl (steric strain) or benzyl (electron withdrawing effect) groups attached to the sulfur atom. The reason for this observation is probably the steric strain between the anthracene framework and the donor molecules of the lithium atom. To minimize the strain the imaginary C-S-Li angle is widened (around $129^{\circ}$ for $\mathbf{7}, \mathbf{9}, 12$ and 13 compared to $126^{\circ}$ for 8) and the S-C bond elongated. Because known diimidosulfinates exhibit mostly dimeric structures the sulfur carbon bonds are not elongated since the substituent on the sulfur atom do not interfere with the coordinating solvent.

For the bis-diimidoanthracenylsulfinates the same trend can be seen in the NMR spectra as for the mono-diimidoanthracenylsulfinates. For 12-14 the expected intensity distribution of $4: 4$ for the anthracene proton signals is transformed into a 2:2:4 pattern. For the diimidosulfinates carrying the tert-butyl substituent at the nitrogen atoms the protons resonate differently even at room temperature while the diimidosulfinates possessing trimethylsilyl groups exhibit only broad signals at $25^{\circ} \mathrm{C}$. By cooling 13 to $-60^{\circ} \mathrm{C}$ the broad signals can be resolved and the anticipated 2:2:4 distribution is obtained. As already mentioned in the previous chapter this is due to the longer $\mathrm{N}-\mathrm{Si}$ bond (1.87 $\AA$ compared to $1.47 \AA$ for $\mathrm{N}-\mathrm{C}$ ) making a rotation around the $S-C$ bond easier. Unfortunately the ${ }^{4} J$ and the ${ }^{5} J$ coupling can still not be seen even at $-60^{\circ} \mathrm{C}$. Because a NOESY experiment made it possible to determine the conformation of $\mathbf{1 0}$ in solution an additional NOESY spectrum of $\mathbf{1 2}$ was recorded. Since the peaks in the ${ }^{1} \mathrm{H}$-NMR spectrum of $\mathbf{1 2}$ were still broad the NOESY spectrum was recorded at $-70^{\circ} \mathrm{C}$. Surprisingly it showed that at low temperatures the signal for the protons at the ${ }^{t} \mathrm{Bu}$ groups split up in four different peaks whereas the four peaks form two pairs of signals which exhibit the same integrated intensity. Since the diimidosulfinates can stand transoid or cisoid to each other this conformational freedom is probably responsible for the peak splitting. A similar observation was also found by Schwab. ${ }^{[151]}$ Even more interesting are the signals in the aromatic region. At 
low temperature the distribution of the integrated signals changes from 2:2:2:2 to 1:1:2:4. The NOESY spectrum shows the expected cross peaks between all signals except for the single hydrogen atoms which show no cross peak between each other. Unfortunately there is no cross peak between the aromatic signals and the peaks for the ${ }^{t} \mathrm{Bu}$ groups making an assignment of the conformation in solution impossible.

The results presented here show that 9,10-dibromoanthracene can be selectively lithiated at one position and reacts cleanly with sulfurdiimides to give a lithium diimidosulfinate. The subsequent metal exchange reaction can be accomplished although the lithium complexes seem to be very stable and only two other metals could be coordinated by the ligand. Unfortunately the idea of the stepwise synthesis of a heterobimetallic complex as described in the beginning of this chapter does not work out. After one side of the desired ligand is synthesized the second lithiation is hindered by the electron withdrawing effect of the diimidosulfinate.

Furthermore it was shown that 9,10-dibromoanthracene is a suitable candidate for the linkage of two sulfurdiimides. The resulting coupled diiimidosulfinates are obtained in good yields and high purity. In addition, all diimidoanthracenylsulfinates show interesting features in solution. The hindered rotation around the carbon sulfur bond results in some of the hydrogen atoms attached to the anthracene framework being magneticly unequivalent. This made it possible to determine the likeliest conformation even in solution. Unfortunately, the metal exchange reactions with the bis-diimidoanthracenylsulfinates proceed even worse than the ones with the mono- diimidoanthracenylsulfinates. Most tested metal compounds did not react with the diimidosulfinates or gave no defined products. A second approach to hydrolyze the sulfinates and afterwards deprotonate the sulfinic acid with metal amides or hydrides failed, too. In the case of $\mathrm{AlMe}_{2} \mathrm{Cl}$ a reaction took place but it was not selective enough to receive the desired heterobimetallic complex. Therefore, it can be stated that the bis-diimidoanthracenylsulfinates are suitable ligands for bimetallic complexes but not the optimal choice for the synthesis of heterobimetallic complexes due to the low selectiveness of the metal exchange reactions. However further experiments with different metal chlorides and metal amides are necessary to broaden the field of metals that can be coordinated by the bis-diimidoanthracenylsulfinates. Even better would be to find a different approach for the metal exchange or another spacer more suitable for the stepwise synthesis of a heterobimetallic complex. 


\subsection{Magnesium Sulfinates and Sulfonates}

Another approach to synthesize bimetallic compounds, starting from diimidosulfinates, is to add another coordination site to the diimidosulfinate anion. First experiments in our working group from Deuerlein ${ }^{[152]}$ and Meinholz ${ }^{[153]}$ who added a phosphane side arm to a sulfurdiimide and Meyer ${ }^{[145]}$ who used a picolyl substituent showed promising results. Both ligands have an additional donor site which is able to coordinate a metal atom (see Figure 2-23).
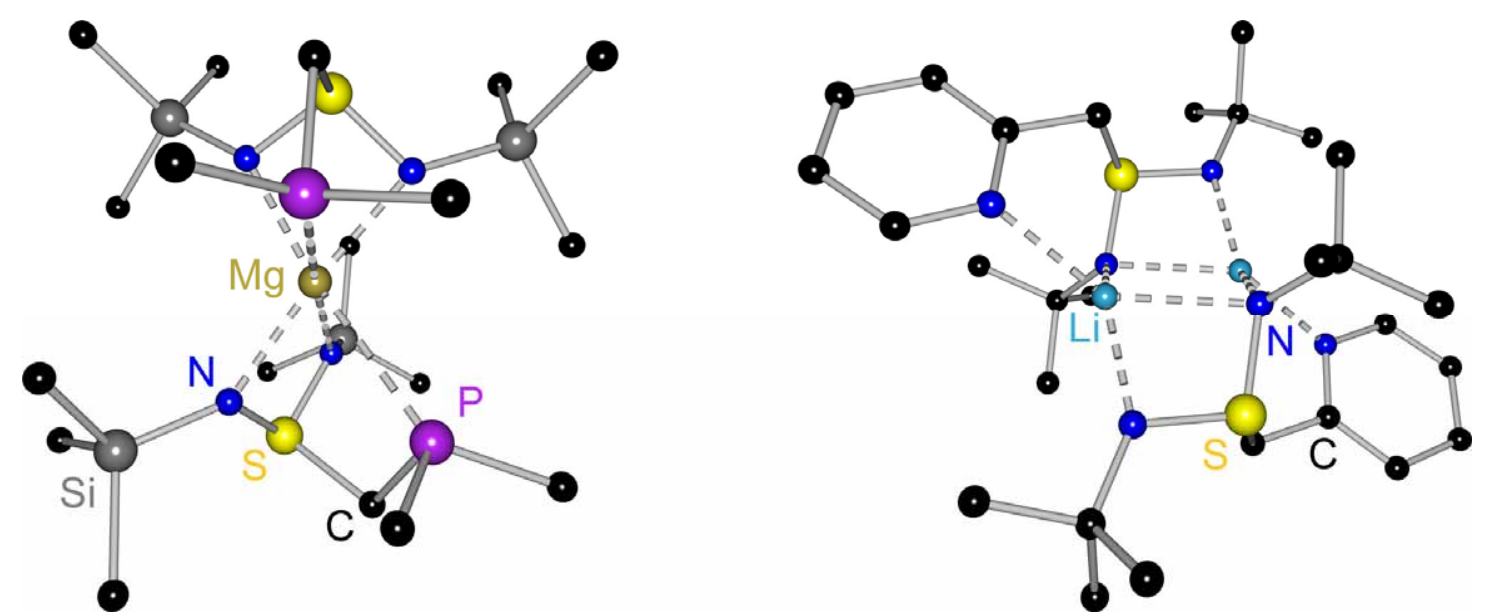

Figure 2-23: Molecular structure of $\left[\mathrm{Mg}\left\{\left(\mathrm{NSiMe}_{3}\right)_{2} \mathrm{SCH}_{2} \mathrm{PMe}_{2}\right\}_{2}\right]$ (left) and [2- $\left.\mathrm{PyCH}_{2} \mathrm{~S}\left(\mathrm{~N}^{t} \mathrm{Bu}\right)_{2} \mathrm{Li}\right]_{2}$. All hydrogen atoms have been omitted for clarity.

In contrast to both ligands shown above the side arm of a triimidosulfonate does not participate in the coordination of a metal atom chelated by the two nitrogen atoms bearing the negative charge, and therefore is open for the coordination of a second metal atom. The sulfurtriimide is an anologe to sulfur trioxide where the oxygen atoms are isoelectronicly replaced with RN-groups. Glemser and Wegener ${ }^{[154]}$ succeeded in synthesizing the first analogue to sulfur trioxide, the sulfurtriimide $\mathrm{S}\left(\mathrm{NSiMe}_{3}\right)_{3} .{ }^{[155]}$ Since then much effort has been put into the investigation of this new compound class and their coordination properties, but the elaboration of this area was often hampered by the limited synthetic access to sulfurimido molecules. Until 1996, when our group reported a new synthetic approach, ${ }^{[156]}$ only two reactions where known starting from $\mathrm{NSF}_{3}{ }^{[157]}$ or $\mathrm{OSF}_{4}{ }^{[158]}$ which are quite hazardous and give only poor yields. Since then the group of Chivers ${ }^{[159,160]}$ as well as our group got interested in the bonding situation ${ }^{[161,162]}$ as well as in the coordination pattern of tert-butylsulfurtriimide and the associated sulfurtriimido-organyl suloinates. ${ }^{[90,140,163]}$ 
As mentioned before the advantage of the sulfurtriimides compared to the sulfurdiimides is their additional coordination site that can be employed in the syntheses of bimetallic complexes. ${ }^{\text {[90] }}$

But they have drawbacks, too. The necessary nucleophilic attack to generate the desired organyl triimidosulfonate works only with small or planar nucleophiles. A steric argument would not be valid if a direct orthogonal attack above or underneath the $\mathrm{SN}_{3}$ plane was favored, as there is sufficient room to attack the sulfur atom directly (see Figure 2-24). The reactive surface, which displays the area of charge accumulation and charge depletion, however, shows the absence of electron density in the $\mathrm{SN}_{3}$ plane at the bisections of the $\mathrm{N}-\mathrm{S}-\mathrm{N}$ angles at the sulfur atom but no hole in the reactive surface on top or underneath the sulfur atom. ${ }^{[162]}$ The carbanionic nucleophile has to approach the sulfur atom along the NSN bisection in the $\mathrm{SN}_{3}$ plane or in an angle of less than about $45^{\circ}$ which is only feasible for small or planar carbanions. Bulky anions cannot reach the holes, due to the steric hindrance of the $\mathrm{N}^{t} \mathrm{Bu}$ groups in the equatorial region of the trigonal planar molecule.

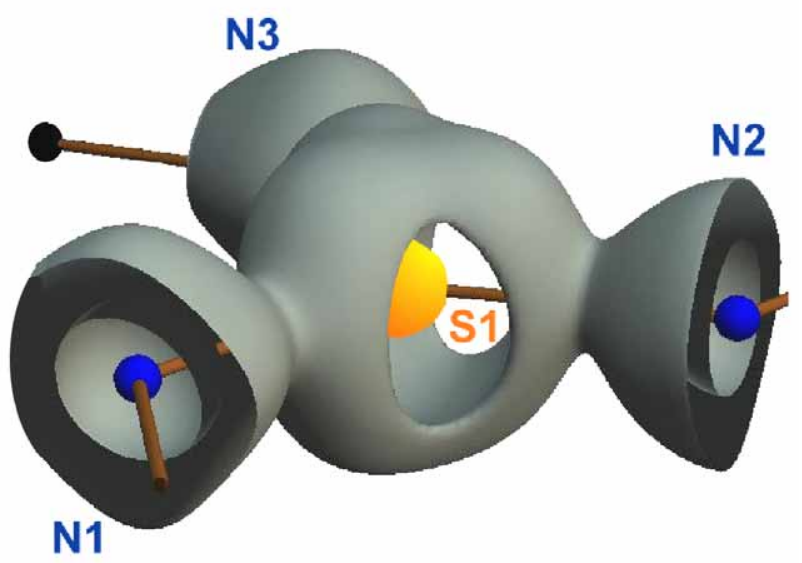

Figure 2-24: Reactive surface of $\mathrm{S}\left(\mathrm{N}^{t} \mathrm{Bu}\right)_{3}$.

Our approach to tackle this problem was to employ Grignard reagents. Since lithium organics, the most frequently used nucleophiles, are rather hard according to Pearson, ${ }^{[136-138]}$ we anticipated that the soft-soft interactions of the magnesium organics and the sulfur atom would facilitate a reaction even with sterically more demanding substituents. In addition to the softer character, the Grignard reagents also have a lower reactivity compared to the lithium organics what would also result in fewer side reactions and higher yields of the triimidosulfonates. 
Organomagnesium compounds and especially Grignard reagents represent a rapidly developing field ${ }^{[164-167]}$ ever since they were discovered by Barbier in $1899^{[168]}$ and harnessed by Grignard in $1900 .{ }^{[169]}$ Like their organolithium congeners they are key substances in the preparative organic chemistry but also for organometallic chemists. ${ }^{[170-172]}$

Nevertheless, little is known about the reactions of Grignard reagents with sulfurimide compounds. ${ }^{[68]}$ Although Kuyper showed in 1976 that sulfur diimides react readily with Grignard reagents ${ }^{[173]}$ and that this reaction can be used for titrating Grignard solutions, its chemical versatility was not explored any further. To close the gap a range of sulfurimides where reacted with various Grignard reagents in this work. Although the fundamental idea was to add Grignard reagents to sulfurtriimides the approach was first tested with sulfurdiimides which are synthetically easier accessible.

The magnesium diimidosulfinates resulting from the addition of Grignard reagents to the sulfurdiimides should be interesting precursors for the synthesis of magnesium and lithium/magnesium sulfur ylides in analogy to the lithium sulfur ylides $\left[(\mathrm{THF}) \mathrm{Li}_{2}\left\{\mathrm{RHCS}\left(\mathrm{N}^{t} \mathrm{Bu}\right)_{2}\right\}\right]_{2}{ }^{[72-74,87]}$ previously synthesized in our group. The sulfur ylides play an important role in organic synthesis ${ }^{[174-176]}$ as $\mathrm{R}_{2} \mathrm{C}$-transfer reagents for one-step epoxidation, cyclopropanation or aziridination. In a reaction with an additional equivalent of the Grignard reagent magnesium diimidosulfinates could be deprotonated at the sulfur-bound carbon $\mathrm{C}_{\alpha}$-atom to give the related magnesium sulfur ylides which should be even more selective for $\mathrm{C}-\mathrm{C}$ coupling reactions than their lithium analogues since their basicity is lower. Furthermore by deprotonation of the magnesium diimidosulfinates with an organolithium base heterobimetallic sulfur ylides could be accessible.

\subsubsection{Magnesium diimidosulfinates}

Although the sulfurdiimides react readily with lithium organic compounds the yield and the purification by crystallization is often difficult or time consuming. While the reaction with MeLi proceeds without problems and the methyldiimidosulfinate is obtained in good yields the reaction with EtLi and BzLi is not that straightforward. Though the ethyldiimidosulfinate as well as the benzyldiimidosulfinate are formed (see Figure 2-25) the yields are poor and the crystallization time is measured in weeks rather than days. ${ }^{[145]}$ 

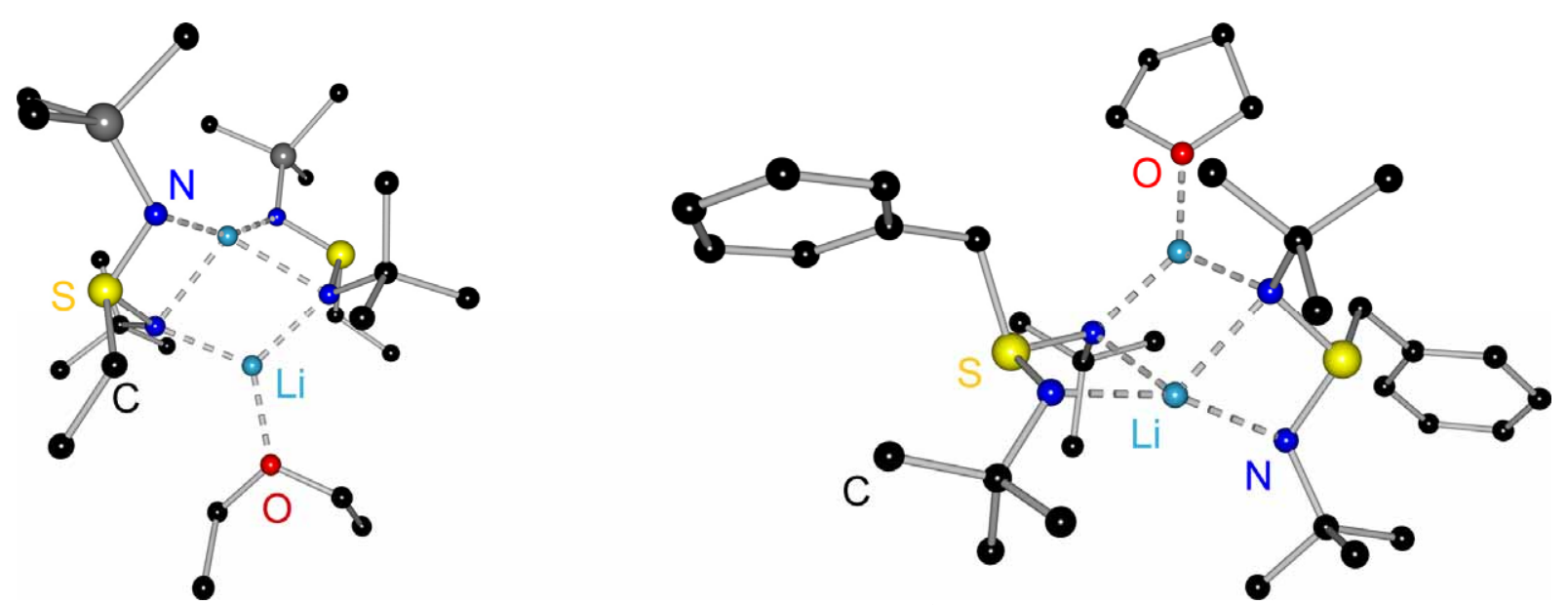

Figure 2-25: Molecular structure of $\left[\left(\mathrm{Et}_{2} \mathrm{O}\right)_{0.5} \mathrm{Li}\left\{\left(\mathrm{N}^{t} \mathrm{Bu}\right)\left(\mathrm{SiMe}_{3}\right) \mathrm{SEt}_{2}\right.\right.$ (15) (left) and $\left[(\mathrm{THF})_{0.5} \mathrm{Li}\left\{\left(\mathrm{N}^{t} \mathrm{Bu}\right)_{2} \mathrm{SBz}\right]_{2}(\mathbf{1 6})\right.$ (right). All hydrogen atoms have been omitted for clarity.

$\left[\left(\mathrm{Et}_{2} \mathrm{O}\right)_{0.5} \mathrm{Li}\left\{\left(\mathrm{N}^{t} \mathrm{Bu}\right)\left(\mathrm{SiMe}_{3}\right) \mathrm{SEt}_{2}(\mathbf{1 5})\right.\right.$ and $\left[(\mathrm{THF})_{0.5} \mathrm{Li}\left\{\left(\mathrm{N}^{t} \mathrm{Bu}\right)_{2} \mathrm{SBz}\right]_{2}\right.$ (16) both crystallize as dimers with one lithium atom coordinated by the four nitrogen atoms of the ligands while the second lithium atom is coordinated by one nitrogen atom of each ligand and a donor base. Although the first ethyldiimidosulfinate synthesized by Wrackmeyer ${ }^{[177]}$ exhibited a step-shaped structural motif without any donor base the described structural motif of $\mathbf{1 5}$ and $\mathbf{1 6}$ is well known for diimidosulfinates. ${ }^{[67,68,76]}$ Most bond lengths and angles are also in line with the literature reports. Only one of the $\mathrm{N}-\mathrm{S}-\mathrm{C}$ angles in $\mathbf{1 6}$ is considerably more acute than the other $\left(105.6^{\circ} \mathrm{vs} .98 .9^{\circ}\right)$. This is due to an interaction of one hydrogen atom attached to the tert-butyl group with the $\pi$-system of the benzyl substituent (see Figure 2-26). Another interesting fact is the absence of any disorder in 15. Up to now, all structures containing the tert-butyltrimethylsilyl-sulfurdiimide exhibited a disorder of the substituents at the nitrogen atoms in the solid state.

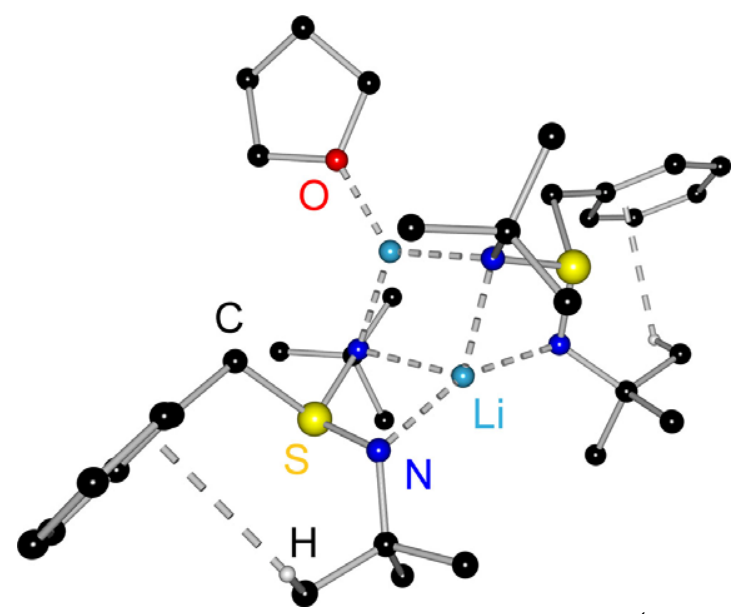

Figure 2-26: Hydrogen bond in $\left[(\mathrm{THF})_{0.5} \mathrm{Li}\left\{\left(\mathrm{N}^{t} \mathrm{Bu}\right)_{2} \mathrm{SBz}\right]_{2}\right.$. 
Surprisingly, in $\mathbf{1 5}$ no such disorder can be observed. A closer look at the structure shows that the trimethylsilyl groups are attached to the nitrogen atoms coordinating only one lithium atom while the nitrogen atoms coordinating both lithium atoms bear tert-butyl groups. The reason for this is probably the steric strain since the donor base is also interacting with the second lithium atom.

Because of the mentioned difficulties during the synthesis of the lithium diimidosulfinates, it was tried to react different sulfurdiimides with a variety of Grignard reagents. Deuerlein already succeeded in adding a phenyl Grignard and a benzyl Grignard to tert-butyl-sulfurdiimide. ${ }^{[152]}$ To further investigate this reactions more Grignard reagents and other sulfurdiimides where employed. By adding the appropriate Grignard reagent $\mathrm{RMgX}$ to a sulfurdiimide, compounds of the general formula [(THF $)_{2} \mathrm{MgX}\left\{(\mathrm{NR})_{2} \mathrm{SR}\right]$ can be obtained in both high yield and purity (see Scheme 2-7). Storage of the solutions at $-24{ }^{\circ} \mathrm{C}$ yields colorless crystals suitable for X-ray structure analysis after one day.

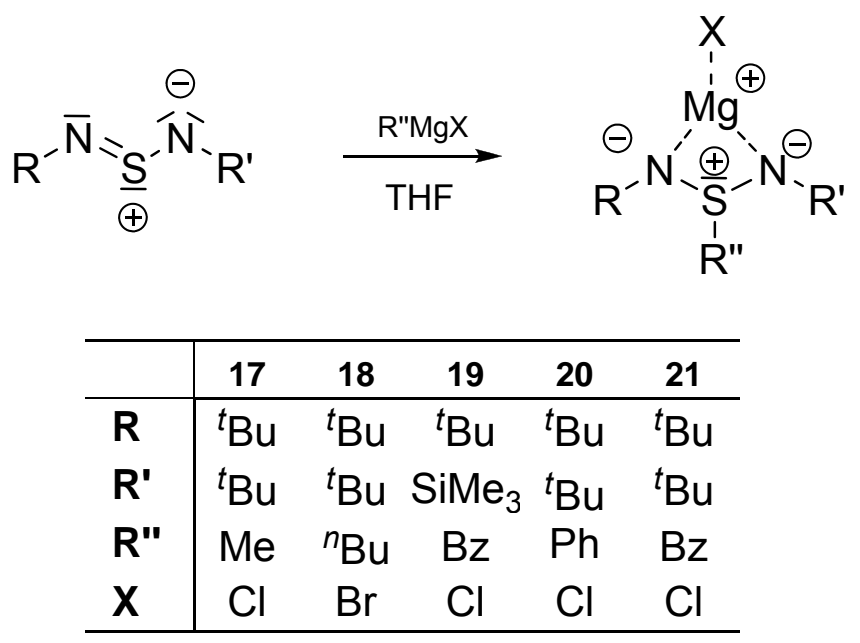

Scheme 2-7: Preparation of the magnesium diimidosulfinates 17-21.

By employing the above described reaction $\left[(\mathrm{THF})_{2} \mathrm{MgBr}\left\{\left(\mathrm{N}^{t} \mathrm{Bu}\right)_{2} \mathrm{SMe}\right]\right.$ (17), $\left[(\mathrm{THF})_{2} \mathrm{MgCl}\left\{\left(\mathrm{N}^{t} \mathrm{Bu}\right)_{2} \mathrm{~S}^{n} \mathrm{Bu}\right](\mathbf{1 8})\right.$ and $\left[(\mathrm{THF})_{2} \mathrm{MgCl}\left\{\left(\mathrm{N}^{t} \mathrm{Bu}\right)\left(\mathrm{NSiMe}_{3}\right) \mathrm{SBz}\right]\right.$ (19) could be synthesized and structurally characterized. 19 was synthesized during the work on the diploma thesis ${ }^{[74]}$ but is discussed here, too, because of the structural similarities. In the structural discussion the three compounds are also compared with $\left[(\mathrm{THF})_{2} \mathrm{MgCl}\left\{\left(\mathrm{N}^{t} \mathrm{Bu}\right)_{2} \mathrm{SPh}\right] \quad(\mathbf{2 0})\right.$ and $\left[(\mathrm{THF})_{2} \mathrm{MgCl}\left\{\left(\mathrm{N}^{t} \mathrm{Bu}\right)_{2} \mathrm{SBz}\right] \quad\right.$ (21) already synthesized earlier by Deuerlein. ${ }^{[152]}$ 
So far, metal diimidosulfinates where known to crystallize mostly as dimers. ${ }^{[69,71]}$ Various structural motifs were found but the one thing they all had in common was the dimeric aggregation. Only in the presence of a polydentate donor base like TMEDA monomers could be crystallized. ${ }^{[82]}\left[(\mathrm{THF}) \mathrm{MgCl}\left\{\left(\mathrm{N}^{t} \mathrm{Bu}\right)_{2} \mathrm{SPh}\right]_{2}\right.$ (20) is no exception to this rule of thumb. It crystallizes as a dimer with a central four membered $\mathrm{Mg}_{2} \mathrm{Cl}_{2}$ ring (see Figure 2-27).

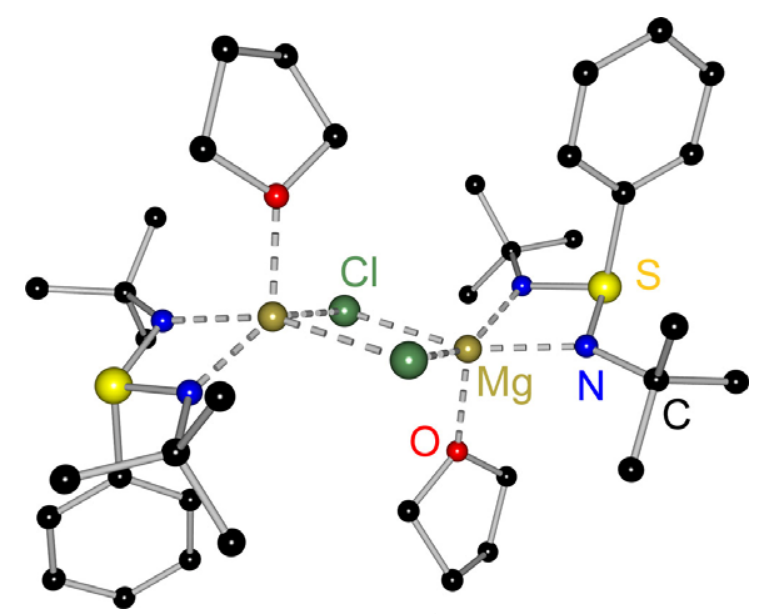

Figure 2-27: Molecular structure of $\left[(\mathrm{THF})_{2} \mathrm{MgCl}\left\{\left(\mathrm{N}^{t} \mathrm{Bu}\right)_{2} \mathrm{SPh}\right](20)\right.$. All hydrogen atoms have been omitted for clarity.

Except for the central $\mathrm{Mg}_{2} \mathrm{X}_{2}$ ring, 20 exhibits the same bond lengths and angles within their standard deviation as its published heavier congener $\left[(\mathrm{THF}) \mathrm{MgBr}\left\{\left(\mathrm{NSiMe}_{3}\right)_{2} \mathrm{SPh}\right]_{2}{ }^{[68]}\right.$ Although the structural motif is different, the geometry around the metal atom is very similar in these two compounds. The preferred five-fold coordination of the magnesium atom is achieved by two $\mathrm{Mg}-\mathrm{N}$ contacts to the diimidosulfinate, the interactions with the two chlorine atoms and the coordination of one THF molecule. As a result of this geometry, the chlorine atoms are not positioned at the sterically favorable apex of the square-pyramidal environment of the magnesium atoms, but reside in the base. As already observed for other compounds containing a central $\mathrm{Mg}_{2} \mathrm{X}_{2}$ ring the $\mathrm{Mg}-\mathrm{Cl}$ interactions show a distinct asymmetry $(\Delta(\mathrm{Mg}-\mathrm{Cl})=0.07 \AA) .{ }^{[178-181]}$ This shows that the electron density of the halogen anions is not shared equally between the magnesium atoms. The tertiary carbon atoms of the ${ }^{t} \mathrm{Bu}$ groups are nearly in plane with the $\mathrm{N}-\mathrm{S}-\mathrm{N}$ plane which is tilted $37^{\circ}$ towards the central $\mathrm{Mg}_{2} \mathrm{X}_{2}$ ring. In addition both $\mathrm{N}-\mathrm{S}-\mathrm{N}$ planes are twisted $14^{\circ}$ sidewards to avoid steric strain between the phenyl ring and the THF molecule of the other half of the dimer. 
Table 2-5: Selected bond length $[\AA]$ and angles for 17-21.

\begin{tabular}{cccccc}
\hline Compound & $\mathbf{1 7}$ & $\mathbf{1 8}$ & $\mathbf{1 9}$ & $\mathbf{2 0}$ & $\mathbf{2 1}$ \\
\hline Distances & & & & & \\
S-N1 & $1.6201(59)$ & $1.6277(12)$ & $1.6186(15)$ & $1.6089(17)$ & $1.6285(13)$ \\
S-N2 & $1.6307(54)$ & $1.6346(11)$ & $1.6168(15)$ & $1.6160(17)$ & $1.6218(12)$ \\
S-C & $1.8039(58)$ & $1.8145(14)$ & $1.8393(17)$ & $1.8173(20)$ & $1.8440(15)$ \\
N1-Mg & $2.1263(61)$ & $2.1042(12)$ & $2.1118(17)$ & $2.0815(17)$ & $2.1021(14)$ \\
N2-Mg & $2.0943(56)$ & $2.1504(12)$ & $2.1542(15)$ & $2.0558(18)$ & $2.1697(13)$ \\
Mg-Cl & Mg-Br & $2.3474(6)$ & $2.3407(7)$ & $2.4160(8)$ & \\
& $2.4960(13)$ & & & $2.4841(8)$ & $2.3430(7)$ \\
Mg-O1 & $2.1166(47)$ & $2.0793(11)$ & $2.0909(14)$ & $2.0265(15)$ & $2.1112(12)$ \\
Mg-O2 & $2.0736(56)$ & $2.1116(11)$ & $2.0866(14)$ & & $2.0854(12)$ \\
Angles & & & & & \\
N-S-N & $99.44(15)^{\circ}$ & $99.62(6)^{\circ}$ & $100.05(8)^{\circ}$ & $94.41(8)^{\circ}$ & $99.65(7)^{\circ}$ \\
N-Mg-N & $71.97(0.12)$ & $71.71(0.04)$ & $71.06(0.06)$ & $69.77(0.07)$ & $71.07(0.05)$ \\
C-S-N & $101.75(0.35)$ & $103.89(0.06)$ & $103.00(0.08)$ & $106.04(0.09)$ & $102.20(0.07)$ \\
& $102.28(0.36)$ & $101.56(0.06)$ & $101.89(0.08)$ & $105.90(0.09)$ & $102.31(0.07)$ \\
\hline
\end{tabular}

In contrast to $20, \mathbf{1 7 - 1 9}$ and 21 crystallize as monomers. Although the geometry formed by five-fold coordination at the magnesium atom is maintained, the structural motif shown by 17-19 and 21 is totally different. The $\mathrm{Mg}_{2} \mathrm{X}_{2}$ four-membered ring is not retained but a second THF molecule completes the coordination sphere at the metal ion. The square-pyramidal environment is preserved, but in the monomeric form the halogen anion can occupy the sterically favorable apex of the pyramid.
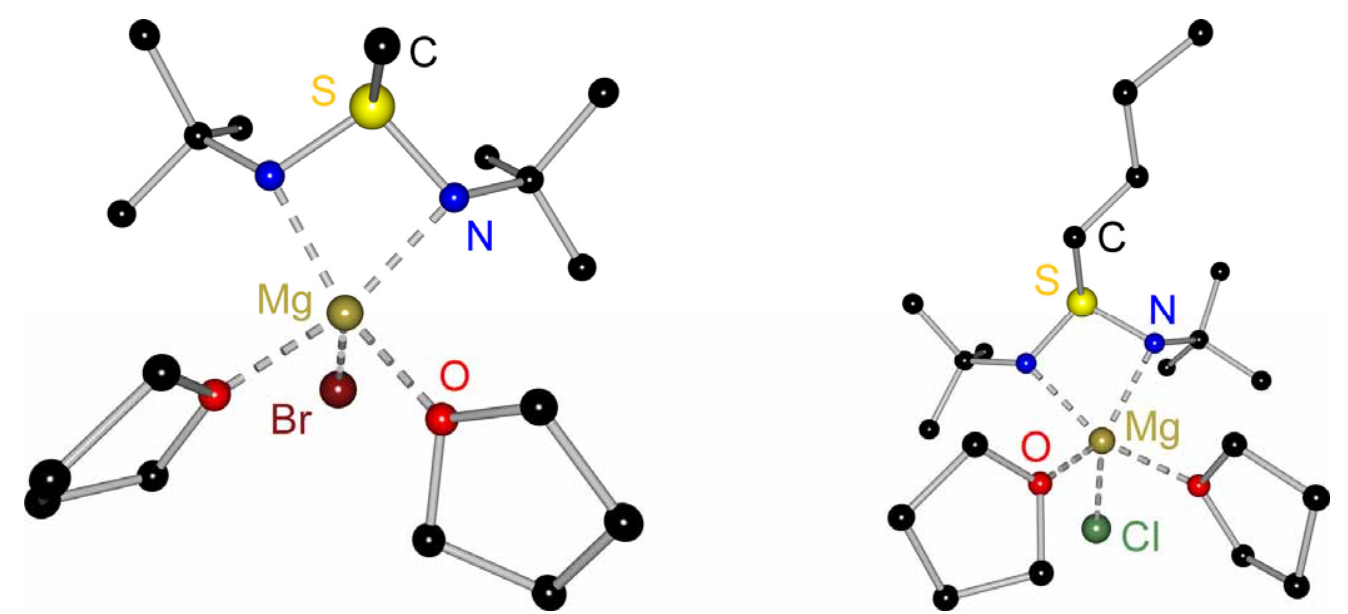

Figure 2-28: Molecular structure of $\left[(\mathrm{THF})_{2} \operatorname{MgBr}\left\{\left(\mathrm{N}^{t} \mathrm{Bu}\right)_{2} \mathrm{SMe}\right]\right.$ (17) (left) and $\left[(\mathrm{THF})_{2} \mathrm{MgCl}\left\{\left(\mathrm{N}^{t} \mathrm{Bu}\right)_{2} \mathrm{~S}^{n} \mathrm{Bu}\right](\mathbf{1 8})\right.$ (right). All hydrogen atoms have been omitted for clarity. 
Different to 20 , the tertiary carbon atoms of the ${ }^{t} \mathrm{Bu}$ groups in 17-19 and 21 point away from the magnesium atom and the $\mathrm{C}-\mathrm{N}$ bonds includes angles of $31^{\circ}$ to $47^{\circ}$ with the $\mathrm{N}-\mathrm{S}-\mathrm{N}$ plane, providing enough space at the other side of this plane for two THF molecules and the organic substituent at the sulfur atom. In 17 (see Figure 2-28) the deviation of the ${ }^{t} \mathrm{Bu}$ groups is much more symmetric $\left(39.5^{\circ}\right.$ and $\left.38.7^{\circ}\right)$ but all other compounds, especially 18 (see Figure 2-28), exhibit a distinct asymmetry $\left(31.2^{\circ}\right.$ and $\left.47.3^{\circ}\right)$ with a larger angle present at the side where the substituent at the sulfur atom is positioned.

The structures of the magnesium diimidosulfinates show that neither the nature of the halogen anions nor the organic substituents at the nitrogen atoms have an impact on the structural motif. So the reason for the formation of a monomer in favor of a dimer must be related to the organic substituent bound to the sulfur atom instead. If a sterically demanding group is present at the sulfur atom there is not enough room for this bulky group and an additional THF molecules at the same side of the N-S-N plane which would be required for a potential dimerization, even if the ${ }^{t} \mathrm{Bu}$ groups at the nitrogen atoms are pointing to the adjacent side.

Although a phenyl group is generally not considered to be sterically particularly demanding, its bulk is sufficient enough to bring the ortho carbon atom in close proximity to the magnesium atom, leaving not enough space for both THF donor molecules. In contrast to that, the methyl group of $\mathbf{1 7}$ provides less sterical demand and the substituents of the other compounds all comprise $\mathrm{CH}_{2}$ spacers able to bend the remaining organic substituent away leaving enough space for the THF molecules.
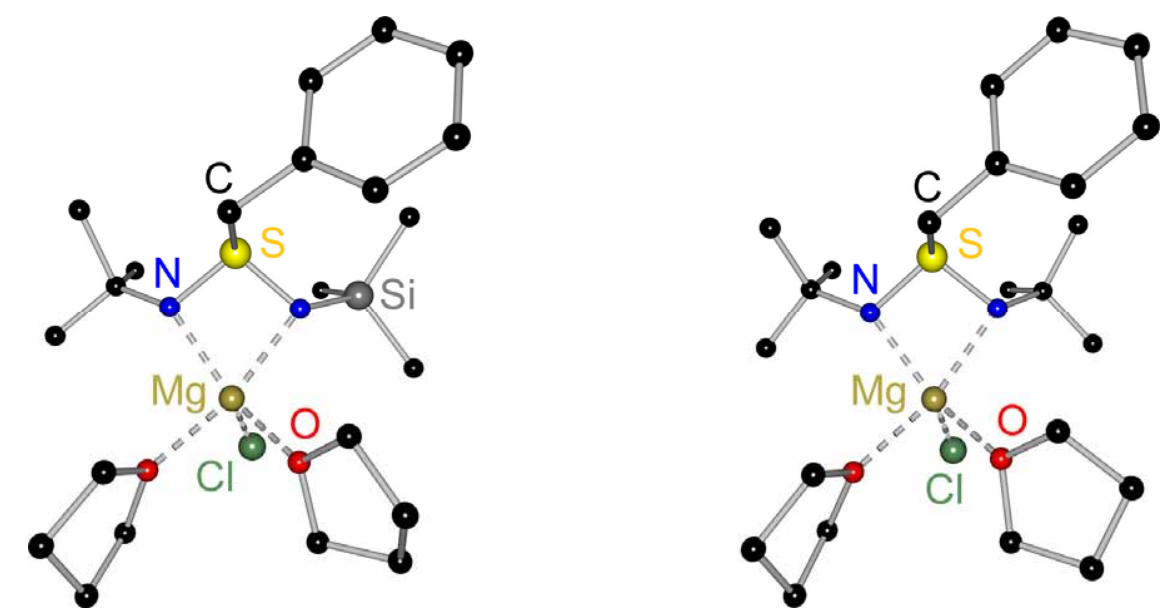

Figure 2-29: Molecular structure of $\left[(\mathrm{THF})_{2} \mathrm{MgCl}\left\{\left(\mathrm{N}^{t} \mathrm{Bu}\right)\left(\mathrm{NSiMe}_{3}\right) \mathrm{SBz}\right](19)\right.$ (left) and $\left[(\mathrm{THF})_{2} \mathrm{MgCl}\left\{\left(\mathrm{N}^{t} \mathrm{Bu}\right)_{2} \mathrm{SBz}\right](\mathbf{2 1})\right.$ (right). All hydrogen atoms have been omitted for clarity. 
Since the THF oxygen atom is a better donor to magnesium than a halogen anion bridging two metal ions, the monomeric form is favored for 17-19 and 21 . Because of the better donor the $\mathrm{Mg}-\mathrm{N}$ and the $\mathrm{Mg}-\mathrm{O}$ contacts are longer in 17-19 and 21 compared to 20. Only the $\mathrm{Mg}-\mathrm{X}$ bond is shorter in 17-19 and 21 than in 20 because the halogen anion is not forced to share its electron density between two metal ions.

Among the monomeric compounds 17-19 and 21 the structural differences are marginal (Figure 2-30). Even the asymmetric diimidosulfinat 19 (see Figure 2-29) exhibits nearly the same bond lengths and angles as its symmetric congener 21. Only the S-C bonds of 19 and 21 (1.84 $\AA$ ) are clearly longer than that of $\mathbf{1 7 ,} \mathbf{1 8}$ and 20 or other organyl diimidosulfinates $\left(1.80 \AA\right.$ on average). ${ }^{[67,68,76]}$ The phenyl substituents at the benzylic carbon atoms withdraw electron density from the S-C bonds, which are therefore destabilized and elongated.

Although 19 possesses a asymmetric sulfur atom, it crystallizes as a racemate in the centrosymmetric space group $P 2_{1} / \mathrm{c}$. In addition, the ${ }^{t} \mathrm{Bu}$ groups and the $\mathrm{SiMe}_{3}$ groups are disordered making an assignment of the isomers impossible.

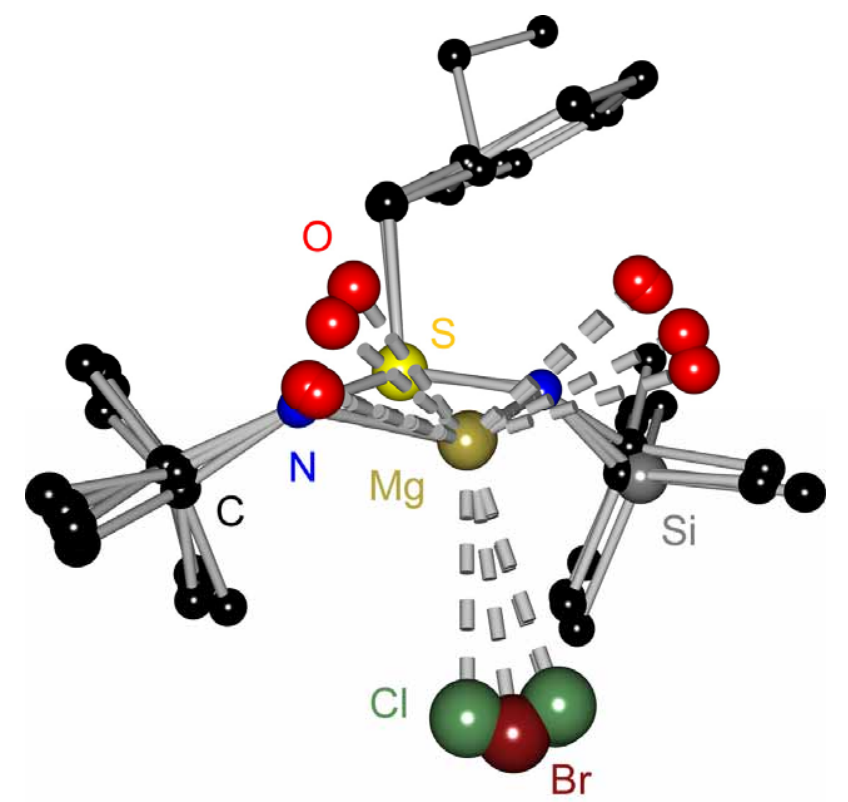

Figure 2-30: Molecular structure overlay of 17-19 and 21, all hydrogen atoms and the carbon atoms of the THF molecules have been omitted for clarity.

The N-S-N bond angles in all presented compounds $\left(94.4^{\circ}-100.1^{\circ}\right)$ are more acute than those in alkali metal derivatives $\left(104.2^{\circ}-110.7^{\circ}\right),{ }^{[68,69]}$ but span almost the same range as in comparable compounds with magnesium atoms or other dicationic metals $\left(94.3^{\circ}-98.5^{\circ}\right) .^{[68,90,139]}$ This can be attributed to the higher charge at the magnesium dication, leading to a stronger repulsion between the positively charged sulfur atom and the metal ion. 
Another interesting fact about the magnesium diimidosulfinates is their behavior in solution. The ${ }^{1} \mathrm{H}$ - and ${ }^{13} \mathrm{C}-\mathrm{NMR}$-spectra all exhibit a double set of signals for 17-21. Integration of all peaks and NOESY experiments displayed that in each double set of signals the peaks shifted to higher field belong together. Figure 2-31 shows the spectra of $\mathbf{1 7}$ measured at different temperatures. The signals for the methyl groups occur between $2.1 \mathrm{ppm}$ and $2.3 \mathrm{ppm}$ while the ${ }^{\mathrm{t}} \mathrm{Bu}$ protons resonate between 1.1 $\mathrm{ppm}$ and $1.3 \mathrm{ppm}$. The spectrum of 17 at $-70{ }^{\circ} \mathrm{C}$ also displays the occurrence of an additional set of signals resulting in a triple set.

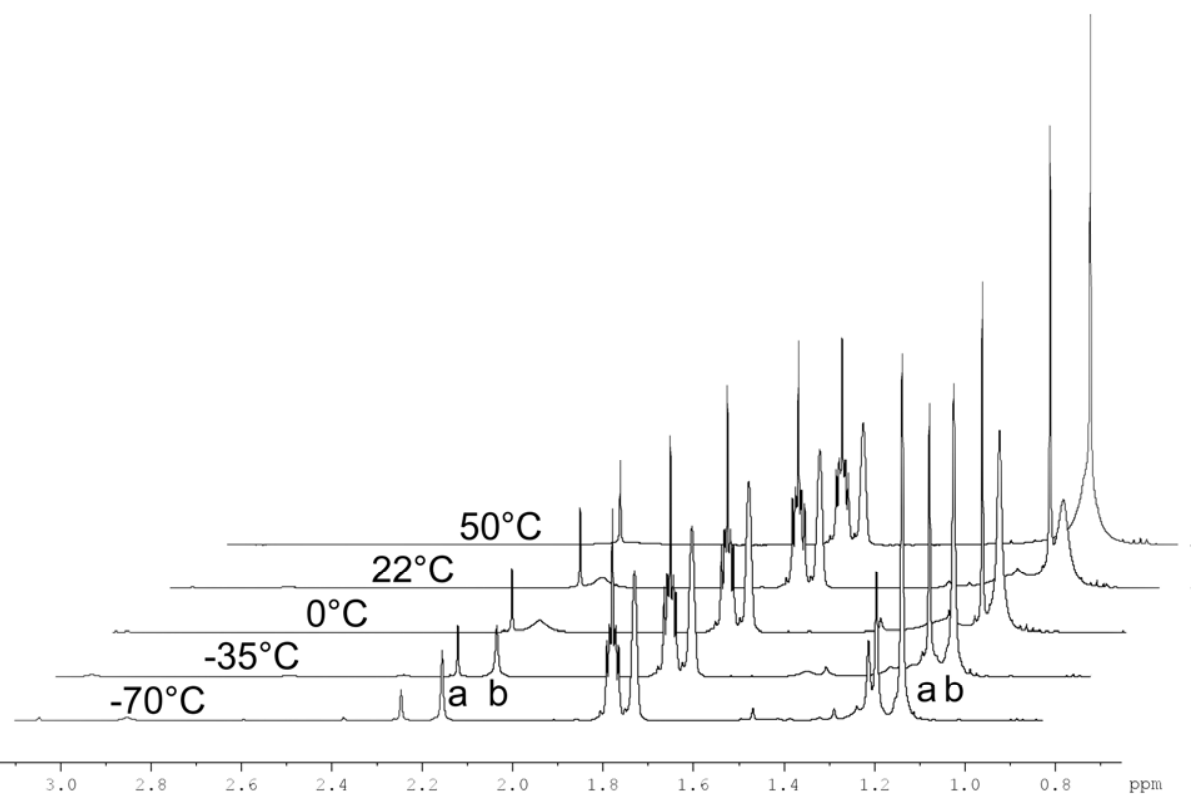

Figure 2-31: ${ }^{1} \mathrm{H}-\mathrm{NMR}$ spectra of 17 at different temperatures $\left(500.132 \mathrm{MHz}, \mathrm{d}_{8}-\mathrm{THF}\right)$.

For the measurements the temperatures as well as the elapsed time since the priming of the samples were adapted. The concentration of the samples was also varied in the different experiments. This way it could be verified that the equilibrium is time, concentration and temperature dependent. Figure 2-31 shows that with lower temperatures even more species are involved and that a higher temperature results in an increase of species $\mathbf{a}$ at the expense of species $\mathbf{b}$. In addition, the peak of $\mathbf{b}$ gets sharper. When the sample is more concentrated the ratio of the integrated intensity of $\mathbf{b}$ divided by the integrated intensity of $\mathbf{a}$ is getting higher. When the elapsed time between priming the sample and the measurement increases the ratio of the integrated intensity of $\mathbf{b}$ divided by the integrated intensity of $\mathbf{a}$ is getting smaller. In addition, the peak for $\mathbf{b}$ is getting broader as more time passes. Since the exchange between $\mathbf{a}$ and $\mathbf{b}$ works in both directions it was verified that both species can be transformed into each other and that the double set of signals is not just due 
to hydrolysis or ligand scrambling. In addition, a ${ }^{15} \mathrm{~N}-\mathrm{HMBC}-\mathrm{spectrum}$ was recorded which showed two cross peaks, for both ${ }^{t} \mathrm{Bu}$ signals with the signal of the nitrogen atoms, at $-270 \mathrm{ppm}$ and $-272 \mathrm{ppm}$ respectively. The proximity of the signals indicates that the chemical environment of the nitrogen atoms is the same for both species. This, coupled with the absence of any amine proton proves that no hydrolysis is responsible for the signal doubling. The first assumption was that the spectra display the equilibrium between the monomeric form shown in the solid state by 17-19 and 21 and a dimeric form similiar to the structure shown by $\mathbf{2 0}$ in the solid state, reminiscent of the Schlenk equilibrium species. To test this assumption a DOSY spectrum was recorded. ${ }^{[182,183]}$ To our surprise the DOSY spectrum showed that both species move with nearly the same speed in solution, indicating that the size of both molecules and the atom numbers should be almost the same. With the help of the recorded DOSY spectrum it was also possible to calculate the size of the molecules in solution. The measurement showed that species $\mathbf{a}$ and $\mathbf{b}$ have $\mathbf{a}$ radius of approximately $4 \AA$. This radius fits the size of the monomeric form that could be observed in the solid state for 17-19 and 21. Because of these experiments and from our earlier experiences with magnesium imidosulfinates ${ }^{[68,184]}$ we think that the second species in solution might be $\left[\mathrm{Mg}\left\{\left(\mathrm{N}^{t} \mathrm{Bu}\right)_{2} \mathrm{SR}\right\}_{2}\right]$ or $\left[(\mathrm{THF}) \mathrm{Mg}\left\{\left(\mathrm{N}^{t} \mathrm{Bu}\right)_{2} \mathrm{SR}\right\}_{2}\right]$. All three compounds are about the same size and should yield very similar peaks in the NMR (see Figure 2-32).
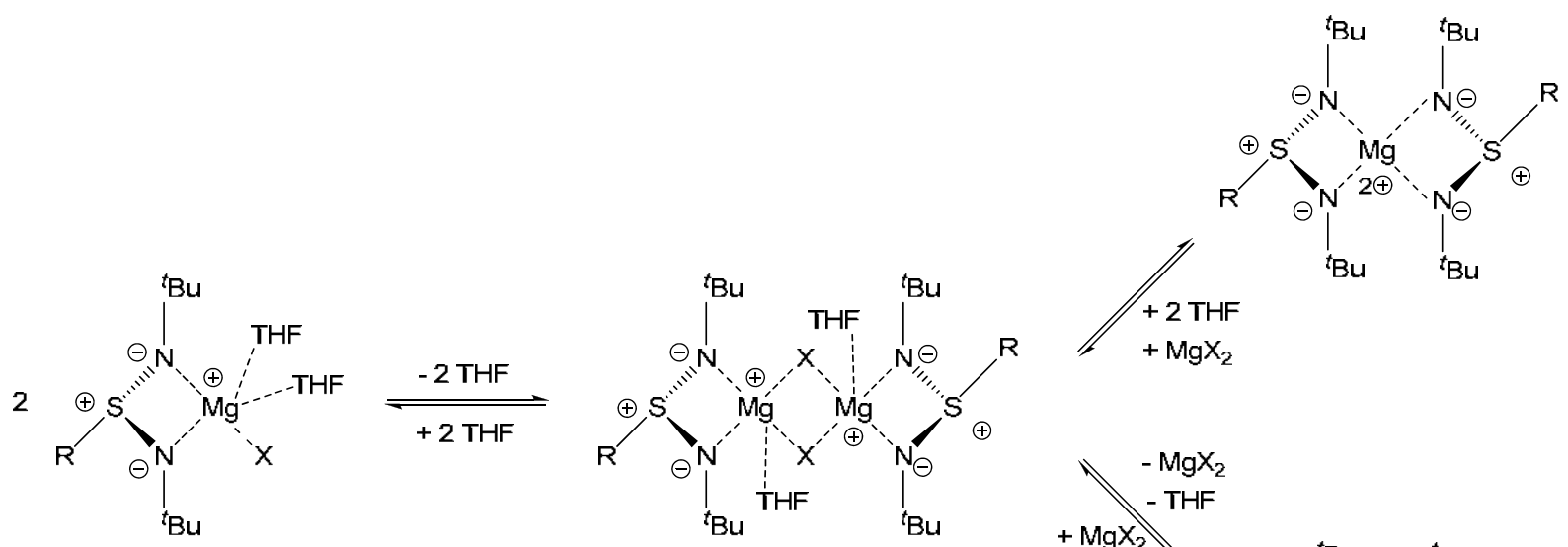

Figure 2-32: Possible conversion of the magnesium diimidosulfinates in solution.

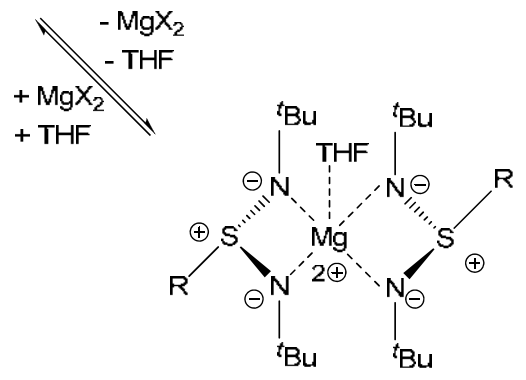


Additional evidence for this assumption provided a NOESY spectrum. This spectrum did not show defined cross peaks between both species but nevertheless cross peaks can be observed between both species and very broad signals next to the ${ }^{t} \mathrm{Bu}$ peaks and the peaks for the methyl groups. This suggests that the exchange between both species $\mathbf{a}$ and $\mathbf{b}$ is mediated through an intermediate that is only shortlived and therefore only yields a very small and broad signal (see Figure 2-32). One possibility would be that this intermediate is a dimeric form similar to the structure of 20 in the solid state.

The experiments in this work showed that sulfur diimides react readily with different Grignard reagents. All products are obtained very pure and in high yields. By varying the steric demand of the substituent at the sulfur atom it is possible to get monomeric or dimeric molecules that can be distinguished by $\mathrm{X}$-ray structure determination in the solid state and show interesting features in solution. The structural motifs of the monomer and the dimer are very different but in contrast to their lithium counterparts the monomeric and the dimeric magnesium diimidosulfinates do not show much variance among each other. The NMR spectra of 17-21 all show a multiple set of signals. It could be determined that the interconversion between the different species is temperature, time and concentration dependent and a reasonable explanation for the signal doubling supported by different NMR experiments was suggested. Nevertheless, an unequivocal assignment to a single process in solution could not be made. Since the reactions of the Grignard reagents with the sulfur diimides proceeded very smoothly further studies on the reactions of Grignard reagents with sulfur triimides were made. Up to now reactions of organolithium reagents with sulfur triimides were only successful with small organic substituents because of the electron concentrations above and below of the $\mathrm{SN}_{3}$ plane. ${ }^{[162]}$ By the application of a HSAB-soft Grignard nucleophile penetration of the electronic shielding should be possible, because it matches the soft character of the sulfur atom. 


\subsubsection{Magnesium triimidosulfonates}

After the results of the experiments described in chapter 2.4.1 it seemed promising to try the reactions with sulfur triimides. The reactions proved to be successful and yielded four magnesium trimiidosulfonates. The obtained triimidosulfonates [(THF)MgX(NtBu) $)_{3} \mathrm{SR}_{2}$ (22: $\mathrm{R}=$ methyl, $\mathrm{X}=\mathrm{Br} ; 2$ 23: $\mathrm{R}={ }^{n}$ butyl, $\mathrm{X}=\mathrm{Cl} ; 2$ 24: $\mathrm{R}=$ phenyl, $\mathrm{X}=\mathrm{Cl}$; 25: $\mathrm{R}=$ benzyl, $\mathrm{X}=\mathrm{Cl}$ ) can readily be synthesized by adding the Grignard reagent to the tert-butylsulfurtriimide (see Scheme 2-8).

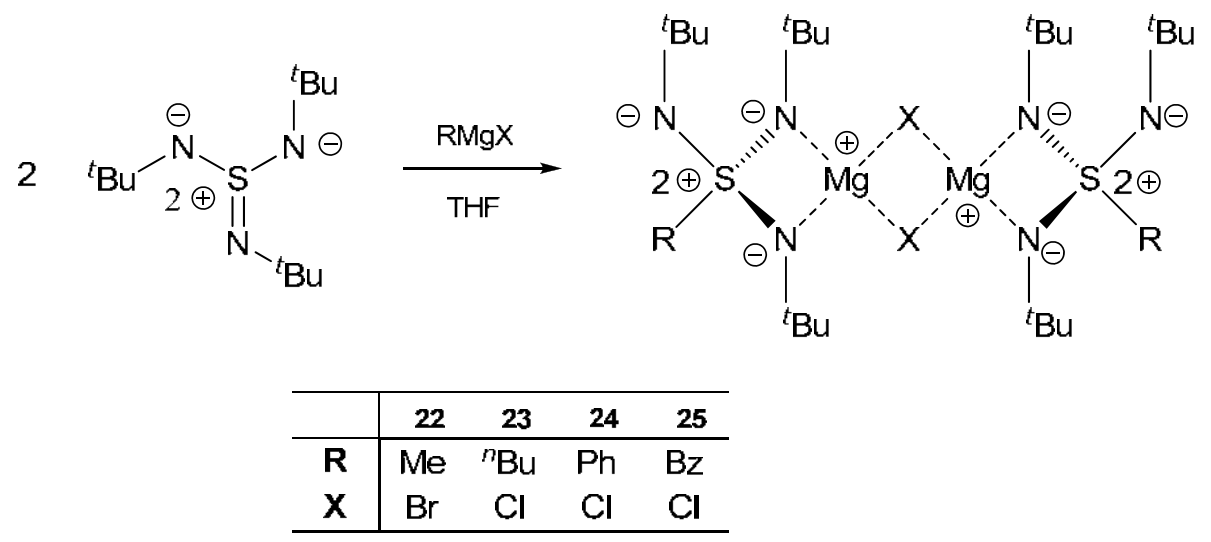

Scheme 2-8: Preparation of the magnesium triimidosulfonates 22-25.

The reaction is straightforward and the products crystallize very well. Therefore the desired magnesium triimidosulfonates are obtained in good yields and high purity after one or two days of storage in the fridge.

Although Deuerlein already synthesized 23 and 24 the determined X-ray structures were of poor quality with low resolution and high $R$-factors. ${ }^{[185]}$ Furthermore Deuerlein did not describe the signal doubling that can be observed in the NMR. Because of this the compounds were synthesized again and the structures in the solid state (Xray) and in solution (NMR) were determined anew. 


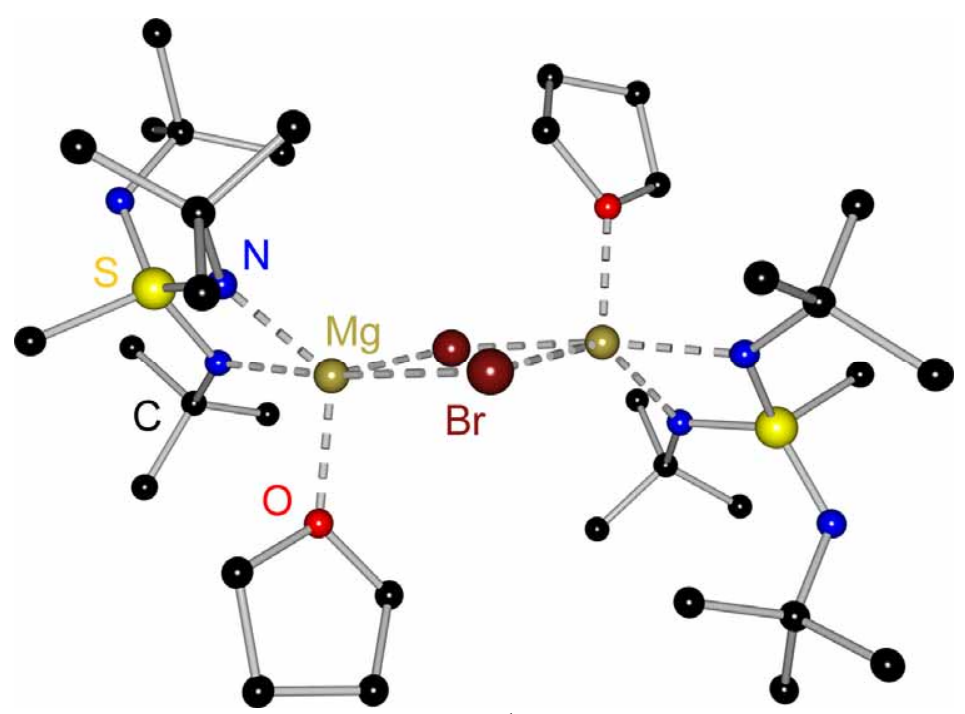

Figure 2-33: Molecular structure of $\left[(\mathrm{THF}) \mathrm{MgBr}\left(\mathrm{N}^{t} \mathrm{Bu}\right)_{3} \mathrm{SMe}_{2}\right.$ (22). All hydrogen atoms have been omitted for clarity.

In contrast to most of their diimidosulfinate analogues $22-25$ crystallize solely as dimers (see Figure 2-33). However, in contradiction to the magnesium diimidosulfinates the triimidosulfonates exhibit bigger differences in the solid state structure due to the change of the substituent at the sulfur atom. Nevertheless, the general dimeric structural motif is preserved. In all structures two ligands are coupled by a central $\mathrm{Mg}_{2} \mathrm{Hal}_{2}$ four-membered ring with the magnesium atoms exhibiting a distorted square-pyramidal coordination polyhedron made up from two nitrogen atoms of the triimidosulfonate monoanion, one oxygen atom of a THF molecule and the two halogen atoms. The sulfur atoms show a distorted tetrahedral environment with very similar angles in all compounds. The non-coordinating $\mathrm{N}^{t} \mathrm{Bu}$ group is pointing away from the metal atom and seems to be in an ideal position to coordinate a second metal (see Figure 2-34).

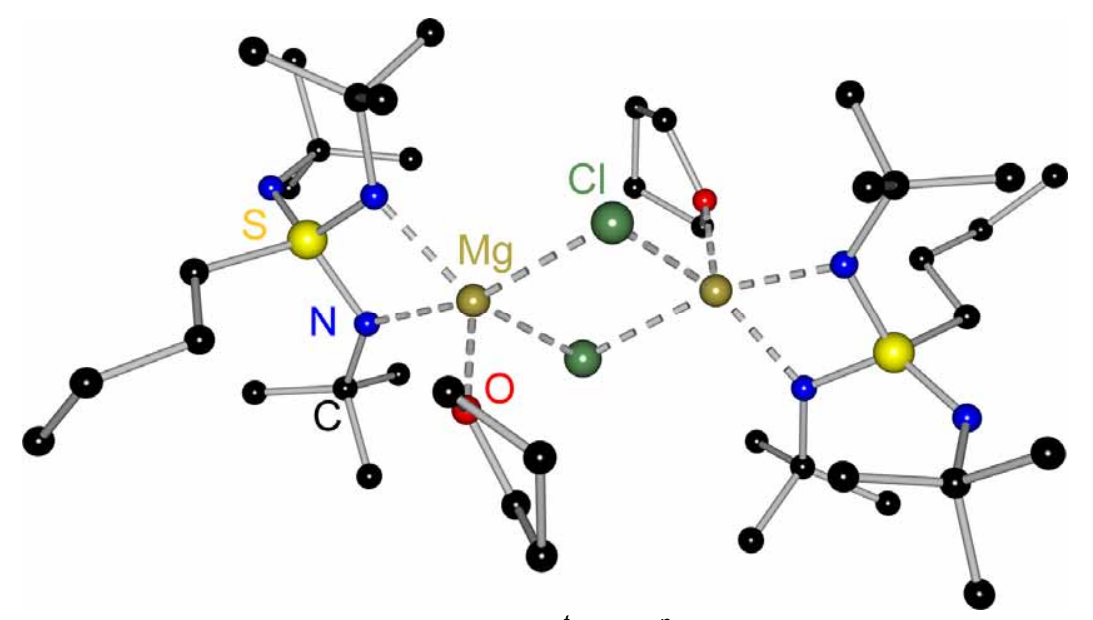

Figure 2-34: Molecular structure of $\left[(\mathrm{THF}) \mathrm{MgCl}\left(\mathrm{N}^{t} \mathrm{Bu}\right)_{3} \mathrm{~S}^{n} \mathrm{Bu}\right]_{2}$ (23). All hydrogen atoms have been omitted for clarity. 
As already mentioned the diimidosulfinates mainly crystallize as monomers with a second donor molecule substituting the second halogen atom in the square pyramidal coordination geometry. Only when the added organic groups are large or inflexible a dimeric form is favored. Since the triimidosulfonates possess a third N $N^{t} B u$ group the steric demand of the ligand is to large for a second donor molecule resulting in exclusively dimeric structures. So changing the organic group makes virtually no difference for the general structural motif. Changing the halogen atom in the central ring has also no serious impact on the overall structure either (see Figure 2-35).

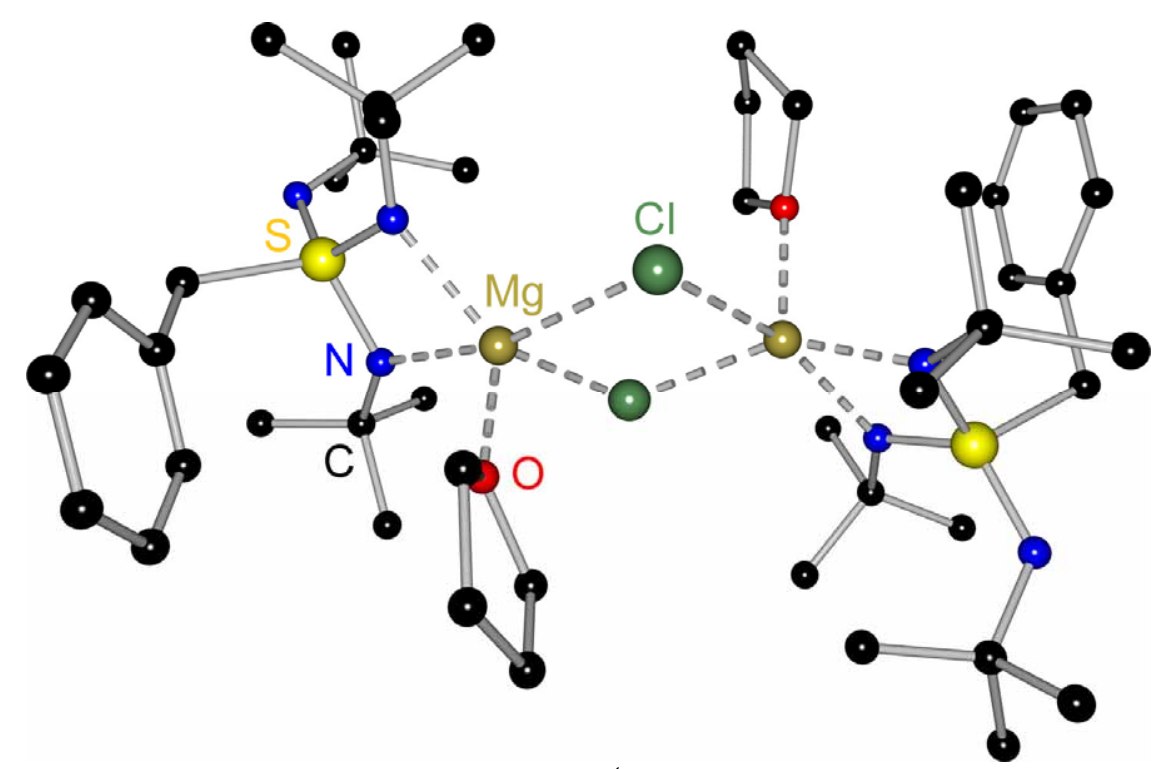

Figure 2-35: Molecular structure of $\left[(\mathrm{THF}) \mathrm{MgCl}\left(\mathrm{N}^{t} \mathrm{Bu}\right)_{3} \mathrm{SBz}\right]_{2}$ (25). All hydrogen atoms have been omitted for clarity.

For $\mathbf{2 2}, \mathbf{2 3}$ and $\mathbf{2 5}$ not only the general structural motifs but also most of the bond lengths and angles are identical within their estimated standard deviations (Table 2-6). Only small differences can be seen for example in the elongation of the $\mathrm{S}-\mathrm{C}$ bond length in $\mathbf{2 5}$ which is due to the electron withdrawing effect of the adjacent phenyl substituent. The differences in the $\mathrm{Mg}-\mathrm{X}$ and $\mathrm{Mg}-\mathrm{O}$ bond lengths in 22 are most likely due to the change of the halogen anion.

When comparing the monomeric structural motif of the diimidosulfinates and the dimeric motif of the triimidosulfonates (see Figure 2-36) it is obvious that the change of the added organic substituent has a more substantial impact on the solid state structure of the latter. ${ }^{[186]}$ 
Table 2-6: Selected bond length $[\AA]]$ for 22-25.

\begin{tabular}{|c|c|c|c|c|}
\hline Compound & 22 & 23 & 24 & 25 \\
\hline \multirow{2}{*}{ S-N1/N3 } & \multirow{2}{*}{$1.5808(21)$} & \multirow{2}{*}{$1.5949(23)$} & $1.5880(21) /$ & $1.5948(20) /$ \\
\hline & & & $1.6017(19)$ & $1.5969(20)$ \\
\hline \multirow{2}{*}{ S-N2/N4 } & \multirow{2}{*}{$1.5976(17)$} & \multirow{2}{*}{$1.6075(22)$} & $1.5976(19) /$ & $1.5936(20) /$ \\
\hline & & & $1.5880(21)$ & $1.5967(20)$ \\
\hline \multirow{2}{*}{ S-N5/N6 } & \multirow{2}{*}{$1.5228(21)$} & \multirow{2}{*}{$1.5282(22)$} & $1.5281(22) /$ & $1.5271(20) /$ \\
\hline & & & $1.5224(20)$ & $1.5257(20)$ \\
\hline \multirow{2}{*}{ C-S1/S2 } & \multirow{2}{*}{$1.7880(22)$} & \multirow{2}{*}{$1.8107(26)$} & $1.7972(32) /$ & $1.8310(24) /$ \\
\hline & & & $1.7972(25)$ & $1.8331(24)$ \\
\hline \multirow{2}{*}{$\mathrm{Mg}-\mathrm{N} 1 / \mathrm{N} 3$} & \multirow{2}{*}{$2.0650(19)$} & \multirow{2}{*}{$2.0692(23)$} & $2.0666(21) /$ & $2.0941(21) /$ \\
\hline & & & $2.0777(21)$ & $2.0903(21)$ \\
\hline \multirow{2}{*}{$\mathrm{Mg}-\mathrm{N} 2 / \mathrm{N} 4$} & \multirow{2}{*}{$2.0677(20)$} & \multirow{2}{*}{$2.0712(21)$} & $2.0774(20) /$ & $2.0703(22) /$ \\
\hline & & & $2.0821(20)$ & $2.0898(21)$ \\
\hline \multirow{2}{*}{ X1-Mg1/Mg2 } & \multirow{2}{*}{$2.6683(9)$} & \multirow{2}{*}{$2.4544(11)$} & $2.4524(10) /$ & $2.4367(13) /$ \\
\hline & & & $2.5165(10)$ & $2.4859(11)$ \\
\hline \multirow{2}{*}{ X2-Mg1/Mg2 } & \multirow{2}{*}{$2.5947(9)$} & \multirow{2}{*}{$2.4874(11)$} & $2.4249(10) /$ & $2.5134(11) /$ \\
\hline & & & $2.5178(9)$ & $2.4621(11)$ \\
\hline \multirow{2}{*}{$\mathrm{Mg}-\mathrm{O}$} & \multirow{2}{*}{$2.0325(18)$} & \multirow{2}{*}{$2.0712(21)$} & $2.0537(18) /$ & $2.0606(19) /$ \\
\hline & & & $2.0452(18)$ & $2.0645(20)$ \\
\hline
\end{tabular}

For the diimidosulfinates the use of different nucleophiles only results in a small change in the twist of the ${ }^{t} \mathrm{Bu}$ groups to the $\mathrm{N}-\mathrm{S}-\mathrm{N}$ plane and a little shift of the halogen atom and the THF molecules while the change of the substituent has a much higher influence on the solid state structure of the triimidosulfonates.

Figure 2-36 shows the main differences between the solid state structures of 22, 23 and 25 to be the different arrangements of the $\mathrm{N}-\mathrm{S}-\mathrm{N}$ planes. The carbon atoms of the ${ }^{t} \mathrm{Bu}$ groups stay in the $\mathrm{N}-\mathrm{S}-\mathrm{N}$ plane and the configuration of the imido groups as well as the organic substituent also do not change a lot.

Thus, both ligands are skewed against each other resulting in a different twist between both $\mathrm{N}-\mathrm{S}-\mathrm{N}$ planes and the central $\mathrm{Mg}_{2} \mathrm{Hal}_{2}$ plane for each organic substituent. 

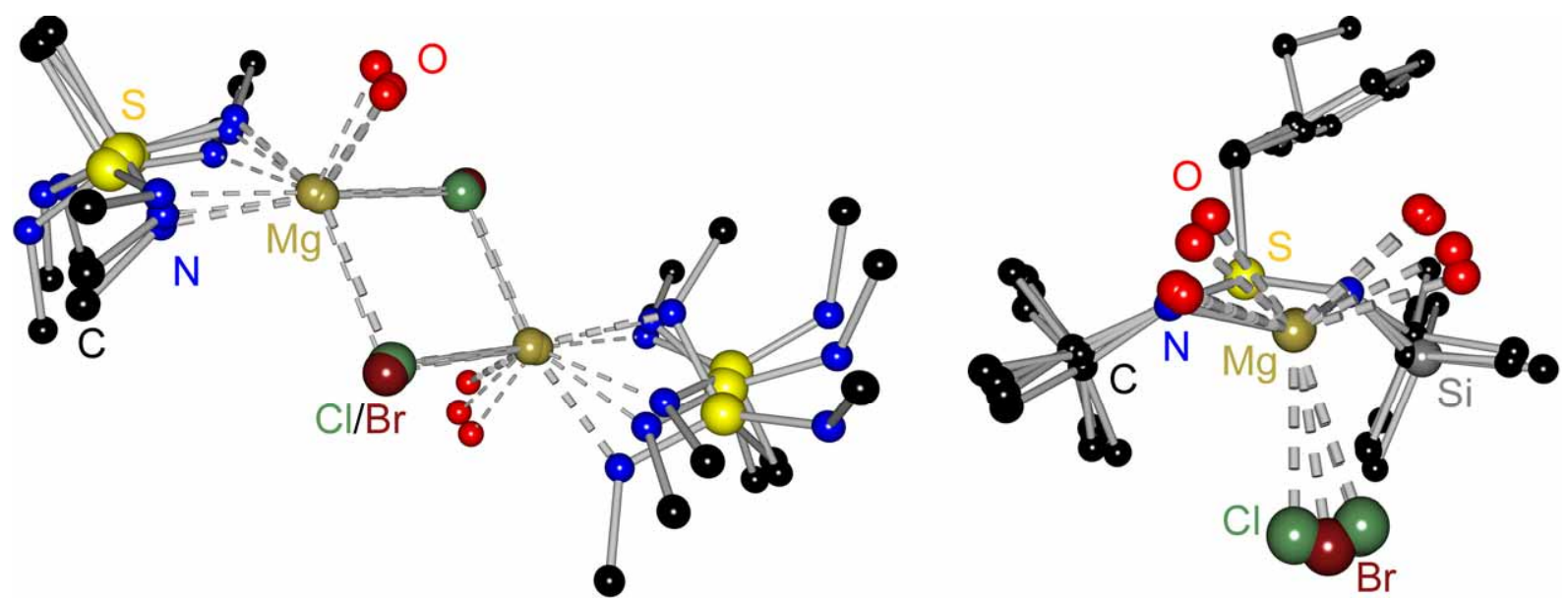

Figure 2-36: Superposition plot of 22, 23 and 25 (left), all hydrogen atoms have been omitted for clarity and only the ipso carbon atoms of the tert-butyl groups and the substituents at the sulfur atoms are shown; superposition plot of four magnesium diimidosulfinates 17-19 and $\mathbf{2 1}$ (right), all hydrogen atoms and the carbon atoms of the THF have been omitted for clarity.

In the structures of 22 and 23 the $\mathrm{N}-\mathrm{S}-\mathrm{N}$ planes are coplanar because of an inversion center in the middle of the $\mathrm{Mg}_{2} \mathrm{X}_{2}$ four-membered ring. 22 and 23 share even more similarities since they exhibit nearly the same torsion angle $\left(75.03^{\circ} \mathrm{vs}\right.$. $74.20^{\circ}$ ) between the $\mathrm{N}-\mathrm{S}-\mathrm{N}$ planes.

Table 2-7: Selected torsion angles and angles between planes $\left[{ }^{\circ}\right]$ for 22-25.

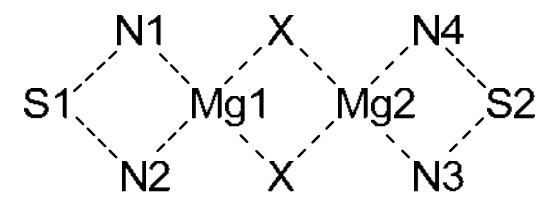

\begin{tabular}{ccccc}
\hline Compound & $\mathbf{2 2}$ & $\mathbf{2 3}$ & $\mathbf{2 4}$ & $\mathbf{2 5}$ \\
\hline $\mathrm{Mg}_{2} \mathrm{X}_{2}-\mathrm{N} 1 \mathrm{~S} 1 \mathrm{~N} 2$ & 50.70 & 35.3 & 66.50 & 42.50 \\
$\mathrm{Mg}_{2} \mathrm{X}_{2}-\mathrm{N} 3 \mathrm{~S} 2 \mathrm{~N} 4$ & 50.70 & 35.3 & 37.00 & 35.20 \\
$\mathrm{~N} 1 \mathrm{~S} 1 \mathrm{~N} 2-\mathrm{N} 3 \mathrm{~S} 2 \mathrm{~N} 4$ & 0.00 & 0.00 & 101.10 & 24.00 \\
S1Mg1Mg2S2- & 73.50 & 82.10 & 46.40 & 72.40 \\
$\mathrm{~N} 1 \mathrm{~S} 1 \mathrm{~N} 2$ & & & & \\
S1Mg1Mg2S2- & 73.50 & 82.10 & 79.00 & 83.70 \\
$\mathrm{~N} 3 \mathrm{~S} 2 \mathrm{~N} 4$ & 75.03 & 74.20 & 33.52 & 58.15 \\
$\mathrm{~N} 1-\mathrm{Mg} 1-\mathrm{Mg} 2-\mathrm{N} 3$ & 75.03 & 74.20 & 44.04 & 97.36 \\
$\mathrm{~N} 2-\mathrm{Mg} 1-\mathrm{Mg} 2-\mathrm{N} 4$ & 62.84 & 49.02 & 9.95 & 21.77 \\
$\mathrm{X}-\mathrm{Mg}-\mathrm{Mg}-\mathrm{N} 1$ & 12.19 & 25.18 & 82.14 & 55.04 \\
$\mathrm{X}-\mathrm{Mg}-\mathrm{Mg}-\mathrm{N} 2$ & 62.84 & 49.12 & 43.47 & 42.33 \\
$\mathrm{X}-\mathrm{Mg}-\mathrm{Mg}-\mathrm{N} 3$ & 12.19 & 25.45 & 38.10 & 36.38 \\
$\mathrm{X}-\mathrm{Mg}-\mathrm{Mg}-\mathrm{N} 4$ & & & & \\
\hline
\end{tabular}


Nevertheless, there are still some differences between both structures. In 22 the deviation of the $\mathrm{N}-\mathrm{S}-\mathrm{N}$ planes out of the $\mathrm{Mg}_{2} \mathrm{X}_{2}$ plane are a lot larger than in 23 $\left(50.70^{\circ}\right.$ vs. $\left.35.3^{\circ}\right)$ and although the torsion angles between the $\mathrm{N}-\mathrm{S}-\mathrm{N}$ planes are nearly the same in both structures the skewing between the $\mathrm{N}-\mathrm{S}-\mathrm{N}$ planes and the $\mathrm{Mg}_{2} \mathrm{X}_{2}$ plane is a lot bigger in $22\left(90^{\circ}-73.5^{\circ}=16.5^{\circ}\right)$ than in $23\left(90^{\circ}-82.3=7.7^{\circ}\right)$. Furthermore, it is obvious that the skewing between the two $\mathrm{N}-\mathrm{S}-\mathrm{N}$ planes and between the $\mathrm{N}-\mathrm{S}-\mathrm{N}$ planes and the $\mathrm{Mg}_{2} \mathrm{X}_{2}$ plane, respectively, is greatest for 24 due to its unique structural motif (see Figure 2-37). Another possibility for the triimidosulfonates to avoid sterical strain is to change the $\mathrm{C}-\mathrm{N}-\mathrm{S}-\mathrm{N}$ torsion angle. For 22-25 the torsion angles lie between $0.0^{\circ}$ (tert-butyl groups are in the $\mathrm{N}-\mathrm{S}-\mathrm{N}$ plane) and $11.2^{\circ}$.

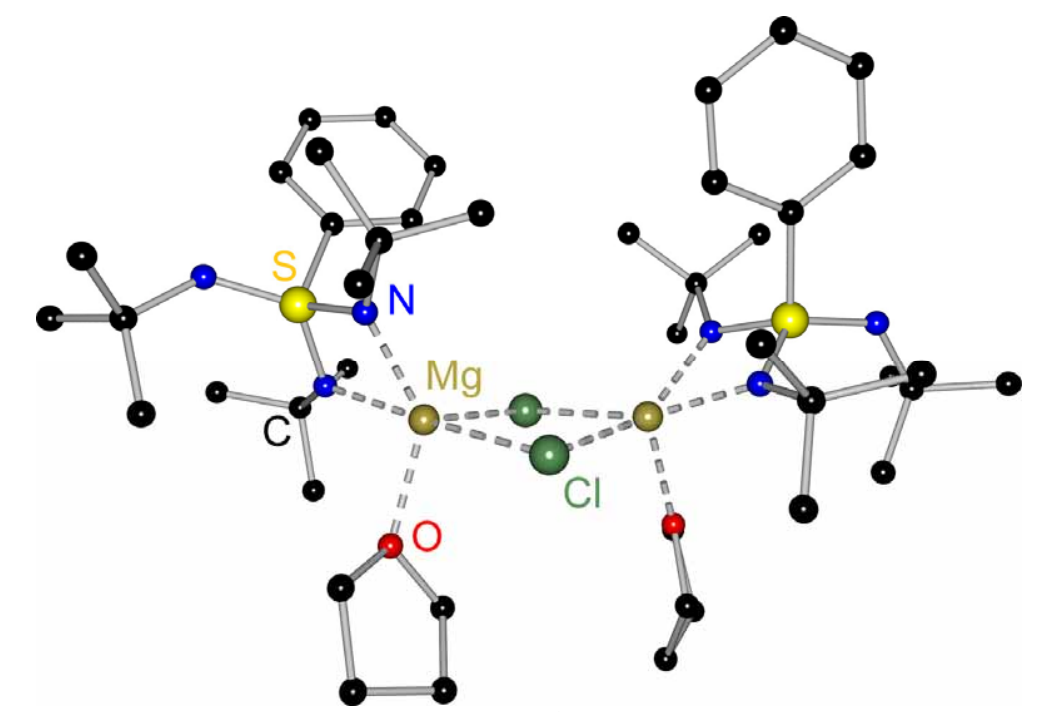

Figure 2-37: Molecular structure of $\left[(\mathrm{THF}) \mathrm{MgCl}\left(\mathrm{N}^{t} \mathrm{Bu}\right)_{3} \mathrm{SPh}\right]_{2}$ (24). All hydrogen atoms have been omitted for clarity.

In the structures of 22, 23 and $\mathbf{2 5}$ the N-S-N planes are located at different sides of the central $\mathrm{Mg}_{2} \mathrm{X}_{2}$ four-membered ring. One is bent up and the other plane bent down along with a trans configuration of the THF molecules and the organic substituent. In 24 both planes are located at the same side of that central ring in a cisoid orientation. The N-S-N planes are heavily skewed (see Table 2-7) to avoid clashing of the ${ }^{\mathrm{t}} \mathrm{Bu}$ groups and the THF molecules. In addition, the $\mathrm{Mg}_{2} \mathrm{X}_{2}$ plane is slightly folded $\left(12^{\circ}\right)$ to give the THF molecules even more space. While in 22, 23 and 25 the complexes are packed in a way to accommodate a THF molecule in the slot between a ${ }^{t} \mathrm{Bu}$ group and another THF molecule of the next complex, in $\mathbf{2 4}$ the phenyl groups of one complex and the THF molecules of another are arranged intertwining resulting in $\pi-\mathrm{H}$ interactions. 
By changing the solvent from $\mathrm{THF}$ to $\mathrm{Et}_{2} \mathrm{O}$ it is possible to crystallize new compounds. Exemplarily $\left[\left(\mathrm{Et}_{2} \mathrm{O}\right) \mathrm{MgBr}\left(\mathrm{N}^{t} \mathrm{Bu}\right)_{3} \mathrm{SMe}_{2}\right.$ (26) was synthesized, isolated and characterized. For the $\mathrm{Et}_{2} \mathrm{O}$ stabilized magnesium triimidosulfonate the structural motif is retained except for the change of the donor molecules (see Figure 2-38).

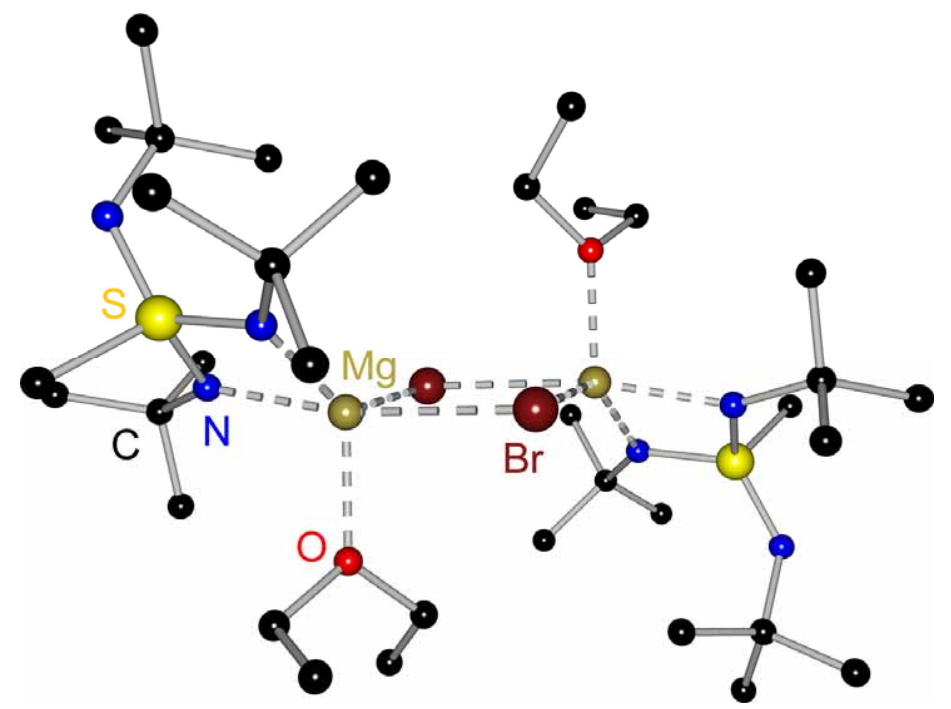

Figure 2-38: Molecular structure of $\left[\left(\mathrm{Et}_{2} \mathrm{O}\right) \mathrm{MgBr}\left(\mathrm{N}^{t} \mathrm{Bu}\right)_{3} \mathrm{SMe}_{2}\right.$ (26). All hydrogen atoms have been omitted for clarity.

As mentioned above $\mathbf{2 2}$ and $\mathbf{2 6}$ crystallize as dimers with one half of the molecule in the asymmetric unit. A comparison of the bond lengths and angles shows some differences (see Table 2-8) but the structural motif stays the same.

Table 2-8: Selected bond lengths $[\AA]$, angles and torsion angles $\left[^{\circ}\right]$ of 22 and $\mathbf{2 6 .}$

\begin{tabular}{cccccc}
\hline Compound & $\mathbf{2 2}$ & $\mathbf{2 6}$ & Compound & $\mathbf{2 2}$ & $\mathbf{2 6}$ \\
\hline Distances & & Angles \\
S-N1 & $1.5808(21)$ & $1.5871(25)$ & $\mathrm{N}-\mathrm{S}-\mathrm{N}$ & $94.98(10)$ & $95.19(12)$ \\
$\mathrm{S}-\mathrm{N} 2$ & $1.5976(17)$ & $1.6005(23)$ & $\mathrm{N}-\mathrm{Mg}-\mathrm{N}$ & $69.07(7)$ & $68.97(9)$ \\
& & & $\mathrm{C}-\mathrm{S}-\mathrm{N}$ & $109.08(11)$ & $108.48(14)$ \\
$\mathrm{S}-\mathrm{N} 5$ & $1.5228(21)$ & $1.5302(23)$ & & $108.63(10)$ & $108.55(13)$ \\
$\mathrm{C}-\mathrm{S} 1$ & $1.7880(22)$ & $1.7961(28)$ & $\mathrm{Mg}_{2} \mathrm{X}_{2}-\mathrm{NSN}$ & 50.70 & 44.50 \\
$\mathrm{Mg}-\mathrm{N} 1$ & $2.0650(19)$ & $2.0817(25)$ & $\mathrm{S} 1 \mathrm{Mg} 1 \mathrm{Mg} 2 \mathrm{~S} 2-\mathrm{NSN}$ & 73.50 & 83.70 \\
$\mathrm{Mg}-\mathrm{N} 2$ & $2.0677(20)$ & $2.0753(24)$ & $\mathrm{N} 1-\mathrm{Mg} 1-\mathrm{Mg} 2-\mathrm{N} 3$ & 75.03 & 74.96 \\
$\mathrm{Br} 1-\mathrm{Mg} 1$ & $2.6683(9)$ & $2.7068(9)$ & $\mathrm{X}-\mathrm{Mg}-\mathrm{Mg}-\mathrm{N} 1$ & 62.84 & 56.25 \\
$\mathrm{Br} 2-\mathrm{Mg} 1$ & $2.5947(9)$ & $2.6099(9)$ & $\mathrm{X}-\mathrm{Mg}-\mathrm{Mg}-\mathrm{N} 2$ & 12.19 & 18.71 \\
$\mathrm{Mg}-\mathrm{O}$ & $2.0325(18)$ & $2.0462(21)$ & & & \\
\hline
\end{tabular}


It is eye-catching that in $\mathbf{2 6}$ all bonds to the magnesium atoms are a little bit smaller than in 22. This can only be attributed to the higher steric demand of the $\mathrm{Et}_{2} \mathrm{O}$ molecule resulting in small bond elongations around the magnesium atom. The distances and angles within each triimidosulfonate are nearly the same but the arrangement of both ligands to each other and to the central $\mathrm{Mg}_{2} \mathrm{X}_{2}$ four fold ring is very different in both structures. Only the torsion angles between the two triimdosulfonates are nearly the same, otherwise all angles (e. g. the twist between the ligands or the angle between ligand and central ring) exhibit distinct differences.

By changing the solvent again, this time from THF to toluene, it is possible to generate new complexes of the general formula $\left[\mathrm{Mg}\left\{\left(\mathrm{N}^{t} \mathrm{Bu}\right)_{3} \mathrm{SR}\right\}_{2}\right]$. Without an additional donor base the magnesium triimidosulfonates can lose $\mathrm{MgHal}_{2}$ and form new complexes. In the case of $\mathbf{2 2}$ the eliminated magnesium bromide can be removed by filtration. From the solution of $\mathbf{2 2}$ in toluene, crystals of $\left[\mathrm{Mg}\left\{\left(\mathrm{N}^{t} \mathrm{Bu}\right)_{3} \mathrm{SMe}\right\}_{2}\right](27)$ could be obtained as colorless plates (see Figure 2-39). However further experiments to generate complexes of the general formula $\left[\mathrm{Mg}\left\{\left(\mathrm{N}^{t} \mathrm{Bu}\right)_{3} \mathrm{SR}\right\}_{2}\right]$ with the other magnesium triimidosulfonates 23-25 were not successful. Apparently the higher solubility in THF of the magnesium bromide compared to the magnesium chloride is a decisive factor for the forming of $\left[\mathrm{Mg}\left\{\left(\mathrm{N}^{t} \mathrm{Bu}\right)_{3} \mathrm{SR}\right\}_{2}\right]$. A further reason might be the smaller steric demand of the methyl group compared to the other sulfur bound substituents.

In 27 one magnesium atom is coordinated by two anions leaving the magnesium atom with a distorted tetrahedral environment.

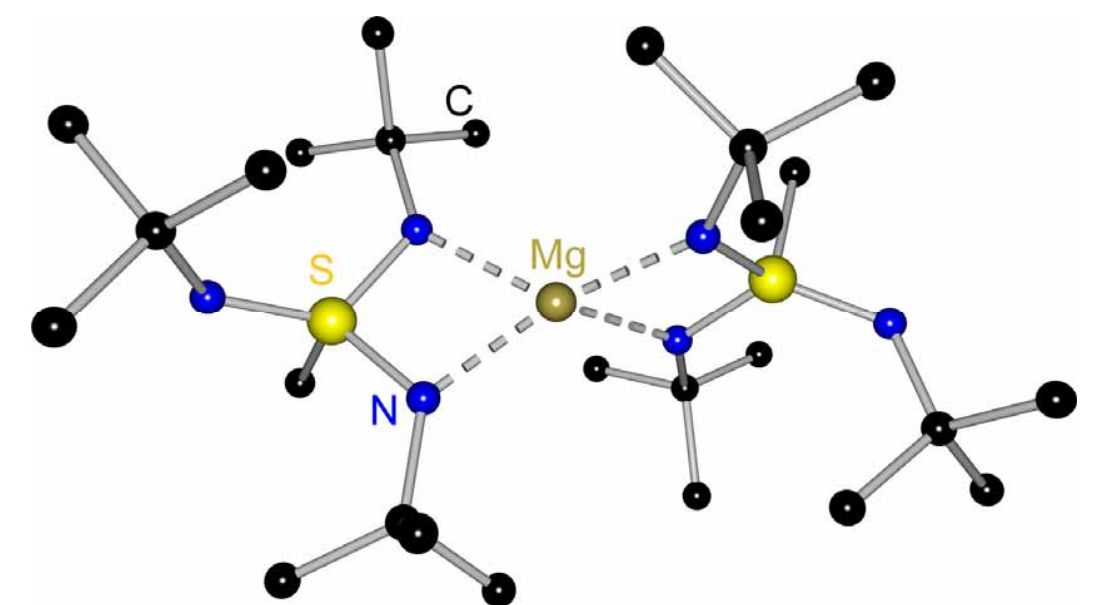

Figure 2-39: Molecular structure of $\left[\mathrm{Mg}\left\{\left(\mathrm{N}^{t} \mathrm{Bu}\right)_{3} \mathrm{SMe}\right\}_{2}\right](27)$. All hydrogen atoms have been omitted for clarity. 
The angles between the nitrogen atoms belonging to the same anion are more acute $\left(70.5^{\circ}\right)$ whereas the angles between the nitrogen atoms belonging to different anions are widened $\left(130.8^{\circ}\right)$. The two anions coordinating the magnesium atom are nearly perpendicular to each other $\left(86.9^{\circ}\right)$. This small deviation is caused by the different steric demand of the methyl group and the non-coordinating imido group. For that reason each half of the dimer is leaning a little bit to the side where the methyl group of the other half is situated. The $\mathrm{Mg}-\mathrm{N}$ bond lengths are considerably shorter than those in 22-25. That could be expected since the magnesium atom is only coordinated by the two anions and no additional donor base is present. The distances in the ligand anion are the same as in 22-25. A similar structural motif was found by Pauer who synthesized [(THF)Mg(NSiMe $)_{2} \mathrm{SPh}^{[68]}$ In this structure the magnesium atom is also coordinated by two anions but the use of THF as solvent and the lower steric strain resulting from the use of diimidosulfinates instead of triimidosulfonates results in an additional THF coordination. The magnesium atom in [(THF $\left.) \mathrm{Mg}\left\{\left(\mathrm{NSiMe}_{3}\right)_{2} \mathrm{SPh}\right\}_{2}\right]$ exhibits a square pyramidal environment with the THF molecule occupying the apex of the pyramid. Because of the coordination geometry the diimidosulfinate anions get very close to each other resulting in distinctly longer Mg-N bond lengths (average 2.14 $\AA$ ).

After it was shown that a variety of organic groups can be added to the sulfurtriimides when Grignard reagents are used instead of lithium organyls the next step was to employ the third imido group as additional donor. This way it should be possible to synthesize bimetallic or even heterobimetallic complexes.

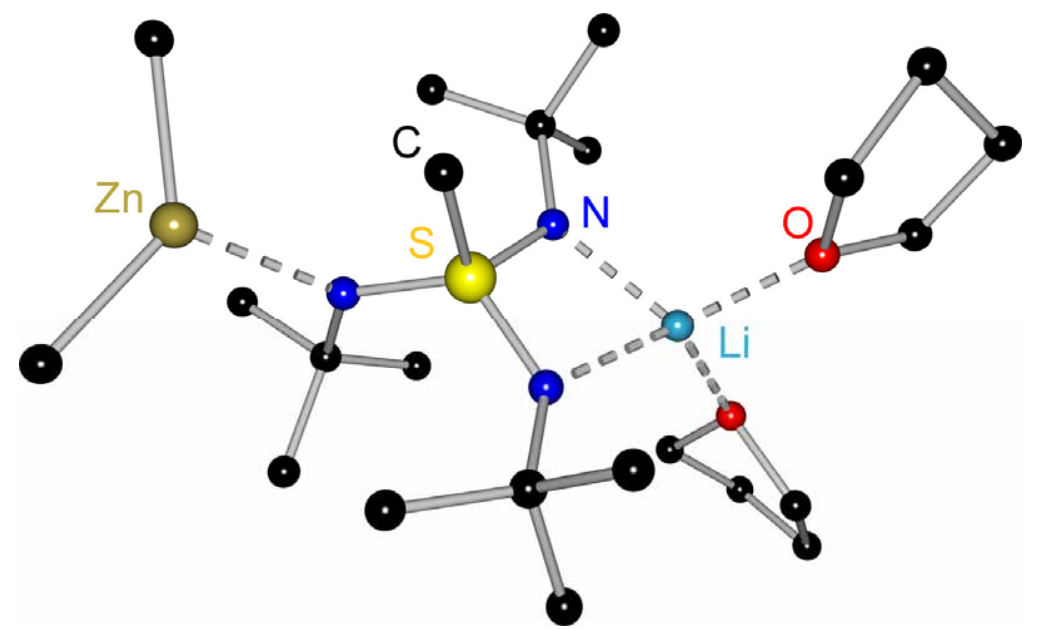

Figure 2-40: Molecular structure of $\left[(\mathrm{THF})_{2} \mathrm{Li}\left(\mathrm{N}^{t} \mathrm{Bu}\right)_{2} \mathrm{SMe}\left(\mathrm{N}^{t} \mathrm{Bu}\right) \mathrm{ZnMe}_{2}\right]$. All hydrogen atoms have been omitted for clarity. 
Earlier work in our group showed that it is indeed possible to coordinate a metal to the third imido group. Walfort synthesized $\left[(\mathrm{THF})_{2} \mathrm{Li}\left(\mathrm{N}^{t} \mathrm{Bu}\right)_{2} \mathrm{SMe}\left(\mathrm{N}^{t} \mathrm{Bu}\right) \mathrm{ZnMe}_{2}\right]$ (see Figure 2-40) by adding dimethyl zinc to [(THF) $\left.{ }_{2} \mathrm{Li}^{\mathrm{i}}\left(\mathrm{N}^{t} \mathrm{Bu}\right)_{3} \mathrm{SMe}\right] .{ }^{[90]}$

To mimic the synthesis of Walfort, 22-25 were reacted with different Lewis acids like dimethyl zinc, trimethyl aluminum or $\mathrm{B}\left(\mathrm{C}_{6} \mathrm{~F}_{5}\right)_{3}$. Unfortunately the experiments did not yield the desired products. Where the experiments with trimethyl aluminum and $\mathrm{B}\left(\mathrm{C}_{6} \mathrm{~F}_{5}\right)_{3}$ only afforded crude mixtures, one distinct compound could be isolated from the reaction with dimethyl zinc. Unexpectedly, dimethyl zinc reacted with 22 under metal exchange yielding $\left[\mathrm{Zn}\left\{\left(\mathrm{N}^{t} \mathrm{Bu}\right)_{3} \mathrm{SMe}\right\}_{2}\right]$ (28). The same complex could be isolated after the reaction of $\mathbf{2 2}$ with $\mathrm{ZnBrPh}$ indicating that the triimidosulfonates have a strong affinity for the zinc atom, resulting in the formation of $\mathbf{2 8}$, even if only unsuitable leaving groups are present in the used zinc compound. 28 exhibits the same structural motif as $\mathbf{2 7}$ with the zinc atom coordinated by two monoanionic triimidosulfonate ligands (Figure 2-41).

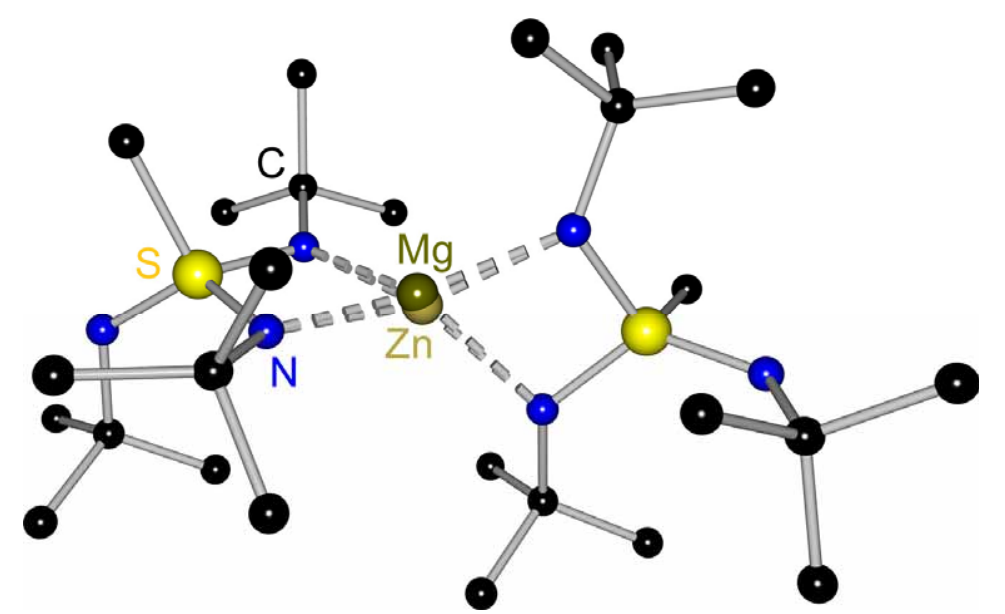

Figure 2-41: Molecular structure of $\left[\mathrm{Zn} / \mathrm{Mg}\left\{\left(\mathrm{N}^{t} \mathrm{Bu}\right)_{3} \mathrm{SMe}\right\}_{2}\right](\mathbf{2 8})$. All hydrogen atoms have been omitted for clarity.

Although $\left[\mathrm{Zn}\left\{\left(\mathrm{N}^{t} \mathrm{Bu}\right)_{3} \mathrm{SMe}\right\}_{2}\right]$ was already synthesized by Walfort $\mathbf{2 8}$ is still a new compound since the zinc atom is disordered with a magnesium atom from 22. The occupancy of the zinc atom refines to $75 \%$ compared to $25 \%$ of the magnesium atom (in a second experiment the ratio of zinc/magnesium was 70/30). The bond lengths and angles of $\mathbf{2 7}$ and $\mathbf{2 8}$ are depicted in Table 2-9. For a better comparison the bond lengths and angles of $\left[\operatorname{Zn}\left\{\left(\mathrm{N}^{t} \mathrm{Bu}\right)_{3} \mathrm{SMe}\right\}_{2}\right]$ synthesized by Walfort are also listed. 
Table 2-9: Selected bond lengths $[\AA]]$ and angles $\left[{ }^{\circ}\right]$ of 27 and 28.

\begin{tabular}{|c|c|c|c|c|}
\hline \multirow[t]{2}{*}{ Compound } & \multirow[t]{2}{*}{27} & \multirow[t]{2}{*}[\mathrm{Zn}\{(\mathrm{N}^{t}\mathrm{Bu})_{3}\mathrm{SMe}\}_{2}]{} & \multicolumn{2}{|c|}{28} \\
\hline & & & $\mathrm{Mg}$ & $\mathrm{Zn}$ \\
\hline \multicolumn{5}{|l|}{ Distances } \\
\hline S-N1 & $1.6013(23)$ & $1.6023(29)$ & \multicolumn{2}{|c|}{$1.5954(18)$} \\
\hline S-N2 & $1.5949(23)$ & $1.5932(28)$ & \multicolumn{2}{|c|}{$1.6029(18)$} \\
\hline S-N3 & $1.5234(24)$ & $1.5192(27)$ & \multicolumn{2}{|c|}{$1.5233(18)$} \\
\hline$S-C$ & $1.7843(28)$ & $1.7827(38)$ & \multicolumn{2}{|c|}{$1.7851(23)$} \\
\hline \multirow{2}{*}{$\mathrm{N} 1-\mathrm{M}$} & \multirow{2}{*}{$2.0445(23)$} & \multirow{2}{*}{$2.0186(27)$} & 2.1600 (199) & $2.0096(29)$ \\
\hline & & & $1.9588(263)$ & $2.0250(35)$ \\
\hline \multirow{2}{*}{$\mathrm{N} 2-\mathrm{M}$} & \multirow{2}{*}{$2.0324(23)$} & \multirow{2}{*}{$2.0035(27)$} & $1.9921(269)$ & $2.0150(36)$ \\
\hline & & & $1.9918(270)$ & $2.0306(36)$ \\
\hline \multicolumn{5}{|l|}{ Angles } \\
\hline \multirow[t]{3}{*}{$\mathrm{N}-\mathrm{S}-\mathrm{N}$} & $94.79(12)$ & $94.34(14)$ & \multicolumn{2}{|c|}{$94.55(9)$} \\
\hline & $70.48(9)$ & $71.27(11)$ & $68.79(76)$ & $70.81(12)$ \\
\hline & $70.49(9)$ & $71.27(11)$ & 72.99 (88) & $71.44(12)$ \\
\hline \multirow{4}{*}{$\mathrm{N}-\mathrm{M}-\mathrm{N}$} & $130.36(9)$ & $130.04(12)$ & $124.48(1.24)$ & $129.18(17)$ \\
\hline & $130.36(9)$ & $130.04(12)$ & $126.80(1.17)$ & $129.29(17)$ \\
\hline & $131.21(15)$ & $130.17(16)$ & $133.06(1.44)$ & $133.57(16)$ \\
\hline & $135.38(15)$ & $135.01(17)$ & $140.33(1.39)$ & $133.84(16)$ \\
\hline \multirow{2}{*}{$\mathrm{C}-\mathrm{S}-\mathrm{N}$} & $108.01(13)$ & $108.54(18)$ & \multicolumn{2}{|c|}{$109.78(11)$} \\
\hline & $107.94(14)$ & $108.60(18)$ & \multicolumn{2}{|c|}{$108.73(10)$} \\
\hline
\end{tabular}

Table 2-9 displays that all three compounds not only exhibit the same structural motif but also show nearly the same distances and angles. Even the metal nitrogen bonds are only slightly different. Therefore it is not surprising that there is a disorder of both metal atoms in 28. Comparison of the structures with other known triimidosulfonate metal complexes shows no striking features. As expected the $\mathrm{N}-\mathrm{S}-\mathrm{N}$ angle in 27 and $\mathbf{2 8}$ as well as in $\mathbf{2 2 - 2 5}$ is considerably more acute than in the known lithium triimidosulfonates, in order to extend the metal-sulfur distance, since the magnesium atom is larger than the lithium atom. All other bond lengths and angles are in the normal range for known triimidosulfonates. $\mathbf{2 7}$ and $\mathbf{2 8}$ are chiral molecules. As well as their analogue synthesized by Walfort they exhibit chirality along the S-M-S axis. Unfortunately all three compounds crystallize in centrosymmetric space groups as racemates. 
An adjacent reaction of $\mathbf{2 8}$ with one equivalent of dimethyl zinc did also not result in a coordination of the third imido group but in a decomposition of the complex (see Figure 2-42).

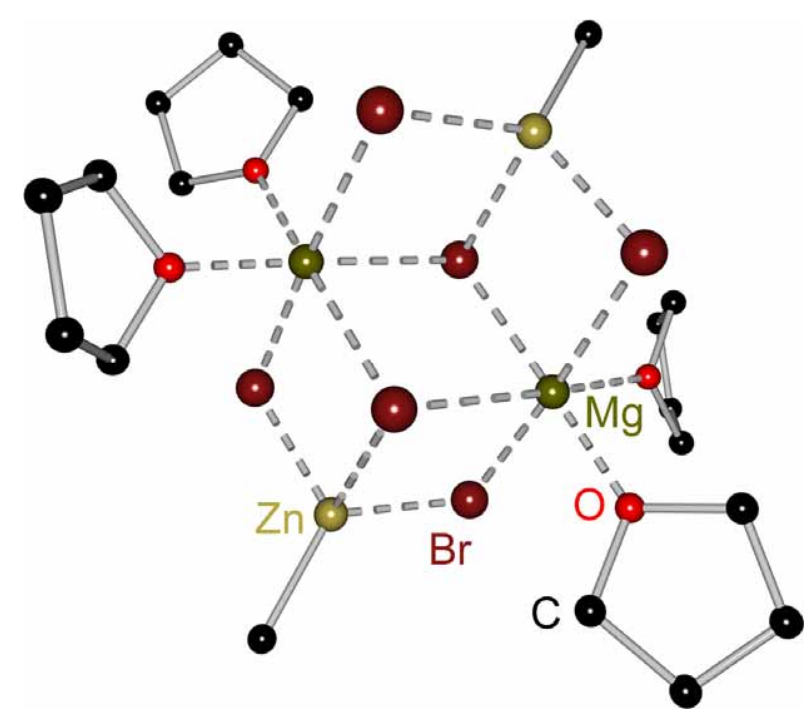

Figure 2-42: Molecular structure of $\left[(\mathrm{THF})_{2} \mathrm{MgBr}_{3} \mathrm{ZnMe}\right]_{2}$. All hydrogen atoms have been omitted for clarity.

In addition to the attempts to use the third imido group as additional donor site, metal exchange reactions were investigated. Although the experiments with different zinc compounds showed that a metal exchange is possible, further reactions with different metal chlorides gave not the desired products. The structures in Figure 2-43 display the liability of the triimidosulfonates against redox and decomposition reactions. In the complex on the left side copper atoms in two different oxidation states are present.
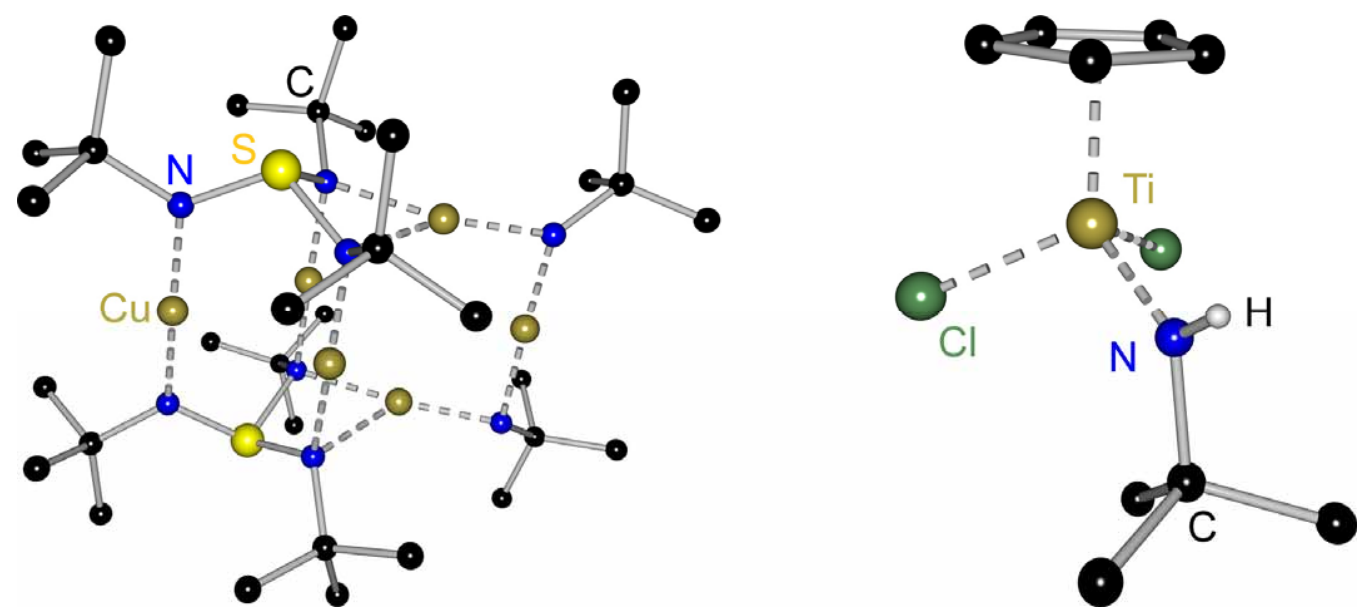

Figure 2-43: Products resulting from the reactions of magnesium triimidosulfonates and $\mathrm{CuCl}$ (left) / $\mathrm{CpTiCl}_{3}$ (right). All hydrogen atoms have been omitted for clarity. 
While the four linear coordinated copper atoms exhibit an oxidation state of one (as in the reagent) the two copper atoms being trigonal planar coordinated are dications. The attempt to hydrolyze the magnesium sulfonates with tert-butylammonium chloride, in order to deprotonate the resulting sulfonic acid with metal amides, only yielded crude mixtures instead of defined products. Although the NMR experiments (discussed later in this chapter) showed that the magnesium sulfonates can be hydrolyzed, tert-butylammonium chloride seems not to be the right reagent for this task.

As their diimido analogues, the triimidosulfonates exhibit a multiple set of the expected resonances in the NMR spectra. Which peaks belong to one species could be determined by integration of the signals and by NOESY experiments. Further NMR experiments at different temperatures (see Figure 2-44) showed that in contrast to the diimidosulfinates, the equilibrium between the two species in solution is not temperature dependent. While for the diimidosulfinates the ratio between both compounds changes from $2.5 / 1$ to $1.5 / 1$ depending on the temperature, the triimidosulfonates only exhibit negligible changes in the ratio of both compounds. This probably arises from the slightly different integration of the signals. Further NMR experiments showed that the same holds true for the time (from priming the sample to measuring it) and the concentration dependence.

Figure 2-44 shows the protons from the coordinating and the non-coordinating $\mathrm{N}^{t} \mathrm{Bu}$ groups of 24 to resonate between $1.0 \mathrm{ppm}$ and $1.6 \mathrm{ppm}$ while the signals for the phenyl group occur between 7.2 ppm and 8.6 ppm.

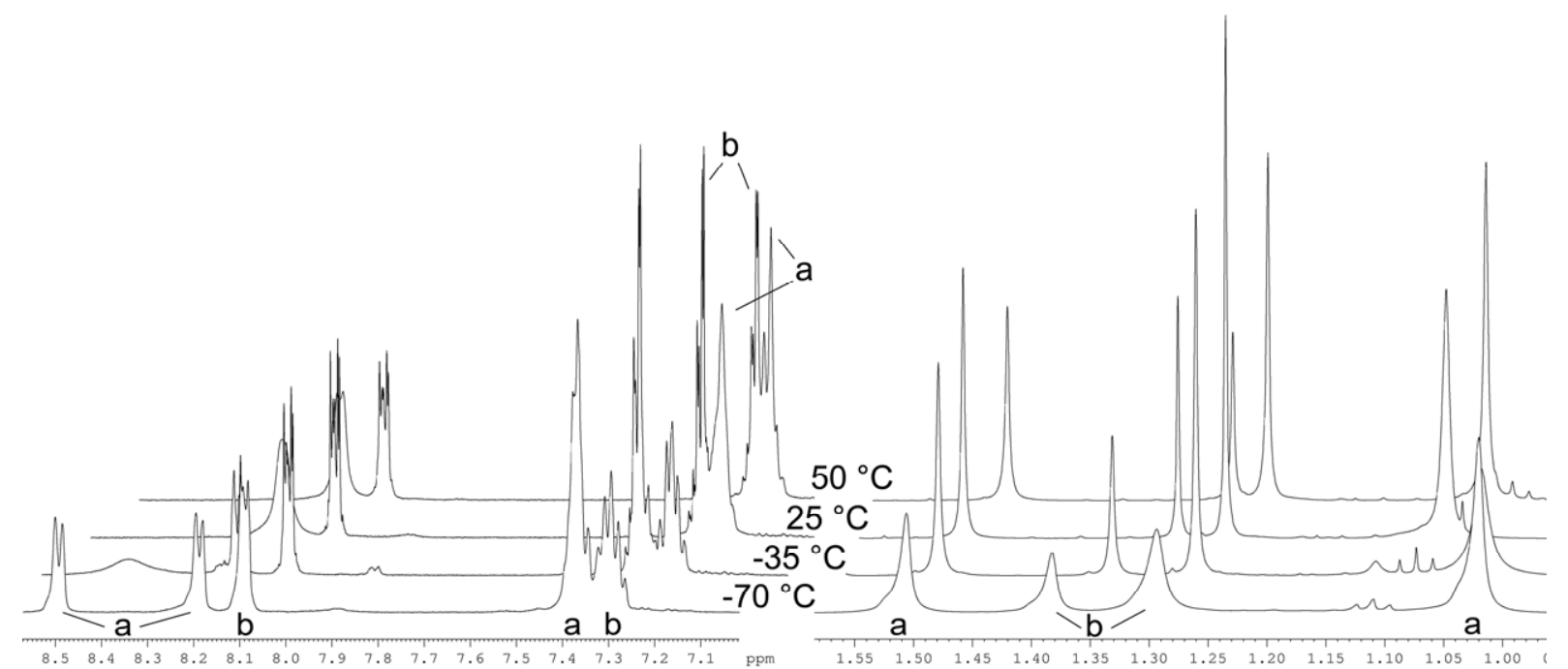

Figure 2-44: ${ }^{1} \mathrm{H}-\mathrm{NMR}$ spectra of 24 at different temperatures; aromatic region left and ${ }^{t} \mathrm{Bu}$ signals right. 
It is conspicuous that for component a the ortho protons of the phenyl substituent can only be resolved at low temperatures while the protons of component $\mathbf{b}$ can be resolved even at higher temperatures. That indicates that the rotation about the S-C axis is somehow hindered in component $\mathbf{b}$. Furthermore, the shift of the signals is noteworthy. While for the diimidosulfinates the change of the shifts for the ${ }^{t} \mathrm{Bu}$ protons and the organic periphery are always in the same direction (to higher or lower field) the change of the shifts for the triimidosulfonates signals are not unitary. As Figure 2-44 shows, the resonances for the ortho protons of the phenyl ring and for the protons of the non-coordinating $N^{t} B u$ group are shifted to lower field for species $\mathbf{b}$ while the proton signal of the coordinating $\mathrm{N}^{t} \mathrm{Bu}$ group is shifted to higher field. The signals for the meta/para protons are even shifted to higher field for lower temperatures and to lower field for higher temperatures. Similar observations can be made for the $\mathbf{2 3}$ and $\mathbf{2 5}$. This indicates that the differences between the triimidosulfonate species in solution are more distinct than for the diimidosulfinate species.

A ${ }^{15} \mathrm{~N}-\mathrm{HMBC}$ spectrum finally revealed the solution for the described facts. A cross peak between a very broad signal which was hardly visible in the ${ }^{1} \mathrm{H}$-spectrum and a ${ }^{15} \mathrm{~N}$-signal which also coupled with a ${ }^{t} \mathrm{Bu}$ group made it evident that one of the species in solution was the protonated ligand. The hydrogen bonded to the nitrogen atom resonates at $3.67 \mathrm{ppm}$, next to the THF signal and exhibits a very broad peak. In Figure 2-44 the sulfonic acid is shown as species $\mathbf{b}$. As expected, the ratio of the signals for the ${ }^{t} \mathrm{Bu}$ groups is 2 to 1 for the sulfonic acid since only one nitrogen atom is protonated. A NOESY spectrum showed that the exchange between the protonated nitrogen atom and the unprotonated nitrogen atoms is slow $(1 \%$ of the molecules in $0.5 \mathrm{~s}$ ). Furthermore, the identification of the sulfonic acid validates the aforementioned assumption that the difference between the two species in solution is bigger for the triimidosulfonates than for the diimidosulfinates. While the diimidosulfinates exhibit a conformational isomerism in solution the signal doubling for the triimidosulfonates is due to another molecule being present in the NMR sample. In addition it provides an explanation, why the ortho protons of the phenyl substituent in $\mathbf{3}$ can be resolved for component $\mathbf{b}$ at room temperature. Since the sulfonic acid does not coordinate any metal, the angle between the two nitrogen atoms is not around $75^{\circ}$, as normally found for the sulfurimido metal complexes, but more obtuse resulting in a hindered rotation around the $\mathrm{S}-\mathrm{C}$ bond. Signals of the triimido sulfonic acid can be found in all NMR spectra of 1-5, indicating that the 
magnesium triimidosulfonates are extremely sensitive to moisture. Even if the NMR tube is filled in the glove box and then sealed off, the spectrum shows traces of the sulfonic acid. Since the NMR spectra were made from filtered off crystals it seems unlikely that the protonated ligand is incorporated during the synthesis. Therefore the only explanation is that the magnesium triimidosulfonates were hydrolyzed by the small amounts of water present in the glovebox and in the NMR solvents or during the filtration process.

The second species $\mathbf{a}$ in solution exhibits two signals for the ${ }^{\mathrm{t}} \mathrm{Bu}$ groups in a ratio of 2 to 1 for 24 and 25 and one broad signal for 22 and 23 . By cooling to $-70^{\circ} \mathrm{C}$, it is possible to resolve the broad signals in 22 and 23, resulting in the expected two signals with a ratio of 2 to 1.22 shows an even more complex spectrum. In solution three components coexist. Two of the species were already described, but the major compound exhibits not two signals with a ratio of 2 to 1 (coordinating/noncoordinating) for the ${ }^{t} \mathrm{Bu}$ groups but three with equal integrals, displaying that the molecule is arranged in a way that yields non-equivalent coordinating $\mathrm{N}^{t} \mathrm{Bu}$ groups. After the synthesis of $\left[\mathrm{Mg}\left\{\left(\mathrm{N}^{t} \mathrm{Bu}\right)_{3} \mathrm{SMe}\right\}_{2}\right]$ a comparison with the NMR-spectrum of $\mathbf{2 7}$ showed that the major compound in the spectrum of 22 is the same as in 27 . This indicates that in solution 22 looses magnesiumbromide and consequently exhibits the same structure as $\mathbf{2 7}$ in solution. This also provides the answer for the three $N^{t} \mathrm{Bu}$ signals. As expected one signal comes from the non-coordinating $N^{t} B u$ group and the crystal structure of $\mathbf{2 7}$ delivers the reason for the differences of the coordinating ones. One coordinating $N^{t} B u$ group resides on the same side as the methyl group and the other one is opposite to another $\mathrm{N}^{t} \mathrm{Bu}$ group resulting in different resonance frequencies.

With this information in mind a DOSY spectrum of $\mathbf{2 2}$ was recorded. It showed that the third species, exhibiting only one signal for the ${ }^{t} \mathrm{Bu}$ groups at room temperature, is a little bit smaller in solution than 27. As expected the DOSY spectrum showed that the set of signals belonging to the sulfonic acid exhibits a much lower atom number and therefore moves faster in solution. A second DOSY spectrum of $\mathbf{2 3}$ confirmed that the triimidosulfonate species is bigger than the protonated ligand but smaller as 27. Therefore it can be concluded that the magnesium triimidosulfonates are most likely monomeric in solution. 
As described the tert-butylsulfurtriimide reacts readily with different Grignard reagents resulting in very pure magnesium triimidosulfonates in good yields. By using Grignard reagents it was possible to broaden the field of available triimidosulfonates. Where up to this point only small and flat organic groups could be added to the sulfurtriimides, now a variety of organic substituents can be used. This new selection of organic substituents shows that the triimidosulfonates are interesting ligands. It is easy to change their coordination geometry within the complexes because the triimidosulfonate ligand reacts very flexible to the requirements of the sulfur-bound substituent by either changing the twist between both ligands in the dimer or even changing the whole structural motif as shown by 24 . Comparison of the $\mathrm{C}-\mathrm{N}-\mathrm{S}-\mathrm{N}$ torsion angles of the magnesium triimidosulfonates (between $0.0^{\circ}$ and $13.3^{\circ}$ ) and the magnesium diimidosulfinates (between $40^{\circ}$ and $50^{\circ}$ ) further emphasizes the flexibility of the sulfur imido ligands. Additionally, the broadened field of possible substituents should enhance the solubility in nearly all organic solvents since the organic periphery can now be adapted to the desired solvent. Another interesting fact is the flexibility of the ligand not only towards the changing of the sulfur bound substituent but also to the change of the solvent. The comparison of $\mathbf{2 2}$ with $\mathbf{2 6}$ displays that the arrangement of the triimidosulfonate can also be changed very easily by the variation of the donor base. The effect is even more drastic when a non-donating solvent is used. Then new complexes with a different structural motif are formed. The NMR experiments showed that the ligands are very sensitive to moisture resulting in a fast protonation and the forming of sulfonic acid. Furthermore, the spectra in solution showed that the conformation in solution must be nearly the same as in the solid state.

Although the presented results display that the magnesium triimidosulfonates are adaptable ligands with a lot of conformational freedom the coordination of a second metal was not possible. In spite of the result of Walfort, an additional example for the coordination potential of the pending third imido group could not be synthesized. However, the coordination experiments showed that a metal exchange is possible, although the reactions are not without problems. Therefore, further coordination experiments with different Lewis bases and triimidosulfonate metal complexes (with the exception of magnesium) should be performed to realize the coordination of a second metal by the pending imido group. 


\section{FiELD TEST OF THE InCOATEC MicROFOCUS SOURCE}

\subsection{Introduction}

Since von Laue performed the first X-ray scattering experiment in 1912 the field of X-ray diffraction developed rapidly. ${ }^{[187]}$ Starting from cold-cathode tubes as X-ray sources and photographical films as detectors for the scattering effect, the equipment evolved fast. Soon there where hot-cathode tubes which provided higher intensities $^{[188]}$ and enhanced cameras that suited the requirements of the crystallographers better. ${ }^{[189]}$ Another break-through was the development of moveable detectors that were able to measure reflections at different angles to the primary beam. Galley was one of the first to build such a system in $1935 .{ }^{[190]}$ Later improved mounting devices were added to the goniometers that allowed the crystal to be oriented at different orientations. ${ }^{[191]}$ First Geiger counters were employed as detectors on these goniometers but they were soon replaced by scintillation counters that detect impulses proportional to the incoming energy of the X-ray photons and have a reasonably short dead-time. ${ }^{[192]}$ With the new detectors more reflections could be measured in a shorter period of time and their intensities could be determined more accurately. In addition, new X-ray sources became available around 1950. Due to the better cooling a rotating anode permitted to run the systems on a higher loading than the equivalent fixed anode systems. ${ }^{[193]}$ Another idea to realize higher performances was to use focus points with smaller radii. This led to the new microfocus X-ray sources. ${ }^{[194]}$ The next big progress in X-ray diffraction was the development of area detectors (multiwire detectors ${ }^{[195]}$ and charge coupled devices $\left.^{[196]}\right)$. With those new detectors more reflections could be collected in a shorter period of time, initiating the structure determination of proteins and other large molecules. Although the development of new detectors and X-ray sources flourished another problem had to be addressed. Since the X-ray tubes gave radiation beyond the $\mathrm{K}_{\alpha}$ emission the additional wavelengths had to be filtered somehow. The first development in this field was established during the 1960s when the graphite monochromators replaced the $\beta$-filters. This was the device of choice until 1982 when Göbel developed mirror optics that were capable of monochromating the X-ray beam. ${ }^{[197]}$ Since then new graded multilayer mirrors ${ }^{[198,199]}$ were developed which, in contrast to total reflection mirrors ${ }^{[200]}$ and capillary optics ${ }^{[201]}$, can 
simultaneously focus and monochromate the X-ray beam. This concept of using a microfocus X-ray source in combination with focusing X-ray optics for diffraction experiments, that was first pioneered by Arndt in the early Nineties, ${ }^{[198]}$ provides an attractive alternative to the conventional sealed tube sources with graphite monochromators that are still used for the majority of small-molecule single-crystal structure determinations. Their basic design, except for the introduction of capillary optics, has hardly changed for the last 50 years. Since the development of graded multilayer mirrors for $\mathrm{MoK}_{\alpha}$ radiation ${ }^{[202,203]}$ this concept is further supported. The Incoatec Microfocus Source (further referred to as $1 \mu \mathrm{S}$ ) employed in the experiments reported here, combines graded multilayer mirrors with an air-cooled $30 \mathrm{~W}$ microfocus sealed tube, resulting in a source characterized by a high flux density. In the comparison of this source with a conventional Bruker sealed tube, equipped with a graphite monochromator and a monocap glass capillary collimator (further referred to as tube), every effort was made to ensure that all other factors that could influence the quality of the resulting crystal structures were as similar as possible. By mounting both sources on the same goniometer, it proved possible to compare the same crystals, in the same orientation and at the same data collection temperature, using the same detector, wavelength $\left(\mathrm{MoK}_{\alpha}\right)$ and processing software.

\subsection{Setup and Data Processing}

\subsubsection{Description of the experiments}

The test crystals were chosen to represent a cross section of typical small-molecule crystal structures. They included an isoquinoline (O), a diimidosulfur complex ${ }^{[186]}$ $(\mathbf{O M})$ and a strongly absorbing tungsten salt ${ }^{[204]}$ (S). The structures of these molecules are depicted in Figure 3-1. The isoquinoline crystallizes in the monoclinic space group $P 2_{1}$ with a single molecule in the asymmetric unit, the diimidosulfur complex in the monoclinic space group $P 2_{1} / c$ also with one molecule in the asymmetric unit, and the tungsten salt in the monoclinic space group $P 2_{1} / n$ with a single ion pair in the asymmetric unit. In the diimidosulfur complex, the trimethylsilyl and the tert-butyl substituents on the nitrogen atoms are disordered, making the selected crystals even more representative. 

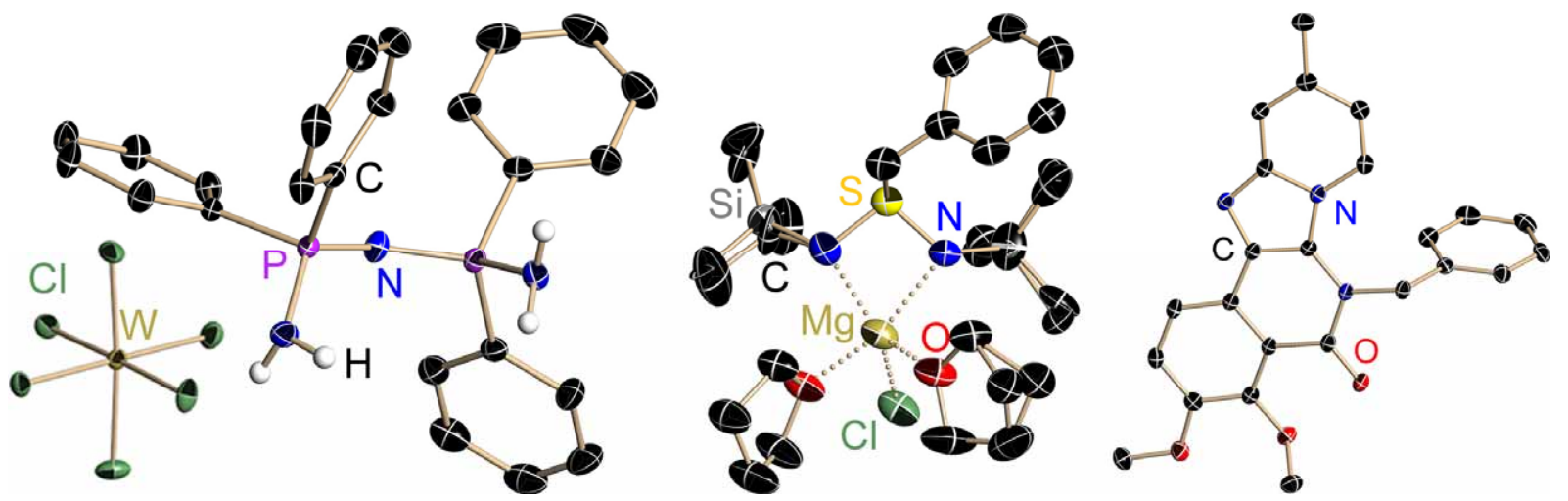

Figure 3-1: Tungsten salt ( $\mathrm{S} / \mathrm{left})$, diimidosulfur complex (OM/center) and isoquinoline (O/right).

One major challenge of the experiments was the different beam width of the $1 \mu S$ and the conventional sealed tube. To provide a fair comparison, small crystals that were better suited for the small beam size of the I $\mu S$ and larger crystals that matched the width of the beam from the conventional source were investigated for each compound for both sources.

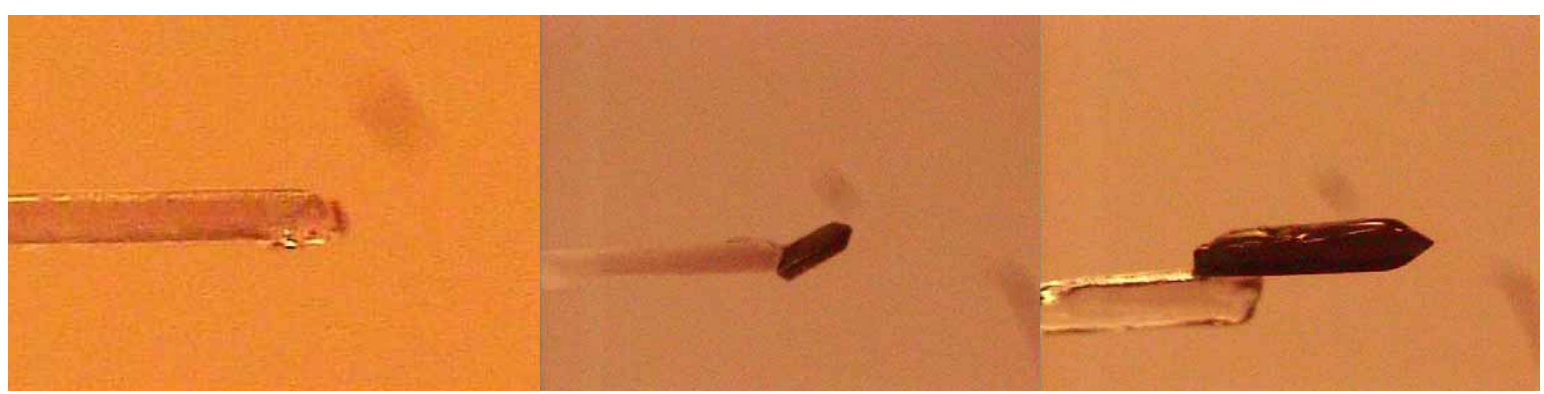

Figure 3-2: Crystals of different size $\left(\mathbf{O}_{\text {small }}\right.$ left/ $\mathbf{S}_{\text {small }}$ middle/ $\mathbf{S}_{\text {large }}$ right $)$.

The resulting four data sets for each substance were processed and compared. In addition, another experiment was performed in which a small and a larger blockshaped crystal of triphenylthiophosphane ${ }^{[205]}$ (Figure 3-3) were employed that closely matched the diameters of each X-ray beam.

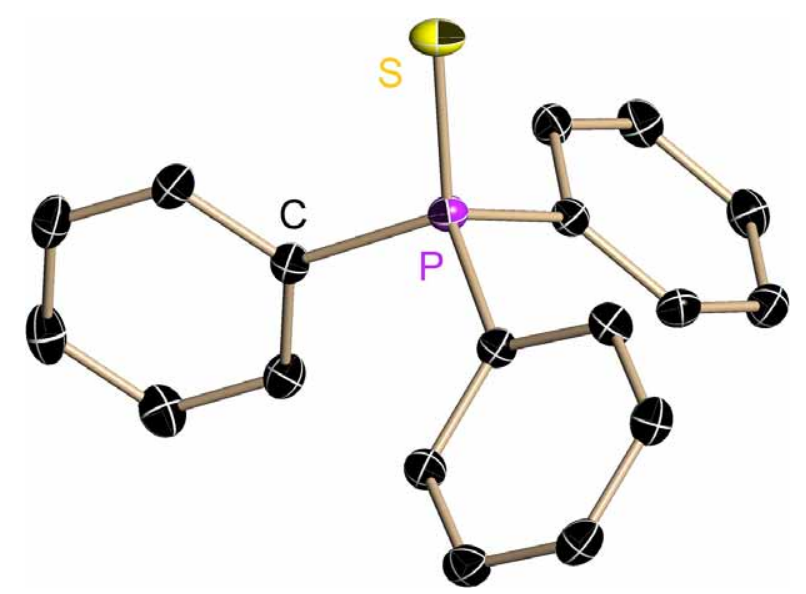

Figure 3-3: Structure of triphenylthiophosphane (P). 
In this experiment the volume of the crystal irradiated was supposed to be almost constant throughout the data collection, so it was of interest to compare the results without using SADABS ${ }^{[206]}$ to scale the data.

\subsubsection{Diffractometer set-up}

All experiments were performed with a Bruker Smart Apex II system based on a D8 Goniometer. In addition to the original fine-focus sealed tube source with graphite monochromator and a $0.50 \mathrm{~mm}$ glass capillary collimator, an Incoatec Microfocus Source with Quazar mirror optics $(l \mu S)$ was attached to the goniometer with its beam direction perpendicular to the omega rotation axis of the goniometer. So it was in the same plane as the beam from the conventional source and the normal to the detector face (Figure 3-4). The crystal position was placed in the image focus of the multilayer optic.

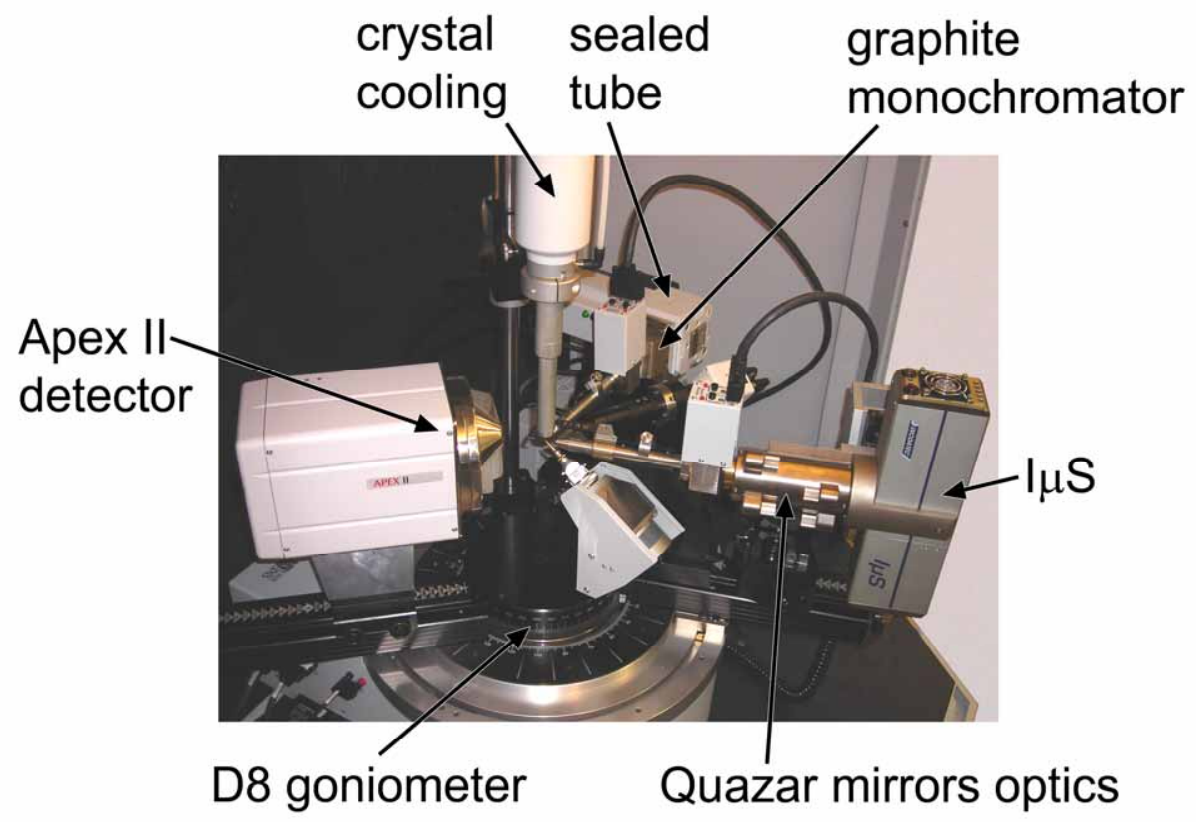

Figure 3-4: Diffractometer setup.

All experiments were performed at $100 \mathrm{~K}$ with $\mathrm{MoK}_{\alpha}$-radiation at generator settings of $50 \mathrm{kV} / 40 \mathrm{~mA}$ for the sealed tube and $50 \mathrm{kV} / 0.6 \mathrm{~mA}$ for the $1 \mu \mathrm{S}$. For the data collection, flash-cooled crystals were mounted on the tip of the same glass fibre, ${ }^{[207,208]}$ data were collected using $180^{\circ} \omega$-scans with $0.3^{\circ}$ step-width in different $\varphi$-positions. After collecting data with one source, the experiment was repeated with the second source, keeping the temperature and the position of the crystal 
unchanged. The experimental settings are shown in Table 3-1. Equal exposure times for both sources could not be realized in all cases, because an adequate exposure time for the sealed tube would in some cases have resulted in saturating the detector with the $1 \mu \mathrm{S}$. In such cases the exposure time was chosen independently for each source to reach the integration limit of $0.80 \AA$ for the sealed tube and avoid topped pixels for the $1 \mu \mathrm{S}$.

Table 3-1: Experimental settings for each data set.

\begin{tabular}{|c|c|c|c|c|}
\hline Compound & sample & crystal size [mm] & runs & $\begin{array}{c}\text { exposure time }[\mathrm{s} \\
\text { (sealed tube/ } \\
\mid \mu \mathrm{S})\end{array}$ \\
\hline organic $(\mathbf{0})$ & $\mathbf{O}_{\text {small }}$ & $0.10 \times 0.05 \times 0.05$ & 4 & $90 / 30^{*}$ \\
\hline $\begin{array}{c}(C C D C: 724643- \\
724646)\end{array}$ & $\mathbf{O}_{\text {large }}$ & $0.30 \times 0.25 \times 0.15$ & 4 & $15 / 10^{*}$ \\
\hline organometallic (OM) & $\mathrm{OM}_{\text {small }}$ & $0.20 \times 0.15 \times 0.10$ & 4 & 60 \\
\hline $\begin{array}{c}\text { (CCDC:724647- } \\
724650)\end{array}$ & $\mathrm{OM}_{\text {large }}$ & $0.50 \times 0.40 \times 0.30$ & 4 & 5 \\
\hline salt (S) & $\mathbf{S}_{\text {small }}$ & $0.20 \times 0.15 \times 0.10$ & 4 & $20 / 5^{*}$ \\
\hline $\begin{array}{c}\text { (CCDC:724653- } \\
724656)\end{array}$ & $\mathbf{S}_{\text {large }}$ & $0.70 \times 0.20 \times 0.20$ & 4 & 3 \\
\hline phosphane (P) & $\mathbf{P}_{\text {small }}$ & $0.10 \times 0.10 \times 0.10$ & 7 & 5 \\
\hline $\begin{array}{c}\text { (CCDC:724651- } \\
724652)\end{array}$ & $\mathbf{P}_{\text {large }}$ & $0.40 \times 0.40 \times 0.40$ & 7 & 5 \\
\hline
\end{tabular}

* the exposure time that was necessary in the sealed tube experiment in order to reach the integration limit of $0.8 \AA$ would have caused topped pixels in the I $\mu \mathrm{S}$ measurement

\subsubsection{Data processing and structure refinement}

All data sets were integrated to a resolution of $0.80 \AA$ using SAINT v7.34 $A^{[209]}$ as implemented in the Apex II Software package v2.1. ${ }^{[209]}$ Scaling was performed with SADABS-2007/5. ${ }^{[206]}$ The structures were solved by direct methods (SHELXS-97) ${ }^{[210]}$ and refined by full-matrix least-squares against $F^{2}$ (SHELXL-97). ${ }^{[210]}$ All nonhydrogen atoms were refined with anisotropic displacement parameters. The hydrogen atoms were refined isotropically at calculated positions using a riding model with their isotropic displacement parameters constrained to be equal to 1.5 times the equivalent isotropic displacement parameters of their pivot atoms for terminal $\mathrm{sp}^{3}$ carbon atoms and 1.2 times for all other carbon atoms. 
The positions of the hydrogen atoms in the $\mathrm{NH}_{2}$-groups were determined by inspection of the residual electron density and refined isotropically with distance restraints. Disordered moieties were refined using distance restraints (DFIX) and ADP restraints (DELU, SIMU and ISOR).

The comparison of the data was performed in three stages. Scaling procedures such as those employed in the program SADABS are designed to enhance the data quality by applying empirical corrections, for example for variations in the volume of the crystal irradiated and absorption by the crystal and its support, that make the intensities of equivalent reflections more equal. This inevitably leads to the reduction of systematic errors and a general leveling of data quality, which could suppress the differences that are of interest here. For this reason, the first comparison was made after integrating the data with SAINT but before scaling with SADABS. For area detectors that inevitably collect redundant data but are subject to a variety of systematic errors that require correction, this empirical scaling could also be regarded as an essential part of the experiment designed to obtain the best quality data, so the second comparison was performed after scaling. The third comparison was made after solving and refining the structures to obtain the best possible structure, subject to the limitations of the independent atom model (IAM), to see to what extent the different sources leave their fingerprints in the final refined structures. For the $\mathbf{P}_{\text {small }}$ and $\mathbf{P}_{\text {large }}$ datasets a different processing strategy was employed. To reduce the corrective influence of the software, both data sets where integrated by the simple sum method without profile fitting, ${ }^{[209]}$ and no scaling or absorption corrections were applied.

\subsection{Comparison of the Beam Profiles}

First the flux densities of the primary beams were compared. Figure 3-5 shows the beam profiles of the two sources in the detector plane. For this measurement the detector was placed at the position usually occupied by the crystal and was exposed for $5 \mathrm{~s}$ to an attenuated primary beam. For comparison purposes there is a detailed profile analysis communicated by Pinkerton. ${ }^{[211]}$ 

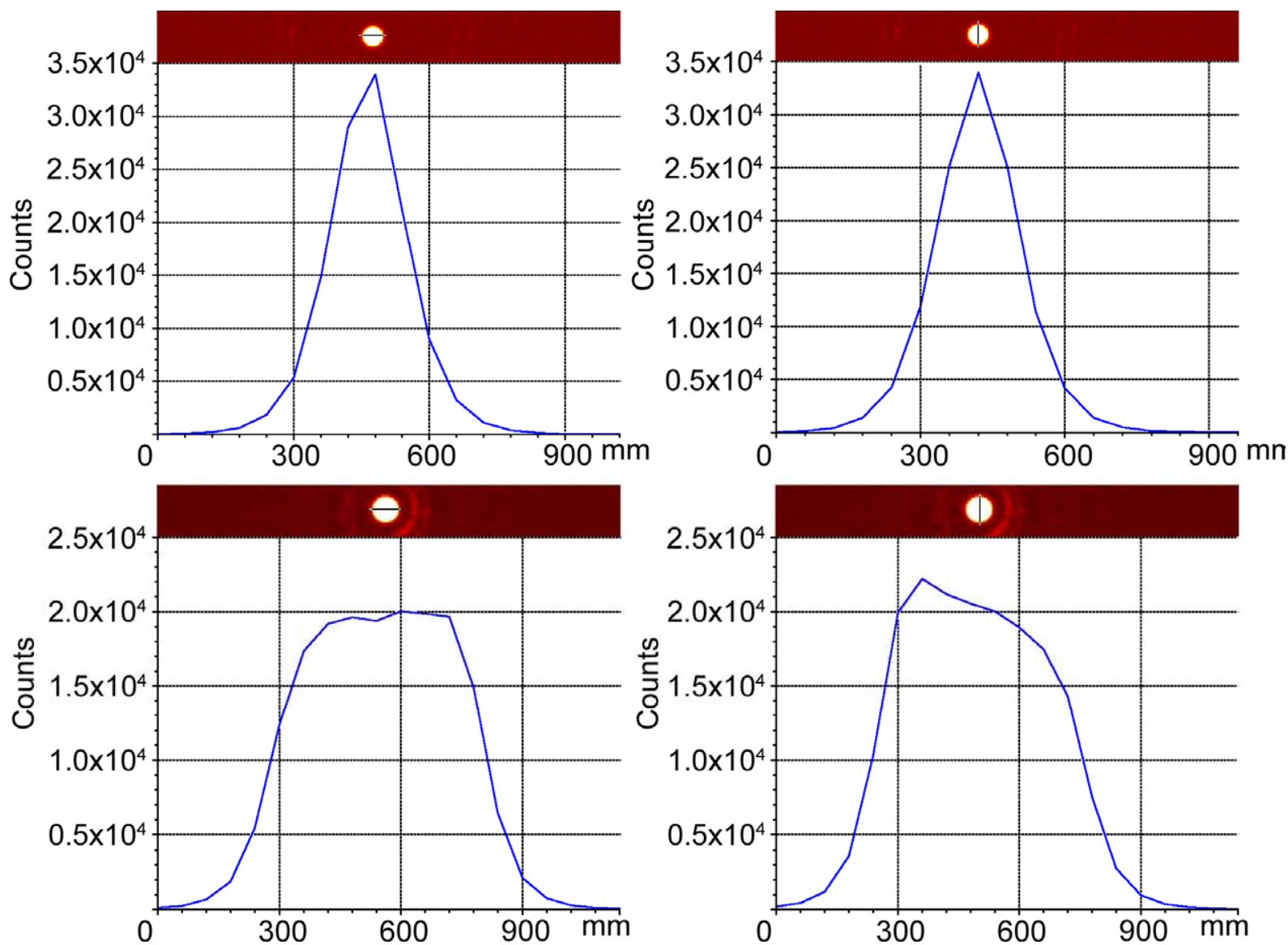

Figure 3-5: Profiles of the beam from the $I \mu S$ (top) and the sealed tube (bottom) (left) perpendicular to the $\omega$ axis of the goniometer and (right) parallel to it.

The full width at half maximum (FWHM) of the beam from the sealed tube is about $0.50 \mathrm{~mm}$ in both directions and it shows a pronounced intensity plateau (see Figure 3-5). The measured half width of the $I \mu S$ is only $0.16 \mathrm{~mm}$. The $I \mu S$ beam shows no intensity plateau but a very symmetrical Gaussian shape profile. If the point spread function caused by the phosphorescent screen is taken into account the corrected beam size is $0.49 \mathrm{~mm} \times 0.49 \mathrm{~mm}$ for the sealed tube and $0.14 \mathrm{~mm} \times 0.14 \mathrm{~mm}$ for the $\mathrm{l} \mu \mathrm{S}$. The beam divergence of the $\mathrm{l} \mu \mathrm{S}$ is $5 \mathrm{mrad}$ where the sealed tube exhibits a beam divergence of $7 \mathrm{mrad}$.

The I $\mu$ S produces more counts at the peak maximum $\left(3.4 \times 10^{4}\right.$ vs. $2.2 \times 10^{4}$ counts $)$ but less integral counts $\left(4.6 \times 10^{5}\right.$ vs. $13.9 \times 10^{5}$ integral counts $)$ relative to the sealed tube. This yields a four times higher flux density of $30.0 \times 10^{6}$ counts $/ \mathrm{mm}^{2}$ for the I $\mu$ S compared to $7.4 \times 10^{6}$ counts $/ \mathrm{mm}^{2}$ for the sealed tube.

Figure 3-6 depicts the shapes of the primary beams. At the left the very narrow and sharp beam profile of the I $\mu \mathrm{S}$ with no plateau is shown and at the right the broader top-hat shaped beam of the sealed tube. 

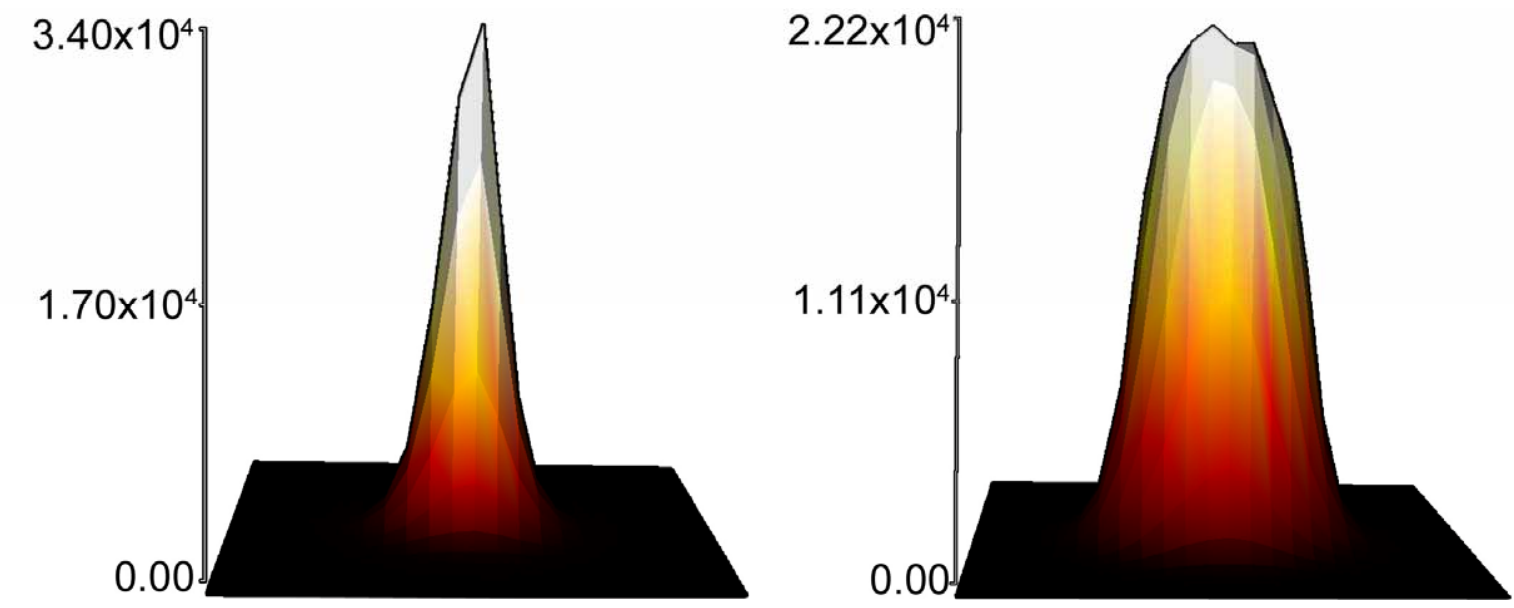

Figure 3-6: $3 d$-shape of the I $\mu S$ (left) and of the sealed tube beam (right).

\subsection{Data Quality after Integration}

For comparison purposes the mean intensity $(<>)$, the mean intensity divided by its standard deviation $\left\langle(/ / \sigma)_{\mathrm{s}}\right\rangle$ and the index $R_{\text {sym }}{ }^{i}$ from the SAINT output are listed in Table 3-2.

Table 3-2: Selected values from the SAINT output.

\begin{tabular}{|c|c|c|c|c|}
\hline sample & source & $<1>$ & $<(I / \sigma)_{s}>$ & $R_{\text {sym }}$ \\
\hline \multirow{2}{*}{$\mathbf{O}_{\text {small }}$} & $1 \mu \mathrm{S}$ & 147.9 & 12.14 & 0.152 \\
\hline & sealed tube & 20.8 & 5.77 & 0.098 \\
\hline \multirow{2}{*}{$\mathbf{O}_{\text {large }}$} & $I \mu S$ & 5072.0 & 56.40 & 0.160 \\
\hline & sealed tube & 1387.7 & 37.54 & 0.054 \\
\hline \multirow{2}{*}{$\mathrm{OM}_{\text {small }}$} & $I \mu S$ & 523.3 & 33.34 & 0.082 \\
\hline & sealed tube & 49.6 & 6.54 & 0.123 \\
\hline \multirow{2}{*}{$\mathbf{O M}_{\text {large }}$} & $\mid \mu S$ & 5300.5 & 45.83 & 0.077 \\
\hline & sealed tube & 2537.6 & 30.57 & 0.052 \\
\hline \multirow{2}{*}{$\mathbf{S}_{\text {small }}$} & $I \mu S$ & 5593.1 & 41.60 & 0.186 \\
\hline & sealed tube & 1211.8 & 37.83 & 0.089 \\
\hline \multirow{2}{*}{$\mathbf{S}_{\text {large }}$} & $I \mu S$ & 5640.8 & 32.90 & 0.357 \\
\hline & sealed tube & 2899.8 & 21.96 & 0.138 \\
\hline
\end{tabular}

${ }^{i} R_{\text {sym }}=\sum|I-\langle I\rangle| / \sum|I|$ 
$</>$ and $\left\langle(\mid / \sigma)_{\mathrm{s}}>\right.$ are larger for all experiments performed with the $\mathrm{I} \mu \mathrm{S}$. Nevertheless, the higher $\left\langle(/ / \sigma)_{\mathrm{s}}>\right.$ of the $| \mu \mathrm{S}$ is accompanied by high $R_{\text {sym }}$ values in almost all experiments, showing a distinct variation of the symmetry equivalent intensities from their mean values. The biggest differences are shown by the $\mathbf{O}_{\text {small }}$ datasets. Although the exposure time for the $1 \mu \mathrm{S}$ was only a third of that for the sealed tube, $</>$ and $\left\langle(\mid / \sigma)_{\mathrm{s}}>\right.$ are much higher (by factors of more than 7 and 2 , respectively) for the $\mathrm{I} \mu \mathrm{S}$ dataset, and the same trend holds true for all crystals. The differences are more pronounced when comparing the datasets of small and weakly diffracting crystals, but even for strongly diffracting compounds and large crystals, where the sealed tube might be expected to be superior because of a higher total flux, the I $\mu \mathrm{S}$ still gives higher values of $\langle/\rangle$ and $\left\langle(\mid / \sigma)_{s}\right\rangle$. Although the reflections from the $\mid \mu S$ are more intense, $R_{\text {sym }}$ is always lower for the sealed tube datasets with the exception of $\mathbf{O M}_{\mathrm{small}}$. This outlier might be explained by the much lower $\left\langle(I / \sigma)_{\mathrm{s}}\right\rangle$ (i.e. more noisy data) for the sealed tube. This experiment also showed the largest intensity differences between the two sources, $<>$ for the $\mid \mu S$ being more than ten times higher.

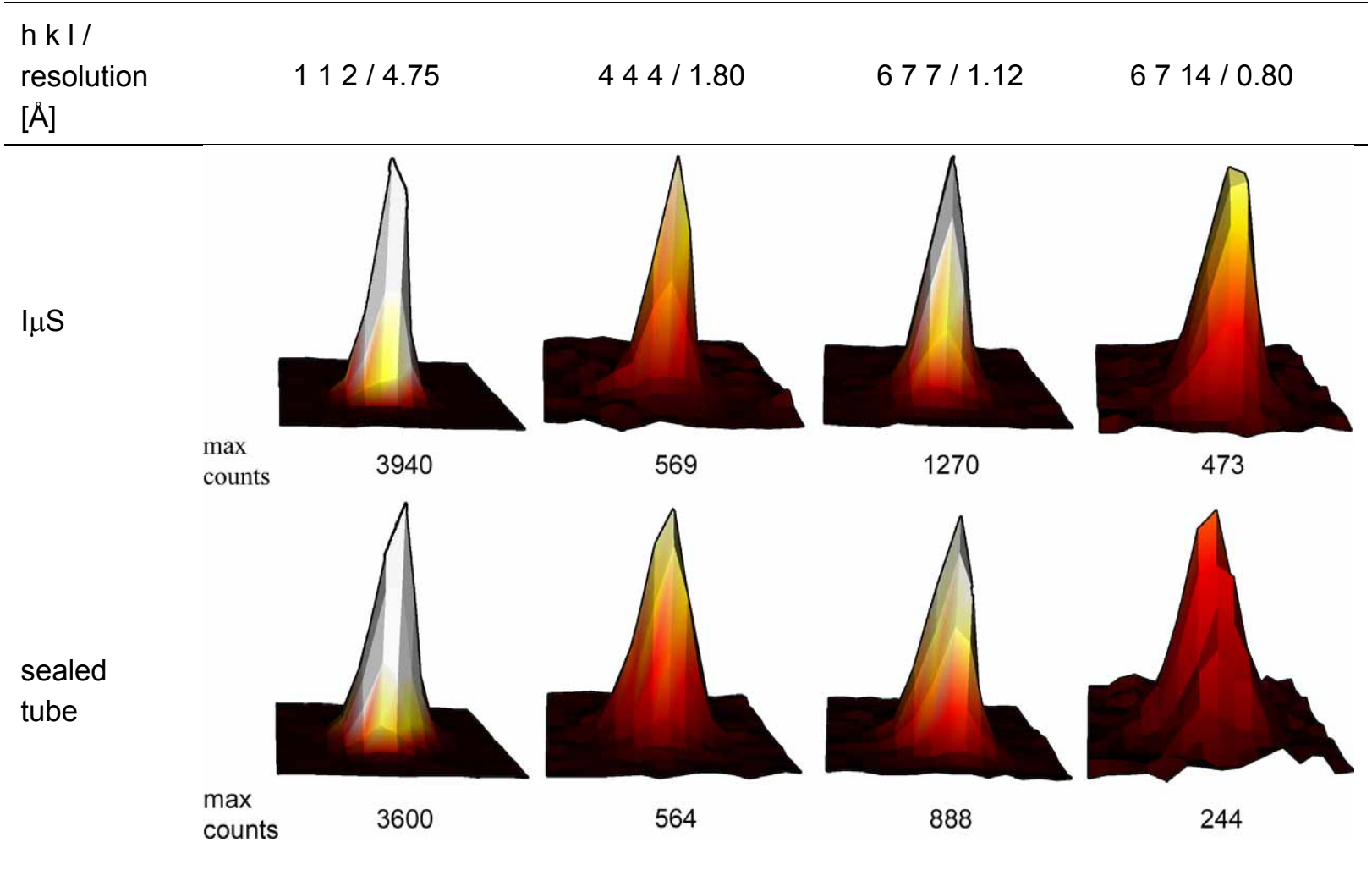

Figure 3-7: Comparison of reflection profiles (all profiles are shown in a 15 pixel $\times 15$ pixel box) at different resolutions for $\mathbf{O M}_{\text {large }}$. 
The ratios of the <> values between the two sources are larger than those of $\left.<(I / \sigma)_{\mathrm{s}}\right\rangle$, in part due to the contribution of counting statistics, increasing $\sigma_{\mathrm{s}}$ when $l$ is larger, but also because $\sigma_{\mathrm{s}}$ values appear to be higher for the $1 \mu \mathrm{S}$, probably as a result of the less effective profile fitting. Because of the sharper beam profile of the $I \mu \mathrm{S}$, the effects of crystal imperfections and orientation on the reflection profile will be less effectively smoothed out, adversely affecting the fit to the reference profile. That the use of different X-ray sources result in different reflection profiles can be seen in Figure 3-7. The reflection profiles of the $I \mu S$ resemble the beam profiles being more slender and spiky than the profiles of the sealed tube.

Although the $I \mu S$ delivers higher intensity values than the sealed tube for small crystals, the variance of the mean intensity value of the symmetry equivalent reflections is larger as a result of changes in the intensity-weighted volume irradiated. This effect is enhanced if a strongly absorbing sample of excessive size is investigated (e.g. $\mathbf{S}_{\text {large }}$ ). The $R_{\text {sym }}$ value of 0.357 indicates errors that are large enough that even with an absorption correction the resulting structure factors do not enable a satisfactory structure refinement (see chapter 3.6). An integration box size refinement was employed during data integration with SAINT, but none of the crystals showed appreciable differences in the box size between the two sources and so it can be concluded that the reflection spot sizes are similar for both sources.

Although the effective $I \mu S$ beam diameter is appreciably smaller at the crystal, this is probably compensated by a somewhat larger beam divergence for the $1 \mu \mathrm{S}$, and probably the dominant contribution is the mosaicity of the flash-cooled crystals.

\subsection{Data Quality after Scaling with SADABS}

The spherical harmonics used for the refinement and the weighted $R$-index based on the agreement of equivalent reflection intensities for $I>1.5 \sigma$ before $\left(w R 2_{\text {int(b) }}\right)^{\text {ii }}$ and after $\left(w R 2_{\text {int(a) }}\right)$ it has been minimized by SADABS are listed in Table 3-3. The result of merging the mean intensities divided by their standard deviations $\left\langle(/ / \sigma)_{\mathrm{m}}\right\rangle, R_{\mathrm{int}}{ }^{\mathrm{iii}}$ and $R_{\text {sigma }}{ }^{\text {iv }}$ after scaling with SADABS, calculated using XPREP, ${ }^{[212]}$ are also

\footnotetext{
"wR2 $2_{\text {int }}=\sum w\left(F_{o}^{2}-\left\langle F_{o}^{2}\right\rangle\right)^{2} / \sum w\left(\left\langle F_{o}^{2}\right\rangle\right)^{2}$

iii $R_{\text {int }}=\sum\left|F_{o}^{2}-\left\langle F_{o}^{2}\right\rangle\right| / \sum F_{o}^{2}$

${ }^{\text {iv }} R_{\text {sigma }}=\sum \sigma\left(F_{o}^{2}\right) / \sum F_{o}^{2}$
} 
included. Scaling substantially improves the agreement between equivalent reflections in all cases. Whereas before scaling the variation of the equivalent intensities is higher for the $\mathrm{I} \mu \mathrm{S}$ data, after correction the values are much closer. The larger correction needed for the $I \mu S$ data is attributed to the larger variations in the intensity-weighted volume of the crystal irradiated. After correction, the data quality indices tend to be better for the $\mathrm{l} \mu \mathrm{S}$ for small and weakly diffracting crystals, but worse for the strongly diffracting salt crystals $\mathbf{S}_{\text {small }}$ and $\mathbf{S}_{\text {large. }}$.

Table 3-3: Statistics before ( $\left.w R 2_{\text {int(b) }}\right)$ and after scaling by SADABS (remaining columns).

\begin{tabular}{|c|c|c|c|c|c|c|c|}
\hline sample & $\begin{array}{c}\text { spherical } \\
\text { harmonics }\end{array}$ & source & $w R 2_{\text {int(b) }}$ & $w R 2_{\text {int(a) }}$ & $<(I / \sigma)_{m}>$ & $R_{\text {int }}$ & $R_{\text {sigma }}$ \\
\hline \multirow{2}{*}{$\mathbf{O}_{\text {small }}$} & \multirow[t]{2}{*}{$6 / 3$} & $\mathrm{I} \mu \mathrm{S}$ & 0.0935 & 0.0249 & 21.63 & 0.0303 & 0.0394 \\
\hline & & sealed tube & 0.0643 & 0.0314 & 12.92 & 0.0547 & 0.0772 \\
\hline \multirow{2}{*}{$\mathbf{O}_{\text {large }}$} & \multirow{2}{*}{$6 / 3$} & $\mid \mu S$ & 0.0848 & 0.0240 & 44.51 & 0.0176 & 0.0166 \\
\hline & & sealed tube & 0.0482 & 0.0240 & 39.13 & 0.0173 & 0.0165 \\
\hline \multirow{2}{*}{$\mathrm{OM}_{\text {small }}$} & \multirow[t]{2}{*}{$6 / 3$} & $\mid \mu S$ & 0.0861 & 0.0301 & 34.33 & 0.0223 & 0.0161 \\
\hline & & sealed tube & 0.0822 & 0.0350 & 15.99 & 0.0570 & 0.0515 \\
\hline \multirow{2}{*}{$\mathbf{O M}_{\text {large }}$} & \multirow{2}{*}{$6 / 3$} & $\mid \mu S$ & 0.0784 & 0.0381 & 36.45 & 0.0247 & 0.0156 \\
\hline & & sealed tube & 0.0607 & 0.0378 & 31.83 & 0.0246 & 0.0166 \\
\hline \multirow{2}{*}{$\mathbf{S}_{\text {small }}$} & \multirow{2}{*}{$8 / 5$} & $1 \mu \mathrm{S}$ & 0.1234 & 0.0389 & 40.52 & 0.0267 & 0.0169 \\
\hline & & sealed tube & 0.0971 & 0.0275 & 55.28 & 0.0172 & 0.0117 \\
\hline \multirow{2}{*}{$\mathbf{S}_{\text {large }}$} & \multirow{2}{*}{$8 / 5$} & $1 \mu S$ & 0.1586 & 0.0716 & 21.27 & 0.0594 & 0.0348 \\
\hline & & sealed tube & 0.1296 & 0.0538 & 26.30 & 0.0383 & 0.0251 \\
\hline
\end{tabular}

The larger corrections needed for the I $\mu$ S data are clearly apparent in the SADABS diagnostic plots (Figure 3-8). In these diagrams the normalized scale factor (upper graph) and the smoothed $R_{\text {int }}$ (lower graph) are shown for the large organic crystal $\mathbf{O}_{\text {large }}$ as a function of the scan and frame numbers. Although deviations from a horizontal line can indicate a miscentered crystal, in this case they are almost certainly the result of changes in the effective crystal volume irradiated, which as discussed already are more pronounced for the I $\mu \mathrm{S}$. 


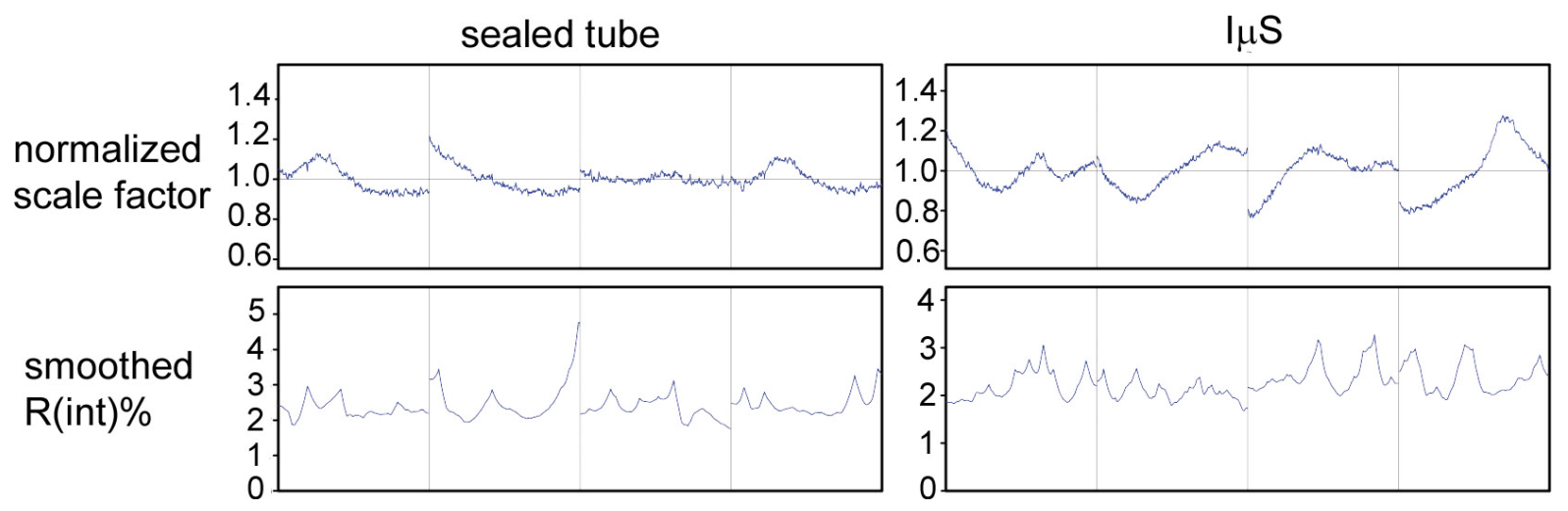

Figure 3-8: SADABS diagnostic plots for $\mathbf{O}_{\text {large }}$ : sealed tube (left) and $l \mu S$ (right).

However, as Table 3-3 shows, $w R 2_{\text {int }}, R_{\text {int }}$ and $\left\langle(I / \sigma)_{\mathrm{m}}>\right.$ are mostly lower for the $| \mu \mathrm{S}$ data sets after absorption correction and scaling. This not only indicates that the experimental errors that require correction are higher for the $I \mu S$ data sets, but also that appropriate software is capable of making an adequate correction so that the higher diffraction intensities using the $I \mu S$ lead to higher quality data. This results in a greater improvement of the $w R 2_{\text {int }}$ for the $\mathrm{I} \mu \mathrm{S}$ data sets and good $R_{\text {int }}$ values after the correction. However, the larger variance of the intensities of the equivalent reflections does result in larger standard deviations for the $1 \mu S$ intensity data after processing and merging with SADABS, reducing the corresponding $\left\langle(I / \sigma)_{m}\right\rangle$ values. Thus although the raw $\left\langle(I / \sigma)_{s}>\right.$ values given in Table 3-2 are always higher for the $I \mu S$ data, Table 3-3 shows that for $\mathbf{S}_{\text {small }}$ and $\mathbf{S}_{\text {large }}$ the order has been reversed after scaling and merging. For the smaller and weakly diffracting crystals the higher peak intensity of the $1 \mu \mathrm{S}$ is still the determining factor for the final data quality, but for larger and strongly diffracting crystals the results are more equal, especially when the different exposure times (see Table 3-1) are taken into account.

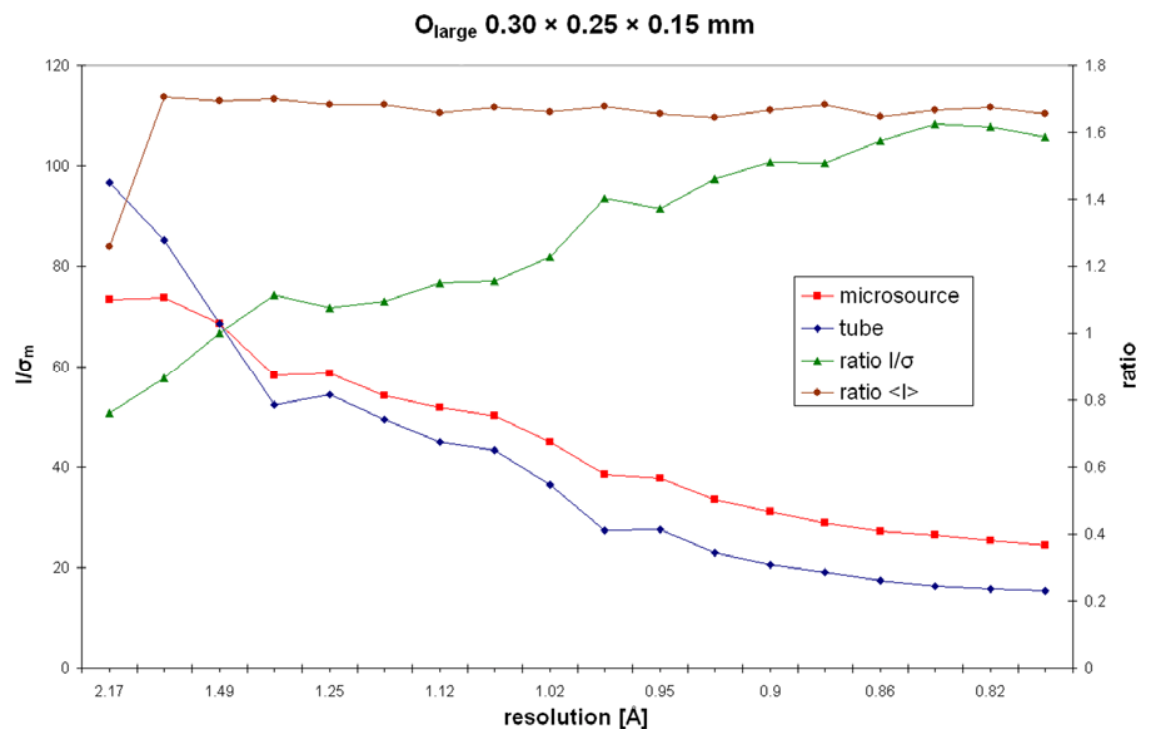

Figure 3-9: Resolution dependence of $<(/ / \sigma)_{m}>$ and the ratios of $<(/ / \sigma)_{m}>$ and $</>$ (I $\mu S /$ sealed tube). 
When the intensities produced by the $\mathrm{l} \mu \mathrm{S}$ are divided by the corresponding values of the sealed tube the resulting ratio is always smaller at low resolution and increases with higher scattering angles. This tendency is shown by all datasets. Even though the mean intensity is generally lower for the experiments with the sealed tube, the $<(I / \sigma)_{\mathrm{m}}>$ value at low resolution is higher in the example shown in Figure 3-9, but the ratio becomes less than unity at a resolution of $1.49 \AA$.

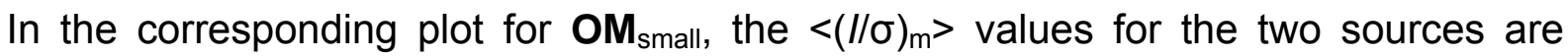
almost equal at the lowest resolution, but at $0.82 \AA$ the value for the $I \mu S$ is 3.6 times as high as for the sealed tube.

At low resolution, $\sigma$ is dominated by the variance of the intensities of the equivalents, but at higher resolution it is more affected by random noise, allowing the higher intensities from the $I \mu S$ to give higher $\left\langle(I / \sigma)_{m}\right\rangle$ values. This suggests that the $I \mu S$ is superior when data are required to the highest possible resolution, e. g. for the experimental determination of charge density or for the solution of structures from very small crystals by direct methods.

\subsection{Data Quality after Refinement}

The $R 1$ (all data) $)^{v}, R 1\left(F_{\mathrm{o}}>4 \sigma\left(F_{\mathrm{o}}\right)\right), w R 2^{\mathrm{vi}}$, the standard deviation of a selected bond length (esd), and the range of the residual electron density ${ }^{[213]}\left(\Delta \rho_{0}\right)^{\text {vii }}$ after leastsquares structure refinement are compared in Table 3-4.

After least-squares structure refinement, the various figures of merit are comparable for the two sources, except for the two small crystals, for which the I $\mu \mathrm{S}$ gave much

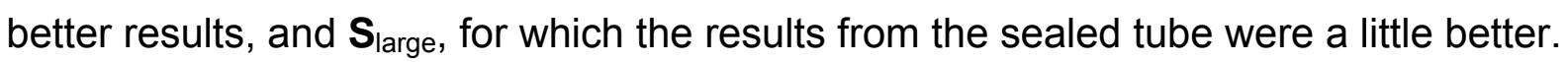
This suggests that for $\mathbf{S}_{\text {large }}$ even SADABS was not able to compensate completely for the absorption errors and different effective volumes irradiated (a $R 1$ value of 0.0235 might still be acceptable for a routine structure determination, but the large residual density difference would give cause for concern).

\footnotetext{
${ }^{\vee} R 1=\sum|| F_{o}|-| F_{c}|| / \sum\left|F_{o}\right|$$$
{ }^{\mathrm{vi}} w R 2=\sqrt{\sum\left[w\left(F_{o}^{2}-F_{c}^{2}\right)^{2}\right] / \sum\left[w\left(F_{o}^{2}\right)^{2}\right]}
$$$$
{ }^{\text {vii }} \Delta \rho_{0}=\rho_{0, \text { max }}-\rho_{0, \text { min }}
$$ 
Table 3-4: Selected quality criteria after structure refinement.

\begin{tabular}{|c|c|c|c|c|c|c|}
\hline Sample & source & $R 1$ (all data) & $R 1\left(F_{\mathrm{o}}>4 \sigma\left(F_{\mathrm{o}}\right)\right)$ & $w R 2$ & esd $[\AA]]$ & $\Delta \rho_{0}\left[\mathrm{e} / \AA^{3}\right]$ \\
\hline \multirow{2}{*}{$\mathbf{O}_{\text {small }}$} & I $\mu S$ & 0.0508 & 0.0378 & 0.0875 & 0.0024 & 0.34 \\
\hline & sealed tube & 0.0824 & 0.0519 & 0.0984 & 0.0033 & 0.39 \\
\hline \multirow{2}{*}{$\mathbf{O}_{\text {large }}$} & $I \mu S$ & 0.0271 & 0.0268 & 0.0729 & 0.0015 & 0.32 \\
\hline & sealed tube & 0.0271 & 0.0263 & 0.0696 & 0.0015 & 0.29 \\
\hline \multirow{2}{*}{$\mathrm{OM}_{\text {small }}$} & $1 \mu S$ & 0.0534 & 0.0450 & 0.1159 & 0.0021 & 0.80 \\
\hline & sealed tube & 0.0967 & 0.0562 & 0.1546 & 0.0031 & 0.87 \\
\hline \multirow{2}{*}{$\mathrm{OM}_{\text {large }}$} & I $\mu S$ & 0.0429 & 0.0407 & 0.1112 & 0.0018 & 0.85 \\
\hline & sealed tube & 0.0427 & 0.0382 & 0.1050 & 0.0017 & 0.86 \\
\hline \multirow{2}{*}{$\mathbf{S}_{\text {small }}$} & $\mid \mu S$ & 0.0157 & 0.0153 & 0.0370 & 0.0017 & 1.20 \\
\hline & sealed tube & 0.0147 & 0.0141 & 0.0329 & 0.0016 & 1.09 \\
\hline \multirow{2}{*}{$\mathbf{S}_{\text {large }}$} & $I_{\mu} \mathrm{S}$ & 0.0235 & 0.0228 & 0.0593 & 0.0023 & 2.47 \\
\hline & sealed tube & 0.0203 & 0.0185 & 0.0427 & 0.0020 & 1.37 \\
\hline
\end{tabular}

The values of $R 1$ for $F_{0}>4 \sigma\left(F_{0}\right)$ also reflect the larger number of weak reflections for the small crystals measured with the sealed tube. A single estimated standard deviation of a representative central bond length is shown in Table 4; these esds show the same trends as the $R$-indices. The disordered region of $\mathbf{O M}_{\text {small }}$ had to be refined isotropically against the sealed tube data because anisotropic refinement was unstable. For the less noisy $1 \mu S$ data the anisotropic refinement was successful for both crystals.

\subsection{Experiments with Crystals that Matched the Beam Diameter}

In these experiments, triphenylthiophosphane $(\mathbf{P})$ crystals were chosen to match the diameter of the beam and data were collected with identical exposure times ( $5 \mathrm{~s}$ per frame). This required a relatively large crystal of dimensions $0.40 \times 0.40 \times 0.40 \mathrm{~mm}$ for the sealed tube and a rather small crystal of dimensions $0.10 \times 0.10 \times 0.10 \mathrm{~mm}$ for the $1 \mu \mathrm{S}$ (volume ratio 64:1). Triphenylthiophosphane was chosen because good crystals of any desired dimensions can be easily obtained. It crystallizes in the monoclinic space group $P 2{ }_{1} / c$ with two molecules in the asymmetric unit. Since the molecule contains no heavy atom the structure refinement was made without 
employing an absorption or scaling correction to minimize the correcting influence of the data reduction software. The refined structure should thus be a direct measure of the raw data quality.

Table 3-5: Selected statistics for compound $\mathbf{P}$.

\begin{tabular}{ccc}
\hline & $\mathrm{I \mu S}$ & sealed tube \\
\hline$</>$ & 1234.46 & 1102.36 \\
$<(/ / \sigma)_{\mathrm{s}}>$ & 20.29 & 19.59 \\
$R_{\text {sym }}$ & 0.057 & 0.046 \\
$<(/ / \sigma)_{\mathrm{m}}>$ & 28.60 & 28.44 \\
$R_{\text {int }}$ & 0.0564 & 0.0458 \\
$R_{\text {sigma }}$ & 0.0206 & 0.0210 \\
$R 1\left(F_{\mathrm{o}}>4 \mathrm{sig}\left(F_{\mathrm{o}}\right)\right)$ & 0.0288 & 0.0295 \\
$R 1(\mathrm{all}$ data $)$ & 0.0346 & 0.0354 \\
$\mathrm{wR2}$ & 0.0850 & 0.0845 \\
esd $[\AA](\mathrm{P}-\mathrm{C})$ & 0.14 & 0.14 \\
$\Delta \rho_{0}\left[\mathrm{e} / \AA^{3}\right]$ & 0.65 & 0.66 \\
\hline
\end{tabular}

Except for the slightly larger value of $R_{\text {int }}$ for the $1 \mu \mathrm{S}$ (because of variations in the effective volume irradiated despite the small crystal employed) the results shown in Table 3-5 are remarkably similar for the two sources, despite the large difference in the size of the crystals. It was anticipated that the $R_{\text {int }}$ would be lower for the I $\mathrm{SS}$ data set since the $I \mu S$ yields a higher $I / \sigma$ value and the quality (e. g. low mosaicity, no encapsulations, no satellites, etc.) of a small crystal is usually better than that of a larger crystal but surprisingly the opposite is the case. The effect that the sealed tube gives better $R_{\text {int }}$ values although the $I \mu \mathrm{S}$ shows higher $/ / \sigma$ values can be observed in nearly all measurements that are described in this work. This trend only changes if the $/ / \sigma_{\mathrm{m}}$ values of the tube are very small $(<4)$ or the I $\mu \mathrm{S}$ gives a by far higher $/ / \sigma_{\mathrm{m}}$ value.

Still Table 3-5 underlines the ability of the $1 \mu \mathrm{S}$ to give data of comparable quality to those from a sealed tube with much smaller crystals, and the desirability of matching the crystal size to the beam cross section. 


\subsection{Conclusion}

From the experiments presented in this work it is clear that the optimum choice of source is determined by the size and diffracting power of the available crystals, and that the best results are obtained when source and crystals are matched. For sufficiently large crystals with dimensions $\geq 300 \mu \mathrm{m}$, both sources yield very acceptable X-ray data for the structures. Except for large, strongly diffracting crystals the I $\mathrm{S}$ data are as good or better than the sealed tube data. For very small crystals (dimensions of $100 \mu \mathrm{m}$ or less) the sealed tube cannot compete with the $1 \mu \mathrm{S}$; in extreme cases only the $1 \mu \mathrm{S}$ yields satisfactory data. Since in many cases it is not possible to grow large crystals (e. g. materials- and nano-science, MOFs, quality screening in drug production) not all samples can be measured with the sealed tube but it is feasible to measure almost all samples with the $1 \mu \mathrm{S}$. Therefore the main advantage of the $1 \mu \mathrm{S}$ seems to be the broader field of application also one has to be even more careful with the selection of a sample that has the proper size for the $1 \mu \mathrm{S}$ - in most cases the crystals tend to be too large for the fine-focused beam which leads to the observed variance of the symmetry equivalent reflections and all associated secondary effects described above.

Even in routine structure determination, the possibility to use smaller crystals has the advantage that systematic errors such as absorption are reduced, that the crystal is less likely to be twinned, and also that it is less likely to split on flash cooling. However, accurate centering of small crystals is important, and it is essential to scale the data to correct for the changes in the intensity-weighted volume of the crystal irradiated. The results presented here show that modern scaling software is more than up to this task.

Other advantages of the $I \mu S$ are the very low energy consumption ( $30 \mathrm{~W}$ ), the fact that no water cooling is required, the lower exposure times and the very low maintenance required. The $I \mu S$ used in these tests has been in almost continuous use for over a year with no maintenance and no significant drop in X-ray intensity. 


\section{CONCLUSION AND FUTURE OBJECTIVES}

\subsection{Bimetallic Complexes}

The experiments described in chapter 2 show that the diimidosulfinates are suitable ligands for the forming of bimetallic or in some cases even heterobimetallic complexes. Whether added to a metallocene as additional donor site or as coupled diimidosulfinates, the electropositive charged sulfur atom allows it to place the sulfur imides into nearly every organic periphery. Although up to now this was only possible for the sulfur diimides, since the triimides only react with lithium organics that have a small sterical demand, the results presented in chapter 2.4 .2 make the same diversity accessible for the sulfur triimides. The performed experiments display that the use of the HSAB-soft Grignard reagents facilitates the introduction of nearly every organic groups even with a higher sterical demand. In addition the yields are better and the purification is much easier since the magnesium complexes tend to crystallize a lot better than their lithium analogues. Since the nucleophilic addition to the sulfur atom is straightforward, it was possible during this thesis to couple sulfur imides with a lot of different spacers, tune the structural motif of the synthesized complexes and influence the arrangement of the studied ligands.

Although the analyzed sulfinates and sulfonates react very flexibly and adaptively when the organic substituents are varied, the metal exchange reactions are rather difficult. In spite of many exchange reactions that were performed with coupled diimidosulfinates the lithium atom could only be replaced by an aluminum atom and a zinc atom. Unfortunately the selectiveness of these reactions was rather poor making the synthesis of a heterobimetallic complex impossible. The same holds true for the metal exchange reactions with magnesium sulfinates and sulfonates. An exchange of the magnesium atom with a zinc atom was possible but many other reactions with different metal amides and metal halogens yielded only starting material. The attempts to initiate the coordination of a second metal by the pending imido group of the magnesium sulfonates fared even worse. Either a metal exchange took place or in most cases the reaction did not proceed at all. Apparently Walfort could only synthesize $\left[(\mathrm{THF})_{2} \mathrm{Li}\left(\mathrm{N}^{t} \mathrm{Bu}\right)_{2} \mathrm{SMe}\left(\mathrm{N}^{t} \mathrm{Bu}\right) \mathrm{ZnMe}_{2}\right]$, the only example where the pending imido group coordinates a second metal, because in the associated lithium reagent the NR group already exhibits a intermolecular coordination to the lithium atom of a neighboring molecule. Since the third imido group is not pre-coordinated in the 
magnesium sulfonate reagents, the coordination of another metal seems not to be favored. One possibility to solve this problem would be to perform a metal exchange after the addition of the Grignard reagent. Obviously the change from magnesium to lithium should result in the formation of a molecule that is capable of using the third imido group as additional donor. The use of other metals could also lead to this precoordination.

To bypass the problems of the failed metal exchange reactions a detour, resulting in the formation of sulfinic or sulfonic acids, could be the solution. Since the direct metal exchange is not working it could be concluded that the lithium and magnesium complexes are just too stable. This is not entirely surprising since according to Pearson the hard nitrogen atoms will interact more strongly with metals like lithium and magnesium than with the softer transition metals. The hydrolysis of sulfinates or sulfonates and subsequent deprotonation reactions with different metal amides or metal hydrides could help to avoid this problem. By the NMR spectra of the magnesium sulfonates, which always showed traces of the associated sulfonic acid, it was proved that the hydrolysis reaction is indeed possible. Since Walfort showed that the use of tert-butyl-ammonium chloride as hydrolysis reagent proved to be successful it was used in the course of this work. Unfortunately the herein described sulfinates and sulfonates decomposed during the reaction with this reagent. Apparently milder reaction conditions are necessary for the hydrolysis to work. Cyclopentadienyl could be an interesting candidate for this type of reaction since one hydrogen atom is relatively acidic and the resulting cyclopentadienyl lithium could be separated from the product without problems.

Summarized, the results presented in this thesis show, that the possibilities to build up different diimidosulfinates and triimidosulfonates are nearly unlimited. Thanks to the electropositive sulfur atom nearly every organic group can be added to the sulfurimides resulting in a variety of ligands that can be further tuned. In addition the sulfinates and sulfonates have the ability to react very flexible to this changes, therefore creating ligand systems that can be tailored for the task at hand. The only drawback of the described systems is the limited access to transition metal complexes. As already pointed out the lithium and magnesium complexes can be synthesized without problems but the metal exchange is somewhat hampered. 


\subsection{Field Test of the Incoatec Microfocus Source}

The comparison of both sources displayed that a clear statement like 'one source is better than the other' is not possible. Both sources have their 'strengths' and their 'weaknesses'. The data sets produced by the $I \mu S$ yield higher $<>$ and $/ / \sigma$ values whereas the ones from the sealed tube normally exhibit better $R_{\text {int }}$ values. Especially the comparison in chapter 3.7 showed that both sources can deliver data sets with nearly the same high quality when a crystal that matches the beam diameter is used. Therefore the samples are determining what source is suited best. If mainly small crystals have to be measured the $I \mu S$ should be used but for geologists who primarily examine large crystals which contain heavy absorbers the sealed tube would be the better choice.

Although both sources have their field of application one must mention that the $1 \mu \mathrm{S}$ still has some advantages. First of all it is more versatile since a large crystal can most of the time be cut into a smaller one while it is often not possible to make a small crystal larger. Anyhow, it is most of the time better to use a smaller crystal since it is less likely to be twinned, has a smaller mosaicity and the effect of absorption is reduced. For medium sized crystals both sources deliver good data sets but the I $\mu \mathrm{S}$ still has the advantage of lower exposure times. In addition, the I $\mu \mathrm{S}$ is more efficient, since it exhibits a very low energy consumption, $30 \mathrm{~W}$ compared to $2000 \mathrm{~W}$ for the sealed tube, and does not need any water cooling. But all these advantages also have a price. When using the $\mathrm{I} \mu \mathrm{S}$ the crystallographer has to work even more precisely since errors during the centering of the crystal have a bigger effect on the data quality, due to the small beam and the sharp beam profile. Furthermore a proper scaling of the data is essential to get rid of the errors arising from the variance of the symmetry equivalent reflections. Last but not least the high flux density of the $\mathrm{l} \mu \mathrm{S}$ makes it possible to measure high resolution data sets which are needed for experimental charge density studies. Although up to now it was common sense that for such studies the crystal volume irradiated must be constant, first results presented here look promising. 


\section{ZUSAMMENFASSUNG UND ZUKÜNFTIGE ZIELE}

\subsection{Bimetallische Komplexe}

Die in Kapitel 2 beschriebenen Experimente zeigen, dass die Diimidosulfinate geeignete Liganden für die Synthese von bimetallischen als auch heterobimetallischen Komplexen sind. Ob als zusätzliche Koordinationsstelle an einem Metallocen oder als gekoppelte Diimidosulfinate, dass positiv polarisierte Schwefelatom erlaubt es, die Schwefelimide in nahe zu jedwede organische Umgebung zu integrieren. Obwohl das bisher nur für Schwefeldiimide möglich war, da die Schwefeltriimide nur mit lithiumorganischen Verbindungen reagieren die einen kleinen sterischen Anspruch haben, machen die Resultate, die in Kapitel 2.4.2 präsentiert wurden, diese große Auswahl auch für die Schwefeltriimide zugänglich. Die durchgeführten Experimente zeigen, dass die Nutzung der HSAB-weichen Grignardverbindungen die Einführung diverser organischer Gruppen ermöglicht. Zusätzlich verbessern sich die Ausbeuten und auch die Aufreinigung ist einfacher, weil die Magnesiumkomplexe besser kristallisieren als ihre Lithiumanaloga. Da die nucleophile Addition an das Schwefelatom so problemlos verläuft, war es während dieser Arbeit möglich Schwefelimide mit verschiedenen Spacern zu koppeln, Strukturmotive der synthetisierten Komplexe einzustellen und die Anordnung der untersuchten Liganden zu beeinflussen.

Obwohl die analysierten Sulfinate und Sulfonate sehr flexibel und anpassungsfähig reagieren, gestalten sich die Metallaustauschreaktionen eher schwierig. Trotz vieler durchgeführter Austauschreaktionen mit gekoppelten Diimidosulfinaten konnten das Lithiumatom nur durch ein Aluminiumatom und ein Zinkatom ersetzt werden. Unglücklicherweise ist die Selektivität dieser Reaktionen eher schlecht, was die Synthese eines heterobimetallischen Komplexes unmöglich macht. Dasselbe trifft auch auf die Metallaustauschreaktionen mit Magnesiumsulfinaten und -sulfonaten zu. Ein Austausch des Magnesiumatoms mit einem Zinkatom war zwar möglich, aber viele andere Reaktionen mit verschiedenen Metallamiden und Metallhalogeniden lieferten nur Ausgangsmaterial. Die Versuche ein zweites Metall durch die freie Imidogruppe des Magnesiumsulfonates zu koordinieren verliefen sogar noch schlechter. Entweder wurde das Metall ausgetauscht oder es fand gar keine Reaktion statt. Scheinbar konnte Walfort $\left[\left(\mathrm{THF}_{2} \mathrm{Li}\left(\mathrm{N}^{t} \mathrm{Bu}\right)_{2} \mathrm{SMe}\left(\mathrm{N}^{t} \mathrm{Bu}\right) \mathrm{ZnMe}_{2}\right]\right.$, das einzige Beispiel in dem die freie Imidogruppe ein zweites Metall koordiniert, nur synthetisieren, weil im zugehörigen Lithiumedukt die NRGruppe schon eine intermolekulare Koordination zum Lithiumatom eines 
Nachbarmoleküls zeigt. Da die dritte Imidogruppe in den Magnesiumsulfonatedukten nicht vorkoordiniert ist, scheint eine Koordination eines weiteren Metalls nicht bevorzugt zu sein. Eine Möglichkeit um dieses Problem zu lösen, wäre einen Metallaustausch nach der Reaktion mit der Grignardverbindung zu machen. Offensichtlich führt der Austausch von Magnesium mit Lithium zur Bildung eines Moleküls das in der Lage ist die dritten Imidogruppe als zusätzlichen Donor zu nutzen. Außerdem könnte auch der Austausch mit anderen Metallen die gewünschte Vorkoordination herbeiführen.

Um das Problem der fehlgeschlagenen Metallaustauschreaktionen zu umgehen, könnte ein Umweg über die sulfinischen oder sulfonischen Säure zum Erfolg führen. Da der direkte Metallaustausch nicht funktioniert, könnte man daraus schließen, dass die Lithium- und Magnesiumkomplexe einfach zu stabil sind. Das ist nicht völlig überraschend, da nach Pearson das harte Stickstoffatom stärker mit Metallen wie Lithium oder Magnesium interagiert als mit den eher weicheren Übergangsmetallen. Durch die Hydrolyse der Sulfinate oder Sulfonate mit anschließender Deprotonierung durch Metallamide oder Metallhydride ließe sich dieses Problem vermeiden. Durch die NMR-Spektren der Magnesiumsulfonate, die immer Spuren der zugehörigen sulfonischen Säure enthielten, ist belegt, dass die Hydrolysereaktion realisierbar ist. Weil Walfort tert-Butylammoniumchlorid erfolgreich als Hydrolysereagenz einsetzte, wurde es auch in dieser Arbeit benutzt. Leider zersetzten sich die in dieser Arbeit beschriebenen Sulfinate und Sulfonate bei der Reaktion mit diesem Reagenz. Scheinbar sind mildere Bedingungen nötig damit die Hydrolyse abläuft. Cyclopentadien könnte ein interessanter Kandidat für eine derartige Reaktion sein, da es ein relativ acides Wasserstoffatom besitzt und das entstehende Lithiumcyclopentadienyl einfach abgetrennt werden könnte.

Zusammengefasst zeigen die Ergebnisse dieser Arbeit, dass die Möglichkeiten Diimidosulfinate und Triimidosulfonate aufzubauen fast unbegrenzt sind. Dank des partiell positiv geladenen Schwefelatoms kann fast jede organische Gruppe an die Schwefelimide addiert werden, was in einer Vielzahl von Liganden resultiert, die dann weiter verändert werden können. Zusätzlich haben die Sulfinate und Sulfonate die Fähigkeiten sehr flexibel auf die Veränderung der organischen Reste zu reagieren und können so für die ausstehenden Aufgaben maßgeschneidert werden. Der einzige Nachteil der beschriebenen Systeme ist der limitierte Zugang zu Übergangsmetallkomplexen. Wie bereits beschrieben können die Lithium- und Magnesiumkomplexe ohne Probleme synthetisiert werden, aber der Metallaustausch gestaltet sich schwierig. 


\subsection{Feldversuche mit der Incoatec Microfocus Source}

Der Vergleich beider Röntgenquellen zeigte, dass eine klare Aussage wie "eine Quelle ist besser als die Andere" nicht möglich ist. Beide Quellen haben ihre Stärken und ihre Schwächen. Die Datensätze der $\mid \mu S$ zeigen höhere $</>$ und $\| \sigma$ Werte, während die der Sealed Tube normalerweise bessere $R_{\text {int }}$ Werte liefern. Besonders die Vergleiche in Kapitel 3.7 lassen erkennen das beide Quellen Datensätze mit vergleichbar hoher Qualität liefern können, wenn ein Kristall benutzt wird der zur Strahlbreite passt. Von daher bestimmen die Proben, die man messen will, welche Quelle am besten geeigntet ist. Wenn meistens kleine Kristalle gemessen werden, sollte die $I \mu S$ benutzt werden, aber für Geologen, die hauptsächlich große Kristalle untersuchen, die starke Absorber enthalten, ist die Sealed Tube die bessere Wahl.

Obwohl beide Quellen ihre Anwendungsgebiete haben, sollte man erwähnen, dass die $1 \mu S$ trotzdem noch ein paar Vorteile hat. Erstens ist sie vielseitiger, da ein großer Kristall fast immer kleiner geschnitten werden kann, während es meist nicht möglich ist einen kleinen Kristall zu vergrößern. Ohnehin ist es oftmals besser einen kleinen Kristall zu benutzen, weil sie weniger oft verzwillingt sind, eine kleinere Mosaizität besitzen und die Absorptionseffekte geringer sind. Für mittelgroße Kristalle liefern beide Quellen gute Datensätze aber die I $\mu \mathrm{S}$ hat immer noch den Vorteil der kürzeren Belichtungszeiten. Zusätzlich ist die $1 \mu \mathrm{S}$ ökonomischer, da sie einen sehr geringen Energieverbrauch hat (30 W verglichen mit $2000 \mathrm{~W}$ für die Sealed Tube) und keine Wasserkühlung benötigt. Aber all diese Vorteile haben ihren Preis. Wenn die I $\mu S$ benutzt wird, muss der Kristallograph noch präziser arbeiten, weil Fehler in der Zentrierung des Kristalls auf Grund des schmalen Strahls und des spitzen Strahlprofils noch größere Auswirkungen haben. Weiterhin ist ein gutes skalieren der Daten essentiell, um die Fehler, die durch die Varianz der symmetrieäquivalenten Reflexe entstehen, zu korrigieren. Abschließend muss noch erwähnt werden, dass es durch die hohe Flussdichte der $I \mu S$ möglich ist, hoch aufgelöste Datensätze aufzunehmen, die für experimentelle Elektronendichteuntersuchungen gebraucht werden. Obwohl bisher die Überzeugung bestand, dass für solche Untersuchungen das bestrahlte Kristallvolumen immer konstant sein muss, sehen ersten Resultate unserer Arbeitsgruppe vielversprechend aus. 


\section{EXPERIMENTAL SECTION}

\subsection{General}

All experiments were carried out either in an atmosphere of purified, dry nitrogen or argon by using modified Schlenk techniques ${ }^{[214,215]}$ or in an argon drybox. The glass vessels were dried for several hours at $120^{\circ} \mathrm{C}$, assembled hot, and cooled down under vacuum. The solvents were freshly distilled from sodium-potassium alloy ( $\mathrm{Et}_{2} \mathrm{O}, n$-pentane) or potassium (dem, THF, n-hexane) prior to use and degassed. The reactants were commercially available or synthesized according to published procedures $\mathrm{S}\left(\mathrm{N}^{t} \mathrm{Bu}\right)_{2},{ }^{[216]} \mathrm{S}\left(\mathrm{N}^{t} \mathrm{Bu}\right)_{3},{ }^{[217]} \mathrm{S}\left(\mathrm{NSiMe}_{3}\right)_{2}{ }^{[218]}$ and $\mathrm{S}\left(\mathrm{NSiMe}_{3}\right)\left(\mathrm{N}^{t} \mathrm{Bu}\right) .{ }^{[219]}$

\subsection{Analytical Methods}

\subsubsection{Mass spectroscopy}

Mass spectra were recorded with the electron ionization method (El-MS: $70 \mathrm{eV}$ ) on a Finnigan MAT 95 spectrometer. The mass-to-charge ratios $(\mathrm{m} / \mathrm{z})$ of the fragment ions are based on the molecular masses of the isotopes with the highest natural abundance. The molecular peak $\mathrm{M}$ is defined as the compound without coordinating solvent. Some spectra were unspecific as the ionic character and the lability of the synthesized compounds made the measurements difficult. Due to the reactivity and solubility of the compounds no electron spray ionization (ESI-MS) or fast atom bombardment (FAB-MS) mass spectra could be recorded.

\subsubsection{NMR spectroscopy}

All NMR spectra were recorded on Bruker Avance 400 or 500 spectrometers. The chemical shifts $\delta$ are given in ppm with positive values for low-field shifts relative to tetramethyl silane as external standard. 


\subsubsection{Elemental analyses}

Elemental analyses were performed by the "Mikroanalytisches Labor des Instituts für Anorganische Chemie der Universität Göttingen" with an elementar Vario EL3 apparatus.

The determined values deviate more than usual from the calculated ones, as the substances were highly sensible to oxygen and moisture. The inclusion of argon, from canning in an argon drybox, led to systematic errors.

\subsection{Syntheses and Characterizations}

\subsection{1 [(THF) $\left.\left\{\mathrm{Li}\left(\mathrm{N}^{t} \mathrm{Bu}\right)_{2} \mathrm{SCpFeCp}\right\}_{2}\right](1)$}

The crystal structure can be found in chapter 2.2 and 7.5.1. All other analytical data and the synthesis can be found in the literature. ${ }^{[130]}$

Empirical Formula: $\mathrm{C}_{40} \mathrm{H}_{62} \mathrm{Fe}_{2} \mathrm{Li}_{2} \mathrm{~N}_{4} \mathrm{OS}_{2} \quad$ Molecular weight: $804.64 \mathrm{~g} \mathrm{~mol}^{-1}$

\subsection{2 $\left[(\mathrm{THF})_{4} \mathrm{Li}_{2}\left\{(\mathrm{NSiMe})_{2} \mathrm{~S}_{2} \mathrm{C}_{12} \mathrm{H}_{8}\right](2) /\left[(\mathrm{THF})_{1.5} \mathrm{Li}_{2}\left\{\left(\mathrm{NSiMe}_{3}\right)_{2} \mathrm{~S}_{2} \mathrm{C}_{12} \mathrm{H}_{8}\right]_{\infty}(3)\right.\right.$}

A suspension of $3.1 \mathrm{~g}$ (10 mmol) 4,4'-dibromobiphenyl in $15 \mathrm{~mL} \mathrm{Et}_{2} \mathrm{O}$ was treated with $11.2 \mathrm{~mL}(20 \mathrm{mmol})$ of a $1.79 \mathrm{M}$ solution of ${ }^{n} \mathrm{BuLi}$ at $-78{ }^{\circ} \mathrm{C}$. After stirring for two hours the resulting white solid was filtered off and washed with cold hexane.

$4.0 \mathrm{~g}(8.7 \mathrm{mmol})$ of the 4,4'-dilithiumbiphenyl were suspended in THF (in the case of 3 a 1:1 THF/hexane mixture was used) and $3.6 \mathrm{~g}(17.4 \mathrm{mmol}) \mathrm{S}\left(\mathrm{NSiMe}_{3}\right)_{2}$ were added at $-78{ }^{\circ} \mathrm{C}$. After stirring over night part of the solvent was removed under reduced pressure. After two days storage at $4{ }^{\circ} \mathrm{C}$ colorless crystals suitable for X-ray diffraction were obtained. For 3 the highest peaks in the mass spectrum and the peaks shown in the NMR spectrum where the same as for 2 . The elemental analysis for $\mathbf{3}$ gave no satisfying results. 
Empirical Formula: $\mathrm{C}_{40} \mathrm{H}_{76} \mathrm{Li}_{2} \mathrm{~N}_{4} \mathrm{O}_{4} \mathrm{~S}_{2} \mathrm{Si}_{4}$

$$
\mathrm{C}_{30} \mathrm{H}_{56} \mathrm{Li}_{2} \mathrm{~N}_{4} \mathrm{O}_{1.50} \mathrm{~S}_{2} \mathrm{Si}_{4}
$$

Molecular weight: $804.64 \mathrm{~g} \mathrm{~mol}^{-1}$

$687.15 \mathrm{~g} \mathrm{~mol}^{-1}$

Yield (\%): $6.16 \mathrm{~g}, 7.1 \mathrm{mmol}$ (71\% referring to 4,4'-dibromobiphenyl) / $4.18 \mathrm{~g}$, $6.10 \mathrm{mmol}$ (61\% referring to 4,4'-dibromobiphenyl).

Elem. analysis in \% found (calc.): C: 55.47 (55.38), H: 9.47 (8.72), N: 6.69 (6.50), S: 7.79 (7.39).

${ }^{1} \mathrm{H}-N M R\left(400 \mathrm{MHz}\right.$, thf-d 8 ): $\delta=7.77\left(\mathrm{~d},{ }^{3} \mathrm{~J}_{\mathrm{HH}}=8.0 \mathrm{~Hz}, 4 \mathrm{H}\right.$, ortho), $7.50\left(\mathrm{~d},{ }^{3} \mathrm{~J}_{\mathrm{HH}}=8.0\right.$ $\mathrm{Hz}, 4 \mathrm{H}$, meta), $3.62\left(\mathrm{~m}, 8 \mathrm{H}, \mathrm{OCH}_{2} \mathrm{CH}_{2}\right), 1.77\left(\mathrm{~m}, 8 \mathrm{H}, \mathrm{OCH}_{2} \mathrm{CH}_{2}\right), 0.11$ (s, $36 \mathrm{H}$, $\left.\mathrm{Si}\left(\mathrm{CH}_{3}\right)_{3}\right)$.

${ }^{13} \mathbf{C}\left\{{ }^{1} \mathbf{H}\right\}-N M R$ (125 MHz, thf-d $\mathbf{8}$ ): $\delta=150.81$ (ipso), 143.54 (para), 127.81 (ortho), 126.99 (meta), $67.4\left(\mathrm{OCH}_{2} \mathrm{CH}_{2}\right), 25.3\left(\mathrm{OCH}_{2} \mathrm{CH}_{2}\right), 1.11\left(\mathrm{Si}\left(\mathrm{CH}_{3}\right)_{3}\right)$.

El-MS: m/z (\%): 565 (12) [M - $2 \mathrm{Li}+\mathrm{H}]^{+}, 464$ (21) [M - $\left.2 \mathrm{Li}-\mathrm{NSiMe}_{3}-\mathrm{CH}_{3}+\mathrm{H}\right]^{+}, 392$ (100) [M - $\left.2 \mathrm{Li}-2 \mathrm{NSiMe}_{3}+\mathrm{H}\right]^{+}, 287(25)\left[\mathrm{M}-2 \mathrm{Li}-\mathrm{S}\left(\mathrm{NSiMe}_{3}\right)_{2}-\mathrm{SiMe}_{3}+\mathrm{H}\right]^{+}, 73$ (26) $\left[\mathrm{SiMe}_{3}\right]^{+}$.

\subsection{3 $\left[\left\{(\mathrm{Ph})_{2} \mathrm{P}\right\}_{2} \mathrm{C}_{6} \mathrm{H}_{4}\right](4)$}

The crystal structure can be found in chapter 2.3.1 and chapter 7.5.4. All other analytical data can be found in the literature. ${ }^{[220]}$

Empirical Formula: $\mathrm{C}_{30} \mathrm{H}_{24} \mathrm{P}_{2}$

Molecular weight: $446.43 \mathrm{~g} \mathrm{~mol}^{-1}$

\subsection{4 $\left[\left\{\mathrm{Me}_{2} \mathrm{Al}\left(\mathrm{N}^{t} \mathrm{Bu}\right)_{2} \mathrm{~S}\right\}_{2} \mathrm{C}_{12} \mathrm{H}_{8}\right](5)$}

A solution of $5.3 \mathrm{~g}(6.6 \mathrm{mmol})$ dilithium-4,4'-bis- tert-butyl-diimidosulfinatebiphenyl in $15 \mathrm{~mL}$ THF was treated with $0.6 \mathrm{~mL}(6.5 \mathrm{mmol}) \mathrm{AlMe}_{2} \mathrm{Cl}$ at $-78{ }^{\circ} \mathrm{C}$. After stirring over night part of solvent was removed under reduced pressure. After two days storage at $4{ }^{\circ} \mathrm{C}$ colorless crystals suitable for $\mathrm{X}$-ray diffraction were obtained.

Empirical Formula: $\mathrm{C}_{40} \mathrm{H}_{72} \mathrm{Al}_{2} \mathrm{~N}_{4} \mathrm{O}_{2} \mathrm{~S}_{2}$ Molecular weight: $759.10 \mathrm{~g} \mathrm{~mol}^{-1}$

Yield (\%): $3.79 \mathrm{~g}, 4.94 \mathrm{mmol}(76 \%)$. 
Elemental analysis in \% found (calc.): C: 61.85 (62.50), H: 9.61 (9.18), N: 8.90 (9.11), S: 10.20 (10.43).

${ }^{1} \mathrm{H}-\mathrm{NMR}\left(500 \mathrm{MHz}\right.$, thf- $\left.\mathrm{d}_{8}\right): \delta=7.98\left(\mathrm{~d},{ }^{3} \mathrm{JHH}=8.2 \mathrm{~Hz}, 4 \mathrm{H}\right.$, meta), $7.80\left(\mathrm{~d},{ }^{3} \mathrm{JHH}_{\mathrm{HH}}=8.4\right.$ $\mathrm{Hz}, 4 \mathrm{H}$, ortho), 1.36 (s, $\left.36 \mathrm{H}, \mathrm{C}\left(\mathrm{CH}_{3}\right)_{3}\right),-0.58--0.68$ (br, $\left.12 \mathrm{H}, \mathrm{Al}\left(\mathrm{CH}_{3}\right)_{2}\right)$.

${ }^{13} \mathrm{C}\left\{{ }^{1} \mathrm{H}\right\}$-NMR (125 MHz, thf-d 8 ): $\delta=150.92$ (ipso), 144.09 (para), 128.96 (ortho),

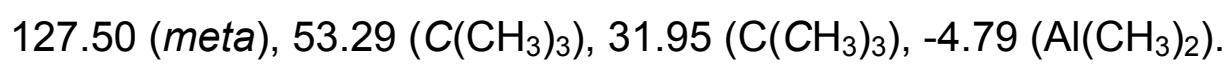

EI-MS: m/z (\%): 502 (11) [M - $2 \mathrm{AlMe}_{2}+\mathrm{H}^{+}, 429$ (13) [M - $\left.2 \mathrm{AlMe}_{2}-\mathrm{N}^{t} \mathrm{Bu}\right]^{+}, 360$ (30) $\left[\mathrm{M}-2 \mathrm{AlMe}_{2}-2 \mathrm{~N}^{t} \mathrm{Bu}+\mathrm{H}\right]^{+}, 289(10)\left[\mathrm{M}-2 \mathrm{AlMe}_{2}-3 \mathrm{~N}^{t} \mathrm{Bu}+2 \mathrm{H}\right]^{+}, 57$ (100) $\left[\mathrm{AlMe}_{2} /^{\mathrm{t}} \mathrm{Bu}\right]^{+}, 41(50)\left[\mathrm{C}_{3} \mathrm{H}_{5}\right]^{+}$.

\subsection{5 $\left[\left\{\mathrm{Me}_{2} \mathrm{Al}\left(\mathrm{NSiMe}_{3}\right)_{2} \mathrm{~S}\right\}_{2} \mathrm{C}_{6} \mathrm{H}_{4}\right](6)$}

To a solution of $4.7 \mathrm{~g}(20 \mathrm{mmol})$ 1,4-dibromobenzene in $30 \mathrm{~mL}$ toluene, $24 \mathrm{~mL}$ of a $1.67 \mathrm{M}$ solution of ${ }^{t} \mathrm{BuLi}(40 \mathrm{mmol})$ were added. After stirring for two hours the resulting light yellow solid was filtered off and washed with cold $\mathrm{Et}_{2} \mathrm{O}$.

$4.2 \mathrm{~g} \mathrm{(16} \mathrm{mmol})$ of the 1,4-dilithiumbenzene where suspended in $20 \mathrm{~mL}$ of $\mathrm{Et}_{2} \mathrm{O}$ and $6.6 \mathrm{~g}(32 \mathrm{mmol})$ of $\mathrm{S}\left(\mathrm{NSiMe}_{3}\right)_{2}$ were added at $-78{ }^{\circ} \mathrm{C}$. After stirring over night the light orange solid was filtered off and washed with cold $\mathrm{Et}_{2} \mathrm{O}$.

A solution of $9.0 \mathrm{~g}$ (12.3 mmol) dilithium-1,4-bis-trimethylsilyldiimdiosulfinatylbenzene in $15 \mathrm{~mL}$ THF was treated with $1.2 \mathrm{~mL}(12.3 \mathrm{mmol})$ of $\mathrm{AlMe} 2 \mathrm{Cl}$ at $-78{ }^{\circ} \mathrm{C}$. After stirring over night part of the yellow suspension was removed under reduced pressure. The remaining solid was then filtered off and the solution was put in the fridge at $4{ }^{\circ} \mathrm{C}$. After two days storage colorless crystals suitable for X-ray diffraction were obtained.

Empirical Formula: $\mathrm{C}_{22} \mathrm{H}_{52} \mathrm{Al}_{2} \mathrm{~N}_{4} \mathrm{~S}_{2} \mathrm{Si}_{4}$

Molecular weight: $603.12 \mathrm{~g} \mathrm{~mol}^{-1}$

Yield (\%): $5.67 \mathrm{~g}, 9.4 \mathrm{mmol}$ (47 \% referring to 1,4-dibromobenzene).

Elemental analysis in \% found (calc.): C: 43.33 (43.81), H: 9.01 (8.69), N: 9.45 (9.29), S: 10.09 (10.63).

${ }^{1} \mathrm{H}-\mathrm{NMR}\left(400 \mathrm{MHz}\right.$, thf- $\left.\mathrm{d}_{8}\right): \delta=8.16-7.98(\mathrm{~m}$, aromatic $4 \mathrm{H}),-0.03(\mathrm{br}, 36 \mathrm{H}$, $\left.\mathrm{Si}\left(\mathrm{CH}_{3}\right)_{3}\right),-0.61--0.72\left(\mathrm{br}, 12 \mathrm{H}, \mathrm{Al}\left(\mathrm{CH}_{3}\right)_{2}\right)$.

${ }^{13} \mathrm{C}\left\{{ }^{1} \mathrm{H}\right\}-N M R\left(100 \mathrm{MHz}\right.$, thf-d 8 ): $\delta=155.78$ (ipso), 127.16 (para), $3.20\left(\mathrm{Si}\left(\mathrm{CH}_{3}\right)_{3}\right)$, $4.71\left(\mathrm{Al}\left(\mathrm{CH}_{3}\right)_{2}\right)$.

EI-MS: m/z (\%): 588 (61) [M - Me] $]^{+}, 574$ (22) [M - $2 \mathrm{Me}+\mathrm{H}^{+}, 530$ (19) [M - $\left.\mathrm{SiMe}_{3}\right]^{+}$, $73(18)\left[\mathrm{SiMe}_{3}\right]^{+}, 57(100)\left[\mathrm{AlMe}_{2}\right]^{+}$. 


\subsection{6 [(THF $\left.)_{2} \mathrm{Li}\left(\mathrm{N}^{\mathrm{t} B u}\right)_{2} \mathrm{SAnBr}\right](7)$ and $\left[\left(\mathrm{Et}_{2} \mathrm{O}\right)_{2} \mathrm{Li}\left(\mathrm{NSiMe}_{3}\right)_{2} \mathrm{SAnBr}\right](9)$}

${ }^{n}$ BuLi $(1.37 \mathrm{~mL}, 2.22 \mathrm{M}, 3.04 \mathrm{mmol})$ was added dropwise to a suspension of 9,10-dibromoanthracene $(1.00 \mathrm{~g}, 2.98 \mathrm{mmol})$ in $25 \mathrm{~mL} \mathrm{Et}{ }_{2} \mathrm{O}$ at $-15^{\circ} \mathrm{C}$. The reaction mixture was stirred for $30 \mathrm{~min}$ before addition of $\mathrm{S}\left(\mathrm{N}^{t} \mathrm{Bu}\right)_{2}(1.04 \mathrm{~g}, 2.98 \mathrm{mmol})$. The suspension is stirred for $30 \mathrm{~min}$ and insoluble particles are removed by filtration. After removal of the solvent, the product was obtained as a red powder. Crystals were obtained from a saturated solution in THF $\left(\mathrm{Et}_{2} \mathrm{O}\right.$ in the case of 9$)$ upon a few days storage at $4{ }^{\circ} \mathrm{C}$.

$\left[(\mathrm{THF})_{2} \mathrm{Li}\left(\mathrm{N}^{\mathrm{t} B u}\right)_{2} \mathrm{SAnBr}\right](7)$ :

Empirical Formula: $\mathrm{C}_{30} \mathrm{H}_{42} \mathrm{BrLiN}_{2} \mathrm{O}_{2} \mathrm{~S}$ Molecular weight: $581.57 \mathrm{~g} \mathrm{~mol}^{-1}$

Yield (\%): $1.33 \mathrm{~g}, 2.27 \mathrm{mmol}(76 \%)$.

Elemental analysis in \% found (calc.): C: 61.90 (61.96), H: 7.21 (7.28), N: 5.05 (4.82), S: 5.71 (5.51).

${ }^{1} \mathrm{H}-N M R\left(500 \mathrm{MHz}\right.$, thf-d 8 ): $\delta=10.59$ (ddd, ${ }^{3} \mathrm{~J}_{\mathrm{HH}}=8.98 \mathrm{~Hz},{ }^{4} \mathrm{~J}_{\mathrm{HH}}=1.19 \mathrm{~Hz},{ }^{5} \mathrm{JHH}_{\mathrm{HH}}=$ $\left.0.73 \mathrm{~Hz}, 1 \mathrm{H}, \mathrm{H}_{5}\right), 9.44\left(\mathrm{ddd},{ }^{3} \mathrm{~J}_{\mathrm{HH}}=8.68 \mathrm{~Hz},{ }^{4} \mathrm{JHH}_{\mathrm{HH}}=1.44 \mathrm{~Hz},{ }^{5} \mathrm{~J}_{\mathrm{HH}}=0.70 \mathrm{~Hz}, 1 \mathrm{H}, \mathrm{H}_{4}\right.$ ), $8.44\left(\mathrm{ddd},{ }^{3} \mathrm{~J}_{\mathrm{HH}}=8.66 \mathrm{~Hz},{ }^{4} \mathrm{~J}_{\mathrm{HH}}=1.60 \mathrm{~Hz},{ }^{5} \mathrm{~J}_{\mathrm{HH}}=0.73 \mathrm{~Hz}, 1 \mathrm{H}, \mathrm{H}_{8}\right), 8.42\left(\mathrm{ddd},{ }^{3} \mathrm{~J}_{\mathrm{HH}}=\right.$ $\left.9.21 \mathrm{~Hz},{ }^{4} \mathrm{~J}_{\mathrm{HH}}=1.42 \mathrm{~Hz},{ }^{5} \mathrm{~J}_{\mathrm{HH}}=0.77 \mathrm{~Hz}, 1 \mathrm{H}, \mathrm{H}_{1}\right), 7.52-7.44\left(\mathrm{~m}, 3 \mathrm{H}, \mathrm{H}_{7}, \mathrm{H}_{3}, \mathrm{H}_{2}\right)$, $7.26\left(\mathrm{ddd},{ }^{3} \mathrm{~J}_{\mathrm{HH}}=8.96 \mathrm{~Hz},{ }^{3} \mathrm{~J}_{\mathrm{HH}}=6.44 \mathrm{~Hz},{ }^{4} \mathrm{~J}_{\mathrm{HH}}=1.26 \mathrm{~Hz}, 1 \mathrm{H}, \mathrm{H}_{6}\right), 3.62(\mathrm{~m}, 8 \mathrm{H}$, $\left.\mathrm{OCH}_{2} \mathrm{CH}_{2}\right), 1.77\left(\mathrm{~m}, 8 \mathrm{H}, \mathrm{OCH}_{2} \mathrm{CH}_{2}\right), 0.95\left(\mathrm{~s}, 18 \mathrm{H}, \mathrm{C}\left(\mathrm{CH}_{3}\right)_{3}\right)$.

${ }^{13} \mathrm{C}\left\{{ }^{1} \mathrm{H}\right\}-N M R\left(125 \mathrm{MHz}\right.$, thf-d $\left.\mathbf{d}_{8}\right): \delta=155.9\left(\mathrm{C}_{10}\right), 132.0-130.7\left(\mathrm{C}_{10 \mathrm{a}}, \mathrm{C}_{4 \mathrm{a}}, \mathrm{C}_{9 \mathrm{a}}, \mathrm{C}_{8 \mathrm{a}}\right)$, $128.8\left(\mathrm{C}_{8}\right), 128.2\left(\mathrm{C}_{5}\right), 128.1\left(\mathrm{C}_{4}\right), 127.6$ - $125.6\left(\mathrm{C}_{7}, \mathrm{C}_{3}, \mathrm{C}_{2}\right), 125.2\left(\mathrm{C}_{1}\right), 123.5\left(\mathrm{C}_{9}\right)$, $123.3\left(\mathrm{C}_{6}\right), 67.4\left(\mathrm{OCH}_{2} \mathrm{CH}_{2}\right), 52.9\left(\mathrm{C}\left(\mathrm{CH}_{3}\right)_{3}\right), 33.8\left(\mathrm{C}\left(\mathrm{CH}_{3}\right)_{3}\right), 25.3\left(\mathrm{OCH}_{2} \mathrm{CH}_{2}\right)$.

El-MS: m/z (\%): $303(32)\left[\mathrm{M}-\mathrm{N}^{t} \mathrm{Bu}-{ }^{t} \mathrm{Bu}+\mathrm{H}\right]^{+}, 288(20)\left[\mathrm{M}-2 \mathrm{~N}^{t} \mathrm{Bu}\right]^{+}, 256(100)[\mathrm{M}-$ $\left.\mathrm{S}\left(\mathrm{N}^{t} \mathrm{Bu}\right)_{2}\right]^{+}, 177(58)$ [anthracene] $^{+}, 118(35)\left[\mathrm{M}-\right.$ anthracene $-\mathrm{Br}-{ }^{t} \mathrm{Bu}+2 \mathrm{H}^{+}, 103$ (32) $\left[\mathrm{M} \text { - anthracene }-\mathrm{Br}-\mathrm{N}^{t} \mathrm{Bu}+\mathrm{H}\right]^{+}, 57(100)\left[{ }^{t} \mathrm{Bu}\right]$.

$\left[\left(\mathrm{Et}_{2} \mathrm{O}\right)_{2} \mathrm{Li}\left(\mathrm{NSiMe}_{3}\right)_{2} \mathrm{SAnBr}\right](9)$ :

Empirical Formula: $\mathrm{C}_{28} \mathrm{H}_{46} \mathrm{BrLiN}_{2} \mathrm{O}_{2} \mathrm{SSi}_{2}$ Molecular weight: $617.76 \mathrm{~g} \mathrm{~mol}^{-1}$

Yield (\%): $1.35 \mathrm{~g}, 2.18 \mathrm{mmol}(73 \%)$. 
${ }^{1} \mathrm{H}-N M R\left(200 \mathrm{MHz}\right.$, thf-d $\left.\mathrm{d}_{8}\right): \delta=9.83\left(\mathrm{br}, 2 \mathrm{H}, \mathrm{H}_{4}, \mathrm{H}_{5}\right), 8.57\left(\mathrm{~d},{ }^{3} \mathrm{~J}_{\mathrm{HH}}=9.00 \mathrm{~Hz}, 2 \mathrm{H}, \mathrm{H}_{1}\right.$, $\left.\mathrm{H}_{8}\right), 7.20$ - $7.32\left(\mathrm{~m}, 4 \mathrm{H}, \mathrm{H}_{6}, \mathrm{H}_{7}, \mathrm{H}_{3}, \mathrm{H}_{2}\right), 3.62\left(\mathrm{~m}, 8 \mathrm{H}, \mathrm{OCH}_{2} \mathrm{CH}_{2}\right), 1.77(\mathrm{~m}, 8 \mathrm{H}$, $\left.\mathrm{OCH}_{2} \mathrm{CH}_{2}\right), 0.20\left(\mathrm{~s}, 18 \mathrm{H}, \mathrm{Si}\left(\mathrm{CH}_{3}\right)_{3}\right)$.

\subsection{7 $\left[\left(\mathrm{Et}_{2} \mathrm{O}\right)(\mathrm{LiBr}) \mathrm{Li}\left(\mathrm{N}^{\mathrm{t} B u}\right)_{2} \mathrm{SAnBr}_{2}(8)\right.$}

${ }^{n}$ BuLi $(1.37 \mathrm{~mL}, 2.22 \mathrm{M}, 3.04 \mathrm{mmol})$ was added dropwise to a suspension of 9,10-dibromoanthracene $(1.00 \mathrm{~g}, 2.98 \mathrm{mmol})$ in $25 \mathrm{~mL} \mathrm{Et}{ }_{2} \mathrm{O}$ at $-15^{\circ} \mathrm{C}$. The reaction mixture was allowed to warm up to room temperature and was stirred for $4 \mathrm{~h}$ before addition of $\mathrm{S}\left(\mathrm{N}^{t} \mathrm{Bu}\right)_{2}(1.04 \mathrm{~g}, 2.98 \mathrm{mmol})$. The suspension was stirred for $30 \mathrm{~min}$ and insoluble particles were removed by filtration. From this solution crystals were obtained after a few days storage at $4{ }^{\circ} \mathrm{C}$. For 8 the highest peaks in the mass spectrum and the peaks shown in the NMR spectrum were the same as for 7 . The elemental analysis for $\mathbf{8}$ gave no satisfying results.

Empirical Formula: $\mathrm{C}_{52} \mathrm{H}_{72} \mathrm{Br}_{4} \mathrm{Li}_{4} \mathrm{~N}_{4} \mathrm{O}_{2} \mathrm{~S}_{2} \quad$ Molecular weight: $1196.66 \mathrm{~g} \mathrm{~mol}^{-1}$

\subsection{8 $\left[\mathrm{Me}_{2} \mathrm{Al}\left(\mathrm{N}^{\mathrm{t} B u}\right)_{2} \mathrm{SAnBr}\right](10)$ and $\left[\mathrm{Zn}\left\{\left(\mathrm{N}^{\mathrm{t} B u}\right)_{2} \mathrm{SAnBr}\right\}_{2}\right](11)$}

AlMe $_{2} \mathrm{Cl}(0.3 \mathrm{~mL}, 3 \mathrm{mmol})$ or $\mathrm{ZnBr}_{2}(0.67 \mathrm{~g}$ in $5 \mathrm{~mL}$ THF, $3 \mathrm{mmol}$ ) was added dropwise to a solution of $7(2.27 \mathrm{~g}, 3 \mathrm{mmol})$ in $10 \mathrm{~mL}$ THF at $-78{ }^{\circ} \mathrm{C}$. The reaction mixture was allowed to warm up to room temperature and was stirred for $4 \mathrm{~h}$. Insoluble particles were removed by filtration and the solution was stored at $4{ }^{\circ} \mathrm{C}$. Orange crystals suitable for X-ray diffraction experiments were obtained after a few days of storage. The yield of $\mathbf{1 1}$ was to low to obtain any further analytical data.

Empirical Formula: $\mathrm{C}_{24} \mathrm{H}_{32} \mathrm{AlBrN}_{2} \mathrm{~S}$ $\mathrm{C}_{60} \mathrm{H}_{84} \mathrm{Br}_{2} \mathrm{~N}_{4} \mathrm{O}_{4} \mathrm{~S}_{2} \mathrm{Zn}$

Molecular weight: $487.47 \mathrm{~g} \mathrm{~mol}^{-1}$ $1214.62 \mathrm{~g} \mathrm{~mol}^{-1}$

$\left[\mathrm{Me}_{2} \mathrm{Al}\left(\mathrm{N}^{\mathrm{t} B u}\right)_{2} \mathrm{SAnBr}\right](\mathbf{1 0})$ :

Yield (\%): $1.07 \mathrm{~g}, 2.19 \mathrm{mmol}(73 \%)$. 
Elemental analysis in \% found (calc.): C: 58.67 (59.14), H: 6.57 (6.57), N: 5.93 (5.75), S: 6.60 (6.57).

${ }^{1} \mathrm{H}-\mathrm{NMR}\left(\mathbf{5 0 0} \mathrm{MHz}\right.$, thf-d 8 ): $\delta=10.15$ (ddd, ${ }^{3} \mathrm{JHH}_{\mathrm{HH}}=8.92 \mathrm{~Hz},{ }^{4} \mathrm{JHH}=1.21 \mathrm{~Hz},{ }^{5} \mathrm{JHH}_{\mathrm{HH}}=$ $\left.0.80 \mathrm{~Hz}, 1 \mathrm{H}, \mathrm{H}_{5}\right), 9.23\left(\mathrm{ddd},{ }^{3} \mathrm{JHH}_{\mathrm{HH}}=9.03 \mathrm{~Hz},{ }^{4} \mathrm{JHH}_{\mathrm{HH}}=1.10 \mathrm{~Hz},{ }^{5} \mathrm{JHH}_{\mathrm{HH}}=0.73 \mathrm{~Hz}, 1 \mathrm{H}, \mathrm{H}_{4}\right)$, $8.65\left(\mathrm{ddd},{ }^{3} \mathrm{JHH}=8.89 \mathrm{~Hz},{ }^{4} \mathrm{JHH}_{\mathrm{HH}}=1.33 \mathrm{~Hz},{ }^{5} \mathrm{JHH}_{\mathrm{HH}}=0.69 \mathrm{~Hz}, 1 \mathrm{H}, \mathrm{H}_{8}\right), 8.64\left(\mathrm{ddd},{ }^{3} \mathrm{JHH}_{\mathrm{HH}}=\right.$ $\left.8.83 \mathrm{~Hz},{ }^{4} \mathrm{JHH}=1.34 \mathrm{~Hz},{ }^{5} \mathrm{JHH}=0.71 \mathrm{~Hz}, 1 \mathrm{H}, \mathrm{H}_{1}\right), 7.77-7.65\left(\mathrm{~m}, 4 \mathrm{H}, \mathrm{H}_{7}, \mathrm{H}_{6}, \mathrm{H}_{3}, \mathrm{H}_{2}\right)$, $1.01\left(\mathrm{~s}, 18 \mathrm{H}, \mathrm{C}\left(\mathrm{CH}_{3}\right)_{3}\right),-0.42\left(\mathrm{~s}, 3 \mathrm{H}, \mathrm{Al}\left(\mathrm{CH}_{3}\right)_{2}\right),-0.60\left(\mathrm{~s}, 3 \mathrm{H}, \mathrm{Al}\left(\mathrm{CH}_{3}\right)_{2}\right)$.

${ }^{13} \mathrm{C}\left\{{ }^{1} \mathrm{H}\right\}-N M R\left(125 \mathrm{MHz}\right.$, thf-d 8 ): $\delta=136.1\left(\mathrm{C}_{10}\right), 134.0\left(\mathrm{C}_{9}\right), 131.7-130.9\left(\mathrm{C}_{10 \mathrm{a}}, \mathrm{C}_{4 \mathrm{a}}\right.$, $\left.\mathrm{C}_{9 \mathrm{a}}, \mathrm{C}_{8 \mathrm{a}}\right), 129.9\left(\mathrm{C}_{8}\right), 129.3\left(\mathrm{C}_{1}\right), 129.5-127.7\left(\mathrm{C}_{7}, \mathrm{C}_{6}, \mathrm{C}_{3}, \mathrm{C}_{2}\right), 125.6\left(\mathrm{C}_{5}\right), 122.7$

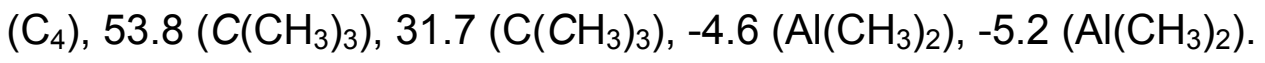

EI-MS: m/z (\%): 473 (100) [M - Me] $]^{+}, 402$ (42) [M - N $\left.{ }^{t} \mathrm{Bu}-\mathrm{Me}+\mathrm{H}\right]^{+}, 359$ (32) [M $\left.\mathrm{N}^{t} \mathrm{Bu}-\mathrm{AlMe}_{2}\right]^{+}, 345(31)\left[\mathrm{M}-\mathrm{N}^{t} \mathrm{Bu}-\mathrm{Me}-{ }^{t} \mathrm{Bu}+\mathrm{H}^{+}, 330(29)\left[\mathrm{M}-2 \mathrm{~N}^{t} \mathrm{Bu}-\mathrm{Me}\right]^{+}, 250\right.$ (27) $\left[\mathrm{M}-\mathrm{N}^{t} \mathrm{Bu}-\mathrm{Me}-{ }^{t} \mathrm{Bu}-\mathrm{Br}+\mathrm{H}\right]^{+}$.

\subsection{9 $\left[\left\{(\mathrm{THF})_{2} \mathrm{Li}\left(\mathrm{N}^{t} \mathrm{Bu}\right)_{2} \mathrm{~S}\right\}_{2} \mathrm{An}\right](12)$ and $\left[\left\{(\mathrm{THF})_{2} \mathrm{Li}\left(\mathrm{NSiMe}_{3}\right)_{2} \mathrm{~S}\right\}_{2} \mathrm{An}\right](13)$}

${ }^{n} \mathrm{BuLi}(2.74 \mathrm{~mL}, 2.22 \mathrm{M}, 6.08 \mathrm{mmol})$ was added dropwise to a suspension of 9,10-dibromoanthracene $(1.00 \mathrm{~g}, 2.98 \mathrm{mmol})$ in $25 \mathrm{~mL} \mathrm{Et} \mathrm{O}_{2} \mathrm{O}$ at $-15^{\circ} \mathrm{C}$. The reaction mixture was stirred for $30 \mathrm{~min}$ and the dilithiated anthracene was isolated by filtration. Yield: $0.78 \mathrm{~g}, 2.3 \mathrm{mmol}(77 \%)$.

$\mathrm{S}\left(\mathrm{N}^{t} \mathrm{Bu}\right)_{2}(0.80 \mathrm{~g}, 4.6 \mathrm{mmol})$ or $\mathrm{S}\left(\mathrm{NSiMe}_{3}\right)_{2}(0.86 \mathrm{~g}, 4.6 \mathrm{mmol})$ was added dropwise to a solution of the dilithiated anthracene $(0.78 \mathrm{~g}, 2.3 \mathrm{mmol})$ in $10 \mathrm{~mL}$ THF at $-78{ }^{\circ} \mathrm{C}$. The reaction mixture was allowed to warm up to room temperature and stirred for $4 \mathrm{~h}$. Insoluble particles were removed by filtration. Crystals were obtained from the saturated solution upon a few days storage at $4{ }^{\circ} \mathrm{C}$.

$\left[\left\{(\mathrm{THF})_{2} \mathrm{Li}\left(\mathrm{N}^{t} \mathrm{Bu}\right)_{2} \mathrm{~S}\right\}_{2} \mathrm{An}\right](\mathbf{1 2}):$

Empirical Formula: $\mathrm{C}_{54} \mathrm{H}_{92} \mathrm{Li}_{2} \mathrm{~N}_{4} \mathrm{O}_{6} \mathrm{~S}_{2}$ Molecular weight: $971.32 \mathrm{~g} \mathrm{~mol}^{-1}$

Yield (\%): $1.65 \mathrm{~g}, 2.21 \mathrm{mmol}(74 \%)$.

Elemental analysis in \% found (calc.): C: 65.82 (66.78), H: 8.88 (9.42), N: 7.86 (6.23), S: 9.13 (7.13). 
${ }^{1} \mathrm{H}-\mathrm{NMR}(\mathbf{5 0 0} \mathrm{MHz}$, thf-d $\mathbf{8}): \delta=10.24\left(\mathrm{br}, 2 \mathrm{H}, \mathrm{H}_{1}, \mathrm{H}_{5}\right), 8.91\left(\mathrm{br}, 2 \mathrm{H}, \mathrm{H}_{8}, \mathrm{H}_{4}\right), 7.61$ (br, $\left.4 \mathrm{H}, \mathrm{H}_{6}, \mathrm{H}_{2}, \mathrm{H}_{3}, \mathrm{H}_{7}\right), 3.62\left(\mathrm{~m}, 16 \mathrm{H}, \mathrm{OCH}_{2} \mathrm{CH}_{2}\right), 1.77\left(\mathrm{~m}, 16 \mathrm{H}, \mathrm{OCH}_{2} \mathrm{CH}_{2}\right), 1.29$ (s, $\left.18 \mathrm{H}, \mathrm{C}\left(\mathrm{CH}_{3}\right)_{3}\right), 1.14\left(\mathrm{~s}, 18 \mathrm{H}, \mathrm{C}\left(\mathrm{CH}_{3}\right)_{3}\right)$.

${ }^{13} \mathrm{C}\left\{{ }^{1} \mathrm{H}\right\}-N M R\left(125 \mathrm{MHz}\right.$, thf-d $\left.\mathrm{d}_{8}\right): \delta=142.6\left(\mathrm{C}_{10}, \mathrm{C}_{9}\right), 129.1\left(\mathrm{br}, \mathrm{C}_{1}, \mathrm{C}_{5}\right), 128.7-128.2$ $\left(\mathrm{m}, \mathrm{C}_{10 \mathrm{a}}, \mathrm{C}_{4 \mathrm{a}}, \mathrm{C}_{9 \mathrm{a}}, \mathrm{C}_{8 \mathrm{a}}\right), 127.7-126.4\left(\mathrm{~m}, \mathrm{C}_{6}, \mathrm{C}_{2}, \mathrm{C}_{3}, \mathrm{C}_{7}\right), 124.7\left(\mathrm{C}_{4}, \mathrm{C}_{8}\right), 56.7$

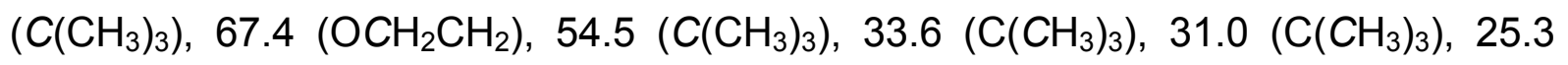
$\left(\mathrm{OCH}_{2} \mathrm{CH}_{2}\right)$.

EI-MS: m/z (\%): $312(22)\left[M-3 N^{t} B u+H^{+}, 256(28)\left[M-3 N^{t} B u-{ }^{t} B u+2 \mathrm{H}^{+}, 118\right.\right.$ (25) $\left[\mathrm{SN}^{t} \mathrm{BuNH}\right]^{+}, 103(28)\left[\mathrm{SN}^{t} \mathrm{Bu}\right]^{+}, 57(100)\left[{ }^{t} \mathrm{Bu}\right]^{+}, 41(44)\left[\mathrm{CH}_{2} \mathrm{CCH}_{3}\right]^{+}$.

$\left[\left\{(\mathrm{THF})_{2} \mathrm{Li}\left(\mathrm{NSiMe}_{3}\right)_{2} \mathrm{~S}\right\}_{2} \mathrm{An}\right](\mathbf{1 3}):$

Empirical Formula: $\mathrm{C}_{42} \mathrm{H}_{76} \mathrm{Li}_{2} \mathrm{~N}_{4} \mathrm{O}_{4} \mathrm{~S}_{2} \mathrm{Si}_{4}$ Molecular weight: $891.43 \mathrm{~g} \mathrm{~mol}^{-1}$

Yield (\%): $1.47 \mathrm{~g}, 2.15 \mathrm{mmol}$ (72 \%).

Elemental analysis in \% found (calc.): C: 56.36 (56.59), H: 9.10 (8.59), N: 6.35 (6.29), S: 7.44 (7.19).

${ }^{1} \mathrm{H}-N M R\left(500 \mathrm{MHz}\right.$, thf-d 8 ): $\delta=10.29\left(\mathrm{~d},{ }^{3} \mathrm{JHH}=8.00 \mathrm{~Hz}, 2 \mathrm{H}, \mathrm{H}_{1}, \mathrm{H}_{5}\right), 9.29\left(\mathrm{~d},{ }^{3} \mathrm{JHH}_{\mathrm{HH}}=\right.$ $\left.9.40 \mathrm{~Hz}, 2 \mathrm{H}, \mathrm{H}_{8}, \mathrm{H}_{4}\right), 7.44$ - $7.28\left(\mathrm{~m}, 2 \mathrm{H}, \mathrm{H}_{6}, \mathrm{H}_{2}\right), 7.29$ - $7.23\left(\mathrm{~m}, 2 \mathrm{H}, \mathrm{H}_{3}, \mathrm{H}_{7}\right), 3.62$ $\left(\mathrm{m}, 16 \mathrm{H}, \mathrm{OCH}_{2} \mathrm{CH}_{2}\right), 1.77\left(\mathrm{~m}, 16 \mathrm{H}, \mathrm{OCH}_{2} \mathrm{CH}_{2}\right),-0.40\left(\mathrm{~s}, 36 \mathrm{H}, \mathrm{Si}\left(\mathrm{CH}_{3}\right)_{3}\right)$.

${ }^{13} \mathrm{C}\left\{{ }^{1} \mathrm{H}\right\}$-NMR (125 MHz, thf-d $\left.\mathrm{d}_{8}\right): \delta=151.4\left(\mathrm{C}_{10}, \mathrm{C}_{9}\right), 130.9-129.4\left(\mathrm{~m}, \mathrm{C}_{10 \mathrm{a}}, \mathrm{C}_{4 \mathrm{a}}, \mathrm{C}_{9 \mathrm{a}}\right.$, $\left.\mathrm{C}_{8 \mathrm{a}}\right), 127.1\left(\mathrm{C}_{1}, \mathrm{C}_{5}\right), 125.2\left(\mathrm{C}_{6}, \mathrm{C}_{2}\right), 124.2\left(\mathrm{C}_{4}, \mathrm{C}_{8}\right), 123.2\left(\mathrm{C}_{3}, \mathrm{C}_{7}\right), 67.4\left(\mathrm{OCH}_{2} \mathrm{CH}_{2}\right)$, $25.3\left(\mathrm{OCH}_{2} \mathrm{CH}_{2}\right), 2.5\left(\mathrm{Si}\left(\mathrm{CH}_{3}\right)_{3}\right)$.

El-MS: m/z (\%): 264 (64) [M - 4 Me], 191 (100) [M - S(NSiMe $)_{2}$ ], 207 (20) [S(NSiMe $)_{2}+\mathrm{H}$ ], 178 (24) [anthracene], 73 (65) [SiMe 3 ].

\subsubsection{0 $\left[\left\{\mathrm{Me}_{2} \mathrm{Al}\left(\mathrm{NSiMe}_{3}\right)_{2} \mathrm{~S}\right\}_{2} \mathrm{An}\right](14)$}

$\mathrm{AlMe}_{2} \mathrm{Cl}(0.3 \mathrm{~mL}, 3 \mathrm{mmol})$ is added dropwise to a solution of $13(2.67 \mathrm{~g}, 3 \mathrm{mmol})$ in $10 \mathrm{~mL}$ THF. at $-78^{\circ} \mathrm{C}$. The reaction mixture is allowed to warm up to room temperature and stirred for $4 \mathrm{~h}$. Insoluble particles are removed by filtration and the solution is stored at $4{ }^{\circ} \mathrm{C}$. Crystals suitable for X-ray diffraction experiments are obtained after a few days of storage. 
Yield (\%): $0.84 \mathrm{~g}, 1.20 \mathrm{mmol}$ (40 \%).

Elemental analysis in \% found (calc.): C: 49.82 (51.24), H: 7.92 (8.03), N: 7.73 (7.97), S: 8.73 (9.12).

${ }^{1} \mathrm{H}$-NMR (500 MHz, thf-d 8 ): $\delta=10.21\left(\mathrm{br}, 2 \mathrm{H}, \mathrm{H}_{1}, \mathrm{H}_{5}\right), 9.29\left(\mathrm{br}, 2 \mathrm{H}, \mathrm{H}_{8}, \mathrm{H}_{4}\right), 7.85$ $7.72\left(\mathrm{~m}, 4 \mathrm{H}, \mathrm{H}_{6}, \mathrm{H}_{2}, \mathrm{H}_{3}, \mathrm{H}_{7}\right),-0.20\left(\mathrm{~s}, 36 \mathrm{H}, \mathrm{Si}\left(\mathrm{CH}_{3}\right)_{3}\right),-0.46\left(\mathrm{br}, 12 \mathrm{H}, \mathrm{Al}\left(\mathrm{CH}_{3}\right)_{2}\right)$.

${ }^{13} \mathrm{C}\left\{{ }^{1} \mathrm{H}\right\}$-NMR (125 MHz, thf-d $\left.\mathbf{d}_{8}\right): \delta=149.2\left(\mathrm{C}_{10}, \mathrm{C}_{9}\right), 129.4-128.8\left(\mathrm{C}_{10 \mathrm{a}}, \mathrm{C}_{4 \mathrm{a}}, \mathrm{C}_{9 \mathrm{a}}\right.$, $\left.\mathrm{C}_{8 \mathrm{a}}\right), 127.9\left(\mathrm{C}_{2}, \mathrm{C}_{3}, \mathrm{C}_{6}, \mathrm{C}_{7}\right), 125.8\left(\mathrm{C}_{1}, \mathrm{C}_{5}\right), 125.2\left(\mathrm{C}_{4}, \mathrm{C}_{8}\right), 2.5\left(\mathrm{Si}\left(\mathrm{CH}_{3}\right)_{3}\right),-4.9$ $\left(\mathrm{Al}\left(\mathrm{CH}_{3}\right)_{2}\right)$.

El-MS: m/z (\%): 687 (100) [M - Me], 573 (64) [M - $\left.\mathrm{SiMe}_{3}-\mathrm{AlMe}_{2}+\mathrm{H}\right]^{+}, 481$ (52) $[\text { S-anthracene-S }]^{2+}, 413(53)\left[\mathrm{M}-4 \mathrm{SiMe}_{3}-+3 \mathrm{H}\right]^{+}, 73(40)\left[\mathrm{SiMe}_{3}\right]^{+}$.

\subsubsection{1 $\left[\left(\mathrm{Et}_{2} \mathrm{O}\right)_{0.5} \mathrm{Li}\left\{\left(\mathrm{N}^{t} \mathrm{Bu}\right)\left(\mathrm{SiMe}_{3}\right) \mathrm{SEt}\right]_{2}(15)\right.$}

A $0.5 \mathrm{M}$ solution of EtLi $(10 \mathrm{~mL}, 5 \mathrm{mmol})$ in THF was added dropwise to a solution of $\mathrm{S}\left(\mathrm{N}^{t} \mathrm{Bu}\right)_{2}(0.87 \mathrm{~g}, 5 \mathrm{mmol})$ in $20 \mathrm{~mL} n$-hexane at $-78^{\circ} \mathrm{C}$ over a period of 15 minutes. After stirring over night two third of the solvents were removed under reduced pressure and the yellow coloured reaction mixture was kept at $4{ }^{\circ} \mathrm{C}$ for two weeks, which afforded pale-yellow crystals suitable for X-ray analysis.

Empirical Formula: $\mathrm{C}_{22} \mathrm{H}_{56} \mathrm{Li}_{2} \mathrm{~N}_{4} \mathrm{OS}_{2} \mathrm{Si}_{2}$ Molecular weight: $526.89 \mathrm{~g} \mathrm{~mol}^{-1}$

Yield (\%): $1.32 \mathrm{~g}, 2.50 \mathrm{mmol}$ (50\%).

${ }^{1} \mathrm{H}$-NMR (500 MHz, $\left.\mathrm{C}_{6} \mathrm{D}_{6}\right): \delta=7.16\left(\mathrm{~s}, \mathrm{C}_{6} \mathrm{D}_{6}\right), 2.62\left(\mathrm{br}, 2 \mathrm{H}, \mathrm{SCH}_{2} \mathrm{CH}_{3}\right), 3.62(\mathrm{~m}$, $\left.16 \mathrm{H}, \mathrm{OCH}_{2} \mathrm{CH}_{2}\right), 1.77\left(\mathrm{~m}, 16 \mathrm{H}, \mathrm{OCH}_{2} \mathrm{CH}_{2}\right), 1.32\left(\mathrm{~s}, 9 \mathrm{H}, \mathrm{C}\left(\mathrm{CH}_{3}\right)_{3}\right), 1.05(\mathrm{br}, 3 \mathrm{H}$, $\left.\mathrm{SCH}_{2} \mathrm{CH}_{3}\right), 0.27\left(\mathrm{~s}, 9 \mathrm{H}, \mathrm{Si}\left(\mathrm{CH}_{3}\right)_{3}\right)$. 


\subsubsection{2 $\left[(\mathrm{THF})_{0.5} \mathrm{Li}\left\{\left(\mathrm{N}^{t} \mathrm{Bu}\right)_{2} \mathrm{SBz}\right]_{2}(16)\right.$}

A $0.19 \mathrm{M}$ solution of BzLi $(8.47 \mathrm{~mL}, 1.61 \mathrm{mmol})$ in THF was added dropwise to a solution of $\mathrm{S}\left(\mathrm{N}^{t} \mathrm{Bu}\right)_{2}(0.262 \mathrm{~g}, 1.50 \mathrm{mmol})$ in $20 \mathrm{~mL} n$-hexane at $-78{ }^{\circ} \mathrm{C}$ over a period of 30 minutes. After an additional stirring of one hour at $-78^{\circ} \mathrm{C}$, the orange coloured reaction mixture was stirred overnight at the room temperature. Subsequently, two third of the solvents were removed under reduced pressure and the contents were kept at $-30{ }^{\circ} \mathrm{C}$ for two months, which afforded pale-yellow crystals suitable for X-ray analysis.

Empirical Formula: $\mathrm{C}_{50} \mathrm{H}_{90} \mathrm{Li}_{2} \mathrm{~N}_{4} \mathrm{O}_{5} \mathrm{~S}_{2} \quad$ Molecular weight: $905.26 \mathrm{~g} \mathrm{~mol}^{-1}$

Yield (\%): $0.75 \mathrm{~g}, 0.99 \mathrm{mmol}(66 \%)$

Elemental analysis in \% found (calc.): C: 62.4 (66.3); H: 8.8 (9.8); N: 8.4 (7.4); S: 10.5 (8.4).

${ }^{1} \mathrm{H}-\mathrm{NMR}\left(\mathbf{5 0 0} \mathrm{MHz}\right.$, thf-d 8 ): $\delta=7.30-7.15\left(\mathrm{~m}, 5 \mathrm{H}\right.$, phenyl), $3.91\left(\mathrm{~s}, 2 \mathrm{H}, \mathrm{PhCH}_{2} \mathrm{~S}\right.$ ), $3.62\left(\mathrm{~m}, 4 \mathrm{H}, \mathrm{OCH}_{2} \mathrm{CH}_{2}\right), 1.77\left(\mathrm{~m}, 4 \mathrm{H}, \mathrm{OCH}_{2} \mathrm{CH}_{2}\right), 1.10\left(\mathrm{~s}, 18 \mathrm{H}, \mathrm{C}\left(\mathrm{CH}_{3}\right)\right)$.

${ }^{13} \mathrm{C}\left\{{ }^{1} \mathrm{H}\right\}$-NMR (125 MHz, thf-d $\mathbf{d}_{\mathbf{8}}$ ): $\delta=134.8$ (ipso), 131.6 (para), 128.6 (meta), 127.9 (ortho), $67.4\left(\mathrm{OCH}_{2} \mathrm{CH}_{2}\right), 66.0\left(\mathrm{PhCH}_{2} \mathrm{~S}\right), 54.1\left(\mathrm{C}_{\left.\left(\mathrm{CH}_{3}\right)_{3}\right),} 32.5\left(\mathrm{C}_{\left.\left(\mathrm{CH}_{3}\right)_{3}\right),}, 25.2\right.\right.$ $\left(\mathrm{OCH}_{2} \mathrm{CH}_{2}\right)$.

EI-MS: m/z (\%): 195 (11) $\left[\mathrm{PhCH}_{2} \mathrm{~S}\left(\mathrm{~N}^{t} \mathrm{Bu}\right)\right]^{+}, 175(54)\left[\mathrm{S}\left(\mathrm{N}^{t} \mathrm{Bu}\right)_{2}+\mathrm{H}\right]^{+}, 119$ (42) $\left[\mathrm{NS}\left(\mathrm{N}^{t} \mathrm{Bu}\right)+2 \mathrm{H}\right]^{+}, 91(100)\left[\mathrm{PhCH}_{2}\right]^{+}, 57(44)\left[{ }^{t} \mathrm{Bu}\right]^{+}$.

\subsubsection{3 [(THF) $)_{2} \mathrm{MgBr}\left\{\left(\mathrm{N}^{t} \mathrm{Bu}\right)_{2} \mathrm{SMe}\right](17),\left[(\mathrm{THF})_{2} \mathrm{MgCl}\left\{\left(\mathrm{N}^{t} \mathrm{Bu}\right)_{2} \mathrm{~S}^{n} \mathrm{Bu}\right](18)\right.$ and $\left[(\mathrm{THF})_{2} \mathrm{MgCl}\left\{\left(\mathrm{N}^{t} \mathrm{Bu}\right)\left(\mathrm{NSiMe}_{3}\right) \mathrm{SBz}\right](19)\right.$}

$5.0 \mathrm{mmol} \mathrm{S}\left(\mathrm{N}^{t} \mathrm{Bu}\right)_{2}$ [for the synthesis of $19 \mathrm{~S}\left(\mathrm{NSiMe}_{3}\right)\left(\mathrm{N}^{t} \mathrm{Bu}\right)$ was used instead] were dissolved in $20 \mathrm{~mL}$ THF. $5.0 \mathrm{mmol} \mathrm{RMgX}$ in THF $\left(\mathrm{X}=\mathrm{Cl}\right.$ or $\mathrm{Br} ; \mathrm{R}=\mathrm{Me},{ }^{n} \mathrm{Bu}$ or Benzyl) were added to this solution at $-78^{\circ} \mathrm{C}$ over a period of $15 \mathrm{~min}$. The mixtures were allowed to warm up to room temperature and stirred overnight. The solvent was removed in vacuo, the residual solids were re-dissolved in a $n$-hexane/THF mixture and insoluble particles were filtered off. The resulting solutions were stored at $-24{ }^{\circ} \mathrm{C}$ and yielded colorless crystals suitable for X-ray structure analyses after 1-3 $d$.

$\left[(\mathrm{THF})_{2} \mathrm{MgBr}\left\{\left(\mathrm{N}^{t} \mathrm{Bu}\right)_{2} \mathrm{SMe}\right](\mathbf{1 7}):\right.$ 
Empirical Formula: $\mathrm{C}_{17} \mathrm{H}_{37} \mathrm{SN}_{2} \mathrm{MgBrO}_{2}$ Molecular weight: $437.77 \mathrm{~g} \mathrm{~mol}^{-1}$

Yield (\%): $1.86 \mathrm{~g}, 4.25 \mathrm{mmol}(85 \%)$.

Elemental analysis in \% found (calc.): C: 45.4 (46.68), H: 8.24 (8.47), N: 6.86 (6.41), S: 7.55 (7.32).

MS (70 eV): m/z (\%): 175 (25) [M $-\mathrm{MgBr}-\mathrm{Me}+\mathrm{H}^{+}, 119(52)\left[\mathrm{M}-\mathrm{MgBr}-\mathrm{N}^{t} \mathrm{Bu}+\right.$ $\mathrm{H}]^{+}, 63(76)\left[\mathrm{M}-\mathrm{MgBr}-\mathrm{N}^{t} \mathrm{Bu}-{ }^{t} \mathrm{Bu}+2 \mathrm{H}\right]^{+}, 57(100)\left[{ }^{t} \mathrm{Bu}\right]^{+}, 41(55)\left[\mathrm{CH}_{2} \mathrm{CCH}_{3}\right]^{+}$.

\section{Major compound:}

${ }^{1} \mathrm{H}-\mathrm{NMR}\left(\mathbf{5 0 0 . 1 3 2} \mathrm{MHz}, \mathbf{d}_{\mathbf{8}}\right.$-THF): $\delta=3.62\left(\mathrm{~m}, 8 \mathrm{H}, \mathrm{OCH}_{2} \mathrm{CH}_{2}\right), 2.18\left(\mathrm{~s}, 3 \mathrm{H}, \mathrm{SCH}_{3}\right)$, $1.77\left(\mathrm{~m}, 8 \mathrm{H}, \mathrm{OCH}_{2} \mathrm{CH}_{2}\right), 1.17\left(\mathrm{~s}, 18 \mathrm{H}, \mathrm{C}\left(\mathrm{CH}_{3}\right)_{3}\right)$.

${ }^{13} \mathrm{C}$-NMR (125.772 MHz, d $\mathbf{d}_{8}$-THF): $\delta=67.4\left(\mathrm{OCH}_{2} \mathrm{CH}_{2}\right), 52.7\left(\mathrm{C}\left(\mathrm{CH}_{3}\right)_{3}\right), 52.0\left(\mathrm{SCH}_{3}\right)$, $32.8\left(\mathrm{C}\left(\mathrm{CH}_{3}\right)_{3}\right), 25.3\left(\mathrm{OCH}_{2} \mathrm{CH}_{2}\right)$.

${ }^{15} \mathrm{~N}-\mathrm{NMR}$ (40.548 MHz, $\mathrm{d}_{8}$-THF): -270.0 $\left(\mathrm{NC}\left(\mathrm{CH}_{3}\right)_{3}\right)$.

Minor compound:

${ }^{1} \mathrm{H}-\mathrm{NMR}\left(\mathbf{5 0 0 . 1 3 2} \mathrm{MHz}, \mathbf{d}_{\mathbf{8}}\right.$-THF): $\delta=3.62\left(\mathrm{~m}, 8 \mathrm{H}, \mathrm{OCH}_{2} \mathrm{CH}_{2}\right), 2.26\left(\mathrm{~s}, 3 \mathrm{H}, \mathrm{SCH}_{3}\right)$, $1.77\left(\mathrm{~m}, 8 \mathrm{H}, \mathrm{OCH}_{2} \mathrm{CH}_{2}\right), 1.22\left(\mathrm{~s}, 18 \mathrm{H}, \mathrm{C}\left(\mathrm{CH}_{3}\right)_{3}\right)$.

${ }^{13} \mathrm{C}-\mathrm{NMR}\left(125.772 \mathrm{MHz}, \mathrm{d}_{8}\right.$-THF): $\delta=67.4\left(\mathrm{OCH}_{2} \mathrm{CH}_{2}\right), 53.4\left(\mathrm{C}\left(\mathrm{CH}_{3}\right)_{3}\right), 53.2\left(\mathrm{SCH}_{3}\right)$, $33.6\left(\mathrm{C}\left(\mathrm{CH}_{3}\right)_{3}\right), 25.3\left(\mathrm{OCH}_{2} \mathrm{CH}_{2}\right)$.

${ }^{15} \mathrm{~N}-\mathrm{NMR}$ (40.548 MHz, $\mathrm{d}_{8}$-THF): -271.8 $\left(\mathrm{NC}\left(\mathrm{CH}_{3}\right)_{3}\right)$.

$\left[(\mathrm{THF})_{2} \mathrm{MgCl}\left\{\left(\mathrm{N}^{t} \mathrm{Bu}\right)_{2} \mathrm{~S}^{n} \mathrm{Bu}\right](\mathbf{1 8}):\right.$

Empirical Formula: $\mathrm{C}_{20} \mathrm{H}_{43} \mathrm{ClMgN}_{2} \mathrm{O}_{2} \mathrm{~S}$ Molecular weight: $435.38 \mathrm{~g} \mathrm{~mol}^{-1}$

Yield (\%): $1.65 \mathrm{~g}, 3.80 \mathrm{mmol}(76 \%)$.

Elemental analysis in \% found (calc.): C: 54.32 (55.24), H: 10.0 (9.9), N: 6.84 (6.44), S: 7.79 (7.36).

MS (70 eV): m/z (\%): $232(10)\left[\mathrm{M}-\mathrm{MgCl}+\mathrm{H}^{+}, 175(30)\left[\mathrm{M}-\mathrm{MgCl}-{ }^{n} \mathrm{Bu}+\mathrm{H}\right]^{+}, 161\right.$ (15) $\left[\mathrm{M}-\mathrm{MgCl}-\mathrm{N}^{t} \mathrm{Bu}+\mathrm{H}^{+}, 119\right.$ (38) $\left[\mathrm{M}-\mathrm{MgCl}-\mathrm{N}^{t} \mathrm{Bu}-{ }^{n} \mathrm{Bu}+2 \mathrm{H}\right]^{+}, 72$ (65) $\left[\mathrm{HN}^{t} \mathrm{Bu}\right]^{+}, 63(48)\left[\mathrm{M}-\mathrm{MgCl}-2{ }^{t} \mathrm{Bu}-{ }^{n} \mathrm{Bu}+3 \mathrm{H}\right]^{+}, 57(45)\left[{ }^{t} \mathrm{Bu}\right]^{+}, 41(100)\left[\mathrm{CH}_{2} \mathrm{CCH}_{3}\right]^{+}$. Major compound:

${ }^{1} \mathrm{H}$-NMR (500.132 MHz, $\mathbf{d}_{\mathbf{8}}$-THF): $\delta=3.62\left(\mathrm{~m}, 8 \mathrm{H}, \mathrm{OCH}_{2} \mathrm{CH}_{2}\right), 2.23(\operatorname{tr}, 2 \mathrm{H}$, $\left.\mathrm{SCH}_{2} \mathrm{CH}_{2} \mathrm{CH}_{2} \mathrm{CH}_{3}\right), 1.77\left(\mathrm{~m}, 8 \mathrm{H}, \mathrm{OCH}_{2} \mathrm{CH}_{2}\right), 1.62\left(\mathrm{~m}, 2 \mathrm{H}, \mathrm{SCH}_{2} \mathrm{CH}_{2} \mathrm{CH}_{2} \mathrm{CH}_{3}\right), 1.39$ 
$\left(\mathrm{m}, \quad 2 \mathrm{H}, \quad \mathrm{SCH}_{2} \mathrm{CH}_{2} \mathrm{CH}_{2} \mathrm{CH}_{3}\right), \quad 1.17\left(\mathrm{~s}, \quad 18 \mathrm{H}, \quad \mathrm{C}\left(\mathrm{CH}_{3}\right)_{3}\right), \quad 0.92 \quad(\mathrm{~m}, \quad 3 \mathrm{H}$, $\mathrm{SCH}_{2} \mathrm{CH}_{2} \mathrm{CH}_{2} \mathrm{CH}_{3}$ ).

${ }^{13}$ C-NMR (125.757 MHz, d d - THF): $\delta=67.43\left(\mathrm{OCH}_{2} \mathrm{CH}_{2}\right), 63.83\left(\mathrm{SCH}_{2} \mathrm{CH}_{2} \mathrm{CH}_{2} \mathrm{CH}_{3}\right)$, $53.51\left(\mathrm{C}\left(\mathrm{CH}_{3}\right)_{3}\right), 33.89\left(\mathrm{C}\left(\mathrm{CH}_{3}\right)_{3}\right), 25.30\left(\mathrm{OCH}_{2} \mathrm{CH}_{2}\right), 23.11\left(\mathrm{SCH}_{2} \mathrm{CH}_{2} \mathrm{CH}_{2} \mathrm{CH}_{3}\right)$, $22.58\left(\mathrm{SCH}_{2} \mathrm{CH}_{2} \mathrm{CH}_{2} \mathrm{CH}_{3}\right), 14.26\left(\mathrm{SCH}_{2} \mathrm{CH}_{2} \mathrm{CH}_{2} \mathrm{CH}_{3}\right)$.

\section{Minor compound:}

${ }^{1} \mathrm{H}-N M R\left(500.132 \mathrm{MHz}, \mathbf{d}_{8}\right.$-THF): $\delta=3.62\left(\mathrm{~m}, 8 \mathrm{H}, \mathrm{OCH}_{2} \mathrm{CH}_{2}\right), 2.36\left(\operatorname{tr}, 2 \mathrm{H}, \mathrm{SCH}_{2^{-}}\right.$ $\left.\mathrm{CH}_{2} \mathrm{CH}_{2} \mathrm{CH}_{3}\right), 1.77\left(\mathrm{~m}, 8 \mathrm{H}, \mathrm{OCH}_{2} \mathrm{CH}_{2}\right), 1.67\left(\mathrm{~m}, 2 \mathrm{H}, \mathrm{SCH}_{2} \mathrm{CH}_{2} \mathrm{CH}_{2} \mathrm{CH}_{3}\right), 1.39(\mathrm{~m}$, $\left.2 \mathrm{H}, \mathrm{SCH}_{2} \mathrm{CH}_{2} \mathrm{CH}_{2} \mathrm{CH}_{3}\right), 1.22\left(\mathrm{~s}, 18 \mathrm{H}, \mathrm{C}\left(\mathrm{CH}_{3}\right)_{3}\right), 0.92\left(\mathrm{~m}, 3 \mathrm{H}, \mathrm{SCH}_{2} \mathrm{CH}_{2} \mathrm{CH}_{2} \mathrm{CH}_{3}\right)$.

${ }^{13} \mathrm{C}$-NMR (125.757 MHz, d d -THF): $\delta=67.43\left(\mathrm{OCH}_{2} \mathrm{CH}_{2}\right), 61.30\left(\mathrm{SCH}_{2} \mathrm{CH}_{2} \mathrm{CH}_{2} \mathrm{CH}_{3}\right)$, $52.97\left(\mathrm{C}\left(\mathrm{CH}_{3}\right)_{3}\right), 33.26\left(\mathrm{C}\left(\mathrm{CH}_{3}\right)_{3}\right), 25.30\left(\mathrm{OCH}_{2} \mathrm{CH}_{2}\right), 23.26\left(\mathrm{SCH}_{2} \mathrm{CH}_{2} \mathrm{CH}_{2} \mathrm{CH}_{3}\right)$, $22.58\left(\mathrm{SCH}_{2} \mathrm{CH}_{2} \mathrm{CH}_{2} \mathrm{CH}_{3}\right), 14.29\left(\mathrm{SCH}_{2} \mathrm{CH}_{2} \mathrm{CH}_{2} \mathrm{CH}_{3}\right)$.

$\left[(\mathrm{THF})_{2} \mathrm{MgCl}\left\{\left(\mathrm{N}^{t} \mathrm{Bu}\right)\left(\mathrm{NSiMe}_{3}\right) \mathrm{SBz}\right](\mathbf{1 9}):\right.$

Empirical Formula: $\mathrm{C}_{22} \mathrm{H}_{41} \mathrm{ClMgN}_{2} \mathrm{O}_{2} \mathrm{SSi} \quad$ Molecular weight: $485.48 \mathrm{~g} \mathrm{~mol}^{-1}$

Yield (\%): $1.99 \mathrm{~g}, 4.10 \mathrm{mmol}(82 \%)$.

Elemental analysis in \% found (calc.): C: 53.84 (54.49), H: 8.41 (8.46), N: 5.65 (5.78).

MS (70 eV): m/z (\%): 191 (47) [M - MgCl $\left.-\mathrm{CH}_{2} \mathrm{Ph}\right]^{+}, 147$ (39) [M - MgCl - Ph $\left.{ }^{t} \mathrm{Bu}\right]^{+}, 135$ (93) $\left[\mathrm{M}-\mathrm{MgCl}-\mathrm{CH}_{2} \mathrm{Ph}-{ }^{t} \mathrm{Bu}+\mathrm{H}^{+}, 119\right.$ (15) $\left[\mathrm{M}-\mathrm{MgCl}-\mathrm{CH}_{2} \mathrm{Ph}-\right.$ $\left.\mathrm{Si}\left(\mathrm{CH}_{3}\right)_{3}+\mathrm{H}\right]^{+}, 91(100)\left[\mathrm{Ch}_{2} \mathrm{Ph}\right]^{+}, 73(31)\left[\mathrm{Si}\left(\mathrm{CH}_{3}\right)_{3}\right]^{+}, 57(19)\left[{ }^{t} \mathrm{Bu}\right]^{+}$.

Major compound :

${ }^{1} \mathrm{H}-N M R\left(500.134 \mathrm{MHz}, \mathbf{d}_{\mathbf{8}}\right.$-THF): $\delta=7.30-7.16\left(\mathrm{~m}, 5 \mathrm{H}, \mathrm{C}_{6} \mathrm{H}_{5}\right), 3.66\left(\mathrm{~d}, 1 \mathrm{H}, \mathrm{SCH}_{2}\right)$, $3.62\left(\mathrm{~m}, 8 \mathrm{H}, \mathrm{OCH}_{2} \mathrm{CH}_{2}\right), 3.27(\mathrm{~d}, 1 \mathrm{H}, \mathrm{SCH})_{2}, 1.77\left(\mathrm{~m}, 8 \mathrm{H}, \mathrm{OCH}_{2} \mathrm{CH}_{2}\right), 1.15(\mathrm{~s}, 9 \mathrm{H}$, $\left.\mathrm{C}\left(\mathrm{CH}_{3}\right)_{3}\right),-0.12\left(\mathrm{~s}, 9 \mathrm{H}, \mathrm{Si}\left(\mathrm{CH}_{3}\right)_{3}\right)$.

${ }^{13}$ C-NMR (125.757, d d -THF): $\delta=133.24$ (ipso), 130.87 (ortho), 128.16 (meta),

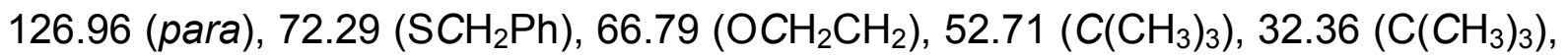
$24.66\left(\mathrm{OCH}_{2} \mathrm{CH}_{2}\right), 1.66\left(\mathrm{Si}\left(\mathrm{CH}_{3}\right)_{3}\right)$.

\section{Minor compound:}

${ }^{1} \mathrm{H}-N M R\left(500.132 \mathrm{MHz}, \mathbf{d}_{8}\right.$-THF): $\delta=7.30$ - $7.16\left(\mathrm{~m}, 5 \mathrm{H}, \mathrm{C}_{6} \mathrm{H}_{5}\right), 3.92\left(\mathrm{~d}, 1 \mathrm{H}, \mathrm{SCH}_{2}\right)$, $3.62\left(\mathrm{~m}, 8 \mathrm{H}, \mathrm{OCH}_{2} \mathrm{CH}_{2}\right), 3.53\left(\mathrm{~d}, 1 \mathrm{H}, \mathrm{SCH}_{2}\right), 1.77\left(\mathrm{~m}, 8 \mathrm{H}, \mathrm{OCH}_{2} \mathrm{CH}_{2}\right), 1.17(\mathrm{~s}, 9 \mathrm{H}$, $\left.\mathrm{C}\left(\mathrm{CH}_{3}\right)_{3}\right),-0.08\left(\mathrm{~s}, 9 \mathrm{H}, \mathrm{Si}\left(\mathrm{CH}_{3}\right)_{3}\right)$. 
${ }^{13}$ C-NMR (125.757 MHz, d d -THF): 133.47 (ipso), 130.56 (ortho), 128.48 (meta),

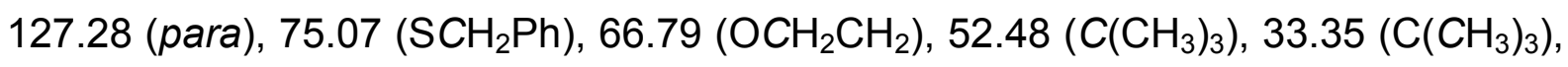
$24.66\left(\mathrm{OCH}_{2} \mathrm{CH}_{2}\right), 2.06\left(\mathrm{Si}\left(\mathrm{CH}_{3}\right)_{3}\right)$.

\subsubsection{4 [(THF)MgX(N $\left.\left.{ }^{t} B u\right)_{3} S R\right]_{2}$ (22: $R=$ methyl, $X=B r ; 23: R={ }^{n}$ butyl, $\mathrm{X}=\mathrm{Cl}$; 24: $\mathrm{R}=$ phenyl, $\mathrm{X}=\mathrm{Cl}$; 25: $\mathrm{R}=$ benzyl, $\mathrm{X}=\mathrm{Cl}$ ) and $\left[\left(\mathrm{Et}_{2} \mathrm{O}\right) \mathrm{MgBr}\left(\mathrm{N}^{t} \mathrm{Bu}\right)_{3} \mathrm{SMe}\right]_{2}(26)$}

$5.0 \mathrm{mmol} \mathrm{S}\left(\mathrm{N}^{t} \mathrm{Bu}\right)_{3}$ were dissolved in $20 \mathrm{~mL}$ THF ( $\mathrm{Et}_{2} \mathrm{O}$ in the case of 26). $5.0 \mathrm{mmol}$ $\mathrm{RMgX}$ in THF (or $\mathrm{Et}_{2} \mathrm{O}$ ) $\left(\mathrm{X}=\mathrm{Cl}\right.$ or $\mathrm{Br} ; \mathrm{R}=\mathrm{Ph}, \mathrm{Me},{ }^{n} \mathrm{Bu}$ or Benzyl) were added to this solution at $-78{ }^{\circ} \mathrm{C}$ over a period of $15 \mathrm{~min}$. The mixtures were allowed to warm up to room temperature and stirred overnight. The solvent was removed in vacuo, the residual solids were re-dissolved in a $n$-hexane/THF mixture and insoluble particles were filtered off. The resulting solutions were stored at $-24^{\circ} \mathrm{C}$ and yielded colorless crystals suitable for X-ray structure analyses after 1-3 d.

$\left[(\mathrm{THF}) \mathrm{MgBr}\left(\mathrm{N}^{t} \mathrm{Bu}\right)_{3} \mathrm{SMe}\right]_{2}(\mathbf{2 2})$ and $\left[\left(\mathrm{Et}_{2} \mathrm{O}\right) \mathrm{MgBr}\left(\mathrm{N}^{t} \mathrm{Bu}\right)_{3} \mathrm{SMe}\right]_{2}(\mathbf{2 6})$

Empirical Formula: $\mathrm{C}_{34} \mathrm{H}_{78} \mathrm{Br}_{2} \mathrm{Mg}_{2} \mathrm{~N}_{6} \mathrm{O}_{2} \mathrm{~S}_{2}$ $\mathrm{C}_{34} \mathrm{H}_{80} \mathrm{Br}_{2} \mathrm{Mg}_{2} \mathrm{~N}_{6} \mathrm{O}_{2} \mathrm{~S}_{2}$
Molecular weight: $875.60 \mathrm{~g} \mathrm{~mol}^{-1}$

$877.60 \mathrm{~g} \mathrm{~mol}^{-1}$

Yield (\%): $1.57 \mathrm{~g}, 3.60 \mathrm{mmol}(72 \%)$ and $1.42 \mathrm{~g}, 3.25 \mathrm{mmol}(65 \%)$.

Elemental analysis in \% found (calc.): C: 46.34 (46.70), H: 8.87 (8.69), N: 7.91 (9.61), S: 5.98 (7.32).

MS (70 eV): m/z (\%): $189(28)\left[\mathrm{M}-\mathrm{MgBr}-\mathrm{N}^{t} \mathrm{Bu}\right]^{+}, 133(24)\left[\mathrm{M}-\mathrm{MgBr}-\mathrm{N}^{t} \mathrm{Bu}-{ }^{t} \mathrm{Bu}\right.$ $+\mathrm{H}^{+}, 77(56)\left[\mathrm{M}-\mathrm{MgBr}-\mathrm{N}^{t} \mathrm{Bu}-2{ }^{t} \mathrm{Bu}+2 \mathrm{H}\right]^{+}, 57(28)\left[{ }^{t} \mathrm{Bu}\right]^{+}, 41(100)\left[\mathrm{CH}_{2} \mathrm{CCH}_{3}\right]^{+}$.

Major compound:

${ }^{1} \mathrm{H}$-NMR (500.132 MHz, $\mathbf{d}_{8}$-THF): $\delta=3.14\left(\mathrm{~s}, 3 \mathrm{H}, \mathrm{SCH}_{3}\right), 1.43\left(\mathrm{~s}, 9 \mathrm{H}, \mathrm{C}\left(\mathrm{CH}_{3}\right)_{3}\right)$, $1.38\left(\mathrm{~s}, 9 \mathrm{H}, \mathrm{C}\left(\mathrm{CH}_{3}\right)_{3}\right), 1.41\left(\mathrm{~s}, 9 \mathrm{H}, \mathrm{C}\left(\mathrm{CH}_{3}\right)_{3}\right)$.

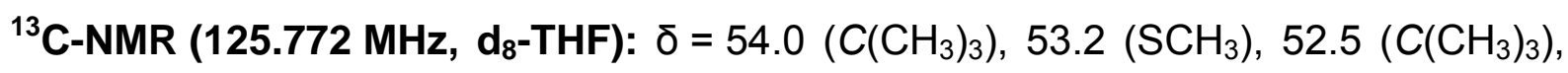
$34.3\left(\mathrm{C}\left(\mathrm{CH}_{3}\right)_{3}\right), 34.0\left(\mathrm{C}\left(\mathrm{CH}_{3}\right)_{3}\right), 33.6\left(\mathrm{C}\left(\mathrm{CH}_{3}\right)_{3}\right)$.

\section{Minor compound:}

${ }^{1} \mathrm{H}$-NMR (500.132 MHz, $\mathbf{d}_{8}$-THF): $\delta=3.62\left(\mathrm{~m}, 8 \mathrm{H}, \mathrm{OCH}_{2} \mathrm{CH}_{2}\right), 3.11\left(\mathrm{~s}, 3 \mathrm{H}, \mathrm{SCH}_{3}\right)$, $1.77\left(\mathrm{~m}, 8 \mathrm{H}, \mathrm{OCH}_{2} \mathrm{CH}_{2}\right), 1.39\left(\mathrm{br}, 27 \mathrm{H}, \mathrm{C}\left(\mathrm{CH}_{3}\right)_{3}\right)$. 


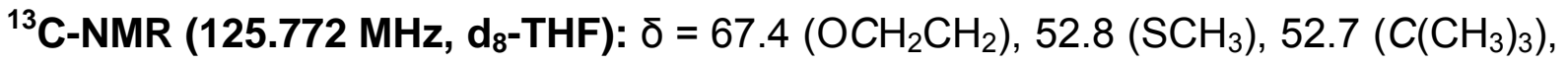
$33.7\left(\mathrm{C}\left(\mathrm{CH}_{3}\right)_{3}\right), 25.3\left(\mathrm{OCH}_{2} \mathrm{CH}_{2}\right)$.

Minor compound (sulfonic acid):

${ }^{1} \mathrm{H}-N M R\left(500.132 \mathrm{MHz}, \mathbf{d}_{8}\right.$-THF): $\delta=2.96\left(\mathrm{~s}, 3 \mathrm{H}, \mathrm{SCH}_{3}\right), 1.34\left(\mathrm{~s}, 9 \mathrm{H}, \mathrm{C}\left(\mathrm{CH}_{3}\right)_{3}\right)$, $1.30\left(\mathrm{~s}, 18 \mathrm{H}, \mathrm{C}\left(\mathrm{CH}_{3}\right)_{3}\right)$.

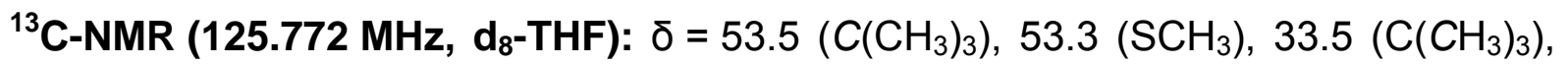
$30.8\left(\mathrm{C}\left(\mathrm{CH}_{3}\right)_{3}\right)$.

$\left[(\mathrm{THF}) \mathrm{MgBr}\left(\mathrm{N}^{t} \mathrm{Bu}\right)_{3} \mathrm{~S}^{n} \mathrm{Bu}\right]_{2}(\mathbf{2 3})$

Empirical Formula: $\mathrm{C}_{40} \mathrm{H}_{88} \mathrm{Cl}_{2} \mathrm{Mg}_{2} \mathrm{~N}_{6} \mathrm{O}_{2} \mathrm{~S}_{2} \quad$ Molecular weight: $868.80 \mathrm{~g} \mathrm{~mol}^{-1}$

Yield (\%): $1.73 \mathrm{~g}, 4.00 \mathrm{mmol}(80 \%)$.

Elemental analysis in \% found (calc.): C: 55.09 (55.30), H: 10.41 (10.21), N: 9.85 (9.67), S: 7.53 (7.38).

MS (70 eV): m/z (\%): $231(42)\left[\mathrm{M}-\mathrm{MgCl}-\mathrm{N}^{t} \mathrm{Bu}\right]^{+}, 175(20)\left[\mathrm{M}-\mathrm{MgCl}-\mathrm{N}^{t} \mathrm{Bu}-{ }^{t} \mathrm{Bu}+\right.$ $\mathrm{H}]^{+}, 119(100)\left[\mathrm{M}-\mathrm{MgCl}-\mathrm{N}^{t} \mathrm{Bu}-2{ }^{t} \mathrm{Bu}+2 \mathrm{H}\right]^{+}, 63(48)\left[\mathrm{M}-\mathrm{MgCl}-{ }^{n} \mathrm{Bu}-\mathrm{N}^{t} \mathrm{Bu}-2\right.$ $\left.{ }^{t} \mathrm{Bu}+3 \mathrm{H}\right]^{+}, 57(24)\left[{ }^{t} \mathrm{Bu}\right]^{+}$.

\section{Major compound:}

${ }^{1} \mathrm{H}-N M R\left(500.132 \mathrm{MHz}, \quad \mathbf{d}_{8}\right.$-THF): $\delta=3.62\left(\mathrm{~m}, 4 \mathrm{H}, \quad \mathrm{OCH}_{2} \mathrm{CH}_{2}\right), \quad 3.27(\mathrm{~m}, 2 \mathrm{H}$, $\left.\mathrm{CH}_{2} \mathrm{CH}_{2} \mathrm{CH}_{2} \mathrm{CH}_{3}\right), 1.77\left(\mathrm{~m}, 4 \mathrm{H}, \mathrm{OCH}_{2} \mathrm{CH}_{2}\right), 1.67\left(\mathrm{~m}, 2 \mathrm{H}, \mathrm{CH}_{2} \mathrm{CH}_{2} \mathrm{CH}_{2} \mathrm{CH}_{3}\right), 1.40$ (br, $\left.27 \mathrm{H}, \mathrm{C}\left(\mathrm{CH}_{3}\right)_{3}\right), 1.37\left(\mathrm{~m}, 2 \mathrm{H}, \mathrm{CH}_{2} \mathrm{CH}_{2} \mathrm{CH}_{2} \mathrm{CH}_{3}\right), 0.96\left(\mathrm{~m}, 3 \mathrm{H}, \mathrm{CH}_{2} \mathrm{CH}_{2} \mathrm{CH}_{2} \mathrm{CH}_{3}\right)$.

${ }^{13} \mathrm{C}$-NMR (125.772 MHz, d $\mathbf{d}_{8}$-THF): $\delta=67.4\left(\mathrm{OCH}_{2} \mathrm{CH}_{2}\right), 61.5\left(\mathrm{CH}_{2} \mathrm{CH}_{2} \mathrm{CH}_{2} \mathrm{CH}_{3}\right), 53.5$ (free $\mathrm{C}\left(\mathrm{CH}_{3}\right)_{3}$ ), 52.5 (bonded $\left.\mathrm{C}\left(\mathrm{CH}_{3}\right)_{3}\right), 33.5$ (bonded $\left.\mathrm{C}\left(\mathrm{CH}_{3}\right)_{3}\right), 33.3$ (free $\left.\mathrm{C}\left(\mathrm{CH}_{3}\right)_{3}\right)$, $27.3\left(\mathrm{CH}_{2} \mathrm{CH}_{2} \mathrm{CH}_{2} \mathrm{CH}_{3}\right), \quad 25.3 \quad\left(\mathrm{OCH}_{2} \mathrm{CH}_{2}\right), \quad 22.4 \quad\left(\mathrm{CH}_{2} \mathrm{CH}_{2} \mathrm{CH}_{2} \mathrm{CH}_{3}\right), \quad 14.5$ $\left(\mathrm{CH}_{2} \mathrm{CH}_{2} \mathrm{CH}_{2} \mathrm{CH}_{3}\right)$.

Minor compound (sulfonic acid):

${ }^{1} \mathrm{H}-N M R\left(500.132 \mathrm{MHz}, \mathbf{d}_{\mathbf{8}}\right.$-THF): $\delta=2.84\left(\mathrm{~m}, 2 \mathrm{H}, \mathrm{CH}_{2} \mathrm{CH}_{2} \mathrm{CH}_{2} \mathrm{CH}_{3}\right), 1.82(\mathrm{~m}, 2 \mathrm{H}$, $\mathrm{CH}_{2} \mathrm{CH}_{2} \mathrm{CH}_{2} \mathrm{CH}_{3}$ ), 1.39 (m, $2 \mathrm{H}, \mathrm{CH}_{2} \mathrm{CH}_{2} \mathrm{CH}_{2} \mathrm{CH}_{3}$ ), 1.34 (s, $\left.9 \mathrm{H}, \mathrm{C}\left(\mathrm{CH}_{3}\right)_{3}\right), 1.29$ (s, $\left.18 \mathrm{H}, \mathrm{C}\left(\mathrm{CH}_{3}\right)_{3}\right), 0.96\left(\mathrm{~m}, 3 \mathrm{H}, \mathrm{CH}_{2} \mathrm{CH}_{2} \mathrm{CH}_{2} \mathrm{CH}_{3}\right)$.

${ }^{13} \mathrm{C}$-NMR (125.772 MHz, d d -THF): $\delta=63.3 \quad\left(\mathrm{CH}_{2} \mathrm{CH}_{2} \mathrm{CH}_{2} \mathrm{CH}_{3}\right), 54.7$ (protonated $\left.\mathrm{C}\left(\mathrm{CH}_{3}\right)_{3}\right), \quad 53.1 \quad\left(\mathrm{C}\left(\mathrm{CH}_{3}\right)_{3}\right), \quad 33.7 \quad\left(\mathrm{C}_{\left.\left(\mathrm{CH}_{3}\right)_{3}\right),} 30.8\right.$ (protonated $\left.\mathrm{C}\left(\mathrm{CH}_{3}\right)_{3}\right), \quad 30.3$ $\left(\mathrm{CH}_{2} \mathrm{CH}_{2} \mathrm{CH}_{2} \mathrm{CH}_{3}\right), 25.3\left(\mathrm{OCH}_{2} \mathrm{CH}_{2}\right), 22.7\left(\mathrm{CH}_{2} \mathrm{CH}_{2} \mathrm{CH}_{2} \mathrm{CH}_{3}\right), 14.3\left(\mathrm{CH}_{2} \mathrm{CH}_{2} \mathrm{CH}_{2} \mathrm{CH}_{3}\right)$. 
Empirical Formula: $\mathrm{C}_{44} \mathrm{H}_{80} \mathrm{Cl}_{2} \mathrm{Mg}_{2} \mathrm{~N}_{6} \mathrm{O}_{2} \mathrm{~S}_{2}$ Molecular weight: $908.78 \mathrm{~g} \mathrm{~mol}^{-1}$

Yield (\%): $1.61 \mathrm{~g}, 3.55 \mathrm{mmol}(71 \%)$.

Elemental analysis in \% found (calc.): C: 57.0 (58.2), H: 8.5 (8.9), N: 9.0 (9.3), S: 6.8 (7.1).

MS (70 eV): m/z (\%): 251 (47) [M - MgCl $\left.-\mathrm{N}^{t} \mathrm{Bu}\right]^{+}, 195(26)\left[\mathrm{M}-\mathrm{MgCl}-\mathrm{N}^{t} \mathrm{Bu}-{ }^{t} \mathrm{Bu}+\right.$ $\mathrm{H}^{+}, 180(16)\left[\mathrm{M}-\mathrm{MgCl}-2 \mathrm{~N}^{t} \mathrm{Bu}\right]^{+}, 139(100)\left[\mathrm{M}-\mathrm{MgCl}-\mathrm{N}^{t} \mathrm{Bu}-2{ }^{t} \mathrm{Bu}+2 \mathrm{H}\right]^{+}, 57$ (8) $\left[{ }^{t} \mathrm{Bu}\right]^{+}$.

\section{Major compound:}

${ }^{1} \mathrm{H}-\mathrm{NMR}\left(\mathbf{5 0 0 . 1 3 2} \mathrm{MHz}, \mathbf{d}_{\mathbf{8}}\right.$-THF): $\delta=8.25\left(\mathrm{~d}, 2 \mathrm{H}\right.$, ortho/ $\left.\mathrm{C}_{6} \mathrm{H}_{5}\right), 7.26(\mathrm{br}, 3 \mathrm{H}$, metalpara), $3.62\left(\mathrm{~m}, 4 \mathrm{H}, \mathrm{OCH}_{2} \mathrm{CH}_{2}\right), 1.77\left(\mathrm{~m}, 4 \mathrm{H}, \mathrm{OCH}_{2} \mathrm{CH}_{2}\right), 1.53(\mathrm{~s}, 9 \mathrm{H}$, $\left.\mathrm{C}\left(\mathrm{CH}_{3}\right)_{3}\right), 1.11\left(\mathrm{~s}, 18 \mathrm{H}, \mathrm{C}\left(\mathrm{CH}_{3}\right)_{3}\right)$.

${ }^{13} \mathrm{C}-\mathrm{NMR}$ (125.757 MHz, d $\mathbf{d}_{\mathbf{8}}$-THF): $\delta=153.3$ (ipso), 129.3 (meta), 129.3 (ortho), 128.0 (para), $67.4\left(\mathrm{OCH}_{2} \mathrm{CH}_{2}\right), 53.5$ (free $\left.\mathrm{C}\left(\mathrm{CH}_{3}\right)_{3}\right), 52.8$ (bonded $\left.\mathrm{C}\left(\mathrm{CH}_{3}\right)_{3}\right), 33.7$ (free $\left.\mathrm{C}\left(\mathrm{CH}_{3}\right)_{3}\right), 32.9$ (bonded $\left.\mathrm{C}\left(\mathrm{CH}_{3}\right)_{3}\right), 25.3\left(\mathrm{OCH}_{2} \mathrm{CH}_{2}\right)$.

Minor compound (sulfonic acid):

${ }^{1} \mathrm{H}-\mathrm{NMR}$ (500.132 MHz, $\mathbf{d}_{8}$-THF): $\delta=8.10$ (m, $2 \mathrm{H}$, ortho), 7.32 (m, $3 \mathrm{H}$, metalpara), $1.35\left(\mathrm{~s}, 9 \mathrm{H}, \mathrm{C}\left(\mathrm{CH}_{3}\right)_{3}\right), 1.31\left(\mathrm{~s}, 18 \mathrm{H}, \mathrm{C}\left(\mathrm{CH}_{3}\right)_{3}\right)$.

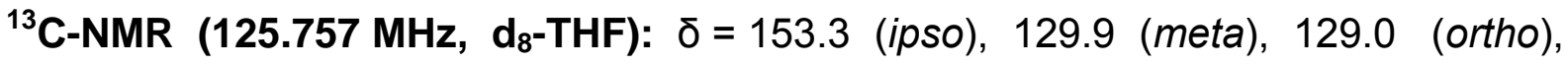
128.2 (para), 55.4 (protonated $\left.\left.\left.\mathrm{C}\left(\mathrm{CH}_{3}\right)_{3}\right), 53.6\left(\mathrm{C}_{(\mathrm{CH}}\right)_{3}\right), 33.3\left(\mathrm{C}_{(\mathrm{CH}}\right)_{3}\right), 31.4$ (protonated $\left.\mathrm{C}\left(\mathrm{CH}_{3}\right)_{3}\right)$.

$\left[(\mathrm{THF}) \mathrm{MgBr}\left(\mathrm{N}^{t} \mathrm{Bu}\right)_{3} \mathrm{SBz}\right]_{2}(\mathbf{2 5})$

Empirical Formula: $\mathrm{C}_{46} \mathrm{H}_{84} \mathrm{Cl}_{2} \mathrm{Mg}_{2} \mathrm{~N}_{6} \mathrm{O}_{2} \mathrm{~S}_{2} \quad$ Molecular weight: $936.83 \mathrm{~g} \mathrm{~mol}^{-1}$

Yield (\%): $1.82 \mathrm{~g}, 3.90 \mathrm{mmol}(78 \%)$.

Elemental analysis in \% found (calc.): C: 58.5 (58.9), H: 9.1 (8.9), N: 9.2 (8.9), S: 6.7 (6.8).

MS (70 eV): m/z (\%): $246(100)\left[\mathrm{M}-\mathrm{MgCl}-\mathrm{CH}_{2} \mathrm{Ph}+\mathrm{H}^{+}, 153(26)[\mathrm{M}-\mathrm{MgCl}-2\right.$ $\left.{ }^{t} \mathrm{Bu}-\mathrm{N}^{t} \mathrm{Bu}+2 \mathrm{H}\right]^{+}, 134(90)\left[\mathrm{M}-\mathrm{MgCl}-\mathrm{CH}_{2} \mathrm{Ph}-2{ }^{t} \mathrm{Bu}+3 \mathrm{H}\right]^{+}, 91(60)\left[\mathrm{Ch}_{2} \mathrm{Ph}\right]^{+}, 78$ (68) $\left[\mathrm{LiN}^{t} \mathrm{Bu}\right]^{+}, 57(35)\left[{ }^{t} \mathrm{Bu}\right]^{+}$.

\section{Major compound:}


${ }^{1} \mathrm{H}-N M R\left(500.134 \mathrm{MHz}, \mathbf{d}_{8}\right.$-THF): $\delta=7.66$ (d, $2 \mathrm{H}$, ortho), 7.27 (m, $3 \mathrm{H}$, meta/para), $4.59\left(\mathrm{~s}, 2 \mathrm{H}, \mathrm{CH}_{2} \mathrm{Ph}\right), 3.62\left(\mathrm{~m}, 4 \mathrm{H}, \mathrm{OCH}_{2} \mathrm{CH}_{2}\right), 1.77\left(\mathrm{~m}, 4 \mathrm{H}, \mathrm{OCH}_{2} \mathrm{CH}_{2}\right), 1.44$ (s, $\left.9 \mathrm{H}, \mathrm{C}\left(\mathrm{CH}_{3}\right)_{3}\right), 1.38$ (s, $\left.18 \mathrm{H}, \mathrm{C}\left(\mathrm{CH}_{3}\right)_{3}\right)$.

${ }^{13}$ C-NMR (125.757 MHz, d d -THF): $\delta=136.1$ (ipso), 132.0 (meta), 128.4 (ortho), 127.7 (para), $68.4\left(\mathrm{CH}_{2} \mathrm{Ph}\right), 67.4\left(\mathrm{OCH}_{2} \mathrm{CH}_{2}\right), 52.8\left(\mathrm{C}\left(\mathrm{CH}_{3}\right)_{3}\right), 33.5$ (free $\left.\mathrm{C}\left(\mathrm{CH}_{3}\right)_{3}\right)$, 33.4 (bonded $\left.\mathrm{C}\left(\mathrm{CH}_{3}\right)_{3}\right), 25.3\left(\mathrm{OCH}_{2} \mathrm{CH}_{2}\right)$.

\section{Minor compound (sulfonic acid):}

${ }^{1} \mathrm{H}-N M R\left(500.132 \mathrm{MHz}, \mathbf{d}_{8}\right.$-THF): $\delta=7.53$ (d, $2 \mathrm{H}$, ortho), 7.06 (m, $3 \mathrm{H}$, metalpara), 4.10 (s, $\left.2 \mathrm{H}, \mathrm{CH}_{2} \mathrm{Ph}\right), 1.34$ (s, $\left.9 \mathrm{H}, \mathrm{C}\left(\mathrm{CH}_{3}\right)_{3}\right), 1.32$ (s, $\left.18 \mathrm{H}, \mathrm{C}\left(\mathrm{CH}_{3}\right)_{3}\right)$.

${ }^{13}$ C-NMR (125.757 MHz, d8-THF): $\delta=136.1$ (ipso), 132.0 (meta), 128.3 (ortho), 127.9 (para), $69.5\left(\mathrm{CH}_{2} \mathrm{Ph}\right), 54.1\left(\mathrm{C}_{\left.\left(\mathrm{CH}_{3}\right)_{3}\right),} 33.6\right.$ (protonated $\left.\mathrm{C}\left(\mathrm{CH}_{3}\right)_{3}\right), 33.4$ $\left(\mathrm{C}\left(\mathrm{CH}_{3}\right)_{3}\right)$.

\subsubsection{5 $\left[\mathrm{Mg}\left\{\left(\mathrm{N}^{t} \mathrm{Bu}\right)_{3} \mathrm{SMe}\right\}_{2}\right](27)$}

$3.0 \mathrm{mmol}$ of $\mathbf{2 2}$ were dissolved in $10 \mathrm{~mL}$ toluene. The resulting mixture was stirred for one hour and the insoluble particles were filtered off. The resulting solutions were stored at $4{ }^{\circ} \mathrm{C}$ and yielded colorless crystals suitable for $\mathrm{X}$-ray structure analyses after 1-3 d.

Empirical Formula: $\mathrm{C}_{26} \mathrm{H}_{60} \mathrm{MgN}_{6} \mathrm{~S}_{2}$

Molecular weight: $545.23 \mathrm{~g} \mathrm{~mol}^{-1}$

Yield (\%): $1.27 \mathrm{~g}, 2.70 \mathrm{mmol}(90 \%)$.

Elemental analysis in \% found (calc.): C: 54.71 (57.27), H: 10.56 (11.09), N: 14.66 (15.41.), S: 10.73 (11.76).

MS (70 eV): m/z (\%): 544 (5) [M] $]^{+}, 529$ (68) [M - Me $]^{+}, 458.3\left[\mathrm{M}-\mathrm{Me}-\mathrm{N}^{t} \mathrm{Bu}\right]^{+}, 416$ (62) $\left[\mathrm{M}-{ }^{t} \mathrm{Bu}-\mathrm{N}^{t} \mathrm{Bu}\right]^{+}, 189(52)\left[\mathrm{M}-\mathrm{Mg}-\mathrm{SMe}-4 \mathrm{~N}^{t} \mathrm{Bu}\right]^{+}, 133(48)\left[\mathrm{M}-\mathrm{Mg}-{ }^{t} \mathrm{Bu}-\right.$ $\left.\mathrm{SMe}-4 \mathrm{~N}^{t} \mathrm{Bu}+\mathrm{H}\right]^{+}, 77(100)[\mathrm{MeSNHNH}]^{+}, 57(20)\left[^{t} \mathrm{Bu}\right]^{+}$

\section{Major compound:}

${ }^{1} \mathrm{H}-\mathrm{NMR}\left(500.132 \mathrm{MHz}, \mathbf{d}_{8}\right.$-THF): $\delta=3.14\left(\mathrm{~s}, 3 \mathrm{H}, \mathrm{SCH}_{3}\right), 1.43\left(\mathrm{~s}, 9 \mathrm{H}, \mathrm{C}\left(\mathrm{CH}_{3}\right)_{3}\right)$, 1.41 (s, $\left.9 \mathrm{H}, \mathrm{C}\left(\mathrm{CH}_{3}\right)_{3}\right), 1.38\left(\mathrm{~s}, 9 \mathrm{H}, \mathrm{C}\left(\mathrm{CH}_{3}\right)_{3}\right)$.

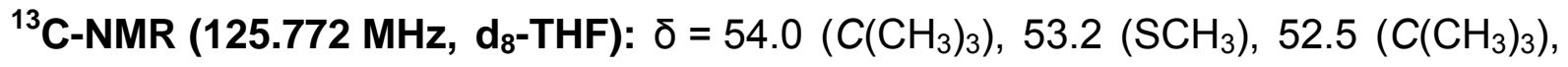

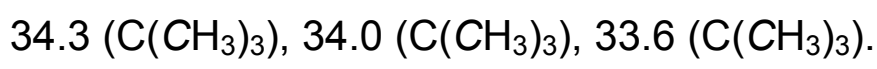

${ }^{15} \mathrm{~N}-\mathrm{NMR}\left(40.548 \mathrm{MHz}, \mathbf{d}_{8}\right.$-THF): $\delta=-258.1\left(\mathrm{NC}\left(\mathrm{CH}_{3}\right)_{3}\right),-258.8\left(\mathrm{NC}\left(\mathrm{CH}_{3}\right)_{3}\right),-259.1$ $\left(\mathrm{NC}\left(\mathrm{CH}_{3}\right)_{3}\right)$. 
Minor compound (sulfonic acid):

${ }^{1} \mathrm{H}-\mathrm{NMR}\left(500.132 \mathrm{MHz}, \mathbf{d}_{\mathbf{8}}\right.$-THF): $\delta=2.96\left(\mathrm{~s}, 3 \mathrm{H}, \mathrm{SCH}_{3}\right), 1.34\left(\mathrm{~s}, 9 \mathrm{H}, \mathrm{C}\left(\mathrm{CH}_{3}\right)_{3}\right)$, $1.30\left(\mathrm{~s}, 18 \mathrm{H}, \mathrm{C}\left(\mathrm{CH}_{3}\right)_{3}\right)$.

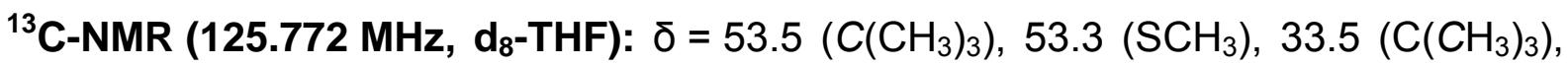
30.8 (protonated $\left.\mathrm{C}\left(\mathrm{CH}_{3}\right)_{3}\right)$.

${ }^{15} \mathrm{~N}-\mathrm{NMR}\left(40.548 \mathrm{MHz}, \mathbf{d}_{\mathbf{8}}\right.$-THF): $\delta=-253.1\left(\mathrm{NHC}\left(\mathrm{CH}_{3}\right)_{3}\right),-261.2\left(\mathrm{NC}\left(\mathrm{CH}_{3}\right)_{3}\right)$.

\subsubsection{6 $\left[\mathrm{Zn}\left\{\left(\mathrm{N}^{t} \mathrm{Bu}\right)_{3} \mathrm{SMe}\right\}_{2}\right](28)$}

The crystal structure can be found in chapter 2.4.2 and chapter 7.5.28. All other analytical data and the synthesis can be found in the literature. ${ }^{[79]}$

Empirical Formula: $\mathrm{C}_{26} \mathrm{H}_{60} \mathrm{~N}_{6} \mathrm{~S}_{2} \mathrm{Zn}$ Molecular weight: $585.53 \mathrm{~g} \mathrm{~mol}^{-1}$ 


\section{Crystallographic SECtion}

\subsection{Crystal Application}

The crystals were taken from the mother liquor using standard Schlenk techniques and placed in perfluorinated polyether oil on a microscope slide. An appropriately sized crystal of high quality was selected under a polarization microscope (for detection of twinning and the presence of satellites) with help of the X-TEMP2 cooling device. ${ }^{[207,208]}$ It was mounted on a glass fibre glued to the magnetic pin of the goniometer head in a way that it was completely coated with the perfluorinated polyether oil. ${ }^{[221]}$ Oil and crystal were shock-cooled in the cold gas stream of an open flow nitrogen cooling device attached to the diffractometer. The amorphous frozen oil served as glue and protected the sensitive compounds along with the nitrogen gas stream from moisture and oxygen. The measurement temperatures varied for the different compounds as the presence of polymorph transitions prohibited cooling to $100 \mathrm{~K}$ for some compounds. The experimental conditions of each measurement are given in the crystallographic tables of section 7.5 .

\subsection{Data Collection and Processing}

\section{Bruker diffractometers:}

Nearly all compounds were either measured on a Bruker D8 goniometer platform, equipped with a SMART APEX II CCD camera. The compounds were measured using graphite monochromated $\mathrm{MoK}_{\alpha}$ radiation $(0.71073 \AA$ ) from a SIEMENS sealed tube with a monocapillary collimator, a Incoatec microfocus source with Quazar mirror optics ${ }^{[222]}$ or on a rotating anode device. The Bruker TXS Mo rotating anode is equipped with an APEX II CCD detector, mounted on a three-circle D8 goniometer, and Incoatec Helios mirrors as monochromator optics, which supplies very intense and brilliant $\mathrm{MoK}_{\alpha}$ radiation $(0.71073 \AA)$.

All crystals were centered optically using a video camera after being mounted on the diffractometer.

Data collection was controlled with the APEX2 package. ${ }^{[223]} A$ test run (usually 50 frames in $\omega$-scan mode at $\varphi=0^{\circ}$ ) was recorded prior to each experiment to check 
the crystal quality, to get a rough estimate of the cell parameters, and to determine the optimum exposure time. All scans of the data collections were performed in an $\omega$-scan mode with a step-width of $-0.3^{\circ}$ at fixed $\varphi$-angles.

The determination of the unit cells and orientation matrices were performed with the tools supplied in the APEX2 package. ${ }^{[223]}$ The collected frames were integrated with SAINT ${ }^{[209]}$ using the $3 \mathrm{~d}$ profiling method described by Kabsch. ${ }^{[224]}$

All data sets were corrected for absorption and scaled using SADABS $^{[206]}$ or TWINABS. ${ }^{[225]}$ XPREP ${ }^{[212]}$ was used to determine the space group prior to the absorption correction, as this is crucial for a correct treatment. SADABS and TWINABS refine an empirical model function by symmetry-equivalent reflections.

Data merging according to the determined symmetry and setup of the files for structure solution and refinement was performed with XPREP. ${ }^{[212]}$

Stoe diffractometer:

The X-ray structure determination of $\mathbf{2 5}$ was performed on a Stoe IPDS II diffractometer using graphite monochromated $\mathrm{MoK}_{\alpha}$ radiation $(0.71073 \AA)$ from a sealed tube and an image plate detector.

The crystal was centered optically using a video camera after mounting on the diffractometer.

All operations from data collection over monitoring up to the data reduction were performed with the X-AREA software package supplied by Stoe \& Cie. ${ }^{[226]} \mathrm{A}$ test run (20 frames in $\omega$-scan mode at $\varphi=0^{\circ}$ ) was recorded prior to the experiment to check the crystal quality, to get a rough estimate of the cell parameters and to determine the optimum exposure time. All scans of the data collection were performed in an $\omega$-scan mode with a step-width of $-1.0^{\circ}$ at fixed $\varphi$-angles. The data collection strategy was chosen in a way that $100 \%$ of the reflections were recorded up to $\sin \theta / \lambda=0.8 \AA$ at an overall redundancy of at least 5 . 


\subsection{Structure Solution and Refinement}

The structures were solved with direct methods using SHELXS. ${ }^{[210]}$ All refinements were performed on $F^{2}$ with SHELXL. ${ }^{[210]}$

If not stated otherwise, the hydrogen atoms of the compounds were refined using a riding model. The positions were geometrically optimized and the $U_{\text {iso }}$ were constrained to $1.2 U_{\text {eq }}$ of the pivot atom or $1.5 U_{\text {eq }}$ of the methyl carbon atom.

In all refinements the function $M\left(p_{i}, k\right)$ (Eq. 7-1) was minimized using the weights $w_{H}$ defined in Eq. 7-2. The variables $g 1$ and $g 2$ are given in the crystallographic tables.

Eq. 7-1: $\quad M\left(p_{i}, k\right)=\sum_{\mathbf{H}} w_{\mathbf{H}}\left[k\left|F_{\text {obs }}(\mathbf{H})\right|^{2}-\left|F_{\text {calc }}(\mathbf{H})\right|^{2}\right]^{2}=\min$

Eq. 7-2: $\quad w_{H}{ }^{-1}=\sigma_{H}{ }^{2}{F_{\mathrm{obs}}}^{2}+(g 1 \cdot P)^{2}+g 2 \cdot P$ with $P=\left(\frac{{F_{\text {obs }}}^{2}+2 F_{\text {calc }}{ }^{2}}{3}\right)$

The results of the refinements were verified by comparison of the calculated and the observed structure factors. Commonly used criteria are the residuals $R 1$ (Eq. 7-3) and $w R 2$ (Eq. 7-4). The $w R 2$ is more significant, because the model is refined against $F^{2}$.

Eq. 7-3: $\quad R 1=\frac{\sum_{H} w_{H}\left(\left|F_{\text {obs }}\right|-\left|F_{\text {calc }}\right|\right)}{\sum_{H} w_{H}\left|F_{\text {obs }}\right|} \quad$ Eq. 7-4: $\quad w R 2=\frac{\sum_{H} w_{H}\left(\left|F_{\text {obs }}\right|^{2}-\left|F_{\text {calc }}\right|^{2}\right)^{2}}{\sum_{H} w_{H}\left|F_{\text {obs }}\right|^{4}}$

Additionally, the GoF (goodness of fit), a figure of merit showing the relation between deviation of $F_{\text {calc }}$ from $F_{\text {obs }}$ and the over-determination of refined parameters, is calculated.

Eq. 7-5:

$$
\mathrm{GoF}=\sqrt{\frac{\sum_{H} w_{H}\left(\left|F_{\text {obs }}\right|-\left|F_{\text {calc }}\right|\right)^{2}}{N-n}}
$$

The residual densities from difference Fourier analysis should be low. Due to the model restrictions the residuals are normally found in the bonding regions. Higher residuals for heavy scatterers are acceptable as they arise mainly from absorption effects and Fourier truncation errors due to the limited recorded resolution range. The 
highest peak and deepest hole from difference Fourier analysis are listed in the crystallographic tables.

Additionally, the orientation, size and ellipticity of the ADP's show the quality of the model. Ideally, the ADP's should be oriented perpendicular to the bonds, be equal in size and show little ellipticity. The ADP's for all atoms of the asymmetric units of the compounds are depicted in section 7.5. All graphics were generated and plotted with the X-Shell program at the $50 \%$ probability level.

If not stated otherwise hydrogen atoms were refined isotropically on calculated positions using a riding model with their $U_{\text {iso }}$ values constrained to equal to 1.5 times the $U_{\text {eq }}$ of their pivot atoms for terminal $\mathrm{sp}^{3}$ carbon atoms and 1.2 times for all other carbon atoms. The position of certain hydrogen atoms (e. g. in $\mathrm{OH}$ groups) were found with a difference Fourier analysis of the rest electron density. The hydrogen bond lengths were restrained to a sensible value and the $U_{\text {iso }}$ were constrained to 1.2 times the $U_{\text {eq }}$ of the pivot atoms.

\subsection{Treatment of Disorder}

Structures containing disordered fragments were refined using constraints and restraints. The geometries of chemically equivalent but crystallographically independent fragments can be fitted to each other by distance restraints. Especially the 1,2 distances (bond lengths) and 1,3 distances (bond angles) are set to be equal within their effective standard deviations. This is helpful for refining disordered positions as the averaging of equivalent fragments implements chemical information and stabilizes the refinement.

Restraints affecting the anisotropic displacement parameters are often essential for the anisotropic refinement of disordered atomic positions. The rigid bond restraints (DELU in SHELXL) $)^{[227]}$ fit the components of the anisotropic displacement parameters along the bonds within esd's. Similarity restraints (SIMU in SHELXL) ${ }^{[227]}$ adjust the ADPs of neighboring atoms within a certain radius to be equal according to their esd's. The ISOR command in SHELXL ${ }^{[227]}$ forces the ADPs to adapt a more spherical, isotropic behavior, which is sometimes necessary to refine positions with minor occupation factors. All restraints of this type are applied as weak restraints with relatively large esd's, as the affected parameters are not perfectly equal. 


\subsection{Crystallographic Details for 1-18 and 22-28}

\subsection{1 [(THF) $\left.\left\{\mathrm{Li}\left(\mathrm{N}^{t} \mathrm{Bu}\right)_{2} \mathrm{SCpFeCp}\right\}_{2}\right](1)$}

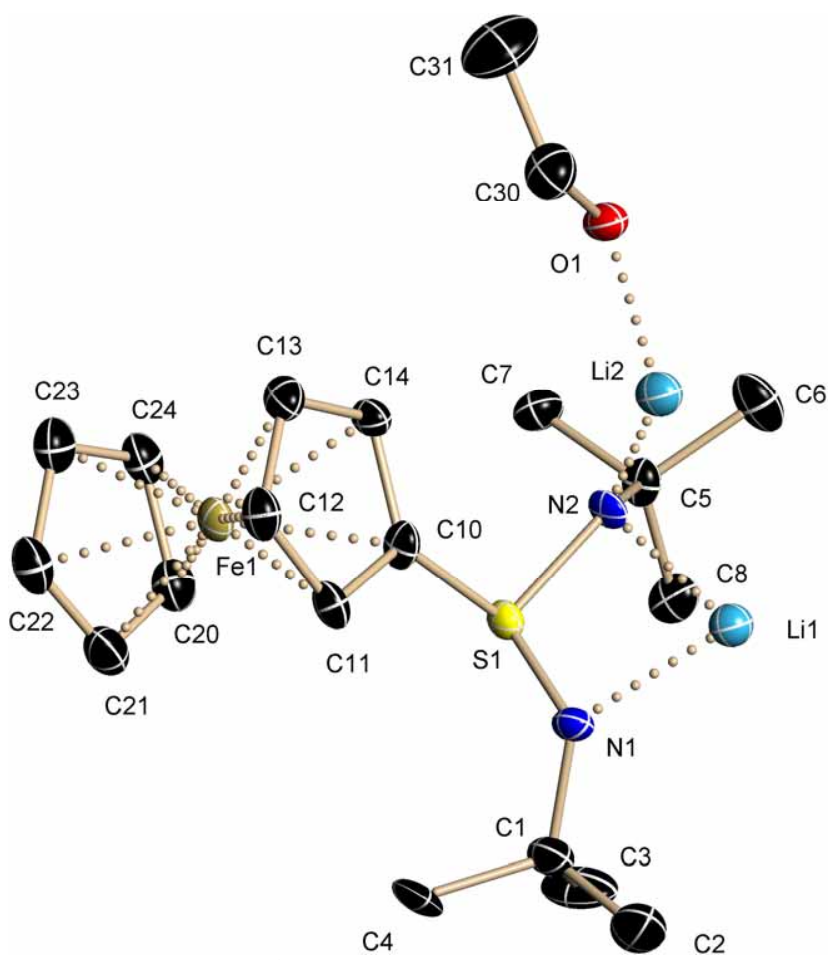

Figure 7-1: Asymmetric unit of $\left[(\mathrm{THF})\left\{\mathrm{Li}\left(\mathrm{N}^{t} \mathrm{Bu}\right)_{2} \mathrm{SCpFeCp}\right\}_{2}\right](\mathbf{1})$. All hydrogen atoms are omitted for clarity.

The crystals of $\mathbf{1}$ were non-merohedrally twinned. The orientation matrices of the two components and the initial cell were determined using CELL_NOW. Those matrices were then used for integrating the domains separately with SAINT. Subsequent absorption correction with TWINABS lead to a HKLF4 file for structure solution and a HKLF5 file for further refinement. The occupancy factors of the two additional domains refined to $13 \%$ and $9 \%$. 
Table 7-1: Crystallographic data for [(THF) $\left.\left\{\mathrm{Li}\left(\mathrm{N}^{t} \mathrm{Bu}\right)_{2} \mathrm{SCpFeCp}\right\}_{2}\right](\mathbf{1})$.

\begin{tabular}{|c|c|c|c|}
\hline structure code & Iron Man & $F(000)$ & 1712 \\
\hline formula & $\begin{array}{l}\mathrm{C}_{40} \mathrm{H}_{62} \mathrm{Fe}_{2} \mathrm{Li}_{2} \\
\mathrm{~N}_{4} \mathrm{OS}_{2}\end{array}$ & max. / min. Transmission & $\begin{array}{l}0.745432 / \\
0.328183\end{array}$ \\
\hline molecular mass $/ \mathrm{g} \cdot \mathrm{mol}^{-1}$ & 804.64 & $\rho_{\text {calc }} / \mathrm{Mg} \cdot \mathrm{m}^{-3}$ & 1.272 \\
\hline crystal size / mm & $0.2 \times 0.2 \times 0.05$ & $\mu / \mathrm{mm}^{-1}$ & 0.824 \\
\hline crystal system & monoclinic & $\theta_{\min } / \theta_{\max }^{\circ}$ & $2.02-25.51$ \\
\hline space group & $C 2 / c$ & reflections all/unique & 7214 / 3814 \\
\hline a / $\AA$ & $14.577(4)$ & data/restraints/parameter & $3814 / 0 / 238$ \\
\hline $\mathrm{b} / \AA$ & $14.651(4)$ & $R 1$ (all data) & 0.1081 \\
\hline$c / \AA$ & $20.673(5)$ & $w R 2$ (all data) & 0.1758 \\
\hline$\beta /^{\circ}$ & $107.917(3)$ & $g 1 / g 2$ & $0.0001 / 35.1067$ \\
\hline$V / \AA^{3}$ & $4201.1(18)$ & GoF & 1.198 \\
\hline Z & 4 & peak/hole: & \\
\hline temperature / $\mathrm{K}$ & $100(2)$ & $\max . / \min . /\left(10^{-6} \mathrm{e} \cdot \AA^{-3}\right)$ & $0.756 /-0.646$ \\
\hline
\end{tabular}

\subsection{2 [(THF $\left.)_{4} \mathrm{Li}_{2}\left\{\left(\mathrm{NSiMe}_{3}\right)_{2} \mathrm{~S}\right\}_{2} \mathrm{C}_{12} \mathrm{H}_{8}\right](2)$}

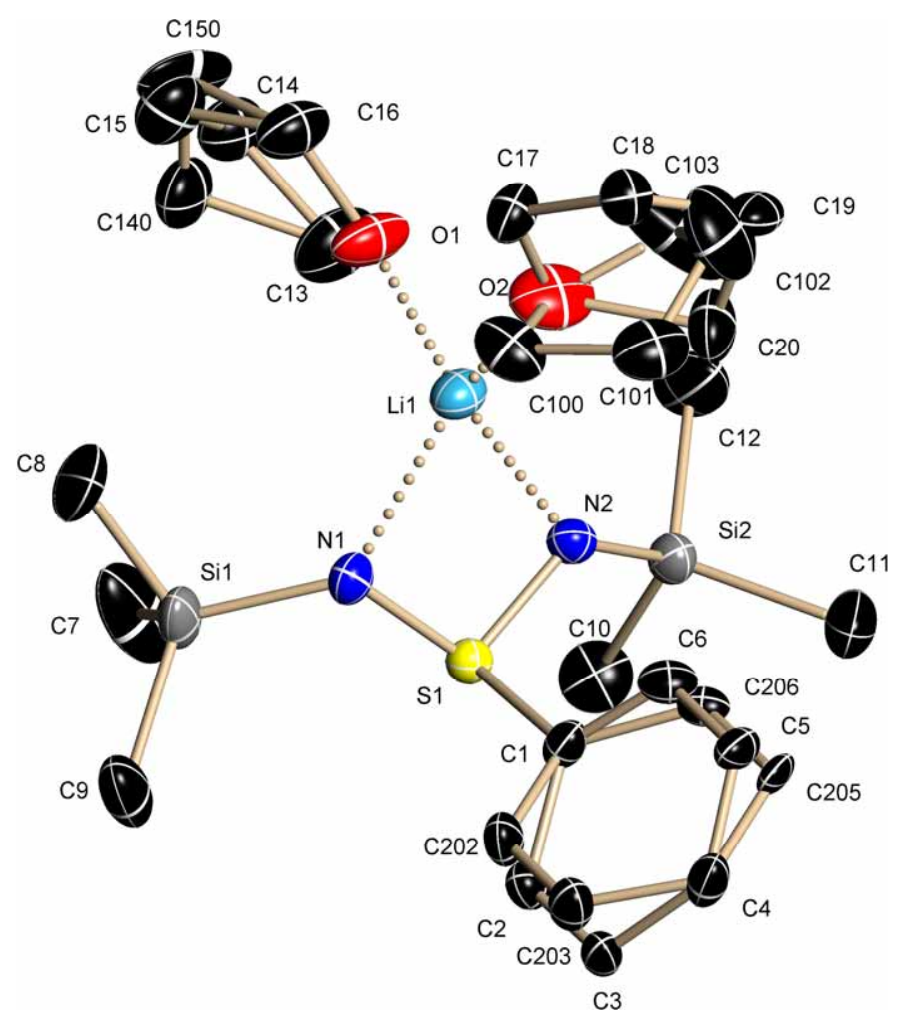

Figure 7-2: Asymmetric unit of $\left[(\mathrm{THF})_{4} \mathrm{~L} \mathrm{~L}_{2}\left\{\left(\mathrm{NSiMe}_{3}\right)_{2} \mathrm{~S}_{2} \mathrm{C}_{12} \mathrm{H}_{8}\right](2)\right.$. All hydrogen atoms are omitted for clarity. 
In the solid state structure both donating THF molecules and the central biphenyl framework are disordered. While in one THF molecule only two carbon atoms are disordered (30\%) the second THF exhibits two different positions (only the position of the oxygen atom is fixed) and therefore induces the disorder at the biphenyl framework by hydrogen bonds. Both occupation factors refine to $50 \%$ indicating that the disorders depend from each other. The disorder in the ring system was stabilized with SADI restraints. Additionally the crystals of $\mathbf{2}$ were non-merohedrally twinned. The orientation matrices of the two components and the initial cell were determined using CELL_NOW. Those matrices were then used for integrating the domains separately with SAINT. Subsequent absorption correction with TWINABS lead to a HKLF4 file for structure solution and further refinement.

Table 7-2: Crystallographic data for $\left[(\mathrm{THF})_{4} \mathrm{Li}_{2}\left\{\left(\mathrm{NSiMe}_{3}\right)_{2} \mathrm{~S}_{2} \mathrm{C}_{12} \mathrm{H}_{8}\right](2)\right.$.

\begin{tabular}{|ll|ll|}
\hline structure code & $\mathrm{D} 50$ & temperature / K & $100(2)$ \\
formula & $\mathrm{C}_{40} \mathrm{H}_{76} \mathrm{Li}_{2} \mathrm{~N}_{4}$ & max. / min. Transmission & $0.6676 / 0.7453$ \\
& $\mathrm{O}_{4} \mathrm{~S}_{2} \mathrm{Si}_{4}$ & & \\
molecular mass $/ \mathrm{g} \cdot \mathrm{mol}^{-1}$ & 867.41 & $\rho_{\text {calc }} / \mathrm{Mg} \cdot \mathrm{m}^{-3}$ & 1.126 \\
crystal size / mm & $0.35 \times 0.2 \times 0.1$ & $\mu / \mathrm{mm}^{-1}$ & 0.24 \\
crystal system & triclinic & $F(000)$ & 470 \\
space group & $P \overline{1}$ & $\theta_{\min } / \theta_{\max }{ }^{\circ}$ & $1.57-25.35$ \\
$\mathrm{a} / \AA$ & $10.1713(16)$ & reflections all/unique & $31830 / 4687$ \\
$\mathrm{~b} / \AA$ & $10.426(3)$ & data/restraints/parameter & $4687 / 17 / 349$ \\
$\mathrm{c} / \AA$ & $13.924(3)$ & $R 1$ (all data) & 0.0417 \\
$\alpha /{ }^{\circ}$ & $80.687(4)$ & $w R 2($ all data) & 0.0946 \\
$\beta /{ }^{\circ}$ & $68.710(6)$ & $g 1 / g 2$ & $0.0483 / 0.6967$ \\
$\gamma /{ }^{\circ}$ & $68.492(5)$ & GoF & 1.043 \\
$\mathrm{~V} / \AA^{3}$ & $1279.4(5)$ & peak/hole: & \\
$\mathrm{Z}$ & 1 & max. / min. / $\left(10^{-6} \mathrm{e} \cdot \AA^{-3}\right)$ & $0.46 /-0.30$ \\
\hline
\end{tabular}




\subsection{3 [(THF $\left.)_{1.5} \mathrm{Li}_{2}\left\{\left(\mathrm{NSiMe}_{3}\right)_{2} \mathrm{~S}\right\}_{2} \mathrm{C}_{12} \mathrm{H}_{8}\right]_{\infty}(3)$}

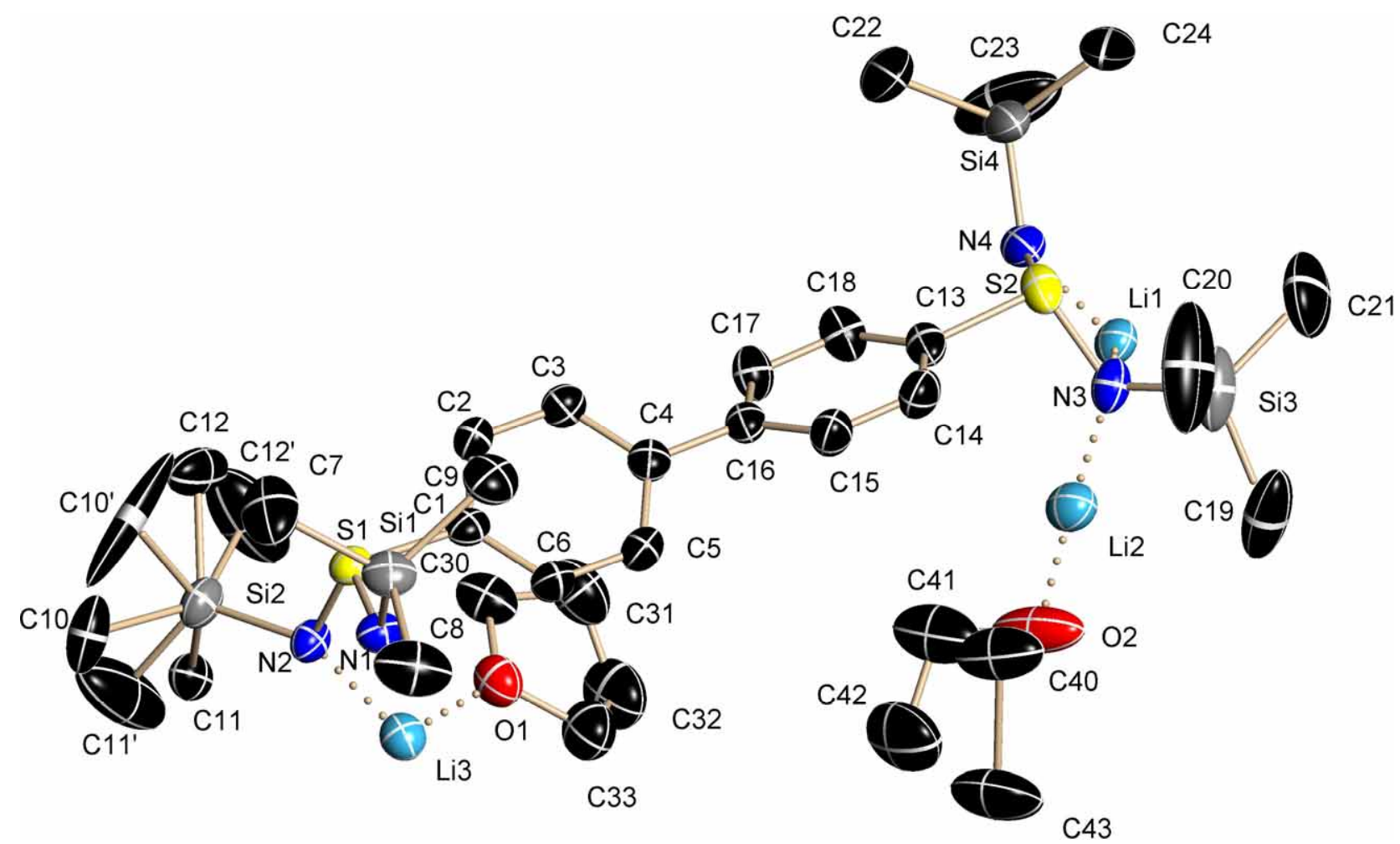

Figure 7-3: Asymmetric unit of $\left[(\mathrm{THF})_{1.5} \mathrm{Li}_{2}\left\{\left(\mathrm{NSiMe}_{3}\right)_{2} \mathrm{~S}_{2} \mathrm{C}_{12} \mathrm{H}_{8}\right]_{\infty}(3)\right.$. All hydrogen atoms are omitted for clarity.

In the solid state structure disorders at one trimethylsilyl group and at one THF donor are present. Although a second position for the trimethylsilyl group could be found (occupation factor $20 \%$ ) the ADP's indicate that there are some more with smaller occupation factors. The THF molecule is completely disordered except for the fixed oxygen atom (occupation factor $50 \%$ ). 
Table 7-3: Crystallographic data for $\left[(\mathrm{THF})_{1.5} \mathrm{Li}_{2}\left\{\left(\mathrm{NSiMe}_{3}\right)_{2} \mathrm{~S}_{2} \mathrm{C}_{12} \mathrm{H}_{8}\right]_{\infty}(3)\right.$.

\begin{tabular}{|ll|ll|}
\hline structure code & $\mathrm{P} 245$ & $F(000)$ & 2960 \\
formula & $\mathrm{C}_{30} \mathrm{H}_{56} \mathrm{Li}_{2} \mathrm{~N}_{4}$ & max. / min. Transmission & $0.5604 / 0.7090$ \\
& $\mathrm{O}_{1.50} \mathrm{~S}_{2} \mathrm{Si}_{4}$ & & \\
molecular mass $/ \mathrm{g} \cdot \mathrm{mol}^{-1}$ & 687.15 & $\rho_{\text {calc }} / \mathrm{Mg} \cdot \mathrm{m}^{-3}$ & 1.088 \\
crystal size / mm & $0.1 \times 0.1 \times 0.05$ & $\mu / \mathrm{mm}^{-1}$ & 0.268 \\
crystal system & orthorhombic & $\theta_{\min } / \theta_{\text {max }}{ }^{-3}$ & $2.16-25.46$ \\
space group & $P b c n$ & reflections all/unique & $56409 / 7750$ \\
a / $\AA$ & $13.4045(13)$ & data/restraints $/$ parameter & $7750 / 23 / 455$ \\
b / $\AA$ & $18.8417(16)$ & $R 1$ (all data) & 0.0993 \\
c / $\AA$ & $33.228(3)$ & $w R 2($ all data $)$ & 0.1967 \\
V / $\AA^{3}$ & $8392.3(13)$ & $g 1 / g 2$ & $0.00 / 19.678499$ \\
Z & 8 & GoF & 1.161 \\
temperature / K & $100(2)$ & peak / hole / $\left(10^{-6} \mathrm{e} \cdot \AA^{-3}\right)$ & $0.587 /-0.341$ \\
\hline
\end{tabular}

\subsection{4 $\left[\left\{(\mathrm{Ph})_{2} \mathrm{P}\right\}_{2} \mathrm{C}_{6} \mathrm{H}_{4}\right](4)$}

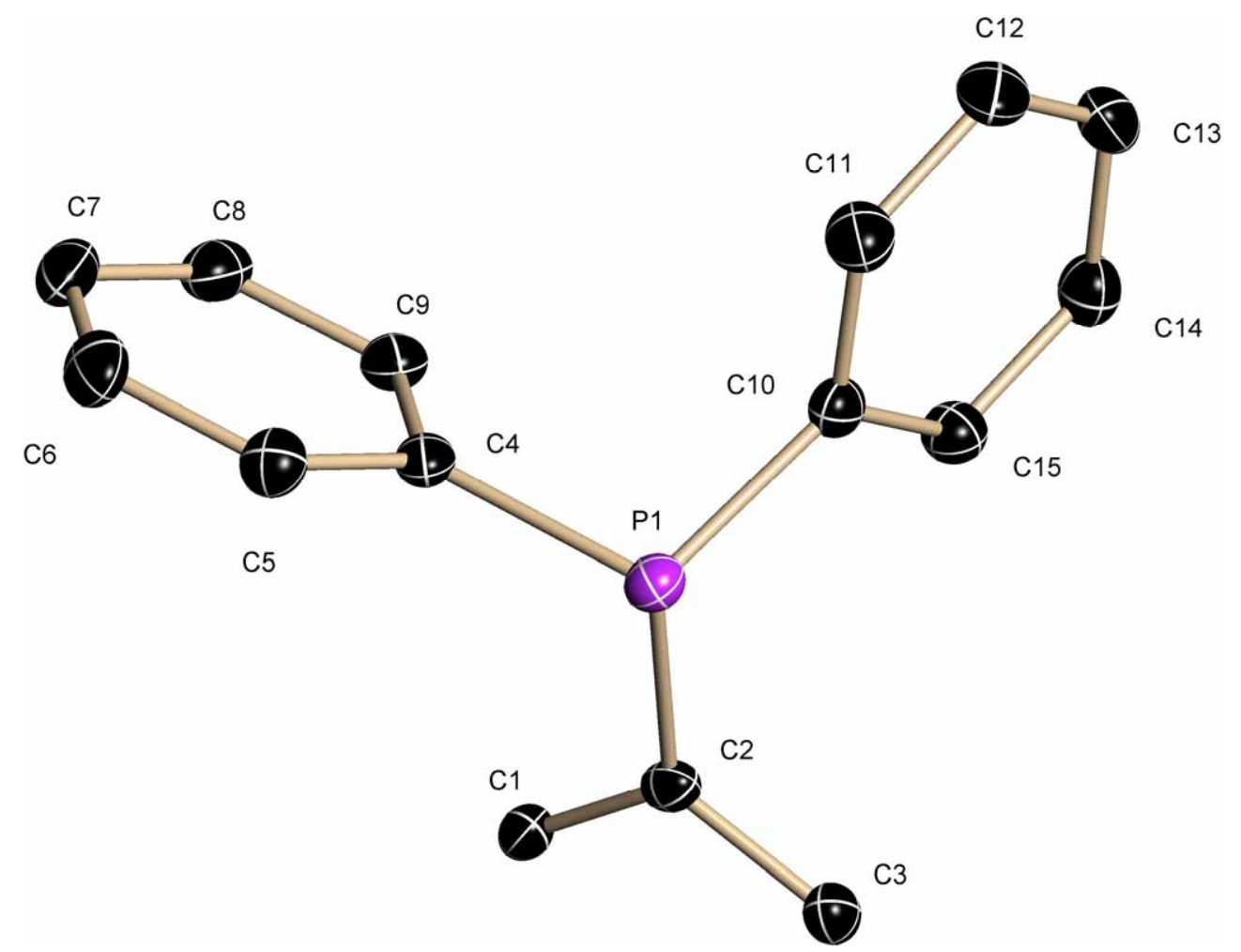

Figure 7-4: Asymmetric unit of $\left[\left\{(\mathrm{Ph})_{2} \mathrm{P}\right\}_{2} \mathrm{C}_{6} \mathrm{H}_{4}\right]$ (4). All hydrogen atoms are omitted for clarity. 
Table 7-4: Crystallographic data for $\left[\left\{(\mathrm{Ph})_{2} \mathrm{P}_{2} \mathrm{C}_{6} \mathrm{H}_{4}\right](4)\right.$.

\begin{tabular}{|ll|ll|}
\hline structure code & Flo26 & $F(000)$ & 468 \\
formula & $\mathrm{C}_{30} \mathrm{H}_{24} \mathrm{P}_{2}$ & max. / min. Transmission & $0.6798 / 0.7454$ \\
molecular mass / g $\cdot \mathrm{mol}^{-1}$ & 446.43 & $\rho_{\text {calc }} /{\mathrm{Mg} \cdot \mathrm{m}^{-3}}^{-3}$ & 1.285 \\
crystal size / mm & $0.15 \times 0.15 \times 0.05$ & $\mu / \mathrm{mm}^{-1}$ & 0.204 \\
crystal system & monoclinic & $\theta_{\min } / \theta_{\text {max }}{ }^{\circ}$ & $2.23-26.67$ \\
space group & $P 2_{1} / n$ & reflections all/unique & $12635 / 2460$ \\
a / $\AA$ & $6.794(2)$ & data/restraints/parameter & $2460 / 0 / 145$ \\
b / $\AA$ & $11.901(4)$ & $R 1$ (all data) & 0.0460 \\
c / $\AA$ & $14.388(4)$ & $w R 2$ (all data) & 0.0900 \\
$\beta / \circ$ & $97.201(4)$ & $g 1 / g 2$ & $0.0388 / 0.7088$ \\
V / $\AA^{3}$ & $1154.2(6)$ & GoF & 1.045 \\
Z & 2 & peak/hole: & \\
temperature / K & $100(2)$ & max. / min. / $\left(10^{-6} \mathrm{e} \cdot \AA^{-3}\right)$ & $0.341 /-0.311$ \\
\hline
\end{tabular}

\subsection{5 $\left[\left\{\mathrm{Me}_{2} \mathrm{Al}\left(\mathrm{N}^{t} \mathrm{Bu}\right)_{2} \mathrm{~S}\right\}_{2} \mathrm{C}_{12} \mathrm{H}_{8}\right](5)$}

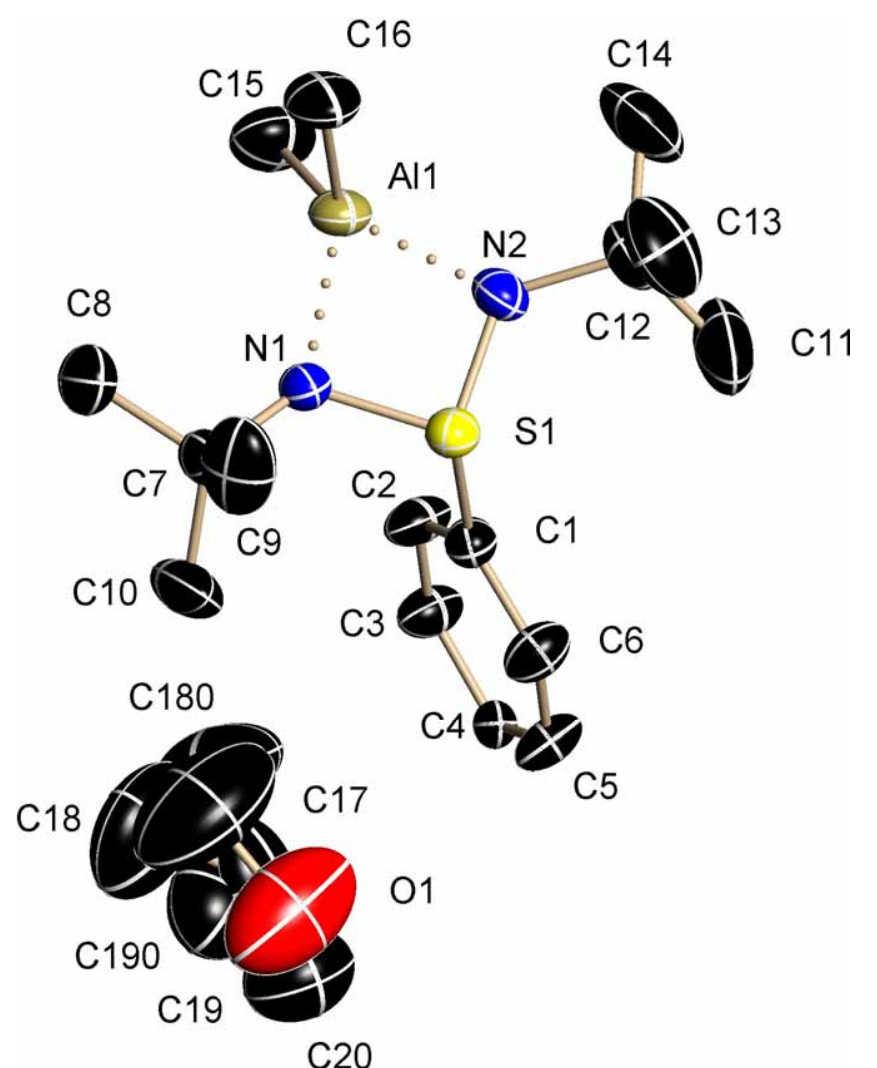

Figure 7-5: Asymmetric unit of $\left[\left\{\mathrm{Me}_{2} \mathrm{Al}\left(\mathrm{N}^{t} \mathrm{Bu}\right)_{2} \mathrm{~S}_{2} \mathrm{C}_{12} \mathrm{H}_{8}\right](\mathbf{5})\right.$. All hydrogen atoms are omitted for clarity. 
In $\mathbf{5}$ only the non-coordinated THF molecule is disordered. A second position for two of the carbon atoms could be found. The occupation factor refines to $20 \%$. A SIMU and a DELU restraint was applied to stabilize the THF molecule. The same was done to one of the tert-butyl groups.

Table 7-5: Crystallographic data for $\left.\mathrm{Me}_{2} \mathrm{Al}\left(\mathrm{N}^{t} \mathrm{Bu}\right)_{2} \mathrm{~S}_{2} \mathrm{C}_{12} \mathrm{H}_{8}\right](5)$.

\begin{tabular}{|ll|ll|}
\hline structure code & $\mathrm{D} 52$ & temperature / K & $100(2)$ \\
formula & $\mathrm{C}_{40} \mathrm{H}_{76} \mathrm{Li}_{2} \mathrm{~N}_{4}$ & max. / min. Transmission & $0.6676 / 0.7453$ \\
& $\mathrm{O}_{4} \mathrm{~S}_{2} \mathrm{Si}_{4}$ & & \\
molecular mass $/ \mathrm{g} \cdot \mathrm{mol}^{-1}$ & 867.41 & $\rho_{\text {calc }} / \mathrm{Mg} \cdot \mathrm{m}^{-3}$ & 1.126 \\
crystal size / mm & $0.35 \times 0.2 \times 0.1$ & $\mu / \mathrm{mm}^{-1}$ & 0.24 \\
crystal system & triclinic & $F(000)$ & 470 \\
space group & $P \overline{1}$ & $\theta_{\min } / \theta_{\max }{ }^{\circ}$ & $1.57-25.35$ \\
a / $\AA$ & $10.1713(16)$ & reflections all/unique & $31830 / 4687$ \\
$\mathrm{~b} / \AA$ & $10.426(3)$ & data/restraints/parameter & $4687 / 17 / 349$ \\
$\mathrm{c} / \AA$ & $13.924(3)$ & $R 1$ (all data) & 0.0417 \\
$\alpha /{ }^{\circ}$ & $80.687(4)$ & $w R 2($ all data) & 0.0946 \\
$\beta /{ }^{\circ}$ & $68.710(6)$ & $g 1 / g 2$ & $0.0483 / 0.6967$ \\
$\gamma /{ }^{\circ}$ & $68.492(5)$ & GoF & 1.043 \\
$\mathrm{~V} / \AA^{3}$ & $1279.4(5)$ & peak/hole: & \\
$\mathrm{Z}$ & 1 & max. / min. / $\left(10^{-6} \mathrm{e} \cdot \AA^{-3}\right)$ & $0.46 /-0.30$ \\
\hline
\end{tabular}




\subsection{6 $\left[\left\{\mathrm{Me}_{2} \mathrm{Al}\left(\mathrm{NSiMe}_{3}\right)_{2} \mathrm{~S}_{2} \mathrm{C}_{6} \mathrm{H}_{4}\right](6)\right.$}

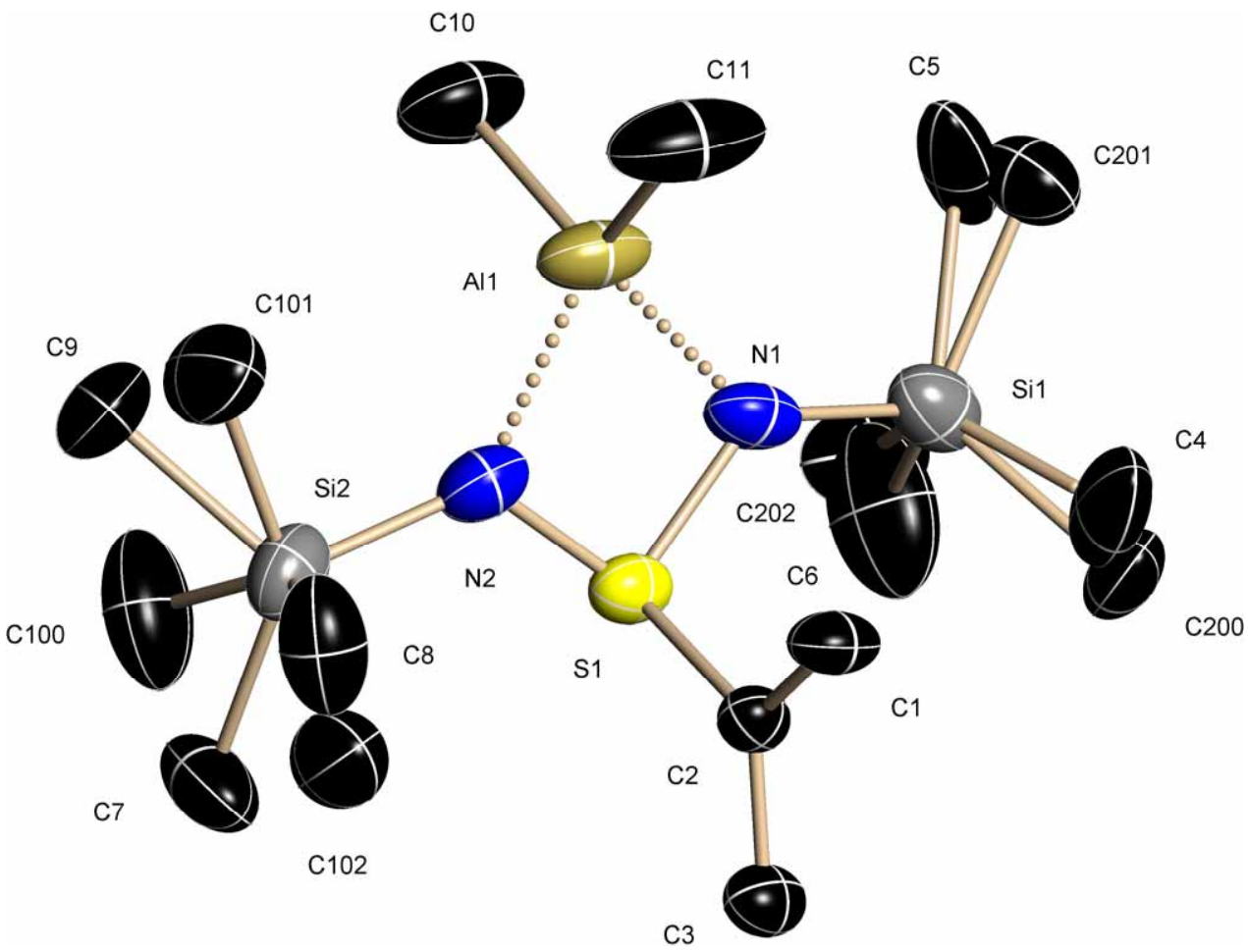

Figure 7-6: Asymmetric unit of $\left[\left\{\mathrm{Me}_{2} \mathrm{Al}\left(\mathrm{NSiMe}_{3}\right)_{2} \mathrm{~S}_{2} \mathrm{C}_{6} \mathrm{H}_{4}\right](6)\right.$. Hydrogen atoms have been omitted for clarity.

In the solid state structure of $\mathbf{6}$ all trimethylsilyl groups are disordered. A second position could be found for the groups with a side occupation factor of $50 \%$ in both cases. To stabilize the disordered groups SIMU and DELU commands were applied.

Table 7-6: Crystallographic data for $\left[\left\{\mathrm{Me}_{2} \mathrm{Al}\left(\mathrm{NSiMe}_{3}\right)_{2} \mathrm{~S}\right\}_{2} \mathrm{C}_{6} \mathrm{H}_{4}\right](6)$.

\begin{tabular}{|ll|ll|}
\hline structure code & $\mathrm{D} 10$ & $F(000)$ & 1304 \\
formula & $\mathrm{C}_{22} \mathrm{H}_{52} \mathrm{Al}_{2} \mathrm{~N}_{4} \mathrm{~S}_{2} \mathrm{Si}_{4}$ & max. / min. Transmission & $0.6432 / 0.7453$ \\
molecular mass / g $\cdot \mathrm{mol}^{-1}$ & 603.12 & $\rho_{\text {calc }} / \mathrm{Mg} \cdot \mathrm{m}^{-3}$ & 1.069 \\
crystal size / mm & $0.1 \times 0.1 \times 0.05$ & $\mu / \mathrm{mm}^{-1}$ & 0.334 \\
crystal system & orthorhombic & $\theta_{\min } / \theta_{\max }{ }^{\circ}$ & $1.78-25.34$ \\
space group & $P c c n$ & reflections all/unique & $21854 / 3431$ \\
a / $\AA$ & $15.7678(11)$ & data/restraints/parameter & $3431 / 16 / 224$ \\
b / $\AA$ & $16.5892(11)$ & $R 1$ (all data) & 0.0667 \\
c / $\AA$ & $14.3223(9)$ & $w R 2$ (all data) & 0.1074 \\
V / $\AA^{3}$ & $3746.4(4)$ & $g 1 / g 2$ & $0.0446 / 2.3232$ \\
Z & 4 & GoF & 1.013 \\
temperature / K & $100(2)$ & peak / hole / $\left(10^{-6} \mathrm{e} \cdot \AA^{-3}\right)$ & $0.376 /-0.383$ \\
\hline
\end{tabular}




\subsection{7 [(THF $\left.)_{2} \mathrm{Li}\left(\mathrm{N}^{\mathrm{t}} \mathrm{Bu}\right)_{2} \mathrm{SAnBr}\right](7)$}

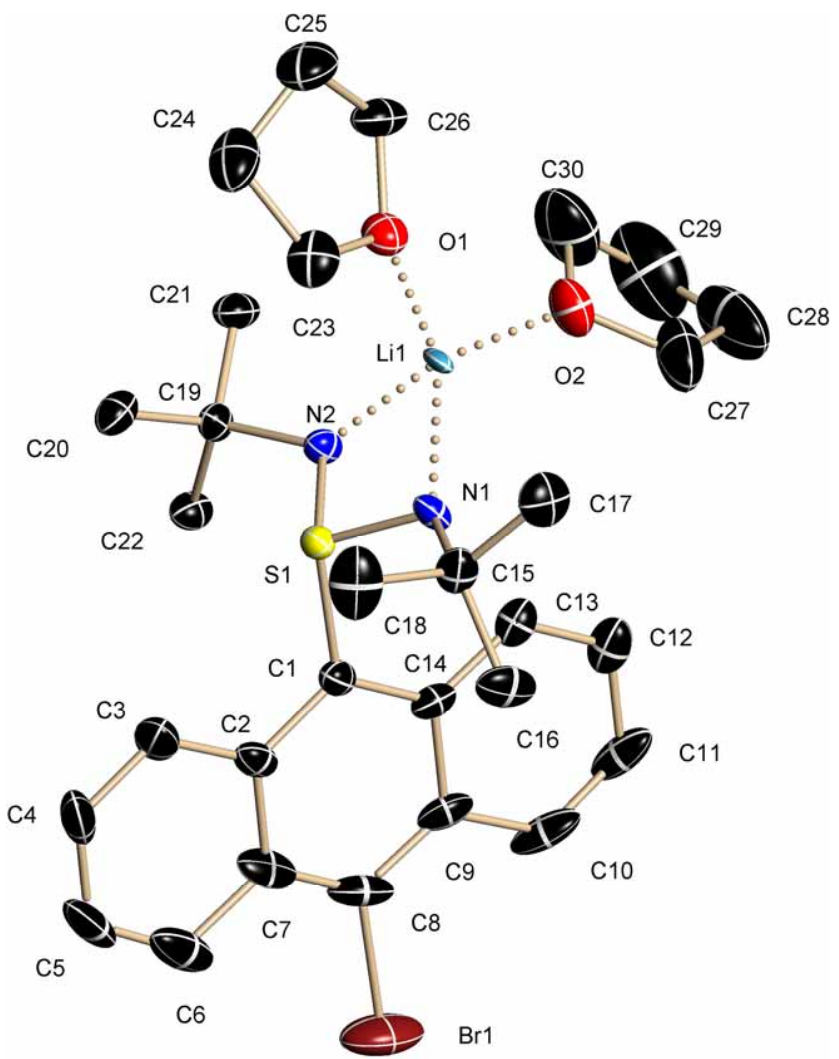

Figure 7-7: Asymmetric unit of $\left[(\mathrm{THF})_{2} \mathrm{Li}\left(\mathrm{N}^{\mathrm{t}} \mathrm{Bu}\right)_{2} \mathrm{SAnBr}\right](7)$. Hydrogen atoms have been omitted for clarity.

Table 7-7: Crystallographic data for $\left[(\mathrm{THF})_{2} \mathrm{Li}\left(\mathrm{N}^{\mathrm{t}} \mathrm{Bu}\right)_{2} \mathrm{SAnBr}\right](7)$.

\begin{tabular}{|ll|ll|}
\hline structure code & Mandy & $F(000)$ & 1224 \\
formula & $\mathrm{C}_{30} \mathrm{H}_{42} \mathrm{BrLiN}_{2} \mathrm{O}_{2} \mathrm{~S}$ & max. / min. Transmission & not determined \\
molecular mass / g $\cdot \mathrm{mol}^{-1}$ & 581.57 & $\rho_{\text {calc }} / \mathrm{Mg} \cdot \mathrm{m}^{-3}$ & 1.281 \\
crystal size / mm & $0.1 \times 0.1 \times 0.05$ & flack x & $0.0256(0.0117)$ \\
crystal system & orthorhombic & $\theta_{\min } / \theta_{\max }{ }^{\circ}$ & $2.19-25.41$ \\
space group & $P n a 2_{1}$ & reflections all/unique & $35006 / 5563$ \\
a / $\AA$ & $17.088(3)$ & data/restraints/parameter & $5563 / 41 / 340$ \\
b / $\AA$ & $11.1177(17)$ & $R 1$ (all data) & 0.0666 \\
c / $\AA$ & $15.878(2)$ & wR2 (all data) & 0.1461 \\
V / $\AA^{3}$ & $3016.5(8)$ & $g 1 / g 2$ & $0.0926 / 0.00$ \\
Z & 4 & GoF & 1.049 \\
temperature / K & $100(2)$ & peak / hole / $\left(10^{-6} \mathrm{e} \cdot \AA^{-3}\right)$ & $0.513 /-0.936$ \\
\hline
\end{tabular}




\subsection{8 $\left[\left(\mathrm{Et}_{2} \mathrm{O}\right)(\mathrm{LiBr}) \mathrm{Li}\left(\mathrm{N}^{\mathrm{t} B u}\right)_{2} \mathrm{SAnBr}\right]_{2}(8)$}

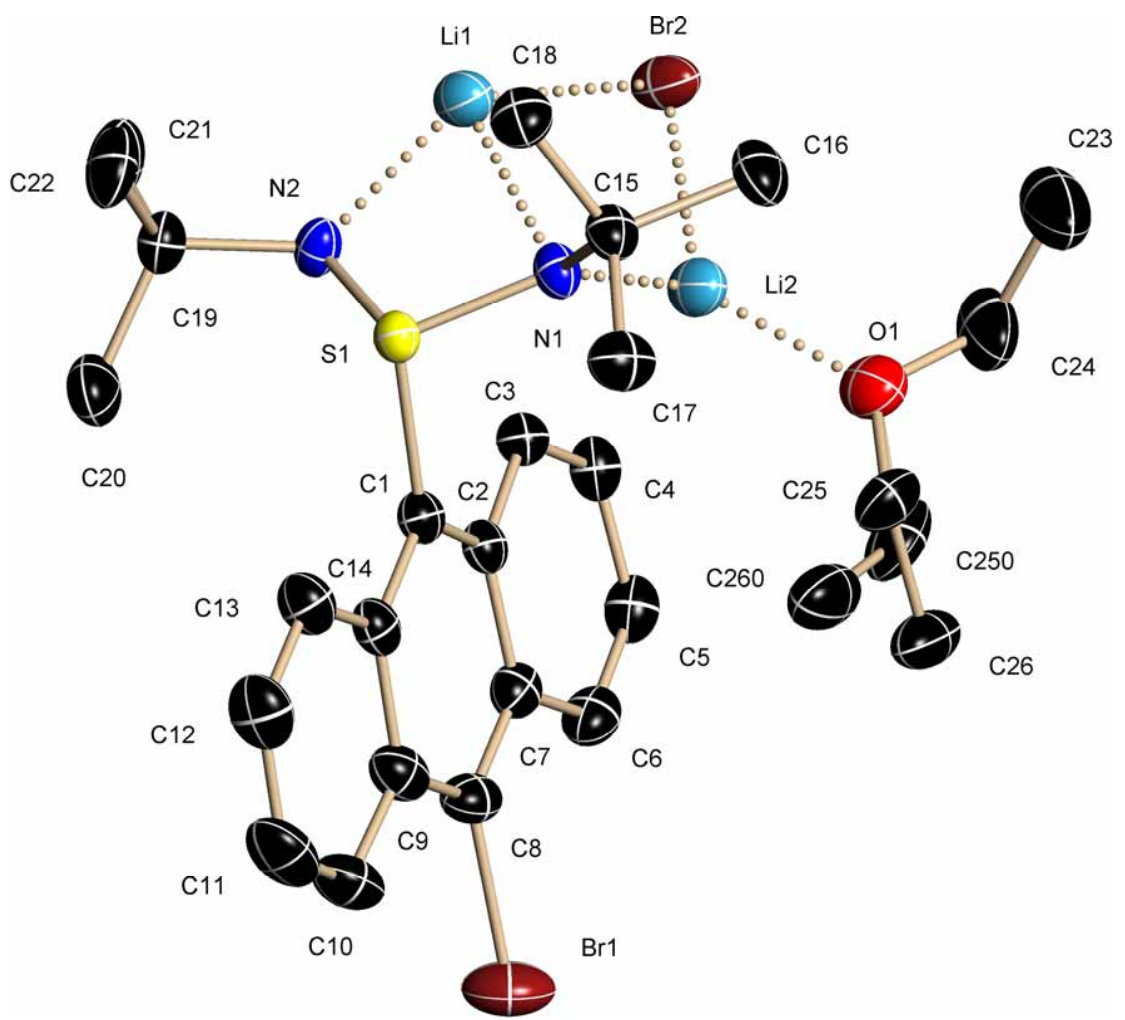

Figure 7-8: Asymmetric unit of $\left.\left[\left(\mathrm{Et}_{2} \mathrm{O}\right)(\mathrm{LiBr}) \mathrm{Li}_{(\mathrm{N}} \mathrm{B} \mathrm{Bu}\right)_{2} \mathrm{SAnBr}\right]_{2}(\mathbf{8})$. Hydrogen atoms have been omitted for clarity.

Table 7-8: Crystallographic data for $\left.\left[\left(\mathrm{Et}_{2} \mathrm{O}\right)(\mathrm{LiBr}) \mathrm{Li}_{(\mathrm{N}} \mathrm{Bu}_{2}\right)_{2} \mathrm{SAnBr}\right]_{2}(\mathbf{8})$.

\begin{tabular}{|c|c|c|c|}
\hline structure code & P61c & $F(000)$ & 1224 \\
\hline formula & $\begin{array}{l}\mathrm{C}_{52} \mathrm{H}_{72} \mathrm{Br}_{4} \mathrm{Li}_{4} \\
\mathrm{~N}_{4} \mathrm{O}_{2} \mathrm{~S}_{2}\end{array}$ & max. / min. Transmission & $0.3653 / 0.4296$ \\
\hline molecular mass $/ \mathrm{g} \cdot \mathrm{mol}^{-1}$ & 1196.66 & $\rho_{\text {calc }} / \mathrm{Mg} \cdot \mathrm{m}^{-3}$ & 1.386 \\
\hline crystal size / mm & $0.2 \times 0.15 \times 0.1$ & $\mu / \mathrm{mm}^{-1}$ & 2.921 \\
\hline crystal system & monoclinic & $\theta_{\min } / \theta_{\max }^{\circ}$ & $1.94-26.44$ \\
\hline space group & $P 2(1) / n$ & reflections all/unique & 43137 / 5893 \\
\hline a / $\AA$ & $12.869(3)$ & data/restraints/parameter & $5893 / 0 / 335$ \\
\hline $\mathrm{b} / \AA$ & $15.765(3)$ & $R 1$ (all data) & 0.0480 \\
\hline$c / \AA$ & $14.182(3)$ & $w R 2$ (all data) & 0.1124 \\
\hline$\beta /{ }^{\circ}$ & $94.951(3)$ & $g 1 / g 2$ & $0.059 / 2.6409$ \\
\hline$V / \AA^{3}$ & $2866.5(11)$ & GoF & 1.079 \\
\hline Z & 2 & peak/hole: & \\
\hline temperature / $\mathrm{K}$ & $100(2)$ & $\max . / \min . /\left(10^{-6} \mathrm{e} \cdot \AA^{-3}\right)$ & $1.081 /-1.097$ \\
\hline
\end{tabular}




\subsection{9 $\left[\left(\mathrm{Et}_{2} \mathrm{O}\right)_{2} \mathrm{Li}\left(\mathrm{NSiMe}_{3}\right)_{2} \mathrm{SAnBr}\right](9)$}

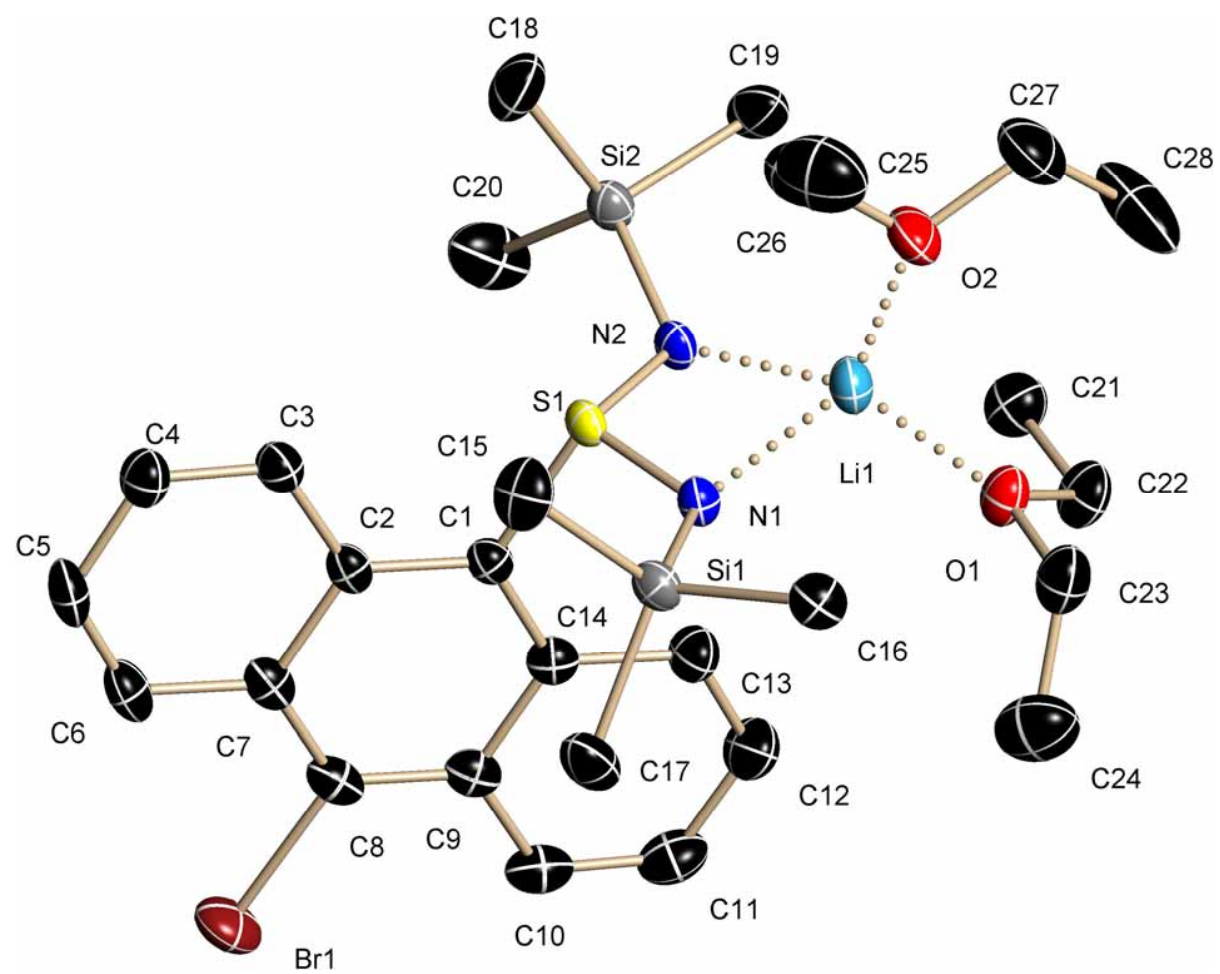

Figure 7-9: Asymmetric unit of $\left[\left(\mathrm{Et}_{2} \mathrm{O}\right)_{2} \mathrm{Li}\left(\mathrm{NSiMe}_{3}\right)_{2} \mathrm{SAnBr}\right](\mathbf{9})$. Hydrogen atoms have been omitted for clarity.

The crystals of 9 were non-merohedrally twinned. The orientation matrices of the additional component and the initial cell were determined using CELL_NOW. Those matrices were then used for integrating the domains separately with SAINT. Subsequent absorption correction with TWINABS lead to a HKLF4 file for structure solution and a HKLF5 file for further refinement. The occupancy factor of the additional domain refined to $15 \%$. 
Table 7-9: Crystallographic data for $\left[\left(\mathrm{Et}_{2} \mathrm{O}\right)_{2} \mathrm{Li}\left(\mathrm{NSiMe}_{3}\right)_{2} \mathrm{SAnBr}\right](9)$.

\begin{tabular}{|c|c|c|c|}
\hline structure code & SiMandy & $F(000)$ & 1304 \\
\hline formula & $\begin{array}{l}\mathrm{C}_{28} \mathrm{H}_{46} \mathrm{BrLiN}_{2} \\
\mathrm{O}_{2} \mathrm{SSi}_{2}\end{array}$ & max. / min. Transmission & $\begin{array}{l}0.327452 / \\
0.429324\end{array}$ \\
\hline molecular mass $/ \mathrm{g} \cdot \mathrm{mol}^{-1}$ & 617.76 & $\rho_{\text {calc }} / \mathrm{Mg} \cdot \mathrm{m}^{-3}$ & 1.222 \\
\hline crystal size / mm & $0.2 \times 0.15 \times 0.1$ & $\mu / \mathrm{mm}^{-1}$ & 1.383 \\
\hline crystal system & monoclinic & $\theta_{\min } / \theta_{\max }^{\circ}$ & $1.65-26.03$ \\
\hline space group & $P 2(1) / n$ & reflections all/unique & 33832 / 7198 \\
\hline a / $\AA$ & $10.917(2)$ & data/restraints/parameter & $7198 / 0 / 345$ \\
\hline $\mathrm{b} / \AA$ & $18.935(2)$ & $R 1$ (all data) & 0.0652 \\
\hline$c / \AA$ & $16.338(3)$ & $w R 2$ (all data) & 0.1009 \\
\hline$\beta /{ }^{\circ}$ & $96.18(2)$ & $g 1 / g 2$ & $0.0311 / 4.0902$ \\
\hline$V / \AA^{3}$ & $3357.7(10)$ & GoF & 1.054 \\
\hline Z & 4 & peak/hole: & \\
\hline temperature / $\mathrm{K}$ & $100(2)$ & $\max . / \min . /\left(10^{-6} \mathrm{e} \cdot \AA^{-3}\right)$ & $0.676 /-0.345$ \\
\hline
\end{tabular}

\subsubsection{0 $\left[\mathrm{Me}_{2} \mathrm{Al}\left(\mathrm{N}^{\mathrm{t} B u}\right)_{2} \mathrm{SAnBr}\right](10)$}

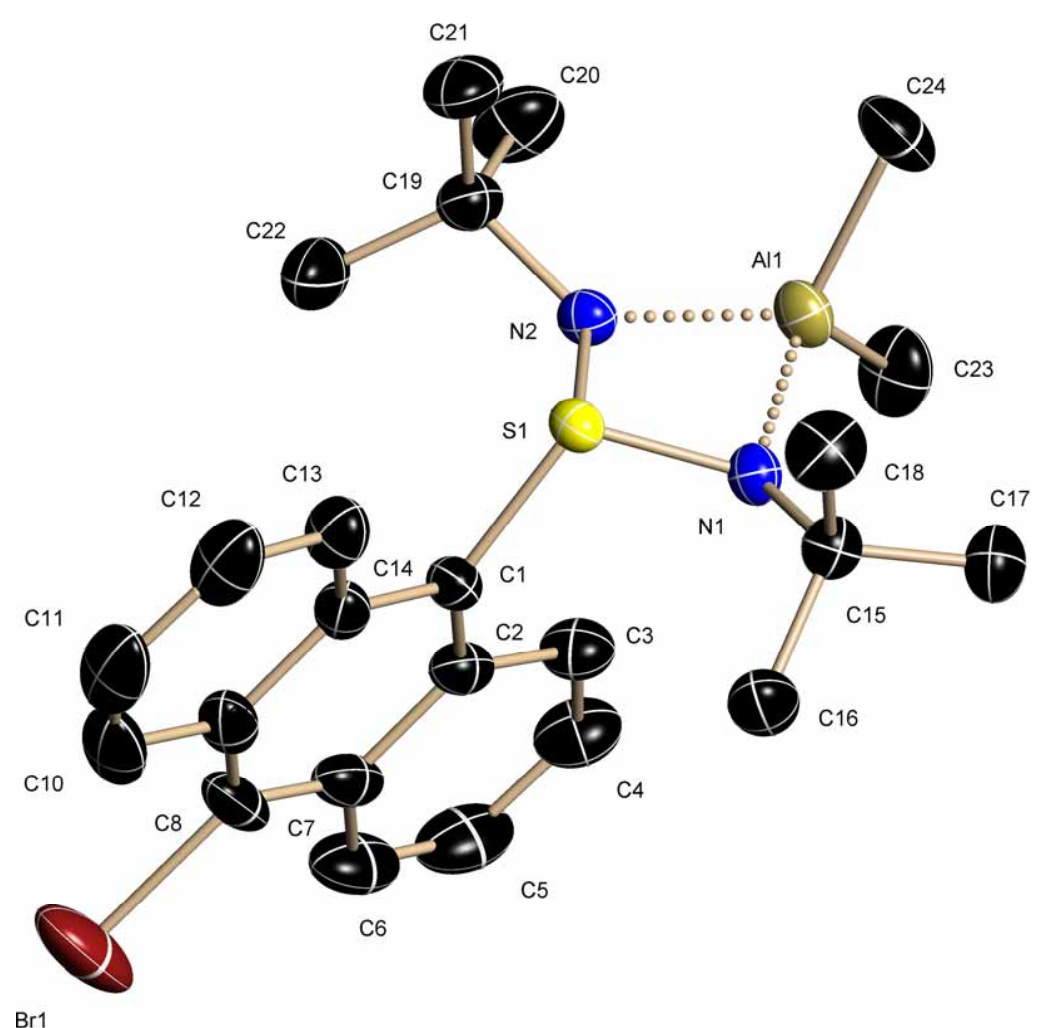

Figure 7-10: Asymmetric unit of $\left[\mathrm{Me}_{2} \mathrm{Al}\left(\mathrm{N}^{t} \mathrm{Bu}\right)_{2} \mathrm{SAnBr}\right](10)$. Hydrogen atoms have been omitted for clarity. 
Table 7-10: Crystallographic data for $\left[\mathrm{Me}_{2} \mathrm{Al}\left(\mathrm{N}^{\mathrm{t} B u}\right)_{2} \mathrm{SAnBr}\right](\mathbf{1 0})$.

\begin{tabular}{|ll|ll|}
\hline structure code & Alana & $F(000)$ & 2032 \\
formula & $\mathrm{C}_{24} \mathrm{H}_{32} \mathrm{AlBrN}_{2} \mathrm{~S}$ & max. / min. Transmission & $0.743953 / 0.99$ \\
molecular mass $/ \mathrm{g} \cdot \mathrm{mol}^{-1}$ & 487.47 & $\rho_{\text {calc }} / \mathrm{Mg} \cdot \mathrm{m}^{-3}$ & 1.315 \\
crystal size / mm & $0.35 \times 0.2 \times 0.15$ & $\mu / \mathrm{mm}^{-1}$ & 1.802 \\
crystal system & orthorhombic & $\theta_{\min } / \theta_{\max }{ }^{-3}$ & $2.22-26.44$ \\
space group & $P b c a$ & reflections all/unique & $58664 / 5056$ \\
a / $\AA$ & $11.6435(11)$ & data/restraints/parameter & $5056 / 0 / 270$ \\
b / $\AA$ & $14.2039(13)$ & $R 1$ (all data) & 0.0533 \\
c / $\AA$ & $29.779(3)$ & $w R 2($ all data $)$ & 0.1235 \\
V / $\AA^{3}$ & $4925.0(8)$ & $g 1 / g 2$ & $0.0614 / 5.8927$ \\
Z & 8 & GoF & 1.019 \\
temperature / K & $100(2)$ & peak / hole / $\left(10^{-6} \mathrm{e} \cdot \AA^{-3}\right)$ & $0.936 /-1.140$ \\
\hline
\end{tabular}

\subsubsection{1 $\left[\mathrm{Zn}\left\{\left(\mathrm{N}^{\mathrm{t} B u}\right)_{2} \mathrm{SAnBr}\right\}_{2}\right](11)$}

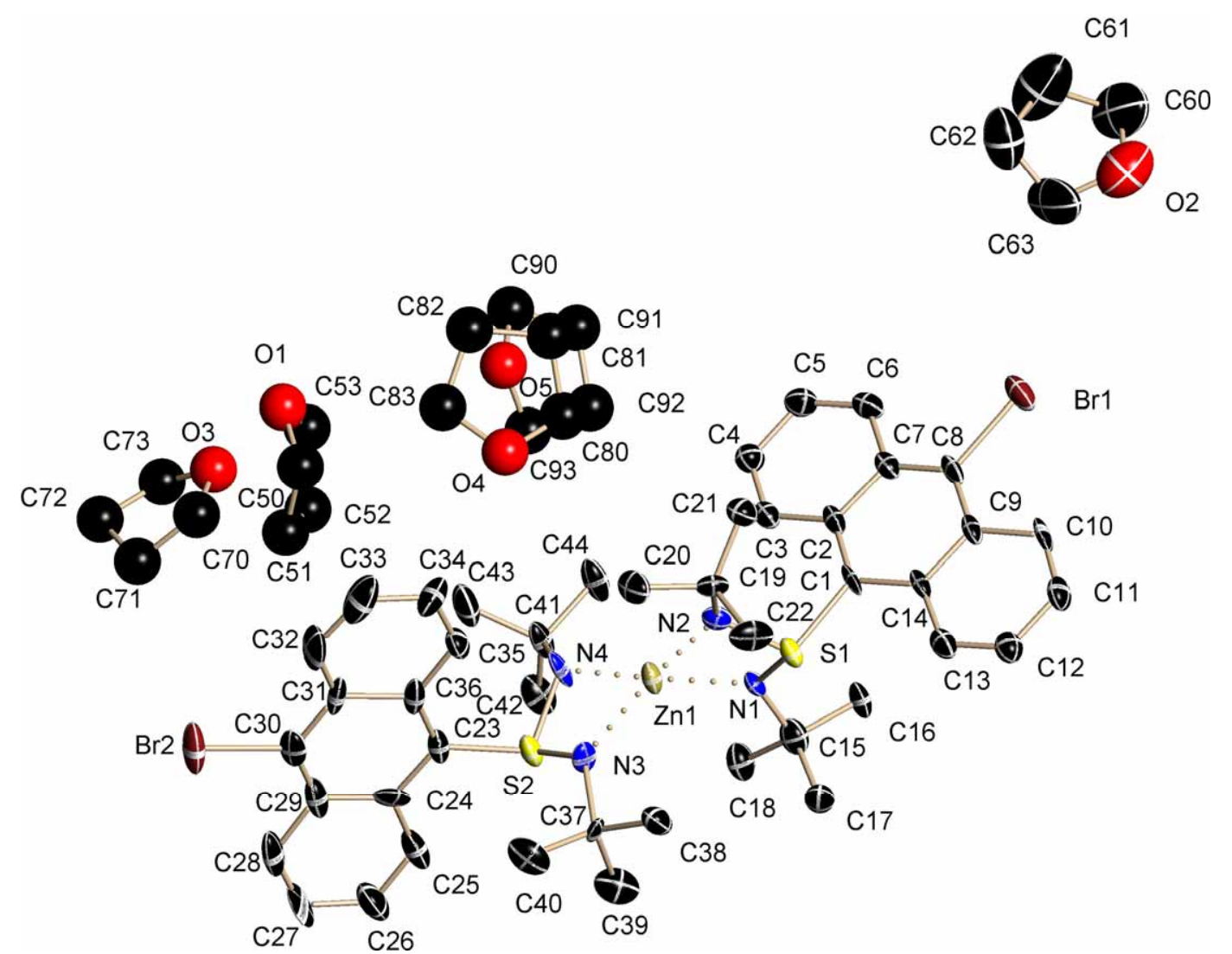

Figure 7-11: Asymmetric unit of $\left[\mathrm{Zn}\left\{\left(\mathrm{N}^{\mathrm{t}} \mathrm{Bu}\right)_{2} \mathrm{SAnBr}\right\}_{2}\right]$ (11). Hydrogen atoms have been omitted for clarity. 
Due to the bad data quality and the high degree of freedom of the solvent molecules all THF molecules, except for one, could only be described isotropically. On the ADP's of all other atoms SIMU and DELU restraints were applied.

Table 7-11: Crystallographic data for $\left[\mathrm{Zn}\left\{\left(\mathrm{N}^{\mathrm{t}} \mathrm{Bu}\right)_{2} \mathrm{SAnBr}\right\}_{2}\right](\mathbf{1 1})$.

\begin{tabular}{|c|c|c|c|}
\hline structure code & P190 & temperature / $\mathrm{K}$ & $100(2)$ \\
\hline formula & $\begin{array}{l}\mathrm{C}_{60} \mathrm{H}_{84} \mathrm{Br}_{2} \mathrm{~N}_{4} \\
\mathrm{O}_{4} \mathrm{~S}_{2} \mathrm{Zn}\end{array}$ & max. / min. Transmission & not determined \\
\hline molecular mass $/ \mathrm{g} \cdot \mathrm{mol}^{-1}$ & 1214.62 & $\rho_{\text {calc }} / \mathrm{Mg} \cdot \mathrm{m}^{-3}$ & 1.391 \\
\hline crystal size / mm & $0.1 \times 0.1 \times 0.1$ & $\mu / \mathrm{mm}^{-1}$ & 1.922 \\
\hline crystal system & triclinic & $F(000)$ & 1272 \\
\hline space group & $P \overline{1}$ & $\theta_{\min } / \theta_{\max }^{\circ}$ & $1.14-25.03$ \\
\hline a / $\AA$ & $8.8839(11)$ & reflections all/unique & $11643 / 7711$ \\
\hline $\mathrm{b} / \AA$ & $18.6414(12)$ & data/restraints/parameter & $7711 / 271 / 564$ \\
\hline$c / \AA$ & $18.711(3)$ & $R 1$ (all data) & 0.0961 \\
\hline$\alpha /{ }^{\circ}$ & $74.337(3)$ & $w R 2$ (all data) & 0.1953 \\
\hline$\beta /{ }^{\circ}$ & $77.409(4)$ & $g 1 / g 2$ & $0.0419 / 46.252$ \\
\hline$\gamma /{ }^{\circ}$ & $81.776(3)$ & GoF & 1.110 \\
\hline$V / \AA^{3}$ & $2900.2(4)$ & peak/hole: & \\
\hline Z & 2 & $\max . / \min . /\left(10^{-6} \mathrm{e} \cdot \AA^{-3}\right)$ & $0.97 /--0.619$ \\
\hline
\end{tabular}




\subsubsection{2 [ $\left.\mathrm{LiNHSiMe}_{3}\right]_{\infty}$}

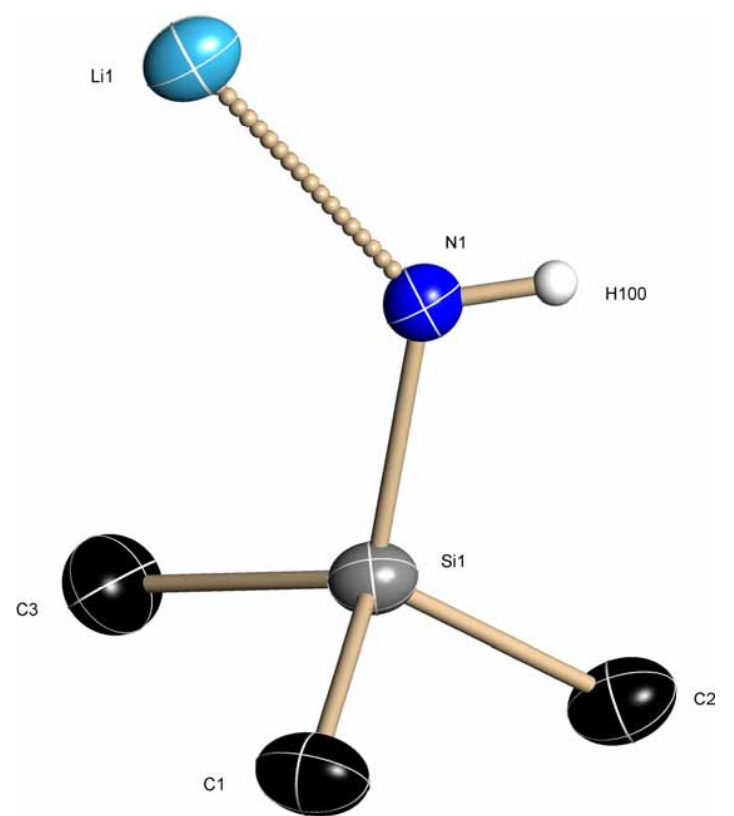

Figure 7-12: Asymmetric unit of [LiNHSiMe $]_{\infty}$. All constraint hydrogen atoms have been omitted for clarity.

The hydrogen atom at the nitrogen atom was found using a difference Fourier analysis of the rest electron density.

Table 7-12: Crystallographic data for $\left[\mathrm{LiNHSiMe}_{3}\right]_{\infty}$.

\begin{tabular}{|ll|ll|}
\hline structure code & $\mathrm{P} 12$ & $F(000)$ & 416 \\
formula & $\mathrm{C}_{12} \mathrm{H}_{40} \mathrm{Li}_{4} \mathrm{~N}_{4} \mathrm{Si}_{4}$ & max. / min. Transmission & $0.89 / 0.99$ \\
molecular mass $/ \mathrm{g} \cdot \mathrm{mol}^{-1}$ & 380.60 & $\rho_{\text {calc }} / \mathrm{Mg} \cdot \mathrm{m}^{-3}$ & 0.979 \\
crystal size / mm & $0.15 \times 0.12 \times 0.1$ & $\mu / \mathrm{mm}^{-1}$ & 0.231 \\
crystal system & monoclinic & $\theta_{\min } / \theta_{\max }{ }^{\circ}$ & $2.23-23.19$ \\
space group & $C 2 / c$ & reflections all/unique & $6209 / 929$ \\
$\mathrm{a} / \AA$ & $18.863(2)$ & data/restraints/parameter & $929 / 0 / 62$ \\
$\mathrm{~b} / \AA$ & $9.1304(10)$ & $R 1$ (all data) & 0.0338 \\
$\mathrm{c} / \AA$ & $7.7416(8)$ & $w R 2($ all data) & 0.1082 \\
$\beta /{ }^{\circ}$ & $104.3990(10)$ & $g 1 / g 2$ & $0.0684 / 0.3792$ \\
$\mathrm{~V} / \AA^{3}$ & $1291.4(2)$ & GoF & 1.261 \\
$\mathrm{Z}$ & 2 & peak/hole: & \\
temperature / K & $100(2)$ & max. / min. / $\left(10^{-6} \mathrm{e} \cdot \AA^{-3}\right)$ & $0.295 /-0.313$ \\
\hline
\end{tabular}




\subsubsection{3 [(THF $\left.)_{3} \operatorname{LiBr}\left(\mathrm{Ph}_{2} \mathrm{PAn}\right)_{2} \mathrm{Et}\right]$}
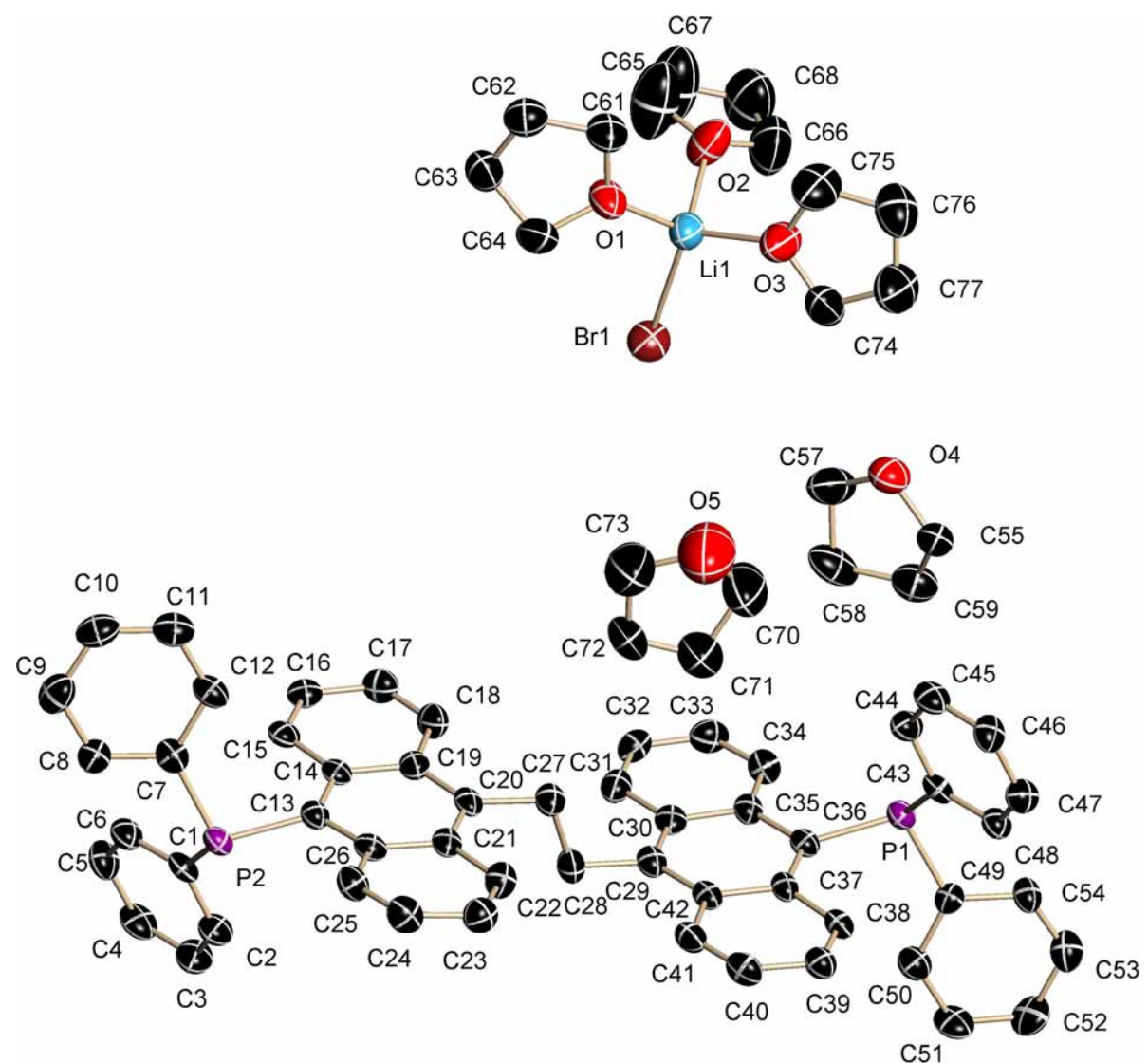

Figure 7-13: Asymmetric unit of $\left[(\mathrm{THF})_{3} \mathrm{LiBr}\left(\mathrm{Ph}_{2} \mathrm{PAn}\right)_{2} \mathrm{Et}\right]$. Hydrogen atoms have been omitted for clarity.

Due to racemic twinning the Flack $\mathrm{x}$ parameter could not be determined. 
Table 7-13: Crystallographic data for [(THF $\left.)_{3} \mathrm{LiBr}\left(\mathrm{Ph}_{2} \mathrm{PAn}\right)_{2} \mathrm{Et}\right]$.

\begin{tabular}{|ll|ll|}
\hline structure code & $\mathrm{P} 122$ & temperature / K & $100(2)$ \\
formula & $\mathrm{C}_{74} \mathrm{H}_{80} \mathrm{BrLiO}_{5} \mathrm{P}_{2}$ & max. / min. Transmission & not determined \\
molecular mass $/ \mathrm{g} \cdot \mathrm{mol}^{-1}$ & 1198.17 & $\rho_{\text {calc }} / \mathrm{Mg} \cdot \mathrm{m}^{-3}$ & 1.285 \\
crystal size $/ \mathrm{mm}$ & $0.2 \times 0.2 \times 0.15$ & $\mu / \mathrm{mm}^{-1}$ & 0.767 \\
crystal system & triclinic & $F(000)$ & 632 \\
space group & $P 1$ & $\theta_{\text {min }} / \theta_{\text {max }}{ }^{\circ}$ & $2.29-25.68$ \\
$\mathrm{a} / \AA$ & $9.151(1)$ & reflections all/unique & $7764 / 6718$ \\
$\mathrm{~b} / \AA$ & $13.141(2)$ & data/restraints $/$ parameter & $6718 / 66 / 748$ \\
$\mathrm{c} / \AA$ & $14.734(2)$ & $R 1$ (all data) & 0.0743 \\
$\alpha /{ }^{\circ}$ & $63.818(2)$ & $w R 2($ all data) & 0.1828 \\
$\beta /{ }^{\circ}$ & $83.047(2)$ & $g 1 / g 2$ & $0.1511 / 0.0963$ \\
$\gamma /{ }^{\circ}$ & $76.953(2)$ & GoF & 1.028 \\
$\mathrm{~V} / \AA^{3}$ & $1548.6(4)$ & peak/hole: & \\
$\mathrm{Z}$ & 1 & max. / min. / $\left(10^{-6} \mathrm{e} \cdot \AA^{-3}\right)$ & $1.173 /-0.367$ \\
\hline
\end{tabular}

\subsubsection{4 $\left[\mathrm{Ph}{ }_{2} \mathrm{P}\left(\mathrm{NH}^{t} \mathrm{Bu}\right)_{2} \mathrm{Br}\right]$}

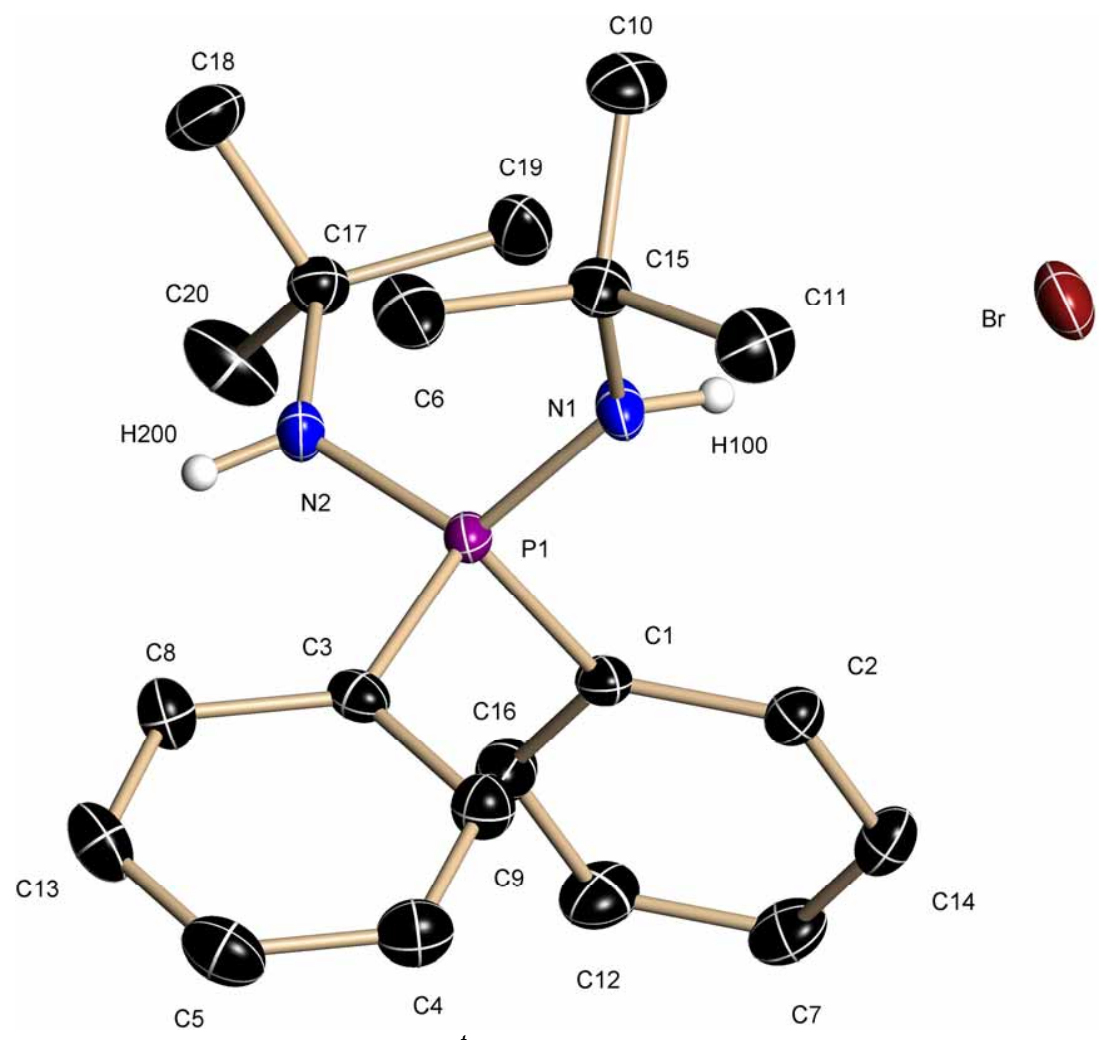

Figure 7-14: Asymmetric unit of $\left[\mathrm{Ph}_{2} \mathrm{P}\left(\mathrm{NH}^{t} \mathrm{Bu}\right)_{2} \mathrm{Br}\right]$. Hydrogen atoms have been omitted for clarity. 
The hydrogen atoms at the nitrogen atoms were found using a difference Fourier analysis of the rest electron density.

Table 7-14: Crystallographic data for $\left[\mathrm{Ph}_{2} \mathrm{P}\left(\mathrm{NH}^{t} \mathrm{Bu}\right)_{2} \mathrm{Br}\right]$.

\begin{tabular}{|ll|ll|}
\hline structure code & $\mathrm{P} 104$ & $F(000)$ & 856 \\
formula & $\mathrm{C}_{20} \mathrm{H}_{30} \mathrm{BrN}_{2} \mathrm{P}$ & max. / min. Transmission & $0.3855 / 0.4299$ \\
molecular mass / g $\cdot \mathrm{mol}^{-1}$ & 409.34 & $\rho_{\text {calc }} /{\mathrm{Mg} \cdot \mathrm{m}^{-3}}^{-3}$ & 1.290 \\
crystal size / mm & $0.2 \times 0.1 \times 0.1$ & $\mu / \mathrm{mm}^{-1}$ & 2.030 \\
crystal system & monoclinic & $\theta_{\min } / \theta_{\text {max }}{ }^{\circ}$ & $2.75-26.77$ \\
space group & $C c$ & reflections all/unique & $22926 / 4485$ \\
a / $\AA$ & $13.985(2)$ & data/restraints/parameter & $4485 / 2 / 231$ \\
b / $\AA$ & $15.936(3)$ & $R 1$ (all data) & 0.0203 \\
c / $\AA$ & $9.5551(17)$ & $w R 2$ (all data) & 0.0513 \\
$\beta / \circ$ & $98.138(2)$ & $g 1 / g 2$ & $0.0285 / 1.3078$ \\
V / $\AA^{3}$ & $2108.0(6)$ & GoF & 1.055 \\
Z & 4 & Flack x parameter & $0.018(4)$ \\
temperature / K & $100(2)$ & peak/hole $\left(10^{-6} \mathrm{e} \cdot \AA^{-3}\right)$ & $0.487 /-0.347$ \\
\hline
\end{tabular}




\subsubsection{5 [\{(THF) $\left.\left.)_{2} \mathrm{Li}\left(\mathrm{N}^{t} \mathrm{Bu}\right)_{2} \mathrm{~S}\right\}_{2} \mathrm{An}\right](12)$}

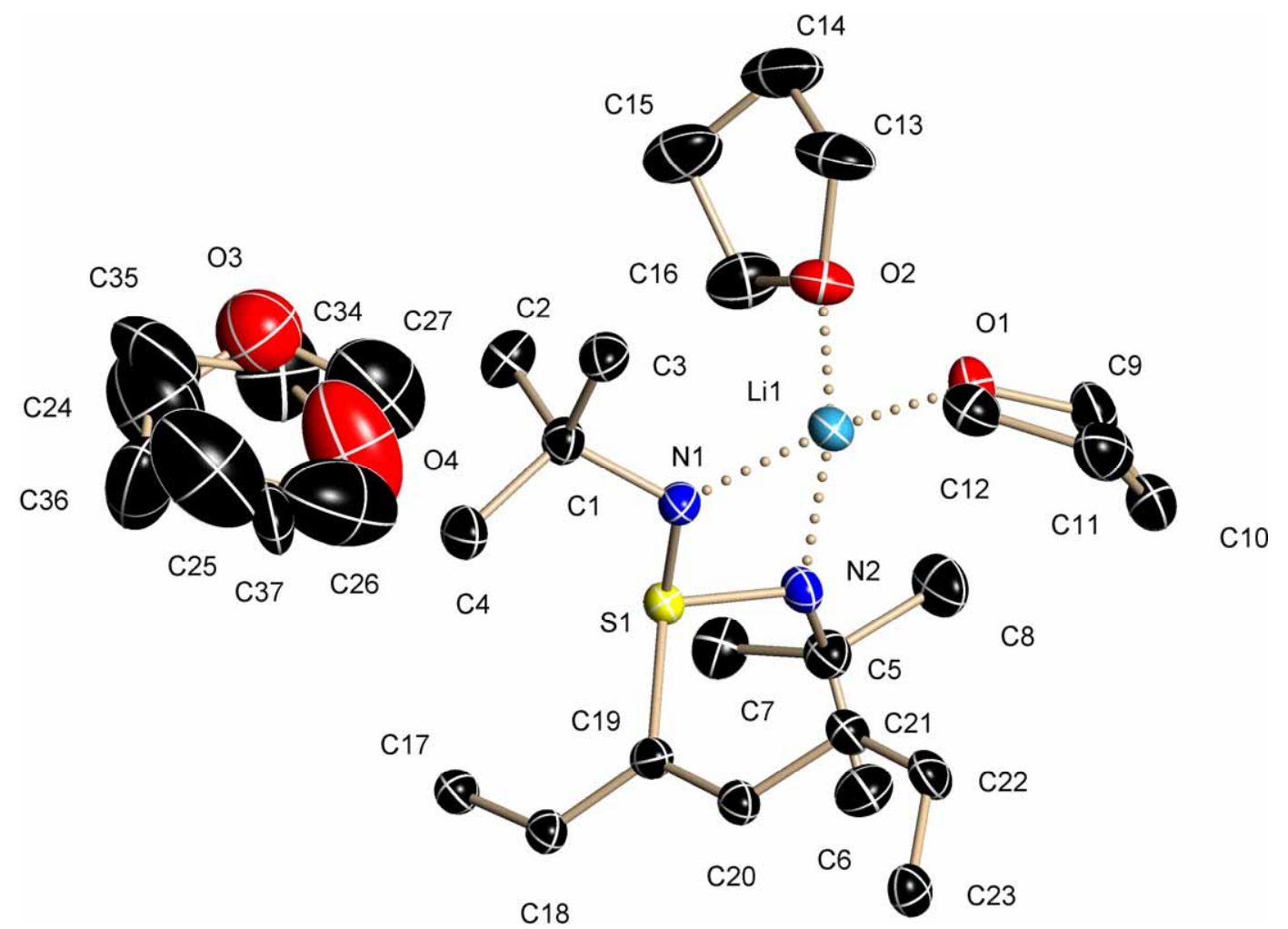

Figure 7-15: Asymmetric unit of $\left[\left\{(\mathrm{THF})_{2} \mathrm{Li}\left(\mathrm{N}^{t} \mathrm{Bu}\right)_{2} \mathrm{~S}\right\}_{2} \mathrm{An}\right](\mathbf{1 2})$. Hydrogen atoms have been omitted for clarity.

Except for the non-coordinated THF molecule no disorders are present. The side occupancy factors of the two THF positions refine to $60 \%$ and $40 \%$.

Table 7-15: Crystallographic data for $\left[\left\{(\mathrm{THF})_{2} \mathrm{Li}\left(\mathrm{N}^{t} \mathrm{Bu}\right)_{2} \mathrm{~S}\right\}_{2} \mathrm{An}\right](\mathbf{1 2})$.

\begin{tabular}{|ll|ll|}
\hline structure code & Doppelmandy & $F(000)$ & 1060 \\
formula & $\mathrm{C}_{54} \mathrm{H}_{92} \mathrm{Li}_{2} \mathrm{~N}_{4} \mathrm{O}_{6} \mathrm{~S}_{2}$ & max. / min. Transmission & $0.6059 / 0.7454$ \\
molecular mass $/ \mathrm{g} \cdot \mathrm{mol}^{-1}$ & 971.32 & $\rho_{\text {calc }} /{\mathrm{Mg} \cdot \mathrm{m}^{-3}}^{-3}$ & 1.115 \\
crystal size / mm & $0.2 \times 0.15 \times 0.15$ & $\mu / \mathrm{mm}^{-1}$ & 0.140 \\
crystal system & monoclinic & $\theta_{\min } / \theta_{\max }{ }^{\circ}$ & $2.42-26.02$ \\
space group & $P 2(1) / n$ & reflections all/unique & $31291 / 5681$ \\
$\mathrm{a} / \AA$ & $10.5726(17)$ & data/restraints/parameter & $5681 / 104 / 341$ \\
$\mathrm{~b} / \AA$ & $17.182(3)$ & $R 1$ (all data) & 0.0669 \\
$\mathrm{c} / \AA$ & $16.000(3)$ & $w R 2($ all data) & 0.1500 \\
$\beta /{ }^{\circ}$ & $95.455(2)$ & $g 1 / g 2$ & $0.0761 / 1.4867$ \\
$\mathrm{~V} / \AA^{3}$ & $2893.5(8)$ & GoF & 1.082 \\
$\mathrm{Z}$ & 2 & peak/hole: & \\
temperature / K & $100(2)$ & max. / min. / $\left(10^{-6} \mathrm{e} \cdot \AA^{-3}\right)$ & $0.501 /-0.521$ \\
\hline
\end{tabular}




\subsubsection{6 [\{(THF $\left.\left.)_{2} \mathrm{Li}\left(\mathrm{NSiMe}_{3}\right)_{2} \mathrm{~S}\right\}_{2} \mathrm{An}\right](13)$}

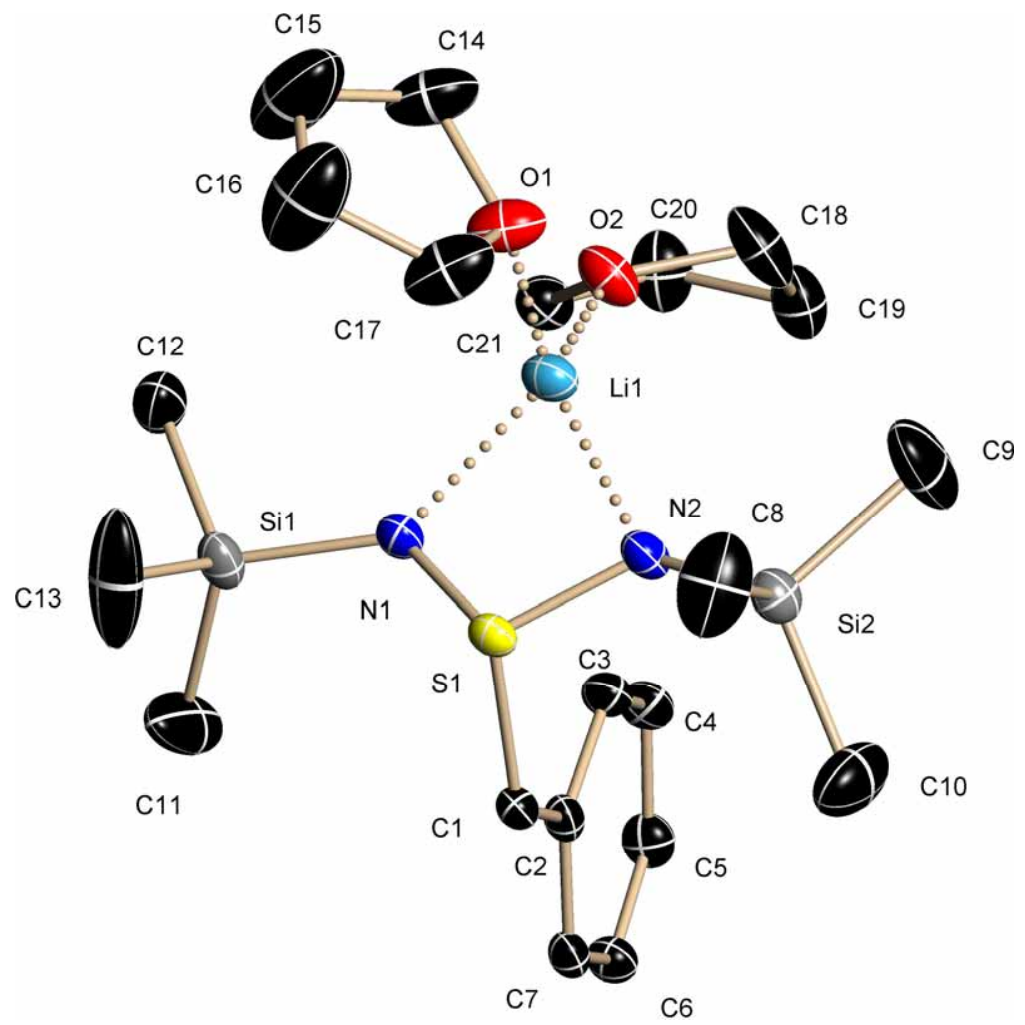

Figure 7-16: Asymmetric unit of $\left[\left\{(\mathrm{THF})_{2} \mathrm{Li}\left(\mathrm{NSiMe}_{3}\right)_{2} \mathrm{~S}\right\}_{2} \mathrm{An}\right](13)$. Hydrogen atoms have been omitted for clarity.

Table 7-16: Crystallographic data for $\left[\left\{(\mathrm{THF})_{2} \mathrm{Li}\left(\mathrm{NSiMe}_{3}\right)_{2} \mathrm{~S}\right\}_{2} \mathrm{An}\right](13)$.

\begin{tabular}{|c|c|c|c|}
\hline structure code & DoppelSiMandy & $F(000)$ & 964 \\
\hline formula & $\begin{array}{l}\mathrm{C}_{42} \mathrm{H}_{76} \mathrm{Li}_{2} \mathrm{~N}_{4} \\
\mathrm{O}_{4} \mathrm{~S}_{2} \mathrm{Si}_{4}\end{array}$ & max. / min. Transmission & $0.6153 / 0.7452$ \\
\hline molecular mass $/ \mathrm{g} \cdot \mathrm{mol}^{-1}$ & 891.43 & $\rho_{\text {calc }} / \mathrm{Mg} \cdot \mathrm{m}^{-3}$ & 1.139 \\
\hline crystal size / mm & $0.15 \times 0.1 \times 0.05$ & $\mu / \mathrm{mm}^{-1}$ & 0.235 \\
\hline crystal system & monoclinic & $\theta_{\min } / \theta_{\max }^{\circ}$ & $1.64-25.39$ \\
\hline space group & $P 2(1) / n$ & reflections all/unique & $30165 / 4750$ \\
\hline a / $\AA$ & $13.5712(14)$ & data/restraints/parameter & $4750 / 0 / 268$ \\
\hline $\mathrm{b} / \AA$ & $10.7302(11)$ & $R 1$ (all data) & 0.0535 \\
\hline$c / \AA$ & $18.6907(18)$ & $w R 2$ (all data) & 0.1088 \\
\hline$\beta /{ }^{\circ}$ & $107.339(2)$ & $g 1 / g 2$ & $0.0624 / 0.9514$ \\
\hline$V / \AA^{3}$ & $2598.1(5)$ & GoF & 1.040 \\
\hline Z & 2 & peak/hole: & \\
\hline temperature / K & $100(2)$ & $\max . / \min . /\left(10^{-6} \mathrm{e} \cdot \AA^{-3}\right)$ & $0.413 /-0.320$ \\
\hline
\end{tabular}




\subsubsection{7 [\{ $\left.\left.\mathrm{Me}_{2} \mathrm{Al}\left(\mathrm{NSiMe}_{3}\right)_{2} \mathrm{~S}\right\}_{2} \mathrm{An}\right](14)$}

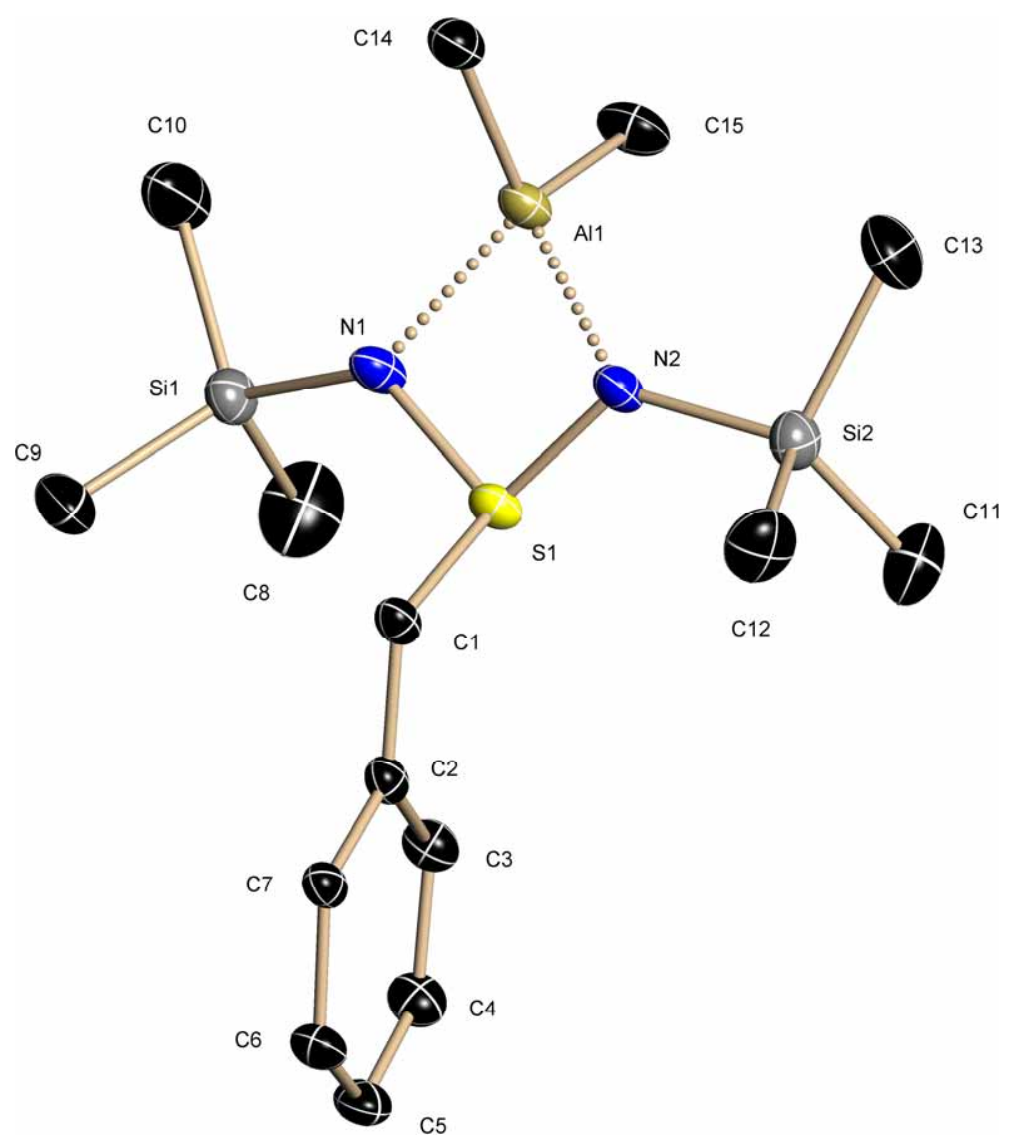

Figure 7-17: Asymmetric unit of $\left[\left\{\mathrm{Me}_{2} \mathrm{Al}\left(\mathrm{NSiMe}_{3}\right)_{2} \mathrm{~S}\right\}_{2} \mathrm{An}\right]$ (14). Hydrogen atoms have been omitted for clarity.

Table 7-17: Crystallographic data for $\left[\left\{\mathrm{Me}_{2} \mathrm{Al}\left(\mathrm{NSiMe}_{3}\right)_{2} \mathrm{~S}\right\}_{2} \mathrm{An}\right]$ (14).

\begin{tabular}{|c|c|c|c|}
\hline structure code & DoppelSiAlana & $F(000)$ & 756 \\
\hline formula & $\mathrm{C}_{30} \mathrm{H}_{56} \mathrm{Al}_{2} \mathrm{~N}_{4} \mathrm{~S}_{2} \mathrm{Si}_{4}$ & max. / min. Transmission & $0.6438 / 0.7454$ \\
\hline molecular mass $/ \mathrm{g} \cdot \mathrm{mol}^{-1}$ & 703.23 & $\rho_{\text {calc }} / \mathrm{Mg} \cdot \mathrm{m}^{-3}$ & 1.137 \\
\hline crystal size / mm & $0.2 \times 0.15 \times 0.15$ & $\mu / \mathrm{mm}^{-1}$ & 0.314 \\
\hline crystal system & monoclinic & $\theta_{\min } / \theta_{\max }^{\circ}$ & $2.00-26.75$ \\
\hline space group & $P 2(1) / n$ & reflections all/unique & 48448 / 4353 \\
\hline $\mathrm{a} / \AA$ & $9.4066(9)$ & data/restraints/parameter & $4353 / 0 / 198$ \\
\hline $\mathrm{b} / \AA$ & $20.374(2)$ & $R 1$ (all data) & 0.0343 \\
\hline$c / \AA$ & $11.5702(12)$ & $w R 2$ (all data) & 0.0746 \\
\hline$\beta /{ }^{\circ}$ & $95.455(2)$ & $g 1 / g 2$ & $0.0337 / 0.8553$ \\
\hline$V / \AA^{3}$ & $2053.8(4)$ & GoF & 1.099 \\
\hline z & 2 & peak/hole: & \\
\hline temperature / $\mathrm{K}$ & $100(2)$ & $\max . / \min . /\left(10^{-6} \mathrm{e} \cdot \AA^{-3}\right)$ & $0.318 /-0.224$ \\
\hline
\end{tabular}




\subsubsection{8 $\left[\left(\mathrm{Et}_{2} \mathrm{O}\right)_{0.5} \mathrm{Li}\left\{\left(\mathrm{N}^{t} \mathrm{Bu}\right)\left(\mathrm{SiMe}_{3}\right) \mathrm{SEt}_{2}(15)\right.\right.$}

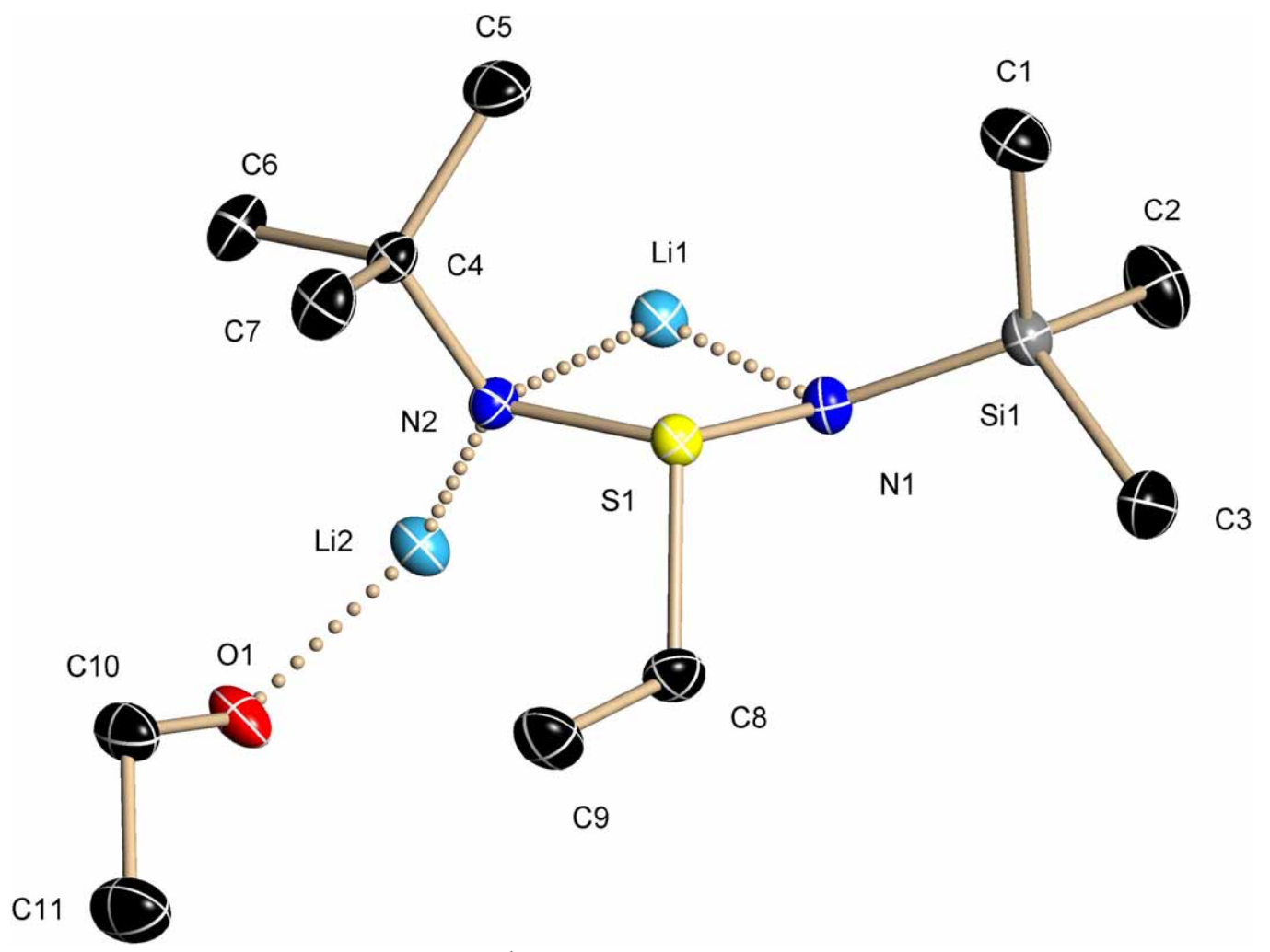

Figure 7-18: Asymmetric unit of $\left[\left(\mathrm{Et}_{2} \mathrm{O}\right)_{0.5} \mathrm{Li}\left\{\left(\mathrm{N}^{t} \mathrm{Bu}\right)\left(\mathrm{SiMe}_{3}\right) \mathrm{SEt}_{2}(\mathbf{1 5})\right.\right.$. Hydrogen atoms have been omitted for clarity.

Table 7-18: Crystallographic data for $\left[\left(\mathrm{Et}_{2} \mathrm{O}\right)_{0.5} \mathrm{Li}\left\{\left(\mathrm{N}^{t} \mathrm{Bu}\right)\left(\mathrm{SiMe}_{3}\right) \mathrm{SEt}_{2}(\mathbf{1 5})\right.\right.$.

\begin{tabular}{|ll|ll|}
\hline structure code & EtLiDiimid & $F(000)$ & 1160 \\
formula & $\mathrm{C}_{22} \mathrm{H}_{56} \mathrm{Li}_{2} \mathrm{~N}_{4} \mathrm{OS}_{2} \mathrm{Si}_{2}$ & max. / min. Transmission & $0.89 / 0.99$ \\
molecular mass / g $\cdot \mathrm{mol}^{-1}$ & 526.89 & $\rho_{\text {calc }} / \mathrm{Mg} \cdot \mathrm{m}^{-3}$ & 1.056 \\
crystal size / mm & $0.15 \times 0.12 \times 0.1$ & $\mu / \mathrm{mm}^{-1}$ & 0.252 \\
crystal system & monoclinic & $\theta_{\min } / \theta_{\max }{ }^{\circ}$ & $2.25-28.00$ \\
space group & $C 2 / c$ & reflections all/unique & $10502 / 3733$ \\
$\mathrm{a} / \AA$ & $16.3989(12)$ & data/restraints/parameter & $3733 / 0 / 159$ \\
$\mathrm{~b} / \AA$ & $12.3531(9)$ & $R 1$ (all data) & 0.0346 \\
$\mathrm{c} / \AA$ & $17.0170(12)$ & $w R 2($ all data $)$ & 0.0779 \\
$\beta /{ }^{\circ}$ & $106.0020(10)$ & $g 1 / g 2$ & $0.0327 / 3.6134$ \\
$\mathrm{~V} / \AA^{3}$ & $3313.7(4)$ & GoF & 1.038 \\
$\mathrm{Z}$ & 4 & peak/hole: & \\
temperature / K & $100(2)$ & max. / min. / $\left(10^{-6} \mathrm{e} \cdot \AA^{-3}\right)$ & $0.390 /-0.255$ \\
\hline
\end{tabular}




\subsubsection{9 [(THF) $)_{0.5} \mathrm{Li}\left\{\left(\mathrm{N}^{t} \mathrm{Bu}\right)_{2} \mathrm{SBz}\right]_{2}(16)$}

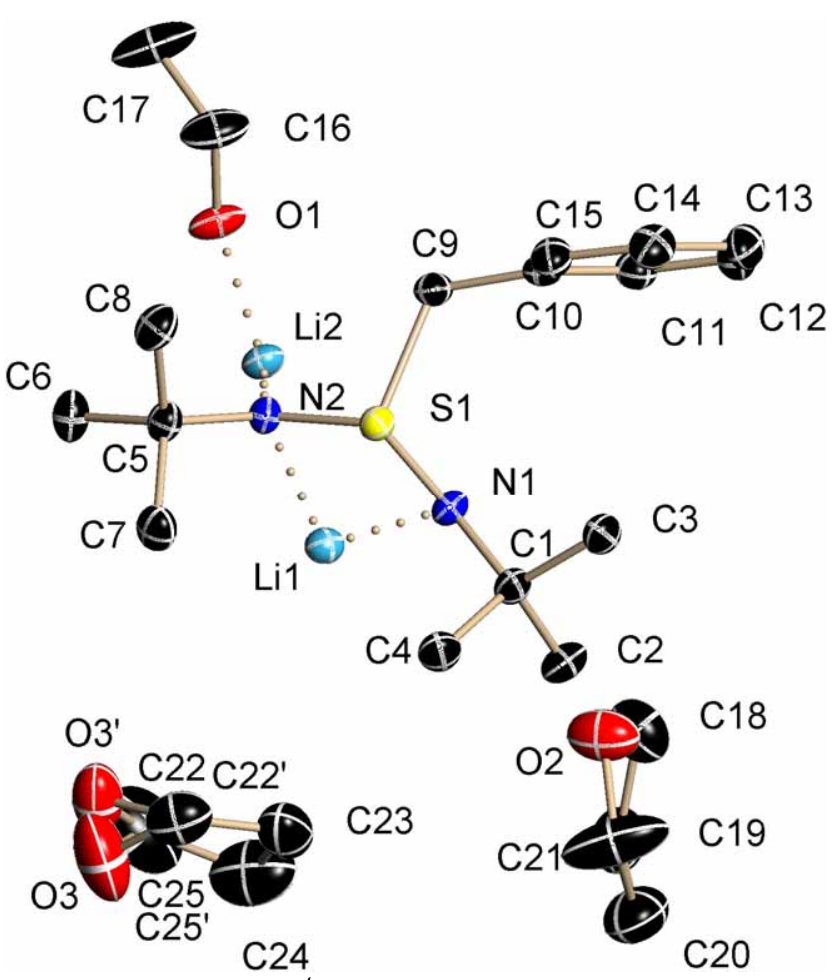

Figure 7-19: Asymmetric unit of $\left[(\mathrm{THF})_{0.5} \mathrm{Li}\left\{\left(\mathrm{N}^{t} \mathrm{Bu}\right)_{2} \mathrm{SBz}\right]_{2}(16)\right.$. Hydrogen atoms have been omitted for clarity.

In the solid state structure of $\mathbf{1 6}$ two carbon atoms and the oxygen atom of one of the two non-coordinated THF molecules are disordered. The side occupancy factors refine to $50 \%$. DFIX, ISOR, EADP and EXYZ commands were used to stabilize the disorder.

Table 7-19: Crystallographic data for $\left[(\mathrm{THF})_{0.5} \mathrm{Li}\left\{\left(\mathrm{N}^{t} \mathrm{Bu}\right)_{2} \mathrm{SBz}\right]_{2}(\mathbf{1 6})\right.$.

\begin{tabular}{|ll|ll|}
\hline structure code & $\mathrm{BzLi}$ & $F(000)$ & 1984 \\
formula & $\mathrm{C}_{50} \mathrm{H}_{90} \mathrm{Li}_{2} \mathrm{~N}_{4} \mathrm{O}_{5} \mathrm{~S}_{2}$ & max. / min. Transmission & $0.88 / 0.99$ \\
molecular mass $/ \mathrm{g} \cdot \mathrm{mol}^{-1}$ & 905.26 & $\rho_{\text {calc }} / \mathrm{Mg} \cdot \mathrm{m}^{-3}$ & 1.115 \\
crystal size / mm & $0.2 \times 0.15 \times 0.15$ & $\mu / \mathrm{mm}^{-1}$ & 0.144 \\
crystal system & monoclinic & $\theta_{\min } / \theta_{\max }{ }^{\circ}$ & $2.18-25.37$ \\
space group & $C 2 / c$ & reflections all/unique & $35720 / 4948$ \\
$\mathrm{a} / \AA$ & $16.3216(10)$ & data/restraints/parameter & $4948 / 16 / 299$ \\
$\mathrm{~b} / \AA$ & $12.2763(8)$ & $R 1$ (all data) & 0.0649 \\
$\mathrm{c} / \AA$ & $26.9940(17)$ & $w R 2($ all data) & 0.1105 \\
$\beta /{ }^{\circ}$ & $94.0910(10)$ & $g 1 / g 2$ & $0.0435 / 7.2428$ \\
$\mathrm{~V} / \AA^{3}$ & $5395.0(6)$ & GoF & 1.027 \\
$\mathrm{Z}$ & 4 & peak/hole: & \\
temperature / K & $100(2)$ & max. / min. / $\left(10^{-6} \mathrm{e} \cdot \AA^{-3}\right)$ & $0.385 /-0.251$ \\
\hline
\end{tabular}




\subsubsection{0 [(THF) $)_{2} \mathrm{MgBr}\left\{\left(\mathrm{N}^{t} \mathrm{Bu}\right)_{2} \mathrm{SMe}\right](17)$}

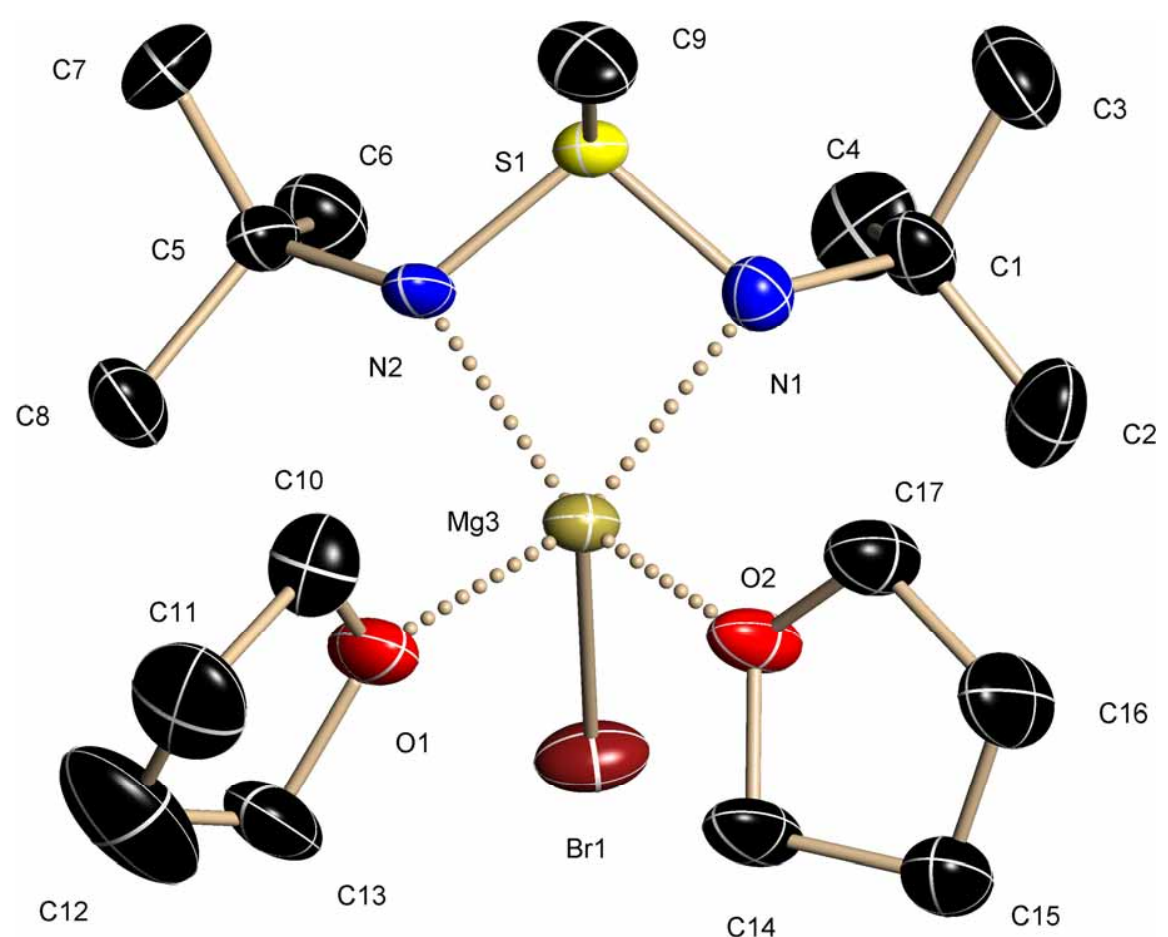

Figure 7-20: Asymmetric unit of $\left[(\mathrm{THF})_{2} \mathrm{MgBr} r\left(\mathrm{~N}^{t} \mathrm{Bu}\right)_{2} \mathrm{SMe}\right](17)$. Hydrogen atoms have been omitted for clarity.

The data had to be recorded at $170 \mathrm{~K}$ since the presence of polymorph transitions prohibited cooling to $100 \mathrm{~K}$. The crystals of 17 were non-merohedrally twinned. The orientation matrices of the additional component and the initial cell were determined using CELL_NOW. Those matrices were then used for integrating the domains separately with SAINT. Subsequent absorption correction with TWINABS lead to a HKLF4 file for structure solution and a HKLF5 file for further refinement. The occupancy factor of the additional domain refined to $50 \%$. 
Table 7-20: Crystallographic data for $\left[(\mathrm{THF})_{2} \mathrm{MgBr} r\left(\mathrm{~N}^{t} \mathrm{Bu}\right)_{2} \mathrm{SMe}\right](\mathbf{1 7})$.

\begin{tabular}{|c|c|c|c|}
\hline structure code & MeDiimid & $F(000)$ & 464 \\
\hline formula & $\mathrm{C}_{17} \mathrm{H}_{37} \mathrm{SN}_{2} \mathrm{MgBrO}_{2}$ & max. / min. Transmission & $0.295741 /$ \\
\hline flack $x$ & $0.0818(85)$ & & 0.429318 \\
\hline molecular mass $/ \mathrm{g} \cdot \mathrm{mol}^{-1}$ & 437.77 & $\rho_{\text {calc }} / \mathrm{Mg} \cdot \mathrm{m}^{-3}$ & 1.284 \\
\hline crystal size / mm & $0.15 \times 0.1 \times 0.05$ & $\mu / \mathrm{mm}^{-1}$ & 1.946 \\
\hline crystal system & monoclinic & $\theta_{\min } / \theta_{\max }^{\circ}$ & $2.24-26.04$ \\
\hline space group & $P c$ & reflections all/unique & 20492 / 4439 \\
\hline a / $\AA$ & $9.763(4)$ & data/restraints/parameter & 4439 / 42 / 225 \\
\hline $\mathrm{b} / \AA$ & $16.860(3)$ & $R 1$ (all data) & 0.0416 \\
\hline$c / \AA$ & $7.371(2)$ & $w R 2$ (all data) & 0.0977 \\
\hline$\beta /{ }^{\circ}$ & $111.02(2)$ & $g 1 / g 2$ & $0.0578 / 0.7348$ \\
\hline$V / \AA^{3}$ & $1132.5(6)$ & GoF & 1.046 \\
\hline Z & 2 & Flack x parameter: & $0.0818(85)$ \\
\hline temperature / $\mathrm{K}$ & $170(2)$ & Peak / hole / $\left(10^{-6} \mathrm{e} \cdot \AA^{-3}\right)$ & $0.69 /-0.40$ \\
\hline
\end{tabular}

\subsubsection{1 [(THF) $)_{2} \mathrm{MgCl}\left\{\left(\mathrm{N}^{t} \mathrm{Bu}\right)_{2} \mathrm{~S}^{n} \mathrm{Bu}\right](18)$}

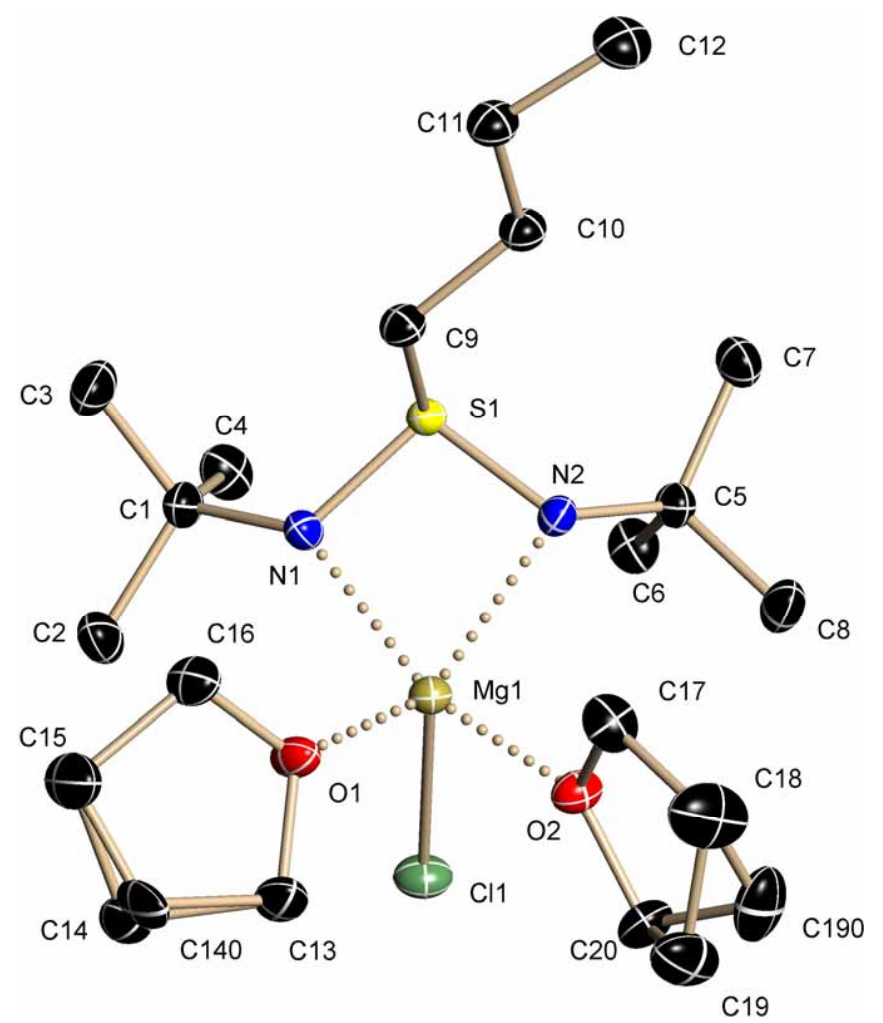

Figure 7-21: Asymmetric unit of $\left[(\mathrm{THF})_{2} \mathrm{MgCl}\left\{\left(\mathrm{N}^{t} \mathrm{Bu}\right)_{2} \mathrm{~S}^{n} \mathrm{Bu}\right](\mathbf{1 8})\right.$. Hydrogen atoms have been omitted for clarity. 
In 18 one carbon atom of each THF molecule is disordered. The side occupancy factors refine to $90 \%$ for $\mathrm{C} 14$ and $60 \%$ for C19. SIMU and DELU restraints were used to stabilize the disorder.

Table 7-21: Crystallographic data for $\left[(\mathrm{THF})_{2} \mathrm{MgCl}\left(\mathrm{N}^{t} \mathrm{Bu}\right)_{2} \mathrm{~S}^{n} \mathrm{Bu}\right](\mathbf{1 8})$.

\begin{tabular}{|ll|ll|}
\hline structure code & nBuDiimid & $F(000)$ & 952 \\
formula & $\mathrm{C}_{20} \mathrm{H}_{43} \mathrm{ClMgN}_{2} \mathrm{O}_{2} \mathrm{~S}$ & max. / min. Transmission & $0.7098 / 0.7454$ \\
molecular mass / g $\cdot \mathrm{mol}^{-1}$ & 435.38 & $\rho_{\text {calc }} /{\mathrm{Mg} \cdot \mathrm{m}^{-3}}^{-3}$ & 1.162 \\
crystal size / mm & $0.15 \times 0.08 \times 0.08$ & $\mu / \mathrm{mm}^{-1}$ & 0.279 \\
crystal system & monoclinic & $\theta_{\min } / \theta_{\text {max }}{ }^{\circ}$ & $2.07-26.37$ \\
space group & $P 2(1) / c$ & reflections all/unique & $44906 / 5064$ \\
a / $\AA$ & $7.3202(8)$ & data/restraints/parameter & $5064 / 40 / 271$ \\
b / $\AA$ & $32.936(4)$ & $R 1$ (all data) & 0.0349 \\
c / $\AA$ & $10.3840(11)$ & $w R 2$ (all data) & 0.0783 \\
$\beta / \circ$ & $96.4210(10)$ & $g 1 / g 2$ & $0.0309 / 1.4478$ \\
V / $\AA^{3}$ & $2487.9(5)$ & GoF & 1.093 \\
Z & 4 & peak/hole: & \\
temperature / K & $100(2)$ & max. / min. / $\left(10^{-6} \mathrm{e} \cdot \AA^{-3}\right)$ & $0.311 /-0.346$ \\
\hline
\end{tabular}

\subsubsection{2 [(THF)MgBr(N $\left.{ }^{t} \mathrm{Bu}\right)_{3} \mathrm{SMe}_{2}(22)$}

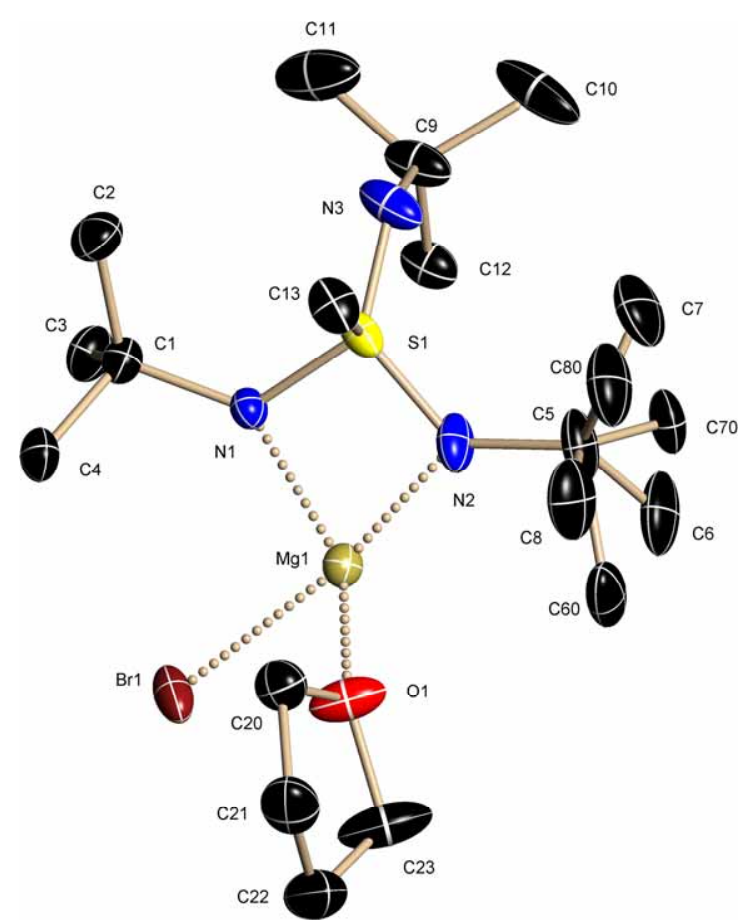

Figure 7-22: Asymmetric unit of $\left[(\mathrm{THF}) \mathrm{MgBr}\left(\mathrm{N}^{t} \mathrm{Bu}\right)_{3} \mathrm{SMe}_{2}\right.$ (22). Hydrogen atoms have been omitted for clarity. 
In 22 one tert-butyl group is disordered. The side occupancy factor for the second position refines to $40 \%$.

Table 7-22: Crystallographic data for $\left[(\mathrm{THF}) \mathrm{MgBr}\left(\mathrm{N}^{t} \mathrm{Bu}\right)_{3} \mathrm{SMe}_{2}(\mathbf{2 2})\right.$.

\begin{tabular}{|ll|ll|}
\hline structure code & MeTrimid & $F(000)$ & 1856 \\
formula & $\mathrm{C}_{17} \mathrm{H}_{38} \mathrm{BrMgN}_{3} \mathrm{OS}$ & max. / min. Transmission & $0.3617 / 0.4288$ \\
molecular mass $/ \mathrm{g} \cdot \mathrm{mol}^{-1}$ & 436.78 & $\rho_{\text {calc }} / \mathrm{Mg} \cdot \mathrm{m}^{-3}$ & 1.319 \\
crystal size / mm & $0.2 \times 0.2 \times 0.05$ & $\mu / \mathrm{mm}^{-1}$ & 2.002 \\
crystal system & orthorhombic & $\theta_{\min } / \theta_{\max }{ }^{\circ}$ & $2.74-25.41$ \\
space group & $P b c a$ & reflections all/unique & $33816 / 4044$ \\
a / $\AA$ & $13.422(3)$ & data/restraints/parameter & $4044 / 0 / 258$ \\
b / $\AA$ & $14.870(3)$ & $R 1$ (all data) & 0.0376 \\
c / $\AA$ & $22.040(5)$ & $w R 2$ (all data) & 0.0743 \\
$\mathrm{~V} / \AA^{3}$ & $4398.8(17)$ & $g 1 / g 2$ & $0.0322 / 4.3500$ \\
$\mathrm{Z}$ & 8 & GoF & 1.055 \\
temperature / K & $100(2)$ & peak / hole / $\left(10^{-6} \mathrm{e} \cdot \AA^{-3}\right)$ & $0.661 /-0.858$ \\
\hline
\end{tabular}

\subsubsection{3 [(THF)MgCl(N $\left.\left.{ }^{t} \mathrm{Bu}\right)_{3} \mathrm{~S}^{n} \mathrm{Bu}\right]_{2}(23)$}

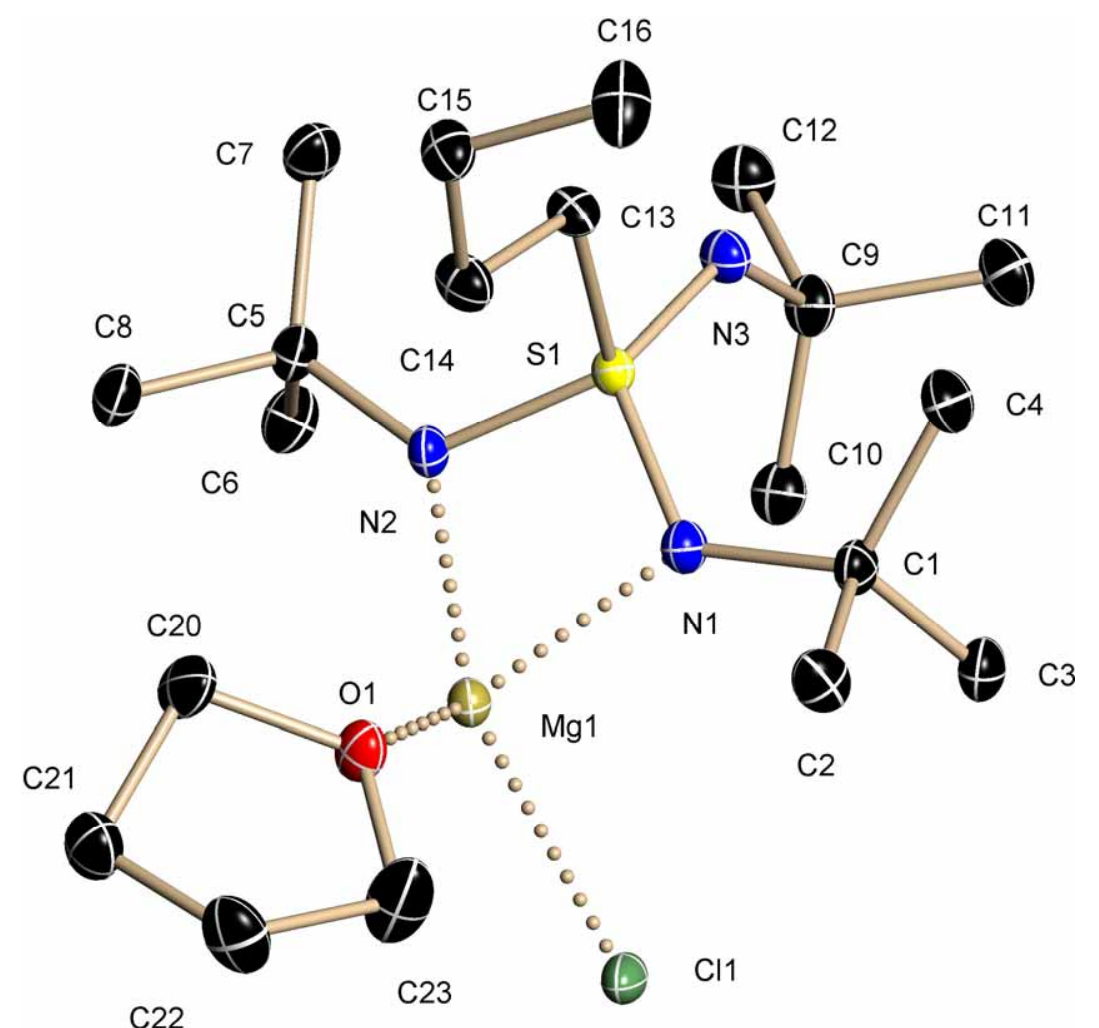

Figure 7-23: Asymmetric unit of $\left[(\mathrm{THF}) \mathrm{MgCl}\left(\mathrm{NBu}^{t}\right)_{3} \mathrm{~S}^{n} \mathrm{Bu}\right]_{2}(23)$. Hydrogen atoms have been omitted for clarity. 
The crystals of $\mathbf{2 3}$ were non-merohedrally twinned. The orientation matrices of the additional component and the initial cell were determined using CELL_NOW. Those matrices were then used for integrating the domains separately with SAINT. Subsequent absorption correction with TWINABS lead to a HKLF4 file for structure solution and a HKLF5 file for further refinement. The occupancy factor of the additional domain refined to $15 \%$.

Table 7-23: Crystallographic data for $\left[(\mathrm{THF}) \mathrm{MgCl}\left(\mathrm{N}^{t} \mathrm{Bu}\right)_{3} \mathrm{~S}^{n} \mathrm{Bu}\right]_{2}(23)$.

\begin{tabular}{|ll|ll|}
\hline structure code & nBuTriimid & temperature / K & $100(2)$ \\
formula & $\mathrm{C}_{40} \mathrm{H}_{88} \mathrm{Cl}_{2} \mathrm{Mg}_{2}$ & max. / min. Transmission & $0.487689 /$ \\
& $\mathrm{N}_{6} \mathrm{O}_{2} \mathrm{~S}_{2}$ & & 0.745214 \\
molecular mass / g.mol ${ }^{-1}$ & 868.80 & $\rho_{\text {calc }} / \mathrm{Mg} \cdot \mathrm{m}^{-3}$ & 1.174 \\
crystal size / mm & $0.1 \times 0.05 \times 0.05$ & $\mu / \mathrm{mm}^{-1}$ & 0.280 \\
crystal system & triclinic & $F(000)$ & 476 \\
space group & $P \overline{1}$ & $\theta_{\text {min }} / \theta_{\text {max }}{ }^{\circ}$ & $2.29-25.43$ \\
a / $\AA$ & $9.2280(11)$ & reflections all/unique & $9031 / 4520$ \\
$\mathrm{~b} / \AA$ & $9.3400(10)$ & data/restraints/parameter & $4520 / 0 / 255$ \\
$\mathrm{c} / \AA$ & $15.3562(10)$ & $R 1$ (all data) & 0.0571 \\
$\alpha /{ }^{\circ}$ & $80.931(2)$ & $w R 2$ (all data) & 0.1309 \\
$\beta /{ }^{\circ}$ & $76.870(2)$ & $g 1 / g 2$ & $0.0849 / 0.7776$ \\
$\gamma /{ }^{\circ}$ & $73.427(2)$ & GoF & 1.026 \\
$\mathrm{~V} / \AA^{3}$ & $1229.0(2)$ & peak/hole: & \\
$\mathrm{Z}$ & 1 & max. / min. / $\left(10^{-6} \mathrm{e} \cdot \AA^{-3}\right)$ & $0.516 /-0.680$ \\
\hline
\end{tabular}




\subsubsection{4 [(THF)MgCl(N $\left.\left.{ }^{t} \mathrm{Bu}\right)_{3} \mathrm{SPh}\right]_{2}(24)$}

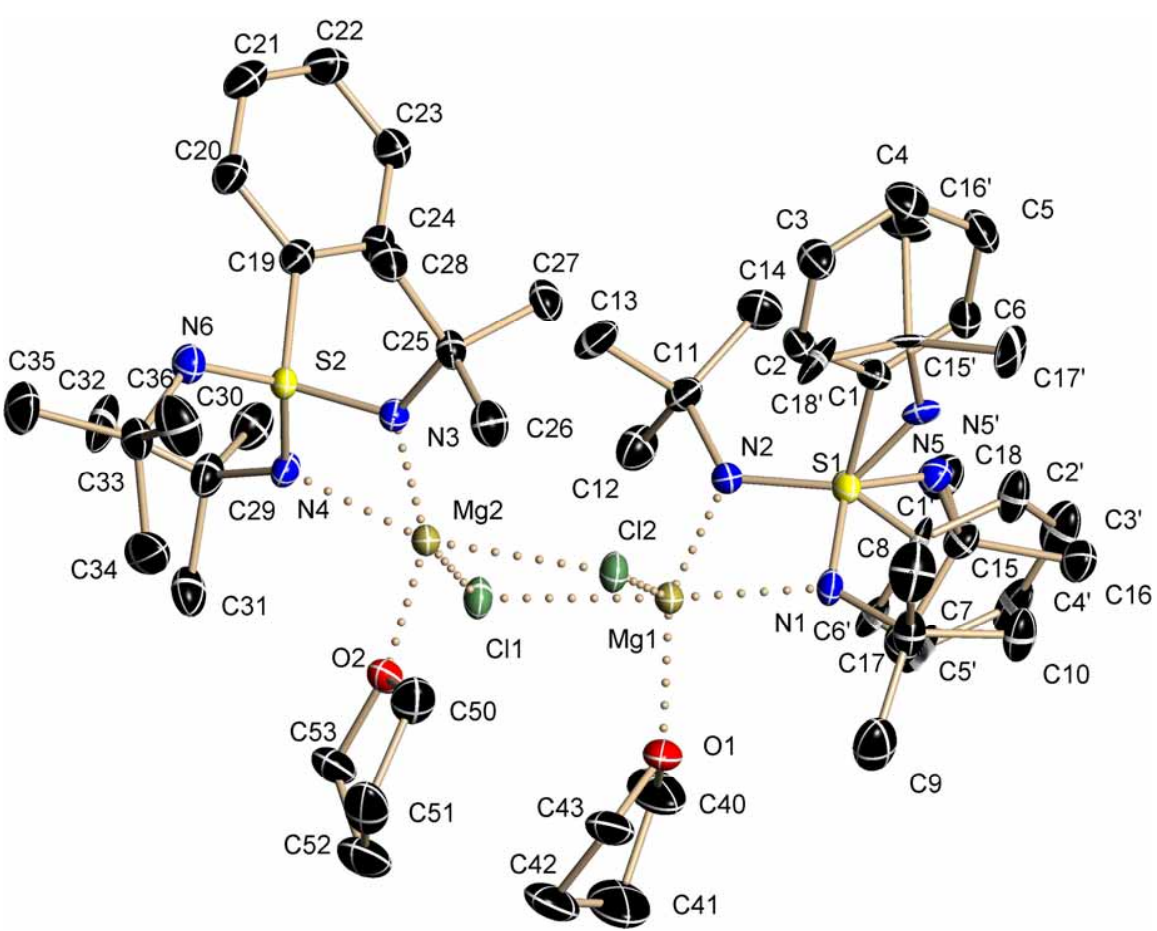

Figure 7-24: Asymmetric unit of $\left[(\mathrm{THF}) \mathrm{MgCl}\left(\mathrm{N}^{t} \mathrm{Bu}\right)_{3} \mathrm{SPh}\right]_{2}(24)$. Hydrogen atoms have been omitted for clarity.

In 24 the positions of the non-coordinating $\mathrm{N}^{t} \mathrm{Bu}$ group and the phenyl substituent are disordered. The side occupancy factor for the smaller domain is $10 \%$. The crystalline samples were racemic twins. The occupancy of the second domain refined to $50 \%$. Therefore the Flack x parameter could not be determined.

Table 7-24: Crystallographic data for $\left[(\mathrm{THF}) \mathrm{MgCl}\left(\mathrm{N}^{t} \mathrm{Bu}\right)_{3} \mathrm{SPh}\right]_{2}(24)$.

\begin{tabular}{|ll|ll|}
\hline structure code & PhTriimid & $F(000)$ & 1968 \\
formula & $\mathrm{C}_{44} \mathrm{H}_{80} \mathrm{Cl}_{2} \mathrm{Mg}_{2}$ & max. / min. Transmission & $0.6489 / 0.7452$ \\
& $\mathrm{~N}_{6} \mathrm{O}_{2} \mathrm{~S}_{2}$ & & \\
molecular mass $/ \mathrm{g} \cdot \mathrm{mol}^{-1}$ & 908.78 & $\rho_{\text {calc }} / \mathrm{Mg} \cdot \mathrm{m}^{-3}$ & 1.197 \\
crystal size / mm & $0.15 \times 0.1 \times 0.05$ & $\mu / \mathrm{mm}^{-1}$ & 0.277 \\
crystal system & orthorhombic & $\theta_{\min } / \theta_{\max }{ }^{\circ}$ & $1.44-25.38$ \\
space group & $P 2_{1} 2_{2} 2_{1}$ & reflections all/unique & $35965 / 9233$ \\
a / $\AA$ & $11.1266(8)$ & data/restraints $/$ parameter & $9233 / 66 / 633$ \\
b / $\AA$ & $16.3889(13)$ & $R 1$ (all data) & 0.0472 \\
c / $\AA$ & $27.660(2)$ & $w R 2($ all data) & 0.0792 \\
V / $\AA^{3}$ & $5043.9(7)$ & $g 1 / g 2$ & $0.08022 / 0.8886$ \\
Z & 4 & GoF & 1.026 \\
temperature / K & $100(2)$ & peak / hole / $\left(10^{-6} \mathrm{e} \cdot \AA^{-3}\right)$ & $0.272 /-0.271$ \\
\hline
\end{tabular}




\subsubsection{5 [(THF)MgCl(N $\left.\left.{ }^{t} \mathrm{Bu}\right)_{3} \mathrm{SBz}\right]_{2}(25)$}

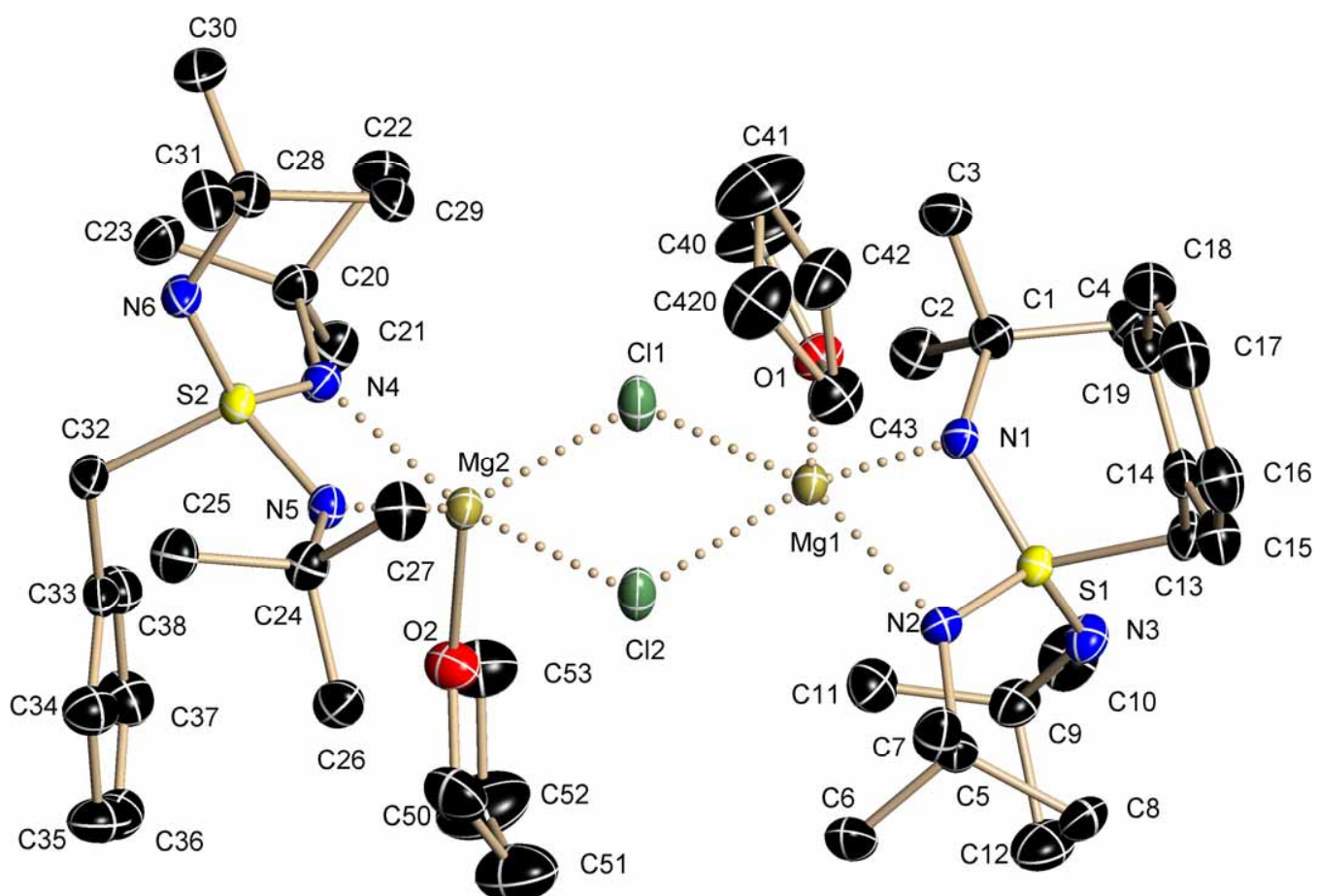

Figure 7-25: Asymmetric unit of $\left[(\mathrm{THF}) \mathrm{MgCl}\left(\mathrm{N}^{t} \mathrm{Bu}\right)_{3} \mathrm{SBz}\right]_{2}(25)$. Hydrogen atoms have been omitted for clarity.

In 25 one carbon atom of one THF molecule is disordered. The side occupancy factors refine to $35 \%$ for C42 and $65 \%$ for C420.

Table 7-25: Crystallographic data for [(THF)MgCl(N $\left.\left.\mathrm{N}^{t} \mathrm{Bu}\right)_{3} \mathrm{SBz}\right]_{2}(25)$.

\begin{tabular}{|c|c|c|c|}
\hline structure code & BzTriimid & temperature / $\mathrm{K}$ & $170(2)$ \\
\hline formula & $\begin{array}{l}\mathrm{C}_{46} \mathrm{H}_{84} \mathrm{Cl}_{2} \mathrm{Mg}_{2} \\
\mathrm{~N}_{6} \mathrm{O}_{2} \mathrm{~S}_{2}\end{array}$ & max. / min. Transmission & $0.5058 / 0.8999$ \\
\hline molecular mass $/ \mathrm{g} \cdot \mathrm{mol}^{-1}$ & 936.83 & $\rho_{\text {calc }} / \mathrm{Mg} \cdot \mathrm{m}^{-3}$ & 1.198 \\
\hline crystal size / mm & $0.35 \times 0.2 \times 0.15$ & $\mu / \mathrm{mm}^{-1}$ & 0.271 \\
\hline crystal system & triclinic & $F(000)$ & 1016 \\
\hline space group & $P \overline{1}$ & $\theta_{\min } / \theta_{\max }^{\circ}$ & $1.69-26.02$ \\
\hline $\mathrm{a} / \AA$ & $12.322(3)$ & reflections all/unique & 26612 / 10222 \\
\hline $\mathrm{b} / \AA$ & $14.472(3)$ & data/restraints/parameter & 10222 / 0 / 569 \\
\hline$c / \AA$ & $15.409(3)$ & $R 1$ (all data) & 0.0713 \\
\hline$\alpha 1^{\circ}$ & $75.81(3)$ & $w R 2$ (all data) & 0.1404 \\
\hline$\beta /{ }^{\circ}$ & $88.29(3)$ & $g 1 / g 2$ & $0.14133 / 0.3568$ \\
\hline$\gamma 1^{\circ}$ & $77.26(3)$ & GoF & 0.998 \\
\hline$V / \AA^{3}$ & $2597.6(9)$ & peak/hole: & \\
\hline z & 2 & $\max . / \min . /\left(10^{-6} \mathrm{e} \cdot \AA^{-3}\right)$ & $0.617 /-0.663$ \\
\hline
\end{tabular}




\subsubsection{6 [(Et $\left.\left.{ }_{2} \mathrm{O}\right) \mathrm{MgBr}\left(\mathrm{N}^{t} \mathrm{Bu}\right)_{3} \mathrm{SMe}\right]_{2}(26)$}

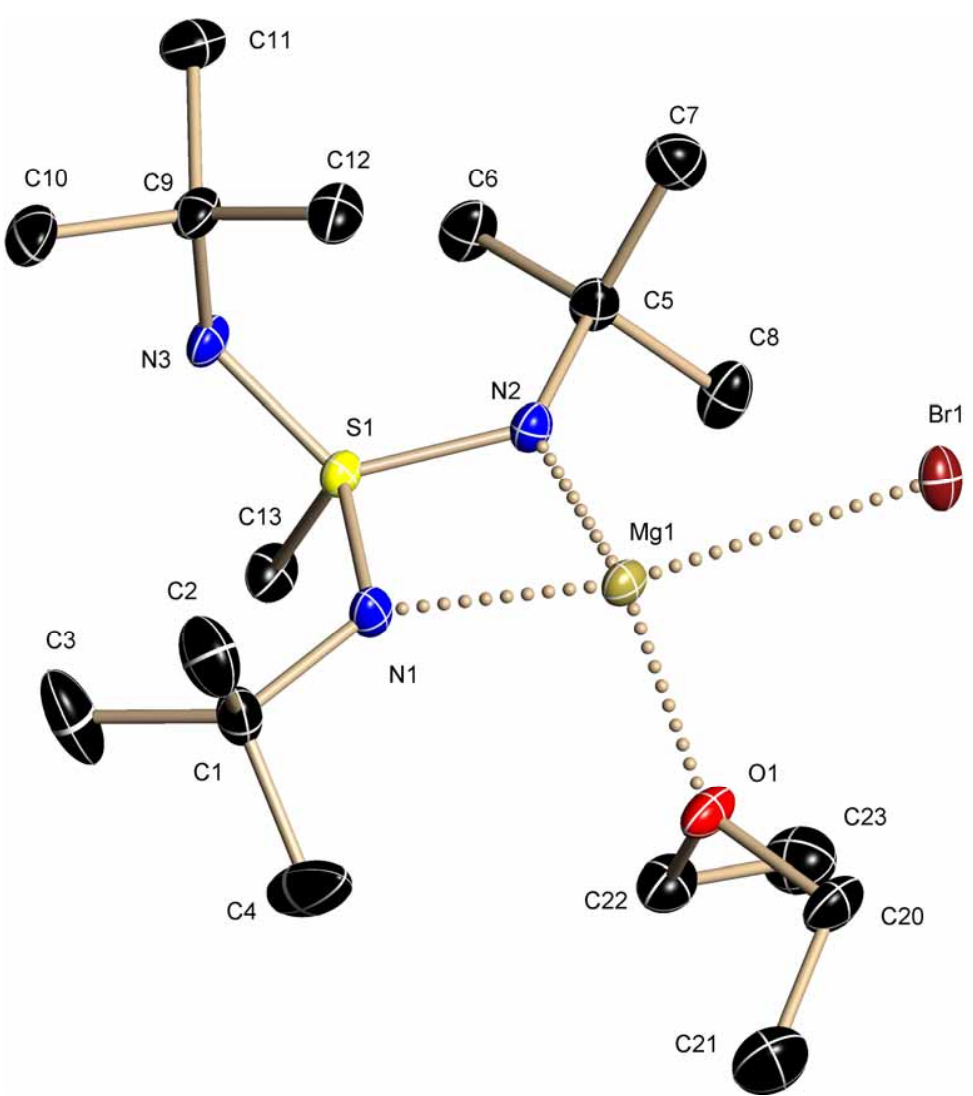

Figure 7-26: : Asymmetric unit of $\left[\left(\mathrm{Et}_{2} \mathrm{O}\right) \mathrm{MgBr}\left(\mathrm{N}^{t} \mathrm{Bu}\right)_{3} \mathrm{SMe}\right]_{2}(26)$. Hydrogen atoms have been omitted for clarity.

Table 7-26: Crystallographic data for $\left[\left(\mathrm{Et}_{2} \mathrm{O}\right) \mathrm{MgBr}\left(\mathrm{N}^{t} \mathrm{Bu}\right)_{3} \mathrm{SMe}_{2}(26)\right.$.

\begin{tabular}{|c|c|c|c|}
\hline structure code & EC2 & $F(000)$ & 936 \\
\hline formula & $\begin{array}{l}\mathrm{C}_{34} \mathrm{H}_{80} \mathrm{Br}_{2} \mathrm{Mg}_{2} \\
\mathrm{~N}_{6} \mathrm{O}_{2} \mathrm{~S}_{2}\end{array}$ & max. / min. Transmission & $0.2929 / 0.4288$ \\
\hline molecular mass $/ \mathrm{g} \cdot \mathrm{mol}^{-1}$ & 877.60 & $\rho_{\text {calc }} / \mathrm{Mg} \cdot \mathrm{m}^{-3}$ & 1.302 \\
\hline crystal size / mm & $0.1 \times 0.1 \times 0.05$ & $\mu / \mathrm{mm}^{-1}$ & 1.967 \\
\hline crystal system & monoclinic & $\theta_{\min } / \theta_{\max }^{\circ}$ & $1.56-25.37$ \\
\hline space group & $P 2_{1} / c$ & reflections all/unique & $28441 / 4109$ \\
\hline a / $\AA$ & $13.8552(8)$ & data/restraints/parameter & $4109 / 0 / 229$ \\
\hline $\mathrm{b} / \AA$ & $15.5992(10)$ & $R 1$ (all data) & 0.0442 \\
\hline$c / \AA$ & $10.9816(7)$ & $w R 2$ (all data) & 0.0960 \\
\hline$\beta /{ }^{\circ}$ & $109.3900(10)$ & $g 1 / g 2$ & $0.021 / 2.7084$ \\
\hline$V / \AA^{3}$ & $2238.8(2)$ & GoF & 1.077 \\
\hline Z & 2 & peak/hole: & \\
\hline temperature / $\mathrm{K}$ & $100(2)$ & $\max . / \min . /\left(10^{-6} \mathrm{e} \cdot \AA^{-3}\right)$ & $0.671 /-0.454$ \\
\hline
\end{tabular}




\subsubsection{7 $\left.\mathrm{Mg}\left\{\left(\mathrm{N}^{t} \mathrm{Bu}\right)_{3} \mathrm{SMe}\right\}_{2}\right](27)$}

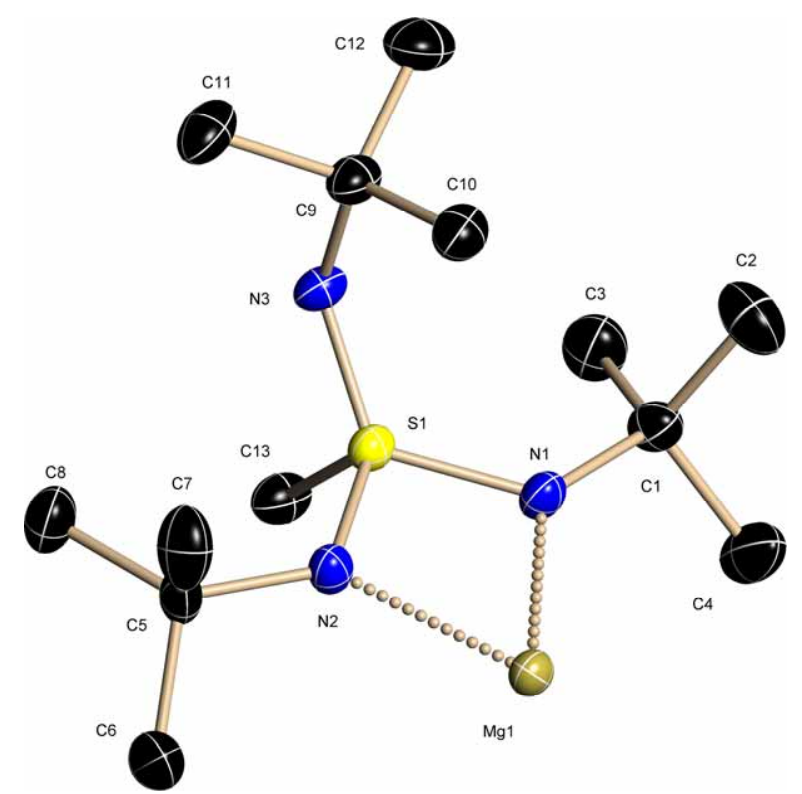

Figure 7-27: Asymmetric unit of $\left.\mathrm{Mg}\left\{\left(\mathrm{N}^{t} \mathrm{Bu}\right)_{3} \mathrm{SMe}\right\}_{2}\right]$ (27). Hydrogen atoms have been omitted for clarity.

The crystals of $\mathbf{2 7}$ were non-merohedrally twinned. The orientation matrices of the additional component and the initial cell were determined using CELL_NOW. Those matrices were then used for integrating the domains separately with SAINT. Subsequent absorption correction with TWINABS lead to a HKLF4 file for structure solution and a HKLF5 file for further refinement. The occupancy factor of the additional domain refined to $22 \%$.

Table 7-27: Crystallographic data for $\left.\operatorname{Mg}\left\{\left(\mathrm{N}^{t} \mathrm{Bu}\right)_{3} \mathrm{SMe}\right\}_{2}\right](27)$.

\begin{tabular}{|c|c|c|c|}
\hline structure code & TriimidMgTriimid & $F(000)$ & 1208 \\
\hline formula & $\mathrm{C}_{26} \mathrm{H}_{60} \mathrm{MgN}_{6} \mathrm{~S}_{2}$ & max. / min. Transmission & $\begin{array}{l}0.401068 / \\
0.745209\end{array}$ \\
\hline molecular mass $/ \mathrm{g} \cdot \mathrm{mol}^{-1}$ & 545.23 & $\rho_{\text {calc }} / \mathrm{Mg} \cdot \mathrm{m}^{-3}$ & 1.105 \\
\hline crystal size / mm & $0.1 \times 0.1 \times 0.05$ & $\mu / \mathrm{mm}^{-1}$ & 0.205 \\
\hline crystal system & monoclinic & $\theta_{\min } / \theta_{\max }^{\circ}$ & $1.92-25.17$ \\
\hline space group & $C 2 / c$ & reflections all/unique & $27048 / 5773$ \\
\hline $\mathrm{a} / \AA$ & $26.111(5)$ & data/restraints/parameter & $5773 / 40 / 170$ \\
\hline $\mathrm{b} / \AA$ & $8.6226(16)$ & $R 1$ (all data) & 0.1011 \\
\hline$c / \AA$ & $17.960(3)$ & $w R 2$ (all data) & 0.1842 \\
\hline$\beta / \circ$ & $125.825(11)$ & $g 1 / g 2$ & $0.0869 / 5.3837$ \\
\hline$V / \AA^{3}$ & $3278.6(11)$ & GoF & 1.029 \\
\hline z & 4 & peak/hole: & \\
\hline temperature / K & $100(2)$ & $\max . / \min . /\left(10^{-6} \mathrm{e} \cdot \AA^{-3}\right)$ & $0.400 /-0.710$ \\
\hline
\end{tabular}




\subsubsection{8 $\left[\mathrm{Zn}\left\{\left(\mathrm{N}^{t} \mathrm{Bu}\right)_{3} \mathrm{SMe}\right\}_{2}\right](28)$}

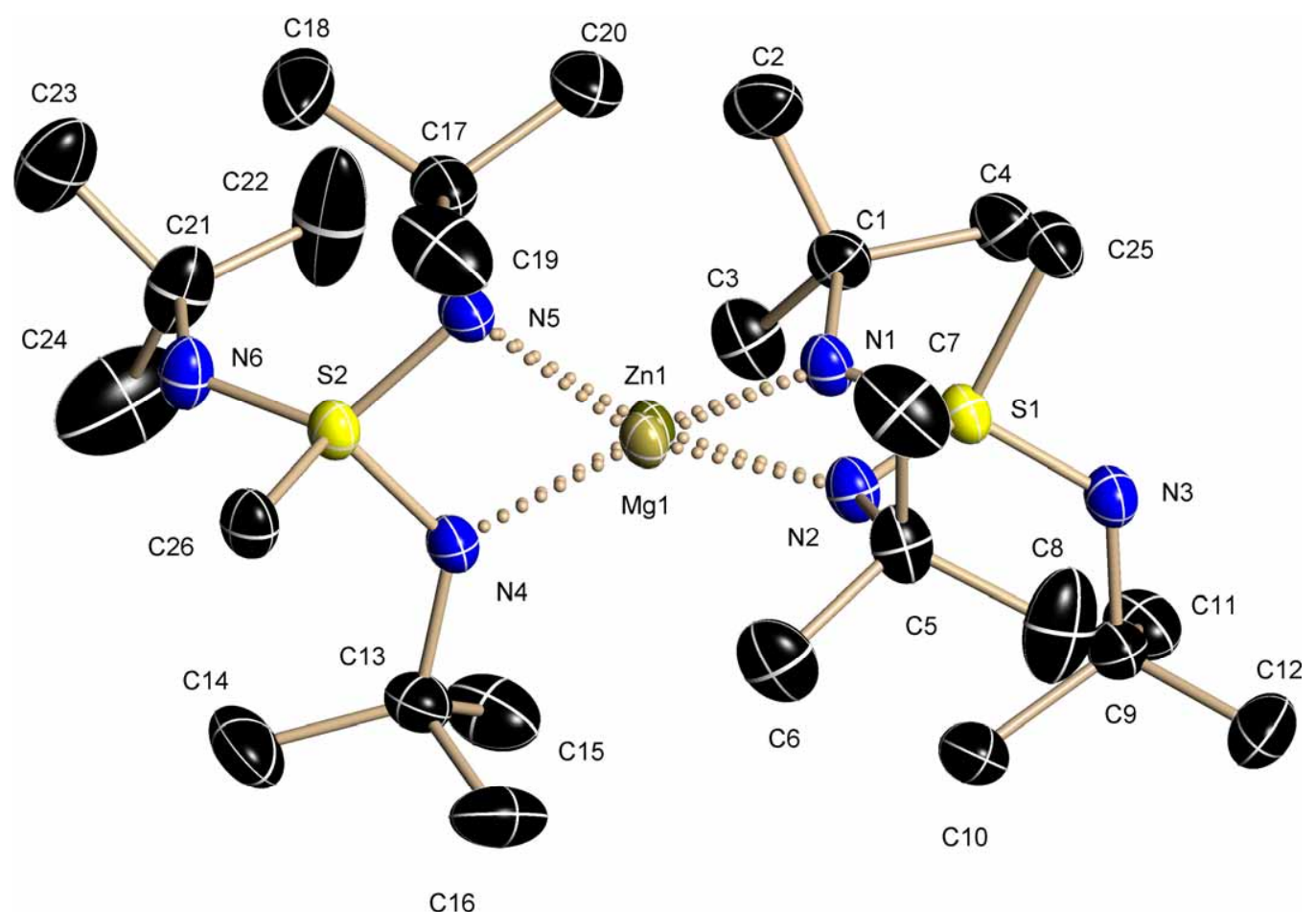

Figure 7-28: Asymmetric unit of $\left[\mathrm{Zn}\left\{\left(\mathrm{N}^{t} \mathrm{Bu}\right)_{3} \mathrm{SMe}\right\}_{2}\right](28)$. Hydrogen atoms have been omitted for clarity.

In 28 the central zinc atom is disordered with a magnesium atom from the reagent. The site occupancy factor of the zinc atom is $75 \%$.

Table 7-28: Crystallographic data for $\left[\mathrm{Zn}\left\{\left(\mathrm{N}^{t} \mathrm{Bu}\right)_{3} \mathrm{SMe}\right\}_{2}\right](\mathbf{2 8})$.

\begin{tabular}{|ll|ll|}
\hline structure code & $\mathrm{P} 282$ & temperature / K & $170(2)$ \\
formula & $\mathrm{C}_{26} \mathrm{H}_{60} \mathrm{Mg}_{0.25}$ & max. / min. Transmission & $0.6739 / 0.7452$ \\
& $\mathrm{~N}_{6} \mathrm{~S}_{2} \mathrm{Zn}_{0.75}$ & & \\
molecular mass $/ \mathrm{g} \cdot \mathrm{mol}^{-1}$ & 576.23 & $\rho_{\text {calc }} / \mathrm{Mg} \cdot \mathrm{m}^{-3}$ & 1.140 \\
crystal size / mm & $0.15 \times 0.1 \times 0.05$ & $\mu / \mathrm{mm}^{-1}$ & 0.713 \\
crystal system & triclinic & $F(000)$ & 631 \\
space group & $P \overline{1}$ & $\theta_{\min } / \theta_{\max }^{\circ}$ & $2.38-25.37$ \\
$\mathrm{a} / \AA$ & $9.987(2)$ & reflections all/unique & $17462 / 6144$ \\
$\mathrm{~b} / \AA$ & $11.321(3)$ & data/restraints $/$ parameter & $6144 / 43 / 340$ \\
$\mathrm{c} / \AA$ & $15.186(4)$ & $R 1$ (all data) & 0.0570 \\
$\alpha /{ }^{\circ}$ & $84.245(5)$ & $w R 2($ all data) & 0.0856 \\
$\beta /{ }^{\circ}$ & $87.695(6)$ & $g 1 / g 2$ & $0.0389 / 0.3290$ \\
$\gamma /{ }^{\circ}$ & $79.297(5)$ & GoF & 1.021 \\
$\mathrm{~V} / \AA^{3}$ & $1678.2(7)$ & peak/hole: & \\
$\mathrm{Z}$ & 2 & max. / min. / $\left(10^{-6} \mathrm{e} \cdot \AA^{-3}\right)$ & $0.227 /-0.332$ \\
\hline
\end{tabular}




\subsubsection{9 [(THF) $\left.)_{2} \mathrm{MgBr}_{3} \mathrm{ZnMe}\right]_{2}$}

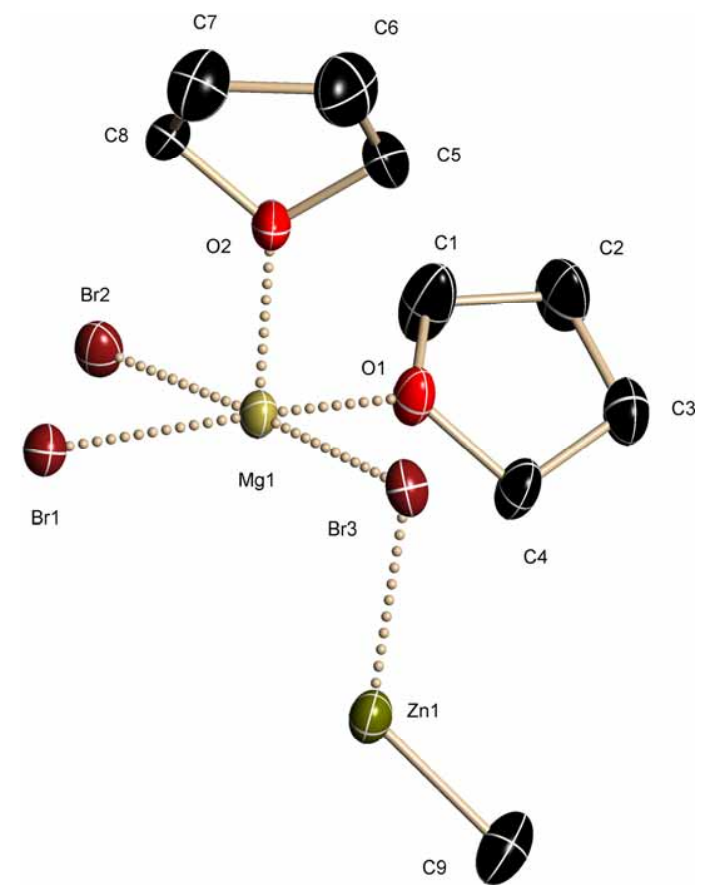

Figure 7-29: Asymmetric unit of $\left[(\mathrm{THF})_{2} \mathrm{MgBr}_{3} \mathrm{ZnMe}\right]_{2}$. Hydrogen atoms have been omitted for clarity.

Table 7-29: Crystallographic data for $\left[(\mathrm{THF})_{2} \mathrm{MgBr}_{3} \mathrm{ZnMe}\right]_{2}$.

\begin{tabular}{|ll|ll|}
\hline structure code & $\mathrm{P} 289$ & temperature / K & $100(2)$ \\
formula & $\mathrm{C}_{18} \mathrm{H}_{38} \mathrm{Br}_{6}$ & max. / min. Transmission & $0.3057 / 0.4299$ \\
& $\mathrm{Mg}_{2} \mathrm{O}_{4} \mathrm{Zn}_{2}$ & & \\
molecular mass $/ \mathrm{g} \cdot \mathrm{mol}^{-1}$ & 977.30 & $\rho_{\text {calc }} / \mathrm{Mg} \cdot \mathrm{m}^{-3}$ & 2.075 \\
crystal size / mm & $0.2 \times 0.15 \times 0.1$ & $\mu / \mathrm{mm}^{-1}$ & 9.260 \\
crystal system & triclinic & $F(000)$ & 472 \\
space group & $P \overline{1}$ & $\theta_{\min } / \theta_{\max }{ }^{\circ}$ & $2.17-26.37$ \\
$\mathrm{a} / \AA$ & $8.842(1)$ & reflections all/unique & $19213 / 3177$ \\
$\mathrm{~b} / \AA$ & $10.246(2)$ & data/restraints/parameter & $3177 / 0 / 146$ \\
$\mathrm{c} / \AA$ & $10.437(2)$ & $R 1$ (all data) & 0.0346 \\
$\alpha /{ }^{\circ}$ & $103.664(3)$ & $w R 2($ all data $)$ & 0.0759 \\
$\beta /{ }^{\circ}$ & $104.098(3)$ & $g 1 / g 2$ & $0.0334 / 2.2160$ \\
$\gamma /{ }^{\circ}$ & $113.235(2)$ & GoF & 1.052 \\
$\mathrm{~V} / \AA^{3}$ & $782.0(2)$ & peak/hole: & \\
$\mathrm{Z}$ & 1 & max. / min. / $\left(10^{-6} \mathrm{e} \cdot \AA^{-3}\right)$ & $0.739 /-0.631$ \\
\hline
\end{tabular}




\subsubsection{0 $\left[\mathrm{Cu}_{3} \mathrm{~S}\left(\mathrm{~N}^{t} \mathrm{Bu}_{3}\right)_{2} \mathrm{Cu}_{2}\left(\mathrm{~N}^{t} \mathrm{Bu}\right)_{2} \mathrm{Cu}\right]$}

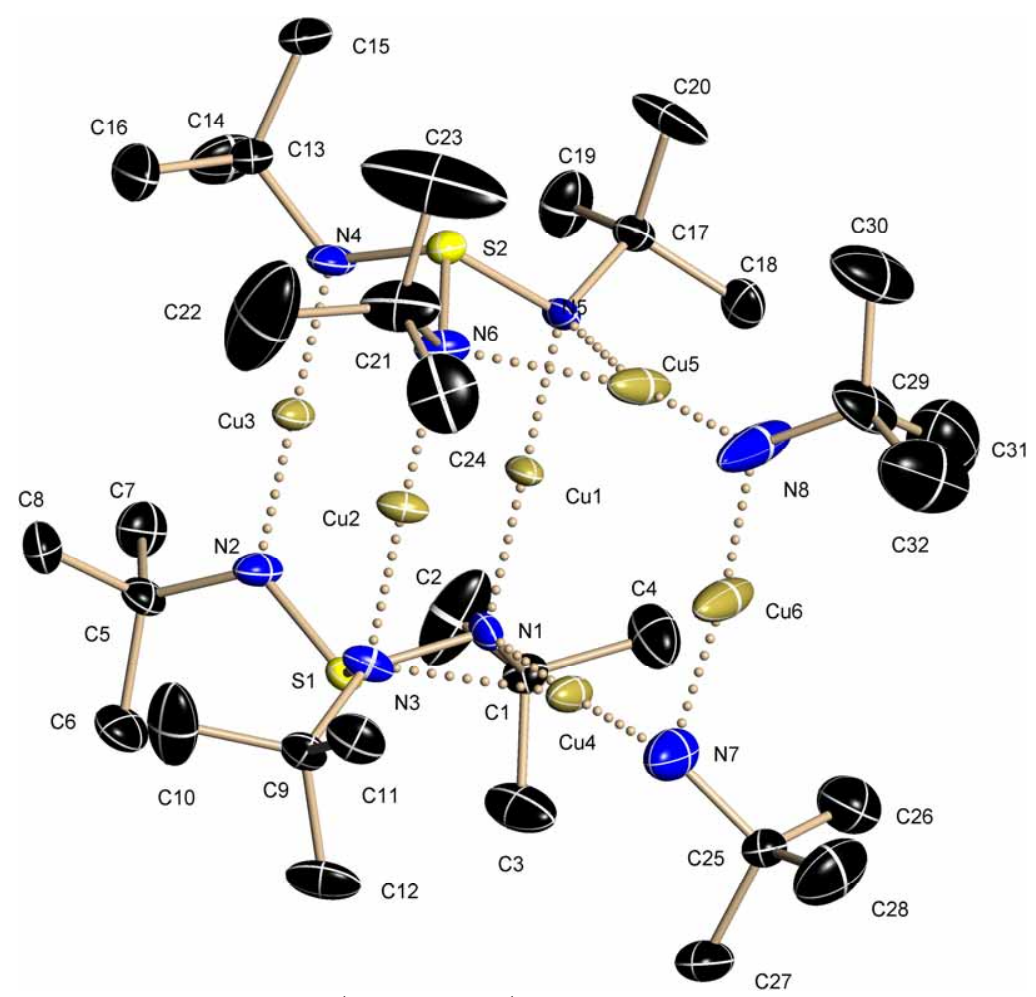

Figure 7-30: Asymmetric unit of $\left[\mathrm{Cu}_{3} \mathrm{~S}\left(\mathrm{~N}^{t} \mathrm{Bu}_{3}\right)_{2} \mathrm{Cu}_{2}\left(\mathrm{~N}^{t} \mathrm{Bu}\right)_{2} \mathrm{Cu}\right]$. Hydrogen atoms have been omitted for clarity.

Due to the poor quality of the crystals the figures of merit and especially the residual density of this dataset are not good enough for a discussion of the bond length.

Table 7-30: Crystallographic data for $\left[\mathrm{Cu}_{3} \mathrm{~S}\left(\mathrm{~N}^{t} \mathrm{Bu}_{3}\right)_{2} \mathrm{Cu}_{2}\left(\mathrm{~N}^{t} \mathrm{Bu}\right)_{2} \mathrm{Cu}\right]$.

\begin{tabular}{|ll|ll|}
\hline structure code & $\mathrm{P} 271$ & temperature / K & $100(2)$ \\
formula & $\mathrm{C}_{32} \mathrm{H}_{72} \mathrm{Cu}_{6} \mathrm{~N}_{8} \mathrm{~S}_{2}$ & max. / min. Transmission & not determined \\
molecular mass $/ \mathrm{g} \cdot \mathrm{mol}^{-1}$ & 1014.34 & $\rho_{\text {calc }} /{\mathrm{Mg} \cdot \mathrm{m}^{-3}}^{-3}$ & 1.533 \\
crystal size / mm & $0.15 \times 0.15 \times 0.1$ & $\mu / \mathrm{mm}^{-1}$ & 2.978 \\
crystal system & triclinic & $F(000)$ & 1052 \\
space group & $P \overline{1}$ & $\theta_{\text {min }} / \theta_{\text {max }}{ }^{\circ}$ & $1.86-25.47$ \\
$\mathrm{a} / \AA$ & $11.737(3)$ & reflections all/unique & $48587 / 8124$ \\
$\mathrm{~b} / \AA$ & $13.932(5)$ & data/restraints/parameter & $8124 / 43 / 457$ \\
$\mathrm{c} / \AA$ & $14.484(4)$ & $R 1$ (all data) & 0.0962 \\
$\alpha /{ }^{\circ}$ & $94.499(6)$ & $w R 2($ all data) & 0.1954 \\
$\beta /{ }^{\circ}$ & $93.836(8)$ & $g 1 / g 2$ & $0.1045 / 16.7661$ \\
$\gamma /{ }^{\circ}$ & $110.723(5)$ & GoF & 1.044 \\
$\mathrm{~V} / \AA^{3}$ & $2196.9(11)$ & peak/hole: & \\
$\mathrm{Z}$ & 2 & max. / min. / $\left(10^{-6} \mathrm{e} \cdot \AA^{-3}\right)$ & $3.586 /-2.563$ \\
\hline
\end{tabular}




\subsubsection{1 $\left[\mathrm{CpTiCl}{ }_{2} \mathrm{NH}^{t} \mathrm{Bu}\right]$}

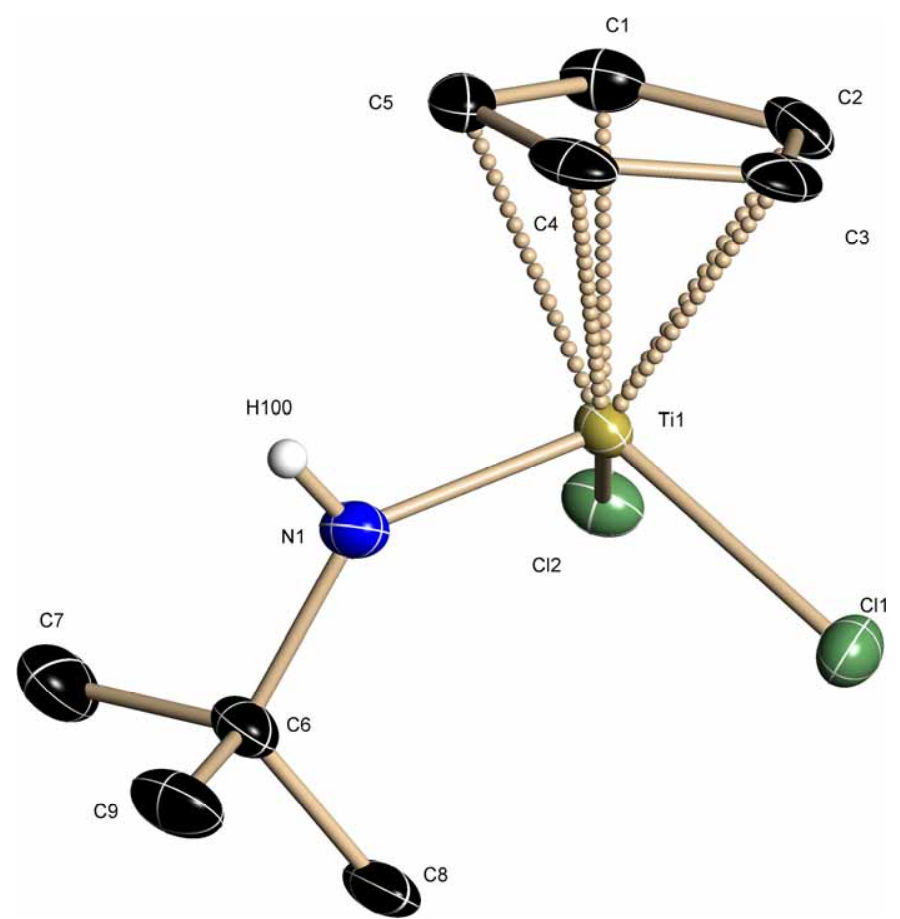

Figure 7-31: Asymmetric unit of $\left[\mathrm{CpTiCl}_{2} \mathrm{NH}^{t} \mathrm{Bu}\right]$. Hydrogen atoms have been omitted for clarity.

Table 7-31: Crystallographic data for $\left[\mathrm{CpTiCl}_{2} \mathrm{NH}^{t} \mathrm{Bu}\right]$.

\begin{tabular}{|c|c|c|c|}
\hline structure code & $\mathrm{EC7}$ & temperature / $\mathrm{K}$ & $100(2)$ \\
\hline formula & $\mathrm{C}_{18} \mathrm{H}_{30} \mathrm{Cl}_{4} \mathrm{~N}_{2} \mathrm{Ti}_{2}$ & max. / min. Transmission & $\begin{array}{l}0.576168 / \\
0.745203\end{array}$ \\
\hline molecular mass $/ \mathrm{g} \cdot \mathrm{mol}^{-1}$ & 512.04 & $\rho_{\text {calc }} / \mathrm{Mg} \cdot \mathrm{m}^{-3}$ & 1.482 \\
\hline crystal size / mm & $0.15 \times 0.15 \times 0.05$ & $\mu / \mathrm{mm}^{-1}$ & 1.167 \\
\hline crystal system & triclinic & $F(000)$ & 264 \\
\hline space group & $P \overline{1}$ & $\theta_{\min } / \theta_{\max }^{\circ}$ & $1.90-25.30$ \\
\hline $\mathrm{a} / \AA$ & $6.084(2)$ & reflections all/unique & 9302 / 2046 \\
\hline $\mathrm{b} / \AA$ & $8.948(2)$ & data/restraints/parameter & $2046 / 0 / 126$ \\
\hline$c / \AA$ & $10.726(4)$ & $R 1$ (all data) & 0.0620 \\
\hline$\alpha /^{\circ}$ & $89.342(4)$ & $w R 2$ (all data) & 0.1439 \\
\hline$\beta /{ }^{\circ}$ & $87.828(13)$ & $g 1 / g 2$ & $0.0984 / 0.00$ \\
\hline$\gamma 1^{\circ}$ & $79.526(12)$ & GoF & 1.035 \\
\hline$V / \AA^{3}$ & $573.8(3)$ & peak/hole: & \\
\hline z & 2 & $\max . / \min . /\left(10^{-6} \mathrm{e} \cdot \AA^{-3}\right)$ & $0.739 /-0.631$ \\
\hline
\end{tabular}




\subsection{Crystallographic Cooperations}

During this doctoral study various molecular structures have been determined by X-ray crystallography as part of the cooperation with other groups. The cooperations with different members of the groups of Prof. Dr. Roesky and Prof. Dr. Stalke lead to seven already printed publications ${ }^{[228-234]}$ and four additional publications that are submitted or already accepted. Crystallographic informations for all published structures are shown in this chapter. All other information can be found in the publications.

\subsubsection{Structures measured for the working group of Prof. Stalke}

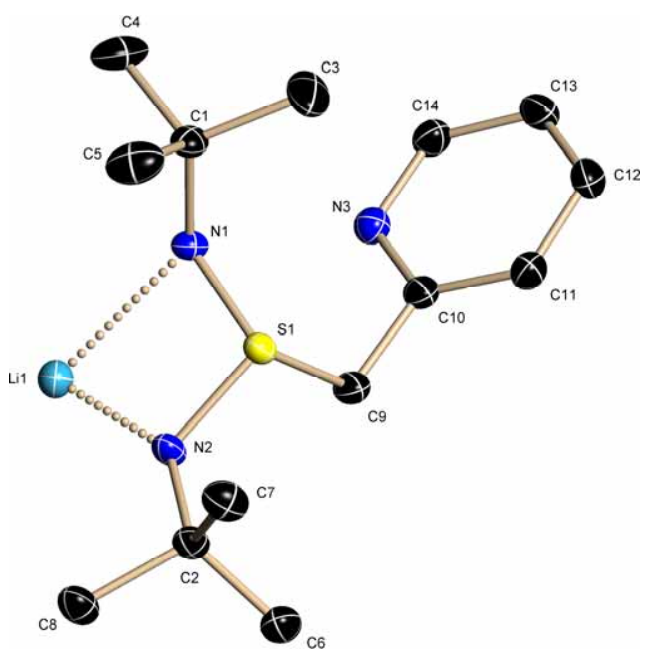

Figure 7-32: Asymmetric unit of EMPic. Hydrogen atoms have been omitted for clarity.

Table 7-32: Crystallographic data for EMPic.

\begin{tabular}{|ll|ll|}
\hline structure code & EMPic & $F(000)$ & 1184 \\
formula & $\mathrm{C}_{28} \mathrm{H}_{48} \mathrm{Li}_{2} \mathrm{~N}_{6} \mathrm{~S}_{2}$ & max. / min. Transmission & 0.6122 / 0.7454 \\
molecular mass / g $\cdot \mathrm{mol}^{-1}$ & 546.73 & $\rho_{\text {calc }} / \mathrm{Mg} \cdot \mathrm{m}^{-3}$ & 1.159 \\
crystal size / mm & $0.2 \times 0.2 \times 0.2$ & temperature / K & $100(2)$ \\
crystal system & monoclinic & $\theta_{\min } / \theta_{\max }^{\circ}$ & $2.26-26.75$ \\
space group & $C 2 / c$ & reflections all/unique & $69271 / 3603$ \\
a / $\AA$ & $9.883(3)$ & data/restraints/parameter & $3603 / 0 / 179$ \\
b / $\AA$ & $18.001(5)$ & $R 1$ (all data) & 0.0492 \\
c / $\AA$ & $17.611(5)$ & $w R 2$ (all data) & 0.1033 \\
$\beta / \circ$ & $91.175(4)$ & $g 1 / g 2$ & $0.0333 / 3.255$ \\
$\mathrm{~V} / \AA^{3}$ & $3132.4(16)$ & GoF & 1.179 \\
$\mathrm{Z}$ & 4 & max. / min. / $\left(10^{-6} \mathrm{e} \cdot \AA^{-3}\right)$ & $0.453 /-0.371$ \\
\hline
\end{tabular}




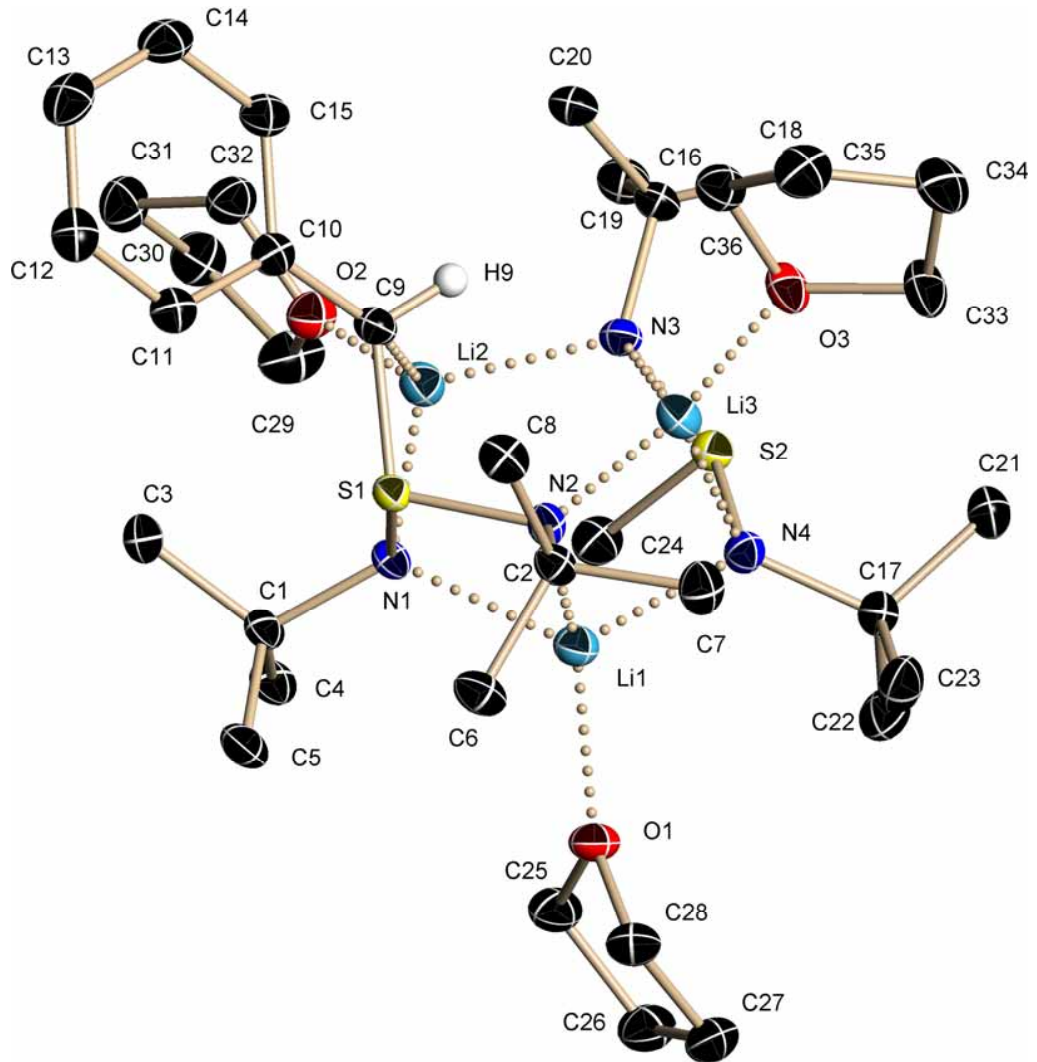

Figure 7-33: Asymmetric unit of EMYlid. Calculated hydrogen atoms have been omitted for clarity.

Table 7-33: Crystallographic data for EMYlid.

\begin{tabular}{|c|c|c|c|}
\hline structure code & EMYlid & $F(000)$ & 3024 \\
\hline formula & $\mathrm{C}_{36} \mathrm{H}_{69} \mathrm{Li}_{3} \mathrm{~N}_{4} \mathrm{O}_{3} \mathrm{~S}_{2}$ & max. / min. Transmission & $0.6763 / 0.7454$ \\
\hline molecular mass $/ \mathrm{g} \cdot \mathrm{mol}^{-1}$ & 690.89 & $\rho_{\text {calc }} / \mathrm{Mg} \cdot \mathrm{m}^{-3}$ & 1.110 \\
\hline crystal size / mm & $0.2 \times 0.2 \times 0.15$ & $\mu / \mathrm{mm}^{-1}$ & 0.165 \\
\hline crystal system & monoclinic & $\theta_{\min } / \theta_{\max }^{\circ}$ & $2.26-26.66$ \\
\hline space group & $C 2 / c$ & reflections all/unique & $58843 / 7712$ \\
\hline a / $\AA$ & $15.284(3)$ & data/restraints/parameter & 7712 / 0 / 450 \\
\hline $\mathrm{b} / \AA$ & $17.129(3)$ & $R 1$ (all data) & 0.0395 \\
\hline$c / \AA$ & $31.676(5)$ & $w R 2$ (all data) & 0.0866 \\
\hline$\beta /{ }^{\circ}$ & $94.386(2)$ & $g 1 / g 2$ & $0.0384 / 7.278$ \\
\hline$V / \AA^{3}$ & $8268(2)$ & GoF & 1.044 \\
\hline Z & 8 & peak/hole: & \\
\hline temperature / $\mathrm{K}$ & $100(2)$ & $\max . / \min . /\left(10^{-6} \mathrm{e} \cdot \AA^{-3}\right)$ & $0.282 /-0.279$ \\
\hline
\end{tabular}




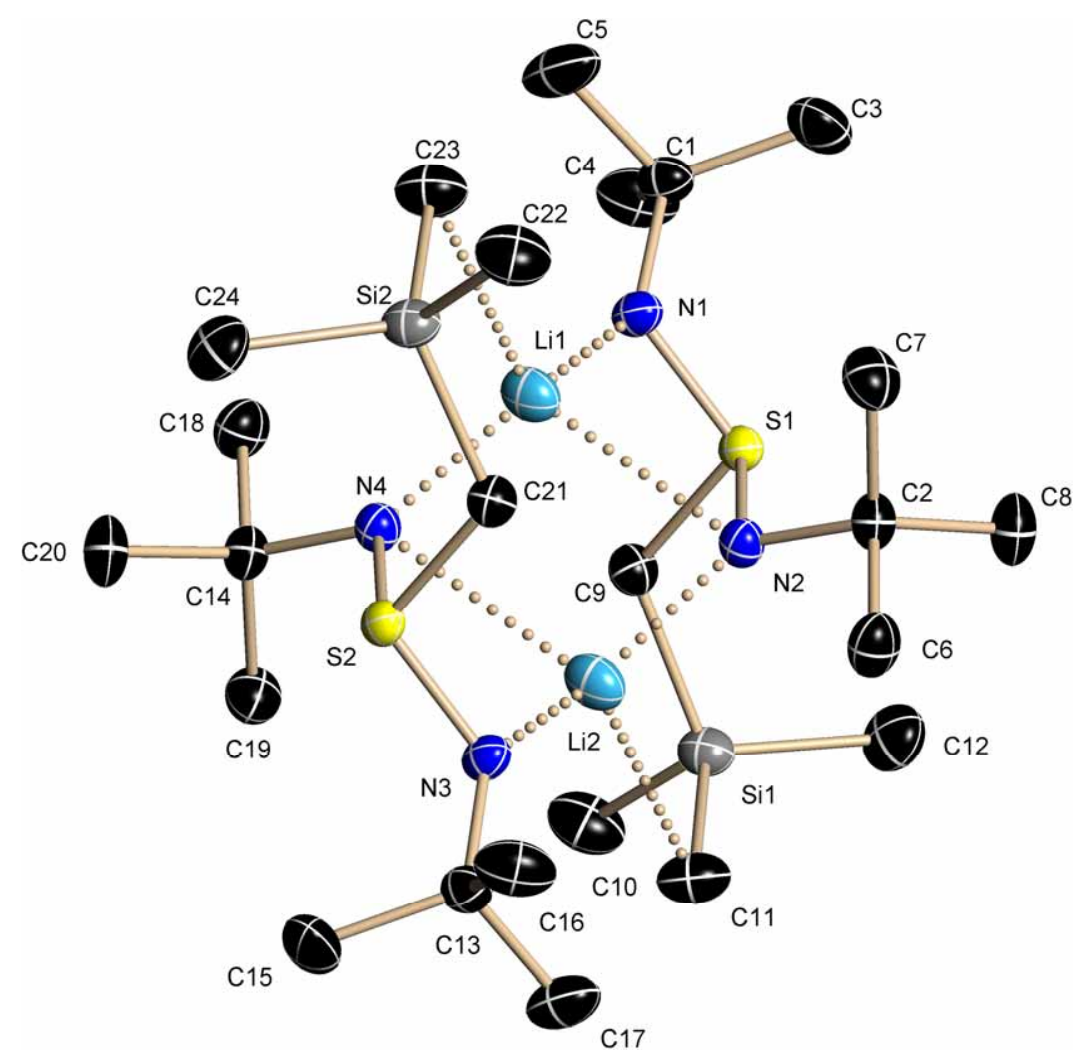

Figure 7-34: Asymmetric unit of EMTMS. Hydrogen atoms have been omitted for clarity.

Table 7-34: Crystallographic data for EMTMS.

\begin{tabular}{|ll|ll|}
\hline structure code & EMTMS & $F(000)$ & 1184 \\
formula & $\mathrm{C}_{24} \mathrm{H}_{58} \mathrm{Li}_{2} \mathrm{~N}_{4} \mathrm{~S}_{2} \mathrm{Si}_{2}$ & max. / min. Transmission & $0.6321 / 0.7457$ \\
molecular mass / g $\cdot \mathrm{mol}^{-1}$ & 536.92 & $\rho_{\text {calc }} / \mathrm{Mg} \cdot \mathrm{m}^{-3}$ & 1.053 \\
crystal size / mm & $0.2 \times 0.2 \times 0.15$ & $\mu / \mathrm{mm}^{-1}$ & 0.246 \\
crystal system & monoclinic & $\theta_{\min } / \theta_{\text {max }}{ }^{\circ}$ & $1.56-26.73$ \\
space group & $P 2(1) / n$ & reflections all/unique & $76006 / 6051$ \\
a / $\AA$ & $9.6576(10)$ & data/restraints/parameter & $6051 / 0 / 347$ \\
b / $\AA$ & $16.7227(17)$ & $R 1$ (all data) & 0.0410 \\
c / $\AA$ & $21.316(2)$ & $w R 2$ (all data) & 0.0911 \\
$\beta / \circ$ & 100.350 & $g 1 / g 2$ & $0.0489 / 0.8694$ \\
$V / \AA$ & GoF & 1.071 \\
Z & $3386.5(6)$ & peak/hole: & \\
temperature / K & 4 & max. / min. / $\left(10^{-6} \mathrm{e} \cdot \AA^{-3}\right)$ & $0.471 /-0.287$ \\
\hline
\end{tabular}




\subsubsection{Structures measured for the working group of Prof. Roesky}
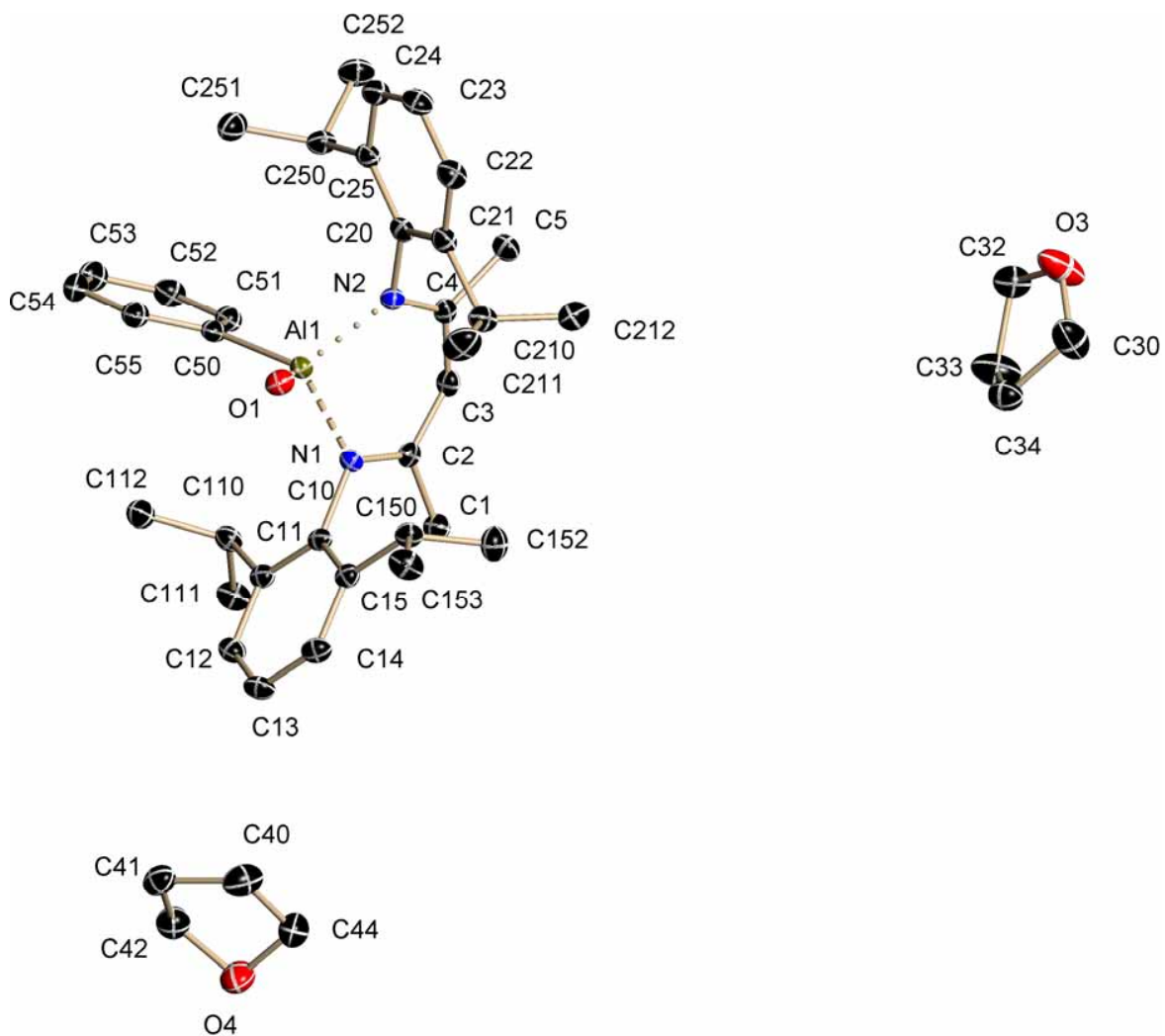

Figure 7-35: Asymmetric unit of YY411. Hydrogen atoms have been omitted for clarity.

Table 7-35: Crystallographic data for YY411.

\begin{tabular}{|c|c|c|c|}
\hline structure code & YY411 & temperature / $\mathrm{K}$ & $100(2)$ \\
\hline formula & $\mathrm{C}_{43} \mathrm{H}_{63} \mathrm{AlN}_{2} \mathrm{O}_{3}$ & max. / min. Transmission & $0.99 / 0.898520$ \\
\hline molecular mass $/ \mathrm{g} \cdot \mathrm{mol}^{-1}$ & 682.93 & $\rho_{\text {calc }} / \mathrm{Mg} \cdot \mathrm{m}^{-3}$ & 1.165 \\
\hline crystal size / mm & $0.4 \times 0.2 \times 0.2$ & $\mu / \mathrm{mm}^{-1}$ & 0.092 \\
\hline crystal system & triclinic & $F(000)$ & 744 \\
\hline space group & $P \overline{1}$ & $\theta_{\min } / \theta_{\max }^{\circ}$ & $2.75 / 25.08$ \\
\hline $\mathrm{a} / \AA$ & $9.0526(10)$ & reflections all/unique & $36861 / 6895$ \\
\hline $\mathrm{b} / \AA$ & $12.0803(14)$ & data/restraints/parameter & 6895 / 0 / 444 \\
\hline$c / \AA$ & $18.727(2)$ & $R 1$ (all data) & 0.0427 \\
\hline$\alpha /^{\circ}$ & $73.6670(10)$ & $w R 2$ (all data) & 0.1073 \\
\hline$\beta /{ }^{\circ}$ & $82.3990(10)$ & $g 1 / g 2$ & $0.0544 / 1.0481$ \\
\hline$\gamma /{ }^{\circ}$ & $86.1870(10)$ & GoF & 1.047 \\
\hline$V / \AA^{3}$ & $1947.1(4)$ & peak/hole: & \\
\hline Z & 2 & $\max . / \min . /\left(10^{-6} \mathrm{e} \cdot \AA^{-3}\right)$ & $0.478 /-0.410$ \\
\hline
\end{tabular}




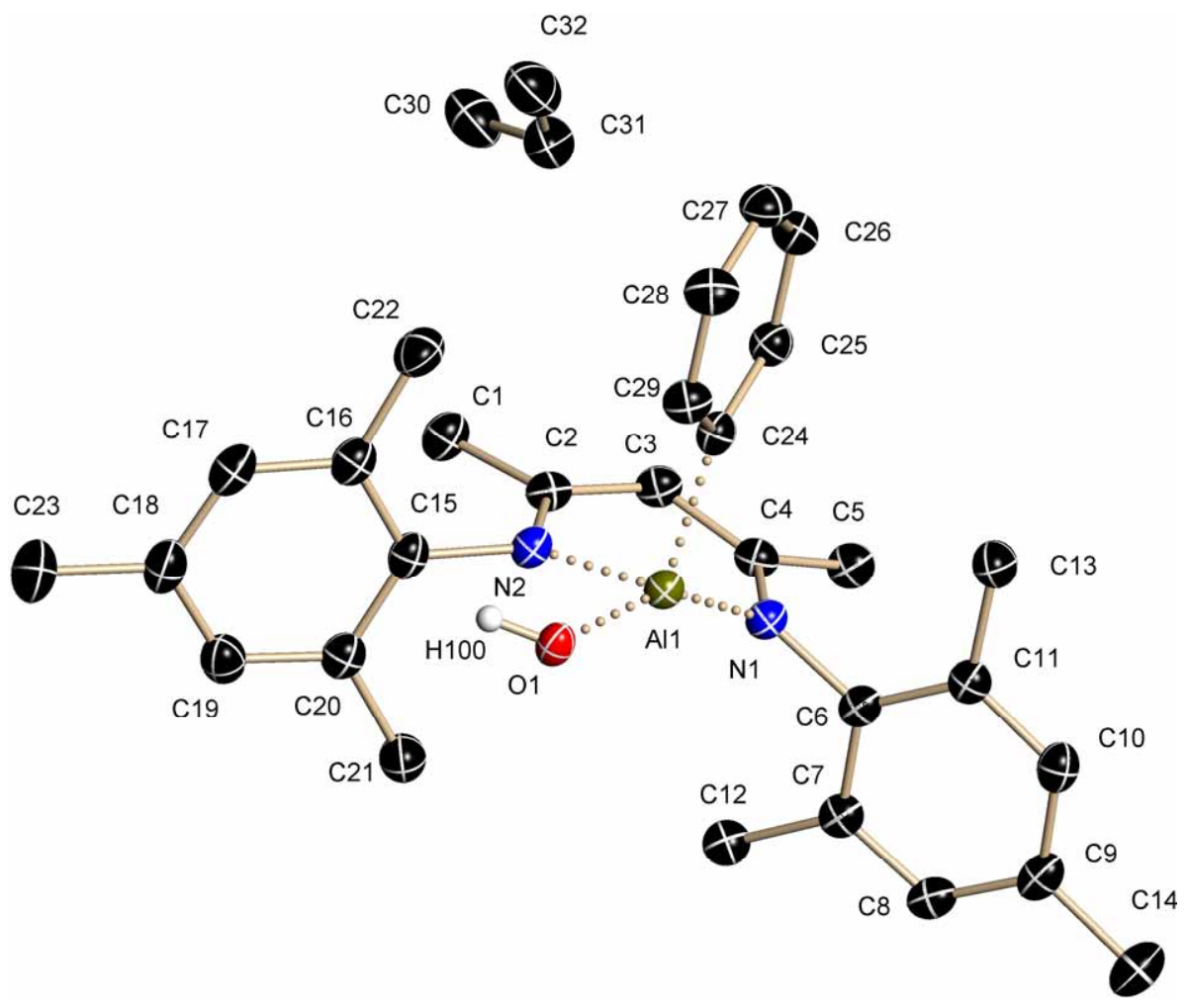

Figure 7-36: Asymmetric unit of YY491. Calculated hydrogen atoms have been omitted for clarity.

Table 7-36: Crystallographic data for YY491.

\begin{tabular}{|c|c|c|c|}
\hline structure code & YY491 & temperature / $\mathrm{K}$ & $100(2)$ \\
\hline formula & $\mathrm{C}_{32} \mathrm{H}_{38} \mathrm{AIN}_{2} \mathrm{O}$ & max. / min. Transmission & $0.99 / 0.786432$ \\
\hline molecular mass $/ \mathrm{g} \cdot \mathrm{mol}^{-1}$ & 493.62 & $\rho_{\text {calc }} / \mathrm{Mg} \cdot \mathrm{m}^{-3}$ & 1.200 \\
\hline crystal size / mm & $0.1 \times 0.1 \times 0.05$ & $\mu / \mathrm{mm}^{-1}$ & 0.101 \\
\hline crystal system & triclinic & $F(000)$ & 530 \\
\hline space group & $P \overline{1}$ & $\theta_{\min } / \theta_{\max }^{\circ}$ & $1.78 / 26.40$ \\
\hline $\mathrm{a} / \AA$ & $11.4187(11)$ & reflections all/unique & $25588 / 5606$ \\
\hline $\mathrm{b} / \AA$ & $11.5317(11)$ & data/restraints/parameter & $5606 / 1 / 336$ \\
\hline$c / \AA$ & $12.1602(11)$ & $R 1$ (all data) & 0.0571 \\
\hline$\alpha /^{\circ}$ & $93.6510(10)$ & $w R 2$ (all data) & 0.1041 \\
\hline$\beta / /^{\circ}$ & $106.2490(10)$ & $g 1 / g 2$ & $0.0428 / 0.7135$ \\
\hline$\gamma /{ }^{\circ}$ & $114.6840(10)$ & GoF & 1.043 \\
\hline$V / \AA^{3}$ & $1366.5(2)$ & peak/hole: & \\
\hline Z & 2 & $\max . / \min . /\left(10^{-6} \mathrm{e} \cdot \AA^{-3}\right)$ & $0.286 /-0.292$ \\
\hline
\end{tabular}




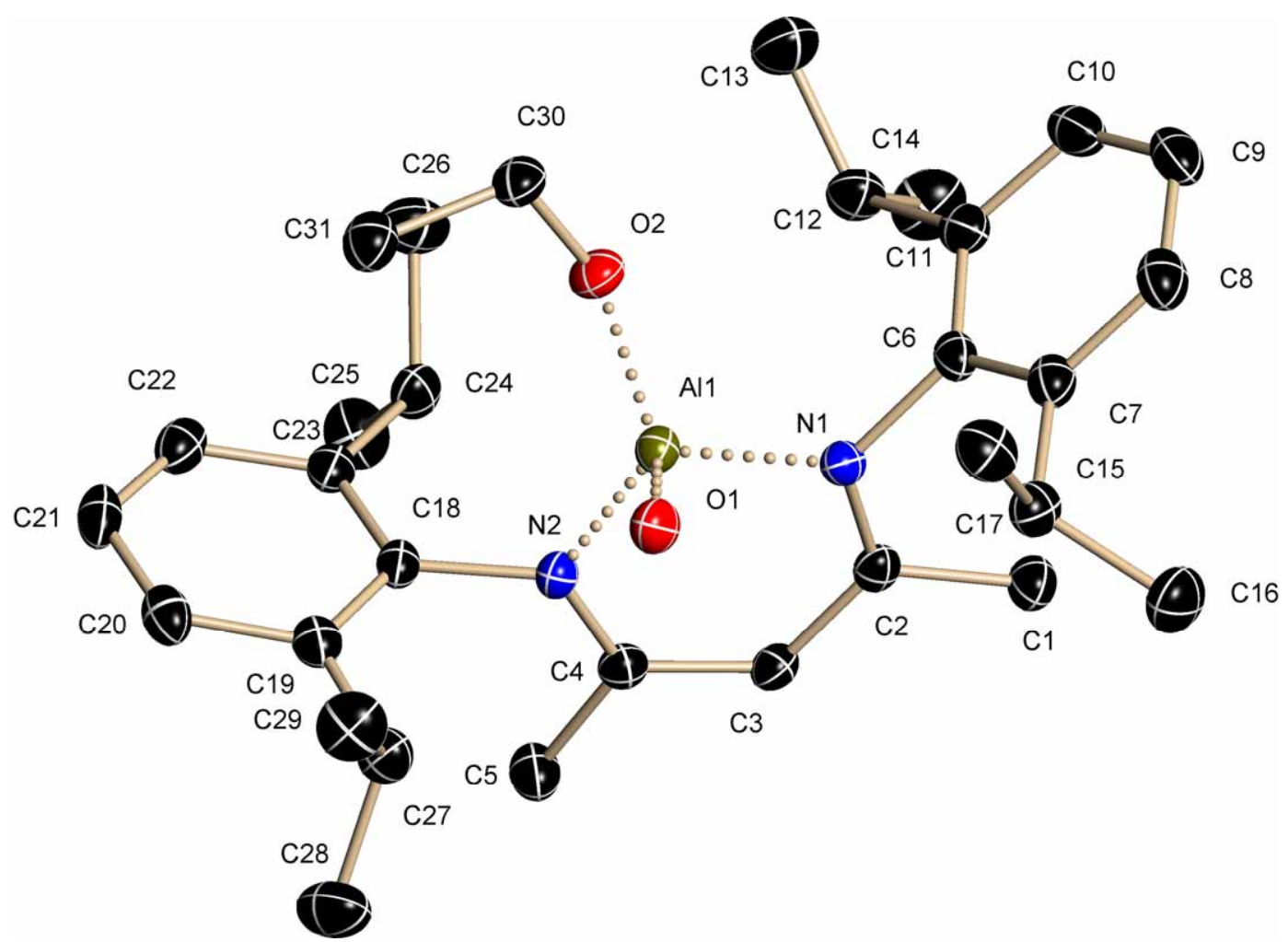

Figure 7-37: Asymmetric unit of YY491. Hydrogen atoms have been omitted for clarity.

Table 7-37: Crystallographic data for YY540.

\begin{tabular}{|c|c|c|c|}
\hline structure code & YY540 & $F(000)$ & 1104 \\
\hline formula & $\mathrm{C}_{31} \mathrm{H}_{47} \mathrm{AIN}_{2} \mathrm{O}_{2}$ & max. / min. Transmission & $0.99 / 0.837852$ \\
\hline molecular mass $/ \mathrm{g} \cdot \mathrm{mol}^{-1}$ & 580.25 & $\rho_{\text {calc }} / \mathrm{Mg} \cdot \mathrm{m}^{-3}$ & 1.134 \\
\hline crystal size / mm & $0.25 \times 0.1 \times 0.05$ & $\mu / \mathrm{mm}^{-1}$ & 0.097 \\
\hline crystal system & monoclinic & $\theta_{\min } / \theta_{\max }^{\circ}$ & $2.34 / 25.59$ \\
\hline space group & $P 2 / C$ & reflections all/unique & $20156 / 5557$ \\
\hline a / $\AA$ & $16.954(2)$ & data/restraints/parameter & 5557 / $1 / 339$ \\
\hline $\mathrm{b} / \AA$ & $10.0454(15)$ & $R 1$ (all data) & 0.0542 \\
\hline$c / \AA$ & $17.892(3)$ & $w R 2$ (all data) & 0.0982 \\
\hline$\beta /{ }^{\circ}$ & $103.031(2)$ & $g 1 / g 2$ & $0.0439 / 1.3951$ \\
\hline$V / \AA^{3}$ & $2968.7(7)$ & GoF & 1.020 \\
\hline Z & 4 & peak/hole: & \\
\hline temperature / K & $100(2)$ & $\max . / \min . /\left(10^{-6} \mathrm{e} \cdot \AA^{-3}\right)$ & $0.317 /-0.268$ \\
\hline
\end{tabular}




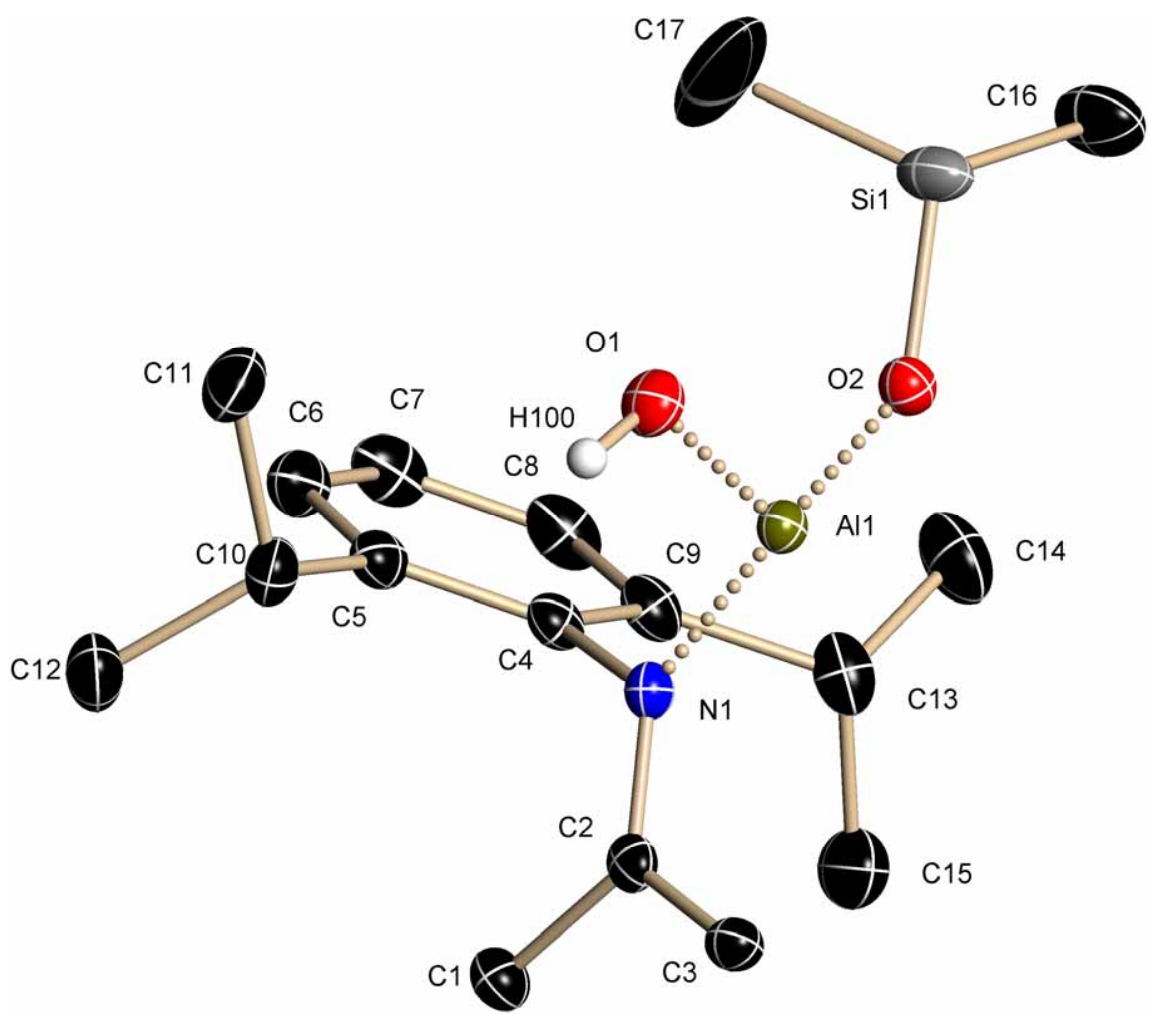

Figure 7-38: Asymmetric unit of YY546. Calculated hydrogen atoms have been omitted for clarity.

Table 7-38: Crystallographic data for YY546.

\begin{tabular}{|c|c|c|c|}
\hline structure code & YY546 & $F(000)$ & 600 \\
\hline formula & $\mathrm{C}_{32} \mathrm{H}_{51} \mathrm{AlN}_{2} \mathrm{O}_{2} \mathrm{Si}$ & max. / min. Transmission & $0.99 / 0.859584$ \\
\hline molecular mass $/ \mathrm{g} \cdot \mathrm{mol}^{-1}$ & 550.82 & $\rho_{\text {calc }} / \mathrm{Mg} \cdot \mathrm{m}^{-3}$ & 1.110 \\
\hline crystal size / mm & $0.15 \times 0.1 \times 0.05$ & $\mu / \mathrm{mm}^{-1}$ & 0.127 \\
\hline crystal system & monoclinic & $\theta_{\min } / \theta_{\max }^{\circ}$ & $2.05 / 26.40$ \\
\hline space group & $P 2_{1} / m$ & reflections all/unique & $20758 / 3468$ \\
\hline a / $\AA$ & $8.8703(10)$ & data/restraints/parameter & $3468 / 1 / 194$ \\
\hline $\mathrm{b} / \AA$ & $19.895(2)$ & $R 1$ (all data) & 0.0509 \\
\hline$c / \AA$ & $10.2310(11)$ & $w R 2$ (all data) & 0.1066 \\
\hline$\beta /{ }^{\circ}$ & $114.0800(10)$ & $g 1 / g 2$ & $0.0441 / 1.2159$ \\
\hline$V / \AA^{3}$ & $1648.4(3)$ & GoF & 1.031 \\
\hline Z & 2 & peak/hole: & \\
\hline temperature / $\mathrm{K}$ & $100(2)$ & $\max . / \min . /\left(10^{-6} \mathrm{e} \cdot \AA^{-3}\right)$ & $0.613 /-0.541$ \\
\hline
\end{tabular}




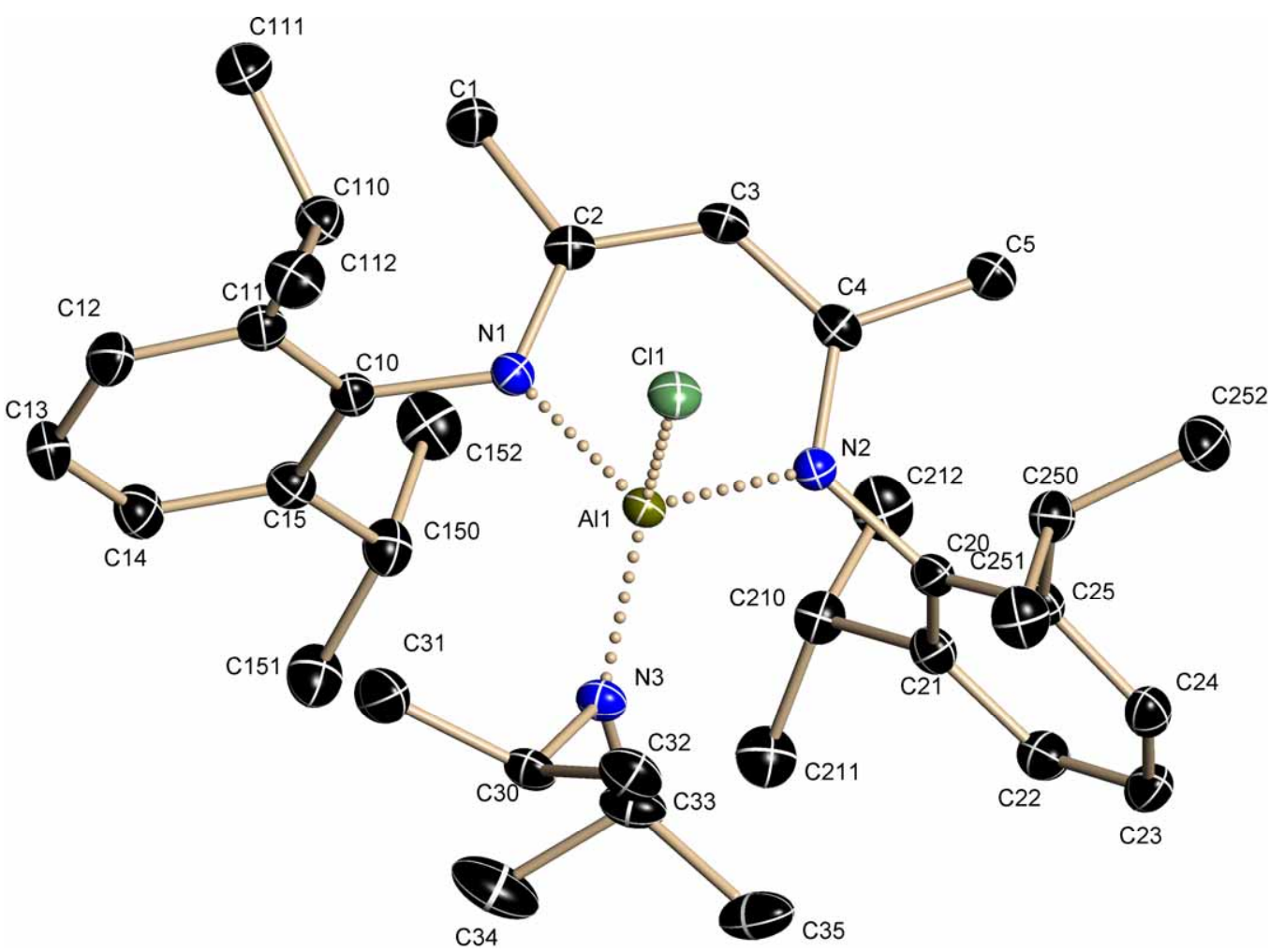

Figure 7-39: Asymmetric unit of YY243. Hydrogen atoms have been omitted for clarity.

Table 7-39: Crystallographic data for YY243.

\begin{tabular}{|c|c|c|c|}
\hline structure code & YY243 & $F(000)$ & 1264 \\
\hline formula & $\mathrm{C}_{35} \mathrm{H}_{55} \mathrm{AICIN}_{3}$ & max. / min. Transmission & $0.99 / 0.894196$ \\
\hline molecular mass $/ \mathrm{g} \cdot \mathrm{mol}^{-1}$ & 580.25 & $\rho_{\text {calc }} / \mathrm{Mg} \cdot \mathrm{m}^{-3}$ & 1.136 \\
\hline crystal size / mm & $0.25 \times 0.2 \times 0.1$ & $\mu / \mathrm{mm}^{-1}$ & 0.165 \\
\hline crystal system & monoclinic & $\theta_{\min } / \theta_{\max }^{\circ}$ & $2.64 / 25.21$ \\
\hline space group & $P 2_{1} / n$ & reflections all/unique & 38060 / 6089 \\
\hline a / $\AA$ & $10.0276(8)$ & data/restraints/parameter & $6089 / 0 / 375$ \\
\hline $\mathrm{b} / \AA$ & $20.3125(16)$ & $R 1$ (all data) & 0.0379 \\
\hline$c / \AA$ & $16.7958(13)$ & $w R 2$ (all data) & 0.0918 \\
\hline$\beta /{ }^{\circ}$ & $97.4050(10)^{\circ}$ & $g 1 / g 2$ & $0.0472 / 1.4306$ \\
\hline$V / \AA^{3}$ & $3392.5(5)$ & GoF & 1.039 \\
\hline Z & 4 & peak/hole: & \\
\hline temperature / $\mathrm{K}$ & $100(2)$ & $\max . / \min . /\left(10^{-6} \mathrm{e} \cdot \AA^{-3}\right)$ & $0.286 /-0.282$ \\
\hline
\end{tabular}




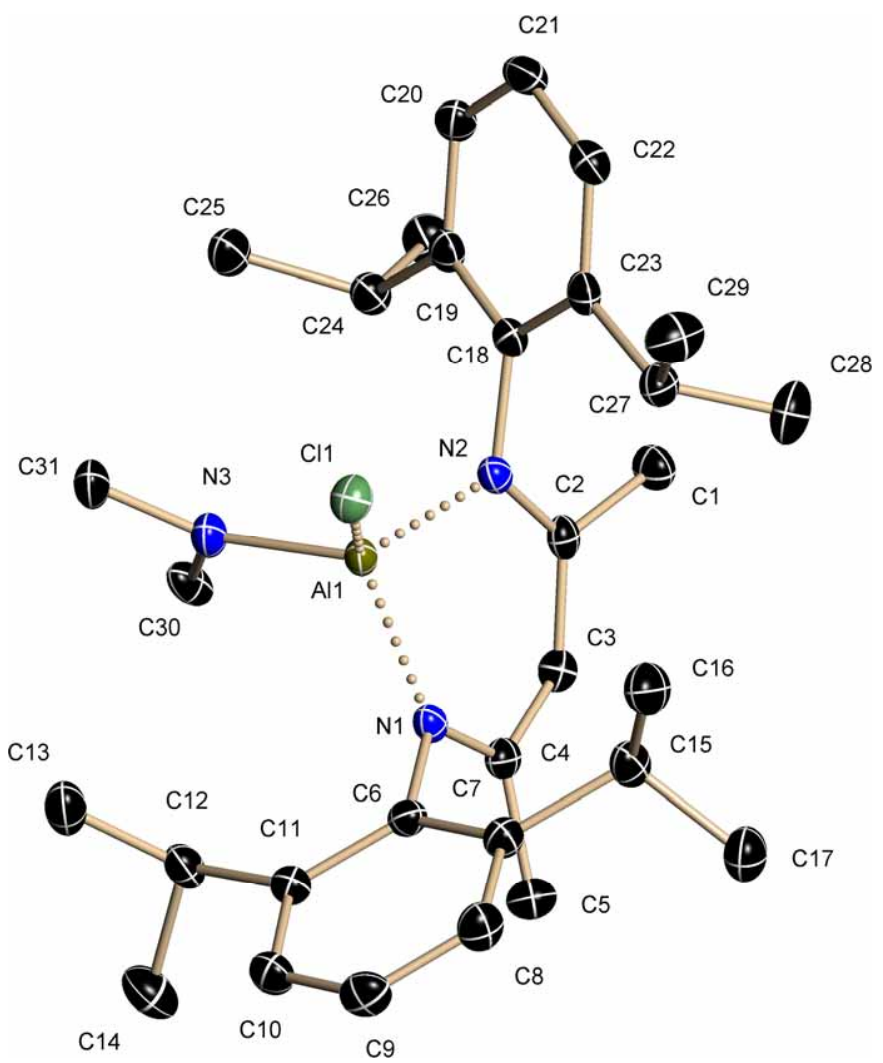

Figure 7-40: Asymmetric unit of YY470. Hydrogen atoms have been omitted for clarity.

Table 7-40: Crystallographic data for YY470.

\begin{tabular}{|c|c|c|c|}
\hline structure code & YY470 & temperature / $\mathrm{K}$ & $100(2)$ \\
\hline formula & $\mathrm{C}_{31} \mathrm{H}_{47} \mathrm{AlCIN}_{3}$ & max. / min. Transmission & $0.99 / 0.731553$ \\
\hline molecular mass $/ \mathrm{g} \cdot \mathrm{mol}^{-1}$ & 524.15 & $\rho_{\text {calc }} / \mathrm{Mg} \cdot \mathrm{m}^{-3}$ & 1.168 \\
\hline crystal size / mm & $0.2 \times 0.1 \times 0.05$ & $\mu / \mathrm{mm}^{-1}$ & 0.181 \\
\hline crystal system & triclinic & $F(000)$ & 568 \\
\hline space group & $P \overline{1}$ & $\theta_{\min } / \theta_{\max }^{\circ}$ & 1.69 / 26.41 \\
\hline a / $\AA$ & $10.5043(8)$ & reflections all/unique & $27557 / 6084$ \\
\hline $\mathrm{b} / \AA$ & $12.3521(10)$ & data/restraints/parameter & 6084 / 0 / 337 \\
\hline$c / \AA$ & $13.4442(11)$ & $R 1$ (all data) & 0.0502 \\
\hline$\alpha /^{\circ}$ & $66.4120(10)$ & $w R 2$ (all data) & 0.1098 \\
\hline$\beta /{ }^{\circ}$ & $72.1260(10)$ & $g 1 / g 2$ & $0.0588 / 0.7810$ \\
\hline$\gamma /^{\circ}$ & $72.6120(10)$ & GoF & 1.034 \\
\hline$V / \AA^{3}$ & $1490.2(2)$ & peak/hole: & \\
\hline Z & 2 & $\max . / \min . /\left(10^{-6} \mathrm{e} \cdot \AA^{-3}\right)$ & $0.503 /-0.289$ \\
\hline
\end{tabular}




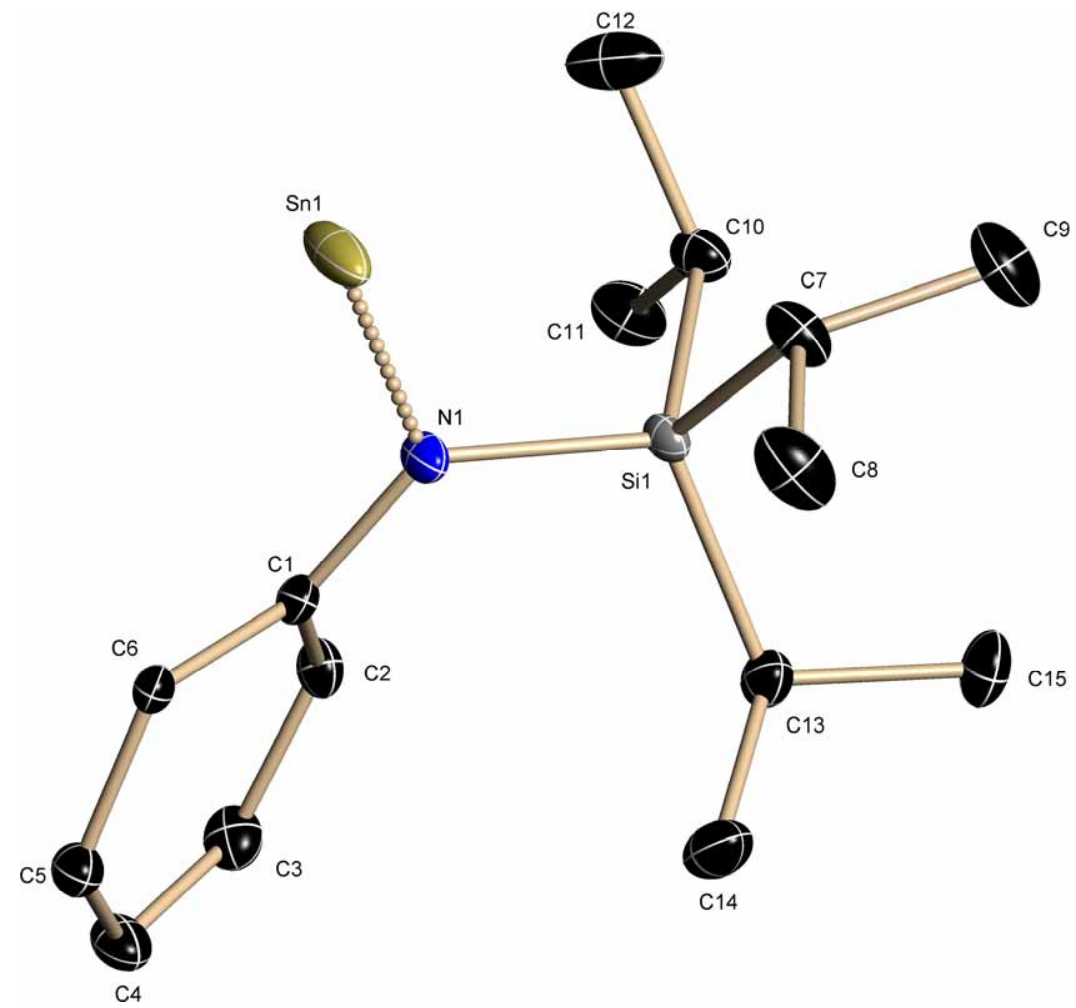

Figure 7-41: Asymmetric unit of VJSn. Hydrogen atoms have been omitted for clarity.

Table 7-41: Crystallographic data for VJSn.

\begin{tabular}{|c|c|c|c|}
\hline structure code & VJSn & $F(000)$ & 1232 \\
\hline formula & $\mathrm{C}_{28} \mathrm{H}_{48} \mathrm{~N}_{2} \mathrm{Si}_{2} \mathrm{Sn}$ & max. / min. Transmission & $0.99 / 0.903898$ \\
\hline molecular mass $/ \mathrm{g} \cdot \mathrm{mol}^{-1}$ & 587.55 & $\rho_{\text {calc }} / \mathrm{Mg} \cdot \mathrm{m}^{-3}$ & 1.334 \\
\hline crystal size / mm & $0.08 \times 0.06 \times 0.06$ & $\mu / \mathrm{mm}^{-1}$ & 0.974 \\
\hline crystal system & monoclinic & $\theta_{\min } / \theta_{\max }^{\circ}$ & $1.93 / 26.38$ \\
\hline space group & $C 2 / c$ & reflections all/unique & 15793 / 2987 \\
\hline $\mathrm{a} / \AA$ & $21.503(2)$ & data/restraints/parameter & $2987 / 0 / 157$ \\
\hline $\mathrm{b} / \AA$ & $9.709(1)$ & $R 1$ (all data) & 0.0340 \\
\hline$c / \AA$ & $14.291(1)$ & $w R 2$ (all data) & 0.0880 \\
\hline$\beta /{ }^{\circ}$ & $101.30(1)$ & $g 1 / g 2$ & $0.0379 / 13.2342$ \\
\hline$V / \AA^{3}$ & $2925.6(5)$ & GoF & 1.095 \\
\hline Z & 4 & peak/hole: & \\
\hline temperature / $\mathrm{K}$ & $100(2)$ & $\max . / \min . /\left(10^{-6} \mathrm{e} \cdot \AA^{-3}\right)$ & $0.550 /-0.691$ \\
\hline
\end{tabular}




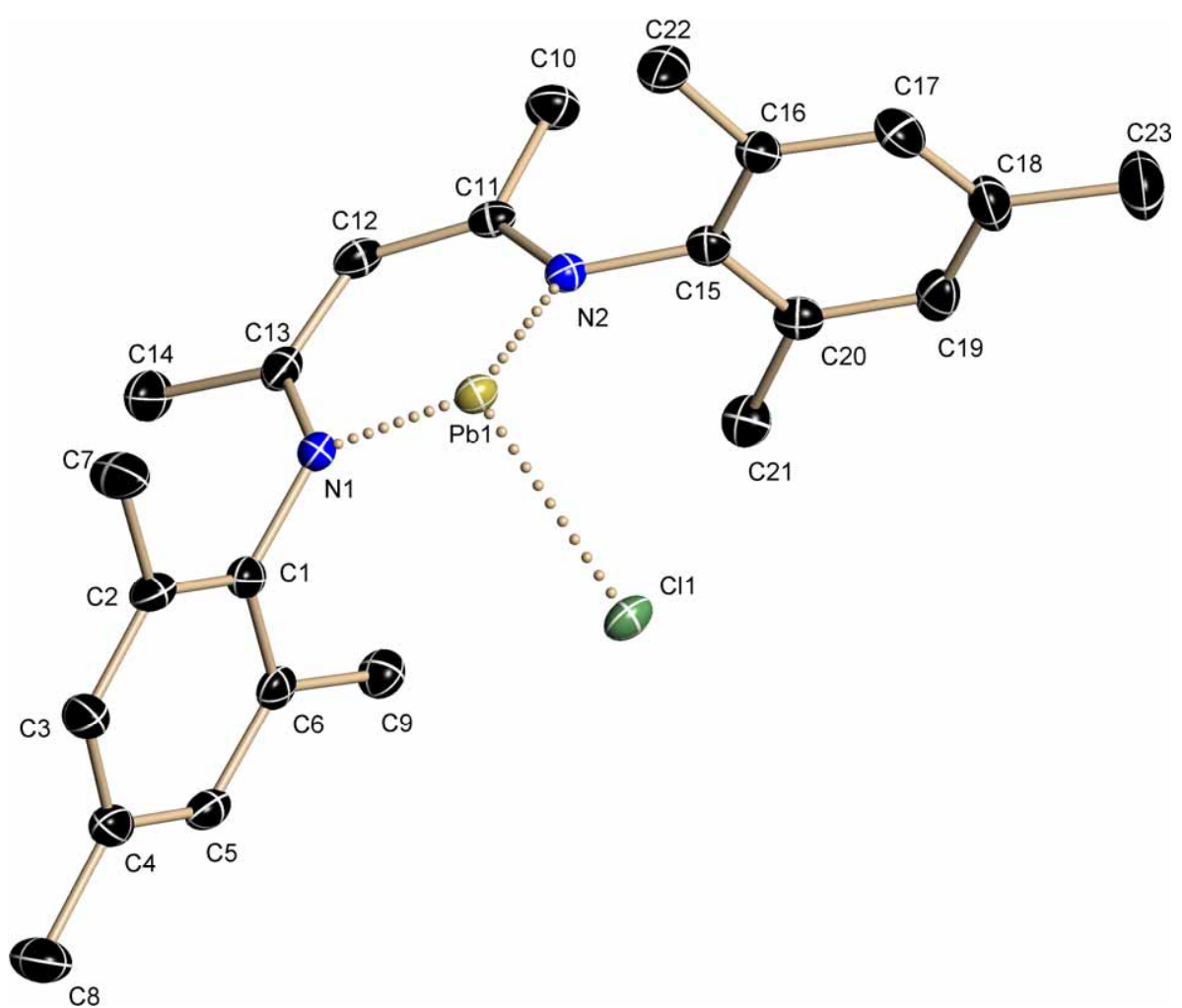

Figure 7-42: Asymmetric unit of VJPb. Hydrogen atoms have been omitted for clarity.

Due to racemic twinning the Flack $\mathrm{x}$ parameter could not be determined.

Table 7-42: Crystallographic data for VJPb.

\begin{tabular}{|c|c|c|c|}
\hline structure code & VJPb & $F(000)$ & 1120 \\
\hline formula & $\mathrm{C}_{23} \mathrm{H}_{29} \mathrm{CIN}_{2} \mathrm{~Pb}$ & max. / min. Transmission & $0.99 / 0.703598$ \\
\hline molecular mass $/ \mathrm{g} \cdot \mathrm{mol}^{-1}$ & 576.12 & $\rho_{\text {calc }} / \mathrm{Mg} \cdot \mathrm{m}^{-3}$ & 1.691 \\
\hline crystal size / mm & $0.2 \times 0.2 \times 0.04$ & $\mu / \mathrm{mm}^{-1}$ & 7.582 \\
\hline crystal system & orthorhombic & $\theta_{\min } / \theta_{\max }^{\circ}$ & $1.95 / 26.41$ \\
\hline space group & $P 2_{1} 2_{1} 2_{1}$ & reflections all/unique & 36538 / 2631 \\
\hline a / $\AA$ & $10.1323(9)$ & data/restraints/parameter & $2631 / 0 / 253$ \\
\hline $\mathrm{b} / \AA$ & $13.3856(11)$ & $R 1$ (all data) & 0.0128 \\
\hline$c / \AA$ & $16.6880(14)$ & $w R 2$ (all data) & 0.0288 \\
\hline$V / \AA^{3}$ & $2263.3(3)$ & $g 1 / g 2$ & $0.0068 / 1.1391$ \\
\hline Z & 4 & GoF & 1.102 \\
\hline temperature / $\mathrm{K}$ & $100(2)$ & peak / hole / $\left(10^{-6} \mathrm{e} \cdot \AA^{-3}\right)$ & $0.507 /-0.312$ \\
\hline
\end{tabular}




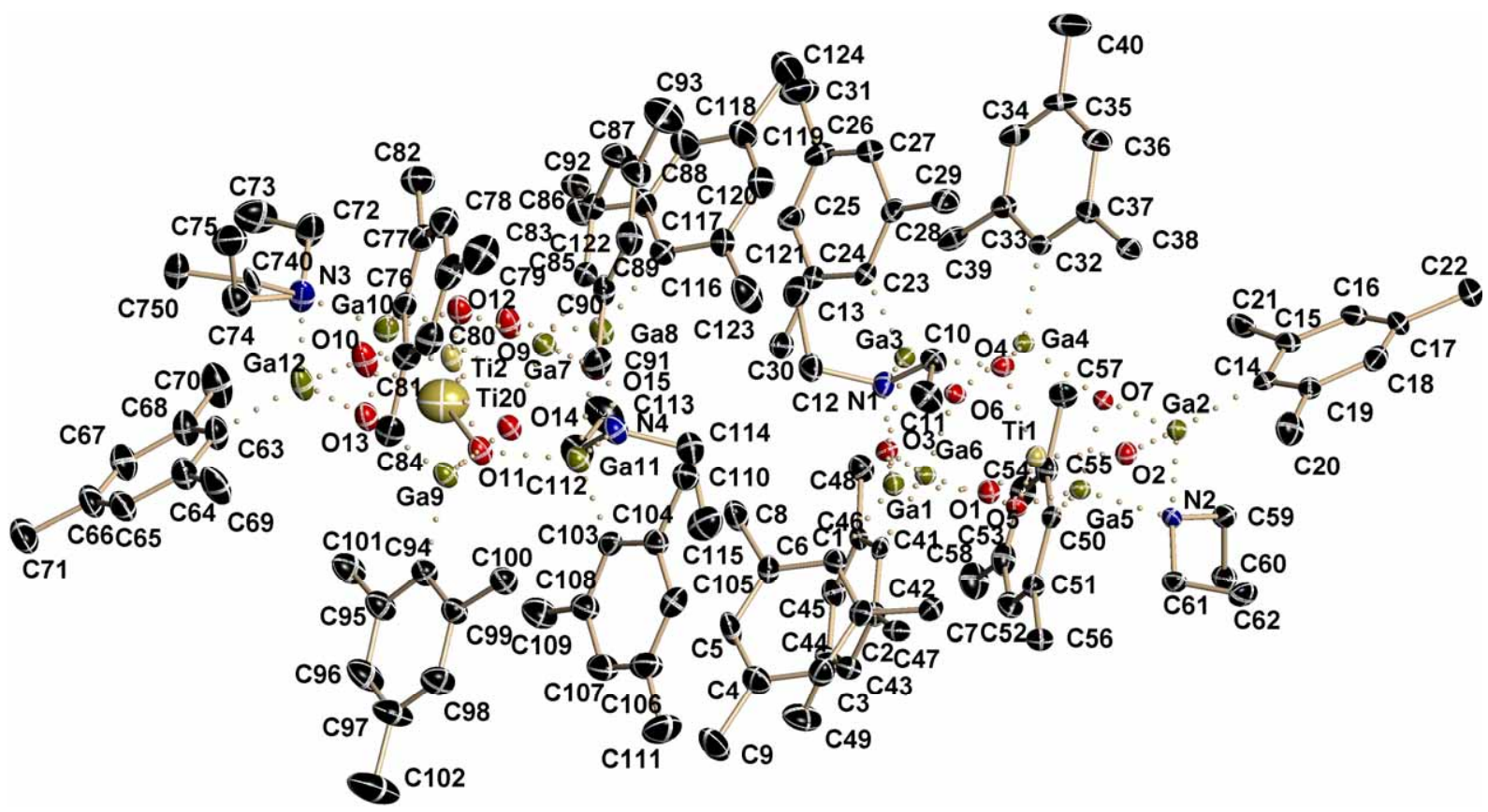

Figure 7-43: Asymmetric unit of NikiGaTi. Hydrogen atoms have been omitted for clarity.

Table 7-43: Crystallographic data for NikiGaTi.

\begin{tabular}{|ll|ll|}
\hline structure code & NikiGaTi & temperature / K & $100(2)$ \\
formula & $\mathrm{C}_{62} \mathrm{H}_{86} \mathrm{Ga}_{6} \mathrm{~N}_{2} \mathrm{O}_{7} \mathrm{Ti}$ & max. / min. Transmission & $0.88927 / 0.99$ \\
molecular mass / g $\cdot \mathrm{mol}^{-1}$ & 1437.55 & $\rho_{\text {calc }} /{\mathrm{Mg} \cdot \mathrm{m}^{-3}}^{-1}$ & 1.492 \\
crystal size / mm & $0.1 \times 0.05 \times 0.02$ & $\mu / \mathrm{mm}^{-1}$ & 2.656 \\
crystal system & triclinic & $F(000)$ & 2944 \\
space group & $P \overline{1}$ & $\theta_{\min } / \theta_{\text {max }}{ }^{\circ}$ & $1.45-25.41$ \\
$\mathrm{a} / \AA$ & $12.9331(12)$ & reflections all/unique & $107236 / 23474$ \\
$\mathrm{~b} / \AA$ & $1453.24(14)$ & data/restraints/parameter & $23474 / 15 / 1474$ \\
$\mathrm{c} / \AA$ & $35.544(3)$ & $R 1$ (all data) & 0.0745 \\
$\alpha /{ }^{\circ}$ & $81.7410(10)$ & $w R 2$ (all data) & 0.0916 \\
$\beta /{ }^{\circ}$ & $81.7230(10)$ & $g 1 / \mathrm{g} 2$ & $0.0321 / 9.3184$ \\
$\gamma /{ }^{\circ}$ & $77.0610(10)$ & GoF & 1.021 \\
$\mathrm{~V} / \AA^{3}$ & $6399.9(10)$ & peak/hole: & \\
$\mathrm{Z}$ & 4 & max. / min. / $\left(10^{-6} \mathrm{e} \cdot \AA^{-3}\right)$ & $0.615 /-0.712$ \\
\hline
\end{tabular}




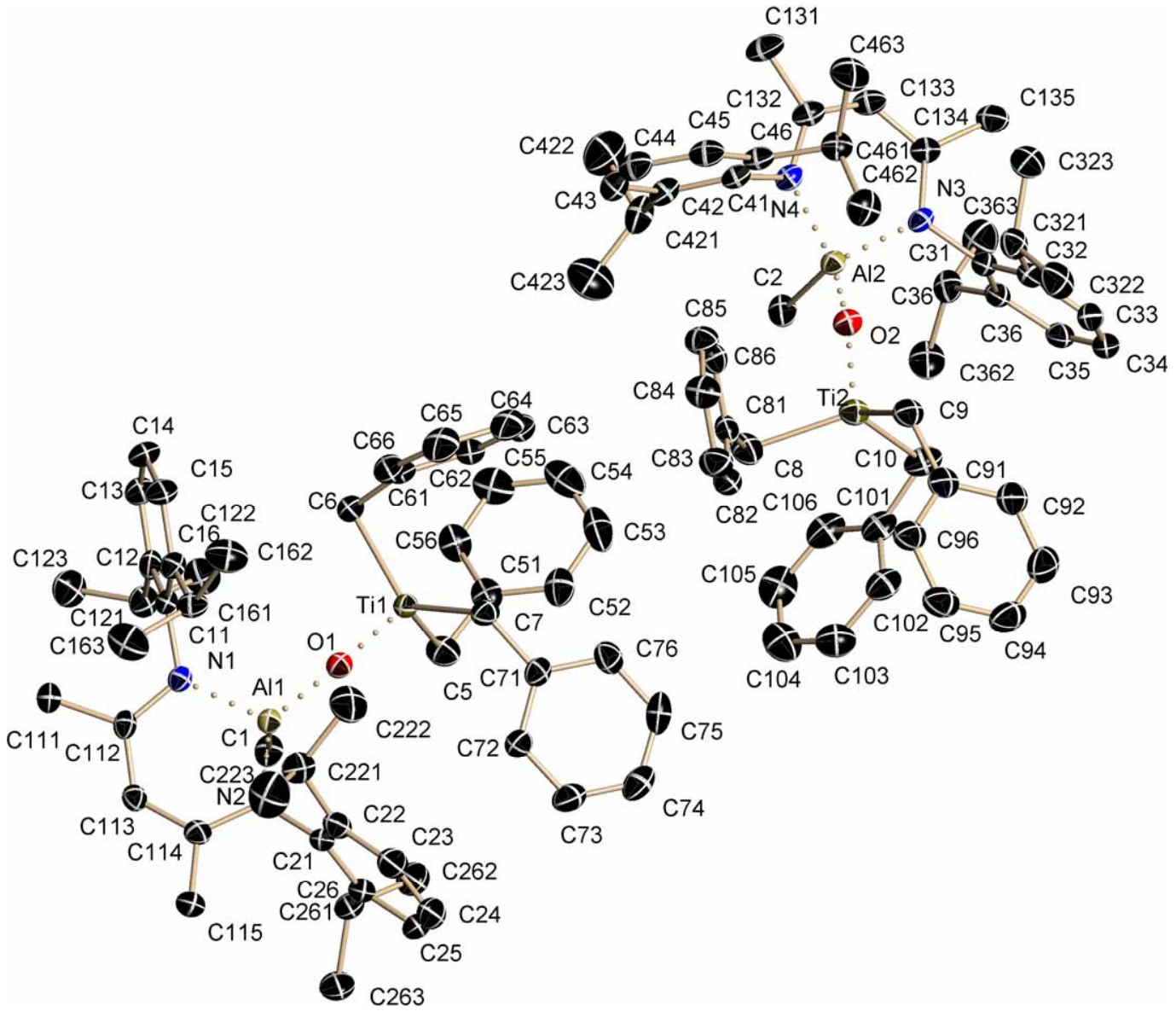

Figure 7-44: Asymmetric unit of NikiTi. Hydrogen atoms have been omitted for clarity.

Table 7-44: Crystallographic data for NikiTi.

\begin{tabular}{|c|c|c|c|}
\hline structure code & NikiTi & $F(000)$ & 3424 \\
\hline formula & $\mathrm{C}_{51} \mathrm{H}_{65} \mathrm{AIN}_{2} \mathrm{OTi}$ & max. / min. Transmission & $0.58 / 0.99$ \\
\hline molecular mass $/ \mathrm{g} \cdot \mathrm{mol}^{-1}$ & 796.93 & $\rho_{\text {calc }} / \mathrm{Mg} \cdot \mathrm{m}^{-3}$ & 1.165 \\
\hline crystal size / mm & $0.15 \times 0.12 \times 0.1$ & $\mu / \mathrm{mm}^{-1}$ & 0.245 \\
\hline crystal system & monoclinic & $\theta_{\min } / \theta_{\max }^{\circ}$ & $2.25-25.26$ \\
\hline space group & $P 2_{1} / c$ & reflections all/unique & 77407 / 18557 \\
\hline a / $\AA$ & $18.312(4)$ & data/restraints/parameter & $18557 / 0 / 1031$ \\
\hline $\mathrm{b} / \AA$ & $23.545(5)$ & $R 1$ (all data) & 0.0338 \\
\hline$c / \AA$ & $21.309(4)$ & $w R 2$ (all data) & 0.1082 \\
\hline$\beta /{ }^{\circ}$ & $98.56(3)$ & $g 1 / g 2$ & $0.0903 /-$ \\
\hline$V / \AA^{3}$ & $9085(3)$ & GoF & 1.037 \\
\hline Z & 8 & peak/hole: & \\
\hline temperature / $\mathrm{K}$ & $100(2)$ & $\max . / \min . /\left(10^{-6} \mathrm{e} \cdot \AA^{-3}\right)$ & $0.60 /-0.42$ \\
\hline
\end{tabular}



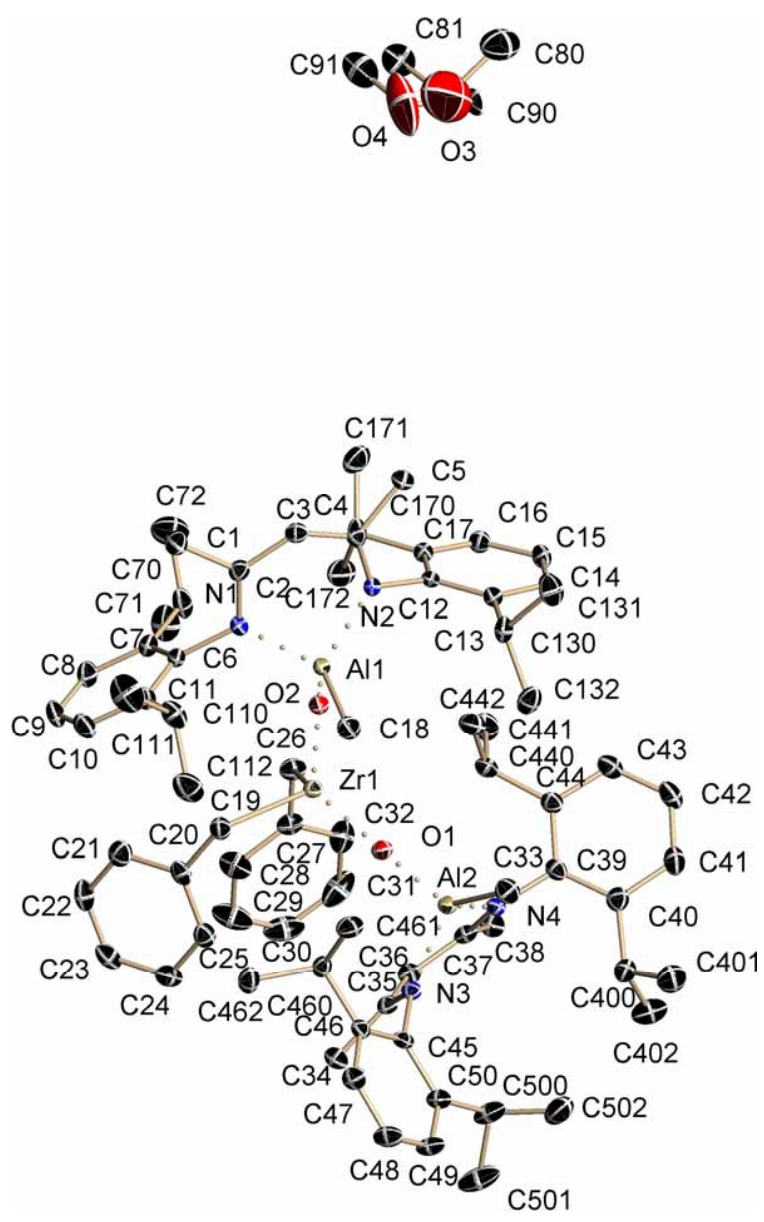

Figure 7-45: Asymmetric unit of NikiZr. Hydrogen atoms have been omitted for clarity.

Table 7-45: Crystallographic data for NikiZr.

\begin{tabular}{|c|c|c|c|}
\hline structure code & NikiZr & temperature / $\mathrm{K}$ & $100(2)$ \\
\hline formula & $\mathrm{C}_{76} \mathrm{H}_{107} \mathrm{Al}_{2} \mathrm{~N}_{4} \mathrm{O}_{3} \mathrm{Zr}$ & max. / min. Transmission & $0.815451 / 0.99$ \\
\hline molecular mass $/ \mathrm{g} \cdot \mathrm{mol}^{-1}$ & 1269.84 & $\rho_{\text {calc }} / \mathrm{Mg} \cdot \mathrm{m}^{-3}$ & 1.178 \\
\hline crystal size / mm & $0.4 \times 0.2 \times 0.05$ & $\mu / \mathrm{mm}^{-1}$ & 0.226 \\
\hline crystal system & triclinic & $F(000)$ & 1362 \\
\hline space group & $P \overline{1}$ & $\theta_{\min } / \theta_{\max }^{\circ}$ & $1.91-25.05$ \\
\hline a / $\AA$ & $12.2881(9)$ & reflections all/unique & $37690 / 10735$ \\
\hline $\mathrm{b} / \AA$ & $17.1318(13)$ & data/restraints/parameter & 10735 / 42 / 827 \\
\hline$c / \AA$ & $19.858(2)$ & $R 1$ (all data) & 0.0459 \\
\hline$\alpha /^{\circ}$ & $111.6850(10)$ & $w R 2$ (all data) & 0.0962 \\
\hline$\beta /{ }^{\circ}$ & $93.8700(10)$ & $g 1 / g 2$ & $0.0468 / 2.3104$ \\
\hline$\gamma /{ }^{\circ}$ & $109.3090(10)$ & GoF & 1.059 \\
\hline$V / \AA^{3}$ & $3579.3(5)$ & peak/hole: & \\
\hline Z & 2 & $\max . / \min . /\left(10^{-6} \mathrm{e} \cdot \AA^{-3}\right)$ & $0.773 /-0.412$ \\
\hline
\end{tabular}




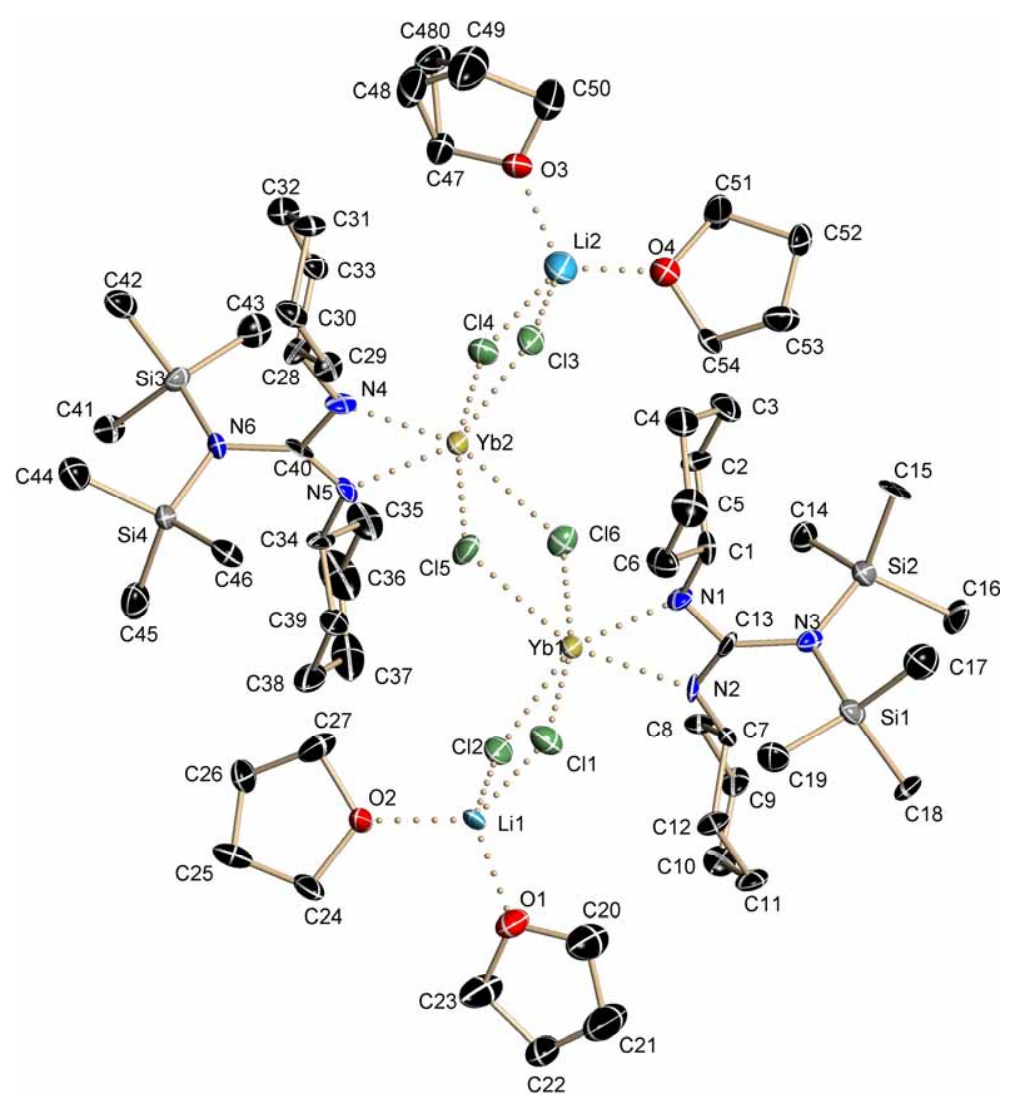

Figure 7-46: Asymmetric unit of ZhangYb. Hydrogen atoms have been omitted for clarity.

Table 7-46: Crystallographic data for ZhangYb.

\begin{tabular}{|ll|ll|}
\hline structure code & ZhangYb & temperature / K & $100(2)$ \\
formula & $\mathrm{C}_{54} \mathrm{H}_{112} \mathrm{Cl}_{6} \mathrm{Li}_{2} \mathrm{~N}_{6}$ & max. / min. Transmission & $0.99 / 0.626027$ \\
& $\mathrm{O}_{4} \mathrm{Si}_{4} \mathrm{Yb}_{2}$ & & \\
molecular mass $/ \mathrm{g} \cdot \mathrm{mol}^{-1}$ & 1594.52 & $\rho_{\text {calc }} / \mathrm{Mg} \cdot \mathrm{m}^{-3}$ & 1.447 \\
crystal size / mm & $0.2 \times 0.2 \times 0.1$ & $\mu / \mathrm{mm}^{-1}$ & 2.867 \\
crystal system & triclinic & $F(000)$ & 814 \\
space group & $P \overline{1}$ & $\theta_{\min } / \theta_{\max }{ }^{\circ}$ & $1.67 / 27.10$ \\
$\mathrm{a} / \AA$ & $10.759(3)$ & reflections all/unique & $43553 / 8057$ \\
$\mathrm{~b} / \AA$ & $12.652(4)$ & data/restraints/parameter & $8057 / 0 / 377$ \\
$\mathrm{c} / \AA$ & $14.657(4)$ & $R 1$ (all data) & 0.0168 \\
$\alpha /{ }^{\circ}$ & $77.330(3)$ & $w R 2($ all data) & 0.0419 \\
$\beta /{ }^{\circ}$ & $71.772(3)$ & $g 1 / g 2$ & $0.0202 / 1.0512$ \\
$\gamma /{ }^{\circ}$ & $78.326(3)$ & GoF & 1.054 \\
$\mathrm{~V} / \AA^{3}$ & $1829.5(9)$ & peak/hole: & \\
$\mathrm{Z}$ & 1 & max. / min. / $\left(10^{-6} \mathrm{e} \cdot \AA^{-3}\right)$ & $1.368 /-0.658$ \\
\hline
\end{tabular}




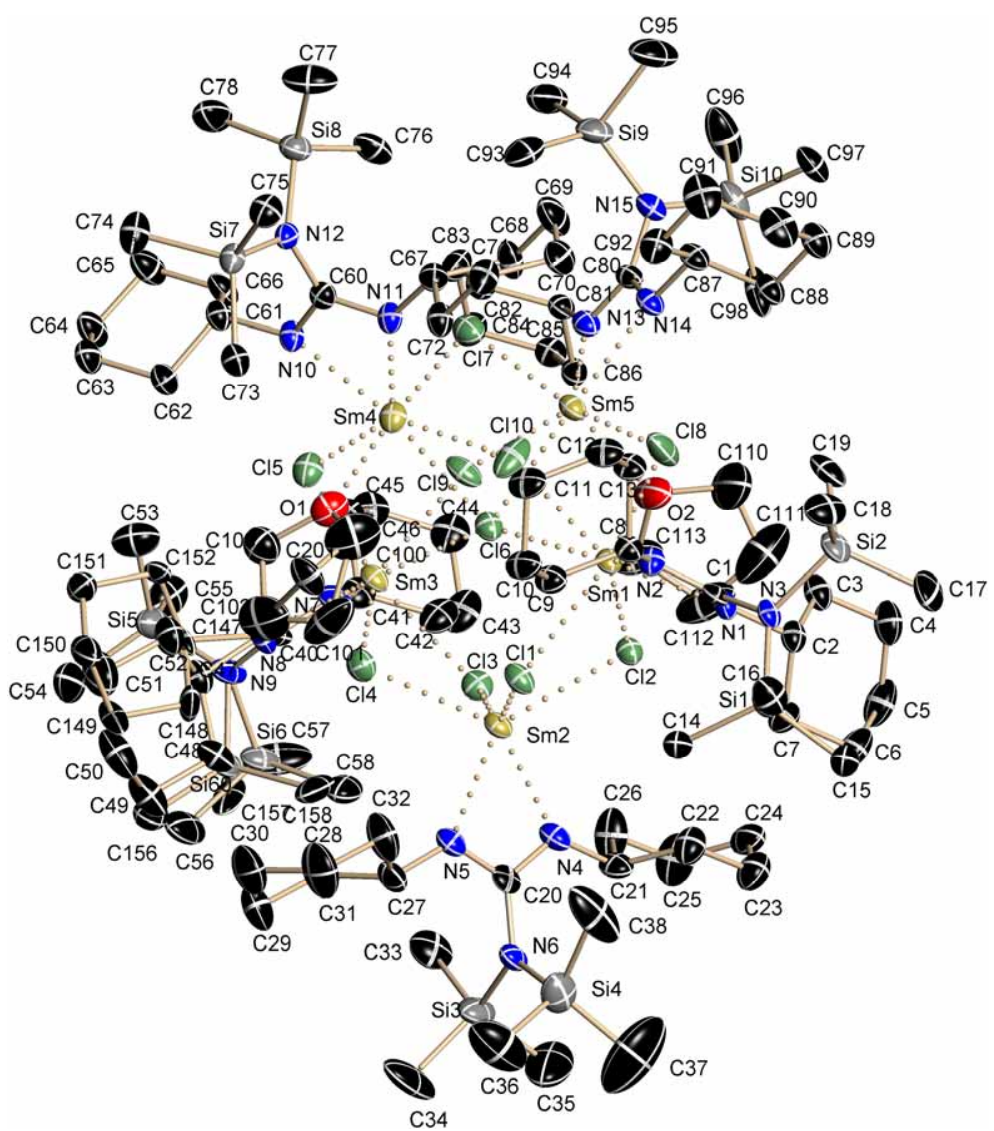

Figure 7-47: Asymmetric unit of ZhangSm. Hydrogen atoms have been omitted for clarity.

Table 7-47: Crystallographic data for ZhangSm.

\begin{tabular}{|c|c|c|c|}
\hline structure code & ZhangSm & temperature / $\mathrm{K}$ & $100(2)$ \\
\hline formula & $\begin{array}{l}\mathrm{C}_{103} \mathrm{H}_{216} \mathrm{Cl}_{10} \mathrm{~N}_{15} \\
\mathrm{O}_{2} \mathrm{Si}_{10} \mathrm{Sm}_{5}\end{array}$ & max. / min. Transmission & $0.4291 / 0.3537$ \\
\hline molecular mass $/ \mathrm{g} \cdot \mathrm{mol}^{-1}$ & 3084.06 & $\rho_{\text {calc }} / \mathrm{Mg} \cdot \mathrm{m}^{-3}$ & 1.417 \\
\hline crystal size / mm & $0.2 \times 0.1 \times 0.1$ & $\mu / \mathrm{mm}^{-1}$ & 2.313 \\
\hline crystal system & triclinic & $F(000)$ & 3150 \\
\hline space group & $P \overline{1}$ & $\theta_{\min } / \theta_{\max }^{\circ}$ & $2.01 / 25.74$ \\
\hline a / $\AA$ & $17.5764(19)$ & reflections all/unique & $144891 / 27482$ \\
\hline $\mathrm{b} / \AA$ & $19.361(2)$ & data/restraints/parameter & 27482 / 76 / 1441 \\
\hline$c / \AA$ & $24.774(3)$ & $R 1$ (all data) & 0.0463 \\
\hline$\alpha /^{\circ}$ & $74.5700(10)$ & $w R 2$ (all data) & 0.0765 \\
\hline$\beta /{ }^{\circ}$ & $70.6270(10))$ & $g 1 / g 2$ & $0.0411 / 0.00$ \\
\hline$\gamma /{ }^{\circ}$ & $66.9270(10)$ & GoF & 0.925 \\
\hline$V / \AA^{3}$ & $7226.3(13)$ & peak/hole: & \\
\hline Z & 2 & $\max . / \min . /\left(10^{-6} \mathrm{e} \cdot \AA^{-3}\right)$ & $0.937 /-1.034$ \\
\hline
\end{tabular}




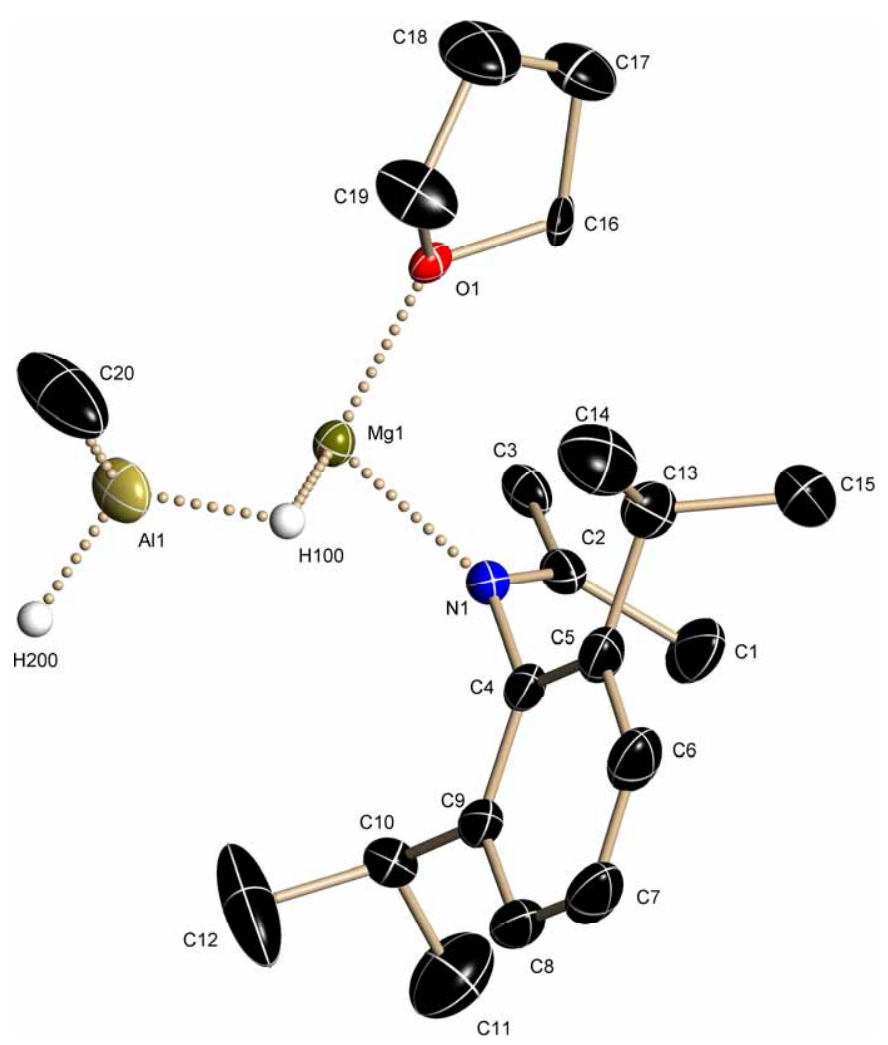

Figure 7-48: Asymmetric unit of S135. Calculated hydrogen atoms have been omitted for clarity.

Table 7-48: Crystallographic data for $\mathrm{S} 135$.

\begin{tabular}{|ll|ll|}
\hline structure code & $\mathrm{S} 135$ & $F(000)$ & 1224 \\
formula & $\mathrm{C}_{34} \mathrm{H}_{55} \mathrm{AlMgN}_{2} \mathrm{O}$ & max. / min. Transmission & $0.7035 / 0.7452$ \\
molecular mass $/ \mathrm{g} \cdot \mathrm{mol}^{-1}$ & 559.09 & $\rho_{\text {calc }} / \mathrm{Mg} \cdot \mathrm{m}^{-3}$ & 1.083 \\
crystal size / mm & $0.15 \times 0.1 \times 0.1$ & $\mu / \mathrm{mm}^{-1}$ & 0.104 \\
crystal system & orthorhombic & $\theta_{\min } / \theta_{\max }{ }^{\circ}$ & $2.27-25.05$ \\
space group & $P b c m$ & reflections all/unique & $46148 / 2701$ \\
a / $\AA$ & $9.795(2)$ & data/restraints $/$ parameter & $2701 / 15 / 209$ \\
b / $\AA$ & $17.905(4)$ & $R 1$ (all data) & 0.0699 \\
c / $\AA$ & $19.544(5)$ & $w R 2$ (all data) & 0.1713 \\
$\mathrm{~V} / \AA^{3}$ & $3427.7(14)$ & $g 1 / g 2$ & $0.0927 / 3.1336$ \\
$\mathrm{Z}$ & 4 & GoF & 1.072 \\
temperature / K & $100(2)$ & peak / hole / $\left(10^{-6} \mathrm{e} \cdot \AA^{-3}\right)$ & $0.563 /-0.530$ \\
\hline
\end{tabular}




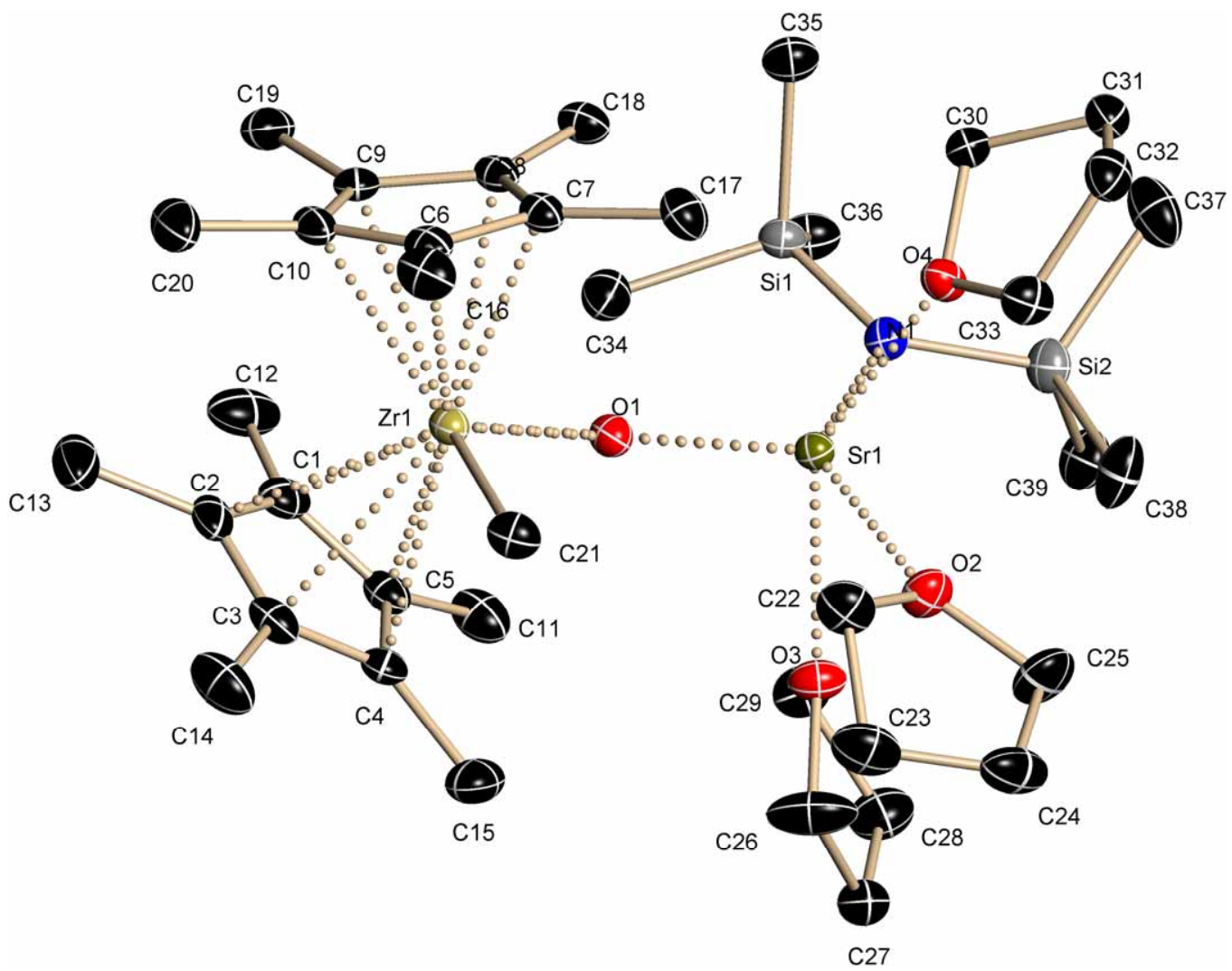

Figure 7-49: Asymmetric unit of S90. Hydrogen atoms have been omitted for clarity.

Table 7-49: Crystallographic data for S90.

\begin{tabular}{|c|c|c|c|}
\hline structure code & S90 & $F(000)$ & 1816 \\
\hline formula & $\mathrm{C}_{39} \mathrm{H}_{75} \mathrm{NO}_{4} \mathrm{Si}_{2} \mathrm{SrZr}$ & max. / min. Transmission & $0.3899 / 0.4293$ \\
\hline molecular mass $/ \mathrm{g} \cdot \mathrm{mol}^{-1}$ & 857.02 & $\rho_{\text {calc }} / \mathrm{Mg} \cdot \mathrm{m}^{-3}$ & 1.255 \\
\hline crystal size / mm & $0.15 \times 0.1 \times 0.05$ & $\mu / \mathrm{mm}^{-1}$ & 1.493 \\
\hline crystal system & monoclinic & $\theta_{\min } / \theta_{\max }^{\circ}$ & $4.45-26.02$ \\
\hline space group & $P 2_{1} / n$ & reflections all/unique & 58894 / 6622 \\
\hline a / $\AA$ & $14.6287(11)$ & data/restraints/parameter & $6622 / 0 / 450$ \\
\hline $\mathrm{b} / \AA$ & $19.5529(14)$ & $R 1$ (all data) & 0.0422 \\
\hline$c / \AA$ & $16.7888(12)$ & $w R 2$ (all data) & 0.0642 \\
\hline$\beta /{ }^{\circ}$ & $109.1100(10)$ & $g 1 / g 2$ & $0.0316 / 0$ \\
\hline$V / \AA^{3}$ & $4537.5(6)$ & GoF & 0.915 \\
\hline Z & 4 & peak/hole: & \\
\hline temperature / $\mathrm{K}$ & $100(2)$ & $\max . / \min . /\left(10^{-6} \mathrm{e} \cdot \AA^{-3}\right)$ & $0.351 /-0.473$ \\
\hline
\end{tabular}




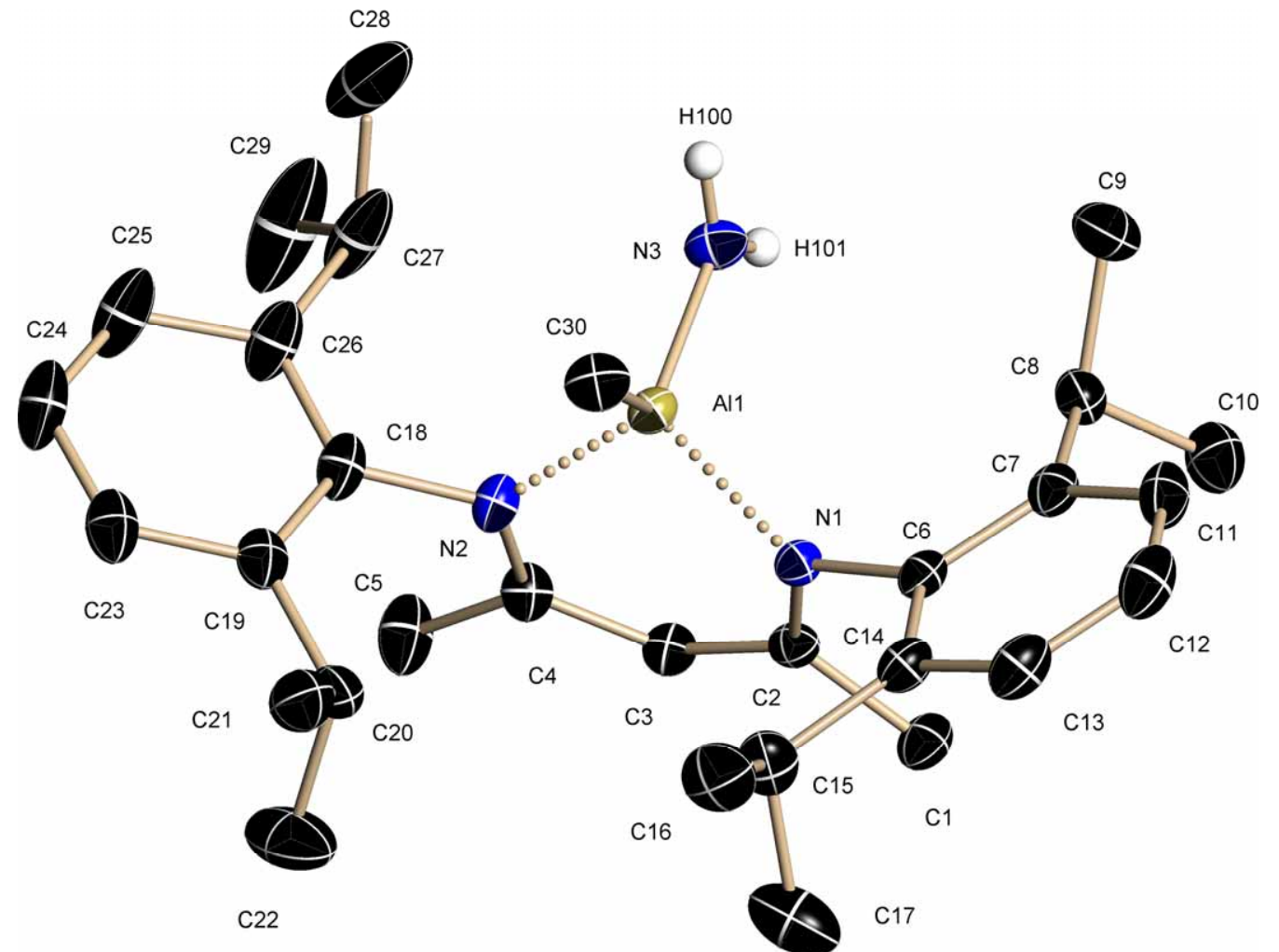

Figure 7-50: Asymmetric unit of $\mathrm{SNH} 2$. Calculated hydrogen atoms have been omitted for clarity.

Table 7-50: Crystallographic data for SNH2.

\begin{tabular}{|ll|ll|}
\hline structure code & $\mathrm{SNH} 2$ & $F(000)$ & 1040 \\
formula & $\mathrm{C}_{30} \mathrm{H}_{46} \mathrm{AIN}_{3}$ & max. / min. Transmission & $0.6479 / 0.7454$ \\
molecular mass $/ \mathrm{g} \cdot \mathrm{mol}^{-1}$ & 475.68 & $\rho_{\text {calc }} /{\mathrm{Mg} \cdot \mathrm{m}^{-3}}^{-3}$ & 1.085 \\
crystal size $/ \mathrm{mm}$ & $0.3 \times 0.2 \times 0.2$ & $\mu / \mathrm{mm}^{-1}$ & 0.091 \\
crystal system & monoclinic & $\theta_{\min } / \theta_{\max }{ }^{\circ}$ & $2.29-26.69$ \\
space group & $P 2{ }_{1} / c$ & reflections all/unique & $64597 / 5586$ \\
$\mathrm{a} / \AA$ & $8.8952(8)$ & data/restraints/parameter & $5586 / 2 / 326$ \\
$\mathrm{~b} / \AA$ & $R 1$ (all data) & 0.0475 \\
$\mathrm{c} / \AA$ & $9.7909(9)$ & $w R 2($ all data) & 0.1068 \\
$\beta /{ }^{\circ}$ & $33.464(3)$ & $g 1 / g 2$ & $0.0367 / 2.0697$ \\
$\mathrm{~V} / \AA^{3}$ & $92.0750(10)$ & GoF & 1.070 \\
$\mathrm{Z}$ & $2912.6(5)$ & peak/hole: & \\
temperature / K & 4 & max. / min. / $\left(10^{-6} \mathrm{e} \cdot \AA^{-3}\right)$ & $0.317 /-0.276$ \\
\hline
\end{tabular}




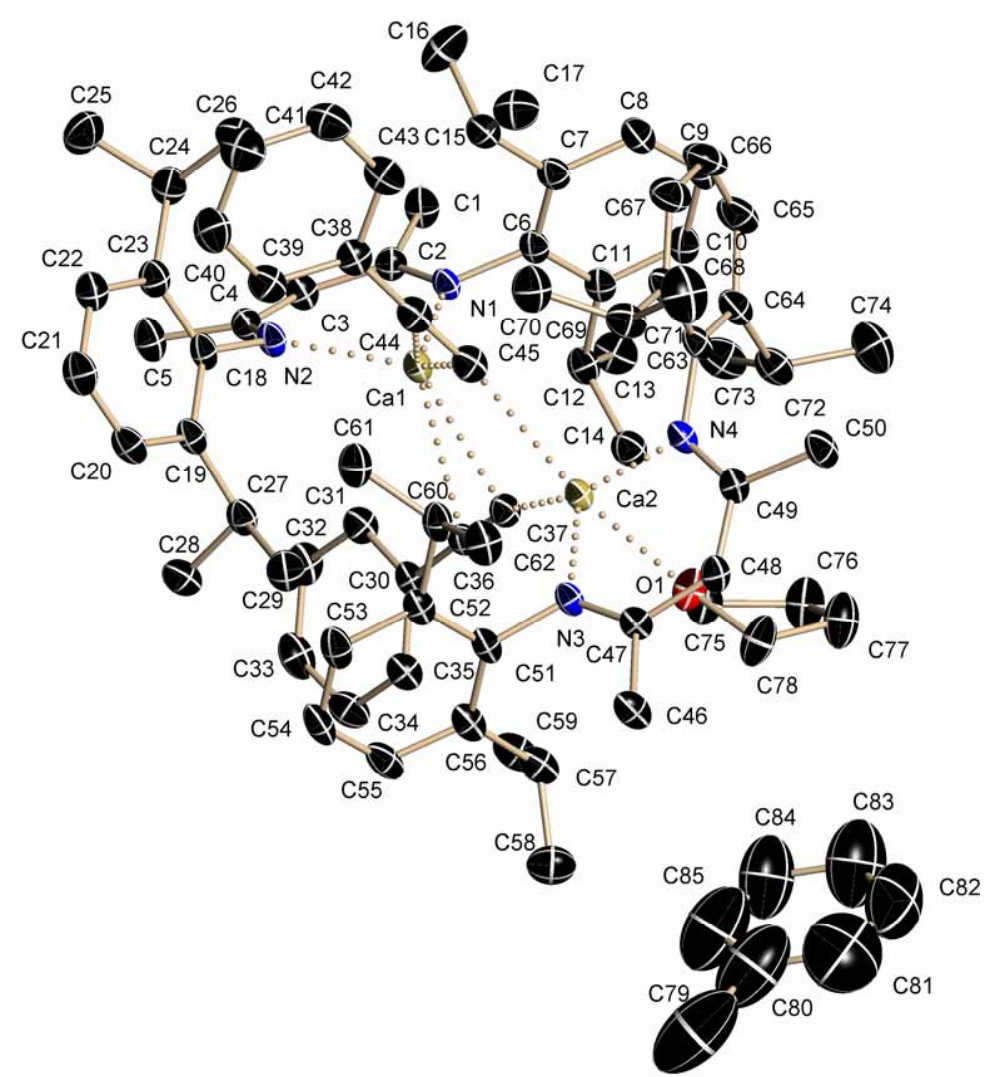

Figure 7-51: Asymmetric unit of S200. Hydrogen atoms have been omitted for clarity.

Due to racemic twinning the Flack $\mathrm{x}$ parameter could not be determined.

Table 7-51: Crystallographic data for S200.

\begin{tabular}{|ll|ll|}
\hline structure code & $\mathrm{S} 200$ & $F(000)$ & 1388 \\
formula & $\mathrm{C}_{85} \mathrm{H}_{108} \mathrm{Ca}_{2} \mathrm{~N}_{4} \mathrm{O}$ & max. / min. Transmission & $0.7454 / 0.6887$ \\
molecular mass / g $\cdot \mathrm{mol}^{-1}$ & 1281.91 & $\rho_{\text {calc }} / \mathrm{Mg} \cdot \mathrm{m}^{-3}$ & 1.139 \\
crystal size / mm & $0.2 \times 0.15 \times 0.1$ & $\mu / \mathrm{mm}^{-1}$ & 0.200 \\
crystal system & monoclinic & $\theta_{\min } / \theta_{\text {max }}{ }^{\circ}$ & $2.50 / 26.36$ \\
space group & $P 2_{1}$ & reflections all/unique & $51066 / 15229$ \\
a / $\AA$ & $12.7628(18)$ & data/restraints/parameter & $15229 / 71 / 838$ \\
$\mathrm{~b} / \AA$ & $16.292(2)$ & $R 1($ all data) & 0.0502 \\
$\mathrm{c} / \AA$ & $17.997(3)$ & $w R 2($ all data $)$ & 0.1124 \\
$\beta /{ }^{\circ}$ & $92.983(2)$ & $g 1 / g 2$ & $0.0634 / 1.0833$ \\
$\mathrm{~V} / \AA^{3}$ & $3736.9(9)$ & GoF & 1.053 \\
$\mathrm{Z}$ & 2 & peak/hole: & \\
temperature / K & $100(2)$ & max. / min. / $\left(10^{-6} \mathrm{e} \cdot \AA^{-3}\right)$ & $0.689 /-0.493$ \\
\hline
\end{tabular}




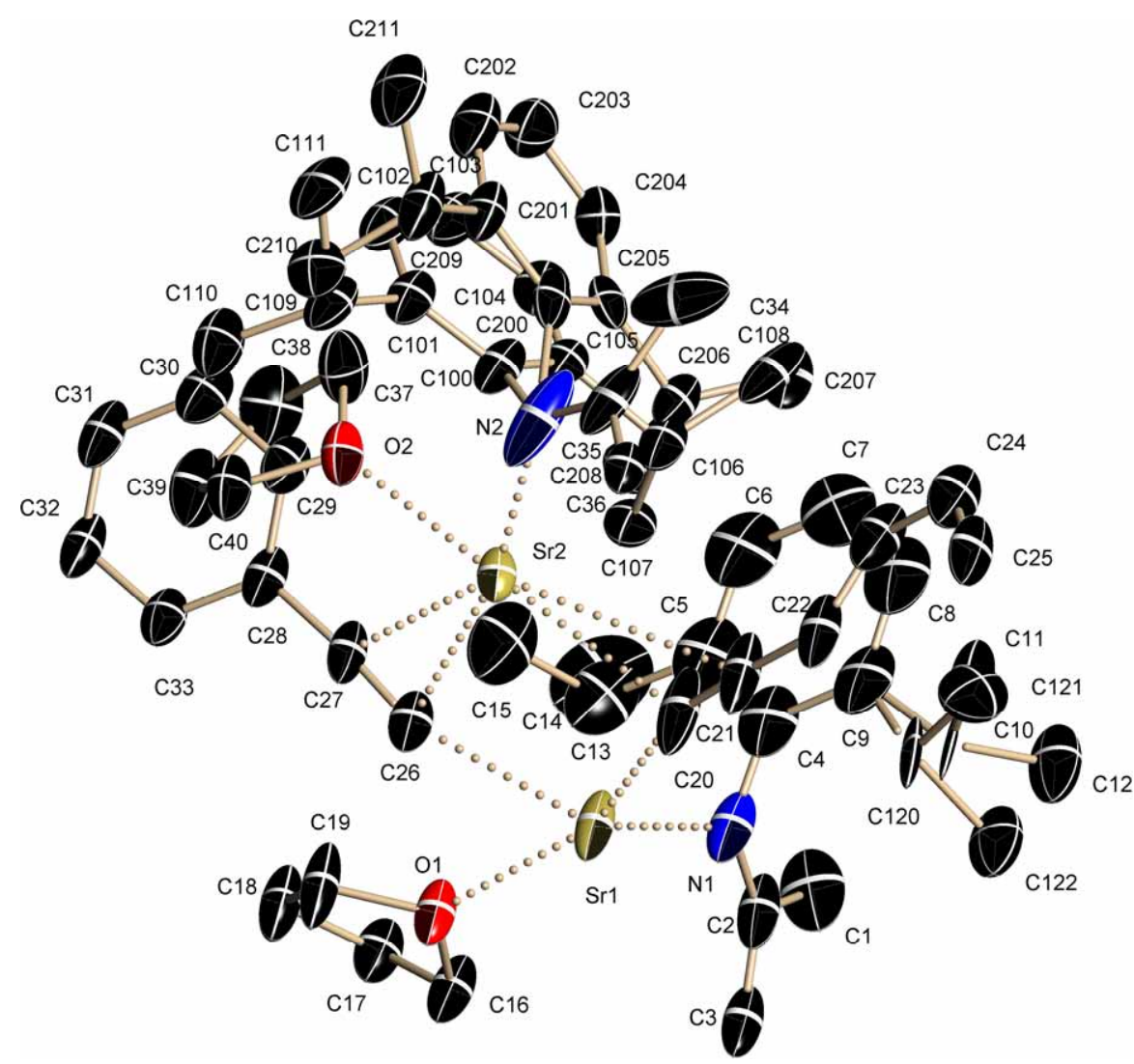

Figure 7-52: Asymmetric unit of S199. Hydrogen atoms have been omitted for clarity.

Table 7-52: Crystallographic data for S199.

\begin{tabular}{|ll|ll|}
\hline structure code & $\mathrm{S} 199$ & $F(000)$ & 2880 \\
formula & $\mathrm{C}_{82} \mathrm{H}_{108} \mathrm{~N}_{4} \mathrm{O}_{2} \mathrm{Sr}_{2}$ & max. / min. Transmission & $0.3512 / 0.4291$ \\
molecular mass $/ \mathrm{g} \cdot \mathrm{mol}^{-1}$ & 1356.96 & $\rho_{\text {calc }} / \mathrm{Mg} \cdot \mathrm{m}^{-3}$ & 1.238 \\
crystal size / mm & $0.15 \times 0.15 \times 0.1$ & $\mu / \mathrm{mm}^{-1}$ & 1.514 \\
crystal system & orthorhombic & $\theta_{\min } / \theta_{\max }{ }^{\circ}$ & $2.54-25.02$ \\
space group & $P n m a$ & reflections all/unique & $73169 / 6607$ \\
a / $\AA$ & $25.361(3)$ & data/restraints/parameter & $6607 / 162 / 585$ \\
$\mathrm{~b} / \AA$ & $20.746(3)$ & $R 1$ (all data) & 0.0970 \\
$\mathrm{c} / \AA$ & $13.833(2)$ & $w R 2$ (all data) & 0.1532 \\
$\mathrm{~V} / \AA^{3}$ & $7277.8(16)$ & $g 1 / g 2$ & $0.0576 / 4.9455$ \\
$\mathrm{Z}$ & 4 & GoF & 1.060 \\
temperature / K & $100(2)$ & peak / hole / $\left(10^{-6} \mathrm{e} \cdot \AA^{-3}\right)$ & $0.615 /-0.702$ \\
\hline
\end{tabular}




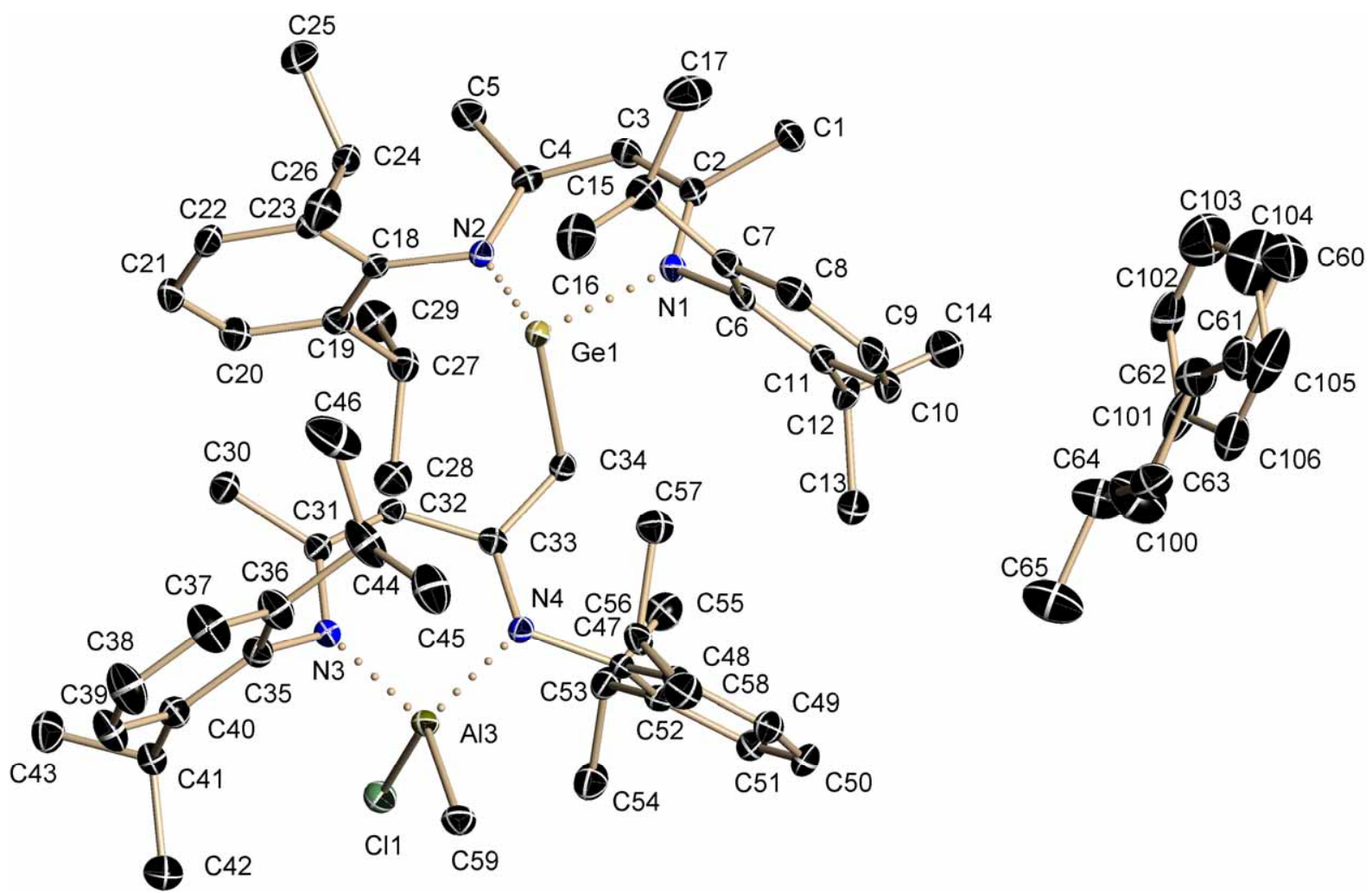

Figure 7-53: Asymmetric unit of SGe. Hydrogen atoms have been omitted for clarity.

Table 7-53: Crystallographic data for SGe.

\begin{tabular}{|c|c|c|c|}
\hline structure code & SGe & $F(000)$ & 2312 \\
\hline formula & $\begin{array}{l}\mathrm{C}_{65.21} \mathrm{H}_{96.75} \mathrm{Al} \\
\mathrm{ClGeN}_{4}\end{array}$ & max. / min. Transmission & $0.7128 / 0.7454$ \\
\hline molecular mass $/ \mathrm{g} \cdot \mathrm{mol}^{-1}$ & 1071.73 & $\rho_{\text {calc }} / \mathrm{Mg} \cdot \mathrm{m}^{-3}$ & 1.143 \\
\hline crystal size / mm & $0.2 \times 0.2 \times 0.2$ & $\mu / \mathrm{mm}^{-1}$ & 0.589 \\
\hline crystal system & monoclinic & $\theta_{\min } / \theta_{\max }^{\circ}$ & $1.41 / 26.02$ \\
\hline space group & $P 2_{1} / n$ & reflections all/unique & $52821 / 12266$ \\
\hline a / $\AA$ & $14.868(1)$ & data/restraints/parameter & $12266 / 0 / 724$ \\
\hline $\mathrm{b} / \AA$ & $20.695(1)$ & $R 1$ (all data) & 0.0446 \\
\hline$c / \AA$ & $20.491(1)$ & $w R 2$ (all data) & 0.0752 \\
\hline$\beta /{ }^{\circ}$ & $98.983(1)$ & $g 1 / g 2$ & $0.0318 / 3.2607$ \\
\hline$V / \AA^{3}$ & $6227.5(4)$ & GoF & 1.012 \\
\hline Z & 4 & peak/hole: & \\
\hline temperature / $\mathrm{K}$ & $100(2)$ & $\max . / \min . /\left(10^{-6} \mathrm{e} \cdot \AA^{-3}\right)$ & $0.361 /-0.311$ \\
\hline
\end{tabular}




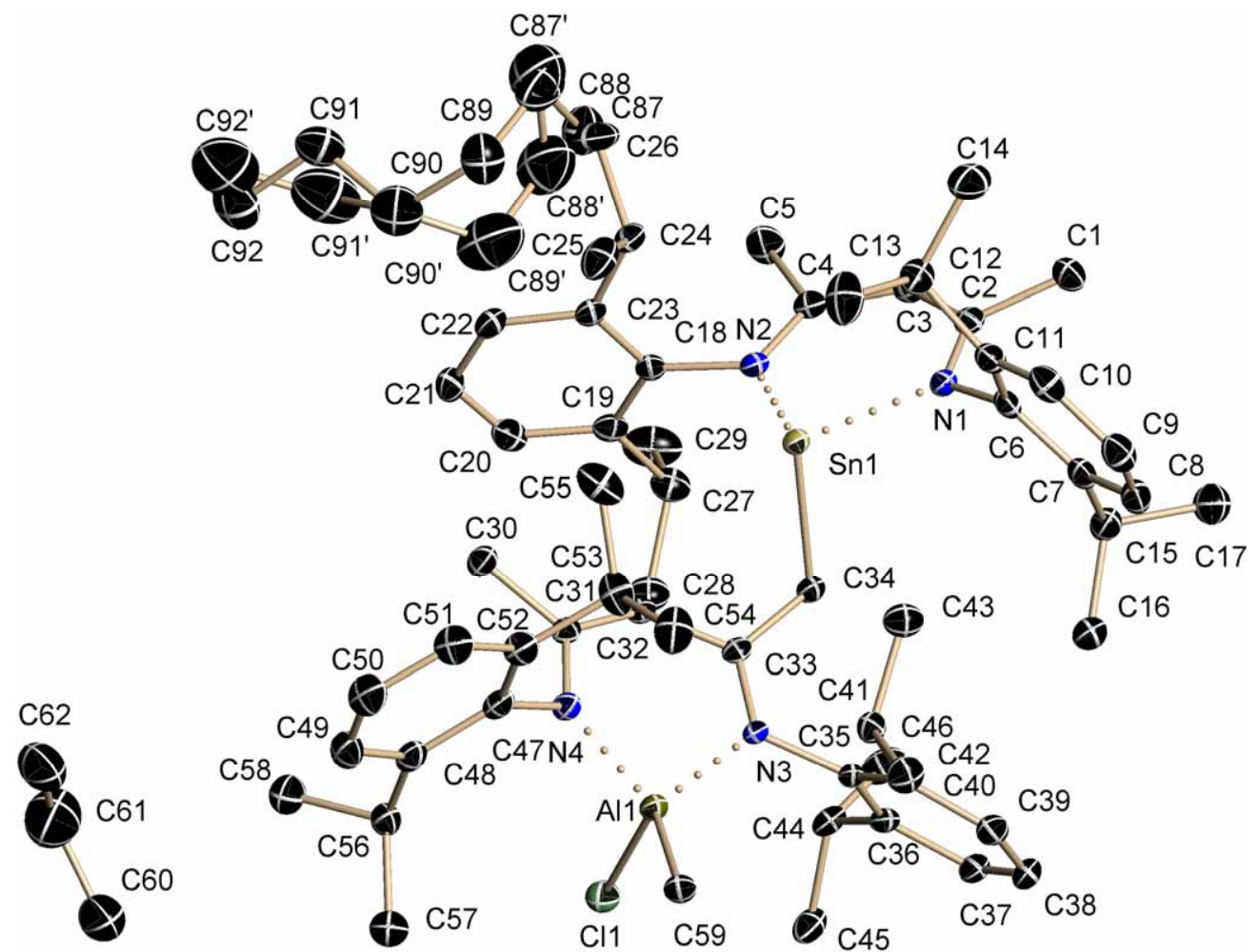

Figure 7-54: Asymmetric unit of SSn. Hydrogen atoms have been omitted for clarity.

Table 7-54: Crystallographic data for SSn.

\begin{tabular}{|c|c|c|c|}
\hline structure code & SSn & $F(000)$ & 2484 \\
\hline formula & $\mathrm{C}_{68} \mathrm{H}_{105} \mathrm{AICIN}_{4} \mathrm{Sn}$ & max. / min. Transmission & $0.6870 / 0.7452$ \\
\hline molecular mass $/ \mathrm{g} \cdot \mathrm{mol}^{-1}$ & 1159.68 & $\rho_{\text {calc }} / \mathrm{Mg} \cdot \mathrm{m}^{-3}$ & 1.178 \\
\hline crystal size / mm & $0.25 \times 0.25 \times 0.2$ & $\mu / \mathrm{mm}^{-1}$ & 0.486 \\
\hline crystal system & monoclinic & $\theta_{\min } / \theta_{\max }^{\circ}$ & $1.35 / 25.42$ \\
\hline space group & $P 2_{1} / n$ & reflections all/unique & 78557 / 12051 \\
\hline$a / \AA$ & $14.345(1)$ & data/restraints/parameter & $12051 / 87 / 737$ \\
\hline $\mathrm{b} / \AA$ & $20.705(1)$ & $R 1$ (all data) & 0.0561 \\
\hline$c / \AA$ & $22.941(1)$ & $w R 2$ (all data) & 0.0775 \\
\hline$\beta /{ }^{\circ}$ & $106.319(1)$ & $g 1 / g 2$ & $0.0333 / 4.3954$ \\
\hline$V / \AA^{3}$ & $6539.1(6)$ & GoF & 1.023 \\
\hline Z & 4 & peak/hole: & \\
\hline temperature / K & $100(2)$ & $\max . / \min . /\left(10^{-6} \mathrm{e} \cdot \AA^{-3}\right)$ & $0.694 /-0.319$ \\
\hline
\end{tabular}




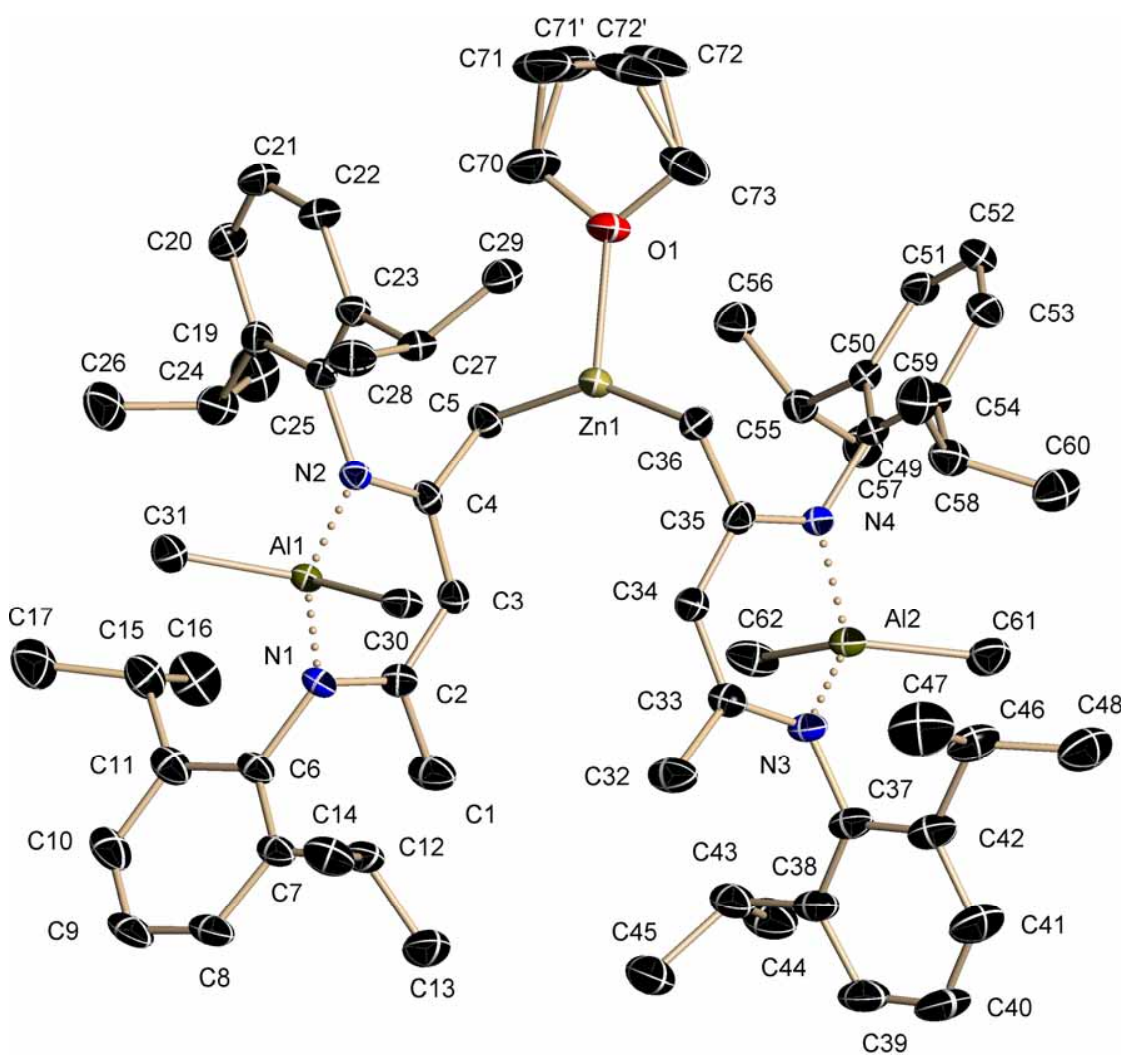

Figure 7-55: Asymmetric unit of SZn. Hydrogen atoms have been omitted for clarity.

Table 7-55: Crystallographic data for SZn.

\begin{tabular}{|c|c|c|c|}
\hline structure code & SZn & temperature / $\mathrm{K}$ & $100(2)$ \\
\hline formula & $\mathrm{C}_{66} \mathrm{H}_{100} \mathrm{Al}_{2} \mathrm{~N}_{4} \mathrm{OZn}$ & max. / min. Transmission & $0.6450 / 0.7452$ \\
\hline molecular mass $/ \mathrm{g} \cdot \mathrm{mol}^{-1}$ & 1084.83 & $\rho_{\text {calc }} / \mathrm{Mg} \cdot \mathrm{m}^{-3}$ & 1.130 \\
\hline crystal size / mm & $0.1 \times 0.1 \times 0.05$ & $\mu / \mathrm{mm}^{-1}$ & 0.455 \\
\hline crystal system & triclinic & $F(000)$ & 1176 \\
\hline space group & $P \overline{1}$ & $\theta_{\min } / \theta_{\max }^{\circ}$ & $2.09 / 25.38$ \\
\hline $\mathrm{a} / \AA$ & $10.312(1)$ & reflections all/unique & $39119 / 11707$ \\
\hline $\mathrm{b} / \AA$ & $13.290(2)$ & data/restraints/parameter & $11707 / 65 / 708$ \\
\hline$c / \AA$ & $24.811(3)$ & $R 1$ (all data) & 0.0654 \\
\hline$\alpha /^{\circ}$ & $83.555(2)$ & $w R 2$ (all data) & 0.1062 \\
\hline$\beta /{ }^{\circ}$ & $88.621(2)$ & $g 1 / g 2$ & $0.0502 / 1.3827$ \\
\hline$\gamma /{ }^{\circ}$ & $70.723(2)$ & GoF & 1.037 \\
\hline$V / \AA^{3}$ & $3188.9(6)$ & peak/hole: & \\
\hline Z & 2 & $\max . / \min . /\left(10^{-6} \mathrm{e} \cdot \AA^{-3}\right)$ & $0.398 /-0.471$ \\
\hline
\end{tabular}




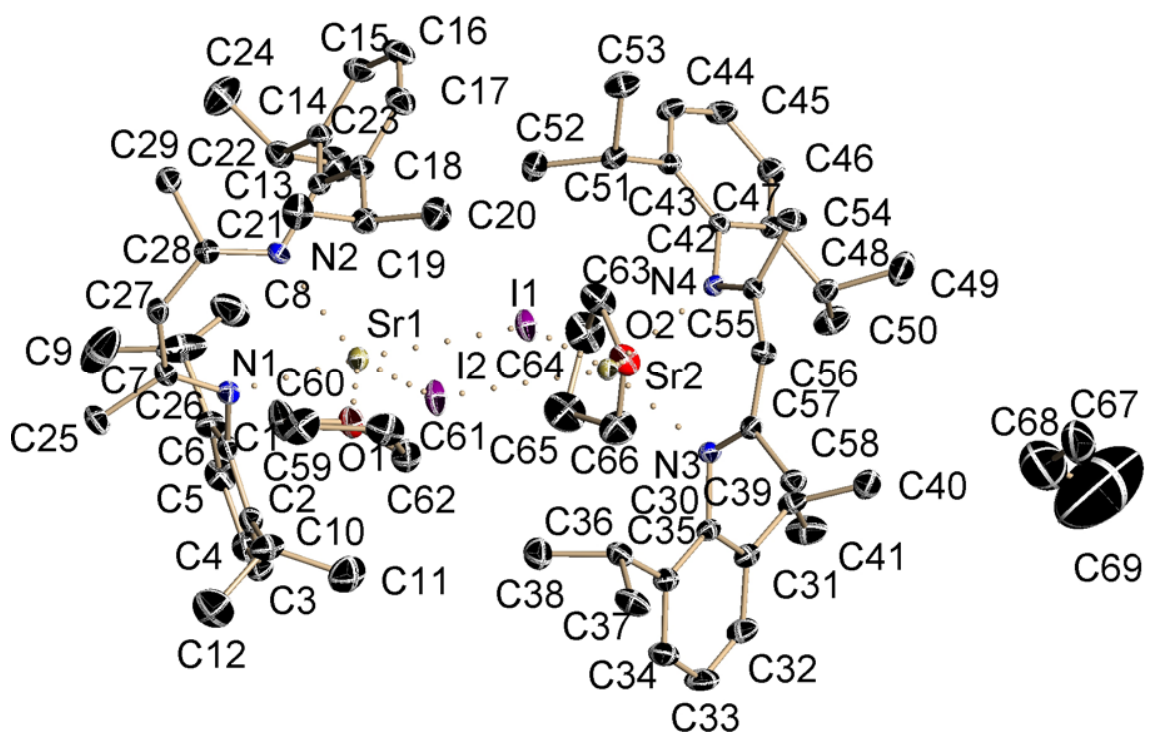

Figure 7-56: Asymmetric unit of SSrl. Hydrogen atoms have been omitted for clarity.

Table 7-56: Crystallographic data for SSrl.

\begin{tabular}{|c|c|c|c|}
\hline structure code & SSrl & $F(000)$ & 2980 \\
\hline formula & $\mathrm{C}_{69} \mathrm{H}_{105} \mathrm{I}_{2} \mathrm{~N}_{4} \mathrm{O}_{2} \mathrm{Sr}_{2}$ & max. / min. Transmission & 0.3849 / 0.4299 \\
\hline molecular mass $/ \mathrm{g} \cdot \mathrm{mol}^{-1}$ & 1451.61 & $\rho_{\text {calc }} / \mathrm{Mg} \cdot \mathrm{m}^{-3}$ & 1.357 \\
\hline crystal size / mm & $0.15 \times 0.15 \times 0.1$ & $\mu / \mathrm{mm}^{-1}$ & 2.413 \\
\hline crystal system & monoclinic & $\theta_{\min } / \theta_{\max }^{\circ}$ & $1.62 / 26.77$ \\
\hline space group & $P 2_{1} / C$ & reflections all/unique & $137550 / 15123$ \\
\hline a / $\AA$ & $21.500(2)$ & data/restraints/parameter & $15123 / 16 / 733$ \\
\hline $\mathrm{b} / \AA$ & $15.487(2)$ & $R 1$ (all data) & 0.0283 \\
\hline$c / \AA$ & $23.025(3)$ & $w R 2$ (all data) & 0.0545 \\
\hline$\beta /{ }^{\circ}$ & $112.088(1)$ & $g 1 / g 2$ & $0.0257 / 3.7174$ \\
\hline$V / \AA^{3}$ & $7104.1(14)$ & GoF & 1.061 \\
\hline Z & 4 & peak/hole: & \\
\hline temperature / K & $100(2)$ & $\max . / \min . /\left(10^{-6} \mathrm{e} \cdot \AA^{-3}\right)$ & $0.698 /-0.439$ \\
\hline
\end{tabular}




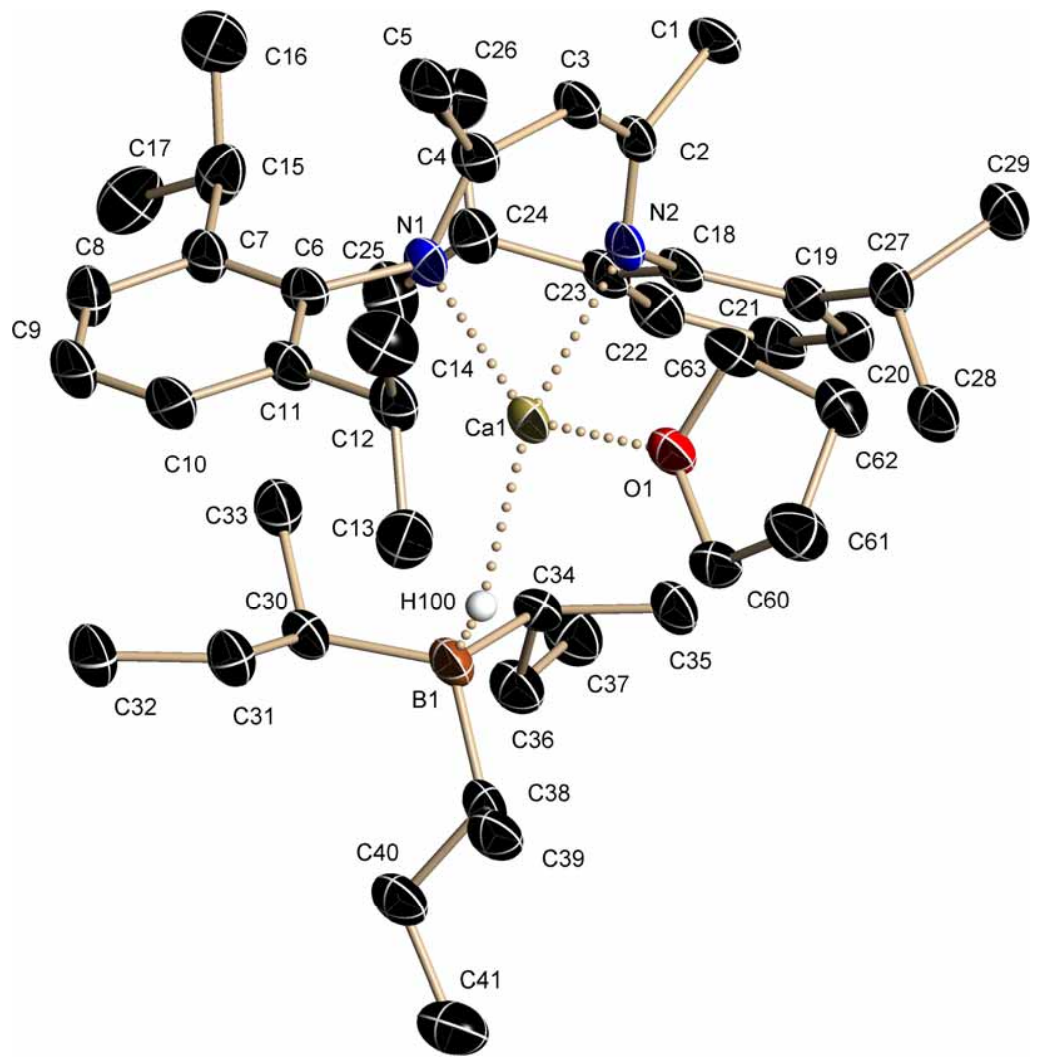

Figure 7-57: Asymmetric unit of $\mathrm{SCaB}$. Calculated hydrogen atoms have been omitted for clarity.

Table 7-57: Crystallographic data for SCaB.

\begin{tabular}{|ll|ll|}
\hline structure code & $\mathrm{SCaB}$ & $F(000)$ & 1576 \\
formula & $\mathrm{C}_{45} \mathrm{H}_{77} \mathrm{BCaN}_{2} \mathrm{O}$ & max. / min. Transmission & $0.4503 / 0.7452$ \\
molecular mass $/ \mathrm{g} \cdot \mathrm{mol}^{-1}$ & 712.98 & $\rho_{\text {calc }} /{\mathrm{Mg} \cdot \mathrm{m}^{-3}}^{-3}$ & 1.089 \\
crystal size / mm & $0.15 \times 0.1 \times 0.1$ & $\mu / \mathrm{mm}^{-1}$ & 0.178 \\
crystal system & monoclinic & $\theta_{\min } / \theta_{\max }{ }^{\circ}$ & $0.99 / 25.51$ \\
space group & $P 2{ }_{1} / c$ & reflections all/unique & $31406 / 7992$ \\
$\mathrm{a} / \AA$ & $20.749(5)$ & data/restraints/parameter & $7992 / 0 / 471$ \\
$\mathrm{~b} / \AA$ & $13.176(3)$ & $R 1$ (all data) & 0.1346 \\
$\mathrm{c} / \AA$ & $16.106(4)$ & $w R 2$ (all data) & 0.1797 \\
$\beta / \circ$ & $99.155(5)$ & $g 1 / g 2$ & $0.0879 / 0.8065$ \\
$\mathrm{~V} / \AA^{3}$ & $4347.0(2)$ & GoF & 1.001 \\
$\mathrm{Z}$ & 4 & peak/hole: & \\
temperature / K & $100(2)$ & max. / min. / $\left(10^{-6} \mathrm{e} \cdot \AA^{-3}\right)$ & $0.381 /-0.602$ \\
\hline
\end{tabular}




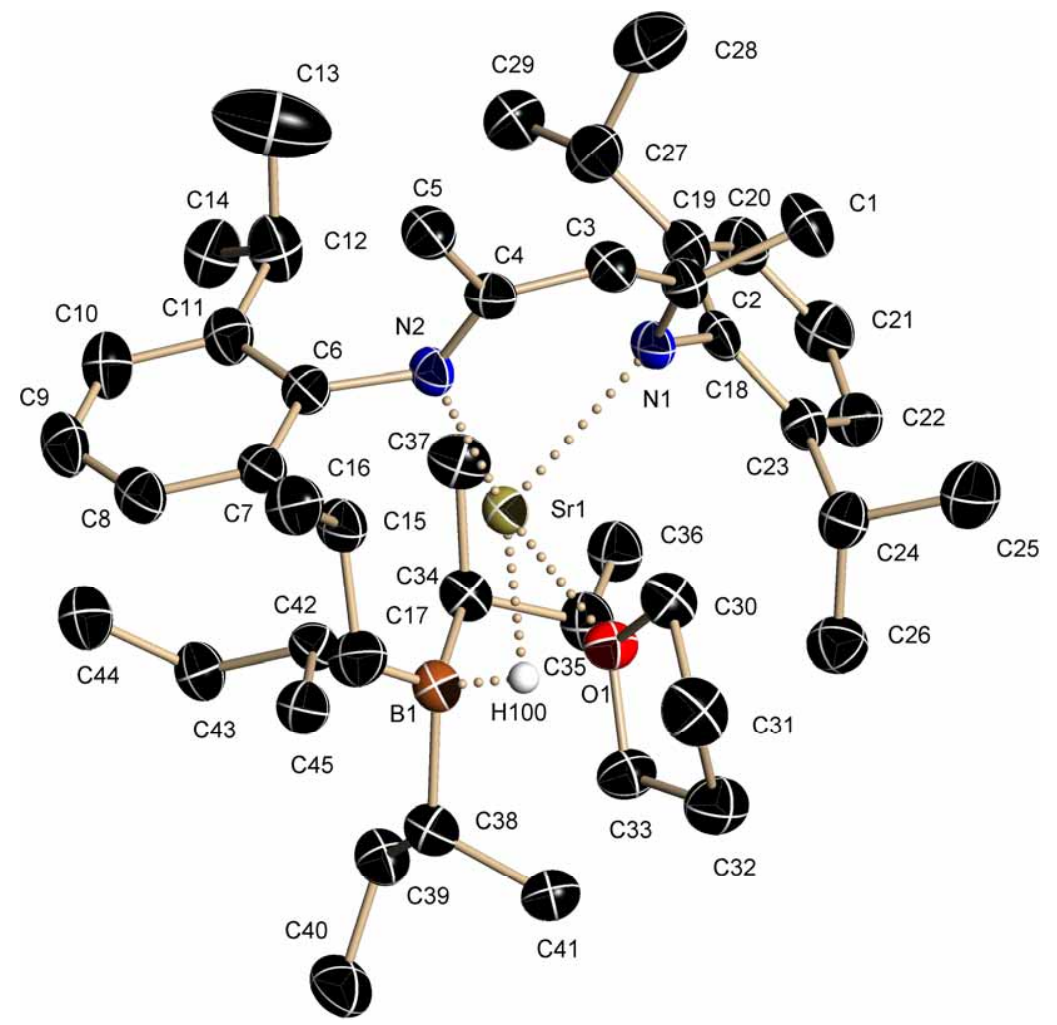

Figure 7-58: Asymmetric unit of SSrB. Calculated hydrogen atoms have been omitted for clarity.

Table 7-58: Crystallographic data for SSrB.

\begin{tabular}{|c|c|c|c|}
\hline structure code & SSrB & $F(000)$ & 1648 \\
\hline formula & $\mathrm{C}_{45} \mathrm{H}_{77} \mathrm{BN}_{2} \mathrm{OSr}$ & max. / min. Transmission & $0.3639 / 0.4288$ \\
\hline molecular mass $/ \mathrm{g} \cdot \mathrm{mol}^{-1}$ & 760.52 & $\rho_{\text {calc }} / \mathrm{Mg} \cdot \mathrm{m}^{-3}$ & 1.148 \\
\hline crystal size / mm & $0.1 \times 0.1 \times 0.1$ & $\mu / \mathrm{mm}^{-1}$ & 1.259 \\
\hline crystal system & monoclinic & $\theta_{\min } / \theta_{\max }^{\circ}$ & $1.82 / 25.11$ \\
\hline space group & $P 2_{1} / c$ & reflections all/unique & $66750 / 7808$ \\
\hline a / $\AA$ & $20.721(4)$ & data/restraints/parameter & $7808 / 21 / 471$ \\
\hline $\mathrm{b} / \AA$ & $13.395(2)$ & $R 1$ (all data) & 0.0624 \\
\hline$c / \AA$ & $16.093(3)$ & $w R 2$ (all data) & 0.0426 \\
\hline$\beta /{ }^{\circ}$ & $100.014(3)$ & $g 1 / g 2$ & $0.0549 / 2.1344$ \\
\hline$V / \AA^{3}$ & $4398.7(13)$ & GoF & 1.077 \\
\hline Z & 4 & peak/hole: & \\
\hline temperature / $\mathrm{K}$ & $100(2)$ & $\max . / \min . /\left(10^{-6} \mathrm{e} \cdot \AA^{-3}\right)$ & $0.659 /-0.488$ \\
\hline
\end{tabular}



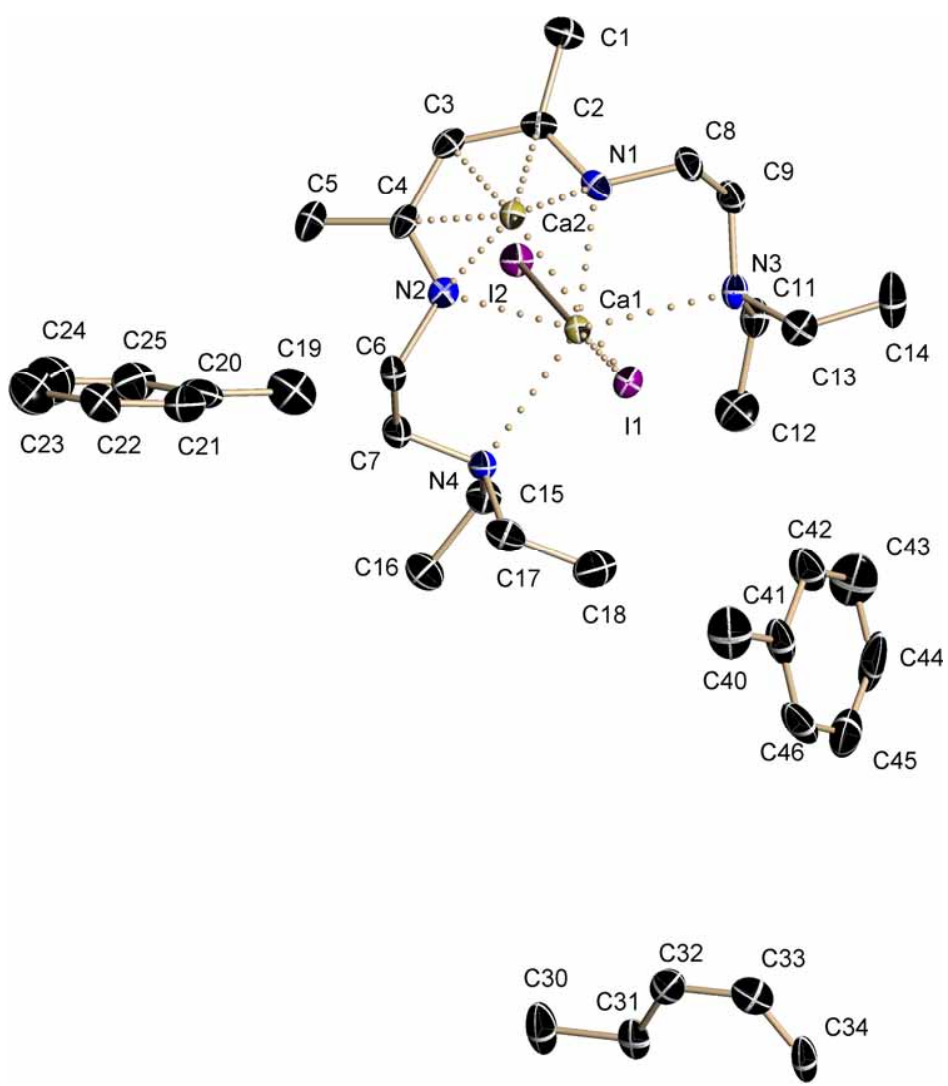

Figure 7-59: Asymmetric unit of S900. Hydrogen atoms have been omitted for clarity.

Table 7-59: Crystallographic data for $\$ 900$.

\begin{tabular}{|c|c|c|c|}
\hline structure code & s900 & $F(000)$ & 1604 \\
\hline formula & $\mathrm{C}_{62} \mathrm{H}_{102} \mathrm{Ca}_{3} \mathrm{I}_{4} \mathrm{~N}_{8}$ & max. / min. Transmission & $0.5823 / 0.7452$ \\
\hline molecular mass $/ \mathrm{g} \cdot \mathrm{mol}^{-1}$ & 1587.36 & $\rho_{\text {calc }} / \mathrm{Mg} \cdot \mathrm{m}^{-3}$ & 1.522 \\
\hline crystal size / mm & $0.15 \times 0.1 \times 0.05$ & $\mu / \mathrm{mm}^{-1}$ & 2.063 \\
\hline crystal system & monoclinic & $\theta_{\min } / \theta_{\max }^{\circ}$ & $1.90 / 25.08$ \\
\hline space group & $P 2 / C$ & reflections all/unique & $49063 / 6112$ \\
\hline a / $\AA$ & $15.550(6)$ & data/restraints/parameter & 6112 / 64 / 366 \\
\hline $\mathrm{b} / \AA$ & $16.668(6)$ & $R 1$ (all data) & 0.0911 \\
\hline$c / \AA$ & $14.904(5)$ & $w R 2$ (all data) & 0.1027 \\
\hline$\beta /{ }^{\circ}$ & $116.273(8)$ & $g 1 / g 2$ & $0.0296 / 17.3674$ \\
\hline$V / \AA^{3}$ & $3464.0(2)$ & GoF & 1.075 \\
\hline Z & 2 & peak/hole: & \\
\hline temperature / $\mathrm{K}$ & $100(2)$ & $\max . / \min . /\left(10^{-6} \mathrm{e} \cdot \AA^{-3}\right)$ & $0.881 /-0.969$ \\
\hline
\end{tabular}




\section{References}

[1] C. Soanes, A. Stevenson, Oxford Dictionary of English, Oxford University Press, Oxford, 2005.

[2] A. Mittasch, E. Theis, Von Davy bis Deacon. Ein halbes Jahrhundert Grenzflächenkatalyse, 1932, p. 31-39.

[3] J. W. Döbereiner, Über neu entdeckte höchst merkwürdige Eigenschaften des Platins und die pneumatisch-capillare Thätigkeit gesprungener Gläser: ein Beitrag zur Corpuscularphilosophie, Schmid, Jena, 1823.

[4] J. Schiff, Briefwechsel zwischen Goethe und Johann Wolfgang Döbereiner (1810-1830), 1914, p. 78.

[5] T. Reschke, Berzelius und Liebig: Ihre Briefe von 1831-1845, Cromm, Göttingen, 1982.

[6] F. Haber, Z. f. Anorg. Chem. 1905, 44, 341-378.

[7] D. Stolzenberg, Fritz Haber, VCH, Weinheim, 1994.

[8] A. Mittasch, Salpetersäure aus Ammoniak, 1953.

[9] J. J. Berzelius, Lehrbuch der Chemie I 1843, p. 110.

[10] W. Eckart, Geschichte der Medizin, Springer, Heidelberg, 1990.

[11] W. Ostwald, Z. Phys. Chem. (Leipzig) 1894, 15, 706-709.

[12] W. Ostwald, Aeltere Lehre von den Berührungswirkungen, Leipzig, 1898, p. 44.

[13] W. Ostwald, Über Katalyse, Nobel Prize Lecture, Stockholm, Sweden, 1909.

[14] I. Langmuir, Trans. Faraday Soc. 1922, 17, 607-612.

[15] F. Fischer, Petroleum Times 1936, 36, 613-614.

[16] E. Houdry, W. F. Burt, A. E. Pew, W. A. Peters, Oil and Gas Journal 1938, 37, 40-45.

[17] G. Natta, P. Pino, P. Corradini, F. Danusso, E. Mantica, G. Mazzanti, G. Morgaglio, J. Am. Chem. Soc. 1955, 77, 1708-1710.

[18] K. Ziegler, E. Holzkamp, H. Breil, H. Martin, Angew. Chem. 1955, 67, 426-427.

[19] P. Zamostny, Z. Belohlav, Appl. Catal. A 2002, 225, 291-299.

[20] J. M. Thomas, W. J. Thomas, Introduction to the Principles of Heterogeneous Catalysis, Academic Press, London, 1967.

[21] W. J. Thomas, Perspectives in Catalysis, Blackwells, Oxford, 1992, p. 251.

[22] M. D. Toscano, K. J. Woycechowsky, D. Hilvert, Angew. Chem. Int. Ed. 2007, 46, 3212-3136.

[23] J. Smidt, W. Hafner, R. Jira, J. Sedlmeier, R. Sieber, R. Rütinger, H. Kojer, Angew. Chem. 1959, 71, 176-182.

[24] R. Jira, Angew. Chem. 2009, 121, 9196-9199; Angew. Chem. Int. Ed. 2009, 48, 291-299.

[25] R. D. Gillard, J. A. Osborn, P. B. Stockwell, G. Wilkinson, Proceedings Chem. Soc. 1964, 284285.

[26] J. A. Osborn, F. H. Jardine, J. F. Young, G. Wilkinson, J. Chem. Soc. A 1966, 1711-1732.

[27] J. Haber, Top. Catal. 2009, 52, 970-981.

[28] W. S. Knowles, Acc. Chem. Res. 1983, 16, 106-112.

[29] W. S. Knowles, Angew. Chem. 2002, 114, 2096-2107; Angew. Chem. Int. Ed. 2002, 41, 19962007.

[30] A. Miyashita, A. Yasuda, H. Takaya, K. Toriumi, T. Ito, T. Souchi, R. Noyori, J. Am. Chem. Soc. 1980, 102, 7932-7934.

[31] R. Noyori, Angew. Chem. 2002, 114, 2108-2123; Angew. Chem. Int. Ed. 2002, 41, 2008-2023.

[32] S. G. Hentges, K. B. Sharpless, J. Am. Chem. Soc. 1980, 102, 4264-4265.

[33] K. B. Sharpless, Angew. Chem. 2002, 114, 2124-2135; Angew. Chem. Int. Ed. 2002, 41, 2024-2035.

[34] W. S. Knowles, R. Noyori, Acc. Chem. Res. 2007, 40, 1238-1239.

[35] H.-J. Wernicke, R. W. Fischer, Chem. Ing. Tech. 2006, 78, 825-834.

[36] G. Kehr, R. Fröhlich, B. Wibbeling, G. Erker, Chem. Eur. J. 2000, 6, 258-266.

[37] E. You-Xian Chen, T. J. Marks, Chem. Rev. 2000, 100, 1391-1434.

[38] G. Kehr, R. Roesmann, R. Fröhlich, C. Holst, G. Erker, Eur. J. Inorg. Chem. 2001, 2, 535-538.

[39] G. Erker, Chem. Commun. 2003, 1469-1476.

[40] M. Bochmann, S. J. Lancaster, Angew. Chem. 1994, 106, 1715-1718; Angew. Chem. Int. Ed. Engl. 1994, 33, 1634-1637. 
[41] K. P. Bryliakov, N. V. Semikolenova, D. V. Yudaev, V. A. Zakharov, H. H. Brintzinger, M. Ystenes, E. Rytter, E. P. Talsi, J. Organomet. Chem. 2003, 683, 92-102.

[42] C. S. Bajgur, S. Sivaram, Curr. Sci. 2000, 78, 1325-1335.

[43] P. Corradini, G. Guerra, L. Cavallo, Acc. Chem. Res. 2004, 37, 231-241.

[44] W. P. Long, D. S. Breslow, J. Am. Chem. Soc. 1960, 82, 1953-1957.

[45] E. P. J. Moore, Polypropylene handbook: Polymerization, Characterization, Properties, Applications, Hanser Publishers, Munich, Germany, 1996.

[46] H. Sinn, W. Kaminsky, Adv. Organomet. Chem. 1980, 19, 99-149.

[47] H. Sinn, W. Kaminsky, H.-J. Vollmer, W. Rüdiger, Angew. Chem. 1980, 92, 396-402; Angew. Chem. Int. Ed. Engl. 1980, 19, 390-393.

[48] J. Storre, C. Schnitter, H. W. Roesky, H.-G. Schmidt, M. Noltemeyer, R. Fleischer, D. Stalke, J. Am. Chem. Soc. 1997, 119, 7505-7513.

[49] W. Kaminsky, K. Külpen, F. R. W. P. Wild, H. H. Brintzinger, Angew. Chem. 1985, 97, 507508; Angew. Chem. Int. Ed. Engl. 1985, 24, 507-508.

[50] W. Kaminsky, Adv. Catal. 2001, 46, 89-159.

[51] F. R. W. P. Wild, M. Wasincionek, G. Huttner, H. H. Brintzinger, J. Organomet. Chem. 1985, 288, 63-67.

[52] J. A. Ewen, R. L. Jones, A. Razavi, J. P. Ferrata, J. Am. Chem. Soc. 1988, 110, 6255-6256.

[53] G. Bai, S. Singh, H. W. Roesky, M. Noltemeyer, H.-G. Schmidt, J. Am. Chem. Soc. 2005, 127, 3449-3455.

[54] S. K. Mandal, P. M. Gurubasavaraj, H. W. Roesky, G. Schwab, D. Stalke, R. B. Oswald, V. Dolle, Inorg. Chem. 2007, 46, 10158-10167.

[55] A. S. Rodrigues, J.-F. Carpentier, Coord. Chem. Rev. 2008, 252, 2137-2154.

[56] A. Nakamura, S. Ito, K. Nozaki, Chem. Rev. 2009, 109, 5215-5244.

[57] Y. Yoshida, S. Matsui, T. Fujita, J. Organomet. Chem. 2005, 690, 4382-4397.

[58] E.-G. Kim, M. L. Klein, Organometallics 2004, 23, 3319-3326.

[59] C. Takayama, Y. Yamaguchi, T. Mise, N. Suzuki, Dalton Trans. 2001, 948-953.

[60] T. S. Teets, D. G. Nocera, J. Am. Chem. Soc. 2009, 131, 7411-7420.

[61] I. Langmuir, J. Am. Chem. Soc. 1919, 41, 868-934.

[62] I. Langmuir, J. Am. Chem. Soc. 1919, 41, 1543-1559.

[63] R. Mews, P. G. Watson, E. Lork, Coord. Chem. Rev. 1997, 158, 233-273.

[64] J. K. Brask, T. Chivers, Angew. Chem. 2001, 113, 4082-4098; Angew. Chem. Int. Ed. 2001, 40, 3960-3976.

[65] G. M. Aspinall, M. C. Copsey, A. P. Leedham, C. R. Russell, Coord. Chem. Rev. 2002, 227, 217-232.

[66] F. Pauer, J. Rocha, D. Stalke, J. Chem. Soc., Chem. Commun. 1991, 20, 1477-1479.

[67] F. Pauer, D. Stalke, J. Organomet. Chem. 1991, 418, 127-128.

[68] S. Freitag, W. Kolodziejski, F. Pauer, D. Stalke, J. Chem. Soc., Dalton Trans. 1993, 34793488.

[69] R. Fleischer, D. Stalke, Coord. Chem. Rev. 1998, 176, 431-450.

[70] R. Fleischer, A. Rothenberger, D. Stalke, Angew. Chem. 1997, 109, 1141-1143; Angew. Chem. Int. Ed. Engl. 1997, 36, 1105-1107.

[71] R. Fleischer, D. Stalke, Organometallics 1998, 17, 832-838.

[72] B. Walfort, R. Bertermann, D. Stalke, Chem. Eur. J. 2001, 7, 1424-1430.

[73] C. Selinka, D. Stalke, Z. Naturforsch. 2003, 58b, 291-298.

[74] T. Schulz, Diploma Thesis, Würzburg (Germany), 2006.

[75] A. G. M. Barrett, A. A. Gray, M. S. Hill, P. B. Hitchcock, P. A. Procopiou, A. J. P. White, Inorg. Chem. 2006, 45, 3352-3358.

[76] F. T. Edelmann, F. Knösel, F. Pauer, D. Stalke, W. Bauer, J. Organomet. Chem. 1992, 438, 110.

[77] R. Fleischer, B. Walfort, A. Gbureck, P. Scholz, W. Kiefer, D. Stalke, Chem. Eur. J. 1998, 4, 2266-2279.

[78] D. Stalke, Proc. Indian Acad. Sci. 2000, 112, 155-170.

[79] B. Walfort, PhD thesis, Würzburg (Germany), 2001.

[80] F. Pauer, PhD thesis, Göttingen (Germany), 1991.

[81] B. Walfort, T. Auth, B. Degel, H. Helten, D. Stalke, Organometallics 2002, 21, 2208-2214.

[82] C. Selinka, S. Deuerlein, T. Häuser, D. Stalke, Inorg. Chim. Acta 2004, 357, 1873-1880.

[83] F. T. Edelmann, Chem. Soc. Rev. 2009, 38, 2253-2268.

[84] L. Bourget-Merle, M. F. Lappert, J. R. Severn, Chem. Rev. 2002, 102, 3031-3065. 
[85] S. K. Mandal, H. W. Roesky, Acc. Chem. Res. 2010, asap.

[86] B. Walfort, D. Stalke, Angew. Chem. 2001, 113, 3965-3969; Angew. Chem. Int. Ed. 2001, 40, 3846-3849.

[87] S. Deuerlein, D. Leusser, U. Flierler, H. Ott, D. Stalke, Organometallics 2008, 27, 2306-2315.

[88] R. Fleischer, D. Stalke, Chem. Commun. 1998, 343-345.

[89] D. Ilge, D. S. Wright, D. Stalke, Chem. Eur. J. 1998, 4, 2275-2279.

[90] B. Walfort, A. P. Leedham, C. R. Russell, D. Stalke, Inorg. Chem. 2001, 40, 5668-5674.

[91] C. Selinka, D. Stalke, Eur. J. Inorg. Chem. 2003, 3376-3382.

[92] M. D. Ward, Chem. Soc. Rev. 1995, 24, 121-134.

[93] K. D. Demadis, C. M. Hartshorn, T. J. Meyer, Chem. Rev. 2001, 101, 2655-2685.

[94] B. S. Brunschwig, C. Creutz, N. Sutin, Chem. Soc. Rev. 2002, 31, 168-184.

[95] J. Rosenthal, J. Bachman, J. L. Dempsey, A. J. Esswein, T. G. Gray, J. M. Hodgkiss, D. R. Manke, T. D. Luckett, B. J. Pistorio, A. S. Veige, D. G. Nocera, Coord. Chem. Rev. 2005, 249, 1316-1326.

[96] J. Woodward, Phil. Trans. 1724, 33, 15-17.

[97] H. M. Powell, Proceedings Chem. Soc. 1959, 3, 73-75.

[98] C. Creutz, H. Taube, J. Am. Chem. Soc. 1973, 95, 1086-1094.

[99] P. Yuan, X. Wu, G. Yu, D. Du, S. H. Liu, J. Organomet. Chem. 2007, 692, 3588-3592.

[100] C. N. Carlson, C. J. Kuehl, R. E. Da Re, J. M. Veauthier, E. J. Schelter, A. E. Milligan, B. L. Scott, E. D. Bauer, J. D. Thompson, D. E. Morris, K. D. John, J. Am. Chem. Soc. 2006, 128, 7230-7241.

[101] A. Vacher, A. Benameur, C. M. Ndiaye, D. Touchard, S. Rigaut, Organometallics 2009, 28, 6096-6100.

[102] A.-C. Ribou, J.-P. Launay, K. Takahashi, T. Nihira, S. Tarutani, C. W. Spangler, Inorg. Chem. 1994, 33, 1325-1329.

[103] H. Vahrenkamp, A. Geiß, G. N. Richardson, J. Chem. Soc., Dalton Trans. 1997, 3643-3651.

[104] R. A. Marcus, Pure Appl. Chem. 1997, 69, 13-29.

[105] O. S. Wenger, Coord. Chem. Rev. 2009, 253, 1439-1457.

[106] C. Belle, J.-L. Pierre, Eur. J. Inorg. Chem. 2003, 4137-4146.

[107] R. E. Stenkamp, Chem. Rev. 1994, 94, 715-726.

[108] C. J. Qin, A. Gavrilova, B. Bosnich, Pure Appl. Chem. 2001, 73, 221-226.

[109] N. J. Aiobaid, C. J. Jones, J. A. McCleverty, Polyhedron 1990, 9, 693-699.

[110] T. Sheng, S. Dechert, I. Hyla-Kryspin, R. F. Winter, F. Meyer, Inorg. Chem. 2004, 44, 38633874.

[111] B. Bosnich, Inorg. Chem. 1999, 38, 2554-2562.

[112] W. K. Chan, Coord. Chem. Rev. 2007, 251, 2104-2118.

[113] M. Al-Anber, T. Stein, S. Vatsadze, H. Lang, Inorg. Chim. Acta 2005, 358, 50-56.

[114] I. Manners, Angew. Chem. 1996, 108, 1712-1731; Angew. Chem. Int. Ed. Engl. 1996, 35, 1602-1621.

[115] S.-J. Liu, Q. Zhao, B.-X. Mi, W. Huang, Adv. Polym. Sci. 2008, 212, 125-144.

[116] J. Wang, H. Li, N. Guo, L. Li, C. L. Stern, T. J. Marks, Organometallics 2004, 23, 5112-5114.

[117] J. L. Kuiper, P. A. Shapley, J. Organomet. Chem. 2007, 692, 1653-1660.

[118] S. Podder, S. Roy, Tetrahedron 2007, 63, 9146-9152.

[119] J. Kuwabara, D. Takeuchi, K. Osakada, Chem. Commun. 2006, 36, 3815-3817.

[120] S.-y. Tosaki, K. Hara, V. Gnanadesikan, H. Morimoto, S. Harada, M. Sugita, N. Yamagiwa, S. Matsunaga, M. Shibasaki, J. Am. Chem. Soc. 2006, 128, 11776-11777.

[121] S. Podder, J. Choudhury, S. Roy, J. Org. Chem. 2007, 72, 3129.

[122] S. Handa, K. Nagawa, Y. Sohtome, S. Matsunaga, M. Shibasaki, Angew. Chem. 2008, 120, 3274-3277; Angew. Chem. Int. Ed. 2008, 47, 3230-3233.

[123] S. Gauthier, R. Scopelliti, K. Severin, Organometallics 2004, 23, 3769-3771.

[124] C. Cobzaru, S. Hild, A. Boger, C. Troll, B. Rieger, Coord. Chem. Rev. 2006, 250, 189-211.

[125] P. Galli, G. Vecellio, J. Polym. Sci., Part A: Polym. Chem. 2004, 42, 396-415.

[126] H. Hagen, J. Boersma, G. van Koten, Chem. Soc. Rev. 2002, 31, 357-364.

[127] P. Jutzi, J. Organomet. Chem. 1990, 400, 1-17.

[128] M. Bochmann, S. J. Lancaster, O. B. Robinson, J. Chem. Soc., Chem. Commun. 1995, $2081-$ 2082.

[129] A. P. Shaw, J. R. Norton, D. Buccella, L. A. Sites, S. S. Kleinbach, D. A. Jarem, K. M. Bocage, C. Nataro, Organometallics 2009, 28, 3804-3814. 
[130] H. W. Roesky, A. Grünhagen, F. T. Edelmann, M. Noltemeyer, Z. Naturforsch. 1989, 44b, 1365-1368.

[131] M. Reent, Diploma thesis, Göttingen (Germany), 2009.

[132] I. Hoppe, M. Marsch, K. Harms, G. Boche, D. Hoppe, Angew. Chem. 1995, 107, 2328-2330; Angew. Chem. Int. Ed. Engl. 1995, 34, 2158-2160.

[133] M. Pfeiffer, T. Stey, H. Jehle, B. Klüpfel, W. Malisch, D. Stalke, V. Chandrasekhar, Chem. Commun. 2001, 4, 337-338.

[134] F. Baier, Z. Fei, H. Gornitzka, A. Murso, S. Neufeld, M. Pfeiffer, I. Rüdenauer, A. Steiner, T. Stey, D. Stalke, J. Organomet. Chem. 2002, 661, 111-127.

[135] T. Stey, J. Henn, D. Stalke, Chem. Commun. 2007, 413-415.

[136] R. G. Pearson, J. Am. Chem. Soc. 1963, 85, 3533-3539.

[137] R. G. Parr, R. G. Pearson, J. Am. Chem. Soc. 1983, 105, 7512-7516.

[138] R. G. Pearson, J. Am. Chem. Soc. 1985, 107, 6801-6806.

[139] R. Fleischer, D. Stalke, J. Organomet. Chem. 1998, 550, 173-182.

[140] D. Leusser, B. Walfort, D. Stalke, Angew. Chem. 2002, 114, 2183-2186; Angew. Chem. Int. Ed. 2002, 41, 2079-2082.

[141] C. Strohmann, D. Schildbach, Polylithium organic compounds: Syntheses and selected molecular structures in The chemistry of organolithium compounds (Eds.: Z. Rappoport, I. Marek), John Wiley \& Sons, Chichester (GB), 2004, pp. 941-996.

[142] T. Stey, D. Stalke, Lead structures in lithium organic chemistry in The chemistry of organolithium compounds (Eds.: Z. Rappoport, I. Marek), John Wiley \& Sons, Chichester (GB), 2004, pp. 47-120.

[143] F. Bertini, L. Calucci, F. Cicogna, B. Gaddi, G. Ingrosso , M. Marcaccio, F. Marchetti, D. Paolucci, F. Paolucci, C. Pinzino, J. Organomet. Chem. 2006, 691, 2987-3002.

[144] D. Stern, N. Finkelmeier, D. Stalke, 2010, in preparation.

[145] J. T. E. Meyer, T. Schulz, S. K. Pandey, D. Stalke, Inorg. Chem. 2010, submitted.

[146] T. Schulz, D. Stalke, Z. Naturforsch. 2010, submitted.

[147] G. Schwab, PhD thesis, Göttingen (Germany), 2008.

[148] G. Schwab, D. Stern, D. Leusser, D. Stalke, Z. Naturforsch. 2007, 62b, 711-716.

[149] H. Ott, C. Däschlein, D. Leusser, D. Schildbach, T. Seibel, D. Stalke, C. Strohmann, J. Am. Chem. Soc. 2008, 190, 11901-11911.

[150] A. F. Holleman, N. Wiberg, Lehrbuch der Anorganischen Chemie, 102. Aufl., de Gruyter, Berlin, 2007.

[151] G. Schwab, D. Stern, D. Stalke, J. Org. Chem. 2008, 73, 5242-5247.

[152] S. Deuerlein, PhD-Thesis, Göttingen (Germany), 2007.

[153] M. M. Meinholz, S. K. Pandey, D. Stalke, 2010, in preparation.

[154] O. Glemser, J. Wegener, Angew. Chem. 1970, 82, 324; Angew. Chem. Int. Ed. Engl. 1970, 9, 309.

[155] S. Pohl, B. Krebs, U. Seyer, G. Henkel, Chem. Ber. 1979, 112, 1751-1755.

[156] R. Fleischer, S. Freitag, F. Pauer, D. Stalke, Angew. Chem. 1996, 108, 208-211; Angew. Chem. Int. Ed. Engl. 1996, 35, 204-207.

[157] O. Glemser, S. Pohl, F.-M. Tesky, R. Mews, Angew. Chem. 1977, 89, 829-830; Angew. Chem. Int. Ed. Engl. 1977, 16, 789-790.

[158] W. Lidy, W. Sundermeyer, W. Verbeek, Z. Anorg. Allg. Chem. 1974, 406, 228-234.

[159] J. K. Brask, T. Chivers, M. Parvez, G. P. A. Yap, Inorg. Chem. 1999, 38, 3594-3595.

[160] J. K. Brask, T. Chivers, M. Parvez, Angew. Chem. 2000, 112, 988-990; Angew. Chem. Int. Ed. 2000, 39, 958.

[161] J. Henn, D. Ilge, D. Leusser, D. Stalke, B. Engels, J. Phys. Chem. A 2004, 108, 9442-9452.

[162] D. Leusser, J. Henn, N. Kocher, B. Engels, D. Stalke, J. Am. Chem. Soc. 2004, 126, 17811793.

[163] S. L. Hinchley, P. Trickey, H. E. Robertson, B. A. Smart, D. W. H. Rankin, D. Leusser, B. Walfort, D. Stalke, M. Bühl, S. J. Obrey, J. Chem. Soc., Dalton Trans. 2002, 4607-4616.

[164] H. Ila, O. Baron, A. J. Wagner, P. Knochel, Chem. Commun. 2006, 6, 583-593.

[165] P. Knochel, W. Dohle, N. Gommermann, F. F. Kneisel, F. Kopp, T. Korn, I. Sapountzis, V. A. Vu, Angew. Chem. 2003, 115, 4438-4456; Angewandte Chemie Int. Ed. 2003, 42, 4302-4320.

[166] F. M. Bickelhaupt, Chem. Soc. Rev. 1999, 28, 17-23.

[167] F. Bickelhaupt, J. Organomet. Chem. 1994, 475, 1-14.

[168] M. Barbier, C. R. Acad. Sci. 1899, 128, 110-111.

[169] V. Grignard, C. R. Acad. Sci. 1900, 130, 1322-1324. 
[170] D. Seyferth, Organometallics 2006, 25, 2-24.

[171] D. Seyferth, Organometallics 2009, 28, 2-33.

[172] T. Murai, F. Asai, J. Am. Chem. Soc. 2007, 129, 780-781.

[173] J. Kuyper, P. C. Keijzer, K. Vrieze, J. Organomet. Chem. 1976, 116, 1-13.

[174] F. A. Carey, R. J. Sundberg, Advanced Organic Chemistry, Part A, Plenum Press, New York, 1984.

[175] K. P. C. Vollhardt, N. E. Schore, Organic Chemistry, W. H. Freeman \& Co Ltd., San Francisco, 1994.

[176] J. March, Advanced Organic Chemistry, Wiley-Interscience, New York, 1992.

[177] B. Wrackmeyer, U. Klaus, W. Milius, Inorg. Chim. Acta 1996, 250, 327-335.

[178] X. Shijing, Q. Minxiw, Z. Naijue, T. Youqi, Sci. China, Ser. B 1986, 1030-1033.

[179] V. Di Noto, S. Bresadola, R. Zannetti, M. Viviani, G. Valle, G. Bandoli, Z. Kristallogr. 1992, $201,161-170$.

[180] V. Di Noto, G. Bandoli, A. Dolmella, B. Zarli, M. Viviani, M. Vidali, Journal of Chemical Crystallography 1995, 25, 375-378.

[181] F. A. Cotton, S. C. Haefner, J. H. Matonic, X. Wang, C. A. Murillo, Polyhedron 1997, 16, 541550.

[182] H. Barjat, G. A. Morris, S. Smart, A. G. Swanson, S. C. R. Williams, J. Magn. Reson. 1995, B108, 170-172.

[183] I. Fernández, E. Martínez-Viviente, F. Breher, P. S. Pregosin, Chem. Eur. J. 2005, 11, 14951506.

[184] T. Schulz, D. Stalke, Eur. J. Inorg. Chem. 2010, submitted.

[185] S. Deuerlein, Diploma Thesis, Würzburg (Germany), 2003.

[186] T. Schulz, S. Deuerlein, D. Stalke, Eur. J. Inorg. Chem. 2010, submitted.

[187] W. Friedrich, P. Knipping, M. von Laue, Sitzungsbericht der kaiserlich Akademischen Wissenschaften München 1912, 303-322.

[188] W. D. Coolidge, Phys. Rev. 1913, 2, 409-430.

[189] K. Weissenberg, Z. Physik 1924, 23, 229-238.

[190] D. P. LeGalley, Rev. Sci. Instrum. 1935, 6, 279-283.

[191] T. C. Furnas, D. Harker, Rev. Sci. Instrum. 1955, 25, 449-453.

[192] R. Hofstadder, J. A. Mclntyre, Nucleonics 1950, 7, 32-37.

[193] A. Taylor, J. Sci. Instrum. 1949, 26, 225-229.

[194] W. Ehrenberg, W. E. Spear, Proc. Phys. Soc. B 1950, 64, 67-76.

[195] C. Cork, D. Fehr, R. Hamlin, W. Vernon, N. H. Xuong, J. Appl. Chem. 1973, 7, 319-323.

[196] W. C. Phillips, M. J. Stanton, D. M. O’Mara, Y. Li, I. Naday, E. M. Westbrook, Proc. SPIE 1993, 2009, 133-138.

[197] H. E. Göbel, Adv. X-Ray Anal. 1982, 24, 123-138.

[198] U. W. Arndt, J. Appl. Crystallogr. 1990, 23, 161-168.

[199] L. Jiang, Z. Al-Mosheky, N. Grupido, Powder Diffraction 2002, 17, 81-93.

[200] U. W. Arndt, J. V. P. Long, P. Duncumb, J. Appl. Crystallogr. 1998, 31, 936-944.

[201] F. A. Hofmann, W. M. Gibson, C. A. MacDonald, D. A. Carter, J. X. Ho, J. R. Ruble, J. Appl. Crystallogr. 2001, 34, 330-335.

[202] A. B. Storm, C. Michaelsen, A. Oehr, C. Hoffmann, Proc. SPIE 2004, 5537, 177-181.

[203] S. J. Coles, M. B. Hursthouse, J. Appl. Crystallogr. 2004, 37, 988-992.

[204] M. Witt, H. W. Roesky, Polyhedron 1989, 8, 1736-1741.

[205] P. W. Codding, K. A. Kerr, Acta Crystallogr., Sect. B. 1978, 34, 3785-3787.

[206] G. M. Sheldrick, SADABS 2007/5, Göttingen, 2007.

[207] T. Kottke, D. Stalke, J. Appl. Crystallogr. 1993, 26, 615-619.

[208] D. Stalke, Chem. Soc. Rev. 1998, 27, 171-178.

[209] Bruker, SAINT v7.34A. , Bruker AXS Inc., Madison (WI, USA), 2005.

[210] G. M. Sheldrick, Acta Crystallogr., Sect. A. 2008, 64, 112-122.

[211] V. V. Zhurov, E. A. Zhurova, A. A. Pinkerton, J. Appl. Crystallogr. 2008, 41, 340-349.

[212] G. M. Sheldrick, XPREP in SHELXTL v6.12, Bruker AXS Inst. Inc., Madison (WI, USA), 2000.

[213] K. Meindl, J. Henn, Acta Crystallogr., Sect. A. 2008, 64, 404-418.

[214] W. Schlenk, Die Methoden der Organischen Chemie in Die Methoden der Organischen Chemie (Ed. J. Houben), G. Thieme, Leipzig, 1924, p. 720.

[215] T. T. Tidwell, Angew. Chem. 2001, 113, 343-349; Angew. Chem. Int. Ed. Engl. 2001, 40, $331-$ 337.

[216] O. J. Scherer, G. Wolmershäuser, Z. Anorg. Allg. Chem. 1977, 432, 173-176. 
[217] R. Fleischer, S. Freitag, D. Stalke, J. Chem. Soc., Dalton Trans. 1998, 193-197.

[218] O. J. Scherer, R. Wies, Z. Naturforsch. 1970, 25b, 1486-1487.

[219] I. Ruppert, V. Bastian, R. Appel, Chem. Ber. 1975, 108, 2329-2339.

[220] H. Christina, E. McFarlane, W. McFarlane, Polyhedron 1988, 7, 1875-1879.

[221] H. Hope, Acta Crystallogr. 1988, B44, 22-26.

[222] T. Schulz, K. Meindl, D. Leusser, D. Stern, J. Graf, C. Michaelsen, M. Ruf, D. Stalke, J. Appl. Crystallogr. 2009, 42, 885-891.

[223] Bruker APEX v2.2-0, Bruker AXS Inst. Inc., Madison (WI, USA), 2007.

[224] W. Kabsch, J. Appl. Crystallogr. 1988, 21, 916-924.

[225] G. M. Sheldrick, TWINABS v1.05 in Bruker APEX v2.1-0, Bruker AXS Inst. Inc., Madison (WI, USA), 2005.

[226] X-AREA, Stoe \& Cie GmbH, Darmstadt, 2002.

[227] P. Müller, R. Herbst-Irmer, A. L. Spek, T. R. Schneider, M. R. Sawaya, Crystal Structure Refinement - A Crystallographer's Guide to SHELXL in IUCr Texts on Crystallography, Vol. 8 (Ed. P. Müller), Oxford University Press, Oxford (England), 2006.

[228] F. Mert-Balci, J. Conrad, K. Meindl, T. Schulz, D. Stalke, U. Beifuss, Synthesis 2008, 22, 3649-3656.

[229] G. B. Nikiforov, H. W. Roesky, T. Schulz, D. Stalke, M. Witt, Inorg. Chem. 2008, 47, 64356443.

[230] Y. Yang, T. Schulz, M. John, A. Ringe, H. W. Roesky, D. Stalke, J. Magull, H. Ye, Inorg. Chem. 2008, 47, 2585-2592.

[231] Y. Yang, T. Schulz, M. John, Z. Yang, V. M. Jiménez-Pérez, H. W. Roesky, P. M. Gurubasavaraj, D. Stalke, H. Ye, Organometallics 2008, 27, 769-777.

[232] A. Stasch, S. P. Sarish, H. W. Roesky, K. Meindl, F. Dall'Antonia, T. Schulz, D. Stalke, Chem. Asian J. 2009, 4, 1451-1457.

[233] Z. Zhang, H. W. Roesky, T. Schulz, D. Stalke, A. Döring, Eur. J. Inorg. Chem. 2009, 32, 48644869 .

[234] V. M. Jiménez-Pérez, B. M. Muñoz-Flores, H. W. Roesky, T. Schulz, A. Pal, T. Beck, Z. Yang, D. Stalke, R. Santillan, M. Witt, Eur. J. Inorg. Chem. 2008, 13, 2238-2243. 


\section{Publications}

[1] F. Mert-Balci, J. Conrad, K. Meindl, T. Schulz, D. Stalke, U. Beifuss, "Microwave-Assisted Three-Component Reaction for the Synthesis of Pyrido[2', $\left.1^{\prime}: 2,3\right]$ imidazo[4,5-c]isoquinolin5(6H)-ones" Synthesis 2008, 22, 3649-3656.

[2] Y. Yang, T. Schulz, M. John, A. Ringe, H. W. Roesky, D. Stalke, J. Magull, H. Ye, "Synthesis, Characterization, and Reaction of Aluminum Halide Amides Supported by a Bulky $\beta$ Diketiminato Ligand" Inorg. Chem. 2008, 47, 2585-2592.

[3] G. B. Nikiforov, H. W. Roesky, T. Schulz, D. Stalke, M. Witt, "On the Quest for New Mixed-Metal $\mu$-Oxo-bridged Complexes: Synthesis of Compounds Containing Transition Metal-Oxygen-Main Group Metal Motifs M-O-M1 (M = Ti, Zr; M1 = Al, Ga) without Cyclopentadienyl Ligands" Inorg. Chem. 2008, 47, 6435-6443.

[4] Y. Yang, T. Schulz, M. John, Z. Yang, V. M. Jiménez-Pérez, H. W. Roesky, P. M. Gurubasavaraj, D. Stalke, H. Ye, "Organoaluminum Hydroxides Supported by $\beta$-Diketiminato Ligands: Synthesis, Structural Characterization, and Reactions" Organometallics 2008, 27, 769-777.

[5] V. M. Jiménez-Pérez, B. M. Muñoz-Flores, H. W. Roesky, T. Schulz, A. Pal, T. Beck, Z. Yang, D. Stalke, R. Santillan, M. Witt, "Monomeric Boron and Tin(II) Heterocyclic Derivatives of 1,8-Diaminonaphthalenes: Synthesis, Characterization and X-ray Structures" Eur. J. Inorg. Chem. 2008, 13, 2238-2243.

[6] T. Schulz, K. Meindl, D. Leusser, D. Stern, J. Graf, C. Michaelsen, M. Ruf, G. M. Sheldrick, D. Stalke, "A comparison of a microfocus X-ray source and a conventional sealed tube for crystal structure determination" J. Appl. Crystallogr. 2009, 42, 885-891.

[7] A. Stasch, S. P. Sarish, H. W. Roesky, K. Meindl, F. Dall'Antonia, T. Schulz, D. Stalke, "Synthesis and Characterization of Alkynyl Compounds of Groups 1 and 2" Chem. Asian J. 2009, 4, 1451-1457.

[8] Z. Zhang, H. W. Roesky, T. Schulz, D. Stalke, A. Döring, "A Chlorine-Centered Cluster of Composition $\left[\left(\mathrm{Me}_{3} \mathrm{Si}\right)_{2} \mathrm{NC}(\mathrm{NCy})_{2} \mathrm{SmCl}_{2}\right]_{5}$ (thf $)_{2}$ and a Comparison with the Heavier Ytterbium Congener $\left[\left(\mathrm{Me}_{3} \mathrm{Si}\right)_{2} \mathrm{NC}(\mathrm{NCy})_{2} \mathrm{YbCl}_{2}\right]_{2}(\mathrm{LiCl})_{2}(\text { thf })_{4} "$ Eur. J. Inorg. Chem. 2009, 32, 4864-4869.

[9] S. P. Sarish, A. Jana, H. W. Roesky, T. Schulz, D. Stalke, M. John, "Well-Defined Heavier Alkaline Earth Metal Borohydride Complexes Stabilized by $\beta$-diketiminate Ligand" Inorg. Chem. 2010, accepted.

[10] T. Schulz, S. Deuerlein, D. Stalke, "Magnesium diimidosulfinates - Conformational Studies in the Solid State and in Solution" Eur. J. Inorg. Chem. 2010, accepted. 
[11] T. Schulz, D. Stalke, "Magnesium triimidosulfonates from Grignard reagents" Eur. J. Inorg. Chem. 2010, accepted.

[12] S. P. Sarish, B. Nekoueishahraki, A. Jana, H. W. Roesky, T. Schulz, D. Stalke, "A New Entry into Aluminum Chemistry: L ${ }^{1}$ AlMe·thf, a Versatile Building Block for Bimetallic and Polymetallic Complexes" Chem. Eur. J. 2010, submitted.

[13] Т. Schulz, D. Stalke, "П-Spacer coupled diimidosulfinates" Z. Naturforsch. 2010, submitted.

[14] T. Schulz, D. Stalke, "Bis(diimido)anthracenylsulfinates" Z. Naturforsch. 2010, submitted.

[15] S. P. Sarish, A. Jana, H. W. Roesky, T. Schulz, D. Stalke, "Trapping Cal ${ }_{2}$ in an Organometallic Matrix" Organometallics 2010, submitted.

[16] E. J. T. Meyer, T. Schulz, S.K. Pandey, D. Stalke, "New Chelating Ligands Based on S-Organosulfurdiimides: Synthesis and Single Crystal X-ray Structures of their Lithium Complexes" Inorg. Chem. 2010, accepted.

[17] D. Stern, M. Granitzka, T. Schulz, D. Stalke, "Polymorphism of dibromo-tetrakis-(tetrahydrofuran-KO)magnesium(II)" Z. Naturforsch. 2010, accepted.

\section{Poster Presentations}

[1] S. Deuerlein, D. Leusser, T. Schulz, D. Stalke, "Crystallisation of a Suitable Polymorph for Charge Density Studies", $4^{\text {th }}$ European Charge Density Meeting, 2006, Brandenburg/Havel, Germany.

[2] T. Schulz, S. Deuerlein, D. Stalke, "Heterobimetallische Komplexe als mögliche Katalysatoren für die Ziegler-Natta-Olefinpolymerisation", Wissenschaftsforum Chemie 2007 - GDChJahrestagung, 2007, Ulm, Germany.

[3] D. Stern, T. Schulz, D. Stalke, "Comparison experiments between the Incoatec microfocus source and a Bruker sealed tube device", 17. Jahrestagung der Deutschen Gesellschaft für Kristallographie, 2009, Hannover, Germany.

\section{TALKS}

[1] T. Schulz, "Mo-InS/Quazar vs. Bruker Sealed Tube/Monocap", Bruker Users Meeting 2007, 2007, Göttingen, Germany 


\title{
CURRICULUM VITAE
}

\author{
Thomas Schulz \\ Weender Landstr. 67 \\ 37075 Göttingen \\ Telefon : 0551/5036785 \\ 0152/28779343 \\ E-mail : thom.schulz@gmx.net
}

Geboren am 24. April 1981 in Osterburg, ledig, eine Tochter (21.11.2007)

\section{Universitäre Ausbildung}

15.03.2010

Erfolgreiche Disputation und Verleihung des Titels

Dr. rer. nat. (Note: magna cum laude)

$10.2006-03.2010$

Promotion im Institut für Anorganische Chemie der Georg-August-Universität Göttingen, in der Arbeitsgruppe von Prof. Dr. D. Stalke mit dem Thema "Ligand Design of Sulfur-Centered Chelates"

Nebenfächer: BWL und Kristallographie

$10.2001-09.2006$

Studium der Chemie (Diplom) an der JuliusMaximilians-Universität Würzburg

$12.2005-09.2006$

Abschluss des Studiums mit der Diplomarbeit "Metallkomplexe asymmetrischer Polyimidoschwefelverbindungen" im Institut für Anorganische Chemie der Julius-Maximilians-Universität Würzburg, im Arbeitkreis von Prof. Braunschweig (Note: sehr gut)

10.2003

Diplom-Vorprüfung (Note: sehr gut) 


\section{Schulische Ausbildung und Zivildienst}

$07.2000-05.2001$

06.2000

$09.1993-06.2000$

$09.1991-07.1993$

$09.1990-07.1991$

$09.1987-07.1990$
Zivildienst bei der Arbeiterwohlfahrt, Braunschweig

Abitur (Note 1,8) und Auszeichnung vom Fonds der chemischen Industrie für den besten Abiturienten im Fach Chemie an der Neuen Oberschule Braunschweig

Gymnasium Neue Oberschule, Braunschweig

Orientierungsstufe Leonardstraße, Braunschweig

Grundschule Comeniusstraße, Braunschweig

Ernst-Thälmann Grundschule Klötze

\section{Praxiserfahrung und Weiterbildungen}

$10.2006-03.2010$

Erfahrung im Umgang mit verschiedenen giftigen, ätzenden und anderen gefährlichen Chemikalien

Assistent/Leitender Assistent verschiedener Praktika an der Georg-August-Universität für Studierende der Chemie, Molekularen Medizin, Biologie und des Lehramtes Chemie

Betreuung und Wartung der Röntgendiffraktometer des Arbeitskreises

Erfolgreiche Teilnahme an verschiedenen
Vorlesungen der Fachrichtung BWL und
Kristallographie


Betreuung und Anleitung von fünf fortgeschrittenen Stundenten und einem Bachelor Studenten

09.2006

03.2006

$02.2005-04.2005$

$08.2004-10.2004$

$06.2001-07.2001$

$08.1997-09.1997$
Sachkundenachweis im Umgang mit Gefahrstoffen gemäß $§ 5$ Abs. $1 \mathrm{Nr} .7$ der Chemikalien-Verbotsverordnung

Fach- und Sachkunde im Strahlenschutz nach StISchV und RöV

Praktikum im Institut für Organische Chemie im Arbeitskreis von Prof. Bringmann an der JuliusMaximilians-Universität Würzburg

Praktikum im Institut für Anorganische Chemie im Arbeitskreis von Prof. Stalke an der JuliusMaximilians-Universität Würzburg

Praktikum im Institut für Organische Chemie im Arbeitskreis von Prof. Bahadir an der TU Braunschweig

Schulpraktikum im Lebensmitteluntersuchungsamt Braunschweig

\section{Sonstige Kenntnisse}

- Fremdsprachenkenntnisse: Englisch (fließend)

(Schüleraustausch mit Wilmington, North Carolina, USA)

Französisch (Grundkenntnisse)

(Schüleraustausch mit Paris, Frankreich)

- Computerkenntnisse: Geübt im Umgang mit MS-Office (Word, PowerPoint, Excel) 